\title{
Systematic revision of the pantropical whip spider family Charinidae Quintero, 1986 (Arachnida, Amblypygi)
}

\author{
Gustavo Silva de MIRANDA ${ }^{\circledR 1, *}$, Alessandro P.L. GIUPPONI ${ }^{2}$, \\ Lorenzo PRENDINI ${ }^{3}$ \& Nikolaj SCHARFF ${ }^{\circ} 4$ \\ ${ }^{1,4}$ Center for Macroecology, Evolution and Climate, Natural History Museum of Denmark, University \\ of Copenhagen, Copenhagen, Denmark. \\ ${ }^{1,4}$ Entomology Department, National Museum of Natural History, Smithsonian Institution, \\ Washington DC, USA. \\ ${ }^{2}$ Laboratório de Referência Nacional em Vetores das Riquetsioses, LIRN-IOC-FIOCRUZ, \\ Rio de Janeiro, RJ, Brazil. \\ ${ }^{3}$ Arachnology Lab, Division of Invertebrate Zoology, American Museum of Natural History, \\ New York, NY, USA. \\ ${ }^{4}$ Zoology Section, Natural History Museum of Denmark, University of Copenhagen, Denmark. \\ *Corresponding author: smiranda.gustavo@gmail.com \\ 2Email: agiupponi@gmail.com \\ ${ }^{3}$ Email: lorenzo@amnh.org \\ ${ }^{4}$ Email: nscharff@snm.ku.dk

\footnotetext{
${ }^{1}$ urn:lsid:zoobank.org:author:81150D94-592A-4CE5-8E88-E60F557A4341

${ }^{2}$ urn:lsid:zoobank.org:author:434112AC-B212-43E8-A5D9-2F5D5619AFC4

${ }^{3}$ urn:lsid:zoobank.org:author:C2D080D0-75DB-4DA1-A101-AB4DCF50FF0A

${ }^{4}$ urn:lsid:zoobank.org:author:F84D2235-66D2-460C-820D-80024068759D
}

\begin{abstract}
The whip spider family Charinidae Quintero, 1986 is the most speciose and widely distributed in the arachnid order Amblypygi Thorell, 1883. It comprises three genera and 95 species distributed across all tropical continents and the eastern Mediterranean. Despite recent advances in the taxonomy of the family, a global revision of all its species, necessary to advance understanding of its systematics, biogeography and evolution, has never been conducted. In the present contribution, the family is revised in its entirety for the first time, including all previous names and 33 new species, 24 in the genus Charinus Simon, 1892: C. alagoanus sp. nov., C. apiaca sp. nov., C. carinae sp. nov., C. carioca sp. nov., C. carvalhoi sp. nov., C. cearensis sp. nov., C. diamantinus sp. nov., C. euclidesi sp. nov., C. goitaca sp. nov., C. guayaquil sp. nov., C. imperialis sp. nov., C. loko sp. nov., C. magalhaesi sp. nov., C. miskito sp. nov., C. mocoa sp. nov., C. monasticus sp. nov., C. palikur sp. nov., C. perquerens sp. nov., $C$. puri sp. nov., C. renneri sp. nov., C. sooretama sp. nov., C. souzai sp. nov., C. susuwa sp. nov., C. una sp. nov.; eight in the genus Sarax Simon, 1892: S. bilua sp. nov., S. dunni sp. nov., S. gravelyi sp. nov., S. indochinensis sp. nov., S. lembeh sp. nov., S. palau sp. nov., S. rahmadii sp. nov., S. tiomanensis sp. nov.; and one in the genus Weygoldtia Miranda et al., 2018: W. consonensis sp. nov. Taxonomic keys to the 132 species (excluding four nomina dubia) are presented and several taxonomic rearrangements implemented. Four subspecies are elevated to species level: Charinus cavernicolus Weygoldt, 2006, C. elegans Weygoldt, 2006, C. longipes Weygoldt, 2006, and Sarax bispinosus (Nair,
\end{abstract}


1934). Sarax batuensis Roewer, 1962 is removed from synonymy with Sarax buxtoni (Gravely, 1915) and S. buxtoni newly synonymized with Sarax rimosus (Simon, 1901). Stygophrynus moultoni Gravely, 1915 is transferred to Sarax, resulting in Sarax moultoni (Gravely, 1915) comb. nov. Ten species are transferred from Charinus to Sarax, resulting in new combinations: S. abbatei (Delle Cave, 1986) comb. nov., S. bengalensis (Gravely, 1911) comb. nov., S. dhofarensis (Weygoldt, Pohl \& Polak, 2002) comb. nov., S. ioanniticus (Kritscher, 1959) comb. nov., S. israelensis (Miranda et al., 2016) comb. nov., S. omanensis (Delle Cave, Gardner \& Weygoldt, 2009) comb. nov., S. pakistanus (Weygoldt, 2005) comb. nov., S. seychellarum (Kraepelin, 1898) comb. nov., S. socotranus (Weygoldt, Pohl \& Polak, 2002) comb. nov. and S. stygochthobius (Weygoldt \& Van Damme, 2004) comb. nov.

Keywords. Taxonomy, biodiversity, Charinus, Sarax, Weygoldtia .

Miranda G.S., Giupponi A.P.L., Prendini L. \& Scharff N. 2021. Systematic revision of the pantropical whip spider family Charinidae Quintero, 1986 (Arachnida, Amblypygi). European Journal of Taxonomy 772: 1-409. https://doi.org/10.5852/ejt.2021.772.1505

\section{Introduction}

The rather limited knowledge of the arachnid order Amblypygi Thorell, 1883 is surprising given their unique appearance and low diversity. Amblypygids can be large, with a leg span up to $60-70 \mathrm{~cm}$, but most species rarely exceed $5 \mathrm{~cm}$. The prosoma is connected to the opisthosoma via a pedicel, the pedipalps are often long and raptorial, and the bodies broad and flat. The most remarkable feature of amblypygids, however, are the thin, elongate first pair of legs that are covered in sensory organs and used as feelers, much like the antennae of insects (Weygoldt 2000a).

The common names of Amblypygi, 'whip spiders' and 'tailless whip scorpions', are misleading, as amblypygids are neither spiders nor scorpions. The long raptorial pedipalps resemble whip scorpions (Thelyphonida Latreille, 1804), and the rounded opisthosoma combined with the pedicel, resembles spiders, but they have no spinnerets or venom glands. Despite the lack of venom, amblypygids appear menacing and are widely feared (Pike 1872; Armas \& Abud Antun 2000; Jiménez \& Llinas-Gutiérrez 2005). Little is known about their biology, but all are nocturnal predators (Weygoldt 2000a; Chapin \& Hebets 2016; Miranda et al. 2016c).

A total of 220 species of Amblypygi, arranged into five families and 17 genera, are known worldwide (Harvey 2013; Miranda et al. 2018a). The oldest known amblypygid fossil can be traced back to the middle Carboniferous, $313 \mathrm{Ma}$ (Wolfe et al. 2016), but fossils are rare and knowledge about the extinct diversity and distribution of Amblypygi is fragmentary.

Despite being a small arachnid order (Harvey 2002a), a few groups of Amblypygi have been thoroughly revised (Weygoldt 1998b, 1999a). Clear diagnosis and delimitation of the species is essential for accurate species identification and improved understanding of the taxonomic diversity but is still lacking for the most speciose family in the order, Charinidae Quintero, 1986, which comprises $40 \%$ of the ordinal species diversity (Harvey 2013) in three genera, Charinus Simon, 1892 (77 species), Sarax Simon, 1892 (17 species) and Weygoldtia Miranda et al., 2018 ( 1 species). Charinidae is also the most widely distributed whip spider family, occurring across all tropical continents and the eastern Mediterranean.

The work of Goodnight \& Goodnight (1946) was a milestone in the literature on Charinidae as it presents the first figure of a complete specimen plus illustrations of some important characters, such as the carapace, sternum, pedipalp in dorsal and ventral views, and the division of the basitibia of leg IV. Quintero (1986) provided the first overview of the family, including a cladistic analysis based on morphological characters. The monophyly of Charinidae was again tested by Weygoldt (1996a), based 
on morphological characters and found to be supported only by symplesiomorphies. An overview of the higher classification of the family was presented by Rahmadi et al. (2010). Previous phylogenetic analyses included only a small number of charinid exemplars, poorly representing the morphological variation in the family, within larger matrices addressing amblypygid phylogeny (Weygoldt 1996a; Garwood et al. 2017). A recent study by the authors attempted to address these deficiencies and understand relationships among the genera and species of Charinidae, based on a more comprehensive sample (Miranda et al. 2021; Fig. 1).

The many new species of Charinidae described in recent years, especially in Brazil (Vasconcelos et al. 2013; Giupponi \& Miranda 2016; Vasconcelos \& Ferreira 2017), the Caribbean (Armas \& Maes 2000; Armas \& Pérez 2001; Armas 2014; Teruel 2016; Armas et al. 2018), and Southeast Asia (Rahmadi et al. 2010; Rahmadi \& Kojima 2010; Miranda \& Reboleira 2019), suggests that the family is far more diverse than previously thought (Giupponi \& Miranda 2016). Despite recent advances in the taxonomy of the family, a global revision of all its species, necessary to advance understanding of its systematics, biogeography and evolution, has never been conducted.

In the present contribution, the family is revised in its entirety for the first time, including all previous names and 33 new species, 24 in the genus Charinus Simon, 1892: Charinus alagoanus sp. nov.; Charinus apiaca sp. nov.; Charinus carinae sp. nov.; Charinus carioca sp. nov.; Charinus carvalhoi sp. nov.; Charinus cearensis sp. nov.; Charinus diamantinus sp. nov.; Charinus euclidesi sp. nov.; Charinus goitaca sp. nov.; Charinus guayaquil sp. nov.; Charinus imperialis sp. nov.; Charinus loko sp. nov.; Charinus magalhaesi sp. nov.; Charinus miskito sp. nov.; Charinus mocoa sp. nov.; Charinus monasticus sp. nov.; Charinus palikur sp. nov.; Charinus perquerens sp. nov.; Charinus puri sp. nov.; Charinus renneri sp. nov.; Charinus sooretama sp. nov.; Charinus souzai sp. nov.; Charinus susuwa sp. nov.; Charinus una sp. nov.; eight in the genus Sarax Simon, 1892: Sarax bilua sp. nov.; Sarax dunni sp. nov.; Sarax gravelyi sp. nov.; Sarax indochinensis sp. nov.; Sarax lembeh sp. nov.; Sarax palau sp. nov.; Sarax rahmadii sp. nov.; Sarax tiomanensis sp. nov.; and one in the genus Weygoldtia Miranda et al., 2018: Weygoldtia consonensis sp. nov. Taxonomic keys to the 132 species (excluding four nomina dubia) are presented and several taxonomic rearrangements implemented. Four subspecies are elevated to species level: Charinus cavernicolus Weygoldt, 2006; Charinus elegans Weygoldt, 2006; Charinus longipes Weygoldt, 2006; Sarax bispinosus (Nair, 1934). Sarax batuensis Roewer, 1962 is removed from synonymy with Sarax buxtoni (Gravely, 1915) and S. buxtoni newly synonymized with Sarax rimosus (Simon, 1901). Stygophrynus moultoni Gravely, 1915 is transferred to Sarax, resulting in Sarax moultoni (Gravely, 1915) comb. nov.

\section{Material and methods}

\section{Morphological nomenclature}

The fourth segment of the pedipalp is referred to as the patella in the present contribution, following Harvey \& West (1998). The homology of this segment has been debated by various authors (Fig. 2). Gaubert (1892) considered the patella of Amblypygi homologous to the patella + tibia of Araneae Clerck, 1757 and Opiliones Sundevall, 1833, a system also used by Van der Hammen (1986). Pocock (1893: 9) criticized the homologies of Gaubert (1892), arguing that, in general, the pedipalps of arachnid orders comprise six segments and "this similarity in the number would lead one to think a priori that the separate segments are numerically homologous each to each throughout the class." Pocock (1893) did not suggest a name for the fourth segment of the pedipalp, however.

Snodgrass (1948) referred to the fourth segment of the pedipalp as the patella in his "Pedipalpi" (comprising Amblypygi, Pseudoscorpiones, Schizomida, Scorpiones and Thelyphonida), but did not mention it explicitly for Amblypygi. Snodgrass (1948) traced homology based on the position of the segments and muscle structure, as described in Börner (1904) and Barrows (1925). This idea was followed 
by later authors, such as Shear et al. (1987), Shultz (1989) and Harvey (1992), until a hypothesis for the homology of the pedipalp segments was formally proposed by Harvey \& West (1998).

Quintero (1981) published an influential work on Amblypygi in which the homologies of Börner (1904) were followed, and the pedipalp segments named as follows: coxae, trochanter, femur, tibia, basitarsus and tarsus. However, Quintero (1981) omitted the claw because the pedipalp tarsus and claw are fused in Phrynidae Thorell, 1883, the group on which his proposal was based. The homology hypothesis of Quintero (1981) was subsequently adopted by Weygoldt (1996a, 1996b, 1998b, 1999a, 2000a), whose work is considered the basis for modern Amblypygi systematics.

Although the number and position of spines on the pedipalp articles are widely used in whip spider systematics, taxonomists disagree on the number of spines on the femur and patella, perhaps because the distinction between spines and setiferous tubercles remains unclear. In the present contribution, spines are generally long cuticular projections, with a seta inserted laterally or basally, situated on the frontal margins of the dorsal and ventral articles of the pedipalp (Figs 3-4, 40B-D). Even small spines resembling setiferous tubercles, possess a seta laterally, never apically (Fig. 40C). Setiferous tubercles, on the other hand, are almost always shorter, possess a seta apically and are scattered across the various segments of the pedipalp. The size of a projection does not reveal its identity, but can provide information about the series of spines to which it belongs.

Counting of the femoral spines commences with the spine closest to the trochanter (proximally; Fig. 3), which is always preceded by a row of one to four setiferous tubercles (Charinidae) or spines (Charontidae Simon, 1892, Phrynichidae Simon, 1892 and Phrynidae). The large spines form the primary row (or series) which, depending on the species, are intercalated with smaller spines, the secondary row (or series). The spines of the secondary row usually occur in the same row as the primary series but, in some species, the secondary ventral row is situated prolaterally, parallel to the primary series (e.g., C. carioca sp. nov., C. diamantinus sp. nov.). Only spines in the primary series are considered when identifying species.

Secondary rows of spines are absent in small species of Charinus and Sarax, such as those from the Caribbean, central Amazonia and continental Southeast Asia, but are usually present in large species, e.g., in the Charinus from the Brazilian Atlantic forest and the Sarax from Borneo. The secondary row therefore appears to be related to the size of the species and is mostly present in males with secondary sexual dimorphism and females of large species (e.g., C. diamantinus sp. nov., C. mysticus Giupponi \& Kury, 2002).

In the present contribution, the parts of the pedipalp and chelicera are termed segments, whereas the multi-articulated leg I and the basitibia and tarsus of leg IV are termed articles, and pseudo-articles, respectively, following Weygoldt (2000a) and Baptista \& Giupponi (2002). The pedipalp spines are counted from proximal to distal on the femur and from distal to proximal on the patella, following Weygoldt (2000a) (Figs 3-4). The teeth of the chelicerae are also counted from distal to proximal. The nomenclature of arolium fine structures follows Wolff et al. (2015).

The largest spine on the patella is considered the first (Fig. 4). The projection between this spine and the distal margin of the article is, usually, a setiferous tubercle, as it possesses a seta apically. However, in some species, mostly Sarax, the seta is inserted laterally on this projection. In such cases, it is considered a spine but not counted as part of the primary series. As on the femur, the patella also possesses two series of spines, primary and secondary. The secondary series always intercalate with the primary series, located in the same row, and always smaller. When the projection between spine I and the distal margin of the patella is a spine, it should be counted as part of the secondary series.

The projection between spine I and the ventrodistal margin of the patella is usually a setiferous tubercle, with the exception of a few species of Charinus, Sarax yayukae Rahmadi, Harvey \& Kojima, 2010, and 
Weygoldtia, in which it is a spine, that may be curved or straight. When a spine is present, it is excluded from the count of the primary series of spines.

Nomenclature for sensilla on the first leg in the present contribution follows Igelmund (1987). Nomenclature of the gonopod structures of males follows Giupponi \& Kury (2013).

\section{Taxon sampling and material examined}

Material was examined for 99 of the 129 Charinidae species during the preparation of this revision. The remaining thirty species are indicated as 'not examined' in the Material section, although a list of repositories, localities, numbers and sex of the type specimens is provided. Species for which material was not examined are assigned to the genera Charinus or Sarax based on the original descriptions and redescriptions, when available. Generic descriptions are presented in order to avoid repetition of constant/invariant characters in the species descriptions.

For practical reasons, all Figures have been placed at the end of the paper.

\section{Material examined is deposited in the following collections}

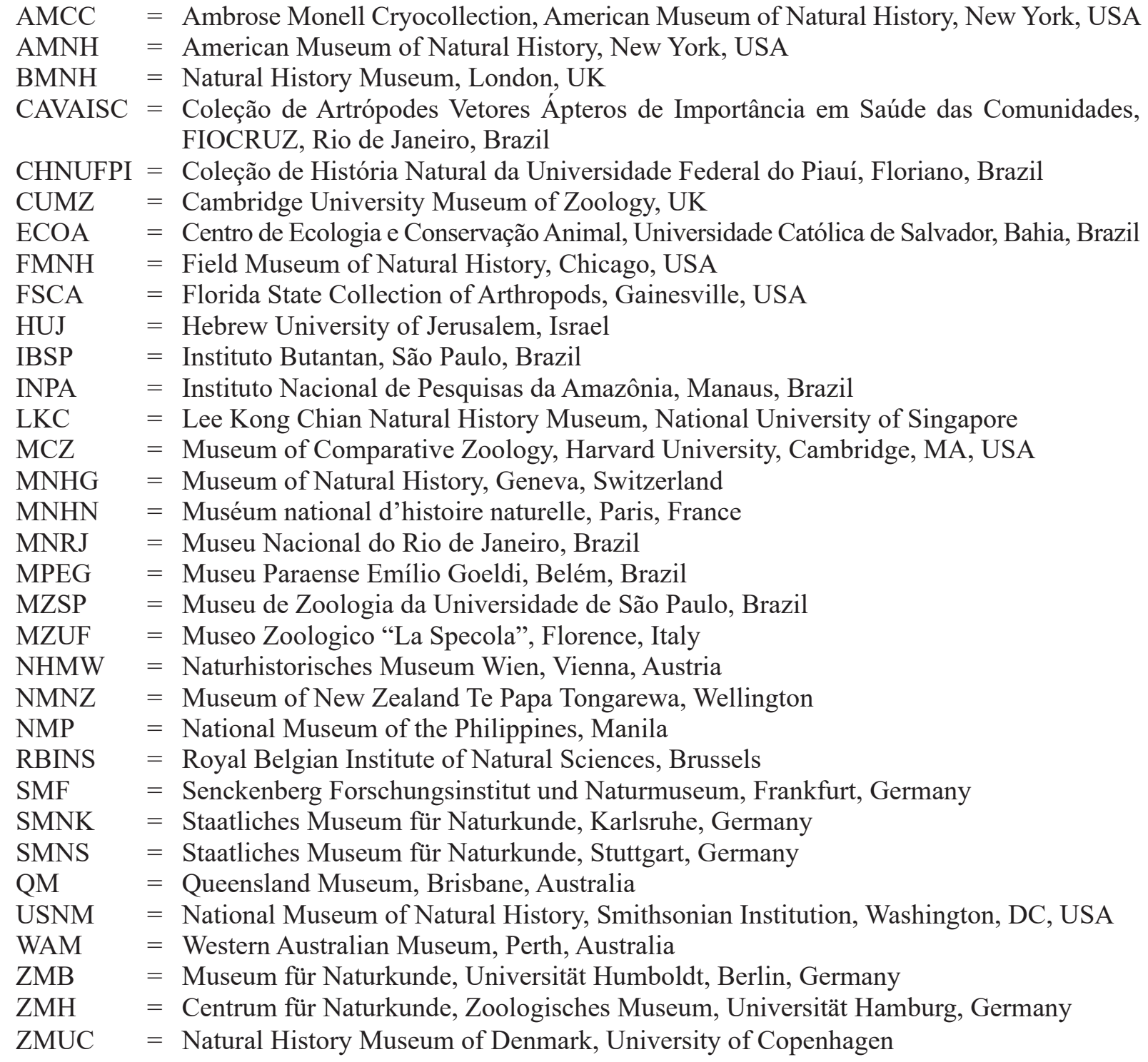




\section{Institutions cited as repositories of material which was not accessed, are as follows}

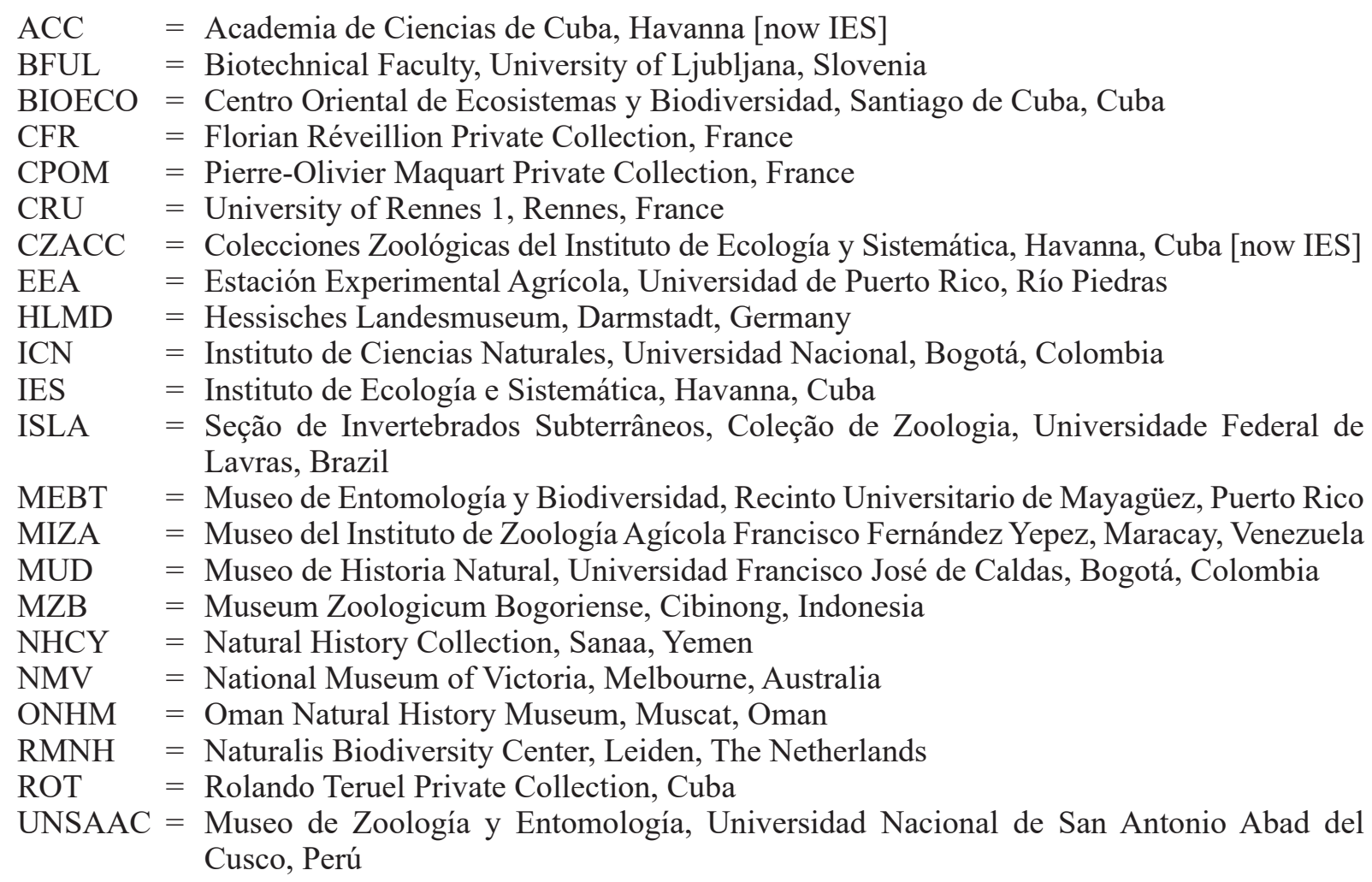

\section{Microscopy, imaging and mapping}

Specimens were studied and measurements recorded using a Leica M205AC stereo microscope. Measurements of pedipalp segments, taken from several specimens when possible, were recorded between the retrolateral condyles of each segment in order to establish fixed landmarks (Baptista \& Giupponi 2002). Measurement accuracy is indicated in the legend of each figure. Total body length, often used as a diagnostic character among species of Charinus, was omitted due to the flexibility of the opisthosoma. The more reliable diagnostic metrics, carapace width, pedipalp femur length, and femur I length were used instead.

Photographs were taken with a BK plus Imaging System from Visionary Digital (Palmyra, PA, USA; http://www.visionarydigital.com) equipped with a Canon 7D digital camera at the Natural History Museum of Denmark. Stacks of images from multiple focal planes were combined using Zerene Stacker (Zerene Systems LLC, http://zerenesystems.com/cms/stacker) and processed in Photoshop CS6 (Adobe, San Jose, CA, USA) to adjust for color, brightness, and contrast. Plates were mounted in Adobe InDesign. To generate the scanning electron micrographs (SEM), specimens were first dehydrated in a series of ethanol concentrations from $75 \%$ to $100 \%$ ethanol, with $10 \%$ differences between consecutive concentrations, for 20-30 min and then stored overnight in 100\% ethanol. Specimens were subsequently cleaned ultrasonically for 30 seconds using a Branson 200 sonicator (Danbury, CT, USA). The parts of the specimens to be mounted were critical point dried using a Baltec CPD-030 dryer (Balzers, Liechtenstein). Dried parts were attached to round-headed rivets using aluminium tape with conductive adhesive and coated with platinum-paladium in a JEOL JFC-2300HR high resolution coater (JEOL, Tokyo, Japan). Scanning electron micrographs were taken with a JEOL JSM-6335F scanning electron microscope at the Natural History Museum of Denmark, and at the Fundação Oswaldo Cruz, Rio de Janeiro.

Maps were created with ArcMap 10.2 (ESRI, Redlands, CA, USA) using vector layers for countries and states/provinces. Geographical coordinates for localities on the labels and information in the literature, were obtained with Google Earth. 


\section{Results}

Class Arachnida Cuvier, 1812

Order Amblypygi Thorell, 1883

Family Charinidae Quintero, 1986

Charinidae Quintero, 1986: 204, 205.

Charinidae - Weygoldt 1996a: 200. — Armas \& Pérez 2001: 62. — Harvey 2003: 3. — Armas 2006b: 225; 2014: 31 .

\section{Type genus}

Charinus Simon, 1892, by original designation.

\section{Included taxa}

Charinus Simon, 1892, Sarax Simon, 1892 and Weygoldtia Miranda, Giupponi, Prendini \& Scharff, 2018.

\section{Diagnosis}

Charinidae may be separated from other families of Amblypygi by the following combination of characters: pedipalp trochanter with two ventral spines (dorsal spine absent); pedipalp tibia with two dorsal spines and one ventral spine; ventral spine on pedipalp tibia situated distally; pedipalp tarsus with one to three dorsal spines; anteroventral apophysis of pedipalp trochanter setiform not spiniform; basal segment of chelicera with four teeth, proximal tooth bicuspid; pedipalp tarsus and claw articulated; distitibia IV with $b c$ and $b f$ series with same trichobothrial counts, from four to nine; tarsus of walking leg with arolium.

\section{Distribution}

Charinids occur on all tropical continents and the eastern Mediterranean. Despite the wide distribution of the family, most of the species are narrowly distributed, often known from one location only. The family has been reported from the following countries and territories: Australia, Belize, Brazil, Cambodia, Colombia, Cuba, Dominican Republic, Ecuador, Equatorial Guinea, French Guiana, Ghana, Greece, Guadeloupe, Guinea, Guyana, India, Indonesia, Israel, Italy, Jamaica, Jordan, Kenya, Laos, Madagascar, Malaysia, Martinique, New Caledonia, Oman, Pakistan, Palau, Panama, Papua New Guinea, Philippines, Puerto Rico, Saint-Barthélemy, Samoa, São Tomé and Príncipe, Seychelles, Sierra Leone, Singapore, Solomon Islands, Somalia, Surinam, Thailand, Timor-Leste, Turkey, US Virgin Islands, Venezuela, Vietnam, Yemen.

\section{Remarks}

The family name Charinidae has been widely used for Amblypygi since first proposed by Quintero (1986) (Appendix, Table 1). However, Pyron et al. (2014) pointed out that Charinidae is a homonym, as the snake family Charinidae Gray, 1849 has nomenclatural priority (Appendix, Table 2), and argued that the whip spider family Charinidae should be suppressed and replaced with the name Charinusiidae.

Quintero \& Shear (2016) submitted a case to the ICZN, demonstrating that Charinidae had been used only nine times for snakes since formalized by Cope (1886a, 1886b), whereas Charinidae had been used more than ninety times for whip spiders since 1986. Quintero \& Shear (2016) suggested the family name should be prioritized for whip spiders rather than for snakes, citing article 23.9 in the Code, the so-called precedence act. As the case is yet to be considered by the ICZN, the opinion of Quintero \& Shear (2016) 
is followed in the present contribution: Charinidae Quintero, 1986 is considered a nomen protectum and a valid name whereas Charinidae Gray, 1849 is considered a nomen oblitum and consequently an invalid name (Quintero \& Shear 2016).

\section{Key to identification of the genera of Charinidae Quintero, 1986}

1. Leg IV distitibia with seven to nine trichobothria in frontal and caudal series; carapace with straight carina anterior to lateral eyes (Fig. 151A)

Weygoldtia Miranda, Giupponi, Prendini \& Scharff, 2018

- Leg IV distitibia with four to six trichobothria in the frontal and caudal series; carapace without straight carina anterior to lateral eyes (Figs 20, 35A, 105C).

2. Opisthosoma without ventral sac cover; seta associated with lateral ocular triad situated posteriorly (Fig. 37A-B).

Charinus Simon, 1892

- Opisthosoma with (Southeast Asian species) or without (African, Indian and Middle Eastern species) ventral sac and ventral sac cover; seta associated with lateral ocular triad situated laterally

Sarax Simon, 1892

Genus Charinus Simon, 1892

Figs 2-102; Tables 1-7

Charinus Simon, 1892: 48 (type species: Phrynus australianus L. Koch, 1867, by original designation). Enantiosarax Mello-Leitão, 1931: 55 (synonymized by Quintero 1983: 46) (type species: Enantiosarax schirchii Mello-Leitão, 1931, by monotypy).

Oligacanthophrynus Caporiacco, 1947: 21 (synonymized by Weygoldt 1998a: 72) (type species: Oligacanthophrynus guianensis Caporiacco, 1947, by original designation).

Speleophrynus Ravelo, 1975: 78-79 (synonymized by Quintero 1983: 27) (type species: Speleophrynus tronchonii Ravelo, 1975, by original designation).

Tricharinus Quintero, 1986: 206 (synonymized by Weygoldt 2000a: 25) (type species: Tricharinus guianensis Quintero, 1986, by original designation).

Charinus - Kraepelin 1895: 46; 1899: 248-249. — Gravely 1915b: 442. — Mello-Leitão 1931: 54. Werner 1935: 471. — Weygoldt 1999b: 48; 2000a: 23-24. — Armas \& Pérez 2001: 62. — Harvey 2003: 3-4. - Armas 2006b: 225; 2014: 31.

Oligacanthophrynus - Caporiacco 1948: 616.

\section{Type species}

Phrynus australianus L. Koch, 1867, by original designation.

\section{Diagnosis}

Charinus may be distinguished from the other two genera of Charinidae by the following combination of characters: lateral eyes situated at least three times diameter of one ocellus from carapace lateral margin, with seta posterior to lateral ocular triad (Fig. 37A-B); setiferous tubercles situated far apart on dorsal carina of pedipalp coxa; female gonopod cushion-like (Figs 5C-D, 7C-D), finger-like or suckerlike (Figs 5A-B, 7A-B); posterior margin of female genital operculum straight or rounded (Fig. 17); area of genital operculum between gonopods and posterior margin smooth in dorsal view (Fig. 17).

Unlike Charinus, in which the area of genital operculum between the gonopods and posterior margin is smooth, and the posterior margin curved dorsally, the area has denticulate projections in Sarax (Figs $106 \mathrm{D}, 113 \mathrm{D})$, and the posterior margin is linear in Weygoldtia. 


\section{Etymology}

Unknown, but likely to be the diminutive of the name Charon.

\section{Description}

CARAPACE. Frontal process well developed, much wider than long, with blunt, rebordered or acute apex (Figs 42C, 54C). Carapace dorsoventrally compressed, wider than long. Median eyes and ocular tubercle or, when tubercle absent, anterior depression, leading to narrow medial sulcus that extends around posterior area of pair of lateral humps situated behind lateral eyespots (Fig. 35A). Anterior margin rounded with fine setae and corners slightly depressed; with 6-10 small setae, two medial setae usually directly anterior to median ocular tubercle (Fig. 37A). Carina originating at anterolateral margin, widening posteriorly from coxa I and onwards, widest dorsal to coxae III and IV, and reaching posterior margin. Many tiny punctations, more abundant in anterior area (Fig. 33A), arranged in lines and spots, irradiating from fovea and interspersed with glabrous areas. Three pairs of deep sulci and very deep, rectangular or triangular fovea (corners form starting point of second and third sulci). First pair of sulci situated slightly posterior to lateral boss and not reaching midline. Four pairs of lateral depressions (first placed over first pair of sulci). Lateral eyes well developed, or reduced to small, whitish spot, without cornea or clearly defined lens (only small roundish knob), rarely absent.

Sternum. Four-segmented, all platelets sclerotized and convex (Fig. 31B). Tritosternum with round base, projected anteriorly into long or small, blunt tubercle, with two apical setae and two basal setae (Fig. 24B). Medial platelet (tetrasternum) rounded, convex, with two setae and few setulae; formed by single (Fig. 30B) or paired (Fig. 24B) platelets. Third platelet (pentasternum) also rounded and convex, but smaller, with shorter setae than second platelet; formed by single (Fig. 30B) or paired (Fig. 24B) platelets. Metasternum paired in anterior half, with anterior setae in membranous region followed by two or three setae in sclerotized area, arranged in longitudinal row from unsclerotized to sclerotized region; distal border with small elevation bearing 2-8 large setae. Sternites separated from each other by twice diameter of medial platelet.

OpISTHosoma. Oblong, with almost indistinguishable punctations, finer than on carapace (Fig. 30A).

GeNITALIA. Female gonopods rounded or oval, sucker-like (barrel shaped), with rounded opening (Fig. 65), finger-like (in C. africanus Hansen, 1921 only) or cushion-like, with wide atrial opening or covered with claw-like projection (Fig. 22). Male gonopods slightly wider than long, soft, only posterolateral margin of dorsal lobes and basal sclerite of lateral lobes sclerotized; median lobes long and thin, lamellar, with wide, rounded tip, almost reaching apex of lateral lobes (Fig. 25).

Chelicerae. Cheliceral furrow with four prolateral teeth (Fig. 10), distal tooth bifid. Fourth tooth twice as long as others and much stouter. Tooth length (from tip to base) IV $>\mathrm{Ia}>\mathrm{Ib}=\mathrm{II}>\mathrm{III}$. Claw with 5-13 denticles (Fig. 11A-B, E-F).

PEDIPALPS. Coxa with dorsal carina rounded in shape; $2-5$ equidistant setae along prolateral margin, and 0-6 setae encircled by round carina. Trochanter with large distal, spiniform, ventral apophysis, bearing many prominent setae, and with blunt apex pointed anteriorly, and two subequal spines, one in median third and other at distal apex of prolateral surface (Fig. 2). Femur with 2-7 dorsal spines in primary series, decreasing in size, sometimes with secondary row of spines (Fig. 3A-D); femur dorsal surface with row of 2-4 setiferous tubercles between spine 1 and proximal margin of segment; 2-6 ventral spines in primary series, sometimes with secondary row of spines; setiferous tubercle or spine between spine ventral 1 and proximal margin, aligned with primary series or displaced dorsally. Patella with 3-6 dorsal spines in primary series, decreasing in lengths (Fig. 4A-D); small setal tubercle between spine I and distal margin of patella; 2-6 ventral spines, distal larger; $1-4$ setiferous tubercles or 1-2 spines 
between ventral spine I and distal margin. Tibia with two dorsal spines, distal at end of proximal half, proximal in proximal third (Fig. 30); ventral spine in distal half, around two-thirds length of tibia, and 2 or 3 setal tubercles proximal to spine; row of 2-5 long, thin setae (longer than others in vicinity). Tarsus with 1-3 curved spines in proximal half (Figs 13,52D); cleaning organ about half article length of tarsus. Claw (apotele) with long, acute, curved apex.

LEGS. All very setose. Femur length on leg I $>$ III $>$ IV $>$ II; ventral corner of prolateral surface of leg II-IV femora projecting into distinct spiniform process. Tibia of leg I with 16-25 articles (up to 47 in regenerated legs); distal articles of tibia each with two small trichobothria, one on dorsal and one on prolateral side of article; one trichobothrium on second, third and fourth (from distal to proximal) articles, close to distal border, all situated dorsally; no trichobothria on other articles. Leg I tarsus (basitarsus + distitarsus) with 23-43 articles (up to 62 in regenerated legs); apical article with claw, tarsal organ and rod sensilla (Fig. 16). Leg IV basitibia with 2-4 pseudo-articles, one trichobothrium on last pseudo-article. Leg IV distitibia with one basal, two median and 13-18 distal trichobothria. Leg IV basitibia-distitibia length BT1 $>$ DT $>$ BT3 $=$ BT4 $>$ BT2. Leg IV basitarsus/distitarsus ratio 7/4, distitarsus tetramerous.

\section{Included taxa}

Charinus acaraje Pinto-da-Rocha, Machado \& Weygoldt, 2002; Charinus acosta (Quintero, 1983); Charinus africanus Hansen, 1921; Charinus aguayoi Moyá-Guzmán, 2009; Charinus alagoanus sp. nov.; Charinus apiaca sp. nov.; Charinus asturius Pinto-da-Rocha, Machado \& Weygoldt, 2002; Charinus australianus (L. Koch, 1867); Charinus bahoruco Teruel, 2016; Charinus belizensis Miranda, Giupponi \& Wizen, 2016; Charinus bichuetteae Giupponi \& Miranda, 2016; Charinus bonaldoi Giupponi \& Miranda, 2016; Charinus bordoni (Ravelo, 1977); Charinus brasilianus Weygoldt, 1972; Charinus brescoviti Giupponi \& Miranda, 2016; Charinus bromeliaea Jocqué \& Giupponi, 2012; Charinus bruneti Teruel \& Questel, 2011; Charinus caatingae Vasconcelos \& Ferreira, 2016; Charinus camachoi (González-Sponga, 1998); Charinus carajas Giupponi \& Miranda, 2016; Charinus caribensis (Quintero, 1986); Charinus carinae sp. nov.; Charinus carioca sp. nov.; Charinus carvalhoi sp. nov.; Charinus cavernicolus Weygoldt, 2006, new rank; Charinus cearensis sp. nov.; Charinus centralis Armas \& Ávila Calvo, 2000; Charinus cubensis (Quintero, 1983); Charinus decu (Quintero, 1983); Charinus desirade Teruel \& Questel, 2015; Charinus diamantinus sp. nov. Charinus diblemma Simon, 1936, nomen dubium; Charinus dominicanus Armas \& Pérez, 2001; Charinus elegans Weygoldt, 2006, stat. nov.; Charinus eleonorae Baptista \& Giupponi, 2003; Charinus euclidesi sp. nov.; Charinus fagei Weygoldt, 1972; Charinus ferreus Giupponi \& Miranda, 2016; Charinus gertschi Goodnight \& Goodnight, 1946; Charinus goitaca sp. nov.; Charinus guayaquil sp. nov.; Charinus guianensis (Caporiacco, 1947), nomen dubium; Charinus guto Giupponi \& Miranda, 2016; Charinus imperialis sp. nov.; Charinus insularis Banks, 1902; Charinus iuiu Vasconcelos \& Ferreira, 2016; Charinus jeanneli Simon, 1936, nomen dubium; Charinus jibaossu Vasconcelos, Giupponi \& Ferreira, 2014; Charinus kakum Harms, 2018; Charinus koepckei Weygoldt, 1972; Charinus loko sp. nov.; Charinus longipes Weygoldt, 2006, stat. nov.; Charinus longitarsus Armas \& Palomino-Cárdenas, 2016; Charinus madagascariensis Fage, 1954; Charinus magalhaesi sp. nov.; Charinus magua Seiter, Schramm \& Schwaha, 2018; Charinus martinicensis Teruel \& Coulis, 2017; Charinus milloti Fage, 1939; Charinus miskito sp. nov.; Charinus mocoa sp. nov.; Charinus monasticus sp. nov.; Charinus montanus Weygoldt, 1972; Charinus muchmorei Armas \& Teruel, 1997; Charinus mysticus Giupponi \& Kury, 2002; Charinus neocaledonicus Kraepelin, 1895; Charinus orientalis Giupponi \& Miranda (2016); Charinus palikur sp. nov.; Charinus papuanus Weygoldt, 2006; Charinus pardillalensis (González-Sponga, 1998); Charinus pecki Weygoldt, 2006; Charinus perezassoi Armas, 2010; Charinus perquerens sp. nov.; Charinus pescotti Dunn, 1949; Charinus platnicki (Quintero, 1986); Charinus potiguar Vasconcelos, Giupponi \& Ferreira, 2013; Charinus puri sp. nov.; Charinus quinteroi Weygoldt, 2002; Charinus reddelli Miranda, Giupponi \& Wizen, 2016; Charinus renneri sp. nov.; Charinus ricardoi Giupponi \& Miranda, 2016; Charinus 
rocamadre Torres-Contreras, García \& Armas, 2015; Charinus ruschii Miranda et al., 2016; Charinus santanensis Vasconcelos \& Ferreira, 2017; Charinus schirchii (Mello-Leitão, 1931); Charinus sillami Réveillion \& Maquart, 2015; Charinus sooretama sp. nov.; Charinus souzai sp. nov.; Charinus spelaeus Vasconcelos \& Ferreira, 2017; Charinus susuwa sp. nov.; Charinus taboa Vasconcelos, Giupponi \& Ferreira, 2016; Charinus tingomaria Ballón-Estacio \& Armas, 2019; Charinus tomasmicheli Armas, 2006; Charinus troglobius Baptista \& Giupponi, 2002; Charinus tronchonii (Ravelo, 1975); Charinus una sp. nov.; Charinus vulgaris Miranda \& Giupponi, 2011; Charinus wanlessi (Quintero, 1983).

\section{Distribution}

Recorded from the following countries and territories: Australia, Belize, Brazil, Colombia, Cuba, Dominican Republic, Ecuador, Equatorial Guinea, French Guiana, Ghana, Guadeloupe, Guinea, Guiana, Jamaica, Kenya, Madagascar, Martinique, New Caledonia, Panama, Papua New Guinea, Puerto Rico, Saint-Barthélemy, Samoa, São Tomé and Príncipe, Sierra Leone, Surinam, US Virgin Islands, Venezuela.

\section{Remarks}

Twelve species previously assigned to Charinus are hereby transferred to Sarax based on the phylogeny of Miranda et al. (2021). Those species share with other species of Sarax the position of the lateral eyes situated near the carapace margin, the finger-like and plunger-like shape of the female gonopod, and the similar shape of the posterior margin of the genital operculum with denticulated surface on the dorsal area and ventral projections aligned with the gonopods.

\section{Key to the identification of the species of Charinus in the Caribbean and Central America}

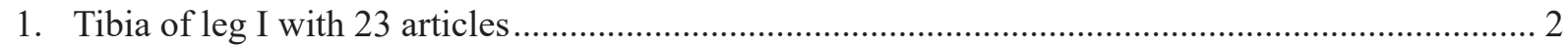

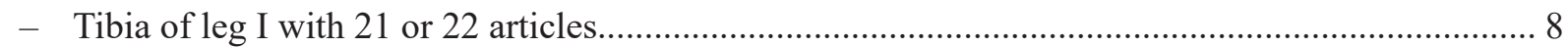

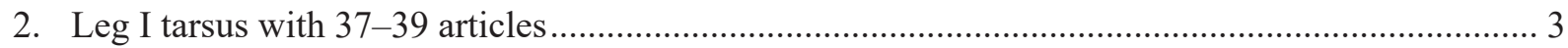

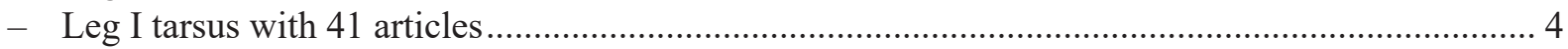

3. Median eyes absent............................................................ . muchmorei Armas \& Teruel, 1997

- Median eyes vestigial, reduced to small blackish spots; sternum platelets divided (Fig. 20E)...........

..C. cubensis (Quintero, 1983) (Fig. 20)

- Median eyes vestigial, reduced to small blackish spots; sternum platelets not divded

C. martinicensis Teruel \& Coulis, 2017

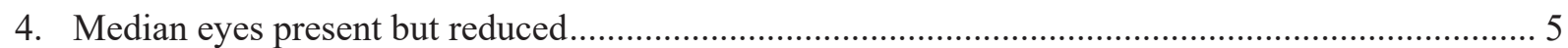

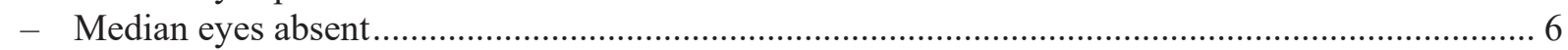

5. Pedipalp femur with three dorsal spines ..................................................... . acosta (Quintero, 1983)

- Pedipalp femur with two dorsal spines ......................................... desirade Teruel \& Questel, 2015

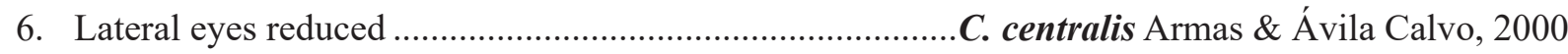

- Lateral eyes well developed................................................................................................... 7

7. Leg I tarsus, first article 1.4-1.9 times as long as second article.

C. reddelli Miranda, Giupponi \& Wizen, 2016

- Leg I tarsus, first article 3 or 4 times as long as second article

C. belizensis Miranda, Giupponi \& Wizen, 2016

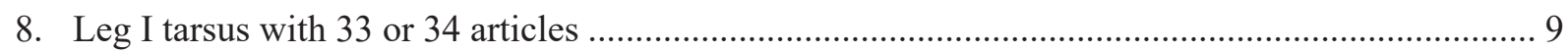

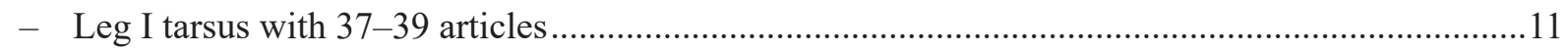


9. Median eyes present but reduced (Fig. 13A)............C. aguayoi Moyá-Guzmán, 2009 (Figs 13-16)

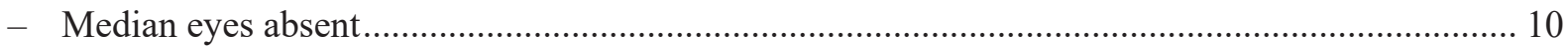

10. Pedipalp patella with three ventral spines (Fig. 21F)

- Pedipalp patella with two ventral spines

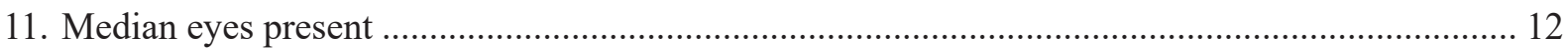

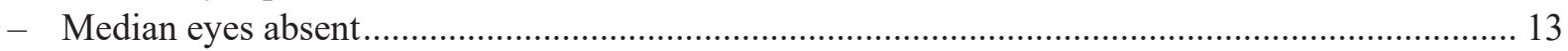

12. Median eyes well developed; pedipalp femur with four dorsal spines......

C. bruneti Teruel \& Questel, 2011

- Median eyes reduced; pedipalp femur with three dorsal spines

C. miskito sp. nov. (Figs 5E-F, 24-26)

13. Leg IV basitibia with two pseudo-articles C. caribensis (Quintero, 1986) (Figs 17-19)

- Leg IV basitibia with three pseudo-articles

14. Leg I tarsus, first article three to five times as long as second article.

- Leg I tarsus, first article shorter or longer than three times second article

15. Cheliceral claw with four teeth

C. magua Seiter, Schramm \& Schwaha, 2018

- Cheliceral claw with five teeth

C. perezassoi Armas, 2010

16. Tritosternum barely reaching base of pedipalp coxae

C. bahoruco Teruel, 2016

- Tritosternum surpassing base of pedipalp coxae

17. Leg I tarsus, first article 4.5 times as long as second article; leg I tarsus with 39 articles

C. decu (Quintero, 1983)

- Leg I tarsus, first article equal in length to second article; leg I tarsus with 37 articles

C. tomasmicheli Armas, 2006

Charinus acosta (Quintero, 1983)

Fig. 12; Table 1

Charinides acosta Quintero, 1983: 32-34, figs 1a, c, 8g, 9a-f, 12c.

Charinus acosta - Delle Cave 1986: 162, fig. II. — Ávila Calvo \& Armas 1997: 31. — Armas \& Teruel 1997: 46. - Armas 2000b: 133-134; 2004: 38; 2005: 271, 273; 2006a: 169-170; 2006b: 225-226, figs 4a-c, 5a-d, 6, 20; 2013b: 91, 94. — Armas \& Ávila Calvo 2000: 291-292. — Weygoldt 2000a: 74. - Baptista \& Giupponi 2002: 106. - Harvey 2003: 4. — Pérez \& Teruel 2004: 170, fig. 12. - Teruel et al. 2009: 201-202, fig. 1. - Teruel 2011: 345, figs 1-3. - Seiter \& Hörweg 2013: 51. - Seiter \& Wolff 2014: 233. — Wolff et al. 2015: 3, figs 2a-b; 2016: 2-4, figs 4-5; 2017: 2-3, 7, fig. 1. - Teruel \& Questel 2015: 46-47. — Torres-Contreras et al. 2015: 127. — Miranda et al. 2016b: 555, 557. - Teruel \& Rodríguez-Cabrera 2016: 135-136, fig. 3a-b.

\section{Diagnosis}

This species may be separated from other Caribbean and Central American Charinus by means of the following combination of characters: carapace frontal process with rounded apex; black median ocular tubercle reduced, sunken in carapace, with well-developed median eyes; lateral eyes well developed, 
black; bifid tooth of cheliceral basal segment with dorsal cusp shorter than ventral cusp; tritosternum projected anteriorly with meso- and metasternum undivided; prolateral surface of cheliceral basal segment with row of six fine setae; cheliceral claw with five teeth; pedipalp femur with three dorsal spines and three ventral spines; pedipalp femur with pair of setiferous tubercles preceding first dorsal and ventral spines; pedipalp patella with three dorsal spines and two ventral spines; pedipalp tarsus with two dorsal spines, proximal spine less than half length of distal spine; tibia of leg I with 23 articles, tarsus I with 41 articles; first tarsal article 1.4 times as long as second article; leg IV basitibia trichobothrium $b c$ situated equidistant between $b f$ and $s b f ; s c$ and $s f$ series each with five trichobothria; female gonopod rounded, flat and cushion-like, without claw-like projection (Quintero 1983: fig. 8g). The male is unknown.

\section{Etymology}

Patronym honoring the Cuban micropaleontologist Dr J.T. Acosta (Quintero 1983).

\section{Type material}

\section{Holotype}

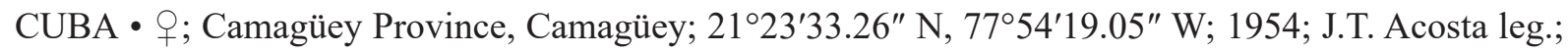
MCZ [not examined].

\section{Measurements}

See Table 1.

\section{Distribution}

Widespread in Cuba, recorded at several locations on the island (Teruel \& Rodríguez-Cabrera 2016), even in the same habitat as other Charinus, e.g., C. wanlessi, although not at the same time of year (Teruel 2011).

\section{Natural history}

Epigean, found in forests, but well adapted to disturbed habitats, e.g., Santiago de Cuba, south of the Sierra Maestra range (Teruel et al. 2009). The widespread distribution of this species may be attributed to its parthenogenetic biology (Armas 2000b, 2005, 2006b).

\section{Remarks}

The internal and external morphology of the Caribbean species of Charinus are quite homogenous, making it difficult to delimit and identify these species (Miranda et al. 2016b). Separating the Cuban species is among the most difficult, especially when comparing C. acosta and C. cubensis. The only reliable characters to separate the two species are the development of the median eyes and the counts of articles on the tarsus of leg I. Charinus acosta has reduced median eyes and the leg I tarsus consists of 41 articles, whereas C. cubensis lacks median eyes (occasionally visible as small blackish spots below the tegument) and the leg I tarsus consists of 36-37 articles. Genetic studies of the different populations of $C$. acosta and other Cuban species may illuminate the true diversity of the genus on the island. 


\section{Charinus aguayoi Moyá-Guzman, 2009}

Figs 12-16; Table 1

Charinus aguayoi Moyá-Guzmán, 2009: 70-71, figs 2-4.

Charinus victori Armas, 2010: 56-58, figs 1a-g, 2a, 4d.

Charinus aguayoi - Armas 2017: 113-114.

Charinus victori - Teruel \& Questel 2015: 47. — Miranda et al. 2016b: 555, 557, fig. 8. — Armas 2017: $113-114$.

\section{Diagnosis}

This species may be separated from other Caribbean and Central American Charinus by means of its dark coloration and secondary sexual dimorphism. Among the Caribbean species in which the male is known, $C$. aguayoi is the only species which exhibits the most distinct secondary sexual dimorphism, i.e., males possess much longer pedipalp segments than females. Compared to other species in which the tibia of leg I consists of 21-23 articles and the leg I tarsus consists of 33 articles, C. aguayoi differs from C. dominicanus, C. muchmorei and C. wanlessi in the presence of median eyes (Fig. 13A). An ontogenetic difference is evident in the size of the median eyes, which are much smaller in adults than immatures.

\section{Etymology}

Patronym honoring Dr Carlos Guillermo Aguayo, a Cuban scientist specializing in tropical invertebrates (Moyá-Guzmán 2009).

\section{Type material}

\section{Holotype}

PUERTO RICO • ₹; Río Grande municipality, 300 m E of El Verde Energy Center Station; 7 Mar. 1999; S. Moyá leg.; tropical rainforest; MEBT [not examined].

\section{Paratypes}

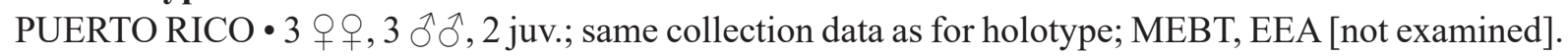

\section{Additional material}

PUERTO RICO • 1 q juv.; Aguas Buenas; 10 Feb. 2012; PRC059; 012CAB • 1 q; same collection data as for preceding; PRC060; 013CAB - 1 \%; same locality as for preceding; 7-17 May 1973; $250 \mathrm{~m}$ a.s.1.; S. Peck et al. leg.; forest at Aguas Buenas cave; AMNH 11 q; Route 123, $1.2 \mathrm{mi} \mathrm{S}$ of intersection with Route 524, between Utuado and Adjunctas; $18^{\circ} 12.314^{\prime} \mathrm{N}, 66^{\circ} 43.728^{\prime} \mathrm{W} ; 15$ Oct. 2009; 377 m a.s.1.; L. Prendini, J. Huff, L. Esposito and H. Yamaguti leg.; degraded rainforest scree slope with small stream along roadside; taken under stones; AMCC [LP 10170] • 1 万; Bosque Nacional

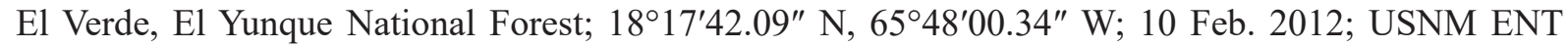

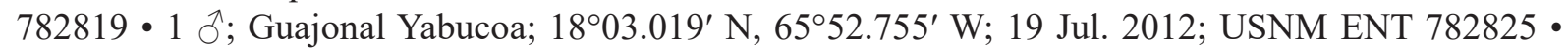
1 क ; same collection data as for preceding; USNM ENT 782808 1 ○े juv.; same collection data as for preceding; USNM ENT $783494 \bullet 1$ juv.; same collection data as for preceding; USNM ENT 783487 • 1 juv.; same collection data as for preceding; USNM ENT 783483 • 1 क ; Guajonales Matuyas, Alto Maunabo; 23 Jul. 2012; USNM ENT 785110 • 1 §; same collection data as for preceding; USNM ENT $782527 \bullet 1$ juv.; same collection data as for preceding; CarBio $2401 \mathrm{~A} \bullet 1$ juv.; same collection data as for preceding; CarBio 541A • 1 juv.; same locality as for preceding; 10 Feb. 2012; PRC 58; CarBio $2540 \mathrm{~A} \bullet 1$ juv.; same collection data as for preceding; CarBio 011CAB $\bullet 1$ क ; same locality; 10 Feb. 2012; PRC057; B10AB • 1 क; Peñuelas, Cueva Mapancha; 7 Jul. 2012; CarBio • 1 ô; Rio Grande 
Rio Yunque, El Verde; $18.321688^{\circ} \mathrm{N}, 65.819908^{\circ} \mathrm{W} ; 16-18 \mathrm{Jul} .2011 ; 100$ m. a.s.1.; Agnarsson et al. Team 1 leg.; PR001; CR-LI/BUR; USNM ENT 392977• 1 ○े; same collection data as for preceding; USNM ENT 392962 • 1 o ; same collection data as for preceding; USNM ENT 392752 • 1 §; same collection data as for preceding; USNM ENT $392988 \bullet 1$ \&; USNM ENT $00392775 \bullet 1$ juv.; same collection data as for preceding; USNM ENT $392904 \bullet 1$ juv. + ; same collection data as for preceding; USNM ENT 392798.

\section{Supplementary description}

CARAPACE. Six anterior setae (Fig. 13A); frontal process triangular. Small granules densely scattered between ocular triads and among sulci. Median eyes present but median ocular tubercle shallow (Fig. 13A); pair of setae on median ocular tubercle; lateral eyes well developed, seta posterior to each lateral ocular triad (Fig. 13A); lateral ocular triad well separated from carapace margin (Fig. 13A).

STERnUm. Tritosternum projected anteriorly with typical setation, long, surpassing base of pedipalp coxae (Fig. 13B); other sternal platelets narrow and concave, each divided (forming pairs), with seta on its top; pentasternum with two setae posteriorly and without setae near membranous region.

Opisthosoma. Ventral sacs and ventral sac cover absent.

GenitaLia. Female genital operculum with large setae posteromedially and some smaller setae near margin (Fig. 14A-C); posterior margin convex (Fig. 14A-B, E); gonopod cushion-like with basal sclerotization (Fig. 14A, C); slit sensilla on lateral side of genital operculum on ventral surface (Fig. 14F). Male gonopod with apex of fistula and base of lateral lobe strongly sclerotized; lateral lobe 2 fimbriate, short (Fig. 15A-B, E); lamella medialis short (Fig. 15A); dorsal lobe with long, acute projections apically (Fig. 15A-C, G); processus internus short (Fig. 15F).

CHELICERAE. Small tooth slightly projecting from retrolateral surface of basal segment, opposite to bifid tooth; retrolateral surface of claw with small row of setae at base of claw; claw with four or five teeth; row of around ten setae on prolateral surface of basal segment; bifid tooth with dorsal cusp larger than ventral cusp.

Pedipalps. Coxal dorsal carina with three setae on anterior margin, without setae encircled by round carina. Femur with three dorsal spines and three ventral spines (Fig. 13D); two prominent setiferous tubercles between dorsal spine 1 and proximal margin; setiferous tubercle between ventral spine 1 and proximal margin. Patella with three dorsal spines in primary series (Fig. 13E); prominent setiferous tubercle distal to spine I, one-third length of spine I; two ventral spines; distinct setiferous tubercle between spine I and distal margin. Tibia with ventral spine distally and seta between spine and distal margin. Tarsus with two dorsal spines, distal spine long, more than half length of tarsus, proximal spine one-third length of distal spine (Fig. 13C); cleaning organ with 29-33 setae in ventral row.

LEGS. Tibia of leg I with 21 articles, tarsus I with 32-34 articles; first tarsal article three times as long as second; tarsal organ situated near base of claw (Fig. 16A, C-D); rod sensilla with four setae in shallow groove (Fig. 16B, E). Leg IV basitibia with three pseudo-articles, without sclerotized, denticulate margin projecting from apex of articles; trichobothrium $b t$ situated in proximal third of pseudo-article; distitibia trichobothrium $b c$ situated closer to $b f$ than to $s b f ; s c$ and $s f$ series each with five trichobothria.

\section{Measurements}

See Table 1. 


\section{Distribution}

Distributed across the island of Puerto Rico.

\section{Natural history}

Found under stones and inside a cave in tropical rainforest. Females may have 4-7 eggs or embryos (Armas 2010).

Charinus bahoruco Teruel, 2016

Fig. 12; Table 1

Charinus bahoruco Teruel, 2016: 7-8, figs 4-6, 7b, 8 .

Charinus sp. - Armas \& Pérez, 2001: 50, 59, 64, figs 2a, c, e, 11. — Armas 2004: 39; 2006b: 229, 242.

\section{Diagnosis}

Based on the description of Teruel (2016), this species may be separated from other Caribbean and Central American Charinus by means of the following combination of characters: median eyes absent, median ocular tubercle small; lateral eyes well developed; tritosternum very short (slightly longer than wide); cheliceral basal segment with retrolateral tooth reduced to vestigial boss; cheliceral claw with four or five teeth; pedipalp femur with three dorsal spines and three ventral spines; pedipalp patella with three dorsal spines and two ventral spines; pedipalp tarsus with two dorsal spines; tibia of leg I with 21 articles, tarsus I with 37 articles; leg IV basitibia with three pseudo-articles; secondary sexual dimorphism present, males larger than females.

This species resembles $C$. dominicanus, but may be differentiated by the number of articles on the tarsus of leg I, which comprises 37 articles in C. bahoruco but 33 in C. dominicanus. Additionally, C. dominicanus bears eight teeth on the cheliceral claw, whereas C. bahoruco bears four or five teeth. The count of 21 articles on tibia of leg I also differentiates C. bahoruco from C. acosta, C. belizensis, C. centralis, C. muchmorei, and C. reddelli, in which the tibia comprises 23 articles. Charinus bahoruco differs from C. acosta, C. aguayoi and C. bruneti in the absence of median eyes, and from C. caribensis in the count of three preudo-articles in basitibia of leg IV. The short tritosternum, which barely reaches base of pedipalp coxae, is a unique character this species shares with $C$. dominicanus.

\section{Etymology}

Noun in apposition referring to the name of the mountain range, Sierra de Bahoruco, where the type locality is located (Teruel 2016).

\section{Type material}

\section{Holotype}

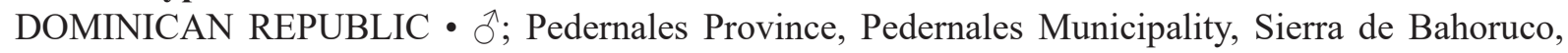
Sección Mencía, Banano, El Mulito [Río Mulito]; 1809'34" N, 7144'56" W; 12 Mar. 2014; 409 m a.s.1.; R. Teruel, F. Kovařík and P. Kindl leg.; BIOECO [not examined].

\section{Paratypes}

DOMINICAN REPUBLIC • 7 $q q, 3$ $\hat{\jmath}, 1$ juv.; same collection data as for holotype; BIOECO [not examined] $\bullet 1 \stackrel{+}{\circ}, 1$; same collection data as for holotype; IES [not examined].

\section{Measurements}

See Table 1. 
MIRANDA G.S. et al., Systematic revision of Charinidae (Arachnida, Amblypygi)

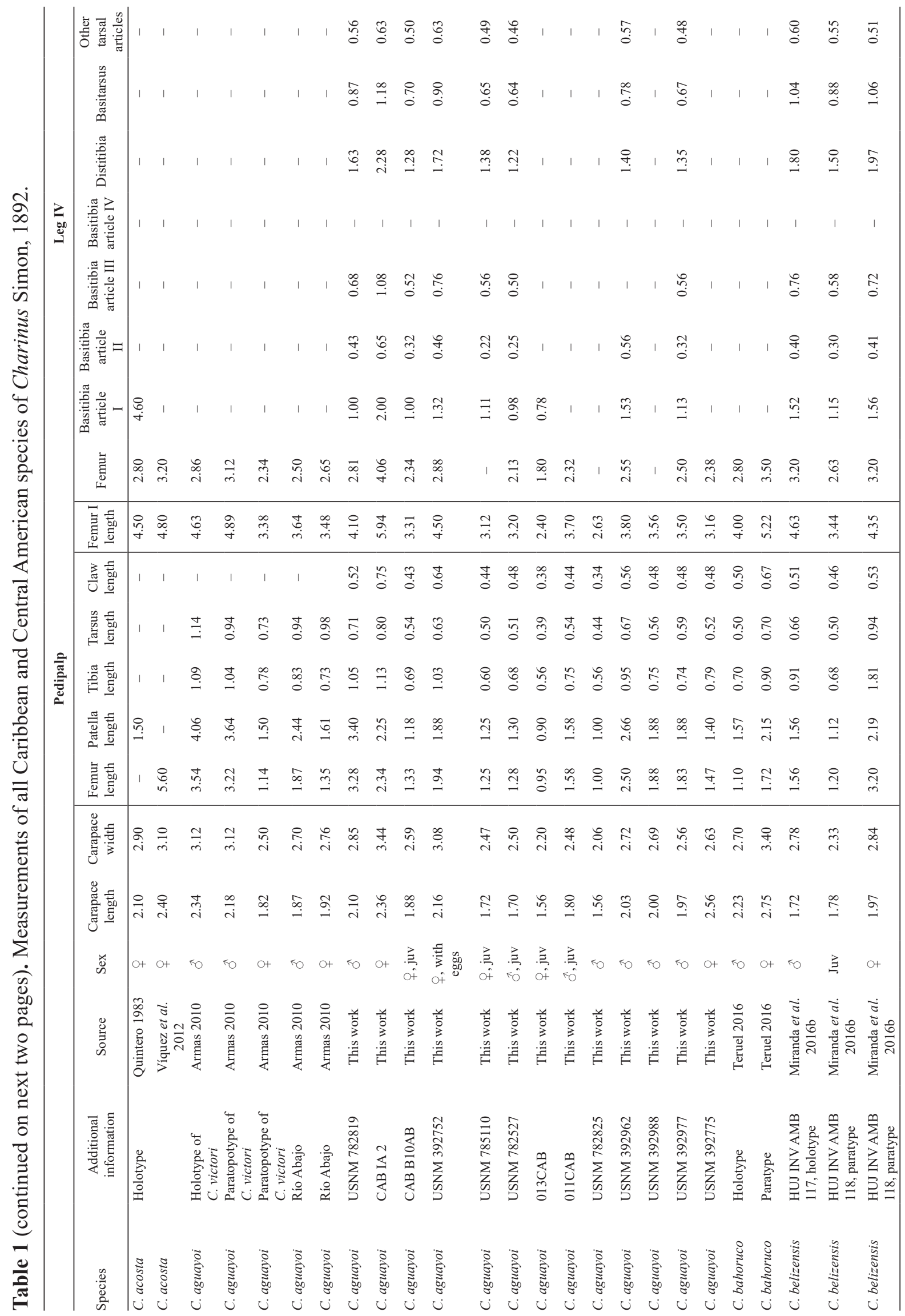




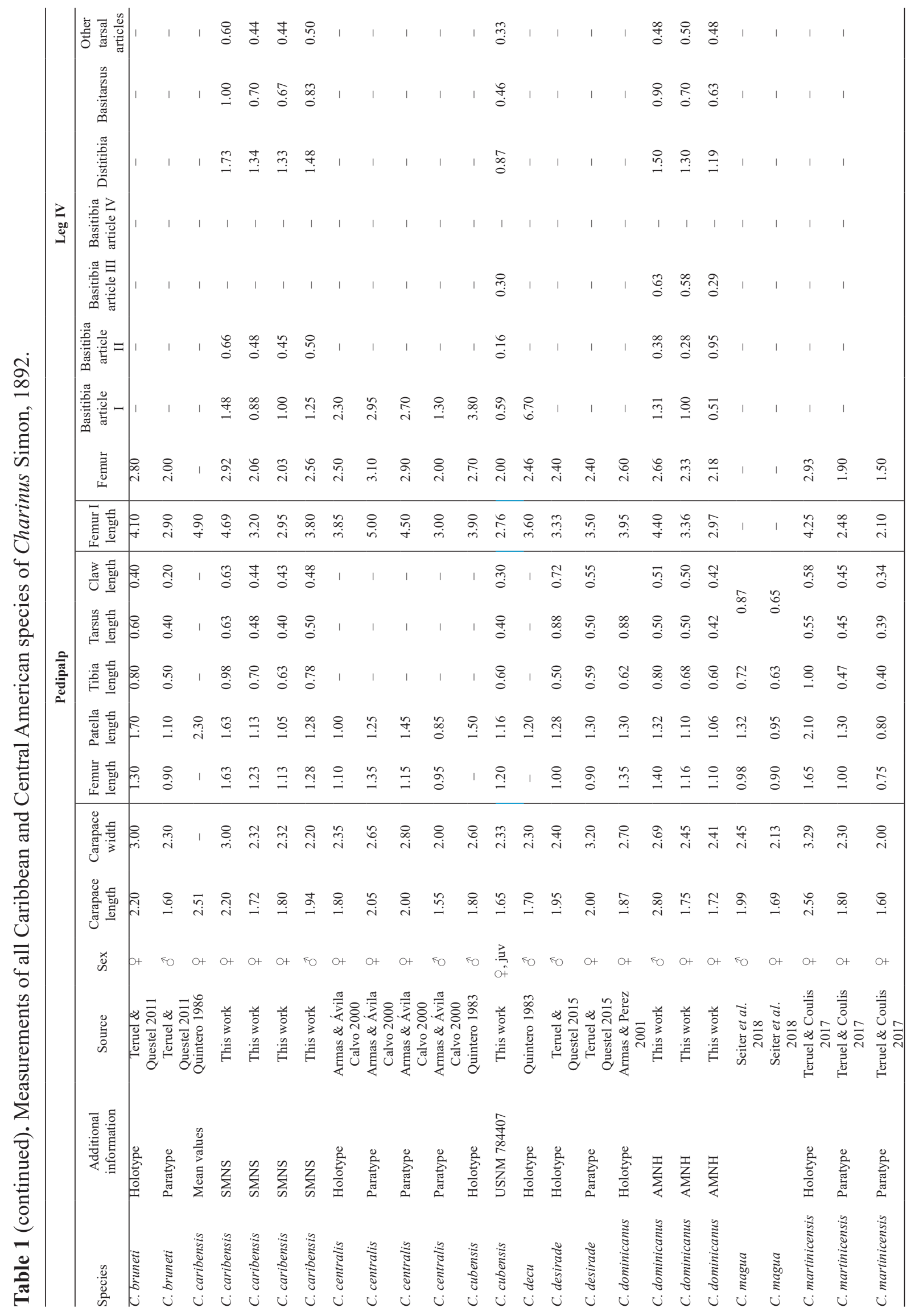




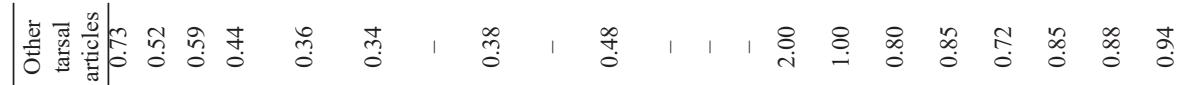

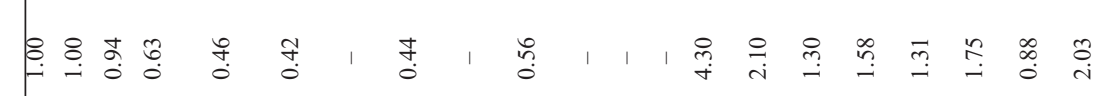

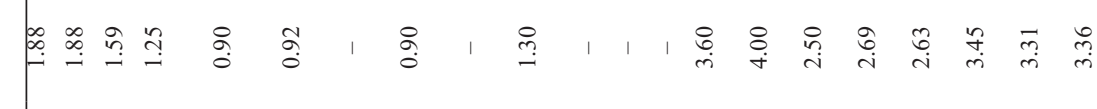

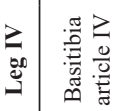

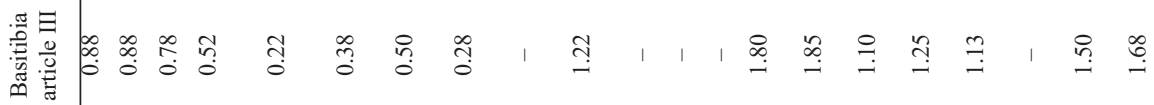

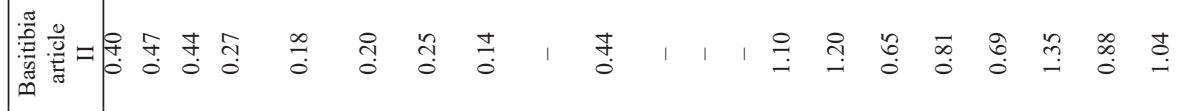

宓

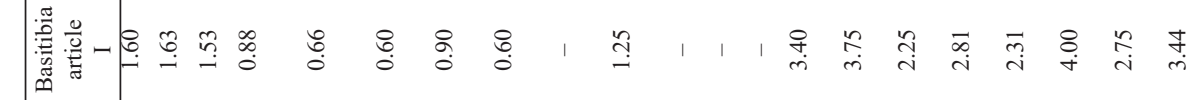

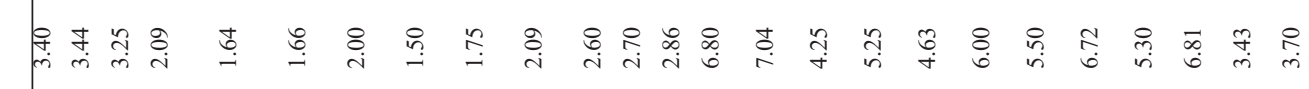

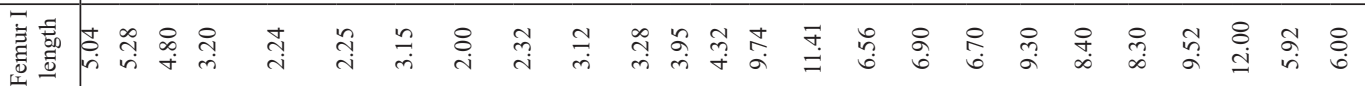

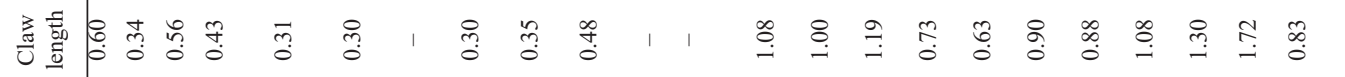

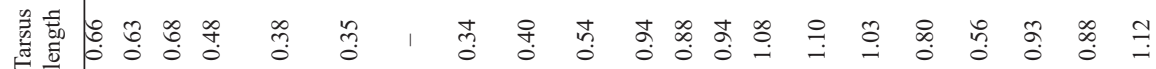

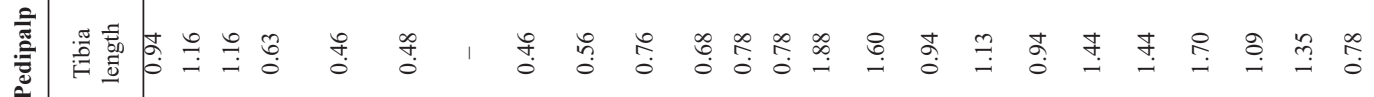

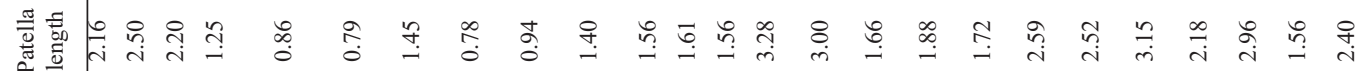

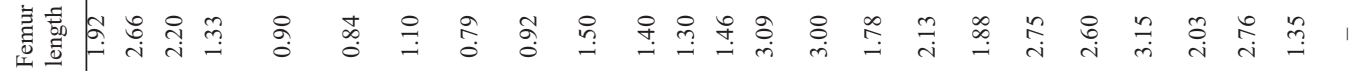

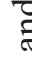

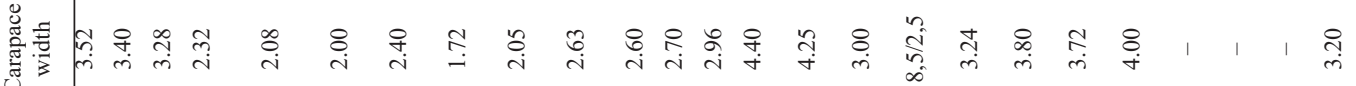

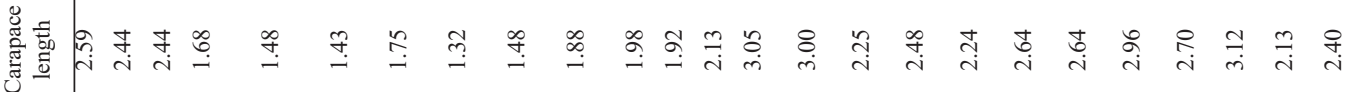

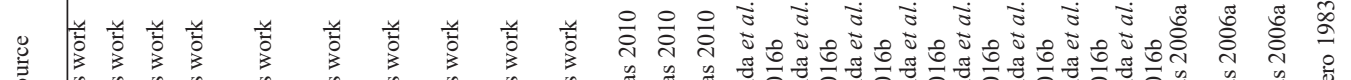

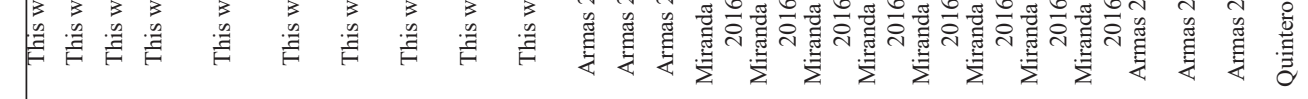

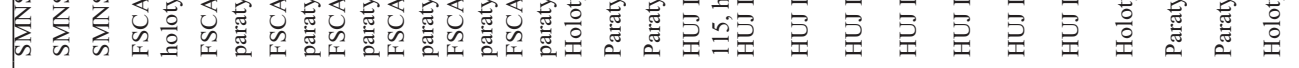
㻤宫宫 


\section{Distribution}

Known only from the westernmost part of the southern watershed of the Sierra de Bahoruco range in the Dominican Republic. Hispaniola is the second largest Caribbean island and contains ten species of whip spiders on its $76192 \mathrm{~km}^{2}$, four of which are endemic to the Dominican Republic, C. bahoruco, C. dominicanus, C. magua and Phrynus kennidae Armas \& Perez Gonzalez, 2001, the first two restricted to the Pedernales and Baharona Provinces, in and around the Sierra de Bahoruco.

\section{Natural history}

Specimens were found under rocks among leaf litter, close to streams, in a broadleaf semideciduous forest (Teruel 2016). Specimens were always in small groups of two to four individuals.

Charinus belizensis Miranda, Giupponi \& Wizen, 2016

Fig. 12; Table 1

Charinus belizensis Miranda et al., 2016b: 547-550, figs 1a, d, 2a-b, 3a, c, 4a, c, 5a-b, g, 6a, d, g, 7a, 8 .

\section{Diagnosis}

This species may be separated from other Caribbean and Central American Charinus by means of the following combination of characters: median eyes and ocular tubercle absent; gonopods cushion-like; cheliceral claw with four teeth; cusps of bifid tooth of basal cheliceral segment with dorsal and ventral projections of equal size; tibia of leg I with 23 articles; tarsus I with 41 articles, first article of leg I tarsus three or four times as long as second article.

\section{Etymology}

Adjective referring to the country, Belize, where the species occurs (Miranda et al. 2016b).

Type material (examined)

\section{Holotype}

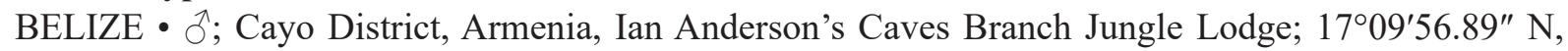
8840'55.89" W; 7 Sep. 2014; G. Wizen leg.; Caves Branch forest, nature trail, under and inside rotting logs; HUJ INV AMB 117.

\section{Paratypes}

BELIZE • 1 + , 1 juv.; same locality as for holotype; 2 Sep. 2014; G. Wizen leg.; HUJ INV AMB 118 • 1 ; ; same collection data as for preceding; MNRJ 9306.

\section{Measurements}

See Table 1.

\section{Distribution}

Known only from the type locality.

\section{Natural history}

Inhabits decomposing parts of fallen tree logs and deserted termite galleries in broadleaf forest; collected with Diplocentrus maya Francke, 1977 (Scorpiones: Diplocentridae Karsch, 1880) and millipedes of the order Platydesmida Cook, 1895. More than one individual was collected in the same log cavity, suggesting a degree of tolerance towards conspecifics. The species was observed to prey on small insects and spiders inside the log. 


\section{Remarks}

A detailed description and comparison with other species of the genus, habitat and behavior can be found in Miranda et al. (2016b).

Charinus bruneti Teruel \& Questel, 2011

Fig. 12; Table 1

Charinus bruneti Teruel \& Questel, 2011: 15-18, figs 1-4;

Charinus bruneti - Teruel \& Questel 2015: 46-47 — Miranda et al. 2016b: 555, 557.

\section{Diagnosis}

Based on the description of Teruel \& Questel (2011), this species may be separated from other Caribbean and Central American Charinus by means of the following combination of characters: median eyes, median ocular tubercle, and lateral eyes well developed; pedipalp femur with four dorsal spines and three ventral spines; pedipalp patella with three dorsal spines, large setiferous tubercle between spine I and distal margin and two ventral spines; pedipalp tarsus with two dorsal spines, distal spine twice as long as proximal spine; tibia of leg I with 22 articles, tarsus I with 39 articles; first tarsal article about three times as long as second; leg IV basitibia with three pseudo-articles.

Charinus bruneti is among the few species of Charinus in the Caribbean and Central America with median eyes, a character present only in C. acosta, C. aguayoi, C. martinicensis and C. miskito sp. nov. The average size of the five species is similar (Table 1), but the count of 39 articles on tarsus of leg I distinguishes C. bruneti from C. acosta, C. aguayoi and C. martinicensis while the count of four dorsal spines on pedipalp femur distinguishes $C$. bruneti from $C$. miskito sp. nov.

\section{Etymology}

Patronym honoring William Brunet (Teruel \& Questel 2011).

\section{Type material}

\section{Holotype}

SAINT BARTHÉLEMY • 9 ; Petite Anse, Anse des Flamands; 1755'19.64" N, 6252'04.96" W; 29 Jun. 2011; K. Questel leg.; BIOECO [not examined].

\section{Paratype}

SAINT BARTHÉLEMY • 1 q; same collection data as for holotype; BIOECO [not examined].

\section{Measurements}

See Table 1.

\section{Distribution}

Known only from the type locality.

\section{Natural history}

Specimens live under rocks in wet, densely forested ravines, and can be found near termite mounds or ant nests. One individual was observed under the same rock as a juvenile Phrynus goesii Thorell, 1889. 


\section{Remarks}

Teruel \& Questel (2011) mentioned the presence of secondary sexual dimorphism in C. bruneti in which the carapace and genital operculum are proportionally narrower in males than in females. This would be unique among amblypygids and a larger number of specimens should be analysed and measured to test this hypothesis, as Teruel \& Questel (2011) only measured two individuals of each sex..

Charinus caribensis (Quintero, 1986)

Figs 12, 17-19; Table 1

Tricharinus caribensis Quintero, 1986: 209, 211-212, figs 18-21, 27-28

Tricharinus caribensis - Weygoldt 1994: 244; 2000a: 25, 43, 129. — Ávila Calvo \& Armas 1997: 31. — Weygoldt et al. 2002: 295. — Armas 2004: 38.

Charinus caribensis - Harvey 2002b: 455; 2003: 5. - Armas 2004: 38; 2006b: 226, figs 6, 7a. Teruel \& Questel 2015: 47. — Miranda et al. 2016: 555, 557.

\section{Diagnosis}

Charinus caribensis may be differentiated from all other Caribbean and Central American Charinus by the leg IV basitibia with two pseudo-articles and by the following combination of characters: median eyes and median ocular tubercle absent; lateral eyes reduced and pale; female genitalia cushion-like (Fig. 17A-D); male genitalia distal margin of fistula on apex of lateral lobe 1 strongly sclerotized; prolateral surface of cheliceral basal segment with transverse row of six small setae, from ventral to dorsal surface; cheliceral basal segment with small tooth in retrolateral row; cheliceral claw with row of setae on retrolateral surface, basally to apically (dorsal side); cheliceral claw with five teeth; secondary sexual dimorphism of pedipalps absent; pedipalp coxa with two dorsal setae encircled by round carina and two on its margin; pedipalp femur with three dorsal spines and three ventral spines (one specimen with four ventral spines); pedipalp femur with setiferous tubercle proximal to ventral spine 1; pedipalp patella with three dorsal spines and two ventral spines; pedipalp tibia with three long ventral setae between spine I and distal margin; pedipalp tarsus with two dorsal spines, distal spine two-thirds length of tarsus and proximal spine half length of distal spine; leg I with 21 tibial and 37-39 tarsal articles; leg IV distitibia with two pseudo-articles; trichobothrium $b t$ situated in proximal third; trichobothrium $b c$ situated closer to $s b f$ than to $b f$ ( $b c$ was equidistant or closer to $b f$ than to $s b f$ in material examined); $s c$ and $s f$ series each with five trichobothria.

\section{Etymology}

Adjective referring to the Caribbean, where the species occurs (Quintero 1986).

\section{Type material}

\section{Holotype}

JAMAICA • 9 ; Parish of St. Catherine, Cave in Luidas Vale; [18 $07^{\prime} 31.47^{\prime \prime}$ N, $77^{\circ} 08^{\prime} 49.48^{\prime \prime}$ W]; 16 Jul. 1957; C.B. Lewis leg.; Institute of Jamaica [not examined].

\section{Additional material}

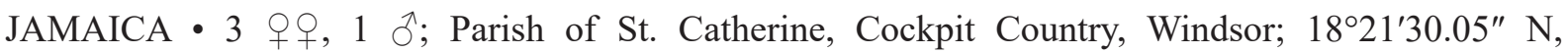
77³9’02.61" W; 15 Apr. 1993; G. Bäuele leg.; under stones, Kegelkarstgebiet forest; SMNS.

\section{Supplementary description}

CARAPACE. Six anterior setae; frontal process triangular. Small granules densely scattered between ocular triads and among sulci. Median eyes and median ocular tubercle absent. Lateral eyes well developed, seta posterior to each lateral ocular triad; lateral ocular triad well separated from carapace margin. 
STERNUM. Tritosternum projected anteriorly with typical setation, long, surpassing base of pedipalp coxae; other sternal plaques small, rounded and divided, with pair of setae on lateral margins; pentasternum without seta adjacent to membranous region and two setae posteriorly.

OpISTHOSOMA. Ventral sacs and ventral sac cover absent.

Genitalia. Female genital operculum with slender setae posteromedially and some smaller setae near margin (Fig. 17A-C); gonopod cushion-like, with closed atrium aperture (Fig. 17A, C-D), base of gonopods sclerotized; genital operculum with smooth surface in dorsal view between gonopods and posterior margin (Fig. 17B). Male gonopod with long median lobes and short fimbriate lateral lobe 2 (Fig. 18A-B, F); dorsal lobe with denticulated surface (Fig. 18D-E); apex of fistula and base of lateral lobe 2 strongly sclerotized.

CheliCerae. Small, flat tooth on retrolateral surface of basal segment, opposite to bifid tooth; small row of setae on retrolateral surface of cheliceral claw; claw with five teeth; row of four setae on prolateral surface of basal segment; bifid tooth with dorsal cusp larger than or equal to ventral cusp.

Pedipalps. Coxal dorsal carina with two setae on anterior border and one seta encircled by round carina. Femur with three dorsal spines and three ventral spines; two prominent setiferous tubercles between dorsal spine 1 and proximal margin; setiferous tubercle between ventral spine 1 and proximal margin. Patella with three dorsal spines; prominent setiferous tubercle distal to spine I, one-third length of spine I; patella with two ventral spines; setiferous tubercle between spine I and distal margin. Tibia with ventral spine distally and three setae between spine and distal margin. Tarsus with two dorsal spines, proximal spine half length of distal spine and distal spine half length of tarsus; cleaning organ with $28-32$ setae in ventral row.

LEGS. Tibia of leg I with 21 articles; tarsus I with 34-39 articles; first tarsal article twice length of second article; tarsal organ close to claw (Fig. 19A, C-D); rod sensilla with four setae in shallow groove (Fig. 19B, E). Leg IV basitibia with two pseudo-articles, without sclerotized, denticulate margin projecting from apex of articles; trichobothrium $b t$ situated in proximal third of pseudo-article; distitibia trichobothrium $b c$ situated closer to $b f$ than to $s b f ; s c$ and $s f$ series each with five trichobothria.

\section{Measurements}

See Table 1.

\section{Distribution}

Known only from the type locality and a new locality record, Windsor.

\section{Natural history}

Can be found inside caves and under stones in Kegelkarst forest areas.

\section{Remarks}

The material examined are the only known specimens besides the holotype (Armas 2004).

Charinus centralis Armas \& Ávila Calvo, 2000

Fig. 12; Table 1

Charinus centralis Armas \& Ávila Calvo, 2000: 290-291, fig. 1a-d. 
Charinus centralis - Harvey 2003: 5. - Armas 2004: 38; 2006b: 227, figs 6, 7b; 2013a: 16. - Teruel et al. 2009: 202, fig. 2. — Armas et al. 2009: 136. — Teruel \& Questel 2015: 47. — Miranda et al. 2016b: 555, 557.

\section{Diagnosis}

Based on the description of Armas \& Ávila Calvo (2000), this species may be separated from other Caribbean and Central American Charinus by means of the following combination of characters: median eyes and median ocular tubercle absent; lateral eyes reduced and unpigmented; tritosternum short and narrow; bifid tooth on cheliceral basal segment with ventral cusp larger than dorsal cusp; pedipalp femur with three dorsal spines and three ventral spines; pedipalp femur with two prominent setiferous tubercles dorsally between spine 1 and proximal margin; pedipalp patella with three dorsal spines and two ventral spines; pedipalp tarsus with two dorsal spines; tibia of leg I with 23 articles, tarsus I with 41 articles; first tarsal article 2.4-3.0 times as long as second article; leg IV basitibia with three pseudoarticles; trichobothrium $b t$ situated in proximal third and $b c$ situated equidistant between $b f$ and $s b f$.

Compared to other Cuban species, C. centralis differs from C. acosta in the absence of median eyes and the larger first article of the leg I tarsus (for details see Miranda et al. 2016b: table 1) and from the geographically closest species, C. cubensis, C. decu, and C. tomasmicheli, as well as $C$. wanlessi, by the different numbers of articles on the antenniform leg I and the distinctive size of the first article of the leg I tarsus.

\section{Etymology}

Adjective referring to the geographical distribution of this species, which occurs in the central region of Cuba (Armas \& Ávilla Calvo 2000).

\section{Type material}

\section{Holotype}

CUBA • P; Sancti Spíritus Province, Maisinicú, Trinidad; [2148’15.12" N, 7959’05.32" W]; 22 Oct. 1985; L.F. de Armas leg.; IES [not examined].

\section{Paratypes}

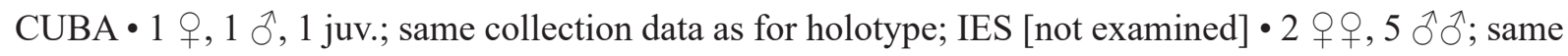
locality as for holotype; 21 May 1985; L.F. de Armas leg.; IES [not examined] - 1 juv.; Guanayara, Trinidad, entrance of cave Las Columnas [Cueva del Veterano]; 19 Mar. 1985; L.F. de Armas leg.; IES [not examined] • 2 우; Guanayara, Trinidad; 24 Oct. 1985; L.F. de Armas leg.; IES [not examined].

\section{Measurements}

See Table 1.

\section{Distribution}

Known from the type locality and two other nearby localities in the Trinidad Municipality of Sancti Spíritus Province, Cuba (Teruel et al. 2009). The species appears to be restricted to the coastal strip of the Guamuhaya Massif.

\section{Natural history}

Found under stones in coastal and sub-coastal forests, from sea level to $100 \mathrm{~m}$ a.s.l. 


\section{Remarks}

Armas \& Ávilla Calvo (2000) mentioned four dorsal spines on the pedipalp patella, but included the long distal setiferous tubercle in the count of dorsal spines.

Charinus cubensis (Quintero, 1983)

Figs 12, 20; Table 1

Charinides cubensis Quintero, 1983: 26, 29-31, figs 8a-e, 9e, 12c.

Charinus acosta - Miranda et al., 2016b: 546.

Charinides cubensis - Armas \& Alayón García 1984: 6. — Weygoldt 1994: 244; 2000a: 43.

Charinus cubensis - Delle Cave 1986: 162, fig. II. - Weygoldt 1994: 244. - Ávila Calvo \& Armas 1997: 31. - Armas 2000a: 138; 2004: 38-39; 2006b: 228, figs 6, 8a-b, 2013a: 16. — Armas \& Ávila Calvo 2000: 292-293. - Harvey 2003: 5. —Teruel et al. 2009: 201-202, fig. 3. - Wolff et al. 2015: 525, 527, 529, 534, 538, figs 2c, 3i, 7. - Teruel \& Questel 2015: 47. — Miranda et al. 2016b: 555, 557. — Gibbons et al. 2019: 498, fig. 1 i.

\section{Diagnosis}

This species may be separated from other Caribbean and Central American Charinus by means of the following combination of characters: median ocular tubercle absent, median eyes with small black pigmentation spot below tegument (Fig. 20A); bifid tooth of cheliceral basal segment with dorsal cusp distinctly longer than ventral cusp; prolateral surface of cheliceral basal segment with row of around 10 setae; tibia of leg I with 21 articles, tarsus I with 37 articles; first tarsal article about 1.8 times as long as subsequent articles; leg IV basitibia with trichobothrium $b c$ situated closer to $b f$ than to $s b f$; leg IV distitibia $s c$ and $s f$ series each with five trichobothria.

\section{Etymology}

Adjective derived from the country to which the species is endemic, Cuba (Quintero 1983).

\section{Type material}

\section{Holotype}

CUBA - Ô; Guantánamo Province, Cueva La Majana; 20²0'40" N, 74²7'52" W; ACC [now IES; L.F. de Armas, pers. com.; not deposited in collection according to Armas $(2004,2014)]$.

\section{Paratypes}

CUBA $・ 2$ 우, 3 juv.; same collection data as for holotype; BMNH [not found in collection].

\section{Additional material}

CUBA 1 juv.; Baracoa Municipality: Alejandro de Humboldt National Park, near Yunque de Baracoa; 20²1'08.11" N, 74³4'28.76" W; USNM ENT 784829 • 2 juv. 우; Alejandro de Humboldt National Park, area around station Bahia de Taco; 20³1'04.14" N, 74³9'32.14" W; Mar.-May 2012; CarBio team leg., USNM ENT 783165, USNM ENT 783162 [both misidentified in Miranda et al. (2016a) as C. acosta; specimens lack part of the carapace and all legs; it is now identified as C. cubensis based on the locality and the development of the eyes] 1 i [misidentified in Miranda et al. (2016a)]; Camagüey, Sierra de Cubitas, Limones, Tuabaquey Ecological Reserve, Boca de Miel; 2134'56.69" N, 77²5'00.47" W; Mar.-Apr. 2012; CarBio team leg.; USNM ENT 784407 • 1 juv. [missing opisthosoma]; same collection data as for preceding; USNM ENT $787694 \cdot 1$ juv. $\lesssim$ [missing leg I; median eyes similar to those of C. cubensis and locality close to previous]; Camagüey, Sierra de Cubitas, Limones,

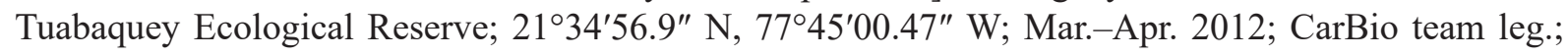


USNM ENT 787692 • 1 juv.; Camagüey, Sierra de Cubitas, Limones, Tuabaquey Ecological Reserve;

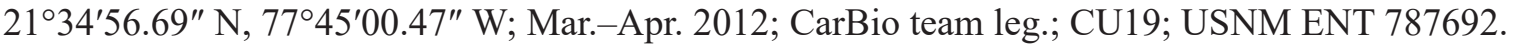

\section{Supplementary description}

CARAPACE. Six anterior setae; frontal process triangular (Fig. 20C). Small granules densely scattered between ocular triads and among sulci. Median ocular tubercle absent, eyes rudimentary, reduced to pair of lenses with dark pigmentation beneath (Fig. 20A); lateral eyes well developed, seta posterior to each lateral ocular triad (Fig. 20A); lateral ocular triad well separated from carapace margin.

STERnUm. Tritosternum projected anteriorly with typical setation, long, surpassing base of pedipalp coxae (Fig. 20B); other sternal plaques small, rounded, divided, with pair of setae on lateral margins (Fig. 20B); pentasternum without seta near membranous region and two setae anteriorly.

Opisthosoma. Ventral sacs and ventral sac cover absent.

Genitalia. Female genital operculum with thin setae posteromedially and smaller setae near margin; gonopod cushion-like, with open atrial aperture, base of gonopods unsclerotized. Adult male not examined.

CHELICERAE. Small flat tooth on retrolateral surface of basal segment, opposite to bifid tooth; small row of setae on retrolateral surface of claw; claw with five teeth; row of around ten setae on prolateral surface of basal segment; bifid tooth in row of teeth on basal segment with dorsal cusp larger than or equal to ventral cusp.

PeDIPALPS. Coxal dorsal carina with three setae on anterior border and without seta encircled by round carina. Femur with three dorsal spines and three ventral spines (Fig. 20E); two prominent setiferous tubercles between dorsal spine 1 and proximal margin; setiferous tubercle between ventral spine 1 and proximal margin. Patella with three dorsal spines (Fig. 20E); prominent setiferous tubercle distal to spine I, one-third length of spine I; two ventral spines; setiferous tubercle between spine I and distal margin (Fig. 20F). Tibia with ventral spine distally and seta between spine and distal margin. Tarsus with two dorsal spines, proximal spine one-third length of distal spine, and distal spine two-third length of tarsus (Fig. 20D); cleaning organ with 28 setae in ventral row.

Legs. Tibia of leg I with 21 articles; tarsus I with 37 articles; first tarsal article about twice length of second article. Leg IV basitibia with three pseudo-articles, without sclerotized, denticulate margin projecting from apex of articles; trichobothrium $b t$ situated in proximal third of pseudo-article; distitibia trichobothrium situated $b c$ closer to $b f$ than to $s b f$, and $s c$ and $s f$ series each with five trichobothria.

\section{Measurements}

See Table 1.

\section{Distribution}

Restricted to the north of Guantanamo Province and north of Camagüey, Cuba.

\section{Natural history}

Charinus cubensis is an epigean and troglophile species that inhabits the karstic coastal area between Baracoa and Maisí (Teruel et al. 2009) and has been found in sympatry with Charinus acosta, Paraphrynus robustus (Franganillo, 1931), Phrynus hispaniolae Armas \& Perez Gonzalez, 2001 (Armas 2006b, 2014). 


\section{Remarks}

As noted above, C. cubensis and C. acosta share many similarities and, excepting the count of articles on the tarsus of leg I, the differences between these species are very subtle. The development of the median eyes may vary, especially in $C$. acosta, which in some specimens may be as reduced as in C. cubensis. The female genitalia of both species are also very similar, presenting a cushion-like surface with the opening of the genital atrium uncovered. Armas \& Ávila Calvo (2000) analyzed topotypes of C. cubensis and stressed that, contrary to Quintero (1983), C. cubensis is more similar to C. wanlessi than to $C$. decu. However, the limits of these species remain confused. A detailed morphological (e.g., using SEM) and molecular study is required to establish the limits of the Cuban Charinus species.

Charinus decu (Quintero, 1983)

Fig. 12; Table 1

Charinides decu Quintero, 1983: 38-40.

Charinides decu - Armas \& Alayón García 1984: 6. — Weygoldt 1994: 244.

Charinus decu - Delle Cave 1986: 162, fig. II. — Ávila Calvo \& Armas 1997: 31. — Armas 2000a: 138; 2004: 39; 2006b: 228, figs 6, 9a-b; 2013a:16; 2013b: 92. — Armas \& Ávila Calvo 2000: 293. — Harvey 2003: 5. — Teruel \& Questel 2015: 47. — Miranda et al. 2016b: 555, 557.

\section{Diagnosis}

Based on the description of Quintero (1983), this species may be separated from other Caribbean and Central American Charinus by means of the following combination of characters: median eyes and median ocular tubercle absent; lateral eyes small, but pigmented; bifid tooth of basal cheliceral segment with ventral cusp longer than dorsal cusp; cheliceral claw with four teeth; small tooth on retrolateral surface of basal cheliceral segment, opposite to bifid tooth; prolateral surface of cheliceral basal segment with transverse row of five setae; pedipalp femur with three dorsal spines and three ventral spines; pedipalp patella with three dorsal spines and two ventral spines; pedipalp tarsus with two dorsal spines; tibia of leg I with 21 articles, tarsus I with 39 articles; first article of tarsus approximately 4.5 times as long as second article; leg IV basitibia, trichobothrium $b t$ situated in proximal third and $b c$ situated equidistant between $b f$ and $s b f$ or slightly closer to $b f$; leg IV distitibia $s c$ and $s f$ series each with 5 trichobothria.

\section{Etymology}

Patronym honoring Dr Vasile Decu (Quintero 1983).

\section{Type material}

\section{Holotype}

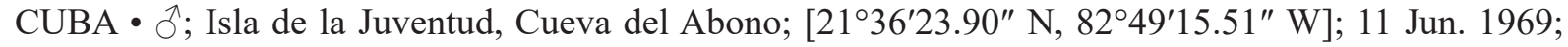
ACC [ACC is now IES; L.F. de Armas, pers. com.; not deposited in collection according to Armas $(2004,2014)]$.

\section{Paratypes}

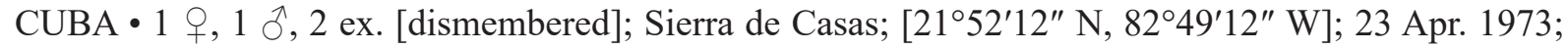
MCZ [not examined].

\section{Measurements}

See Table 1. 


\section{Distribution}

Known only from Isla de la Juventud, Cuba.

\section{Natural history}

This species is known to inhabit disturbed areas (e.g., Sierra Chiquita) and has also been collected inside caves (e.g., Cueva del Lago). It is sympatric with Paraphrynus viridiceps (Pocock, 1893) and Phrynus pinero Armas \& Ávila Calvo, 2001.

\section{Remarks}

In the original description, Quintero (1983), counted four spines on the pedipalp patella, but included the long setiferous tubercle between spine I and the distal margin in the count. Additional differences between $C$. decu and other Caribbean species are discussed by Miranda et al. (2016b).

Charinus desirade Teruel \& Questel, 2015

Fig. 12; Table 1

Charinus desirade Teruel \& Questel, 2015: 43-47, figs 1-4.

Charinus desirade - Teruel 2016: 9. - Teruel \& Coulis 2017: 35.

\section{Diagnosis}

Based on the description of Teruel \& Questel (2015), this species may be separated from other Caribbean and Central American Charinus by means of the following combination of characters: coloration olive-yellowish, immaculate; alcohol preserved specimens uniformly olive-yellowish in color, slightly darker on carapace and pedipalps, venter and chelicerae paler; intersegmental membranes whitish; live animals conspicuously darker and reddish; median ocular tubercle vestigial, median eyes absent and unpigmented, but with pair of small oval, translucent-whitish spots, lateral eyes well developed, silverwhite in color; tritosternum/tetrasternum/pentasternum with 4/2/1 pairs of spiniform setae, respectively; gonopods unsclerotized; minimal secondary sexual dimorphism, females larger, with shorter pedipalp segments than males; pedipalp femur with two dorsal and two ventral spines; pedipalp patella with three dorsal spines (including long setiferous tubercle distal to spine I) and two ventral spines; pedipalp tarsus with two dorsal spines; tibia of leg I with 23 articles, tarsus I with 41 articles; first tarsal article about three times as long as second tarsal article; leg IV basitibia with three pseudo-articles.

\section{Etymology}

Noun in apposition, taken from the type locality, La Désirade (Teruel \& Questel 2015).

\section{Type material}

\section{Holotype}

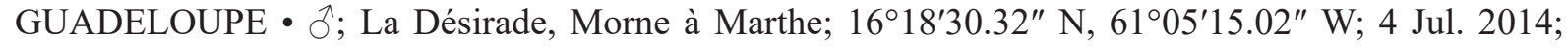
K. Questel, G. Moulard, M. Coulis and E. Curot Lodéon leg.; BIOECO [not examined].

\section{Paratypes}

GUADELOUPE $\bullet 1$ ㅇ, 1 O, 1 juv.; same collection data as for holotype; BIOECO [not examined].

\section{Measurements}

See Table 1. 


\section{Distribution}

Known only from the type locality.

\section{Natural history}

Specimens were collected under a rock of volcanic tuff, with a juvenile of the scorpion Oiclus cf. nanus Teruel \& Chazal, 2010 (Diplocentridae). The rock was semi-buried in the ground, under dry forest.

\section{Remarks}

For comparison with other species, variation and habitat, see Teruel \& Questel (2015).

Charinus dominicanus Armas \& Pérez, 2001

Figs 12, 21-23; Table 1

Charinus dominicanus Armas \& Pérez, 2001: 47, 50, 59, 62-64, figs 11, 14.

Charinus dominicanus - Armas 2004: 39; 2006b: 227-228, 242-243, fig. 6; 2010: 58, 60. - Teruel \& Questel 2015: 47. - Teruel 2016: 3-7, figs 1-3, 7a, 8. — Miranda et al. 2016b: 555, 557, fig. 8; 2018a: 24; 2018b: 36, fig. 14.

\section{Diagnosis}

This species may be separated from other Caribbean and Central American Charinus by means of the following combination of characters: anterior area of carapace broadly convex, slightly narrower in males; median eyes absent (Fig. 21A, C); median ocular tubercle small; lateral eyes well developed (Fig. 21A); tritosternum bottle-shaped, extremely short (wider than long) (Fig. 21B); cheliceral claw with eight teeth; pedipalp tarsus with two dorsal curved spines, distal spine half length of the tarsus, proximal spine half length of distal spine; tibia of leg I with 21 articles, tarsus I with 33 articles; leg IV basitibia with three pseudo-article; leg IV basitibia trichobothrium $b c$ situated equidistant between $b f$ and $s b f$; leg IV distitibia $s c$ and $s f$ series each with five trichobothria.

\section{Etymology}

Adjective referring to the country in which the species occurs (Armas \& Pérez 2001).

\section{Type material}

\section{Holotype}

DOMINICAN REPUBLIC • 1 \%; Barahona Province, La Ciénaga Municipality, Los Charcos, sección San Rafael, Sierra de Bahoruco; [18 $04^{\prime}$ N, $71^{\circ} 06^{\prime}$ W]; IES [not examined].

\section{Additional material (examined)}

DOMINICAN REPUBLIC • 1 क ; Sierra de Bahoruco, south of Barahona, $3.4 \mathrm{~km}$ N of Paraiso on DR 44, small farm with coffee plantation; $18^{\circ} 00^{\prime} 56.46^{\prime \prime} \mathrm{N}, 71^{\circ} 08^{\prime} 40.62^{\prime \prime} \mathrm{W}$; 7-8 Jul. 2010; 115 m a.s.1.; J.H. Huff and S. Schoenbrun leg.; new record; AMCC [LP 10473] • 2 우, 1 § ; Sierra de Bahoruco, 3.4 km N of Paraíso on DR44, S of Barahona, small farm with coffee plantation; $12^{\circ} 00.94^{\prime} \mathrm{N}, 71^{\circ} 08.677^{\prime} \mathrm{W}$; 115 m a.s.1.; 7-8 Jul. 2010; J. Huff and S. Schoenbrun leg.; AMNH.

\section{Measurements}

See Table 1. 


\section{Distribution}

Occurs in the southwestern part of the Dominican Republic.

\section{Natural history}

Lives under stones, sometimes in sympatry with Phrynus marginemaculatus C.L. Koch, 1841.

\section{Remarks}

A supplementary description of the female and first description of the male are provided by Teruel (2016). Details of the ultrastructure of the gonopod and leg I are provided here for the first time (Figs 2223). The cushion-like female gonopod is flat, with a narrow apex (Fig. 22A-B), and resembles that of C. vulgaris. The distal articles of tibia I have trichobothria (Fig. $23 \mathrm{H}-\mathrm{I}$ ). The distal article of tarsus I (Fig. 23A, J) is covered with clavate sensilla (Fig. 23G) and a tarsal organ projecting from the apex, near the claw (Fig. 23D). The clavate sensilla bear multiple linear striations on the surface and an apical pore (Fig. 23G). The tarsal organ has a stalk and three rounded projections at the distal margin. Each rounded projection has a small pore. The rod sensilla is formed by four setae in shallow groove (Fig. 23E). The setae forming the rod sensilla are punctuate (Fig. 23F). Gland openings are present on tarsal article 13 (Fig. 23J).

Charinus magua Seiter, Schramm \& Schwaha, 2018

Fig. 12; Table 1

Charinus magua Seiter et al., 2018: 350-359, figs 1-8.

\section{Diagnosis}

Based in part on Seiter et al. (2018), this species may be separated from other Caribbean and Central American Charinus by means of the following combination of characters: median eyes absent and lateral eyes reduced; cheliceral claw with 2-4 teeth; female gonopods cushion-like with lateral projections directed posteriorly and unsclerotized; tibia of leg I with 21 or 22 articles, tarsus I with 37 or 38 articles; first tarsal article about five times as long as second article; pedipalp femur with three dorsal spines and two ventral spines; pedipalp patella with three dorsal spines and two ventral spines; leg IV basitibia with three pseudo-articles; leg IV distitibia with 16 trichobothria; trichobothrium $b c$ situated closer to $b f$ than to $s b f$.

\section{Etymology}

Noun in apposition taken from the historical Taíno chiefdom of Maguá (Seiter et al. 2018).

\section{Type material}

\section{Holotype}

DOMINICAN REPUBLIC - O’; Monseñor Nouel Province, Subida a Casabíto; $19^{\circ} 01.643^{\prime}$ N, 70²2.762' W; 382 m a.s.l.; Sep. 2016; Seiter, Schramm, Nigl and Teruel leg.; NHMW 29153 [not examined].

\section{Paratypes}

DOMINICAN REPUBLIC • 1 q, 2 juv.; Monseñor Nouel Province, Subida a Casabíto; $19^{\circ} 01.581^{\prime}$ N, 70²8.828' W; 795 m a.s.1.; Sep. 2016; Seiter, Schramm, Nigl and Teruel leg.; NHMW 29154 [not examined] • 2 juv.; same collection data as for preceding; NHMW 29155 [not examined] • 1 क; same collection data as for holotype; NHMW 29156 [not examined]. 


\section{Measurements}

See Table 1.

\section{Distribution}

Known only from Monseñor Nouel Province in the Dominican Republic.

\section{Natural history}

Found under stones partially buried in soil covered with wet and dry leaf litter close to small waterway. Sympatric with Phrynus longipes Pocock, 1894.

Charinus martinicensis Teruel \& Coulis, 2017

Fig. 12; Table 1

Charinus martinicensis Teruel \& Coulis, 2017: 31-35, figs 1-4.

Charinus martinicensis - Seiter et al. 2018: 351.

\section{Diagnosis}

Based on Teruel \& Coulis (2017), this species may be separated from other Caribbean and Central American Charinus by means of the following combination of characters: median eyes reduced; lateral eyes well developed; pedipalp femur with three dorsal spines and three ventral spines; pedipalp patella with three dorsal spines and two ventral spines; pedipalp tarsus with two dorsal spines; tibia of leg I with 23 articles, tarsus I with 37 articles; leg IV basitibia with two or three pseudo-articles.

Charinus martinicensis resembles most Caribbean species of Charinus and shares with C. acosta, C. aguayoi, C. bruneti and C. miskito sp. nov., the presence of median eyes, although also reduced in in C. bruneti and C. martinicensis. Charinus martinicensis differs from these species in the number of articles on the tibia and tarsus of leg I. The basitibia of leg IV consists of two to three pseudo-articles, common to all Caribbean and some South American species.

\section{Etymology}

Latin adjective derived from the name of the island on which the species was collected (Teruel \& Coulis 2017).

\section{Type material}

\section{Holotype}

MARTINIQUE • + ; Sainte-Anne, Morne Manioc; $1^{\circ} 26^{\prime} 00^{\prime \prime}$ N, 60 $51^{\prime} 26^{\prime \prime}$ W; 150 m a.s.1.; 27 Jan. 2017; M. Coulis leg.; RTO [not examined].

\section{Paratypes}

MARTINIQUE • 1 \% ; same collection data as for holotype; RTO [not examined] • 2 + $q$; same locality as for holotype; 30 Aug. 2016; RTO [not examined].

\section{Measurements}

See Table 1. 


\title{
Distribution
}

Known only from the type locality on the island of Martinique.

\section{Natural history}

Specimens were found under limestone rocks in the leaf litter of coastal semideciduous forest.

\section{Remarks}

Teruel \& Coulis (2017: fig. 2c-d) mention that Charinus martinicensis has a fully developed median eyes, a statement contradicted by their figure. The median eyes and ocular tubercle are clearly reduced and, as mentioned by Teruel \& Coulis (2017: 33) are "located inside a deep oval depression of the tegument", typical of charinids with reduced median eyes. Although only female specimens were studied, Teruel \& Coulis (2017) do not provide information regarding the shape of the female gonopod. Similarly, no information is provided about the trichobothria of leg IV.

\author{
Charinus miskito sp. nov. \\ urn:1sid:zoobank.org:act:574FE779-371C-4518-9EE5-55C4DD67AA7F \\ Figs 5E-F, 10C-D, 12, 24-26; Table 1
}

\section{Diagnosis}

This species may be separated from other Caribbean and Central American Charinus by means of the following combination of characters: median eyes and median ocular tubercle present, but reduced (Fig. 24A, C); retrolateral surface of cheliceral claw without row of setae; first (dorsal) tooth bifid, dorsal cusp smaller than ventral cusp (Fig. 10C-D); claw with four denticles (Fig. 10C-D); tibia of leg I with 21 articles, tarsus I with 39 articles; leg IV basitibia with three pseudo-articles; trichobothrium $b c$ situated closer to $b f$ than to $s b f ; s c$ and $s f$ series each with 5 trichobothria.

Charinus miskito sp. nov. resembles C. bruneti, as both possess median eyes, tibia of leg I consists of 21 or 22 articles, and tarsus I consists of 39 articles. However, the median eyes are reduced in C. miskito sp. nov. and well developed in C. bruneti.

\section{Etymology}

A noun in apposition referring to the Miskito, a Native American tribe in Central America.

\section{Type material}

\section{Holotype}

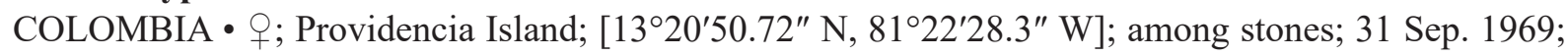
SMNS.

\section{Paratypes}

COLOMBIA $-2 \widehat{\partial} \sigma^{\lambda}$; same collection data as for holotype [chelicerae and gonopod dissected in one paratype]; SMNS.

\section{Description}

CARAPACE. Anterior margin rounded, with six anterior setae (Fig. 24A). Small granules densely scattered between ocular triads and among sulci. Median eyes and ocular tubercle present, but reduced (Fig. 24A, C); lateral eyes well developed, pale; small seta posterior to each lateral ocular triad; lateral ocular triad well separated from carapace margin. 
STERnUm. Tritosternum projected anteriorly into large blunt tubercle, surpassing base of pedipalp coxae, with typical setation (Fig. 24B); medial platelet (tetrasternum) and third platelet (pentasternum) formed by two convex platelets, each with large setae anteriorly, and several smaller setae posteriorly (Fig. 24B); pentasternum smaller than medial platelet, each platelet with seta anteriorly and some setae posteriorly (Fig. 24B); pentasternum without anterior setae in membranous region and with four setae posteriorly.

OpISTHOSOMA. Ventral sacs and ventral sac cover absent.

GenitaLia. Female genital operculum with posterior margin slightly convex, several setae along margin and surface (Fig. 5E-F); gonopods cushion-like with small rounded projection and sclerotized region on projection (Fig. 5E-F); small sclerotized region at base of gonopods (sclerotizations connected to each other) (Fig. 5E-F). Male gonopod with sclerotization at margin of fistula and lateral lobe 1; lateral lobe 2 fimbriate and short (Fig. 25A-B, D); lateral lobe 1 with acute apex (Fig. 25F); processus internus short and with median projection (Fig. 25E); dorsal lobe covered with denticulate projections (Fig. 25C, F).

Chelicerae. Chelicera with small, flat tooth in retrolateral row of basal segment, opposite to bifid tooth (Fig. 10D); bifid tooth with dorsal cusp smaller than ventral cusp; prolateral surface of cheliceral basal segment with transverse row of around ten small setae, ventrally to dorsally; retrolateral surface of claw without row of setae; claw with four teeth (Fig. 10C-D).

Pedipalps. Coxal dorsal carina with two or three setae on anterior border and without seta encircled by round carina. Femur with two distinct setiferous tubercles proximal to spine 1 (Fig. 24E); primary series with three dorsal spines and three ventral spines; femur with one setiferous turbercle between ventral spine 1 and proximal margin. Patella with three dorsal spines and one long setiferous tubercle, about one-third length of spine I, between spine I and distal margin of segment (Fig. 24E); several long setae between ventral spines. Tibia with ventral spine in distal half of article and prominent setiferous tubercle close to base (Fig. 24F); long seta between spine and distal margin. Tarsus with two dorsal spines, distal spine two thirds length of article and proximal spine one-third length of distal spine (Fig. 24D). Ventral row of cleaning organ with $28-32$ setae.

LEGS. Tibia of leg I with 21 articles; tarsus I with 39 articles; tarsal organ situated near claw (Fig. 26A, C-D); rod sensilla with four setae in shallow groove (Fig. 26B, E). Leg IV basitibia with three pseudoarticles, without sclerotized, denticulate projection at distal apex of articles; trichobothrium $b t$ situated in proximal third; leg IV distitibia with trichobothrium $b c$ situated closer to $b f$ than to $s b f ; s c$ and $s f$ series each with five trichobothria.

\section{Measurements}

See Table 1.

\section{Distribution}

Known only from the type locality. Providencia is a volcanic island, part of the territory of Colombia, but biogeographically part of the Caribbean and Central America, its fauna more closely related to Central America and the Lesser Antilles than to the Greater Antilles (Morrone 2006).

\section{Natural history}

Epigean, found under stones. 
Charinus muchmorei Armas \& Teruel, 1997

Fig. 12; Table 1

Charinus muchmorei Armas \& Teruel, 1997: 43-46, figs 1-6.

Charinides sp. - Muchmore 1993: 32. — Ávila Calvo \& Armas 1997: 31.

Charinus muchmorei - Harvey 2003: 6. - Armas 2004: 39; 2006b: 228, figs 6, 10a-b; 2010: 58, 60. Teruel \& Questel 2015: 46-47. - Teruel 2016: 10. — Miranda et al. 2016b: 555, 557. — Teruel \& Coulis 2017: 35 .

\section{Diagnosis}

This species may be separated from other Caribbean and Central American Charinus by means of the following combination of characters: small size; median eyes and median ocular tubercle absent; female gonopod cushion-like; secondary sexual dimorphism absent.

The female gonopod of $C$. muchmorei resembles that of $C$. vulgaris, with a projection at the apex of the external fold covering the atrial opening, but the two species differ in the count of articles on tibia of leg I, 21 in C. vulgaris and 23 in C. muchmorei.

\section{Etymology}

Patronym honoring Dr W.B. Muchmore (Armas \& Teruel 1997).

\section{Type material}

\section{Holotype}

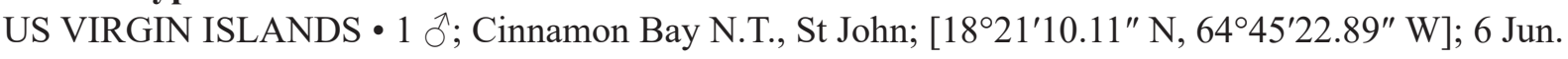
1980; W.B. Muchmore leg.; base of kipok; FSCA WM 5958.

\section{Paratypes}

US VIRGIN ISLANDS - 1 juv., 1 क ; same collection data as for holotype; FSCA WM 5958 • 1 đ̃; same locality as for holotype; 4-6 Jun. 1980; W.B. Muchmore leg.; litter at base of trees; FSCA WM 5930 - 2 우; Cinnamon Bay-Centerline Trail; FSCA [not examined] - 2 juv.; Fredenkstal (probably Frederiksted); FSCA WM 6810 [not examined] - 1 \%; St John Island;

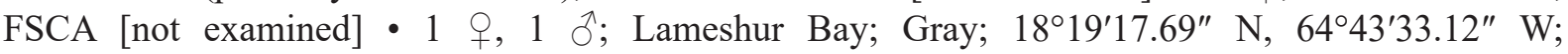

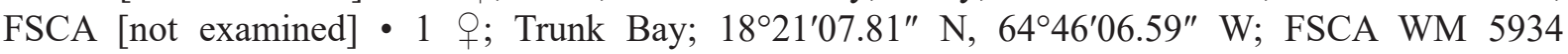

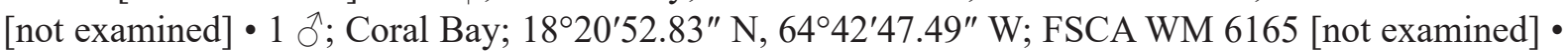
1 §̃, 2 juv.; Coral Bay; 10 Oct. 1979; W.B. Muchmore leg.; ground litter; FSCA WM 5821 • 2 q 0 ; Colabash Boom; 18¹9'39.84" N, 6442'11.49" W; 16 Oct. 1980; W.B. Muchmore leg.; under rocks; FSCA WM 5961.

\section{Supplementary description}

CARAPACE. Six anterior setae; frontal process triangular. Small granules densely scattered between ocular triads and among sulci. Median eyes and median ocular tubercle absent; pair of setae in place of median ocular tubercle; lateral eyes well developed, seta posterior to each lateral ocular triad; lateral ocular triad well separated from carapace margin.

SteRnum. Tritosternum projected anteriorly with typical setation, long, surpassing base of pedipalp coxae; other sternal platelets narrow, concave, each segment divided (forming pairs) with seta anteriorly; pentasternum with two setae anteriorly and without seta near membranous region.

Opisthosoma. Ventral sacs and ventral sac cover absent. 
Genitalia. Female genital operculum with long setae posteromedially and smaller setae near margin; posterior margin convex; gonopod cushion-like, unsclerotized basally; apex pointed and projected. Male gonopod markedly sclerotized at apex of fistula and base of lateral lobe.

CHELICERAE. Small flat tooth on retrolateral surface of basal segment, opposite to bifid tooth; retrolateral surface of claw with two patches of setae, one small, basal, another small, medial; claw with six teeth; row of seven setae on prolateral surface of basal segment; bifid tooth on basal segment with dorsal cusp larger than ventral cusp.

PeDIPALPS. Coxal dorsal carina with three setae on anterior margin and without seta encircled by round carina. Femur with three dorsal spines and four ventral spines; two prominent setiferous tubercles between dorsal spine 1 and proximal margin; setiferous tubercle between ventral spine 1 and proximal margin. Patella with three dorsal spines in primary series; prominent setiferous tubercle between spine I and distal margin, one fifth length of spine I; two ventral spines; prominent setiferous tubercle between spine I and distal margin. Tibia with ventral spine distally and seta between spine I and distal margin. Tarsus with two dorsal spines, proximal spine one-third length of distal spine; cleaning organ with 27 or 28 setae in ventral row of setae.

LeGs. Tibia of leg I with 22 or 23 articles, tarsus I with 37-39 articles; length of first tarsal article equal to sum of lengths of subsequent three or four articles. Leg IV basitibia with three pseudo-articles, without sclerotized, denticulate margin projecting from apex of articles; trichobothrium $b t$ situated in proximal third of pseudo-article; distitibia trichobothrium $b c$ situated closer to $b f$ than to $s b f ; s c$ and $s f$ series each with five trichobothria.

\section{Measurements}

See Table 1.

\section{Distribution}

Known only from St John, US Virgin Islands.

\section{Natural history}

Found under rocks, in ground litter, and at base of trees.

Charinus perezassoi Armas, 2010

Fig. 12; Table 1

Charinus perezassoi Armas, 2010: 60, figs 2b-i, 3f, 4d.

Charinus perezassoi - Teruel \& Questel 2015: 47. — Miranda et al. 2016b: 555, 557. - Teruel 2016: 10. —Armas 2017: 113. — Teruel \& Coulis 2017: 35. — Seiter et al. 2018: 351. — Torres-Contreras et al. 2019: 131 .

\section{Diagnosis}

Based on the description of Armas (2010), this species may be separated from other Caribbean and Central American Charinus by means of the following combination of characters: tegument light yellowish-brown, with faint grey-green hue on opisthosomal tergites; median eyes and ocular tubercle absent; lateral eyes pigmented; tritosternum long and narrow, with typical setation; female gonopods cushion-like with wide openings of genital atrium; narrow cheliceral claw with five teeth; pedipalp femur with three dorsal spines and three ventral spines; pedipalp femur with two prominent setiferous 
tubercles proximal to first dorsal spine; pedipalp patella with three dorsal spines and long setiferous tubercle distal to first spine; pedipalp patella with two ventral spines; pedipalp tarsus with two dorsal spines; tibia of leg I with 21 articles, tarsus I with 37-39 articles; first article of leg I tarsus three times as long as second article; leg IV basitibia with three pseudo-articles; trichobothrium bt situated in proximal third of distitibia; $s c$ and $s f$ series each with five trichobothria. The male is unknown.

Charinus perezassoi occurs together with C. aguayoi on Puerto Rico, but can be distinguished by the absence of median eyes and the different count of articles on the tibia and tarsus of leg I.

\section{Etymology}

Patronym honoring Antonio Pérez Asso (Armas 2010).

\section{Type material}

\section{Holotype}

PUERTO RICO • + ; Patillas Municipality, Barrio Los Pollos, Sierra de Guardarraya, farm at end of road 7757; 1759'53.25" N, 6559'03.17" W; 28 Jul. 2010; 100 m a.s.1.; L.F. de Armas and A. Pérez Asso leg.; disturbed semi-deciduous forest under old sheet of galvanized zinc; IES [not examined].

Paratypes

PUERTO RICO • 9 우; same collection data as for holotype; IES [not examined].

\section{Measurements}

See Table 1.

\section{Distribution}

Known only from the type locality.

\section{Natural history}

All known specimens were collected in a disturbed area, under a zinc sheet. According to Armas (2010), of all females collected, six carried egg sacs, suggesting that populations of $C$. perezassoi may be parthenogenetic. The number of embryos and protonymphs on the females varied between two and seven.

\section{Remarks}

Further comparisons between C. perezassoi and other Caribbean and Central American species may be found in Miranda et al. (2016b).

Charinus reddelli Miranda, Giupponi \& Wizen, 2016

Fig. 12; Table 1

Charinus reddelli Miranda et al., 2016b: 550-554, figs 1b-c, e-f, 2c-h, 3b, d, 4b, d, 5c-f, h, 6b-c, e-f, h, $7 \mathrm{~b}-\mathrm{c}, 8$.

\section{Diagnosis}

This species may be separated from other Caribbean and Central American Charinus by means of the following combination of characters: median eyes and ocular tubercle absent; cheliceral claw with four teeth, bifid tooth of basal cheliceral segment with dorsal and ventral cusps of equal size; leg tibia I with 23 articles; tarsus I with 41 articles; first article of tarsus 1.4-1.9 times as long as second article. 


\section{Etymology}

Patronym honoring Dr James R. Reddel (Miranda et al. 2016b).

\section{Type material}

Holotype

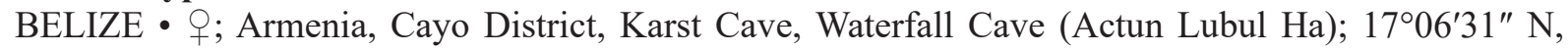
8843'51" W; 30 Aug. 2014; G. Wizen leg.; HUJ INV AMB 115.

\section{Paratypes}

BELIZE - 2 우, 1 ; ; same collection data as for holotype; HUJ INV AMB 116 - 2 우; same collection data as for holotype; MNRJ 9305 - 1 o ; Footprint Cave; $17^{\circ} 07^{\prime} 39^{\prime \prime} \mathrm{N}$, 88 43'56" W; 7 Sep. 2014; P. Naskrecki and G. Wizen leg.; HUJ INV AMB 112 • 2 qo; same collection data as for preceding; HUJ INV AMB $113 \cdot 2$ juv. $q \circ$; same collection data as for preceding; HUJ INV AMB 11.

\section{Measurements}

See Table 1.

\section{Distribution}

Known from the Footprint Cave and the Waterfall Cave (Actun Lubul Ha) in Belize.

\section{Natural history}

The species inhabits karst caves located in the valley of the Caves Branch River in central Belize. At the Footprint Cave, the most frequently encountered prey items were nymphs of Mayagryllus apterus Desutter-Grandcolas \& Hubbell, 1993 (Orthoptera: Gryllidae Laicharting, 1781) and Belicenochrus peckorum Armas \& Víquez, 2010 (Schizomida: Hubbardiidae Cook, 1899). The Waterfall Cave has an abundance of insects (M. apterus, cockroaches) and other arthropods (isopods, spiders, soft ticks). An egg sac contained 4-10 eggs measuring $1.5-1.64 \mathrm{~mm}$ in diameter and, at $25^{\circ} \mathrm{C}$, egg development took ca 150 days. The hatching praenymphae measured 2.2-2.5 $\mathrm{mm}$ and spent 14 days on the mother's back before molting into protonymphae measuring $2.8 \mathrm{~mm}$ in length.

\section{Remarks}

Further details of the description and comparison with other species of the genus, habitat and behavior may be found in Miranda et al. (2016b).

Charinus tomasmicheli Armas, 2006

Fig. 12; Table 1

Charinus tomasmicheli Armas, 2006a: 168-169, figs 1-4.

Charinus tomasmicheli -Armas et al. 2009: 136; 2013a: 16. — Teruel \& Questel 2015:47._ RodríguezCabrera \& Teruel 2016: 1-7, figs 1-7. — Miranda et al. 2016b: 555, 557.

\section{Diagnosis}

Based on the description of a male by Armas (2006a), this species may be separated from other Caribbean and Central American Charinus by means of the following combination of characters: almost uniform light yellowish-brown color in life; median eyes and ocular tubercle absent; lateral eyes pigmented; tritosternum short and narrow with typical setation; bifid tooth of basal cheliceral segment with cusps equal in size; cheliceral claw with four teeth; pedipalp femur with three dorsal spines and three ventral spines; pedipalp femur with two setiferous tubercles proximal to first dorsal spine; pedipalp patella 
with three dorsal spines and two ventral spines; pedipalp patella with large setiferous tubercle between spine I and distal margin; pedipalp tarsus with two dorsal spines; tibia of leg I with 21 articles, tarsus I with 37 articles; first tarsal article same length as subsequent articles; leg IV basitibia with three pseudoarticles; trichobothrium $b t$ situated in proximal third of distitibia; trichobothrium $b c$ situated closer to $s b f$ than to $b f$. Only adult males are known (all females are immature).

Charinus tomasmicheli occurs in the same mountain range as $C$. centralis, in which 23 tibial articles and 41 tarsal articles are present on leg I. Compared to other Cuban species, C. tomasmicheli possess the same number of articles on the tibia of leg I and the median eyes and ocular tubercle are absent as in $C$. cubensis and C. wanlessi. However, the leg I tarsus consists of 33 articles in C. wanlessi, whereas 37 articles are counted in $C$. tomasmicheli; the first article of the leg I tarsus is around twice the length of the subsequent articles in C. cubensis, whereas these articles are about the same length in C. tomasmicheli. Charinus tomasmicheli is very similar to C. acosta, in which the median eyes are present and the cheliceral claw bears five teeth instead of four.

\section{Etymology}

Patronym honoring Tomás Michel Rodriguéz, one of the collectors of the type series (Armas 2006a).

\section{Type material}

Holotype

CUBA - Oे; $^{\text {; }}$ Villa Clara Province, Manicaragua Municipality, Los Manantiales, Guamuhaya Massif, Los Manantiales-Tito cave; $21^{\circ} 59^{\prime} \mathrm{N}, 80^{\circ} 01^{\prime} \mathrm{W} ; 470 \mathrm{~m}$ a.s.1.; $11 \mathrm{Mar}$. 2005; T.M. Rodríguez and R. Chaviano leg.; on wall in dark area near stream; IES [not examined].

\section{Paratypes}

CUBA -1 ; ; same collection data as for holotype but 15 Oct. 2004; on an accumulation of sediments; IES [not examined] $\bullet 1$ subad. क; same collection data as for holotype but 16 Oct. 2004 ; in small cavity

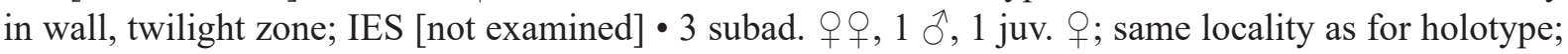
17 Feb. 2006; T.M. Rodríguez leg.; twilight zone; IES [not examined].

\section{Measurements}

See Table 1.

\section{Distribution}

Distributed in caves and forests in the Cuban provinces of Cienfuegos, Sancti Spíritus, and Villa Clara.

\section{Natural history}

The type series was collected in the Los Manantiales-Tito Cave, in the twilight and dark zones. Specimens were caught on the ground and the walls. The proportionally longer legs in relation to the body suggest this species is troglobitic (Armas 2006a). However, Armas (2013a) and Rodríguez-Cabrera \& Teruel (2016) report finding C. tomasmicheli in a semi-dark vestibular zone and in epigean areas. Charinus tomasmicheli is sympatric with Paraphrynus viridiceps at most localities; at Caletón de Don Bruno, C. tomasmicheli is sympatric with Phrynus marginemaculatus and, at La Tatagua and Palma Sola, with Phrynus decoratus Teruel \& Armas, 2005 (Armas 2006a; Rodríguez-Cabrera \& Teruel 2016).

Charinus wanlessi (Quintero, 1983)

Fig. 12; Table 1

Charinides wanlessi Quintero, 1983: 35-37, figs 10a-e, 12c. 
Charinides wanlessi - Armas \& Alayón García 1984: 6. — Weygoldt 1994: 244.

Charinus wanlessi - Delle Cave 1986: 162, fig. II. - Armas 2000a: 138; 2004: 39; 2006b: 228, 229, figs 6, 11a-b; 2010: 58, 60; 2013a: 16, 18. - Harvey 2003: 7. — Teruel et al. 2009: 202, 203, fig. 4. — Teruel \& Questel 2015: 47. — Miranda et al. 2016b: 555, 557.

\section{Diagnosis}

Based on the description of Quintero (1983), this species may be separated from other Caribbean and Central American Charinus by means of the following combination of characters: carapace, pedipalps and leg I femur, yellowish-brown; abdominal tergites and femora of legs lighter, more yellowish than carapace, without pattern; median eyes and ocular tubercle absent; lateral eyes reduced, whitish; male gonopod, apex of fistula and lateral lobe strongly sclerotized; cheliceral basal segment without tooth on retrolateral surface; bifid tooth with dorsal cusp distinctly longer than ventral cusp; transverse row of six setae near base of cheliceral basal segment; pedipalp femur with three or four dorsal spines; two prominent setiferous tubercles proximal to femur spine 1; pedipalp femur with three ventral spines and small setiferous tubercle proximal to first spine; pedipalp patella with three dorsal spines, two ventral spines and two distinct setiferous tubercles proximal to spine II; three prominent setiferous tubercles between spine I and distal margin; pedipalp tarsus with two dorsal spines, distal spine more than twice length of proximal spine; tibia of leg I with 21 articles, tarsus I with 33 articles; first tarsal article almost three times length of subsequent article; leg IV basitibia with three pseudo-articles; trichobothrium $b c$ situated closer to $s b f$ than to $b f ; s c$ and $s f$ series each with five trichobothria.

\section{Etymology}

Patronym honoring Dr Fred R. Wanless (Quintero 1983).

\section{Type material}

\section{Holotype}

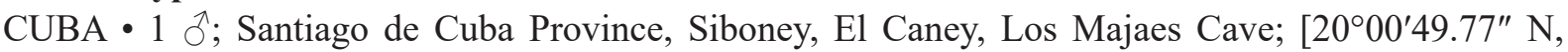
7546'41.85" W]; Dec. 1966; C. Fundora leg.; ACC [now IES; L.F. de Armas, pers. com.; not deposited in collection according to Armas $(2004,2014)]$.

\section{Paratypes}

CUBA $・ 1$ juv.; same collection data as for holotype; ACC $\bullet 2+q, 1 \hat{\jmath}, 1$ juv.; same locality as for holotype; 23 Mar. 1969; MCZ [not examined] • 2 juv.; Granma Province, Cueva de Banega; [1958'38.42" N, $\left.75^{\circ} 52^{\prime} 31.21^{\prime \prime} \mathrm{W}\right]$; 20 Mar.1973; ACC ISR 56 [not examined].

\section{Measurements}

See Table 1.

\section{Distribution}

Known from the Cuban provinces of Granma, Santiago de Cuba, and Siboney.

\section{Natural history}

Troglophile species that lives under stones inside and outside caves. Found in dry coastal forests (Playa de Juraguá) and semi-deciduous forests, up to $300 \mathrm{~m}$ above sea level (Matías, Tercer Frente) (Armas 2006b).

\section{Remarks}

See Miranda et al. (2016b) for comparison of C. wanlessi with other Cuban and Caribbean Charinus. 
Key to the identification of the species of Charinus in Amazonia and northern South America

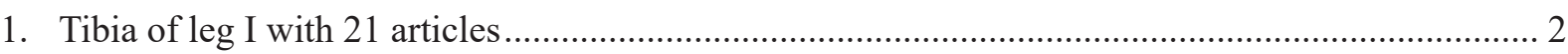

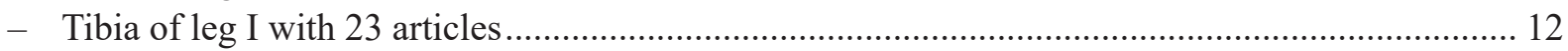

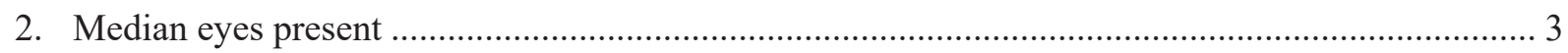

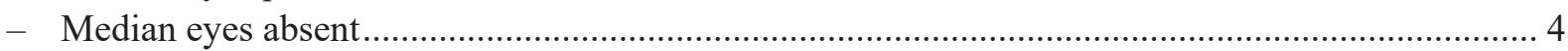

3. Leg I tarsus with 37 articles; lateral eyes reduced

- Leg I tarsus with 25-28 articles; lateral eyes well developed (Fig. 31A)

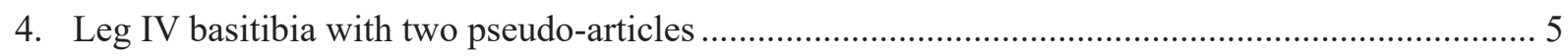

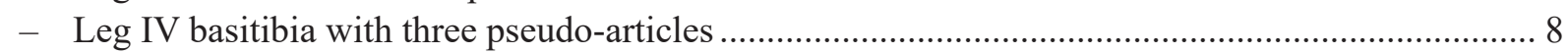

5. Leg I tarsus with 26 articles; length of first article equal to length of subsequent five articles......

C. carvalhoi sp. nov. (Fig. 28)

- Leg I tarsus with 37 articles; length of first article subequal to length of subsequent articles

6. Leg IV distitibia, trichobothrium $b c$ equidistant between $b f$ and $s b f$.

C. ricardoi Giupponi \& Miranda, 2016

- Leg IV distitibia, trichobothrium $b c$ situated closer to $s b f$ than to $b f$

7. Pedipalp femur with three dorsal and three ventral spines; cheliceral claw with four teeth

C. bonaldoi Giupponi \& Miranda, 2016

- Pedipalp femur with two dorsal and two ventral spines; cheliceral claw with six teeth ....

C. bichuetteae Giupponi \& Miranda, 2016

8. Cheliceral claw with four teeth......

C. magalhaesi sp. nov. (Fig. 30)

- Cheliceral claw with five to seven teeth

9. Lateral eyes reduced; cheliceral claw with seven teeth; tritosternum reduced...

C. ferreus Giupponi \& Miranda, 2016

- Lateral eyes unmodified; cheliceral claw with four or five teeth; tritosternum well developed...... 10

10. Pedipalp femur with four dorsal and four ventral spines (Fig. 32E-F)

- Pedipalp femur with three dorsal and three ventral spines.

C. perquerens sp. nov. (Fig. 32)

11. Pair of setae in place of median eyes present; base of female gonopod unsclerotized.

.C. guto Giupponi \& Miranda, 2016

- Pair of setae in place of median eyes absent; base of female gonopod sclerotized...

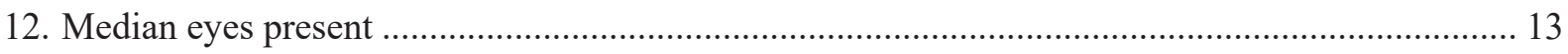

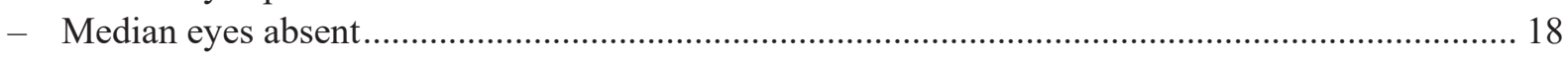

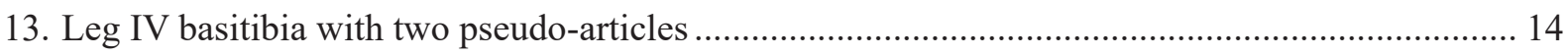

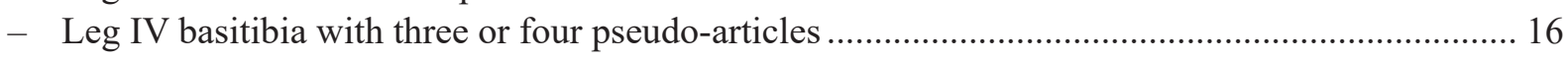


14. Median eyes reduced; pedipalp patella with three ventral spines. C. platnicki (Quintero, 1986)

- Median eyes unmodified; pedipalp patella with two ventral spines

15. Pedipalp femur with four ventral spines......

C. brescoviti Giupponi \& Miranda, 2016

- Pedipalp femur with three ventral spines..... C. bromeliaea Jocqué \& Giupponi, 2012

16. Leg IV basitibia with four pseudo-articles; carapace with dark, mottled pattern (Fig. 29A).

C. gertschi Goodnight \& Goodnight, 1946 (Figs 5C-D; 29)

- Leg IV basitibia with three pseudo-articles; carapace without distinctive markings

17. Tritosternum short, slightly surpassing base of pedipalp coxae ( 2.75 times as long as wide); pedipalp patella with three ventral spines

C. carajas Giupponi \& Miranda, 2016 (Fig. 8E-H)

- Tritosternum long, markedly surpassing base of pedipalp coxae (3 times as long as wide); pedipalp patella with two ventral spines

C. sillami Réveillion \& Maquart, 2015 (Fig. 33)

18. Leg IV basitibia with three pseudo-articles

- Leg IV basitibia with two pseudo-articles

19. Lateral eyes absent.....

C. bordoni (Ravelo, 1977)

- Lateral eyes present, but reduced.

C. tronchonii (Ravelo, 1975)

20. Tegument covered with claviform setae

C. quinteroi Weygoldt, 2002

- Tegument covered with acuminate setae

21. Pedipalp femur with three ventral spines; meso- and metasternum granular in shape.

C. camachoi (González-Sponga, 1998)

- Pedipalp femur with two ventral spines; tetra- and pentasternum shaped like flattened platelets

C. pardillalensis (González-Sponga, 1998)

Charinus bichuetteae Giupponi \& Miranda, 2016

Fig. 27; Table 2

Charinus bichuetteae Giupponi \& Miranda, 2016: 23-25, figs 2h, 3h, 11a-f.

\section{Diagnosis}

Based on Giupponi \& Miranda (2016), this species may be separated from other Charinus in Amazonia and northern South America by means of the following combination of characters: tegument pale yellow in color; median eyes and median ocular tubercle absent; lateral eyes well developed; small, rounded, markedly sclerotized tetra- and pentasternum; cushion-like female gonopod with lateral projections directed posteriorly, covering opening of internal seminal receptacles (atrium); pedipalp femur with two dorsal spines and three ventral spines; pedipalp tarsus with two spines, proximal spine small, ca one quarter length of distal spine; tibia of leg I with 21 articles, tarsus I with 37 articles; leg IV basitibia with two pseudo-articles; trichobothrium $b t$ situated in proximal third of distitibia; leg IV distitibia with 16 trichobothria; trichobothrium $b c$ situated closer to $s b f$ than to $b f$.

Charinus bichuetteae is one of ten species of Charinus in Amazonia and northern South America in which the basitibia of leg IV consists of two pseudo-articles; the others are C. bonaldoi, C. brescoviti, C. bromeliaea, C. carvalhoi sp. nov., C. camachoi, C. pardillalensis, C. platnicki, C. quinteroi and C. ricardoi. Charinus bichuetteae differs from C. bromeliaea and C. carvalhoi sp. nov. in the cushionlike gonopods, which are sucker-like in C. bromeliaea and in C. carvalhoi sp. nov. The absence of 
median eyes and ocular tubercle differentiates C. bichuetteae from C. brescoviti and C. bromeliaea. Seven of these species lack median eyes and median ocular tubercle, and can be differentiated from C. bichuetteae by the number of teeth on the cheliceral claw and the number of spines on the pedipalp femur.

\section{Etymology}

Patronym honoring Dr Maria Elina Bichuette (Giupponi \& Miranda 2016).

\section{Type material}

\section{Holotype}

BRAZIL - ô; Pará, Vitória do Xingu Municipality, AL 44, Gruta do China; 9 Jul. 2009; D. Pedroso, Pellegatti-Franco, M.E. Bichuette and T.L.C. Scatolini leg.; MNRJ 9204.

\section{Paratypes}

BRAZIL 1 ố; same collection data as for holotype; MNRJ $9173 \cdot 1$ +, Pará, Vitória do Xingu Municipality, AL 19, Paratizão; 10 Jul. 2009; D. Pedroso, F. Pellegatti-Franco, M.E. Bichuette and T.L.C. Scatolini leg.; MNRJ 9174 • 1 \% , 1 juv. + ; Altamira Municipality, AL 05, Gruta do Sismógrafo; 05'52'44" S, 5339'29" W; 7 Jul. 2009; D. Pedroso, F. Pellegatti-Franco, M.E. Bichuette and T.L.C. Scatolini leg.; MNRJ 9172 - 3 우, 1 đ̊; Altamira Municipality, B0103 - Caverna Sugiro-Roncador; 2 Jan. 2011; B0026 - river bank, under stone; 3 Apr. 2011; B0049 - Pedra da Cachoeira Cave; 3 Apr. 2011; M.E. Bichuette, J.E. Gallão, D.M. von Schimonsky and D.R. Pedroso leg.; B0026: riverbank, under stone; B0049: Pedra da Cachoeira Cave; MNRJ 9311.

\section{Measurements}

See Table 2.

\section{Distribution}

Known from the type localites.

\section{Natural history}

Specimens were found on cave walls.

\section{Remarks}

See Giupponi \& Miranda (2016) for more details concerning the taxonomy of C. bichuetteae.

Charinus bonaldoi Giupponi \& Miranda, 2016

Fig. 27; Table 2

Charinus bonaldoi Giupponi \& Miranda, 2016: 10-13, figs 2c, 3c, 4c, 6a-f.

\section{Diagnosis}

Based on Giupponi \& Miranda (2016), this species may be separated from other Charinus in Amazonia and northern South America by means of the following combination of characters: tegument light brown in color; median eyes and median ocular tubercle absent; lateral eyes reduced, pale; tetra- and pentasternum small and rounded; cushion-like gonopods without projections, with internal seminal receptacles; pedipalp almost perpendicular to body, similar to C. ricardoi and Paracharon caecus Hansen, 1921; pedipalp coxa with three setae on margin and two setae encircled by round carina; pedipalp tarsus with small basal spine, ca one-quarter length of distal spine; ventral row of setae of cleaning organ with 


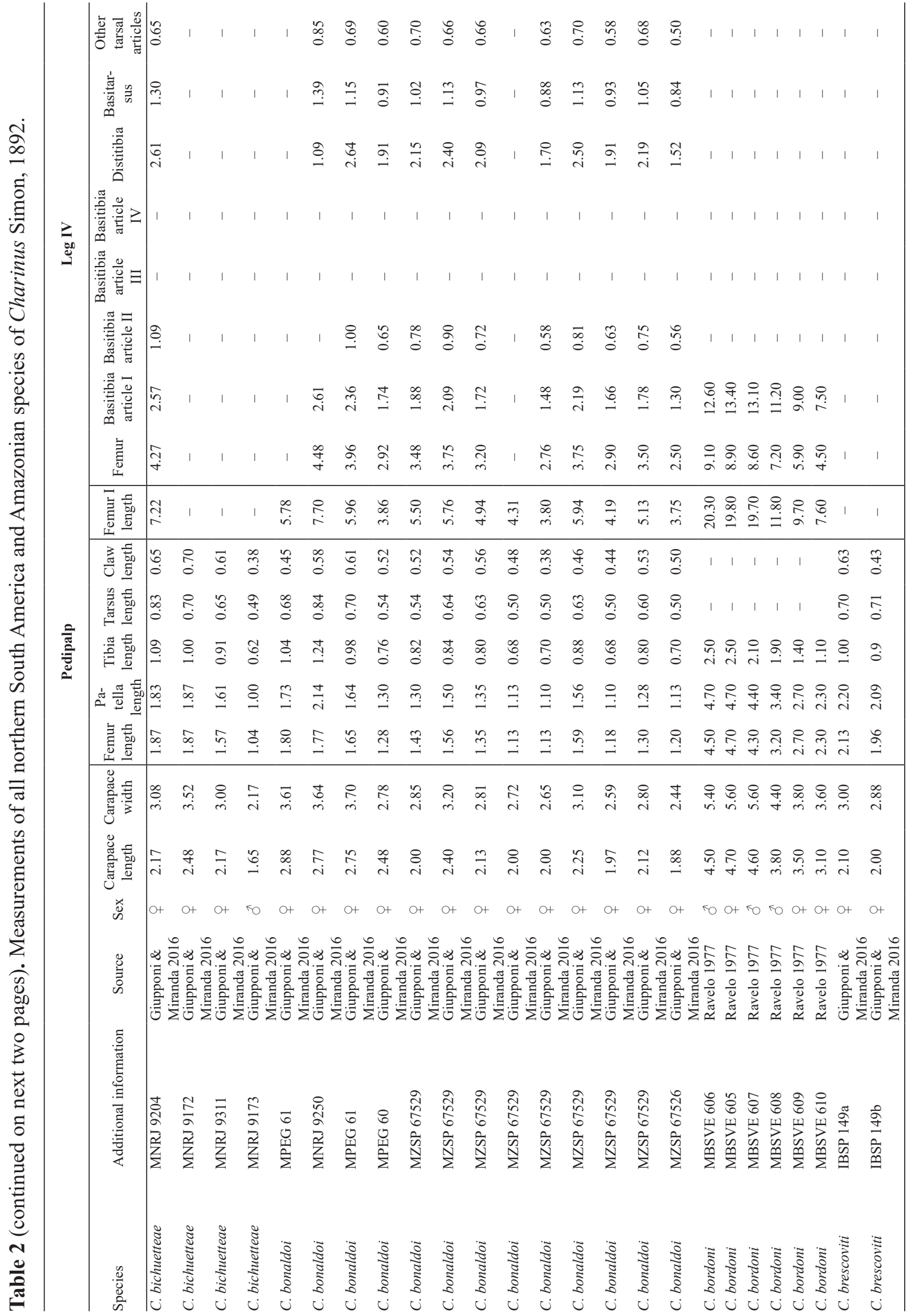




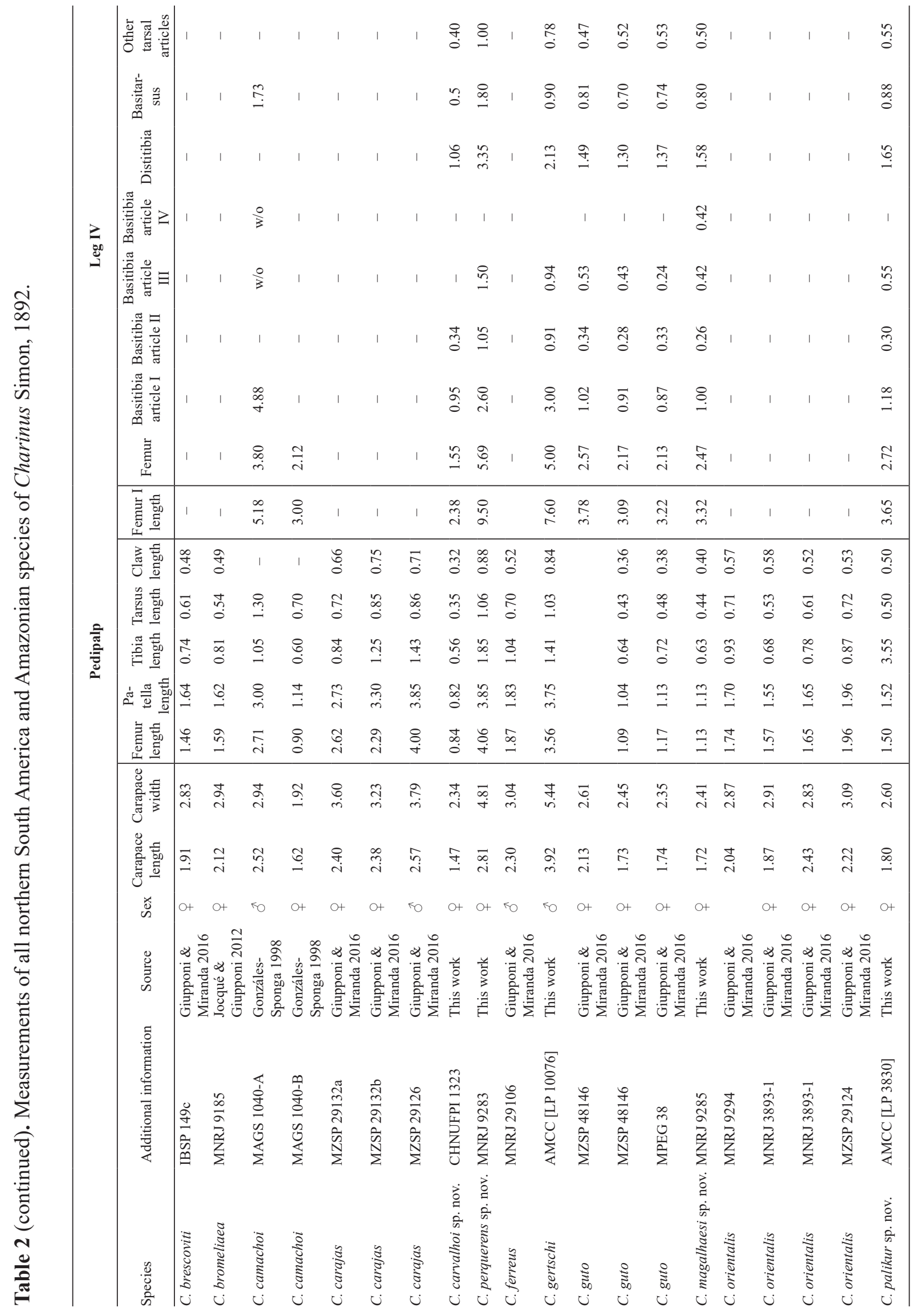




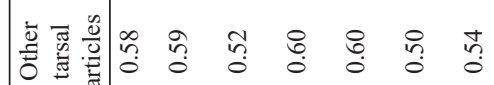

त. 1 กิ

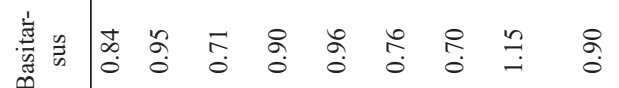

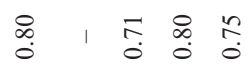

䔍

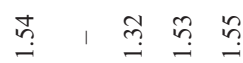

窇

要

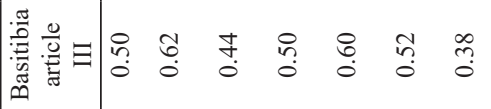

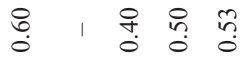

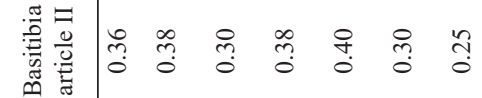

ֻृ. 1 तิ

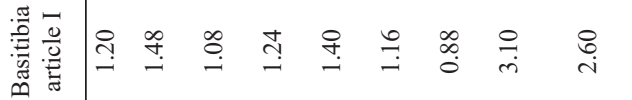

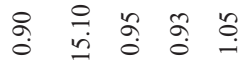

言

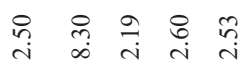

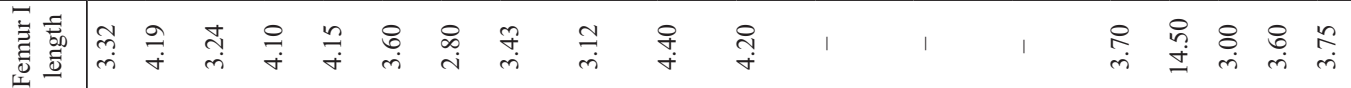

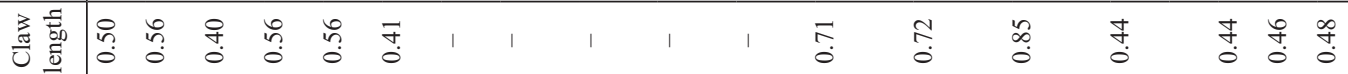

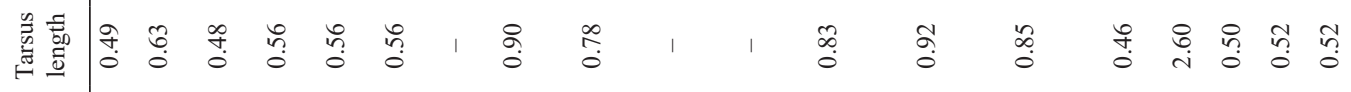

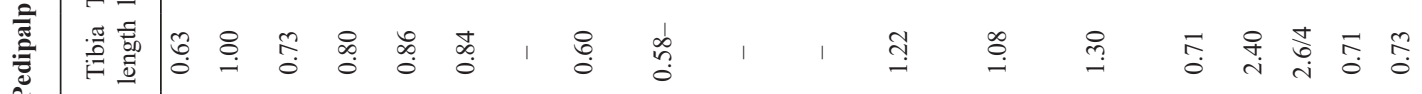

๘

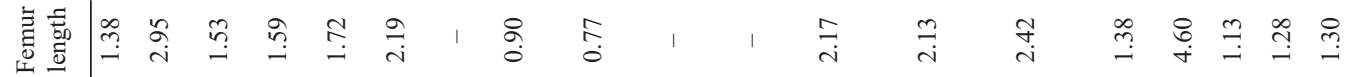

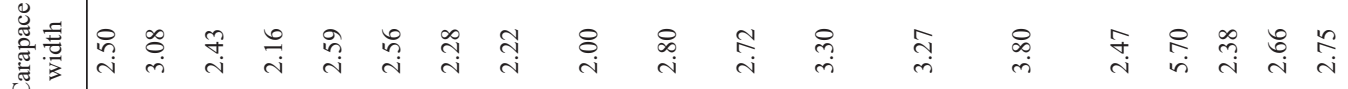

总营

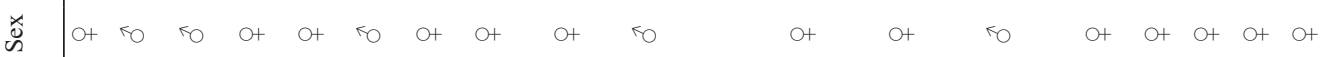

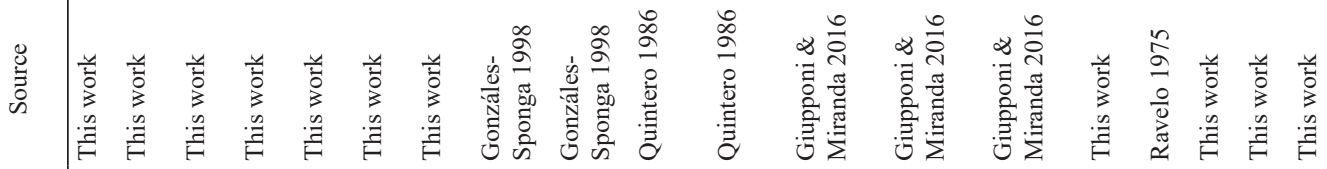

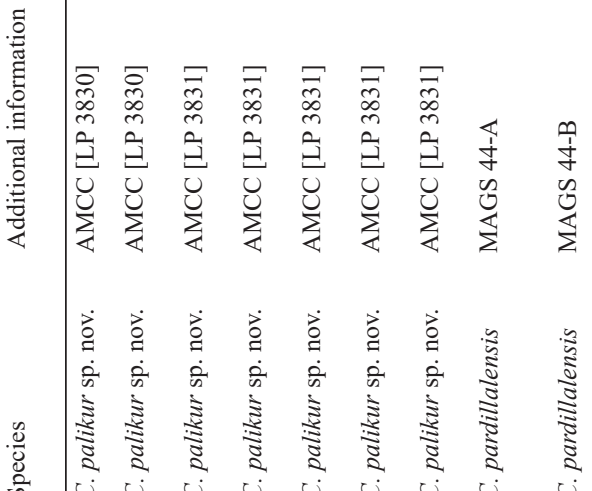

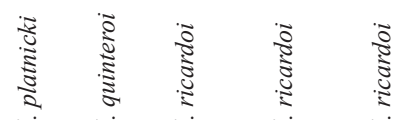

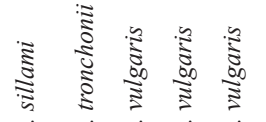


32 or 33 setae; leg IV basitibia with two pseudo-articles; trichobothrium $b t$ situated in proximal third of basitibia; trichobothrium $b c$ situated closer to $s b f$ than to $b f$.

\section{Etymology}

Patronym honoring Dr Alexandre B. Bonaldo (Giupponi \& Miranda 2016).

\section{Type material}

\section{Holotype}

BRAZIL • +; Pará, Benevides; 01¹9'28" S, 48¹7'19" W; 18 Jan. 2002; D.R.S. Souza and A.C. Souza leg.; MPEG AMB 61.

\section{Paratypes}

BRAZIL • 5 q $q$; same data as for holotype; MPEG AMB $61 \bullet 1+, 3$ juv.; same locality as for holotype; 6 Nov. 2001; D.R.S. Souza and A.C. Souza leg.; MPEG $61 \bullet 1$; ; same collection data as for preceding; MPEG $60 \bullet 1$ \&; same collection data as for preceding; MNRJ 9250.

\section{Additional material}

BRAZIL • 11 우, 1 juv.; Pará, Breves; Resex Mapuá; 0103'41.9" S, 50³2'38.92" W; 4-8 Dec. 2012; C.S. Costa leg.; new record; MZSP 67529 • 1 juv.; Pará, Santarém, Trilha Terra Rica, Tapajós National Forest; $02^{\circ} 50^{\prime} 33.7^{\prime \prime}$ S, 545 58'28.3" W; 30 Oct. 2014; A. Coronato, D. Chiriví, J. Cabra and C. Sampaio leg.;

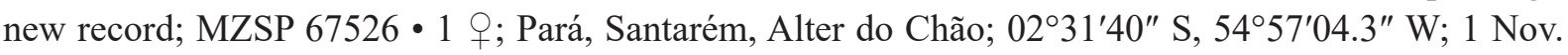
2014; A. Coronato, D. Chiriví, J. Cabra and C. Sampaio leg.; new record; MZSP 67528.

\section{Measurements}

See Table 2.

\section{Distribution}

The distribution of this species is here extended from a single locality in the municipality of Benevides to include the Extractive Reserve in Breves Municipality (Resex Mapuá), a national park in Santarém Municipality (FLONA Tapajós), and the Alter do Chão District, all in the state of Pará, up to $765 \mathrm{~km}$ SW of the type locality.

\section{Natural history}

All samples from the new localities were female and some small females were carrying egg sacs with fewer eggs than adults, similar to what has been observed with the parthenogenetic Sarax ioanniticus (Kritscher, 1959) comb. nov. (Weygoldt 2008), suggesting that C. bonaldoi may also be parthenogenetic.

\section{Remarks}

Despite the large distances between populations (Benevides, Breves and Santarém), no morphological differences were found among the specimens. Specimens from the three new localities are similar in the number of pseudo-articles (two) in the basitibia of leg IV, the number of cheliceral teeth (four, excepting the specimen from Satarém [MZSP 67526], with five), the position of the trichobothria on the distitibia of leg IV, the number of spines on the pedipalp, and the shape of the female genitalia. However, the specimens from Breves, Santarém and Alter do Chão are smaller and paler, which may be the due to the stage of development of the specimens (subadults). See Giupponi \& Miranda (2016) for further comparison of this species with others in the genus. 
Charinus bordoni (Ravelo, 1977)

Fig. 27; Table 2

Speleophrynus bordoni Ravelo, 1977: 18-25, figs 1-2, 3a-c, 4a-d.

Charinides bordoni-Quintero 1983: 28. — González-Sponga 1998: 2, map 1.

Charinus bordoni - Delle Cave 1986: 162, fig. II. — Weygoldt 1994: 242, 244. — Harvey 2003: 4. Galán \& Herrera 2006: 42, 48. — Miranda \& Giupponi 2011: 66, fig. 13. — Jocqué \& Giupponi 2012: 55. — Vasconcelos et al. 2013: 497. — Torres-Contreras et al. 2015: 148. — Miranda et al. 2016c: 31 .

\section{Diagnosis}

Ravelo (1977) provided a diagnosis of the species in which it was compared only with Charinus tronchonii (Ravelo, 1975). The diagnosis is updated here based on the original description. This species may be separated from other Charinus in Amazonia and northern South America by means of the following combination of characters: median and lateral eyes absent; cheliceral claw with five teeth; tibia of leg I with 23 articles, tarsus I with "a bit more than 40 articles"; pedipalp femur with two dorsal spines and two ventral spines decreasing in size from proximal to distal; pedipalp patella with three dorsal spines and two ventral spines, and with large setiferous tubercle between spine I and distal margin; pedipalp tibia with two dorsal spines; leg IV basitibia with three articles (Ravelo 1977 considered the leg IV basitibia to have four articles as he (and Quintero 1983) counted the distitibia as part of the basitibia); leg IV distitibia trichobothrium $b c$ situated closer to $s b f$ than to $b f ; s c$ and $s f$, series each with five trichobothria.

\section{Etymology}

Patronym honoring Carlos Bordón, founder of the Venezuelan Society of Speleology and collector of the type series (Ravelo 1977).

\section{Type material}

\section{Holotype}

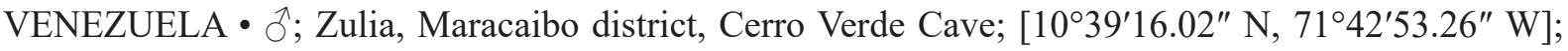
MBSVE 606 [not examined].

\section{Paratypes}

VENEZUELA • 1 § ; same collection data as for holotype MBSVE 607 [not examined] • 1 \%; same collection data as for holotype; MBSVE 605) [not examined] • 1 ; ; same collection data as for holotype; MBSVE 608 [not examined] 1 o; same collection data as for holotype; MBSVE 609 [not examined] • 1 juv. O; same collection data as for holotype; MBSVE 6010 [not examined].

\section{Measurements}

See Table 2.

\section{Distribution}

Known only from the type locality.

\section{Natural history}

Charinus bordoni was found only inside caves in the aphotic zone which, in combination with the complete absence of eyes, indicates it a troglobitic species (Ravelo 1977; Delle Cave 1986). 


\section{Remarks}

Ravelo (1977) described this species in the genus Speleophrynus. Quintero (1983) revised topotypes of Speleophrynus bordoni Ravelo, 1977 and Speleophrynus tronchonii, and considered them to be Charinides based on the number of pseudo-articles in the basitibia of leg IV. Delle Cave (1986) was the first to place in doubt the classification based on the number of pseudo-articles in the basitibia of leg IV and transferred S. bordoni and S. tronchonii to Charinus.

\section{Charinus brescoviti Giupponi \& Miranda, 2016}

Fig. 27; Table 2

Charinus brescoviti Giupponi \& Miranda, 2016: 3-6, figs 1a-e, 2a, 3a, 4a.

\section{Diagnosis}

This species may be separated from other Charinus in Amazonia and northern South America by means of the following combination of characters: tegument brownish-yellow in color; median and lateral eyes well developed; tetra- and pentasternum small, rounded; cushion-like gonopods, lateral projections directed posteriorly and internal seminal receptacles; basal spine on pedipalp tarsus large, two-thirds length of distal spine; ventral row of setae of cleaning organ with 28 setae; leg IV basitibia with two pseudo-articles; leg IV basitibia trichobothrium $b t$ situated in proximal third; leg IV distitibia with 16 trichobothria, basal trichobothria, $b f, b c$ and $s b f$, equidistant.

\section{Etymology}

Patronym honoring Dr Antônio D. Brescovit (Giupponi \& Miranda 2016).

\section{Type material}

\section{Holotype}

BRAZIL • O; Amazonas, Piaçaba, Araçá River; [00²5'17.75" S, 6254'30.24" W]; 18 May 1982;

B. Mascarenhas leg.; IBSP 149.

\section{Paratypes}

BRAZIL • 1 \%; same collection data as for holotype; IBSP $149 \bullet 1 \%, 1$ juv.; same collection data as for holotype; MNRJ 9186.

\section{Measurements}

See Table 2.

\section{Distribution}

Known only from the type locality.

\section{Natural history}

Epigean, found close to a river.

\section{Remarks}

See Giupponi \& Miranda (2016) for a comparison and discussion of this species.

Charinus bromeliaea Jocqué \& Giupponi, 2012

Fig. 27; Table 2 
MIRANDA G.S. et al., Systematic revision of Charinidae (Arachnida, Amblypygi)

Charinus bromeliaea Jocqué \& Giupponi, 2012: 55-58, figs 1-5.

Charinus bromeliaea - Vasconcelos et al. 2013: 497. — Réveillion \& Maquart 2015: 190-192, fig. 1e-f. —Armas et al. 2016: 48. — Miranda et al. 2016c: 29.

\section{Diagnosis}

Based on Jocqué \& Giupponi (2012), this species may be separated from other Charinus in Amazonia and northern South America by means of the following combination of characters: tegument pale yellow-brown; median eyes and median ocular tubercle present; lateral eyes well developed; pedipalp femur with three dorsal spines and three ventral spines; pedipalp patella with three dorsal spines and two ventral spines; pedipalp tibia with two small dorsal spines; tibia of leg I with 23 articles, tarsus I with 25 articles; leg IV basitibia with two pseudo-articles; leg IV distitibia trichobothrium $b c$ situated closer to $s b f$ than to $b f ; s c$ and $s f$ series each with four trichobothria.

According to Jocqué \& Giupponi (2012), the distitibia of leg IV possesses four trichobothria in the $s c$ and $s f$ series, a count otherwise observed only in C. alagoanus sp. nov., from which C. bromeliaea can be distinguished by the number of pseudo-articles on basitibia IV and number of articles on the tarsus of leg I. Jocqué \& Giupponi (2012: 55) mention that the "median and lateral eyes [are] reduced in comparison to average size for the genus", but the development of the eyes is similar to that in other species of Charinus with fully developed eyes. Jocqué \& Giupponi (2012) also described the pedipalp patella $C$. bromeliaea as possessing five dorsal spines, but considered the distal spine and the relatively long proximal setiferous tubercle as spines in their counts, inflating the true number from three. The basitibia of leg IV consists of two pseudo-articles in C. bromeliaea, as in C. bichuetteae, C. bonaldoi, C. brescoviti, C. camachoi, C. carvalhoi sp. nov., C. pardillalensis, C. platnicki, C. quinteroi and C. ricardoi, but $C$. bromeliaea can be distinguished from these species, except for $C$. brescoviti, by the presence of median eyes and a median ocular tubercle. The sucker-like female gonopod further separates C. bromeliaea from C. brescoviti, in which the gonopod is cushion-like. Charinus bromeliaea superficially resembles C. platnicki, but is larger, light brown in color, with the basal spine of the pedipalp tibia about two-thirds the length of the medial spine, rather than about one-quarter its length, as in C. platnicki. Additionally, the distitibia of leg IV possesses four trichobothria in C. bromeliaea and five in C. platnicki.

\section{Etymology}

Noun refering to the habitat of the species, bromeliads (Jocqué \& Giupponi 2012).

\section{Type material}

\section{Holotype}

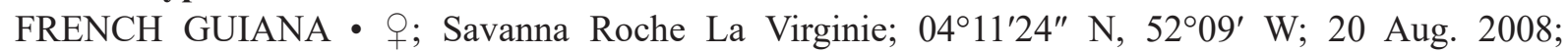
M. Jocqué leg.; in Achmea cf. melionii bromeliads; MNRJ 9185.

\section{Paratypes}

FRENCH GUIANA • 3 우; same collection data as for holotype; MNRJ 9185.

\section{Measurements}

See Table 2.

\section{Distribution}

Known only from the type locality. 


\section{Natural history}

Inhabits bromeliads.

Charinus camachoi (González-Sponga, 1998)

Fig. 27; Table 2

Charinides camachoi González-Sponga, 1998: 2-3, figs 1-8, map 1.

Charinus camachoi - Harvey 2003: 5. — Miranda \& Giupponi 2011: 66, fig. 13. — Jocqué \& Giupponi 2012: 55. — Vasconcelos et al. 2013: 497. — Miranda et al. 2016c: 31.

\section{Diagnosis}

Based on the description of González-Sponga (1998), this species may be separated from other Charinus in Amazonia and northern South America by means of the following combination of characters: median eyes and median ocular tubercle absent; lateral eyes well developed; anterior margin of carapace straight with six setae; sternum with single platelets, not pairs of platelets; males with secondary sexual dimorphism; pedipalp femur with three dorsal spines and three ventral spines; pedipalp patella with four dorsal spines and two ventral spines; pedipalp tibia with two dorsal spines; pedipalp tarsus with two spines, proximal spine one-fifth length of distal spine and distal spine half length of article; tibia of leg I with 22 or 23 articles, tarsus I with 36-38 articles; first tarsal article twice as long as second article; leg IV basitibia with two pseudo-articles; trichobothrium $b c$ situated closer to $s b f$ than to $b f$.

\section{Etymology}

Patronym honoring Carlos Camacho (González-Sponga, 1998).

\section{Type material}

\section{Holotype}

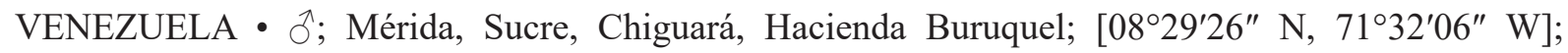
1000 m a.s.1.; 10 Jan. 1988; A.R. Delgado de González and M.A. González-Sponga leg.; MIZA [not examined].

\section{Paratype}

VENEZUELA • 1 क; same collection data as for holotype; MIZA [not examined].

\section{Measurements}

See Table 2.

\section{Distribution}

Known only from the type locality.

\section{Natural history}

According to González-Sponga (1998), C. camachoi inhabits the leaflitter and cracks in slopes produced by erosion in a cloudy evergreen forest, interspersed with Coffea arabica Linnaeus, 1753, Erythrina Linnaeus, 1753, and Musa Linnaeus, 1753. 


\section{Remarks}

González-Sponga (1998: 3) described leg IV of C. camachoi as "with three segments" but did not differentiate the basitibia and distitibia, hence the two proximal segments must be the basitibia and the third, the distitibia. The basitibia of leg IV should be considered to consist of two pseudo-articles in this species, contrary to González-Sponga (1998).

Charinus carajas Giupponi \& Miranda, 2016

Figs $8 \mathrm{E}-\mathrm{H}, 27$; Table 2

Charinus carajas Giupponi \& Miranda, 2016: 15-18, figs 2e, 3e, 4e, g, 8a-f.

\section{Diagnosis}

Based on Giupponi \& Miranda (2016), this species may be separated from other Charinus in Amazonia and northern South America by means of the following combination of characters: median and lateral eyes present; median ocular tubercle and lateral eyes markedly reduced; small, rounded tetra- and pentasternum; reduced tritosternum, slightly surpassing base of pedipalp coxae; cushion-like female gonopod with lateral projections directed posteriorly, covering openings of internal seminal receptacles (atrium); male gonopods with long, curved, wrinkled medial lobes (Fig. 8E-F); lateral lobes fimbriate (Fig. 8E-F, H); dorsal lobe surpassing length of other lobes and with elevated scales (Fig. 8E, G); marked secondary sexual dimorphism evident, males with longer pedipalps, ca twice as long as female pedipalps; pedipalp femur with four dorsal spines; two dorsal spines on pedipalp tarsus, small basal spine, one-quarter length of distal spine; tibia of leg I with 23 articles, tarsus I with 42 articles; leg IV basitibia with three pseudo-articles; leg IV basitibia trichobothrium $b t$ situated in proximal third; leg IV distitibia $s c$ and $s f$ series each with five trichobothria; leg IV distitibia trichobothrium $b f$ equidistant between $b c$ and $s b f$; tegument pale yellow.

This is among the few Amazonian species in which the median eyes and median ocular tubercle are present.

\section{Etymology}

Noun in apposition, taken from the Caraja mountain range where the species was collected, and from the indigenous people known as the karajas (Giupponi \& Miranda 2016).

\section{Type material}

\section{Holotype}

BRAZIL • 1 क; Pará, Carajás National Forest, Gruta N4E-14 AF; 0602'2.096" S, 50¹0'03.741" W; SAD’ 69; 7-12 Oct. 2008; Andrade et al. leg.; MZSP 29136.

\section{Paratypes}

BRAZIL • 1 juv.; same locality as for holotype, Gruta N4E-10; 20 Oct.-1 Nov. 2006; Andrade et al. leg.; MZSP 28287 • 1 juv.; same locality as for holotype, Gruta N4E-21;20 Oct.-1 Nov. 2006; Andrade et al. leg.; MZSP 28288 - 2 juv.; same locality as for holotype, Gruta N4E-22;20 Oct.-1 Nov. 2006; Andrade et al. leg.; MZSP $28289 \bullet 1 \delta^{\top}$; same locality as for holotype, Gruta N4E-22; 06 $02 ' 2.096^{\prime \prime} \mathrm{S}, 50^{\circ} 10^{\prime} 03.741^{\prime \prime} \mathrm{W}$; SAD' 69; 7-12 Oct. 2008; MZSP 29126 • 2 juv.; same locality as for holotype, Gruta N4E-33; 8-12 Feb. 2007; Andrade et al. leg.; MZSP 28290 • 1 đ; same locality as for holotype, Gruta N4E-95; 7-12 Oct. 2008; Andrade et al. leg.; MZSP 29127 • 2 juv.; same locality as for holotype, Gruta N4WS-15; 20 Oct. 
2006; Andrade et al. leg.; MZSP 28292 • 2 우, 1 ठ, 2 juv.; same locality as for holotype, Gruta N4WS8CL; 0605'22.183" S, 50¹1'40.996" W; SAD' 69; 7-12 Oct. 2008; MNRJ 9270 ex MZSP 29132 • 1 juv.; same locality as for holotype, Gruta N5E-03 (new -07); 22 Mar.-3 Apr. 2005; Andrade and Arnoni leg.; MZSP 28281 - 3 juv.; same locality as for holotype, Gruta N5E-04 (new -06); 22 Mar.-3 Apr. 2005; Andrade and Arnoni leg.; MZSP 28282 - 1 juv.; same locality as for holotype, Gruta N5E-05 (new -04); 22 Mar.-3 Apr. 2005; Andrade and Arnoni leg.; MZSP 28283 • 1 juv.; same locality as for holotype, Gruta N5S; 3 May 2005; Andrade and Arnoni leg.; MZSP 28286 • 1 juv.; same locality as for holotype, Gruta N5S-01; 3-13 May 2005; Andrade and Arnoni leg.; MZSP 28285 • 1 q; same locality as for holotype; MII GEM 1722 EU; ISLA 3892 • 1 q, 1 § ; same locality as for holotype; MII GEM 1755EU; ISLA 3890 - 2 우, 1 §ึ; Parauapebas, Projeto N5S, Morro I, Cav. GEM, 1782; 28 Feb. 2011; CARSTE leg.; dry season; ISLA 3897.

\section{Additional material (examined)}

BRAZIL • 1 đं; same locality as for holotype, Gruta GEM 1564 CL Tarzan; 06¹9'04.284" S, 5005'48.261" W; SAD' 69; 17-24 Oct. 2008; Andrade et al. leg.; MZSP 29120 • 1 juv.; same locality as for holotype, Gruta GEM 1590 CL Tarzan; 17-24 Oct. 2008; Andrade et al. leg.; MZSP 29123 - 1 Õ, 3 juv.; same locality as for holotype, Gruta GEM15170, AF Tarzan; 1724 Oct. 2008; Andrade et al. leg.; MZSP 29121 - 1 juv.; same locality as for holotype, Gruta N115, Mangangá, 28 Sep.-3 Oct. 2007; Andrade et al. leg.; MZSP 29115 • 1 juv.; same locality as for holotype, Três Mosqueteiras, Gruta N1-25; 28 Sep.-3 Oct. 2007; Andrade et al. leg.; MZSP 29113 - 1 क; same locality as for holotype; Mangangá, Gruta N1-15; 28 Sep.-3 Oct. 2007; Andrade et al. leg.; MZSP 29116•1 ; Gruta N1-64 Amailton; 28 Sep.-3 Oct. 2007; Andrade et al. leg.; MZSP 29114 • 1 क , 3 juv; same locality as for holotype, Gruta N4E-61; 8-12 Feb. 2007; Andrade et al. leg.; MZSP 28291 - 1 juv.; same locality as for holotype, Gruta N4E-08 CL; 0602'20.419" S, 5009'36.064" W; SAD' 69; 7-12 Oct. 2008; Andrade et al. leg.; MZSP 29134 • 1 juv.; same locality as for holotype, Gruta N4E-10 AF; 0602'20.162" S, 5009'38.277" W; SAD' 69; 7-12 Oct. 2008; Andrade et al. leg.; MZSP 29129 - 1 juv.; same locality as for holotype, Gruta N4E-22 AF; 0602'02.096" S,

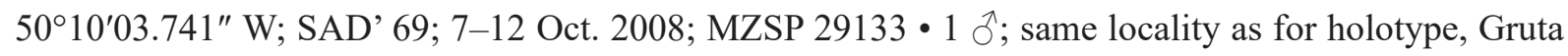
N4E-26 CL; 0602'14.273" S, 50¹0'02.194" W; SAD’ 69; 7-12 Oct. 2008; Andrade et al. leg.; MZSP 29128 - 1 ô; same locality as for holotype, Gruta N4E-33 AF; 0602'26.607" S, 5009'36.64" W; SAD' 69; 7-12 Oct. 2008; Andrade et al. leg.; MZSP 29125 • 1 đ’; same locality as for holotype, Gruta N4E-61 AF; 0602'20.754" S, 50¹0'02.965" W; SAD’ 69; 7-21 Oct. 2008; Andrade et al. leg.; MZSP 29135 - 1 juv.; same locality as for holotype, Gruta N4WS8 AF; 0605'22.183" S, 50¹1'40.996" W; SAD’ 69; 7-12 Oct. 2008; Andrade et al. leg.; MZSP 29137 • 1 q; same locality as for holotype, Gruta N5E-11 (new -21); 22 Mar.-3 Apr. 2005; Andrade and Arnoni leg.; MZSP 28284 • 1 juv.; same locality as for holotype, Gruta N5S21 AF; 0605'15.383" S, 5007'33.51" W; SAD' 69; 7-12 Oct. 2008; Andrade et al. leg.; MZSP 29130 • 1 đ’; same locality as for holotype, Gruta N5S8 CL; 0605'51.597" S, 5007'56.646" W; SAD’ 69; 7-12 Oct. 2008; Andrade et al. leg.; MZSP 21131.

\section{Measurements}

See Table 2.

\section{Distribution}

Known from several iron caves in the northern part of Serra de Carajas, Pará, Brazil. 


\section{Natural history}

Troglophilous, only known from inside iron ore caves.

\section{Remarks}

See Giupponi \& Miranda (2016) for more details about this species.

Charinus carvalhoi sp. nov. urn:1sid:zoobank.org:act:7AFC80A1-EB81-4B11-9CD5-440DAED233F6

Figs 27-28; Table 2

\section{Diagnosis}

This species may be separated from other Charinus in Amazonia and northern South America by means of the following combination of characters: entire tegument covered with claviform setae; first four articles of leg I tarsus very long; leg IV basitibia with two pseudo-articles.

The combination of an extremely elongate first article of the leg I tarsus and the tegument covered with clavate setae are observed only in $C$. carvalhoi sp. nov., C. longitarsus and $C$. montanus. The presence of four long tarsal articles on leg I is unique to C. carvalhoi sp. nov.

\section{Etymology}

Patronym honoring Dr Leonardo Carvalho, collector of the type series, for his contributions to arachnology.

\section{Type material}

\section{Holotype}

BRAZIL - + ; Roraima, Cantá, margin of road BR432, ca $10 \mathrm{~km}$ from Cantá; 02 $35^{\prime} 15.3^{\prime \prime} \mathrm{N}$, 60³8'27.6" W; 23 Jul. 2014; L.S. Carvalho et al. leg.; CNHUFPI 1323; AMCC [LP 13399].

\section{Paratype}

BRAZIL - 1 §’; Roraima, Boa Vista, Campus de Cauamé, Universidade Federal de Roraima; 0252'38.4" N, 6043'13.1" W; 91 m a.s.1.; 22 Jul. 2014; M.C. Schneider leg.; CNHUFPI 1324.

\section{Description}

CARAPACE. Six anterior setae (Fig. 28A); frontal process triangular (Fig. 28C). Small granules densely scattered between ocular triads and among sulci. Median eyes and median ocular tubercle absent (Fig. 28A); lateral eyes well developed, seta posterior to each lateral ocular triad; lateral ocular triad well separated from carapace margin (Fig. 28A).

STERnUm. Tritosternum projected anteriorly with typical setation, long, surpassing base of pedipalp coxae (Fig. 28B); other sternal plaques broad and flat, with pair of setae on lateral borders; pentasternum without setae near membranous region and two setae anteriorly.

Opisthosoma. Ventral sacs and ventral sac cover absent (Fig. 28B).

Genitalia. Female genital operculum with prominent setae posteromedially and smaller setae near margin; gonopod sucker-like, tubular, unsclerotized from base to apex. Male unknown. 
Chelicerae. Small flat tooth on retrolateral surface of basal segment, opposite to bifid tooth; setae absent on retrolateral surface of claw; claw with four teeth; row of six setae on prolateral surface of basal segment; bifid tooth on basal segment with dorsal cusp larger than ventral cusp.

Pedipalps. Coxal dorsal carina with two setae on margin and without seta encircled by round carina. Femur with three dorsal spines and three ventral spines (Fig. 28E); two prominent setiferous tubercles between dorsal spine 1 and proximal margin; setiferous tubercle between ventral spine 1 and proximal margin. Patella with three dorsal spines in primary series (Fig. 28E); prominent setiferous tubercle distal to spine I, one-third length of spine I; two ventral spines (Fig. 28F); setiferous tubercle between spine I and distal margin. Tibia with ventral spine distally and seta between spine and distal margin (Fig. 28F). Tarsus with two dorsal spines, proximal spine one-third length of distal spine (Fig. 28D); cleaning organ with 28 setae in ventral row.

LEGs. Tibia of leg I with 21 articles; tarsus I with 26 articles; first four tarsal articles up to ten times as long as subsequent articles. Leg IV basitibia with two pseudo-articles, without sclerotized, denticulate margin projecting from apex of articles; trichobothrium $b t$ situated in proximal third of pseudo-article; distitibia with trichobothrium $b c$ situated closer to $s b f$ than to $b f, s c$ and $s f$ series each with five trichobothria.

\section{Measurements}

See Table 2.

\section{Distribution}

Known only from the type localities.

\section{Natural history}

Epigean in secondary forest and synanthropic in disturbed areas.

Charinus ferreus Giupponi \& Miranda, 2016

Fig. 27; Table 2

Charinus ferreus Giupponi \& Miranda, 2016: 21-23, figs 2g, 3g, 4h, 10a-f.

\section{Diagnosis}

Based on Giupponi \& Miranda (2016), this species may be separated from other Charinus in Amazonia and northern South America by means of the following combination of characters: tegument pale yellow; median eyes and median ocular tubercle absent; lateral eyes reduced and pale; small, rounded tetra- and pentasternum; reduced tritosternum, slightly surpassing base of pedipalp coxae; male gonopod with long, curved, wrinkled medial lobes; lateral lobe fimbriate; median lobe surpassing lateral and dorsal lobes; female gonopod cushion-like; pedipalp femur with three dorsal spines; spines of pedipalp tibia subequal; basal spine of pedipalp tarsus large, ca two-thirds length of distal spine; tibia of leg I with 21 articles, tarsus I with 37 articles; leg IV basitibia with three pseudo-articles; leg IV basitibia trichobothrium $b t$ situated in proximal third; leg IV distitibia with 16 trichobothria; $s c$ and $s f$ series each with five trichobothria; basal trichobothria $b c$ and $s b f$ situated closer to each other than to $b f$.

\section{Etymology}

The name is an adjective derived from the Latin 'ferrum', referring to the iron ore cave in which the type specimens were collected (Giupponi \& Miranda 2016). 


\section{Type material}

\section{Holotype}

BRAZIL • +; Pará, Carajás National Forest, Gruta S11 D64; 23 May-2 Sep. 2007; Andrade et al. leg.; MZSP 29104.

\section{Paratypes}

BRAZIL • 1 \&; same locality as for holotype, Gruta S11 A03; 23 Aug.-2 Sep. 2007; Andrade et al. leg.; bright area; MZSP 29103 - 3 juv. + \& ; same locality as for holotype, Gruta S11 A05; 23 Jul. -2 Sep. 2007; Andrade et al. leg.; MZSP 29110 • 1 juv.; same locality as for holotype, Gruta S11 A07; 23 Aug.-2 Sep. 2007; Andrade et al. leg.; bright area; MZSP 29112 • 1 क; same locality as for holotype, Gruta S11 B11; 23 Aug.-2 Sep. 2007; Andrade et al. leg.; aphotic; MZSP 29108 • 1 juv.; same locality as for holotype, Gruta S11 B11; 23 Aug.-2 Sep. 2007; Andrade et al. leg.; bright area; MZSP 29109 • 2 juv.; same locality as for holotype, Gruta S11 C27; 23 Aug.-2 Sep. 2007; Andrade et al. leg.; bright area; MZSP 29105 1 § , 1 juv.; same locality as for holotype, Gruta S11 D39; 23 Aug.-2 Sep. 2007; Andrade et al. leg.; MZSP 29106 • 1 +, 1 juv.; same locality as for holotype, Gruta S11 D39; 23 Aug.-2 Sep.

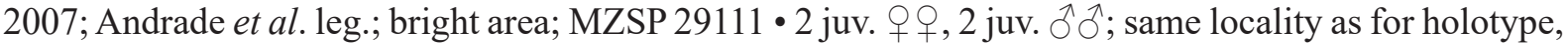
Gruta S11 D64; 23 Aug.-2 Sep. 2007; Andrade et al. leg.; MZSP 29104 • 1 क, 1 juv.; same locality as for holotype, Gruta S11 D64; 23 Aug.-2 Sep. 2007; Andrade et al. leg.; aphotic; MZSP 29107 • 1 O ; same locality as for holotype, Gruta S11 D78; 23 Aug.-2 Sep. 2007; Andrade et al. leg.; aphotic; MZSP 29102.

\section{Measurements}

See Table 2.

\section{Distribution}

Known only from the type localities.

\section{Natural history}

This species is only found inside iron ore caves. It exhibits troglomorphic characters, such as pale coloration and the almost complete absence of eyes, and may be troglobitic.

\section{Remarks}

See Giupponi \& Miranda (2016) for more details about this species.

Charinus gertschi Goodnight \& Goodnight, 1946

Figs 3C-D, 4C-D, 5C-D, 27, 29; Table 2

Charinus gertschi Goodnight \& Goodnight, 1946: 323-327, figs 1-8.

Charinus gertschi - Delle Cave 1986: 162, fig. II. - Weygoldt 2002a: 297. — Harvey 2003: 5. Miranda \& Giupponi 2011: 68, fig. 13. - Jocqué \& Giupponi 2012: 55. — Vasconcelos et al. 2013: 497. — Miranda et al. 2016c: 31.

\section{Diagnosis}

This species may be separated from other Charinus in Amazonia and northern South America by means of the following combination of characters: carapace reddish-brown with darker mottling (Fig. 29A); six setae on anterior margin of carapace; median eyes and median ocular tubercle present (Fig. 29C); lateral eyes well developed; tritosternum projected anteriorly with typical setation (Fig. 29B); other sternal 
platelets wider than long; pedipalp femur with five dorsal spines and five ventral spines (Fig. 3C-D); pedipalp femur with additional small spine proximal and ventral to ventral spine 1; pedipalp patella with five or six dorsal spines (Fig. 29E); pedipalp patella with four ventral spines (Fig. 29F); pedipalp tarsus with two dorsal spines (Fig. 29D); tibia of leg I with 23 articles, tarsus I with 43 articles; leg IV basitibia with four pseudo-articles; female gonopod cushion-like and markedly sclerotized basally (Fig. 5C-D).

\section{Etymology}

Not specified by the authors but evidently a patronym honoring Dr Willis J. Gertsch.

\section{Type material}

\section{Holotype}

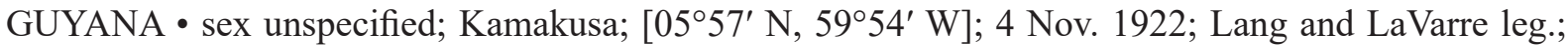
AMNH [not examined].

\section{Paratypes}

GUYANA • 1 ex., sex unspecified; same collection data as for holotype; AMNH [not examined].

SURINAM • number and sex of specimens unspecified; Paramaribo; [05 $\left.50^{\prime} 03.54^{\prime \prime} \mathrm{N}, 55^{\circ} 11^{\prime} 59.40^{\prime \prime} \mathrm{W}\right]$; Stahel leg.; MCZ [not examined].

\section{Additional material}

VENEZUELA: 1 गे; Estado Bolívar, Municipio Gran Sabana, Canaima National Park, Campamento Uruyén, forest SW; $05^{\circ} 40.803^{\prime} \mathrm{N}, 62^{\circ} 28.705^{\prime} \mathrm{W} ; 28$ Jul. 2009; $504 \mathrm{~m}$ a.s.1.; L. Prendini and J.A. Ochoa leg.; primary forest; AMCC [LP 10076].

\section{Description}

CARAPACE. Frontal process large, triangular, not visible in dorsal view, slightly curved anteriorly (Fig. 29C). Small granules densely scattered between ocular triads and among sulci (Fig. 29A). Median eyes well developed, median ocular tubercle shallow (Fig. 29C). Lateral eyes well developed, seta posterior to each lateral ocular triad; lateral ocular lenses directed anterodorsally.

STERnUm. Tritosternum projected anteriorly into small, blunt tubercle (Fig. 29B), with typical setation, surpassing base of pedipalp coxae; medial platelet (tetrasternum) with two convex platelets, with one large and few smaller setae, medially on each plaque. Third platelet (pentasternum) also with two convex platelets, subequal to midline of each platelet, each with one large and few small setae medially. Sternites close to each other. Metasternum not paired, formed by single platelet, with pair of setae anteriorly.

Opisthosoma. Ventral sacs and ventral sac cover absent.

Genitalia. Female genital operculum slightly curved inwards, with several setae along margin and on surface (Fig. 5C-D). Gonopods rounded, cushion-like, without claws, flat, with sclerotized region basally (Fig. 5C-D); flaps on retrolateral margin of gonopods; genital atrium not visible, i.e., completely covered by flaps of gonopod; near margin of genital operculum (Fig. 5C-D).

Chelicerae. Four prolateral teeth; first tooth bifid, Ia larger than Ib. Second tooth larger than third. Fourth tooth one-third larger than III and subequal to Ib. Retrolateral row with small elevation in dorsal region. Prolateral surface of basal segment with vertical row of six large setae. Claw with six denticles.

Pedipalps. Femur with six dorsal spines in primary series (Figs 3C-D, 29E-F); extra spine distal to last dorsal spine (smaller than last two on dextral pedipalp but similar in length on sinistral pedipalp); 
spine between spines 2 and 3, close to spine 3 (Fig. 3C); prominent setiferous tubercle dorsal to spine 1 and attached to its base, with two small setiferous tubercles proximal to spine 1 (Fig. 3C); five ventral spines in primary series (Fig. 29F); small spine distally, close to distal border; prolateral spine attached to base of spine I. Patella with five dorsal spines (Figs 4C-D, 29E); spine between spine I and distal margin of tibia, one-third length of spine I; one (sinistral pedipalp) or two (dextral pedipalp) small spines proximal to spine V; five ventral spines decreasing in size (Figs 4C-D, 29F). Tibia with two dorsal spines, proximal spine two-thirds length of distal spine; ventral spine situated in distal half of tibia, two-thirds length of basal dorsal spine. Tarsus with two small dorsal spines (Fig. 29D); proximal spine two-thirds length of distal spine; cleaning organ about half length of tarsus, with 31 setae in ventral row; claw long, with acute, curved tip.

LEGs. Tibia of leg I with 23 articles; tarsus I with 41 articles; modified claw at apex of leg; leg covered with many bristles, club sensilla, and pit organs. Leg IV basitibia with four pseudo-articles, with one trichobothrium submedial on last pseudo-article; distitibia trichobothrium $b c$ equidistant between $b f$ and $s b f ; s c$ and $s f$ series each with five trichobothria.

\section{Measurements}

See Table 2.

\section{Distribution}

Known from Guyana, Surinam and Venezuela.

\section{Natural history}

Epigean, found in forested areas.

\section{Remarks}

According to Goodnight \& Goodnight (1946), the pedipalp patella bears seven dorsal spines, but the actual number of spines is six, as the distal setiferous tubercle was included in the count (based on their illustration). Goodnight \& Goodnight (1946: 325, fig. 4) did not describe the number of spines on the pedipalp tarsus, but it is possible to see the spines on their illustration.

Charinus guianensis (Caporiacco, 1947), nomen dubium

Oligacanthophrynus guianensis Caporiacco, 1947: 21.

Oligacanthophrynus guianensis - Caporiacco 1948: 616, fig. 9. — Vanni et al. 1988: 376.

Charinus guianensis - Weygoldt 1998a: 72; 2002a: 297 [designated as nomen dubium].

\section{Etymology}

Not specified by the author, but appears to be an adjective referring to Guyana, the country in which the type locality is located.

\section{Type material}

\section{Holotype}

GUYANA • juv.; Castra Marlissa [Campo di Marlissa, according to Weygoldt (1998a)], Upper DemeraraBerbice (region 10); [0454' N, 58 $\left.{ }^{\circ} 15^{\prime} \mathrm{W}\right]$; MZUF 1798. 


\section{Distribution}

The type locality, Marlissa, is probably the name of a river in the Upper Demerara-Berbice region of Guyana. The precise locality could not be located, hence the coordinates provided are an approximation of where the type specimen was collected.

\section{Remarks}

Caporiacco (1947) introduced the generic name Oligacanthophrynus Caporiacco, 1947 with a short description of the genus. The holotype of Oligacanthophrynus guianensis Caporiacco, 1947 was described in more detail by Caporiacco (1948) and revisited fifty years later by Weygoldt (1998a), who considered Oligacanthophrynus a junior synonym of Charinus and concluded that the specimen used in Caporiacco's (1947) description was a protonymph, probably conspecific with C. gertschi. The characters present in the protonymph, however, are insufficient to assign $C$. guianensis to any known species due to its incomplete development, so Weygoldt (2002a) considered the species a nomen dubium.

Due to the uncertainty regarding the systematics of the species in the Guianas and Surinam, it is presently impossible to determine the identity of $C$. guianensis, and shall remain so until adult specimens are collected at the type locality.

Charinus guto Giupponi \& Miranda, 2016

Fig. 27; Table 2

Charinus guto Giupponi \& Miranda, 2016: 13-15, figs 2d, 3d, 4d, 7a-e.

\section{Diagnosis}

Based on Giupponi \& Miranda (2016), this species may be separated from other Charinus in Amazonia and northern South America by means of the following combination of characters: tegument light brown; median eyes and median ocular tubercle absent; lateral eyes well-developed, but pale; small, rounded tetra- and pentasternum; cushion-like gonopods with lateral projections directed posteriorly, covering aperture of internal seminal receptacles; two dorsal spines on pedipalp tarsus, small basal spine, one-quarter length of distal spine; tibia of leg I with 21 articles, tarsus I with 37 articles; leg IV basitibia with three pseudo-articles; leg IV basitibia trichobothrium $b t$ situated in proximal third; leg IV distitibia with 14 trichobothria; basal trichobothria, $b f, b c$ and $s b f$ equidistant; $s c$ and $s f$ series each with five trichobothria.

Charinus guto resembles C. vulgaris, but possesses more spines on the pedipalp femur and patella.

\section{Etymology}

Patronym honoring José Augusto Pereira Barreiros nicknamed Guto (in memoriam; Giupponi \& Miranda 2016).

\section{Type material}

\section{Holotype}

BRAZIL • +; Pará, Belém, Bosque Rodrigues Alves; 01²7'21" S, 48³0'16" W; 27 Oct. 2002; R. Pintoda-Rocha leg.; MZSP 48146.

\section{Paratypes}

BRAZIL • 3 우; same collection data as for holotype; MZSP $48146 \bullet 1+$; same collection data as for holotype; MNRJ 9188 • 1 juv. + ; same locality as for holotype; 8 Nov. 2001; J.A.P. Barreiros leg.; 
MPEG 59 • 1 q; same locality as for holotype; 8 Nov. 2001; J.A.P. Barreiros leg.; MNRJ $9202 \bullet 1$; same locality as for holotype; 8 Apr. 2001; A.B. Bonaldo et al. leg.; MPEG $37 \bullet 1$ o; same locality as for holotype; 8 Apr. 2001; A.B. Bonaldo et al. leg.; MPEG 38.

\section{Measurements}

See Table 2.

\section{Distribution}

Known only from the type locality.

\section{Natural history}

Found in leaf litter. Synanthropic.

\section{Remarks}

See Giupponi \& Miranda (2016) for more details about this species.

Charinus magalhaesi sp. nov. urn:1sid:zoobank.org:act:748735F1-D676-4C38-AC45-4F6E99F51B6C

Figs 27, 30; Table 2

\section{Diagnosis}

This species may be separated from other Charinus in Amazonia and northern South America by means of the following combination of characters: tegument covered with clavate setae; median eyes and median ocular tubercle absent (Fig. 30C); female gonopods cushion-like; leg IV basitibia with three pseudo-articles; cheliceral claw with four or five teeth.

Charinus magalhaesi sp. nov. resembles $C$. vulgaris, but the setae on the carapace and pedipalp patella are clavate, as in C. carvalhoi sp. nov., C. longitarsus, C. montanus and C. quinteroi. Charinus magalhaesi sp. nov. may be distinguished from these species by the combination of cushion-like gonopods, the absence of median eyes and median ocular tubercle, and the length of the first tarsal article of leg I which is equal to the sum of the subsequent two articles.

\section{Etymology}

Patronym honoring Dr Celio Magalhaes, for his contribution to the study of freshwater crustaceans and his efforts towards conservation of the Amazon.

\section{Type material}

\section{Holotype}

BRAZIL • ; Amazonas, Manaus, Reserva Florestal Adolpho Ducke; 02 ${ }^{\circ} 58^{\prime} 31.59^{\prime \prime}$ S, 5958'42.33" W; 18 Mar. 2015; A.P.L.Giupponi and G.S. Miranda leg.; under wooden house; INPA ex MNRJ 9285.

\section{Paratypes}

BRAZIL・ 3 juv. $q$ + ; same collection data as for holotype; INPA ex MNRJ $9285 \bullet 1$ juv.; same collection data as for holotype; MNRJ 9279 • 1 q; same collection data as for holotype; MNRJ 9282, AMCC [LP 13406] • 1 \&; same collection data as for holotype; MNRJ 9278, AMCC [LP 13393]. 


\section{Description}

CARAPACE. Six anterior setae (Fig. 30A); clavate setae scattered across carapace; frontal process triangular (Fig. 30C). Small granules densely scattered between ocular triads and among sulci. Median eyes and median ocular tubercle absent (Fig. 30C); lateral eyes well developed (Fig. 30A), seta posterior to each lateral ocular triad; lateral ocular triad well separated from carapace margin (Fig. 30A).

STERnUm. Tritosternum projected anteriorly with typical setation, long, surpassing base of pedipalp coxae (Fig. 30B); other sternal platelets small and flat, each with pair of setae; pentasternum with two setae near membranous region and two setae anteriorly (Fig. 30B).

Opisthosoma. Ventral sacs and ventral sac cover absent.

Genitalia. Female genital operculum with prominent setae posteromedially and some smaller setae near margin; gonopod cushion-like, with base unsclerotized. Male unknown.

CheliceraE. Small, flat tooth on retrolateral surface of basal segment, opposite to bifid tooth; retrolateral surface of claw with continous row of setae, basally to medially; claw with four teeth; row of five setae on prolateral surface of basal segment; bifid tooth on basal segment with dorsal cusp larger than ventral cusp.

Pedipalps. Coxal dorsal carina with three prominent setae encircled by round carina and three setae on margin. Femur with three dorsal and three ventral spines (Fig. 30E); two prominent setiferous tubercles between first dorsal spine and proximal margin; setiferous tubercle between ventral spine 1 and proximal margin. Patella with three dorsal spines in primary series; prominent setiferous tubercle distal to spine I, one fifth length of spine I (Fig. 30E); two ventral spines (Fig. 30F); prominent setiferous tubercle between spine I and distal margin. Tibia with ventral spine distally and seta between spine and distal margin. Tarsus with two dorsal spines (Fig. 30D), proximal spine one-third length of distal spine; cleaning organ with 30-39 setae in ventral row.

LEGS. Tibia of leg I with 21 articles, tarsus I with 36-38 articles; length of first tarsal article equal to sum of lengths of two subsequent articles. Leg IV basitibia with three pseudo-articles, without sclerotized, denticulate margin projecting from apex of articles; trichobothrium $b t$ situated in proximal third of pseudo-article; distitibia trichobothrium $b c$ situated closer to $s b f$ than to $b f, s c$ and $s f$ series each with five trichobothria.

\section{Measurements}

See Table 2.

\section{Distribution}

Known only from the type locality.

\section{Natural history}

Found under house on sandy soil at the Reserva Florestal Adolpho Ducke; not found in the forest.

Charinus orientalis Giupponi \& Miranda, 2016

Fig. 27; Table 2

Charinus orientalis Giupponi \& Miranda, 2016: 18-21, figs 2f, 3f, 4f, 9a-e. 


\section{Diagnosis}

Based on Giupponi \& Miranda (2016), this species may be separated from other Charinus in Amazonia and northern South America by means of the following combination of characters: tegument pale yellow; cushion-like female gonopod with lateral projections directed posteriorly, covering opening of internal seminal receptacles (atrium); median and lateral eyes present, but median ocular tubercle and lateral eyes markedly reduced, as in C. carajas; median ocular tubercle situated in depression; small, rounded tetra- and pentasternum; weakly sclerotized margin of sternum; pedipalp femur with three dorsal spines; proximal spine of pedipalp tarsus ca one-quarter length of distal spine; tibia of leg I with 21 articles, tarsus I with 37 articles; leg IV basitibia with three pseudo-articles; leg IV basitibia trichobothrium $b t$ situated in proximal third; leg IV distitibia with 16 trichobothria; leg IV distitibia $b f, b c$ and $s b f$ trichobothria equidistant; $s c$ and $s f$ series each with five trichobothria.

\section{Etymology}

Latin adjective meaning 'eastern', referring to the Sierra Leste mountain range inhabited by the species (Giupponi \& Miranda 2016).

\section{Type material}

\section{Holotype}

BRAZIL • +; Pará, Curionópolis, Projeto Serra Leste, SL-82 cave; 7 Jul. 2010; CARSTE leg.; dry season; MNRJ 9249.

\section{Paratypes}

BRAZIL • 2 ㅇ; Pará, Carajás National Forest, Serra do Leste; 0558'35.171" S, 49³7'55.377" W; SAD' 69; 17-24 Oct. 2008; Andrade et al. leg.; MZSP 29118 • 1 क ; same collection data as for preceding; Curionópolis; SL-82 cave; 7 Jul. 2010; CARSTE leg.; Projeto Serra do Leste; dry season; MNRJ 9249• 3 우, 2 juv.; same collection data as for preceding; SL-82 cave; 7 Jul. 2010; CARSTE leg.; Projeto Serra Leste; dry season; ISLA 3893 - 1 juv. + ; same collection data as for preceding; SL-75 CL cave; 0557'54.473" S, 49³7'55.023" W; SAD' 69; 17-24 Oct. 2008; Andrade et al. leg.; MZSP 29119 • 3 우, 1 juv. O+; same collection data as for preceding; SL-82 CL cave; 05 57'29.644" S, 49³8'13.262" W; SAD' 69; 17-24 Oct. 2008; Andrade et al. leg.; MZSP 29124.

\section{Measurements}

See Table 2.

\section{Distribution}

This is the only species from the Carajas region which occurs outside the National Reserve, in a cave near the municipality of Curionópolis.

\section{Natural history}

Troglophilous, found only in iron ore caves.

\section{Remarks}

See Giupponi \& Miranda (2016) for more details about this species.

Charinus palikur sp. nov. urn:lsid:zoobank.org:act:9865F856-E11E-429E-AE38-F697DB6EA076

Figs $7 \mathrm{C}-\mathrm{D}, 27,31$; Table 2 


\section{Diagnosis}

This species may be separated from other Charinus in Amazonia and northern South America by means of the following combination of characters: carapace with broad, pale yellowish marks radiating from fovea; carapace extended anteriorly (Fig. 31A); retrolateral spines of pedipalp trochanter distinctly smaller than prolateral spine; female gonopod cushion-like with flap of cushion curved posteriorly to anteriorly (Fig. 7C-D); first tarsal article of leg I as long as sum of lengths of subsequent four articles; white annulus absent from second tarsal article of legs II-IV.

Charinus palikur sp. nov. may be differentiated from other species by the darker coloration, larger and more numerous pedipalp spines, the proximal tarsal article of leg I elongated, and the cushion-like gonopod of the female. Charinus palikur sp. nov. resembles C. platnicki, but can be differentiated from the latter by the well-developed median eyes and median ocular tubercle, and the lower count of leg I tarsal articles.

\section{Etymology}

Noun in apposition referring to the Palikur (or Paiikwené), one of the few indigenous tribes remaining in French Guiana.

\section{Type material}

\section{Holotype}

FRENCH GUIANA - \; Approuague-Kaw, Kaw Mountains, area around Amazon Nature Lodge;

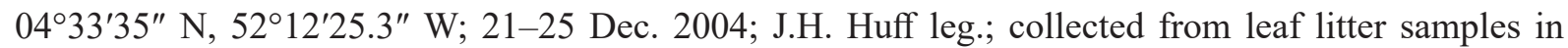
primary tropical rainforest; AMCC [LP 3832].

\section{Paratypes}

FRENCH GUIANA - 2 우, 1 ơ; Roura, Cacao, along trail Sentier Molokoi; 04³3'41.1" N, 52 $27^{\prime} 44^{\prime \prime} \mathrm{W}$; $95 \mathrm{~m}$ a.s.1.; 19 Dec. 2004; J.H. Huff leg.; primary tropical rainforest, under rocks and wood;

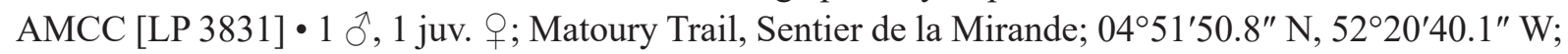
$47 \mathrm{~m}$ a.s.1.; 18 Dec. 2004; J.H. Huff leg.; primary tropical rainforest, under rocks and wood; AMCC [LP 3833].

\section{Description}

CARAPACE. Six anterior setae; carapace extended anteriorly (Fig. 31A); frontal process triangular (Fig. 31C). Small granules, densely scattered between ocular triads and among sulci; dark coloration, with broad, pale yellowish marks radiating from fovea; median eyes present; median ocular tubercle shallow (Fig. 31C); lateral eyes well developed, seta posterior to each lateral ocular triad; lateral ocular triad well separared from carapace margin.

STERnUm. Tritosternum projected anteriorly with typical setation, long, surpassing base of pedipalp coxae (Fig. 31B); other sternal platelets narrow and concave, with pair of setae anteriorly; pentasternum with four setae anteriorly and without seta near membranous region.

OpISTHosoma. Ventral sacs and ventral sac cover absent.

Genitalia. Female genital operculum with prominent setae posteromedially and some smaller setae near margin (Fig. 7C-D); lateromedian region of genital operculum with pair of deep transverse sulci; gonopod cushion-like with base slightly sclerotized (Fig. 7C-D); flap of gonopod curved posteriorly to anteriorly (Fig. 7C-D). Male gonopod with apex of fistula and base of lateral lobes sclerotized. 
Chelicerae. Small tooth projecting from retrolateral surface of basal segment, opposite to bifid tooth; retrolateral surface of claw without row of setae; claw with six teeth; row of four setae on prolateral surface of cheliceral basal segment; bifid tooth on basal segment with dorsal cusp larger than ventral cusp.

PEDIPALPS. Coxal dorsal carina with one prominent seta dorsally encircled by round carina and with two setae on margin. Femur with three dorsal spines and three or more (up to five in large males) ventral spines (Fig. 31E-F); two prominent setiferous tubercles between first dorsal spine and proximal margin; spine between ventral spine 1 and proximal margin. Patella with four dorsal spines in primary series (Fig. 31E); prominent setiferous tubercle distal to spine I, one-third length of spine I; three or four (in large males) ventral spines; prominent setiferous tubercle between spine I and distal margin. Tibia with ventral spine distally and seta between spine and distal margin. Tarsus with two dorsal spines, proximal spine one-third length of distal spine (Fig. 31D); cleaning organ with 28-35 setae in ventral row.

Legs. Tibia of leg I with 21 articles; tarsus I with 25-28 articles; length of first tarsal article equal to sum of lengths of subsequent three or four articles. Leg IV basitibia with three pseudo-articles, without sclerotized, denticulate margin projecting from apex of articles; trichobothrium $b t$ situated medially on pseudo-article; distitibia trichobothrium $b c$ situated closer to $s b f$ than to $b f, s c$ and $s f$ series each with five trichobothria.

\section{Measurements}

See Table 2.

\section{Distribution}

Known only from French Guiana.

\section{Natural history}

Found under rocks and wood in tropical forest.

Charinus pardillalensis (González-Sponga, 1998)

Fig. 27; Table 2

Charinides pardillalensis González-Sponga, 1998: 3-8, figs 9-13, map 1.

Charinus pardillalensis - Harvey 2003: 7, fig. 13. - Jocqué \& Giupponi 2012: 55. — Vasconcelos et al. 2013: 497. - Miranda et al. 2016c: 31.

\section{Diagnosis}

Based on González-Sponga (1998), this species may be separated from other Charinus in Amazonia and northern South America by means of the following combination of characters: median eyes and median ocular tubercle absent; pedipalp femur with three dorsal spines and two ventral spines; pedipalp patella with four dorsal spines and two ventral spines; tarsus with two dorsal spines; leg IV basitibia with two pseudo-articles.

\section{Etymology}

Adjective derived from the name of the hill on which the type material was collected (González-Sponga 1998). 


\section{Type material}

\section{Holotype}

VENEZUELA • + ; Aragua, San Casimiro municipality, Morro de Pardillal; [ $\left.10^{\circ} 00^{\prime} 16^{\prime \prime} \mathrm{N}, 67^{\circ} 00^{\prime} 50^{\prime \prime} \mathrm{W}\right]$; 500 m a.s.1.; 12 Aug. 1978; A.R. Delgado de Gonzalez, J.A. Gonzalez and M.A. González-Sponga leg.; MIZA [not examined].

\section{Paratypes}

VENEZUELA • 1 \%; same collection data as for holotype; MIZA [not examined] 4 ex.; same collection data as for holotype; MIZA [not examined].

\section{Measurements}

See Table 2.

\section{Distribution}

Known only from the type locality.

\section{Natural history}

According to González-Sponga (1998), this species was found in an area of savanna and forest, and inhabits crevices in clay slopes caused by erosion.

\section{Remarks}

Charinus pardillalensis was described based on females whereas males are unknown. The median and lateral ocular tubercles are equally weakly developed. The leg IV basitibia of this species was described as consisting of two pseudo-articles, but Jocqué \& Giupponi (2012) suggested the basitibia of this species consists of three pseudo-articles.

Charinus perquerens sp. nov.

urn:1sid:zoobank.org:act:3ED8B7F8-C8A9-400C-B62C-793ACDD69184

Figs 27, 32; Table 2

\section{Diagnosis}

Charinus perquerens sp. nov. can be separated from other Charinus in Amazonia and northern South America by means of the following combination of characters: relatively large size; female gonopod cushion-like; pedipalp femur with four dorsal spines and four ventral spines (Fig. 32E-F).

Charinus perquerens sp. nov. can be differentiated from C. magalhaesi sp. nov., the closest species geographically, by the greater number of pedipalp spines, including four dorsal spines and four ventral spines on the femur.

\section{Etymology}

Noun in apposition taken from the noun 'perquerens', meaning 'researcher', honoring scientists of the National Institute for Amazonian Research (INPA), Manaus, Brazil.

\section{Type material}

\section{Holotype}

BRAZIL • O; Amazonas, Manaus, Campus INPA; 0305'41.67" S, 5959'22.41" W; 17-19 Mar. 2015, A.P.L. Giupponi and G.S. Miranda leg.; INPA ex MNRJ 9283. 
Paratypes

BRAZIL • 7 juv.; same collection data as for holotype; MNRJ 9283.

\section{Description}

CARAPACE. Six anterior setae (Fig. 32A); frontal process triangular (Fig. 32C). Small granules, densely scattered between ocular triads and among sulci. Median eyes and median ocular tubercle absent (Fig. 32C); lateral eyes well developed, seta posterior to each lateral ocular triad; lateral ocular triad well separated from carapace margin (Fig. 32A).

STERnUM. Tritosternum projected anteriorly with typical setation, long, surpassing base of pedipalp coxae (Fig. 32B); other sternal platelets narrow and concave, with pair of setae anteriorly; pentasternum with four setae anteriorly and without seta near membranous region.

CHELICERAE. Small, flat tooth on retrolateral surface of basal segment, opposite to bifid tooth; seta absent on retrolateral surface of cheliceral claw; cheliceral claw with five teeth; three or four rows of 20 setae on prolateral surface of cheliceral basal segment; bifid tooth on basal segment with dorsal cusp larger than ventral cusp.

Opisthosoma. Ventral sacs and ventral sac cover absent.

GeNITALIA. Female genital operculum with prominent setae posteromedially and some smaller setae near margin; gonopod cushion-like markedly sclerotized from base to apex. Male unknown.

Pedipalps. Coxal dorsal carina with one to three prominent setae encircled by round carina and two or three setae at margin. Femur with four dorsal spines and four ventral spines (Fig. 32E-F); three prominent setiferous tubercles between first dorsal spine and proximal margin; one setiferous tubercle between ventral spine 1 and proximal margin. Patella with three dorsal spines in primary series (Fig. 32E); prominent setiferous tubercle distal to spine I, one fifth length of spine I; two ventral spines; prominent setiferous tubercle between spine I and distal margin. Tibia with ventral spine distally and two setae between spine and distal margin. Tarsus with two dorsal spines, proximal spine one-third length of distal spine (Fig. 32D); cleaning organ with 28 setae in ventral row.

LeGs. Tibia of leg I with 21 articles; tarsus I with 35-37 articles; first tarsal article shorter than subsequent articles. Leg IV basitibia with three pseudo-articles, without sclerotized, denticulate margin projecting from apex of articles; trichobothrium $b t$ situated in proximal third of pseudo-article; distitibia trichobothrium $b c$ situated closer to $s b f$ than to $b f, s c$ and $s f$ series each with five trichobothria.

\section{Measurements}

See Table 2.

\section{Distribution}

Known only from the type locality.

\section{Natural history}

Found under tree trunks and stones in area of secondary tropical forest.

Charinus platnicki (Quintero, 1986)

Fig. 27; Table 2

Tricharinus platnicki Quintero, 1986: 211, figs 13-15, 17, 22-28. 
Charinus platnicki - Harvey 2002b: 455; 2003: 7. — Weygoldt 2002a: 297.- Miranda \& Giupponi 2011: 66, fig. 13. — Vasconcelos et al. 2013: 497. — Miranda et al. 2016c: 31.

\section{Diagnosis}

Based on the description of Quintero (1986), this species may be separated from other Charinus in Amazonia and northern South America by means of the following combination of characters: tegument dark, blackish in color; small median eyes and median ocular tubercle; lateral eyes well developed; female gonopod cushion-like; bifid tooth of cheliceral basal segment with dorsal cusp larger than ventral cusp; cheliceral claw with four teeth; pedipalp femur with three dorsal spines and four ventral spines; pedipalp patella with three dorsal spines and three ventral spines, and setiferous tubercle between dorsal spine 1 and distal margin; pedipalp tarsus with two dorsal spines, distal spine long, half length of tarsus, proximal spine one-third length of distal spine; tibia of leg I with 23 articles, tarsus I with 37 articles; leg IV basitibia with two pseudo-articles; $s c$ and $s f$ series each with five trichobothria; trichobothrium $b c$ situated closer to $s b f$ than to $b f$.

Charinus platnicki and C. gertschi are distinct species differing in the number of spines on the pedipalp femur and patella, the number of articles with the tibia and tarsus of leg I, and the number of pseudoarticles in the basitibia of leg IV.

\section{Etymology}

Patronym honoring Dr Norman I. Platnick (Quintero 1986).

\section{Type material}

\section{Syntypes}

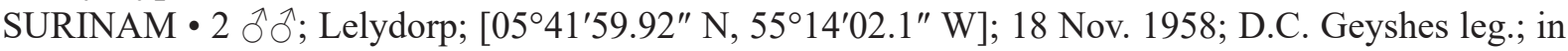

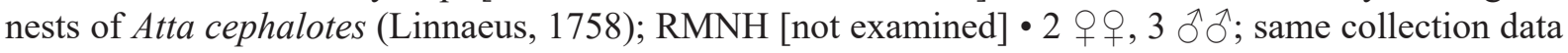
as for preceding; Dec. 1958; D.C. Geyshes leg.; in nests of Atta sexdens (Linnaeus, 1758); RMNH [not

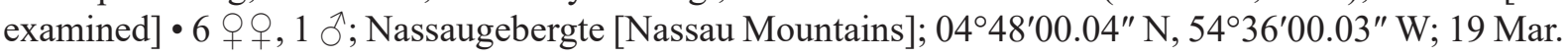
1949; D.C. Geyshes leg.; in Bromelia uriezca [sic]; RMNH [not examined].

\section{Measurements}

See Table 2.

\section{Distribution}

Known from Surinam. The type locality of one paratype of C. gertschi, Paramaribo, is near the locality of C. platnicki, Lelydorp. Considering that most species of Charinus have restricted distributions, the paratype of C. gertschi from Paramaribo may be conspecific with C. platnicki. Unfortunately, the type material of both species was not deposited as designated (AMNH, MCZ and RMNH) hence the material could not be checked. Further investigation of topotypes is needed to address this question.

\section{Natural history}

Known to inhabit bromeliads and the nests of leafcutter ants, Atta cephalotes and A. sexdens. Charinus platnicki and C. bromeliaea are the only charinid species thus far known to inhabit bromeliads, the first in leaves of Aechmea sp. in French Guiana, and the second in Bromelia sp. in Surinam (Quintero 1986; Jocqué \& Giupponi 2012)

\section{Remarks}

Weygoldt (2000a) synonymized Tricharinus with Charinus but did not transfer the species from the former genus to the latter. Harvey (2002b) created the new combinations with C. caribensis, C. guianensis, and C. platnicki. 
Charinus quinteroi Weygoldt, 2002

Fig. 27; Table 2

Charinus quinteroi Weygoldt, 2002a: 297.

Tricharinus guianensis Quintero, 1986: 209-211, figs 16, 27 (junior secondary homonym of Charinus guianensis Caporiacco, 1948).

Charinus guianensis - Harvey 2002b: 455; 2003: 5 .

Charinus quinteroi - Giupponi \& Baptista 2003: 173 [unnecessary replacement name for Tricharinus guianensis Quintero, 1986]. — Miranda \& Giupponi 2011: 66, fig. 13. — Jocqué \& Giupponi 2012: 55. — Vasconcelos et al. 2013: 497. — Miranda et al. 2016c: 31.

\section{Diagnosis}

Based on Quintero (1986), this species may be separated from other Charinus in Amazonia and northern South America by means of the following combination of characters: carapace, pedipalps and femora of walking legs uniformly pale blackish; clavate setae, with some short, acuminate setae on carapace, pedipalps and abdominal tergites; median eyes and median ocular tubercle absent; lateral eyes well developed; basal segment of chelicera without tooth on side of bifid tooth; bifid tooth with dorsal cusp longer than ventral; pedipalp femur with four dorsal spines; pedipalp patella with four dorsal spines; pedipalp tarsus with two small dorsal spines; tibia of leg I with 23 articles, tarsus I with 37 articles; leg IV basitibia with two pseudo-articles; trichobothrium $b c$ equidistant between $b f$ and $s b f ; s c$ and $s f$ series with five trichobothria.

The claviform setae observed in C. quinteroi are also present in C. carvalhoi sp. nov., C. longitarsus, $C$. magalhaesi sp. nov., and C. montanus. The last four species also share the long first article of the leg I tarsus, which was not reported for $C$. quinteroi.

\section{Etymology}

Patronym honoring Dr Diomedes Quintero (Weygoldt 2002a).

\section{Type material}

\section{Holotype}

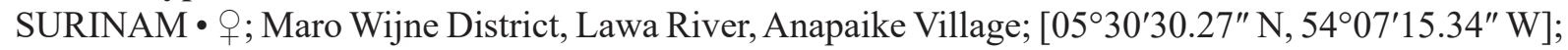
8-28 Nov. 1963; B. Malkin leg.; conspecific juv.; AMNH [not examined].

\section{Paratypes}

GUYANA - 3 o ; Kartabo, Bartica District; [06²4'15.56" N, 58³7'32.97" W]; 16 Feb. 1921; W.M. Wheeler leg.; in ant nest; AMNH [not examined] - 1 q; same locality as for preceding; 4 Jun. 1924; W.M. Wheeler leg.; AMNH [not examined].

\section{Measurements}

See Table 2.

\section{Distribution}

Known from Guyana and Surinam.

\section{Natural history}

The paratypes from Guyana were collected inside an ant nest, a remarkable environment, unusual for whip spiders (Quintero 1986). This species was collected in sympatry with Heterophrynus alces Pocock, 1902. 


\section{Remarks}

Quintero (1986: 209) described the pedipalp spines as follows. Initially, he noted "femur, ventral border with five spines" but went on to describe the position of the five dorsal spines (Fd-1-5), not the ventral spines. Quintero (1986: 209) subsequently noted the count of dorsal spines on the pedipalp patella as "dorsal border of tibia with five spines," followed by details of the position and size of these spines "Td-1 very small and displaced ventrally." This leads to the conclusion that Quintero (1986: 209) was consistently referring to the dorsal spines of the femur, not the ventral spines, and did not describe any details of spines on the ventral border of the femur.

Considering that Quintero (1986) was referring to the dorsal spines on the femur, it is probable that C. quinteroi possesses four dorsal spines, not five. This is because Quintero (1986) mentioned that "the first spine is very small (the paratypes possess a setiferous tubercle in its place, slightly displaced dorsally)." Two or three setiferous tubercles are always situated proximal to the first spine, their position varying from dorsally to frontally, depending on the species.

The number of spines on the pedipalp patella also differs from the original description, as Quintero (1986) included the long distal setiferous tubercle in the count of dorsal spines, resulting in five, rather than the true count of four dorsal spines.

Charinus ricardoi Giupponi \& Miranda, 2016

Fig. 27; Table 2

Charinus ricardoi Giupponi \& Miranda, 2016: 6-10, figs 2b, 3b, 5a-e.

\section{Diagnosis}

Based on Giupponi \& Miranda (2016), this species may be separated from other Charinus in Amazonia and northern South America by means of the following combination of characters: tegument yellowishbrown; median eyes and median ocular tubercle absent; lateral eyes reduced, pale; small, rounded tetraand pentasternum; cushion-like gonopods without projections and with internal seminal receptacles; pedipalp almost perpendicular to longitudinal axis, similar to that of Paracharon caecus; two dorsal spines on pedipalp tarsus, small proximal spine, one-quarter length of distal spine; basitibia of leg IV with two pseudo-articles; leg IV basitibia trichobothrium $b t$ situated in proximal third; leg IV distitibia with 16 trichobothria; leg IV distitibia trichobothria $b f, b c$ and $s b f$ equidistant.

The gonopods of C. ricardoi are similar to those of C. bonaldoi, but the pedipalp proportions and length of the pedipalp segments are greater in the former.

\section{Etymology}

Patronym honoring Dr Ricardo Pinto-da-Rocha (Giupponi \& Miranda 2016).

\section{Type material}

\section{Holotype}

BRAZIL • 9 ; Amazonas, Presidente Figueiredo, Gruta Areia Branca; 23-31 Aug. 2003; R. Pinto-daRocha leg.; MZSP 22036.

\section{Paratypes}

BRAZIL - 3 o $O$; same collection data as for holotype; MZSP 22036 - 1 juv.; Amazonas, Presidente Figueiredo, Gruta dos Animais; 23-31 Aug. 2003; R. Pinto-da-Rocha leg.; MZSP 22049・1 ㅇ, 1 o; same collection data as for preceding; MZSP 22063. 


\section{Measurements}

See Table 2.

\section{Distribution}

Known only from the type locality.

\section{Natural history}

Possibly troglophile, found only in Amazonian caves.

\section{Remarks}

See Giupponi \& Miranda (2016) for more details about this species.

\section{Charinus sillami Réveillion \& Maquart, 2015}

Figs 27, 33; Table 2

Charinus sillami Réveillion \& Maquart, 2015: 192-194.

Charinus sillami-Armas et al. 2016: 48.

\section{Diagnosis}

Charinus sillami is the only Charinus in Amazonia and northern South America with the following combination of characters: median eyes present (Fig. 33A, C); tibia of leg I and tarsus I with 23 and 37 articles, respectively; leg IV basitibia with three pseudo-articles.

\section{Etymology}

Patronym honoring David Sillam-Dussès (Réveillion \& Maquart 2015).

\section{Type material}

\section{Holotype}

FRENCH GUIANA • ${ }_{+}$; Commune de Sinnamary, Barrage de Petit Saut; $05^{\circ} 03^{\prime} 46.67^{\prime \prime}$ N, 53 $02^{\prime} 51.26^{\prime \prime} \mathrm{W}$; Mar. 2013; D. Sillam-Dussès leg.; in nest of termite, Neocapritermes taracua Krishna and Araujo, 1968; BMNH [not examined].

\section{Paratypes}

FRENCH GUIANA • 1 क; same collection data as for holotype; AMCC [LP 13448] • 1 ô; same collection data as for holotype; BMNH [not examined] 1 1 ; same collection data as for holotype; found in Spinitermes sp. nests; CPOM [not examined] - 1 q, 1 §ं; Barrage de Petit Saut; Mar. 2014; CFR [not examined].

\section{Description}

CARAPACE. Six anterior setae (Fig. 33A); carapace extended anteriorly; frontal process triangular (Fig. 33C). Small granules, densely scattered between ocular triads and among sulci. Median eyes present (Fig. 33A, C); median ocular tubercle shallow; lateral eyes well developed, seta posterior to each lateral ocular triad; lateral ocular triad well separated from carapace margin.

STERnUm. Tritosternum projected anteriorly with typical setation, long, surpassing base of pedipalp coxae (Fig. 33B); other sternal platelets narrow and concave, with pair of setae anteriorly; pentasternum with two setae anteriorly and without seta near membranous region. 
OPSTHOSOMA: Ventral sacs and ventral sac cover absent.

GENITALIA. Female genital operculum with prominent setae posteromedially and some smaller setae near margin; pair of deep transverse sulci lateromedially; gonopod cushion-like, flat, unsclerotized basally. Male gonopod with apex of fistula and base of lateral lobe sclerotized.

CHELICERAE. Small tooth projecting from retrolateral surface of basal segment, opposite to bifid tooth; retrolateral surface of claw with medial row of setae; claw with five teeth; row of four setae on prolateral surface of basal segment; bifid tooth on basal segment with dorsal cusp larger than ventral cusp.

PEDIPALPS. Coxal dorsal carina with prominent seta encircled by round carina and two setae at margin. Femur with three dorsal spines and three ventral spines (Fig. 33E-F); two prominent setiferous tubercles between first dorsal spine and proximal margin; spine between ventral spine 1 and proximal margin. Patella with three dorsal spines in primary series (Fig. 33E); prominent setiferous tubercle distal to spine I, one-third length of spine I; two ventral spines (Fig. 33F); prominent setiferous tubercle between spine I and distal margin. Tibia with ventral spine distally and seta between spine and distal margin. Tarsus with two dorsal spines, proximal spine one-third length of distal spine (Fig. 33D); cleaning organ with 30 setae in ventral row.

LEGS. Tibia of leg I with 23 articles; tarsus I with 37 articles; first tarsal article approximately same length as subsequent articles. Leg IV basitibia with three pseudo-articles, without sclerotized, denticulate margin projecting from apex of articles; trichobothrium $b t$ situated medially on pseudo-article; distitibia with trichobothrium $b c$ situated slightly closer to $s b f$ than to $b f$, and $s c$ and $s f$ each with five trichobothria.

\section{Measurements}

See Table 2.

\section{Distribution}

Known only from the type locality.

\section{Natural history}

Found in termite nests.

\section{Remarks}

Charinus sillami possesses a proximal spine on the pedipalp femur ventrally, that is not part of the primary series (additional spines are present dorsally), not described by Réveillion \& Maquart (2015). This character may be important to distinguish this species from other species of Charinus occurring in the vicinity. The distal spine on the pedipalp tarsus points forward, whereas the proximal spine is directed dorsally (Fig. 33D). Réveillion \& Maquart (2015) mentioned that the anterior border of the carapace is dentate but, on examination, it was found to be smooth with some small tubercles, as in other species of Charinus. Additionally, the female gonopod is cushion-like and not sucker-like as stated in the original description.

Charinus tronchonii (Ravelo, 1975)

Fig. 27; Table 2

Speleophrynus tronchonii Ravelo, 1975: 79-84, figs 1-3, 4a-e.

Charinides tronchonii - Quintero 1983: 28. — González-Sponga 1998: 2, map 1. 
Charinus tronchonii - Delle Cave 1986: 163, fig. II. - Weygoldt 1994: 242, 244. - Harvey 2003: 7. — Galán \& Herrera 2006: 42, 48. — Miranda \& Giupponi 2011: 66, fig. 13. — Jocqué \& Giupponi 2012: 55. - Vasconcelos et al. 2013: 497. — Torres-Contreras et al. 2015: 148. — Miranda et al. 2016c: 31 .

\section{Diagnosis}

Based on the original description, supplemented by observations of Quintero (1983), this species may be separated from other Charinus in Amazonia and northern South America by means of the following combination of characters: median eyes and median ocular tubercle absent; lateral eyes reduced; sternum with undivided platelets, not pairs; pedipalp femur with three dorsal spines and three or four ventral spines; pedipalp patella with three dorsal spines and large setiferous tubercle between spine I and distal margin, and two prominent setiferous tubercles, decreasing in size, proximal to spine III; pedipalp patella with two ventral spines; pedipalp tibia with two dorsal spines, distal spine very long, more than half length of tibia, proximal spine one-third length of distal spine; cheliceral claw with five or six teeth; pedipalp tarsus with two dorsal spines; tibia of leg I with 23 articles, and with 41 articles; leg IV basitibia with three articles (Ravelo (1975), and also Quintero (1983), considered the distitibia to be part of the tibia, resulting in a count of four articles); leg IV distitibia trichobothrium $b c$ situated closer to $s b f$ than to $b f ; s c$ and $s f$ series each with five trichobothria.

\section{Etymology}

Patronym honoring Juan Antonio Tronchoni (Ravelo 1975).

\section{Type material}

Holotype

VENEZUELA • + ; Falcón, Cave 2 of River Hueque, $6.5 \mathrm{~km} \mathrm{~N} 50^{\circ} \mathrm{E}$ of Cabure village; [11 $11^{\prime} 14.09^{\prime \prime} \mathrm{N}$, 69³7'57.73" W]; 700 m a.s.1.; 9 Apr. 1971; O. Linares leg.; MBSVE 617 [not examined].

\section{Paratypes}

VENEZUELA • 2 우; same locality as for holotype; 9 Apr. 1971; O. Ravelo leg.; MBSVE 14, 612 [not examined] 11 गे; same locality as for holotype; 9 Apr. 1971; O. Ravelo leg.; MBSVE 611 [not examined] 1 1 ; same collection data as for holotype; MBSVE 618 [not examined] 1 juv. + ; same locality as for holotype; 9 Apr. 1971; O. Ravelo leg.; MBSVE 15 [not examined] 1 juv. ô; same

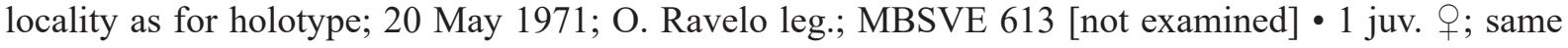
locality as for holotype; 20 May 1971; O. Ravelo leg.; MBSVE 614 [not examined].

\section{Measurements}

See Table 2.

\section{Distribution}

Known only rom the type locality.

\section{Natural history}

Charinus tronchonii was the first species of the genus to be considered troglobitic in South America (Ravelo 1975), due to the absence of median eyes.

Charinus vulgaris Miranda \& Giupponi, 2011

Fig. 27; Table 2

Charinus vulgaris Miranda \& Giupponi, 2011: 62-65, figs 1-11, 13. 
Charinus vulgaris - Vasconcelos et al. 2013: 469, fig. 12. — Vasconcelos \& Ferreira 2016: 185. Miranda et al. 2016c: 31.

\section{Diagnosis}

Based on Miranda \& Giupponi (2011), this species may be separated from other Charinus in Amazonia and northern South America by means of the following combination of characters: sternum tri-segmented, with second and third platelets rounded and convex; pedipalp femur with three dorsal spines and two ventral spines; pedipalp patella with four dorsal spines and two ventral spines; pedipalp tibia with two dorsal spines, proximal spine less than half length of distal spine, and one ventral spine; pedipalp tarsus with two dorsal spines; leg tibia I with 21 articles; leg IV basitibia with three pseudo-articles; distitibia with 16 or 17 trichobothria.

\section{Etymology}

Latin adjective meaning 'ordinary, common', referring to the microhabitats in which the specimens were collected (Miranda \& Giupponi 2011).

\section{Type material}

\section{Holotype}

BRAZIL • P; Rondônia, Porto Velho, São João Bosco, Rio Madeira and Santo Antônio neighbourhoods; Feb. 2011; G.S. Miranda leg.; MNRJ 9106.

\section{Paratypes}

BRAZIL • 3 juv.; same locality as for holotype; Dec. 2009; MNRJ $9104 \bullet 11$ q $q, 6$ juv.; same collection data as for holotype; MNRJ 9105; 1 \&, 1 juv.; same collection data as for holotype; IBSP 226.

\section{Additional material}

BRAZIL • 1 q; Rondônia, Porto Velho, Campus da Faculdade São Lucas; 29 Jul. 2008; P.I. Silva et al leg.; small secondary forest with stream; daytime; MNRJ 9274 • 1 + ; Rondônia, Porto Velho; MNRJ 9275 - 1 क; Bahia, Salvador; ECOA 2493 - 1 o; same collection data as for preceding; ECOA $2050 \bullet 1$ juv. + ; same collection data as for preceding; ECOA $2440 \bullet 1$ q; same collection data as for preceding; ECOA 2438.

\section{Description}

CARAPACE. Six anterior setae; frontal process triangular. Small granules densely scattered between ocular triads and among sulci. Median eyes and median ocular tubercle absent; lateral eyes well developed, with seta posterior to each lateral ocular triad; lateral ocular triad well separated from carapace margin.

STERnUM. Tritosternum projected anteriorly, with typical setation, long, surpassing base of pedipalp coxae; other sternal platelets narrow, concave, with pair of setae anteriorly; pentasternum with two setae anteriorly and without seta near membranous region.

OpISTHOSOMA. Ventral sacs and ventral sac cover absent.

GeNITALIA. Female genital operculum with prominent setae posteromedially and some smaller setae near margin; gonopod cushion-like, slightly sclerotizated from base to apex. Male unknown.

CHELICERAE. Small, flat tooth on retrolateral surface of basal segment, opposite to bifid tooth; retrolateral surface of cheliceral claw without seta; claw with four or five teeth; row of ten setae on prolateral surface of basal segment; bifid tooth on basal segment with dorsal cusp larger than ventral cusp. 
PedipalPs. Coxal dorsal carina with prominent seta encircled by round carina and three setae on margin. Femur with three dorsal spines and three ventral spines; two prominent setiferous tubercles between dorsal spine 1 and proximal margin; one setiferous tubercle between ventral spine 1 and proximal margin. Patella with three dorsal spines in primary series; one prominent setiferous tubercle distal to spine I, one-third length of spine I; two ventral spines; prominent setiferous tubercle between spine I and distal margin. Tibia with ventral spine distally and seta between spine and distal margin. Tarsus with two dorsal spines, proximal spine one-third length of distal spine; cleaning organ with 30-31 setae in ventral row.

Legs. Tibia of leg I with 21 articles; tarsus I with 37 articles; first tarsal article similar in length to subsequent articles. Leg IV basitibia with three pseudo-articles, without sclerotized, denticulate margin projecting from apex of articles; trichobothrium $b t$ situated in proximal third of pseudo-article; distitibia trichobothrium $b c$ situated closer to $s b f$ than to $b f, s c$ and $s f$ series each with five trichobothria.

\section{Measurements}

See Table 2.

\section{Distribution}

Charinus vulgaris was described from Porto Velho, Rondônia (southern Amazonia) but has also been collected in a disturbed area of Salvador, Bahia (eastern Brazil). There is reason to suspect that the population in Salvador was introduced from Amazonia, because of the human history in the area. During the gold rush in Rondônia, when intensive mining occuring at the Madeira River, large numbers of people migrated between northeastern Brazil and Porto Velho, facilitating the translocation of species such as $C$. vulgaris along with plants.

\section{Natural history}

All specimens collected thus far are female, suggesting this species is parthenogenetic, and bolstering the hypothesis that its occurrence in Salvador may be the result of translocation from Porto Velho.

\section{Key to the identification of the species of Charinus in western South America}

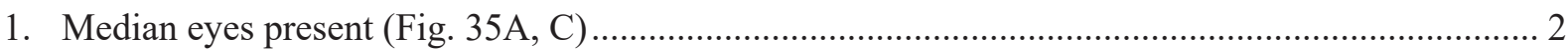

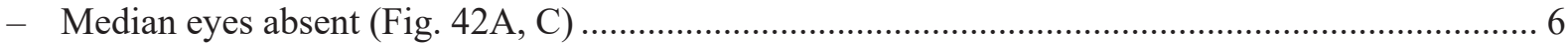

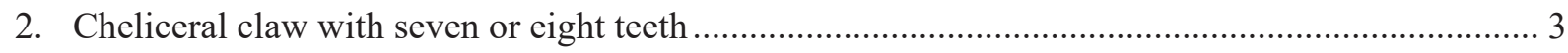

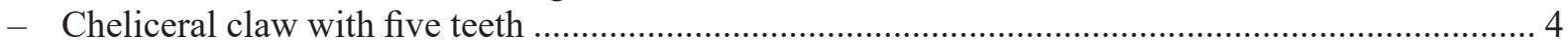

3. Pedipalp femur with five dorsal spines and four ventral spines; pedipalp patella with five dorsal spines and three ventral spines

C. tingomaria Ballón-Estacio \& Armas, 2019

- Pedipalp femur with four dorsal spines and four ventral spines; pedipalp patella with four dorsal spines and two ventral spines (Figs 36C-D, 40A) ............ C. insularis Banks, 1902 (Figs 2, 36-41)

4. Leg I tarsus with 27-30 articles .......................... C. longitarsus Armas \& Palomino-Cárdenas, 2016

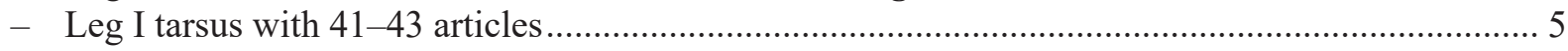

5. Pedipalp patella with four dorsal spines and three ventral spines; leg IV basitibia with four pseudoarticles...

- Pedipalp patella with three dorsal spines and two ventral spines (Fig. 35E); leg IV basitibia with three pseudo-articles C. guayaquil sp. nov. (Fig. 35)

6. Leg IV basitibia with two pseudo-articles C. mocoa sp. nov. (Figs 5G-H, 42)

- Leg IV basitibia with three pseudo-articles 


\section{Charinus guayaquil sp. nov. urn:1sid:zoobank.org:act:032D5F71-C742-48E8-BA93-B9488833BAD9}

Figs 34-35; Table 3

\section{Diagnosis}

This species may be separated from other Charinus in western South America by means of the following combination of characters: small size; tegument pale whitish in color; reduced median and lateral eyes (Fig. 35A, C); median ocular tubercle absent (Fig. 35C); female gonopod cushion-like; cheliceral claw with five teeth; leg IV basitibia with three pseudo-articles; $s c$ and $s f$ series each with five trichobothria.

\section{Etymology}

Noun in apposition referring to the municipality in which the type locality is situated.

\section{Type material}

\section{Holotype}

ECUADOR • 1 \%; Guayas, Guayaquil, Bosque Protector Cerro Blanco; 02 $12^{\circ} 56.39^{\prime \prime}$ S, 8001'4.87" W; 96 m a.s.1.; 31 Mar. 2011; A. Chagas, A. Giupponi and A. Kury leg.; MNRJ 9302.

\section{Paratype}

ECUADOR • 1 \%; same collection data as for holotype; MNRJ 9301.

\section{Description}

CARAPACE. Ten anterior setae (Fig. 35A); frontal process triangular, visible in dorsal view (Fig. 35C). Small granules densely scattered between ocular triads and among sulci. Median eyes reduced, median ocular tubercle absent (Fig. 35C); pair of setae near remnants of median eyes; lateral eyes weakly developed, pale, seta posterior to each lateral ocular triad (Fig. 35A).

STERnUm. Tritosternum projected anteriorly, with typical setation (Fig. 35B); other sternal platelets broad, flat, with pair of setae on each side and some smaller setae posteriorly; pentasternum with six setae anteriorly and without seta near membranous region (Fig. 35B).

Opisthosoma. Ventral sacs and ventral sac cover absent.

Genitalia. Female genital operculum with prominent setae posteromedially and smaller setae near margin; posterior margin of gonopod with pair of shallow lateral sulci; gonopod cushion-like, with retrolateral margins of fold projecting over other margin; base of gonopods unsclerotized. Male unknown.

CHELICERAE. Small tooth, slightly projecting from retrolateral surface of basal segment, opposite to bifid tooth; retrolateral surface of claw with two patches of setae, one basal, other medial; claw with five teeth; transverse row of around five setae on prolateral surface of basal segment; bifid tooth on basal segment with cusps subequal in size.

PeDipalps. Coxal dorsal carina with two prominent setae encircled by round carina and two setae on margin. Femur with three dorsal and three ventral spines (Fig. 35E-F); two prominent setiferous tubercles between dorsal spine 1 and proximal margin; setiferous tubercle between ventral spine 1 and proximal margin. Patella with three dorsal spines in primary series (Fig. 35E); prominent setiferous tubercle distal to spine I, one-third length of spine I; patella with two ventral spines in primary series; setiferous tubercle between spine I and distal margin. Tibia with ventral spine distally and two setae between spine and distal margin. Tarsus with two dorsal spines, proximal spine one-third length of distal spine (Fig. 35D); cleaning organ with 31 setae in ventral row. 
Legs. Tibia of leg I with 23 articles; tarsus I with 41 articles; first tarsal article slightly longer than second article. Leg IV basitibia with three pseudo-articles, without sclerotized, denticulate margin at apex of articles; trichobothrium $b t$ situated in proximal third of pseudo-article; distitibia trichobothrium $b c$ equidistant between $s b f$ and $b f, s c$ and $s f$ series each with five trichobothria.

\section{Measurements}

See Table 3.

\section{Distribution}

Known only from the type locality. This is the first species described from continental Ecuador.

\section{Natural history}

Found under flat stones on the forest floor. The type specimens were together under the same stone. A species of Phrynus was collected in sympatry.

Charinus insularis Banks, 1902

Figs 1-2, 34, 36-41; Table 3

Charinus insularis Banks, 1902: 67, 68, pl. 2 fig. 8.

Charinus insularis - Snodgrass 1902: 79-80. — Mello-Leitão 1931: 54. — Werner 1935: 471. — Dunn 1949: 7. — Roth \& Craig 1970: 119. — Weygoldt 1972b: 123. — Stockton 1976: 57-61, figs 1-4. —Delle Cave 1986: 156, fig. II. — Peck \& Kukalova-Peck 1986: 165. — Peck \& Peck 1986: 44-46. - Hernández Pacheco et al. 1992: 89, 125, 133, 135, 141, 146, 149-150, 154, 158, 167. - Baert et al. 1996: 13-16, fig. 7, map 4. - Harvey 2003: 5-6. - Miranda \& Giupponi 2011: 62, 67, fig. 13. - Jocqué \& Giupponi 2012: 55. — Vasconcelos et al. 2013: 497. — Baert \& Mahnert 2015: 2-3, 8-13, 70-71, 73-74, fig. 3. - Miranda et al. 2016c: 19, 31.

\section{Diagnosis}

This species may be separated from other Charinus in western South America by means of the following combination of characters: well-developed median eyes and median ocular tubercle (Fig. 36A); female gonopods cushion-like with small acute projection at apex of dorsal flap (Fig. 37E-F); male gonopod with thin, fimbriate lateral lobe 2 (Fig. 38A-B, D); dorsal lobe with acute spiky projections (Fig. 38AD, F); cheliceral claw with seven teeth and short row of setae on retrolateral view (Fig. 39D).

\section{Etymology}

Although unspecified in the original description, the species name evidently refers to the provenance of this species on an island, in this case the Galapagos Islands, to which it appears to be endemic.

\section{Type material}

\section{Syntypes}

ECUADOR • Galapagos Islands: Albemarle Island (as Isla Isabela); [repository unknown] • Narboro Island; [repository unknown] • Chatham Island; [repository unknown] • Hood Island; [repository unknown] [not examined].

\section{Additional material}

ECUADOR • 1 protonymph; Galapagos Islands; RBINS 26445/23.2.6 • 1 क, 1 exuvium; Galapagos

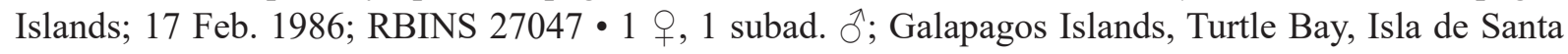


Cruz; 14 Jan. 1965; J. and N. Leleup leg. 1 क [most legs and one pedipalp detached]; in crevice at foot of ravine, $1200 \mathrm{~m}$ from beach; RBINS • 1 क , 1 ภ; Isla de Santa Cruz; 17 Feb. 1965; J. and N. Leleup leg.; entrance of cave, under stone on clay [label indicates 2 우 and 1 juv., but vial contains only two specimens, one juvenile and another slightly larger, both with opisthosoma detached, hence impossible to determine sex of specimens]; RBINS • 1 ㅇ, 2 juv. $\widehat{\jmath}$; Española crest; 26 Apr. 1992; 25 m a.s.1.; S. Peck and J. Cook leg.; under Opuntia Miller, 1754 bark and rocks; RBINS 92-143 1 q, 2 juv. + ㅇ, 2 juv. $\overbrace{}^{\lambda}$; 1988; L. Baert, K. Desender and J.P. Maelfait leg.; RBINS $27318 \bullet 1$ q, 1 juv. $\overbrace{}^{\lambda}$; RBINS 26445/23.2.1 - 2 juv. 우, 2 juv. $\widehat{o} \delta^{\top}$; Isla de Santa Cruz, $800 \mathrm{~m}$ from pier of St Darwin; Dec. 1964; J. and N. Leleup leg.; at bottom of deep crevice (10 m); under rubble stone with soil and wet sand; RBINS • 1 \&, 6 juv.; Isla de Santa Cruz; 17 Nov. 1964; J. and N. Leleup leg.; volcanic cave, $3.5 \mathrm{~km} \mathrm{~N}$

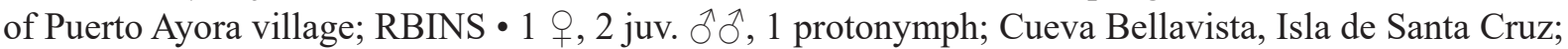
160 m a.s.l.; 22 Jan. 1989; S. Peck et al. leg.; RBINS • 1 juv.; Santa Fé; Oct. 1964; J. and N. Leleup leg.; RBINS • 1 \%; Bellavista, Isla de Santa Cruz; 150 m a.s.1.; S. Peck leg.; bottle traps in caves; RBINS 96-97 • 1 q; Puerto Ayora, Isla de Santa Cruz; 28 Dec. 1991; S. Abedrabbo leg.; RBINS • 2 우; Hornemeu Farm, Isla de Santa Cruz; 250 m a.s.l.; Nov. 1964; J. and N. Leleup leg.; RBINS • 4 juv. + $O$; RBINS 768 • 1 + juv.; Pampa, 36 km from coast, Isla de Isabela; 600-1000 m a.s.1.; Nov. 1964; J. and N Leleup; RBINS • Isla de Santa Cruz; 1 km from coast; 20 m a.s.l.; Feb. 1965; J. and N. Leleup leg.; inside cave; RBINS.

\section{Supplementary description}

CARAPACE. Six anterior setae (Fig. 36A); frontal process triangular (Fig. 37D), not visible in dorsal view. Small granules, densely scattered between ocular triads and among sulci (Figs 36A, 37A-D). Median eyes present; median tubercle shallow (Fig. 37D); one pair of setae on median ocular tubercle; lateral eyes well developed, with seta posterior to lateral ocular triad (Fig. 37B)

STERnUm. Tritosternum projected anteriorly, with typical setation (Fig. 36B); other sternal platelets divided, concave, with one seta on each side of platelets and smaller setae posteriorly (Fig. 37B); pentasternum with four setae anteriorly and seta on membranous region (Fig. 37B).

Opisthosoma. Ventral sacs and ventral sac cover absent.

Genitalia. Female genital operculum with prominent setae posteromedially and some smaller setae near margin (Fig. 37E); gonopod cushion-like, flat, with projection on apex of retrolateral side of fold (Fig. 37E-F); base of gonopods sclerotized. Male gonopod markedly sclerotized at base of fistula and lateral lobe; lateral lobe 2 not fimbriate.

ChELICERAE. Small tooth projecting from retrolateral surface of basal segment, opposite to bifid tooth (Fig. 39A-G); retrolateral surface of claw with small patches of setae basally and medially (Fig. 39DE); claw with seven teeth; transverse row of around eight setae on prolateral surface of basal segment; bifid tooth on basal segment with dorsal cusp larger than ventral cusp; setae on basal segment with acute apex and serrate margin (Fig. 39F), setae on claw with mop-like apex (Fig. 39G); hinge between basal segment and cheliceral claw with multiple slit sensilla (Fig. 39C).

PedipalPs. Coxal dorsal carina with three setae encircled by round carina and four setae on margin. Femur with four dorsal spines and four ventral spines (Figs 2, 36C-D, 40A-D); two prominent setiferous tubercles between dorsal spine 1 and proximal margin; spine between ventral spine 1 and proximal margin (Fig. 2). Patella with four dorsal spines in primary series (Fig. 36C-D); prominent setiferous tubercle distal to spine I, one-third length of spine I; two ventral spines in primary series (Fig. 2); prominent setiferous tubercle between spine I and distal margin. Tibia with ventral spine distally and two or three setae between spine and distal margin (Figs 2,36D). Tarsus with two dorsal spines, proximal 
spine one-third length of distal spine; cleaning organ with 27-30 setae in ventral row. Spines with gland openings (Fig. 40D).

LEGS. Tibia of leg I with 23 articles (up to 29 in regenerated legs); tarsus I with 43 articles (up to 53 in regenerated legs); first tarsal article similar in length to subsequent articles; slit sensilla present on tarsal article 21. Leg IV patella with pair of trichobotria dorsally; surface surrounding trichobothrial insertions filled with erect scales (Fig. 41A). Leg IV basitibia with four pseudo-articles, with sclerotized, denticulate margin at apex of articles; trichobothrium $b t$ situated in proximal third of pseudo-article; distitibia trichobothrium $b c$ situated slightly closer to $s b f$ than to $b f, s c$ and $s f$ series each with five trichobothria. Leg IV tarsus with projection between claws similar in length to last tarsal article; arolium microstructures with linear pattern at lip (Fig. 41C-D), randomly scattered at truncus (Fig. 41C, E).

\section{Measurements}

See Table 3.

\section{Distribution}

This comparatively large species is endemic to the Galapagos archipelago, and has been recorded on several islands (Baert \& Mahnert 2015).

\section{Natural history}

Found inside and outside caves in cave entrances, ravines, under stones and rubble.

\section{Remarks}

The type material was collected during the Hopkins Stanford Galapagos Expedition, but the original description does not specify where the material is deposited. According to Dunn (1949), the type specimens may be in the collection of the Stanford University, California, but cannot be located.

The opisthosoma of the subadult male (the only male examined) is wrinkled and the genitalia distorted, hence impossible to describe. The large female specimen from Española (RBINS 92-143) appears to be adult, but has duplicate trichobotria ( $2 s b f, 2 b c$ and $2 b t$ ), a character thus far known to occur only in juveniles (Weygoldt 2000a).

Miranda \& Giupponi (2011) misinterpreted the female gonopod of $C$. insularis, stating it is sucker-like. However, the species has a cushion-like gonopod with an acute apical projection (Fig. 37E-F).

Charinus koepckei Weygoldt, 1972

Fig. 34; Table 3

Charinus koepckei Weygoldt, 1972a: 281-285, figs 1-6.

Charinus koepckei - Delle Cave 1986: 162, fig. II. - Harvey 2003: 6. - Miranda \& Giupponi 2011: 62, 67, fig. 13. - Jocqué \& Giupponi 2012: 55. - Vasconcelos et al. 2013: 497. - Armas et al. 2016: 48. — Miranda et al. 2016c: 19, 31. — Ballón-Estacio \& Armas 2019: 15-16.

Charinus koepkei - Weygoldt 1999c: 104, figs 2-3, 186-187.

\section{Diagnosis}

This species may be separated from other Charinus in western South America by means of the following combination of characters: large size; pronounced pedipalps; median and lateral eyes well developed; median ocular tubercle shallow; female gonopod cushion-like; leg IV basitibia with four pseudo-articles. 


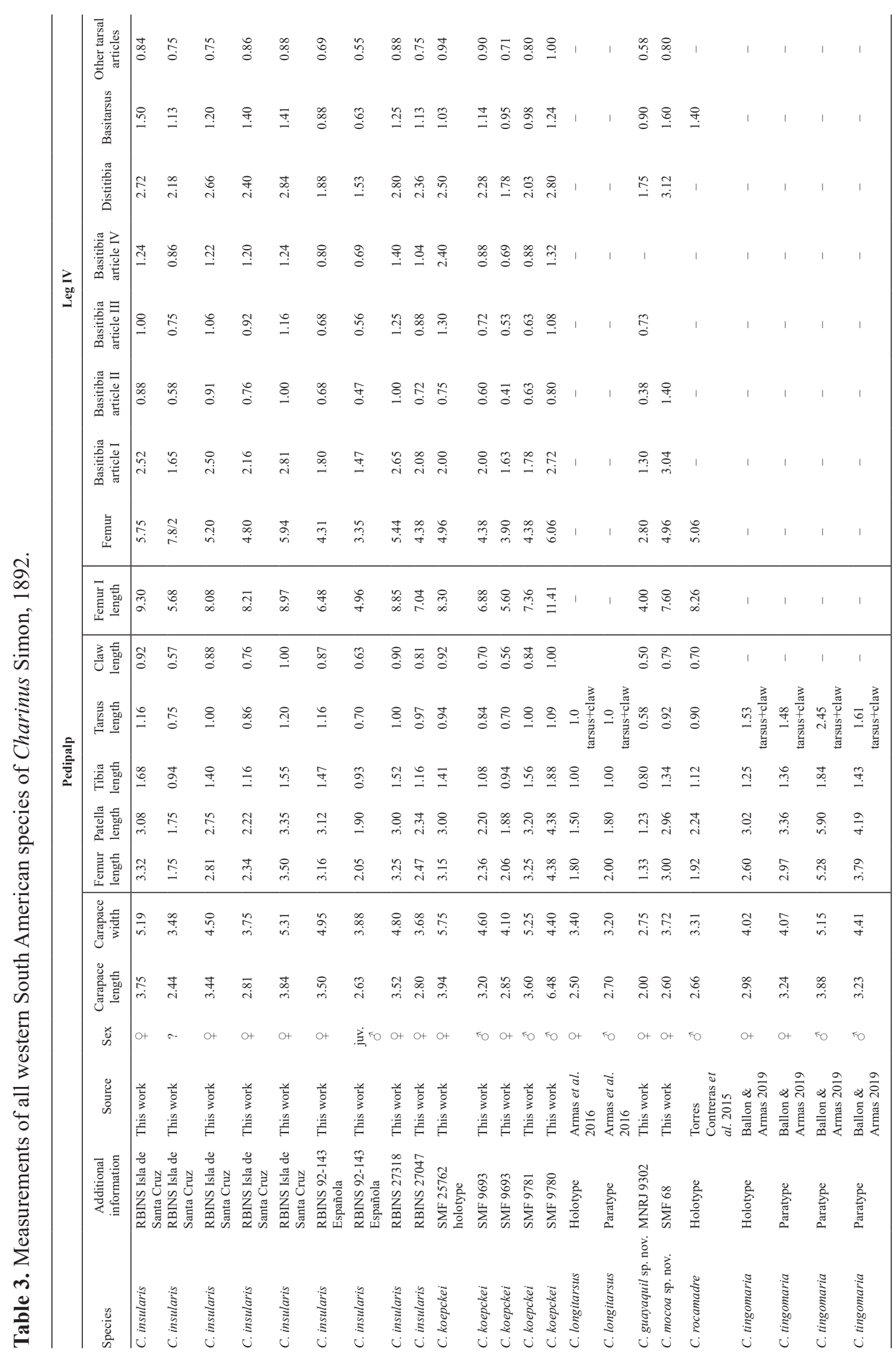




\section{Etymology}

Patronym honoring Dr Hans-Wilhelm Koepcke (Weygoldt 1972).

\section{Type material}

\section{Holotype}

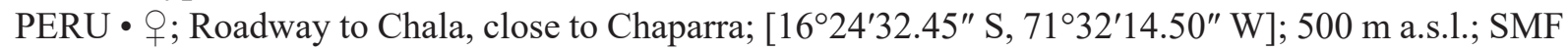
25762.

\section{Paratypes}

PERU • 1 †, 1 O̊; Hacienda Taulis; 1700 m a.s.1.; 29 Apr. 1954; Koepcke leg.; SMF $9693 \bullet 2$ q ; Mejia, near Mollendo; 350-500 m a.s.1.; 15 Jan. 1956; Koepcke leg.; SMF 9781 • 1 §; Chala-Chaparra (probably between the two districts); 6 Jan. 1956; Koepcke leg.; SMF 9780 • 2 q 9,1 Oे, 2 juv., 2 praenymphs; La Florida; 1200 m a.s.1.; 20 Apr. 1953; Koepcke leg.; SMF 9692.

\section{Supplementary description}

CARAPACE. Six anterior setae; frontal process triangular, not visible in dorsal view. Small granules densely scattered between ocular triads and among sulci. Median eyes present; median ocular tubercle shallow; pair of setae on median ocular tubercle; lateral eyes well developed, with seta posterior to lateral ocular triad.

STERNUM. Tritosternum projected anteriorly, with typical setation; other sternal platelets divided, concave, with seta on each side of platelets and smaller setae basally; pentasternum with four setae anteriorly and seta on membranous region.

Opisthosoma. Ventral sacs and ventral sac cover absent.

GeNitALiA. Female genital operculum with prominent setae posteromedially and some smaller setae near margin; gonopod cushion-like; gonopods sclerotized basally; rounded base with narrow, pointed apex. Male gonopod with base of fistula and lateral lobe sclerotized; lateral lobe 2 not fimbriate.

CheliCERAE. Small tooth projecting from retrolateral surface of basal segment, opposite to bifid tooth; retrolateral surface of claw without seta; claw with five teeth; transverse row of 6-8 setae on prolateral surface of basal segment; bifid tooth on basal segment with dorsal cusp larger than ventral cusp.

PEDIPALPS. Coxal dorsal carina without seta encircled by round carina and four setae on margin. Femur with three or four dorsal spines and three or four ventral spines; two prominent setiferous tubercles between dorsal spine 1 and proximal margin; spine between ventral spine 1 and proximal margin. Patella with four dorsal spines in primary series; prominent setiferous tubercle distal to spine I, one-third length of spine I; three ventral spines in primary series; prominent setiferous tubercle between spine I and distal margin. Tibia with ventral spine distally and seta between spine and distal margin. Tarsus with two dorsal spines, proximal spine half length of distal spine; cleaning organ with 24-30 setae in ventral row.

LeGs. Tibia of leg I with 23 articles (up to 31 in regenerated legs); tarsus I with 43 articles (up to 46 in regenerated legs); first tarsal article similar in length to subsequent articles. Leg IV basitibia with four pseudo-articles, without sclerotized, denticulate margin projecting from apex of articles; trichobothrium $b t$ situated in proximal third of pseudo-article; distitibia trichobothrium $b c$ situated closer to $b f$ than to $s b f$ (situated closer to $s b f$ in one paratype), $s c$ and $s f$ series each with five trichobothria.

\section{Measurements}

See Table 3. 


\section{Distribution}

Known only from the type localities.

\section{Natural history}

The species has minor secondary sexual dimorphism, with males slightly larger than females.

Charinus longitarsus Armas \& Palomino-Cárdenas, 2016

Fig. 34; Table 3

Charinus longitarsus Armas \& Palomino-Cárdenas in Armas et al., 2016: 44-48, figs 1-2.

Charinus longitarsus - Miranda et al. 2016c: 31.

\section{Diagnosis}

Based on the description of Armas \& Palomino-Cárdenas (2016), this species may be separated from other Charinus in western South America by means of the following combination of characters: carapace, chelicerae, pedipalps and opisthosomal tergites moderately dark, yellowish-brown; legs pale yellowish-brown; ocular tubercle black; carapace and pedipalps with clavate setae; median and lateral eyes well developed; basal segment of chelicera without tooth in retrolateral row; bifid tooth on basal segment with dorsal cusp larger than ventrodistal; cheliceral claw with five teeth; pedipalp femur with three dorsal spines, three ventral spines, and two setiferous tubercles proximal to first dorsal spine; pedipalp femur with spine proximal to first ventral spine of primary series; pedipalp patella with four dorsal spines and two ventral spines, and with long setiferous tubercle between spine I and distal margin; pedipalp tarsus with two dorsal spines; leg IV basitibia with three pseudo-articles; trichobothrium $b c$ situated closer to $s b f$ than to $b f$; leg IV distitibia $s c$ and $s f$ series each with five trichobothria; tibia of leg I with 23 articles, tarsus I with 27-30 articles.

Charinus longitarsus differs from other Charinus species in the combination of the long first article of the leg I tarsus, the clavate setae on the tegument, and sternites with plate-like platelets. These characters are otherwise present only in C. carvalhoi sp. nov., C. magalhaesi sp. nov. and C. montanus. Charinus carvalhoi sp. nov. and C. montanus may be easily distinguished by the shape of the female gonopod, which is sucker-like, and the number of pseudo-articles in the basitibia of leg IV, three in C. longitarsus compared with four in C. montanus and and two in C. carvalhoi sp. nov. Charinus montanus exhibits secondary sexual dimorphism, with the male pedipalps longer than those of the female, but sexual dimorphism is not mentioned in the original description of $C$. longitarsus.

\section{Etymology}

Adjective referring to the elongate first tarsal segment of the antenniform leg I (Armas et al. 2016).

\section{Type material}

Holotype

PERU • 9 ; Cusco Department, La Convención Province, Huyro; 1300'03" S, 72³3'13" W; $1642 \mathrm{~m}$ a.s.l.; 13 Feb. 2016; A.C. Palomino C. leg.; UNSAAC [not examined].

\section{Paratype}

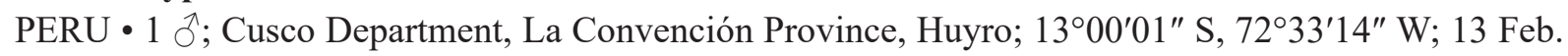
2016; A.C. Palomino C. leg.; UNSAAC [not examined]. 


\section{Measurements}

See Table 3.

\section{Distribution}

Known only from the type localities.

\section{Natural history}

The type specimens were found under small stones along trails in an area of humid montane subtropical forest, at an altitude of $1210-1642 \mathrm{~m}$, where the median annual temperature is $23.3^{\circ} \mathrm{C}$ and mean annual precipitation is $1052 \mathrm{~mm}$ (Armas et al. 2016). Three females with brood sacs were found with six, seven and eight eggs or embyos, respectively (Armas et al. 2016).

\section{Remarks}

Armas et al. (2016: 49, fig. 2d) described the female gonopod as sucker-like but their figure illustrates a cushion-like gonopod, which is markedly sclerotized at the apex and margin.

Charinus mocoa sp. nov. urn:1sid:zoobank.org:act:E0F7C84C-83C1-4839-B3BD-E3A0E75BC4C6

Figs 5G-H, 10E-F, 34, 42; Table 3

\section{Diagnosis}

This species may be separated from other Charinus in western South America by means of the following combination of characters: four anterior setae on carapace (Fig. 42A); median eyes absent (Fig. 42A, C); bifid tooth of basal segment with ventral cusp larger than dorsal cusp (Fig. 10E-F); leg IV basitibia with two pseudo-articles.

\section{Etymology}

Noun in apposition taken from the type locality.

\section{Type material}

\section{Holotype}

COLOMBIA • P; Putumayo Department, Mocoa; [0109'08.42" N, 76³9'03.8" W]; 21 Jul. 1956; H. Sturm leg.; SMF 68.

\section{Description}

CARAPACE. Four anterior setae (Fig. 42A); frontal process triangular, not visible in dorsal view (Fig. 42C). Small granules densely scattered between ocular triads and among sulci. Median eyes and median ocular tubercle absent (Fig. 42C); pair of setae in place of median eyes; lateral eyes reduced, pale, seta posterior to lateral ocular triad.

STERnUm. Tritosternum projected anteriorly, with typical setation (Fig. 42B); other sternal platelets divided into two, with acuminate setae anteriorly on each platelet and some smaller setae posteriorly (Fig. 42B); pentasternum with six setae anteriorly and two setae near membranous region.

Opisthosoma. Ventral sacs and ventral sac cover absent. 
Genitalia. Female genital operculum with prominent setae posteromedially and smaller setae near margin (Fig. 5G-H); posterior margin of genital operculum with pair of shallow lateral sulci (Fig. 5G$\mathrm{H}$ ); gonopod cushion-like; base of gonopods slightly sclerotized (Fig. 5G-H). Male unknown.

ChELICERAE. Small, flat tooth on retrolateral surface of basal segment, opposite to bifid tooth (Fig. 10F); retrolateral surface of claw with row of setae from base to midline; claw with five teeth (Fig. 10E-F); transverse row of five setae on prolateral surface of basal segment; bifid tooth of basal segment with ventral cusp larger than dorsal cusp (Fig. 10E-F).

PedipalPs. Coxal dorsal carina with four setae encircled by round carina and three setae on margin. Femur with three dorsal spines and three ventral spines (Fig. 42E-F); two prominent setiferous tubercles between dorsal spine 1 and proximal margin; setiferous tubercle between ventral spine 1 and proximal margin. Patella with three dorsal spines in primary series (Fig. 42E); prominent setiferous tubercle distal to spine I, one-third length of spine I; two ventral spines in primary series; setiferous tubercle between spine I and distal margin. Tibia with ventral spine distally and four setae between spine and distal margin. Tarsus with two dorsal spines, distal spine half length of tarsus and proximal spine one-third length of distal spine (Fig. 42D); cleaning organ with 28-33 setae in ventral row.

LEGS. Leg IV basitibia with two pseudo-articles, without sclerotized, denticulate margin at apex of articles; trichobothrium $b t$ situated in proximal third of pseudo-article; distitibia with trichobothrium $b c$ situated closer to $s b f$ than to $b f, s c$ and $s f$ series each with five trichobothria.

\section{Measurements}

See Table 3.

\section{Distribution}

Armas et al. (2012) recorded several juveniles and/or poorly preserved specimens of Charinus from different localities in Colombia and provided photographs of the first charinid specimens recorded from the country. Armas et al. (2012) could not precisely identify the Charinus species due to the poor preservation of the material, and suggested the specimens resembled C. acosta. The specimen from the Sucre Department was excluded from the map because a precise locality was unavailable. However, C. rocamadre is also known from Sucre and differs from C. acosta in the development of the median eyes, which are absent in C. rocamadre, but present (although reduced) in C. acosta.

\section{Additional records}

Additional records of Colombian Charinus, the identities of which have not been verified by the authors, are as follows: Girón, $07^{\circ} 04^{\prime} 26.29^{\prime \prime}$ N, 73¹0'09.36" W, Santander Department, 1 Aug. 2009, 700 m a.s.1., S. García leg., in courtyard of house (urban area), tropical dry forest (specimen found under tree trunk lying on the ground), 1 juv. (ICN Am-074); Usme, 04³0'22.92" N, 7406'28.62" W [coordinates from Armas et al. (2012) are incorrect], Cundinamarca Department, 3 May 2009, M. Isaza leg., 1 juv. (MUD); Villavieja, 031' $13^{\prime \prime} \mathrm{N}, 75^{\circ} 13^{\prime} 07^{\prime \prime} \mathrm{W}$, Huila Department, Dec. 2011, D. Hoyos Velásquez leg., under stone in courtyard of hotel, 1 juv., kept alive by collector; Espinal, 04 $08^{\prime} 59.35^{\prime \prime}$ N, $74^{\circ} 53^{\prime} 03.63^{\prime \prime}$ W, Tolima Department, 327 m a.s.1., D. López Lezama leg., under stone in courtyard of house, in area of tropical dry forest, 1 juv. [photograph]; Sucre Department, Jul. 2008, R. Botero-Trujillo leg., 1 (Colección Entomológica de la Universidad de Antioquia, Medellín).

\section{Remarks}

The holotype and only known specimen lacks leg I. 
MIRANDA G.S. et al., Systematic revision of Charinidae (Arachnida, Amblypygi)

Charinus rocamadre Torres-Contreras, García \& Armas, 2015

Fig. 34; Table 3

Charinus rocamadre Torres-Contreras et al., 2015: 145-148, fig. 1a-h.

Charinus rocamadre - Torres-Contreras et al. 2019: 131, 138-139, figs 1-6.

\section{Diagnosis}

This species may be separated from other Charinus in western South America by means of the following combination of characters: tegument pale yellowish-brown; median eyes and median ocular tubercle absent, with pair of small setae instead; lateral eyes present, unpigmented, with seta posterior to lateral ocular triad; female gonopod cushion-like; bifid tooth of basal cheliceral segment with dorsal cusp longer than ventral cusp, and with prominent tooth on retrolateral row adjacent to bifid tooth; cheliceral claw with five teeth; pedipalp femur with three dorsal spines and three ventral spines; pedipalp femur with setiferous tubercle between ventral spine I and proximal margin; pedipalp patella with three dorsal spines and two ventral spines, and with long setiferous tubercle between dorsal spine I and distal margin; pedipalp tarsus with two dorsal spines; tibia of leg I with 23 articles, tarsus I with 41 or 42 articles; leg IV basitibia with three articles.

\section{Etymology}

Noun in apposition referring to the cave in which the species was found (Torres-Contreras et al. 2015).

\section{Type material}

\section{Holotype}

COLOMBIA - §i; Sucre Departament, Roca Madre Cave, Tolú Viejo, corregimiento La Piche; 09³0'50.1" N, 75²3'36.6" W; 4 Jan. 2015; R. Torres leg.; ICN Am-100 [not examined].

\section{Measurements}

See Table 3.

\section{Distribution}

Known from the type locality only.

\section{Natural history}

The cave in which the holotype was collected is located in a tropical dry forest, at an altitude of $337 \mathrm{~m}$. The outside forest is warm and dry, with an average temperature of $26.8^{\circ} \mathrm{C}$, relative humidity of $77 \%$, and annual precipitation between 1000 and $1200 \mathrm{~mm}$. The holotype was collected under a rock in the twilight zone of the cave and, at the time of sampling, the air temperature was $27^{\circ} \mathrm{C}$ and relative humidity of 80\%. Heterophrynus caribensis Armas, Torres-Contreras \& Alvarez, 2015 was collected in the same cave.

\section{Remarks}

Torres-Contreras et al. (2019) described the female of C. rocamadre, provided additional details concerning the male gonopod, and published a DNA barcode of the species. See Torres-Contreras et al. (2015) and Torres-Contreras et al. (2019) for more details. 
Charinus tingomaria Ballón-Estacio \& Armas, 2019

Fig. 34; Table 3

Charinus tingomaria Ballón-Estacio \& Armas, 2019: 16-19, figs 2-11.

\section{Diagnosis}

Based in part on Ballón-Estacio \& Armas (2019), this species may be separated from other Charinus in western South America by means of the following combination of characters: median and lateral eyes and median ocular tubercle well developed; female gonopod cushion-like; male gonopods with fistula, dorsal lobe and lateral lobe 2 markedly sclerotized; males with pedipalp femur and patella longer than females; tibia of leg I with 23 articles and tarsus I with 43 articles; leg IV basitibia with four pseudoarticles; $s c$ and $s f$ series each with five trichobothria.

Charinus tingomaria resembles C. gertschi, C. insularis and C. koepckei but may be distinguished from C. gertschi by the smaller number of dorsal and ventral spines on the pedipalp patella (seven dorsal spines and four ventral spines are present in $C$. gertschi); from $C$. insularis by the greater number of spines on the pedipalp femur and patella; and from C. koepckei by its smaller size, secondary sexual dimorphism of the pedipalps, undivided tetrasternum and pentasternum, and cushion-like female gonopods.

\section{Etymology}

Noun in apposition taken from the type locality.

\section{Type material}

\section{Holotype}

PERU • P; Huánuco Departament, Provincia Leoncio Prado, Parque Nacional Tingo María, Cueva de

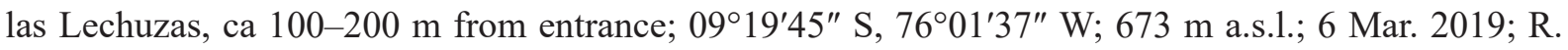
Ballon Estacio leg.; under stones; MHNS [not examined].

\section{Paratypes}

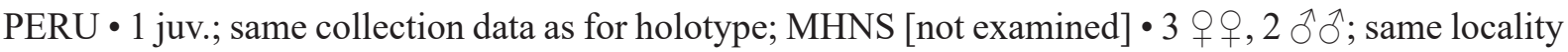
as for holotype; 21 Mar. 2019; R. Ballón, A. Ricra and W. Fernández leg.; under stones, dark zone, more than $220 \mathrm{~m}$ from entrance; MHNS [not examined].

\section{Measurements}

See Table 3.

\section{Distribution}

Known only from the type localities.

\section{Natural history}

The species is found from the entrance to deeper regions of the cave, and is sympatric with Heterophrynus elaphus Pocock, 1903.

\section{Remarks}

According to Ballón-Estacio \& Armas (2019), the pedipalp femur possesses six ventral spines, but these authors also counted spines outside the primary series, i.e., small spines between larger spines which are situated prolaterally. The true count of ventral spines on the femur, according to Ballón-Estacio \& Armas (2019: 18, fig. 5) is four. 


\section{Key to the identification of the species of Charinus in eastern South America}

1. Leg IV distitibia with four trichobothria in frontal and caudal series; leg IV basitibia with three pseudo-articles

- Leg IV distitibia with five or six trichobothria frontal and caudal series; leg IV basitibia with two or four pseudo-articles

2. Leg IV distitibia with five trichobothria in frontal and caudal series ............................................. 3

- Leg IV distitibia with six trichobothria in frontal and caudal series ............................................ 12

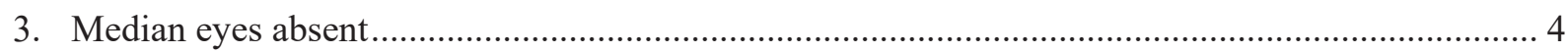

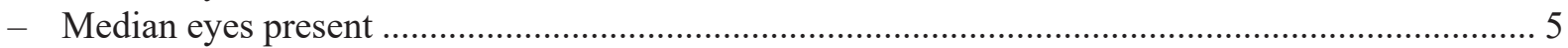

4. Tibia of leg I with 21 articles; leg I tarsus with 37 articles; leg IV basitibia with two pseudo-

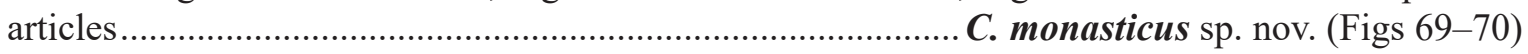

- Tibia of leg I with 23 articles; leg I tarsus with 41 articles; leg IV basitibia with four pseudoarticles............................................................................. troglobious Baptista \& Giupponi, 2002

5. Pedipalp femur with three dorsal spines; pedipalp patella with two ventral spines

C. una sp. nov. (Figs 78-79)

- Pedipalp femur with more than three dorsal spines; pedipalp patella with more than two ventral spines

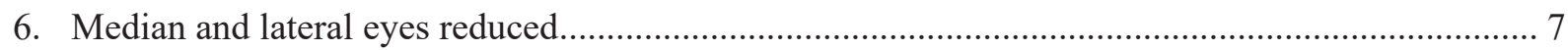

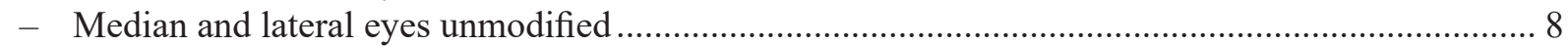

7. Median ocular tubercle present but reduced; reduced median eyes with dark pigmentation; pedipalp patella dorsal spine IV two-thirds length of dorsal spine III

C. taboa Vasconcelos, Giupponi \& Ferreira, 2016

- Median ocular tubercle absent, reduced eyes situated directly on tegument; reduced median eyes unpigmented; pedipalp patella dorsal spine IV one-fifth length of dorsal spine III ....

C. spelaeus Vasconcelos \& Ferreira, 2017

8. Cheliceral basal segment with long (distinct) tooth adjacent to bifid tooth

C. sooretama sp. nov. (Figs 7E-F, 9C-D, 75)

- Cheliceral basal segment with short (indistinct) tooth adjacent to bifid tooth

9. Base of female gonopod unsclerotized ..................... euclidesi sp. nov. (Figs 6C-D, 9A-B, 61-63)

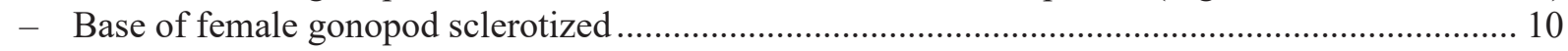

10. Pedipalp tibia with two ventral spines ...................................... . diamantinus sp. nov. (Figs 57-60)

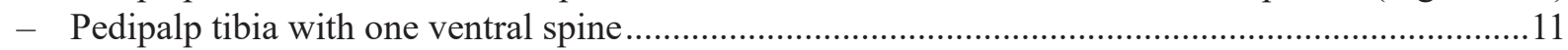

11. Curved carina present between ocular triads and lateral margin of carapace; cheliceral claw with nine teeth.

C. souzai sp. nov. (Figs 76-77)

- Curved carina absent between ocular triads and lateral margin of carapace (Fig. 48A-B); cheliceral claw with six or seven teeth

C. brasilianus Weygoldt, 1972 (Figs 8C-D, 48)

12. Leg I tarsus with 28 articles

C. montanus Weygoldt, 1972

- Leg I tarsus with 41 articles

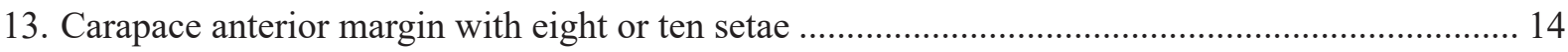

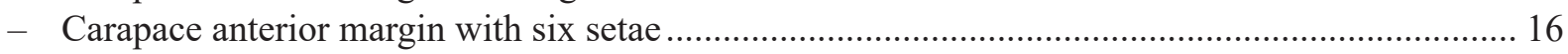


14. Carapace anterior margin with ten setae; median ocular tubercle absent; pedipalp patella with spine between ventral spine I and distal margin

C. eleonorae Baptista \& Giupponi, 2003

- Carapace anterior margin with eight setae; median ocular tubercle present; pedipalp patella with setiferous tubercles between ventral spine I and distal margin

15. Pedipalp tarsus with two dorsal spines (Fig. 47D)

C. apiaca sp. nov. (Figs 5A-B, 47)

- Pedipalp tarsus with three dorsal spines C. caatingae Vasconcelos \& Ferreira, 2016

16. Carapace anterior margin projected anteriorly C. santanensis Vasconcelos \& Ferreira, 2017

- Carapace anterior margin rounded.

17. Leg I tarsus, first article equal in length to subsequent three articles

C. jibaossu Vasconcelos, Giupponi \& Ferreira, 2014

- Leg I tarsus, first article equal in length to all subsequent articles

18. Pedipalp tarsus with three dorsal spines

- Pedipalp tarsus with two dorsal spines

19. Cheliceral claw with four teeth

C. mysticus Giupponi \& Kury, 2002

- Cheliceral claw with 9-13 teeth

20. Pedipalp coxa, rounded dorsal carina containing seven setae

- Pedipalp coxa, rounded dorsal carina containing two or five setae

21. Pedipalp patella with six ventral spines (Fig. 49F); cheliceral claw with 13 teeth

C. carinae sp. nov. (Figs 3A-B, 4A-B, 49-51)

- Pedipalp patella with three or four ventral spines; cheliceral claw with ten teeth.

C. goitaca sp. nov. (Figs 64-65)

22. Pedipalp coxa, rounded dorsal carina containing five setae; pedipalp patella with six dorsal spines .................... C. ruschii Miranda, Milleri-Pinto, Gonçalves-Souza, Giupponi \& Scharff, 2016

- Pedipalp coxa, rounded dorsal carina containing two setae; pedipalp patella with four dorsal spines

C. carioca sp. nov. (Figs 6E-F, 52-53)

23. Pedipalp coxa, rounded dorsal carina containing no setae

- Pedipalp coxa, rounded dorsal carina containing setae

24. Pedipalp patella with three dorsal spines....

C. acaraje Pinto-da-Rocha, Machado \& Weygoldt, 2002 (Figs 7A-B, 8A-B)

- Pedipalp patella with five dorsal spines.

25. Pedipalp femur with four dorsal spines ....

C. renneri sp. nov. (Figs 6A-B, 10I-J, 73-74)

- Pedipalp femur with five dorsal spines

C. asturius Pinto-da-Rocha, Machado \& Weygoldt, 2002

26. Pedipalp femur with five dorsal spines

C. cearensis sp. nov. (Figs 54-56)

- Pedipalp femur with four dorsal spines

27. Pedipalp femur with five ventral spines.

- Pedipalp femur with four ventral spines 
28. Pedipalp femur with secondary row of dorsal spines; pedipalp patella, distance from ventral spine I to distal margin half length of spine

- Pedipalp femur without secondary row of dorsal spines; pedipalp patella, distance from ventral spine I to distal margin greater than length of spine C. iuiu Vasconcelos \& Ferreira, 2016

29. Cheliceral claw with up to 13 teeth; median and lateral eyes reduced

C. potiguar Vasconcelos, Giupponi \& Ferreira, 2013

- Cheliceral claw with 11 teeth; median and lateral eyes unmodified.

C. imperialis sp. nov. (Figs 66-68)

Charinus acaraje Pinto-da-Rocha, Machado \& Weygoldt, 2002

Figs 7A-B, 8A-B, 43; Table 4

Charinus acaraje Pinto-da-Rocha et al., 2002: 110-113, figs 8-12.

Charinus acaraje - Baptista \& Giupponi 2003: 80. — Miranda \& Giupponi 2011: 66, fig. 13. Vasconcelos et al. 2013: 496-497, fig. 12; 2014: 155, 162. — Vasconcelos \& Ferreira 2016: 185. - Miranda et al. 2016c: 18-29.

\section{Diagnosis}

This species may be separated from other Charinus in eastern South America by means of the following combination of characters: two setae, prolateral and retrolateral, on dorsal surface of chelicerae; cheliceral claw with eight teeth and with complete row of setae on retrolateral surface; pedipalp femur with three dorsal spines and three ventral spines; leg IV distitibia $s c$ and $s f$ series each with six trichobothria.

This species resembles $C$. una sp. nov., but differs in the larger size, six trichobothria in the $s c$ and $s f$ series, and eight teeth on the cheliceral claw.

\section{Etymology}

Noun in apposition referring to 'acarajé', a famous dish in Bahia, the state in which the type locality is located (Pinto-da-Rocha et al. 2002).

\section{Type material}

\section{Holotype}

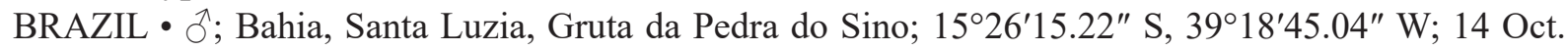
1997; B.S. Santos leg.; MZSP 1829.

\section{Additional material}

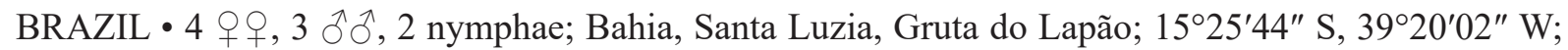
3 Nov. 2002; A.P.L. Giupponi and R.C. Baptista leg.; new record; MNRJ 9297 • 1 q; Bahia, Camacã, Reserva Particular do Patrimônio Natural da Serra Bonita; $15^{\circ} 23^{\prime} 02.63^{\prime \prime}$ S, 39³3'46.68" W; 11-15 Jun. 2009; V. Dill, A. Chagas Jr, D. Pedroso, A.P.L. Giupponi, A. Kury leg.; new record; MNRJ 9125.

\section{Supplementary description}

Only the male was previously known. A description of the female and supplementary description of the male are presented below.

CARAPACE. Curved carina between ocular triads and carapace margin, closer to margin, with small transverse projection medially; anterior margin rounded, with six anterior setae; frontal process large, 
subtriangular, not visible in dorsal view. Median eyes and median ocular tubercle present; median ocular tubercle shallow, slightly higher than carapace surface, with pair of small setae. Lateral eyes well developed, pale, small seta posterior to each lateral ocular triad; lenses directed anteriorly and dorsally.

STERnUm. Tritosternum rounded posteriorly and projected anteriorly into large, blunt tubercle, surpassing base of pedipalp coxae, with typical setation; medial platelet (tetrasternum) with single convex platelet, with pair of large setae anteriorly, and several small setae posteriorly; third platelet (pentasternum) with single convex platelet, smaller than medial platelet, with two setae anteriorly and some setae posteriorly; metasternum with one or two anterior setae in membranous region and two or three setae posteriorly.

Opisthosoma. Ventral sacs and ventral sac cover absent.

Genitalia. Female gonopod with posterior margin of genital operculum slightly convex, several setae on surface and along margin (Fig. 7A-B); small sclerotized region at base of gonopods, not connected to each other; gonopods sucker-like with large disc and small openings (Fig. 7A-B). Male gonopod with spine-like projections over apex of fistula, LoD, and LoL2 (Fig. 8A-B).

Chelicerae. Small, flat tooth in retrolateral row of basal segment. Prolateral surface with transverse row of six small setae, from ventral to dorsal. Three setae, retrolateral, retromedial, and prolateral along dorsodistal margin, near membranous region of claw. Claw with eight teeth and row of setae on retrolateral surface from base to near apex (dorsal side).

Pedipalps. Coxal dorsal carina with one or two small setae encircled by round carina and three setae on anterior margin. Femur with three dorsal spines in primary series; two distinct setiferous tubercles proximal to first dorsal spine; three ventral spines; large spine between ventral spine 1 and proximal margin. Patella with three dorsal spines; setiferous tubercle distal to spine I, about one fourth length of spine I; three ventral spines decreasing in size; setiferous tubercle between spine I and distal margin. Tibia with two dorsal spines; ventral spine in distal half of tibia; prominent setiferous tubercle near base of ventral spine; three long setae between spine and distal margin. Tarsus with two dorsal spines, distal spine half length of tarsus and proximal spine one-third length of distal spine. Ventral row of brush with 32-34 setae.

Legs. Tibia of leg I with 23 articles; tarsus I with 41 articles. Leg IV basitibia with four pseudoarticles; trichobothrium $b t$ situated in proximal third; distal apex of basitibial pseudo-articles with dark, denticulate projection; distitibia trichobothrium $b c$ situated closer to $s b f$ than to $b f ; s f$ and $s c$ series each with six trichobothria; distitarsus with distinct white annulus distally on first article.

\section{Measurements}

See Table 4.

\section{Distribution}

Known from inside and outside caves in southern Bahia, Brazil.

\section{Natural history}

Species with secondary sexual dimorphism, i.e., males exhibit longer pedipalps and larger body size. 


\section{Charinus alagoanus sp. nov. urn:Isid:zoobank.org:act:0109E9FB-0C24-436A-A96C-8B5B530F0AD2}

Figs 10G-H, 43-46; Table 4

\section{Diagnosis}

This species may be separated from other Charinus in eastern South America by means of the following combination of characters: median and lateral eyes present (Fig. 44A); cheliceral claw with eight teeth (Fig. 10G-H); tibia of leg I with 23 articles, tarsus I with 41 articles; leg IV basitibia with three pseudoarticles; distitibia $s c$ and $s f$ series each with four trichobothria.

\section{Etymology}

Adjective refering to the Brazilian state of Alagoas in which the type locality is located.

\section{Type material}

\section{Holotype}

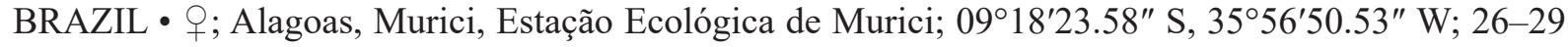
Jul. 2012; C.S. Costa, D.M.C. de Alcântara, P. de S. Dias and S.S. Nihei leg.; MNRJ 9294.

\section{Paratype}

BRAZIL • 1 q; Alagoas, Murici, Estação Ecológica de Murici, UFAL, Barranco; 09¹5.186' S, 3551.017' W; 200 m a.s.l.; 17 Aug. 2006; MNRJ 9295.

\section{Description}

CARAPACE. Carina ventral to lateral eyes, closer to carapace margin; frontal process large, subtriangular, not visible in dorsal view (Fig. 44C). Median eyes and median ocular tubercle present (Fig. 44C); median tubercle shallow, slightly higher than carapace surface, with pair of small setae; lateral eyes well developed, pale, small seta posterior to each lateral ocular triad.

STERNUM. Tritosternum projected anteriorly into small blunt tubercle, surpassing base of pedipalp coxae, with typical setation (Fig. 44B); medial platelet (tetrasternum) and third platelet (pentasternum) with single convex platelet, with pair of large setae anteriorly, and several small setae posteriorly; metasternum with anterior setae in membranous region; two or three setae, forming longitudinal row, posteriorly.

Opisthosoma. Ventral sacs and ventral sac cover absent.

Genitalia. Female genital operculum slightly convex (Fig. 45B), with several setae on surface and along margin (Fig. 45A-C); sucker-like gonopods unsclerotized basally (Fig. 45A); gonopods with dorsal projection on retrolateral side (Fig. 45D-E); laterodistal margin of genital operculum with slit sensilla ventrally (Fig. 45F). Male unknown.

Chelicerae. Small tooth in retrolateral row of basal segment (Fig. 10H); prolateral surface with row of around seven small setae, from ventral to dorsal surface; two setae, prolateral and retrolateral on dorsodistal border margin near membranous region of claw; claw with eight teeth and row of setae only present medially on retrolateral surface (Fig. 10G-H).

Pedipalps. Coxa with one or two small setae on rounded carina and three setae on anterior margin. Femur with three distinct setiferous tubercles proximal to spine 1 (Fig. 44E); primary series with four dorsal spines and three ventral spines (Fig. 44E-F); large ventral spine proximal to spine 1. Patella with four dorsal spines (Fig. 44E); large setiferous tubercle distal to spine I, about one-third length of spine I; three ventral spines decreasing in size (Fig. 44F); setiferous tubercle between spine I and distal margin. Tibia with two dorsal spines; ventral spine in distal half; two long setae between spine and distal margin. 


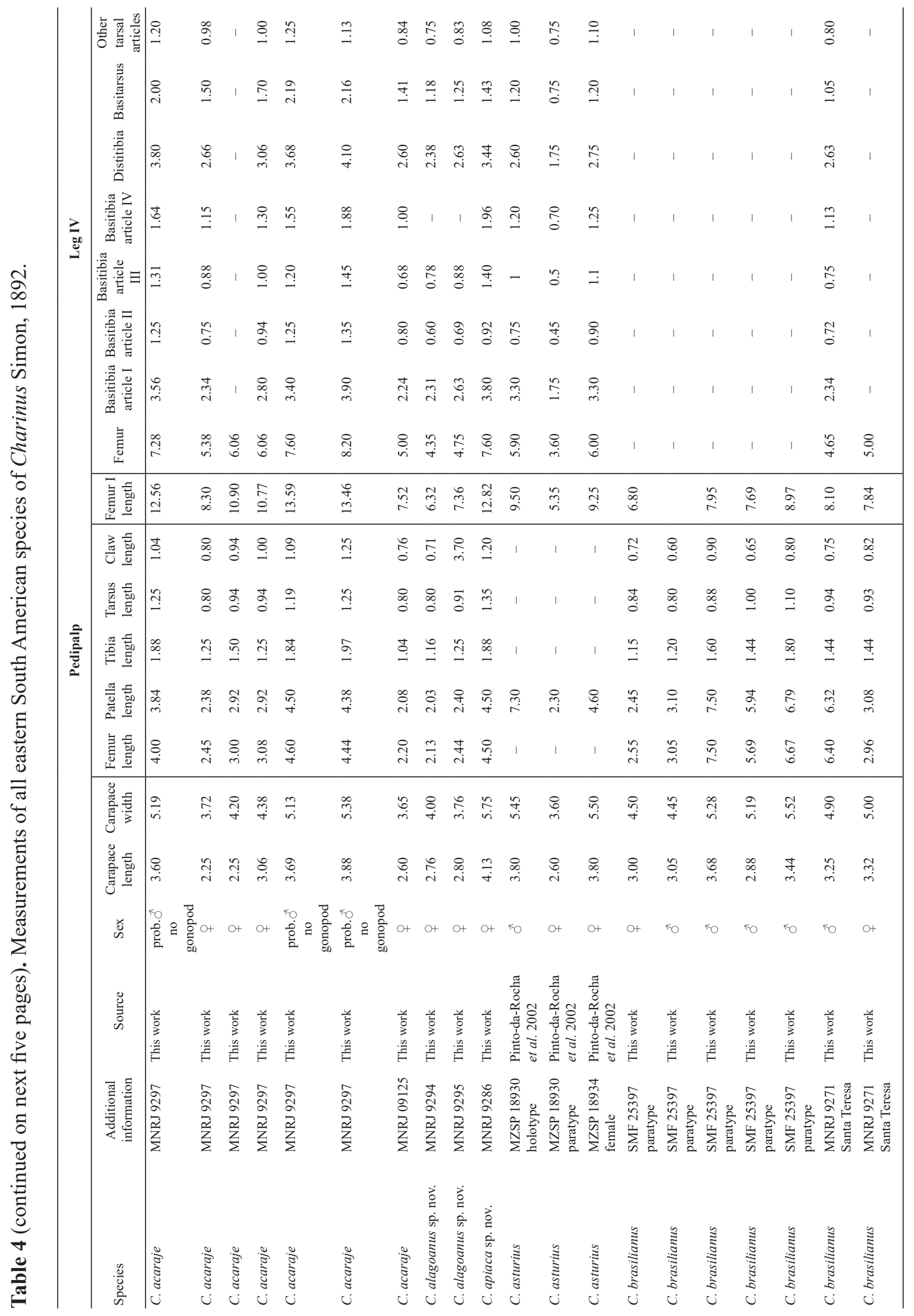




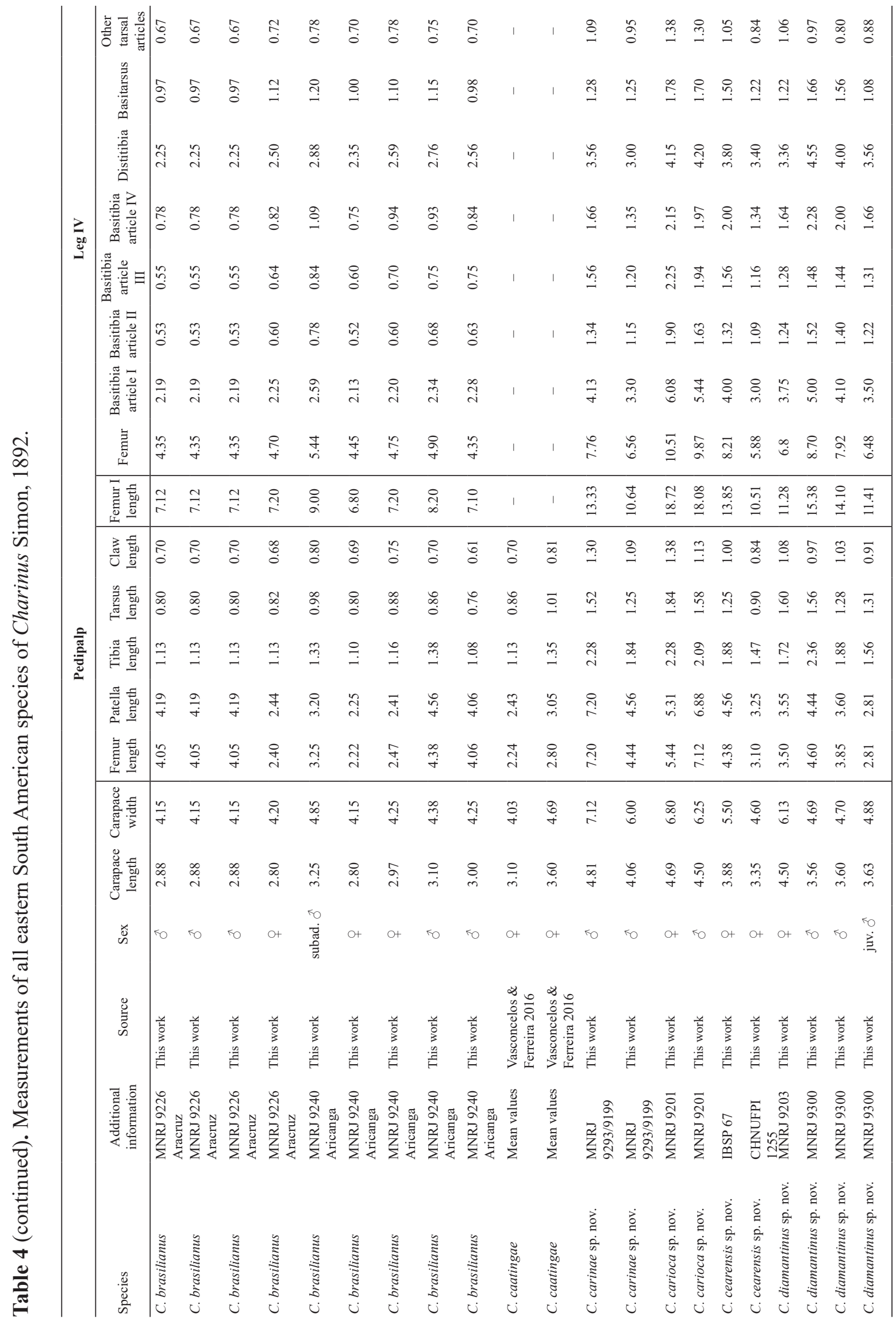




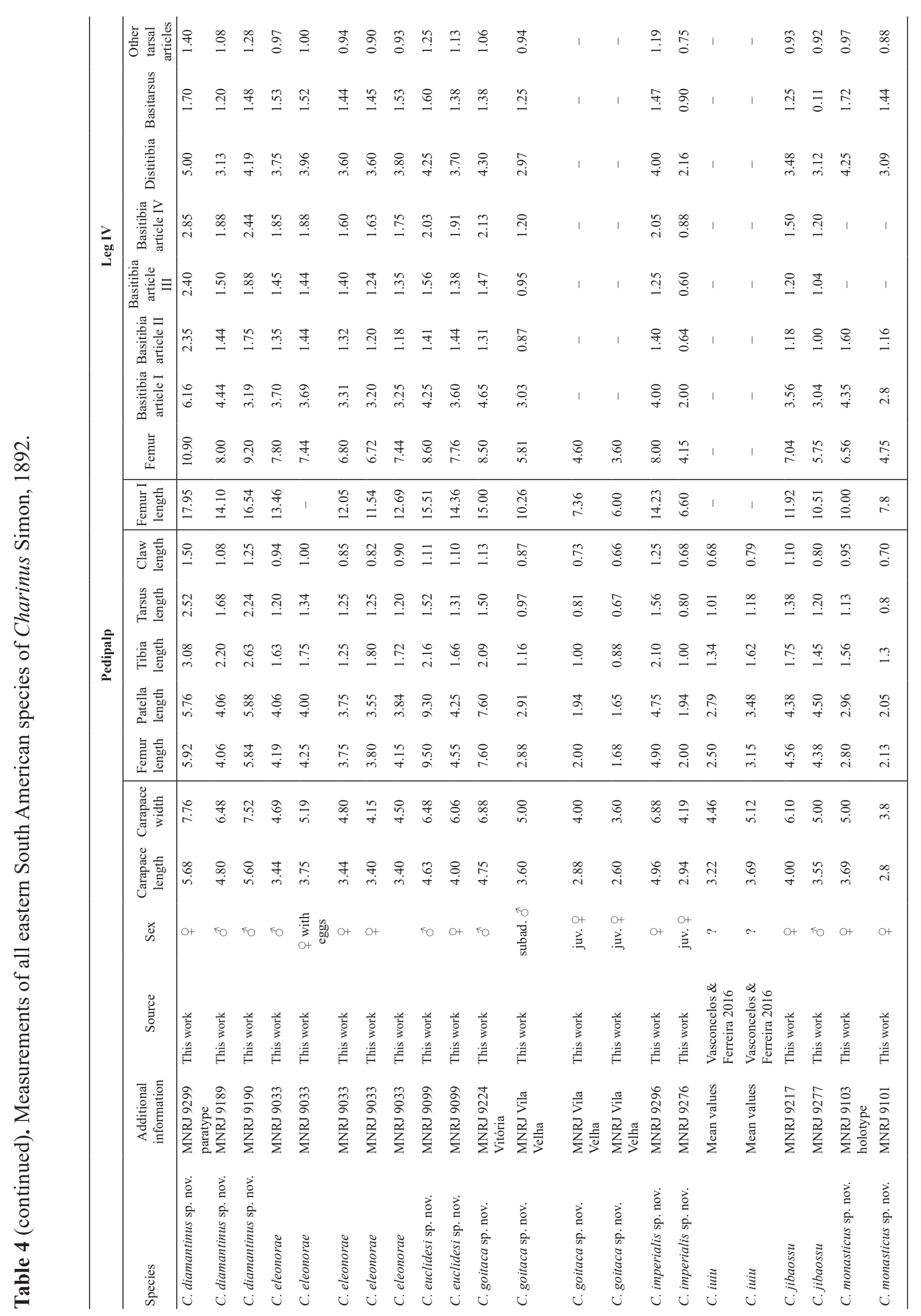




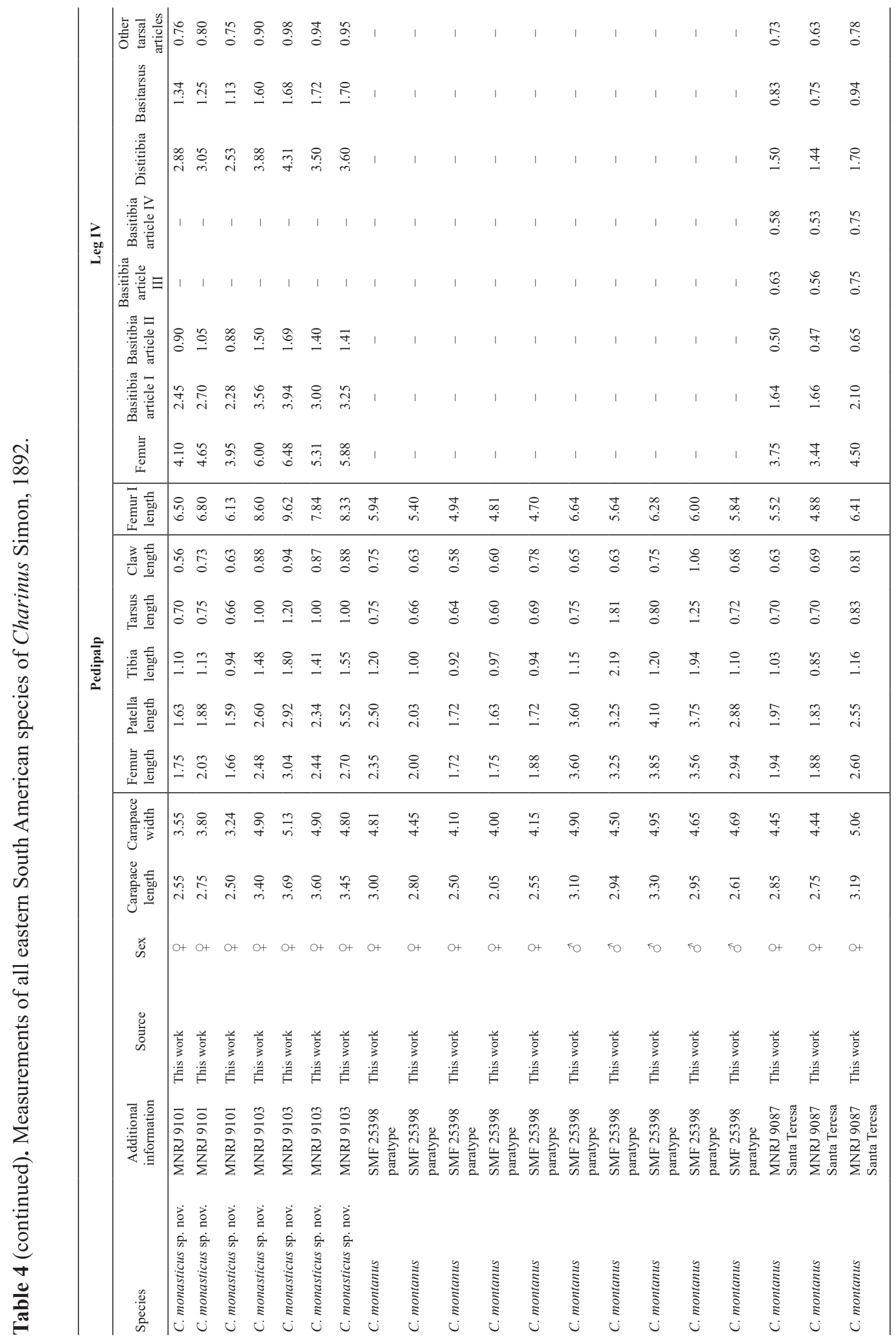




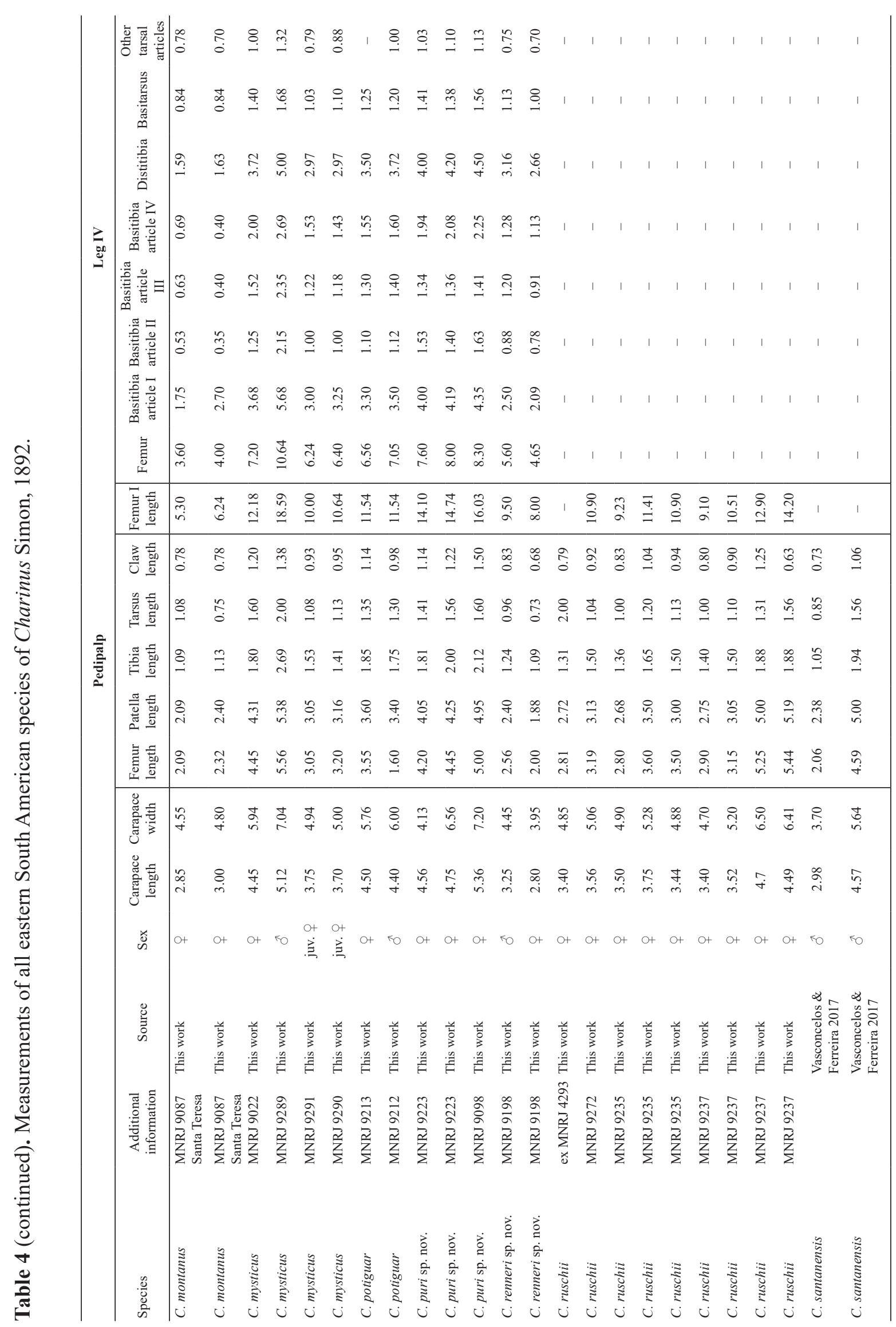


MIRANDA G.S. et al., Systematic revision of Charinidae (Arachnida, Amblypygi)

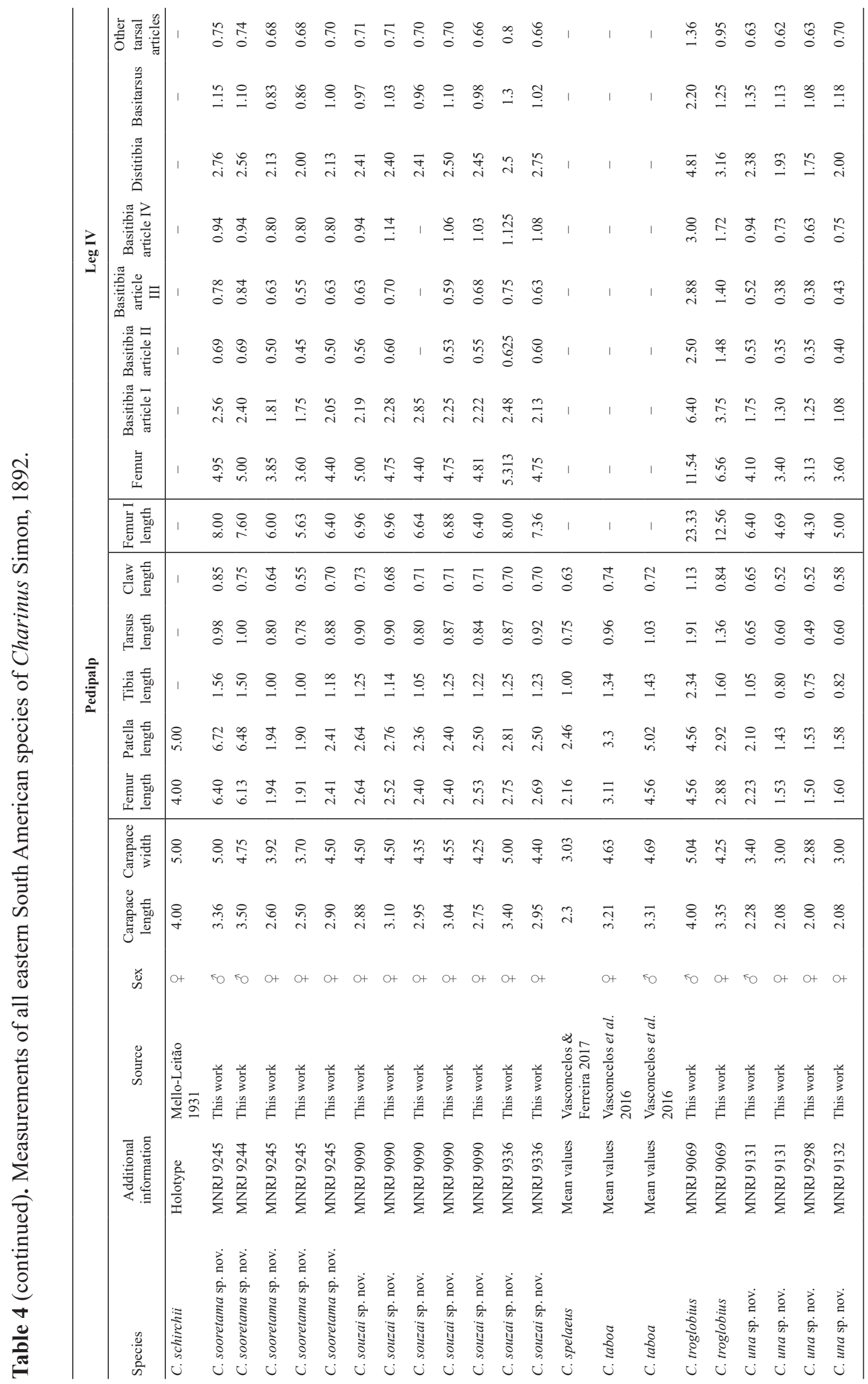


Pedipalp tarsus with two dorsal spines, proximal spine half length of distal spine (Fig. 44D). Cleaning brush with $32-36$ setae.

Legs. Tibia of leg I with 23 articles; tarsal organ situated near base of tarsal claw (Fig. 46A, C-D); rod sensilla composed of four setae in shallow groove (Fig. 46B, E); tarsus I with 41 articles. Leg IV basitibia with three pseudo-articles; trichobothrium $b t$ situated medially on article; distal apex of basitibial pseudo-articles with dark, denticulate projection; distitibia trichobothrium $b c$ situated closer to $s b f$ than to $b f ; s c$ and $s f$ series each with four trichobothria; distitarsus with distinct white annulus distally on first article.

\section{Measurements}

See Table 4.

\section{Distribution}

Known only from the type locality.

\section{Natural history}

Found under fallen tree trunks and stones in tropical forest.

Charinus apiaca sp. nov. urn:1sid:zoobank.org:act:259DB50B-0398-4321-81FD-60128AB7971D

Figs $5 \mathrm{~A}-\mathrm{B}, 43$, 47; Table 4

\section{Diagnosis}

This species may be separated from other Charinus in eastern South America by means of the following combination of characters: eight setae on anterior carapace margin (Fig. 47A); cheliceral claw with 11-14 teeth; female gonopods sucker-like, sclerotized basally, and curved posteriorly (Fig. 5A-B).

This species resembles other Charinus from the north of the state of Rio de Janeiro, but can be differentiated by its large size and the presence of an extra series of ventral spines on the pedipalp femur (Fig. 47F).

\section{Etymology}

Noun in apposition referring to Apiacá, a city near the type locality.

\section{Type material}

\section{Holotype}

BRAZIL • '; Espírito Santo, Apiacá, Fazenda Santa Maria; 2109'13.68" S, 41³3'59.04" W; 12 Aug. 2003; R.L.C. Baptista leg.; lower corridor; MNRJ 9286.

\section{Paratype}

BRAZIL - 1 juv.; same locality as for holotype; Jan. 1989; R.L.C. Baptista leg.; under rotten bark; MNRJ 9074.

\section{Description}

CARAPACE. Small granules densely scattered between ocular triads and among sulci. Median eyes well developed (Fig. 47A, C); median ocular tubercle weakly developed; pair of setae on median ocular tubercle; lateral eyes well developed, pale, seta posterior to lateral ocular triad; lateral ocular triad well separated from carapace margin; eight anterior setae; frontal process triangular. 
STERnUm. Tritosternum projected anteriorly with typical setation, long, surpassing base of pedipalp coxae (Fig. 47B); other sternal platelets narrow and concave, with pair of setae anteriorly on plaque and some smaller setae posteriorly; pentasternum with ten setae anteriorly and four setae near membranous region.

Opisthosoma. Ventral sacs and ventral sac cover absent.

GenitaLia. Female genital operculum with short setae posteromedially (Fig. 5A-B); gonopod suckerlike, markedly sclerotized basally (Fig. 5A-B); constriction present near apex, apex not broad, slightly wider than stem (Fig. 5A-B); sucker-like appendages separated from each other (Fig. 5A-B). Male unknown.

CHeLICERAE. Teeth absent on retrolateral surface of basal segment, opposite to bifid tooth; retrolateral surface of claw with discontinous row of setae, long patch basally and another medially; claw with 1114 teeth; two rows of several setae on prolateral surface of basal segment; bifid tooth on basal segment with dorsal cusp larger than ventral cusp.

Pedipalps. Coxal dorsal carina with four (dextral) or six (sinistral) prominent setae encircled by round carina and four (dextral) or three (sinistral) setae on margin. Femur with six or seven dorsal spines and six ventral spines (Fig. 47E-F); femur with one spine between dorsal spines 2 or 3; three prominent setiferous tubercles between dorsal spine 1 and proximal margin (Fig. 47E); spine between ventral spine 1 and proximal margin (Fig. 47F); spine ventral to this extra spine; spine between spines 1 and 2 and spines 2 and 3 (Fig. 47F). Patella with six dorsal spines in primary series (Fig. 47E); prominent setiferous tubercle distal to spine I, one-third length of spine I; five ventral spines (Fig. 47F); small setiferous tubercle between spine I and distal margin. Tibia with ventral spine distally and two setae between spine and distal margin. Tarsus with two (dextral) or three (sinistral) dorsal spines, two larger spines subequal, third spine situated near base of proximal spine (Fig. 47D); cleaning organ with 28-30 setae in ventral row.

LEGS. Tibia of leg I with 23 articles; tarsus I with 41 articles; first tarsal article shorter than subsequent article. Leg IV basitibia with four pseudo-articles, with sclerotized, denticulate margin at apex of articles; trichobothrium $b t$ situated in proximal third of pseudo-article; distitibia trichobothrium $b c$ situated closer to $s b f$ than to $b f, s c$ and $s f$ series each with six trichobothria.

\section{Measurements}

See Table 4.

\section{Distribution}

Known only from the type locality.

\section{Natural history}

The holotype was collected inside a cave whereas the paratype was found under rotten tree bark.

Charinus asturius Pinto-da-Rocha, Machado \& Weygoldt, 2002

Fig. 43; Table 4

Charinus asturius Pinto-da-Rocha et al., 2002: 108-110, figs 1-7, 13-14.

Charinus asturius - Baptista \& Giupponi 2003: 80. - Miranda \& Giupponi 2011: 66, fig. 13. Vasconcelos et al. 2013: 496, fig. 12. — Vasconcelos \& Ferreira 2016: 186. - Armas et al. 2016: 48. — Miranda et al. 2016c: 16, 18, 27, 29. — Segovia et al. 2018: 2-4, fig. 3; 2020: 2-6, fig. 1. 


\section{Diagnosis}

This species may be separated from other Charinus in eastern South America by means of the following combination of characters: median eyes well developed; female gonopod sucker-like, slightly sclerotized anteroventrally; male genitalia slightly sclerotized at base of fistula and lateral lobe; cheliceral claw with up to eight teeth; secondary sexual dimorphism, males larger than females, with elongation of pedipalps; pedipalp femur with five or six dorsal spines and four or five ventral spines in primary series, with small spine proximal to ventral spine 1; pedipalp patella with six or seven dorsal spines and four or five ventral spines; pedipalp tarsus with two small subequal dorsal spines, distal spine slightly longer than proximal spine; tibia of leg I with 23 articles, tarsus I with 41 articles; leg IV basitibia with four pseudo-articles; trichobothrium $b c$ situated closer to $s b f$ than to $b f, s c$ and $s f$ series each with six trichobothria.

\section{Etymology}

Adjective referring to the Príncipe de Asturias, a ship that sank near the type locality, Ilha Bela, in 1916 (Pinto-da-Rocha et al. 2002).

\section{Type material}

\section{Holotype}

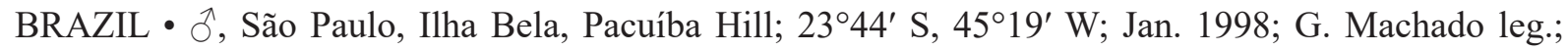
MZSP 18930.

\section{Paratypes}

BRAZIL • 1 q; same collection data as for holotype; MZSP $18930 \bullet 1$; same collection data as for

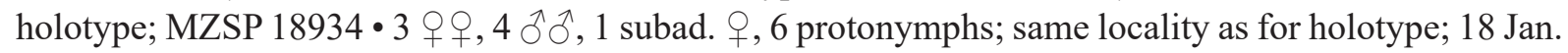
1999; R. Pinto-da-Rocha and G. Machado leg.; MZSP 16900.

\section{Measurements}

See Table 4.

\section{Distribution}

Known only from the type locality, on an island off the southeast coast of Brazil.

\section{Natural history}

For details on the natural history and morphology see Pinto-da-Rocha et al. (2002) and Segovia et al. $(2018,2020)$.

Charinus brasilianus Weygoldt, 1972

Figs $8 \mathrm{C}-\mathrm{D}, 43$, 48; Table 4

Charinus brasilianus Weygoldt, 1972b: 108-115, figs 1-11, 22a.

Charinus brasilianus - Weygoldt 1972c: 100, fig. 7a-b; 1972d: 37-40, figs 8-9, 10a-b; 1975: 311; 1996a: 187, 189-190, figs 2, 13-14, 22, 40; 1999b: 52, fig. 6; 1999c: 107, figs 8-10; 2000a: 15, 17, 75, 98, figs 6-9, 15, 152-153, 212; 2000b figs 348, 4-5; 2006a: 239-240, 245-246, fig. 13. Weygoldt et al. 1972: 209-246, figs 14d, 16b, 18c, 19. — Delle Cave 1986: 162, fig. II. — Proctor 1998: 160. — Harvey 2003: 4-5. — Baptista \& Giupponi 2003: 80. — Haupt 2009: 18, fig. 4. — Miranda \& Giupponi 2011: 66, fig. 13. - Jocqué \& Giupponi 2012: 59. — Vasconcelos et al. 2013: 495, fig. 12. — Vasconcelos \& Ferreira 2016: 185. — Miranda et al. 2016c: 19, 21, 29, 31. 


\section{Diagnosis}

This species may be separated from C. monasticus sp. nov., C. taboa, C. troglobius, and C. una sp. nov. by the presence of well-developed median and lateral eyes. It differs from $C$. diamantinus sp. nov., C. euclidesi sp. nov., C. souzai, and C. sooretama sp. nov., in the lower number of teeth on the cheliceral claw: six teeth are present in C. brasilianus whereas more than six are present in the other species.

\section{Etymology}

Although unspecified, the species name is evidently an adjective referring to Brazil, the country in which the type locality is located.

\section{Type material}

\section{Holotype}

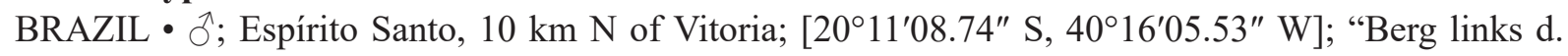
Strass u. Nova Almeida"; Weygoldt leg.; Oct. 1970; MNRJ 9014.

\section{Paratypes}

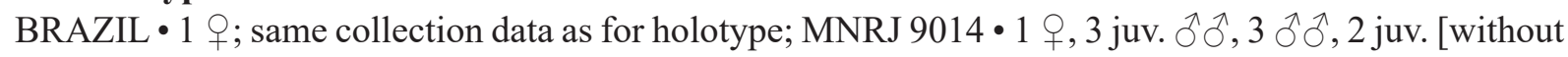
gonopod]; same collection data as for holotype; SMF 25397.

\section{Additional material}

BRAZIL • 1 †, 1 ठ̊; Espírito Santo, Santa Tereza, Nova Valssugana; May 2005; T. Souza leg., MNRJ 9271 - 1 juv. O; Espírito Santo, Santa Tereza, Reserva Santa Lúcia; 1956'10" S, 40³6’06" W; 15-19

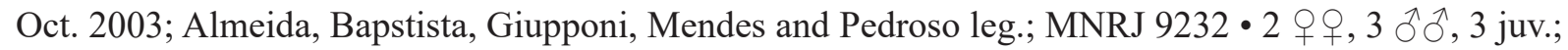
Espírito Santo, Aracruz, Parque Natural Municipal do Aricanga; $19^{\circ} 49^{\prime} 07.21^{\prime \prime} \mathrm{S}, 40^{\circ} 19^{\prime} 47.57^{\prime \prime}$ W; 17 Oct. 2005; MNRJ 9240 • 2 우, 1 juv. ô; Espírito Santo, Aracruz, Aricanga; MNRJ $9233 ・ 1$ ô; Espírito

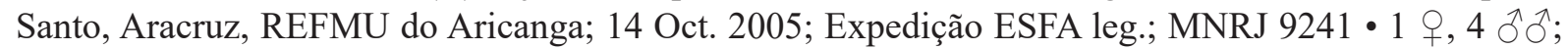
Espírito Santo, Aracruz, Parque Natural Municipal David Victor Farina; $19^{\circ} 55^{\prime} 55.67^{\prime \prime}$ S, 4007'39.22" W; 15 Oct. 2005; A. Giupponi, A. Kury, V. Orrico, M. Milleri, R. Rodrigues and T. Souza leg.; MNRJ 9226.

\section{Supplementary description}

CARAPACE. Frontal process large, triangular, not visible in dorsal view; median eyes and median ocular tubercle present (Fig. 48A-B, G); lateral eyes well developed, small seta posterior to each lateral ocular triad; lenses directed anteriorly and dorsally.

STERnum. Tritosternum projected anteriorly into large blunt tubercle; medial platelet (tetrasternum) and third platelet (pentasternum) with one convex platelet, with pair of setae anteriorly and few small setae posteriorly (Fig. 48H); metasternum with clear division in anterior half, and with anterior seta in membranous region and seta in sclerotized area, where sulcus terminates; anterior margin with small elevation bearing longitudinal row of five large setae with longitudinal series of smaller setae anterior to them.

Opisthosoma. Ventral sacs and ventral sac cover absent.

Genitalia. Female genital operculum posterior margin straight, with few setae along margin and on surface; gonopods sucker-like, with wrinkled, folded cushion basally. Male gonopods with fimbriate LoL2, separated from LoL1 (Fig. 8C-D).

Chelicerae. Prolateral surface of basal article with vertical row of three or four setae; claw with six or seven teeth. 
PEDIPALPs. Femur with four (males) or five (females) dorsal spines and two prominent setiferous tubercles proximal to spine 1 (Fig. 48C, E); four or five ventral spines with one setiferous tubercle proximal to spine 1 and small spine displaced from primary series dorsal to spine 1 (Fig. 48D, F). Patella with five dorsal spines; spine distal to spine 1, about one-third length of spine 1 (Fig. 48C, E); three or four conspicuous ventral spines, decreasing in size, with small setiferous tubercles and spines forming secondary series between primary series of spines (Fig. 48D, F). Tibia with two dorsal spines; ventral spine situated in distal half, two-thirds length of proximal dorsal spine; two setae between spine and distal margin. Tarsus with two small curved spines, distal spine one-fifth length of tarsus, and proximal spine half length of distal spine. Ventral row of cleaning brush organ with 25-29 setae.

Legs. Tibia of leg I with 23 or more articles (one specimen with 27 articles, another with 31); tarsus I with 41 or more articles (one specimen with 44 articles, another with 43); first (distal) article of tibia with two small trichobothria, second article with one, third article with two, and fourth article with one. Leg IV basitibia with four pseudo-articles, with trichobothrium situated at distal end of first half of last pseudo-article; distitibia trichobothrium $b c$ situated closer to $s b f$ than to $b f ; s c$ and $s f$ series each with five trichobothria.

\section{Measurements}

See Table 4.

\section{Distribution}

Populations of $C$. brasilianus were collected in several different municipalities, e.g., Aracruz, Aricanga, and Santa Teresa, in the vicinity of the type locality.

\section{Natural history}

This species occurs under stones and fallen tree trunks in tropical forest.

Charinus caatingae Vasconcelos \& Ferreira, 2016

Fig. 43; Table 4

Charinus caatingae Vasconcelos \& Ferreira, 2016: 187-190, figs 1-11.

Charinus caatingae - Armas et al. 2016: 48. — Miranda et al. 2016c: 29.

\section{Diagnosis}

This species may be separated from other Charinus in eastern South America by means of the following combination of characters: anterior margin of carapace slightly extended with eight prominent setae; lateral eyes reduced to an eyespot; female gonopods sucker-like, length similar to width, opening rounded, margins with small folds and pronounced bottleneck below them; cheliceral claw with 8-10 teeth; pedipalp femur with four or five dorsal spines and four or five ventral spines; pedipalp patella with five or six dorsal spines and three or four ventral spines; pedipalp tarsus with three dorsal spines; tibia of leg I with 23 articles, tarsus I with 41 articles; leg IV basitibia with four pseudo-articles; $s c$ and $s f$ series each with six trichobothria.

\section{Etymology}

Noun referring to the Caatinga biome in which the type locality is located (Vasconcelos \& Ferreira 2016). 


\section{Type material}

\section{Holotype}

BRAZIL • +; Bahia, Várzea Nova, Fazenda Jurema Cave; $11^{\circ} 03^{\prime 2} 23.51^{\prime \prime}$ S, 4105'34.47" W; 21 Jan. 2012; R.L. Ferreira leg.; ISLA 3918 [not examined].

\section{Paratypes}

BRAZIL• 4 + $q$; same locality as for holotype; 2 Jan. 2008, R.L. Ferreira leg.; ISLA 3919 to ISLA 3921, ISLA 4104 [not examined] $\bullet 2$ + $O$; same locality as for holotype; 7 Jan. 2014; R.L. Ferreira leg.; ISLA 4996 to ISLA 4997 [not examined].

\section{Measurements}

See Table 4.

\section{Distribution}

Known only from the type locality (Fig. 43).

\section{Natural history}

Fazenda Jurema Cave is relatively small (ca $100 \mathrm{~m}$ long) and belongs to the Una limestone group, located in the Caatinga biome, the only semi-arid biome in Brazil. Specimens were collected mainly in the terminal part of the cave, where the phreatic level is visible. Vasconcelos \& Ferreira (2016) noted that despite surveying other caves in the area, specimens of $C$. caatingae were only collected in the Fazenda Jurema Cave, suggesting that the species may be endemic to this cave. Potential prey includes crickets (Endecous sp.) and moths (Tineidae Latreille, 1810). The vegetation outside the cave was partially removed for corn and manioc crops; additionally, an electric pump was installed inside the cave to pump water for crop irrigation. Due to alterations of the natural environment inside and outside the cave, the species is considered to be severely threatened (Vasconcelos \& Ferreira 2016).

\section{Charinus carinae sp. nov. urn:lsid:zoobank.org:act:188D8800-BFCB-4E25-912D-3BA2106651CE \\ Figs 3A-B, 4A-B, 43, 49-51; Table 4}

\section{Diagnosis}

This species may be separated from other Charinus in eastern South America by means of the following combination of characters: large size; cheliceral claw with 13 teeth; pedipalp coxae with seven setae encircled by dorsal rounded carina; secondary series of spines on pedipalp segments present (Figs $3 \mathrm{~A}-$ B, 49E); distitibia of leg IV with $s c$ and $s f$ with six trichobothria.

The presence of seven setae encircled by the dorsal rounded carina of the coxa is otherwise observed only in C. goitaca sp. nov., from which C. carinae sp. nov. differs in the greater number of ventral spines on the pedipalp patella, i.e., six spines in $C$. carinae sp. nov. compared with three or four spines in C. goitaca sp. nov., and the greater number of cheliceral teeth, i.e., ten in C. carinae sp. nov. compared with thirteen in $C$. goitaca sp. nov.

\section{Etymology}

This species is a patronym honoring Carine C. Gonçalves Galvão for her immeasurable support to the first author during the preparation of this work. 


\section{Type material}

\section{Holotype}

BRAZIL - O; $^{\prime}$ Rio de Janeiro, Arraial do Cabo, Ilha de Cabo Frio, Trilha do Farol Velho; [22 52'53.29" S, 42॰00'17.17" W]; E.H.W. leg.; MNRJ 9293.

\section{Paratypes}

BRAZIL • 4 ô $\widehat{o}$; same collection data as for holotype; MNRJ 9199.

\section{Description}

CARAPACE. Frontal process large, subtriangular, not visible in dorsal view (Fig. 49C); median eyes and median ocular tubercle present (Fig. 49A, C); median ocular tubercle shallow, slightly higher than carapace surface, with pair of small setae (Fig. 49C); lateral eyes well developed, pale, small seta posterior to each lateral ocular triad (Fig. 49A); lenses directed anteriorly and dorsally.

STERNUM. Tritosternum projected anteriorly into blunt tubercle, surpassing base of pedipalp coxae (Fig. 49B); medial platelet (tetrasternum) and third platelet (pentasternum) with single convex platelet, with pair of large setae anteriorly, and several small setae posteriorly; metasternum with five large setae anteriorly at margin between membranous and sclerotized regions, and longitudinal row of several small setae, from anterior to posterior (Fig. 49B); four to six setae in posterior area.

OpISTHOSOMA. Ventral sacs and ventral sac cover absent.

Genitalia. Male gonopod rectangular (Fig. 50C); LoL2 fimbriate with long projections (Fig. 50B, D); LoL1 acute, with spine-like projections (Fig. 50E); LaM long and thin, surpassing lateral lobes (Fig. 50A-B); fistula with small globular projection ventrally (Fig. 50F). Female unknown.

CHELICERAE. Small tooth in retrolateral row of basal segment; prolateral surface with transverse row of around eight small setae, from ventral to dorsal surface; three setae at dorsodistal margin, prolateral, retromedial and retrolateral, near membranous region of claw; claw with thirteen teeth and row of setae on retrolateral surface from base to near apex (dorsal side).

PEDIPALPS. Coxal rounded carina enclosing two to five small setae, and with four to five setae on anterior margin. Femur with three distinct setiferous tubercles proximal to spine 1 (Figs 3A-B, 49E); primary series with five dorsal spines, with smaller spine between spines 3 and 4 , and another smaller spine between spines 4 and 5 (Figs 3A-B, 49E); five ventral spines, small spine between spines 1 and 2, two small between spines 2 or 3, and small spines between spines 3 and 4, and spines 4 and 5 (Fig. 49F); additional spine, situated prolateral to primary series, between spines 1 and 2; large spine proximal to ventral spine 1, with small spine near its base. Pedipalp patella with six dorsal spines (Figs 4A-B, 49E); large setiferous tubercle distal to spine I, about one-third length of spine I (Fig. 4A-B); six ventral spines; small spine between spines II and III; two to five setiferous tubercles between spine I and distal margin. Tibia with two dorsal spines, proximal spine two-thirds length of distal spine; ventral spine situated in distal half of tibia; three long setae between spine and distal margin. Tarsus with three dorsal spines, two distal spines subequal and one-fifth length of tarsus (Fig. 49D); proximal spine smaller, ca one-third length of other two spines, situated closer to large proximal spine and with long setae at its base; ventral row of cleaning brush with 27-29 setae.

LeGs. Tibia of leg I with 23 articles (up to 29 articles on regenerated legs), tarsus I with 41 articles (up to 49 on regenerated legs); tarsal organ situated close to base of claw (Fig. 51A-B); rod sensilla with six setae in shallow groove (Fig. 51C). Leg IV basitibia with four pseudo-articles; trichobothrium $b t$ situated in proximal third; distal apex of basitibial pseudo-articles with dark, denticulate projection; 
distitibia trichobothrium $b c$ situated closer to $s b f$ than to $b f ; s c$ and $s f$ series each with six trichobothria; distitarsus with distinct white annulus distally on first article.

\section{Measurements}

See Table 4.

\section{Distribution}

Known only from the type locality (Fig. 43).

Charinus carioca sp. nov. urn:lsid:zoobank.org:act:81F5FF9E-DACF-4B61-9893-94369C73B8F8

Figs $6 \mathrm{E}-\mathrm{F}, 43$, 52-53; Table 4

\section{Diagnosis}

This species may be separated from other Charinus in eastern South America by means of the following combination of characters: large size; short sucker-like female gonopod (Fig. 6E-F); cheliceral claw with nine teeth; pedipalp femur with five dorsal spines and five ventral spines (Fig. 52E-F); pedipalp patella with four dorsal spines and five ventral spines (Fig. 52E-F); marked secondary sexual dimorphism (Fig. 53A-B); leg IV distitibia $s c$ and $s f$ series each with six trichobothria.

Charinus carioca sp. nov. resembles C. taboa in the shape of the frontal process of the carapace, but is easily distinguished from the latter by the higher number of trichobothria in the $s c$ and $s f$ series of the leg IV distitibia, six in C. carioca sp. nov. compared with five in C. taboa.

\section{Etymology}

Noun in apposition taken from to the word 'carioca', referring to those born in Rio de Janeiro.

\section{Type material}

\section{Holotype}

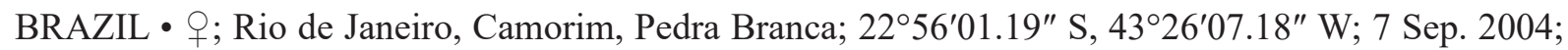
Giupponi and Pedroso leg.; MNRJ 9201.

\section{Paratypes}

BRAZIL • 2 q $\uparrow, 1$ ऽ ; same collection data as for holotype; MNRJ 9201.

\section{Description}

CARAPACE. Six anterior setae; frontal process triangular, with small apical projection (Fig. 52C). Small granules densely scattered between lateral eyes and among sulci. Median eyes well developed (Fig. 52A, C); median ocular tubercle weakly developed; pair of setae on median ocular tubercle; lateral eyes well developed, seta posterior to lateral ocular triad; lateral ocular triad well separated from carapace margin.

STERnUm. Tritosternum projected anteriorly with typical setation, long, surpassing base of pedipalp coxae (Fig. 52B); other sternal platelets narrow and concave, with pair of setae anteriorly on plaque and some smaller setae posteriorly; pentasternum with fourteen setae anteriorly and four setae near membranous region.

Opisthosoma. Ventral sacs and ventral sac cover absent. 
GENITALIA. Female genital operculum with prominent setae posteromedially and some smaller setae near margin (Fig. 6E-F); gonopod sucker-like and slightly sclerotized basally (Fig. 6E-F); tubular projection without constriction (Fig. 6E-F).

CHELICERAE. Small flat tooth on retrolateral surface of basal segment, opposite to bifid tooth; retrolateral surface of cheliceral claw with continous row of setae, basally to medially; claw with nine teeth; row of eleven setae on prolateral surface of basal segment; bifid tooth on basal segment with dorsal cusp larger than ventral cusp.

PEDIPALPS. Coxal dorsal carina with two setae encircled by round carina and four setae on margin. Femur with five dorsal spines and five ventral spines (Fig. 52E-F); spine between dorsal spine 2 and 3 and spine 3 and 4; three prominent setiferous tubercles between dorsal spine 1 and proximal margin; spine between ventral spine 1 and proximal margin; spine between ventral spines 1 and 2, 2 or 3 and 3 and 4. Patella with four dorsal spines in primary series (Fig. 52E-F); prominent setiferous tubercle distal to spine I, one-third length of spine I; patella with five ventral spines; spine between spines 2 or 3 and 3 and 4; prominent setiferous tubercle between spine I and distal margin. Tibia with ventral spine distally and two setae between spine and distal margin. Tarsus with three dorsal spines, distal spine subequal to proximal spine (Fig. 52D); third spine situated proximally, near base of proximal spine; cleaning organ with $27-28$ setae in ventral row.

LeGs. Tibia of leg I with 23 articles, tarsus I with 41 articles; first tarsal article shorter than second article. Leg IV basitibia with four pseudo-articles, with sclerotized, denticulate margin projecting from apex of articles; trichobothrium $b t$ situated near midline of pseudo-article; distitibia trichobothrium $b c$ situated closer to $s b f$ than to $b f, s c$ and $s f$ series each with six trichobothria.

\title{
Measurements
}

See Table 4.

\section{Distribution}

Known only from the type locality.

\section{Natural history}

Specimens were found in the photic zone of a gneiss cave, near a small river. Specimens were only observed at night, on the roof and in crevices in the roof, of the cave.

\author{
Charinus cearensis sp. nov. \\ urn:1sid:zoobank.org:act:1041FC16-D0B0-4CDF-BC9E-AC5B2AA993C9
}

Figs 43, 54-56; Table 4

\section{Diagnosis}

This species may be separated from other Charinus in eastern South America by means of the following combination of characters: carapace with carina ventral to lateral eyes; cheliceral claw with nine teeth; leg IV basitibia with four articles.

This species resembles C. potiguar, but can be differentiated by the smaller number of cheliceral teeth, with nine teeth in C. cearensis sp. nov. compared with thirteen teeth in C. potiguar, and greater number of spines on the pedipalp patella in $C$. cearensis sp. nov.

\section{Etymology}

Adjective refering to Ceará, the Brazilian state in which the type locality is located. 


\section{Type material}

\section{Holotype}

BRAZIL • + ; Ceará, Ubajara, Parque Nacional de Ubajara, Gruta de Ubajara; [0350' S, 40 $53^{\prime} 59^{\prime \prime}$ W]; Jul. 1979; Ricardo leg.; IBSP 67.

\section{Paratypes}

BRAZIL • 1 क; same locality as for holotype; 0349'57.2" S, 4053'59.4" W; 29-28 Jul. 2013; L.S. Carvalho and D.N. Lima leg.; cave's drainage flue; CHNUFPI 1255, AMCC [LP 13401] • 1 O ; same collection data as for preceding; CHNUFPI $1252 \bullet 1$; ; same collection data as for preceding; CHNUFPI $1254 \bullet 1$ \&; same collection data as for preceding; CHNUFPI $1253 \bullet 1$; ; same collection data as for preceding; CHNUFPI 1251・1 $\hat{\text {; }}$; same collection data as for preceding; CHNUFPI $1250 \bullet 1$; ; same collection data as for preceding; CHNUFPI 1256.

\section{Description}

CARAPACE. Six anterior setae (Fig. 54A); frontal process triangular, visible in dorsal view (Fig. 54C). Small granules densely scattered between ocular triads and among sulci; lateral margin, ventral to lateral eyes, with small carina. Median eyes well developed (Fig. 54C); median ocular tubercle shallow, with pair of setae; lateral eyes well developed, seta posterior to lateral ocular triad; lateral ocular triad well separated from carapace margin.

STERnUm. Tritosternum projected anteriorly with typical setation, long, surpassing base of pedipalp coxae (Fig. 54B); other sternal platelets narrow and concave, with pair of setae anteriorly on plaque and some smaller setae posteriorly; pentasternum with four setae anteriorly and two setae near membranous region.

OpISTHOSOMA. Ventral sacs and ventral sac cover absent.

GENITALIA. Female genital operculum with prominent setae posteromedially and some smaller setae near margin (Fig. 55A-C); gonopod sucker-like, unsclerotized basally (Fig. 55A, C, F); tubular from base to apex, with broad aperture (Fig. 55A, F); genital operculum with smooth surface between gonopod and distal margin (Fig. 55D); sensilla on lateral margin of genital operculum (Fig. 55E). Male unknown.

CheliCerae. Small tooth projecting from retrolateral surface of basal segment, opposite to bifid tooth; retrolateral surface of claw with continuous row of setae, basally to medially; claw with nine teeth; row of setae on prolateral surface of basal segment with eight setae in one row; bifid tooth on basal segment with dorsal cusp larger than ventral cusp.

PeDIPALPS. Coxal dorsal carina with four prominent setae encircled by round carina and five setae on margin (Fig. 54A). Femur with five dorsal spines and four or five ventral spines (Fig. 54E-F); spine between dorsal spines 2 or 3; two prominent setiferous tubercles between dorsal spine 1 and proximal margin; spine between ventral spine 1 and proximal margin; small spine ventral to extra spine proximal to ventral spine 1, near articulation between femur and trochanter. Patella with five dorsal spines in primary series (Fig. 54E); prominent setiferous tubercle distal to spine I, one-third length of spine I; four ventral spines (Fig. 54F); prominent setiferous tubercle between spine I and distal margin. Tibia with ventral spine distally and five setae between spine and distal margin. Tarsus with two dorsal spines, proximal spine one-third length of distal spine (Fig. 54D); cleaning organ with 25-28 setae in ventral row.

Legs. Tibia of leg I with 23 articles, tarsus I with 41 articles; first tarsal article shorter than second article; rod sensilla with five setae in shallow groove; tarsal organ situated close to base of tarsal claw (Fig. 56A, C). Leg IV basitibia with four pseudo-articles, with sclerotized, denticulate margin projecting 
from apex of articles; trichobothrium $b t$ situated medially on pseudo-article; distitibia trichobothrium $b c$ closer to $s b f$ than to $b f, s c$ and $s f$ series each with six trichobothria.

\section{Measurements}

See Table 4.

\section{Distribution}

Known only from the type locality.

\section{Natural history}

According to L.S. Carvalho (pers. com.), C. cearensis sp. nov. is uncommon and only found near drainage flues in the dark zone of the cave (Gruta de Ubajara). Searches of nearby caves, such as Gruta do Morcego Branco, ca $50 \mathrm{~m}$ from the type locality, as well as outside the caves, were unsuccessful in finding additional specimens, suggesting the species is restricted to Gruta de Ubajara. A schizomid, Rowlandius ubajara Santos, Ferreira \& Buzatto, 2013, is also endemic to the cave.

\section{Remarks}

The holotype possesses an extra spine between dorsal spines 3 and 4 on the femur of the sinistral pedipalp. The holotype possesses four ventral spines on the pedipalp femur whereas the paratype possesses five ventral spines, the last spine appearing to be a duplication of the previous spine, as both spines are similar in length and color. The basitibia of leg IV consists of three pseudo-articles on one leg and two pseudo-articles on the other, in the holotype, whereas the basitibia consists of four pseudoarticles on both legs of the paratype.

\section{Charinus diamantinus sp. nov.}

urn:lsid:zoobank.org:act:1AB27030-B5CC-4EA6-A499-E552B3981C38

Figs 43, 57-60; Table 4

\section{Diagnosis}

This species may be separated from other Charinus in eastern South America by means of the following combination of characters: large size; small carina ventral to lateral eyes; cheliceral claw with 8-10 teeth; pedipalp tarsus with two or three dorsal spines (Fig. 57D); secondary sexual dimorphism present (Fig. 58A-B); leg IV basitibia with four pseudo-articles.

This species resembles $C$. euclidesi sp. nov., from which it may be differentiated by the smaller number of spines on the pedipalp femur and patella.

\section{Etymology}

Adjective referring to the Diamantina Plateau, a geological formation in the Brazilian state of Bahia, where the type locality is located.

\section{Type material}

\section{Holotype}

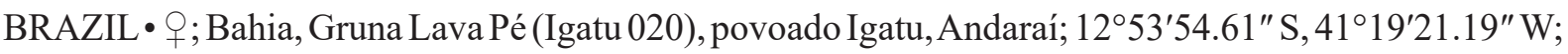
10 Mar. 2012; MNRJ. 


\section{Paratypes}

BRAZIL • 1 क; Bahia, Andaraí; Giupponi and Baptista leg.; MNRJ $9299 \bullet 1$ O̊; Gruna Lava Pé (Igatu 020), povoado Igatu, Andaraí; A.P.L. Giupponi, G.S. Miranda, M.E. Bichuette and J.E. Gallão. leg.; MNRJ $9189 \bullet 1$ ô, 1 juv.; Bahia, Povoado Igatu, Andaraí, Gruna Parede Vermelha (Igatu 010); 11 Mar. 2012; A.P.L. Giupponi, G.S. Miranda, M.E. Bichuette and J.E. Gallão leg.; MNRJ 9190 • 1 §’; Bahia, Gruta do Lapão, Lençóis; 9 Mar. 2012; MNRJ 9288 • 1 ex. [without gonopod], 1 juv.; Bahia, Igatu; MNRJ $9203 \cdot 2$ đ̊ ô; Bahia, Igatu; MNRJ 9300.

\section{Description}

CARAPACE. Weak carina ventral to lateral eyes, closer to carapace margin than to lateral eyes; frontal process large, subtriangular, not visible in dorsal view (Fig. 57C). Median eyes and median ocular tubercle present (Fig. 57C); median ocular tubercle shallow, slightly higher than carapace surface, with pair of small setae. Lateral eyes well developed, pale, small seta posterior to each lateral ocular triad (Fig. 57A).

STERnUm. Tritosternum projected anteriorly into small, blunt tubercle, barely surpassing base of pedipalp coxae (Fig. 57B); medial platelet (tetrasternum) and third platelet (pentasternum) forming single convex platelet, with pair of large setae anteriorly, and several small setae posteriorly; metasternum with anterior seta in membranous region; two or three setae forming longitudinal row posteriorly.

OpISTHOSOMA. Ventral sacs and ventral sac cover absent.

GenitaLia. Female genital operculum slightly convex, with several setae along margin and on surface; base of sucker-like gonopods sclerotized; small claws projecting from distal border. Male gonopod with thin sclerotized region in distal border of fistula and at base of lateral lobes; LoL2 fimbriate (Fig. 59AB); LaM elongated, reaching LoD (Fig. 59A-B); LoD covered with denticulate projections (Fig. 59C).

CHELICERAE. Small tooth in retrolateral row of basal segment; prolateral surface with transverse row of ca ten small setae, from dorsal to ventral; three setae, retrolateral, retromedial, and prolateral, on dorsodistal margin, near membranous region of claw; claw with 8-10 teeth and row of setae on retrolateral surface from base to near apex (dorsal side).

PedipalPs. Coxal dorsal carina with five or six small setae and three or four setae on anterior margin. Femur with three distinct setiferous tubercles proximal to spine 1 (Fig. 57E); primary series with four dorsal spines and smaller spine between spines 1 and 2, and (in some specimens) between spines 2 or 3 (Fig. 57E); small spine, similar in size to spine 4 (suggesting a duplication) may also be present between spines 3 and 4 (present on sinistral pedipalp of adult female (MNRJ 9299), two adult males (MNRJ 9190 and MNRJ 9300), juvenile (MNRJ 9288), and, as smaller spine, on both pedipalps of adult male (MNRJ 9189; Fig. 57E); four ventral spines, with small spine between spines 1 and 2 and between spines 2 or 3 (Fig. 57F); spine parallel to ventral spine 1, near base; large ventral spine proximal to spine 1. Patella with three dorsal spines (Fig. 57E); large setiferous tubercle distal to spine I, about one-third length of spine I; three ventral spines decreasing in size (Fig. 57F); two or three setiferous tubercles between spine I and distal margin. Tibia with two dorsal spines, proximal spine two-thirds length of distal spine; two or three ventral spines, longest spine in distal half and other(s) medially on tibia. Tarsus with three dorsal spines (also present in juveniles) (Fig. 57D); ventral row of cleaning brush with 24-27 setae.

LEGs. Tibia of leg I with 23 articles (up to 36 on regenerated legs), tarsus I with 41 articles (up to 57 on regenerated legs); leg apex with small modified claw, emerging from common base, with sensilla ventral to it (Fig. 60A-B); lateral claws smaller than medial claw (Fig. 60A-C); rod sensilla with six setae in shallow groove (Fig. 60D). Leg IV basitibia with four pseudo-articles; trichobothrium $b t$ situated in 
proximal third; distal apex of pseudo-articles with dark, denticulate projection; distitibia trichobothrium $b c$ situated closer to $s b f$ than to $b f ; s c$ and $s f$ series each with five trichobothria; distitarsus with marked white annulus distally on first article.

\section{Measurements}

See Table 4.

\section{Distribution}

Occurs in several caves in the Diamantina Plateau, in the Brazilian state of Bahia.

\section{Natural history}

Known only from caves. This is a large species with secondary sexual dimorphism, i.e., the pedipalps are larger in males than females.

Charinus eleonorae Baptista \& Giupponi, 2003

Fig. 43; Table 4

Charinus eleonorae Baptista \& Giupponi, 2003: 80-84, figs 1-14.

Charinus eleonorae - Trajano \& Bichuette 2010: 12. - Miranda \& Giupponi 2011: 66, fig. 13. Vasconcelos et al. 2013: 496, fig. 12. — Torres-Contreras et al. 2015: 148. — Monte et al. 2015: 6, figs 1, 4. — Vasconcelos \& Ferreira 2016: 185. — Miranda et al. 2016c: 19, 29.

\section{Diagnosis}

This species may be separated from other Charinus in eastern South America by means of the following combination of characters: anterior margin of carapace with corners weakly developed into small roundish knobs; median ocular tubercle indistinct; lateral eyes present, but reduced, with flattened lenses; female gonopods small, slightly longer than wide, sucker-like, with rounded opening; cheliceral claw with nine or twelve teeth; pedipalp femur with three dorsal spines and three ventral spines; pedipalp patella with four dorsal spines and three ventral spines; pedipalp tarsus with two long spines similar in length; tibia of leg I with 23 articles, tarsus I with 40 or 41 articles; leg IV basitibia with four pseudo-articles.

\section{Etymology}

Patronym honoring Dr Eleonora Trajano (Baptista \& Giupponi 2003).

\section{Type material}

\section{Holotype}

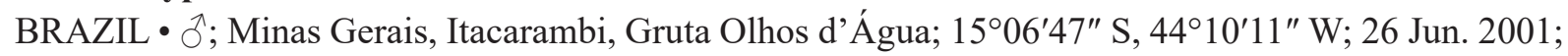
R.L.C. Baptista and A.P.L. Giupponi leg.; MNRJ 9070.

\section{Paratypes}

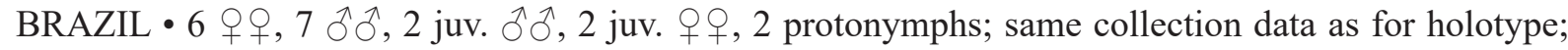
MNRJ $9033 \bullet 1$ ते; same collection data as for holotype; MZSP [not examined] $\bullet 1 \hat{\jmath}$, same collection data as for holotype; CZACC [now IES; L.F. de Armas, pers. com.; not examined] 1 \&; same locality as holotype; 10 Jul. 1993; E. Trajano leg.; MNRJ 9024 1 \&, 1 juv.; same locality as for holotype; 30 Mar.-2 Apr. 1994; P. Gnaspini and E. Trajano leg.; MNRJ 9023. 


\section{Supplementary description}

CARAPACE. Ten anterior setae; frontal process triangular, not visible in dorsal view. Small granules densely scattered between ocular triads and among sulci. Median eyes reduced, median ocular tubercle absent; seta near remnants of median eyes; lateral eyes reduced, pale, seta posterior to lateral ocular triad.

SteRnum. Tritosternum projected anteriorly, with typical setation; other sternal platelets narrow, concave, with pair of setae anteriorly and some smaller setae posteriorly; pentasternum with twelve setae anteriorly and three setae near membranous region.

Opisthosoma. Ventral sacs and ventral sac cover absent.

GeNITALIA. Female genital operculum with prominent setae posteromedially and some smaller setae near margin; posterior margin of genital operculum with pair of shallow lateral sulci; gonopod sucker-like, with short stem and wide opening of genital atrium; gonopods unsclerotized basally. Male gonopod with base of fistula and lateral lobe sclerotized; lateral lobe 2 fimbriate.

CheliCERAE. Small tooth projecting slightly from retrolateral surface of basal segment, opposite to bifid tooth; retrolateral surface of claw with two patches of setae, one situated basally, the other medially; claw with 9-12 teeth; transverse row of around ten setae on prolateral surface of basal segment; bifid tooth on basal segment with dorsal cusp larger than ventral cusp.

PEDIPALPS. Coxal dorsal carina with three prominent setae encircled by round carina and three setae on margin. Femur with three dorsal spines and four ventral spines; small spine between dorsal spines 2 and 3; two prominent setiferous tubercles between dorsal spine 1 and proximal margin; long spine between ventral spine 1 and proximal margin; small spine between spines 1 and 2 and 2 and 3. Patella with three dorsal spines in primary series; prominent setiferous tubercle distal to spine I, one-third length of spine I; three ventral spines in primary series; long spine between spine I and distal margin. Tibia with ventral spine distally and five setae between spine and distal margin. Tarsus with two dorsal spines, proximal spine half length of distal spine; cleaning organ with 29-30 setae in ventral row.

LeGs. Tibia of leg I with 23 articles; tarsus I with 41 articles; first tarsal article shorter than subsequent articles. Leg IV basitibia with four pseudo-articles, without sclerotized, denticulate border at apex of articles; trichobothrium $b t$ situated in proximal third of pseudo-article; distitibia trichobothrium $b c$ situated closer to $s b f$ than to $b f, s c$ and $s f$ series each with six trichobothria.

\section{Measurements}

See Table 4.

\section{Distribution}

Known only from the type localities.

\section{Natural history}

All specimens were collected in the dark zone of the cave; none were found in the dry, upper galleries, where the phrynichid, Trichodamon princeps Mello-Leitão, 1935, was abundant. Charinus eleonorae may be found inside small galleries or holes in the cave walls. Females carry up to 15 eggs and five embryos (Baptista \& Giupponi 2003). The cave is experiencing intense human disturbance including the installation of a water pump and construction of a water dam (L.S. Carvalho, pers. com.). 


\section{Charinus euclidesi sp. nov. urn:lsid:zoobank.org:act:CFBC1532-31B7-4BAF-B313-28D02A28179E \\ Figs $6 \mathrm{C}-\mathrm{D}, 9 \mathrm{~A}-\mathrm{B}, 43,61-63$; Table 4}

\section{Diagnosis}

This species may be separated from other Charinus in eastern South America by means of the following combination of characters: cheliceral claw with nine teeth; males with sexually dimorphic pedipalps (Fig. 61A-D); pedipalp coxae with three long setae on margin, and distinct seta encircled by round carina; pedipalp femur with five dorsal spines and five ventral spines (Fig. 61A-B); pedipalp tibia with distinct setiferous tubercle proximally and ventral spine distally; pedipalp tarsus with three dorsal spines (Fig. 61C-D); leg IV distitibia $s c$ and $s f$ series each with six trichobothria.

This species resembles $C$. diamantinus sp. nov., but bears more spines on the pedipalp femur and patella.

\section{Etymology}

Patronym honoring Euclides da Cunha, one of the foremost Brazilian writers, born in the region in which this species was collected.

\section{Type material}

\section{Holotype}

BRAZIL • đ̃; Rio de Janeiro, Cantagalo, Gruta da Pedra Santa, Fazenda da Mineiração Mauá (Euclidelândia); $21^{\circ} 56^{\prime} 16^{\prime \prime}$ S, 42 $15^{\prime} 16^{\prime \prime}$ W; 13 Nov. 2005; M.S. Silva and R.L. Ferreira leg.; MNRJ 9099.

\section{Paratypes}

BRAZIL • 2 q $q$; same collection data as for holotype; MNRJ 9099.

\section{Description}

CARAPACE. Frontal process large, triangular, acute, not visible in dorsal view (Fig. 61F); median eyes large (Fig. 61F); median ocular tubercle shallow, with pair of setae, posterior to eyes; lateral eyes poorly pigmented, but with tapetum (Fig. 61A); small seta posterior to lateral ocular triad.

STERnUm. Tritosternum projected anteriorly into long tubercle (Fig. 61E); median and third platelet rounded, convex, with two setae medially and few small setae posteriorly; metasternum with several small setae anteriorly and three long setae posteriorly.

Opisthosoma. Ventral sacs and ventral sac cover absent.

Genitalia. Female gonopod sucker-like, with apex of gonopods converging (Fig. 6C-D); posterior margin of genital operculum straight, with few setae along margin and on surface (Fig. 6C-D). Male gonopod with LoL2 long and fimbriate (Fig. 9A-B); LoD projecting posteriorly and acuminate apically (Fig. 9A-B).

Chelicerae. Small retrolateral tooth on basal segment. Prolateral surface of basal segment with vertical row of seven setae. Claw with nine small teeth; retrolateral surface of claw with row of setae from base to mid-apex.

PeDIPALPS. Coxal dorsal carina with one or two small setae and four or five setae on anterior margin of round carina. Femur with three distinct setiferous tubercles proximal to spine 1 (Fig. 62A-B); primary series with five dorsal spines and small spine between spines 3 and 4 (Fig. 62A-B); five ventral spines 
and small spine between spines 1 and 2, two small spines between spines 2 and 3, and small spine between spines 3 and 4 and 4 and 5 (Fig. 62C-D); large ventral spine proximal to spine 1 (Fig. 62C-D). Patella with five dorsal spines and small spine between spines 4 and 5 (Fig. 62A-B); large setiferous tubercle distal to spine I, about one-third length of spine I; five ventral spines (Fig. 62C-D). Tibia with two dorsal spines, basal spine two-thirds length of distal spine; ventral spine situated in distal half of tibia, with row of two setiferous tubercles near base of spine; three long setae between spine and distal margin. Tarsus with three dorsal spines, two distal spines subequal and one-fifth length of tarsus; proximal spine smaller, ca one-third length of other two spines, situated near large proximal spine, and with long seta at base (Fig. 61C-D); ventral row of cleaning brush with 27 setae.

LEGS. Tibia of leg I with 23 articles; tarsus I with 41 articles; tarsal organ situated close to base of tarsal claw (Fig. 63C, E); rod sensilla formed by six setae in shallow groove (Fig. 63A-B); slit sensilla situated opposite to tarsal claw (Fig. 63D). Leg IV basitibia with four pseudo-articles; trichobothrium $b t$ situated in proximal third; distal apex of basitibial pseudo-articles with dark, denticulate projection; distitibia trichobothrium $b c$ situated closer to $s b f$ than to $b f ; s c$ and $s f$ series each with six trichobothria; distitarsus with distinct white annulus distally on first article.

\section{Measurements}

See Table 4.

\section{Distribution}

Known only from the type locality.

\section{Natural history}

The known specimens were collected exclusively inside caves.

Charinus goitaca sp. nov. urn:lsid:zoobank.org:act:0DE688BA-BA0C-4280-B9C8-CF1EA02E5353

Figs 43, 64-65; Table 4

\section{Diagnosis}

This species may be separated from other Charinus in eastern South America by means of the following combination of characters: large size; cheliceral claw with ten teeth; pedipalp coxa with seven setae encircled by rounded carina; pedipalp femur with six dorsal spines and five ventral spines (Fig. 64E-F); pedipalp patella with six dorsal spines and three or four ventral spines (Fig. 64E-F); pedipalp tarsus with three dorsal spines (Fig. 64D).

Charinus goitaca sp. nov. resembles C. ruschii, but is darker with a proportionally broader carapace.

\section{Etymology}

Noun in apposition referring to the Goitacá indigenous tribe, who used to live in the area prior to extermination by European colonists.

\section{Type material}

\section{Holotype}

BRAZIL - đ; Espírito Santo, Vitória, house close to Fonte Grande State Park (Parque Estadual da Fonte Grande); 20¹7'17.3" S, 40²0'12.53" W; MNRJ 9224. 
Paratypes

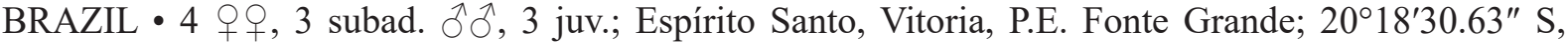
40²0'28.77" W; 12 Jan. 2018; G.S. Miranda and D.R. Pedroso leg.; MNRJ 9360.

\section{Description}

CARAPACE. Six anterior setae; frontal process triangular (Fig. 64C). Small granules densely scattered between lateral eyes and among sulci. Median eyes well developed (Fig. 64C); median ocular tubercle reduced, with pair of setae; lateral eyes well developed, with seta posterior to lateral ocular triad; lateral ocular triad well separated from carapace margin (Fig. 64A).

STERnUm. Tritosternum projected anteriorly with typical setation, long, surpassing base of pedipalp coxae (Fig. 64B); other sternal platelets narrow and concave, with pair of setae anteriorly on plaque and few smaller setae posteriorly; pentasternum with ten setae anteriorly and six setae (three pairs) near membranous region.

OpISTHOSOMA. Ventral sacs and ventral sac cover absent.

GENITALIA. Female genital operculum with prominent setae posteromedially and some smaller setae near margin; gonopod sucker-like and markedly sclerotized basally; constricted near apex, giving appearence of bottleneck (Fig. 65A-D). Male gonopod with apical margin of fistula and lateral lobe sclerotized; lateral lobes fimbriate.

ChELICERAE. Small, flat tooth on retrolateral surface of basal segment, opposite to bifid tooth; retrolateral surface of claw with continous row of setae, basally to medially; claw with ten teeth; three rows of 32 setae on prolateral surface of basal segment; bifid tooth on basal segment with dorsal cusp larger than ventral cusp.

PeDiPALPS. Coxal dorsal carina with seven prominent setae encircled by round carina and four setae on margin. Femur with six dorsal spines and five ventral spines (Fig. 64E-F); one dorsal spine between spines 2 and 3; two prominent setiferous tubercles between dorsal spine 1 and proximal margin; spine between ventral spine 1 and proximal margin; spine between ventral spines 1 and 2 and spines 3 and 4 . Patella with six dorsal spines in primary series (Fig. 64E); prominent setiferous tubercle distal to spine I, one-third length of spine I; three or four ventral spines (Fig. 64F); prominent setiferous tubercle between spine I and distal margin. Tibia with ventral spine distally and three setae between spine and distal margin. Tarsus with three dorsal spines, larger spines aligned (Fig. 64D); spine 3 near base of spine 1; of larger spines, spine 1 two thirds length of spine 2; cleaning organ with 28-31 setae in ventral row.

LEGS. Tibia of leg I with 23 articles; tarsus I with 41 articles; first tarsal article about same length as subsequent article. Leg IV basitibia with four pseudo-articles, with sclerotized, denticulate margin at apex of articles; trichobothrium $b t$ situated submedially on pseudo-article; distitibia trichobothrium $b c$ situated closer to $s b f$ than to $b f, s c$ and $s f$ series each with six trichobothria.

\section{Measurements}

See Table 4.

\section{Distribution}

Known only from the type localities.

\section{Natural history}

Found under stones and tree bark in forested areas. 


\section{Remarks}

As indicated by the measurements (Table 4), the holotype is much larger than the paratypes; the male paratype, despite being smaller, exhibits almost the same number of spines on the pedipalp as the holotype, the only difference being five instead of six dorsal spines on the femur, and fewer teeth on the cheliceral claw (eight instead of ten); the male paratype is probably subadult. The paratype females exhibit more differences in the count of spines on the pedipalp, which might be due to their early stage of development. Both males possess three dorsal spines on the pedipalp tarsus.

Charinus imperialis sp. nov.

urn:1sid:zoobank.org:act:224F52CC-D92D-4D13-83A7-BC409080E3A1

Figs 43, 66-68; Table 4

\section{Diagnosis}

This species may be separated from other Charinus in eastern South America by means of the following combination of characters: cheliceral claw with 11 teeth; pedipalp femur with four dorsal spines and four ventral spines, and small spine between dorsal spines 2 and 3 and spines 3 and 4 (Fig. 66E-F); pedipalp patella with four dorsal spines and three ventral spines (Fig. 66E-F); pedipalp tarsus with two dorsal spines (Fig. 66D); leg IV distitibia $s c$ and $s f$ series each with six trichobothria.

The male is unknown. This species resembles $C$. puri sp. nov., but possesses less spines on the pedipalp.

\section{Etymology}

The species name refers to the type locality, the National Museum and former house of Brazil's Emperor in the $19^{\text {th }}$ century.

\section{Type material}

\section{Holotype}

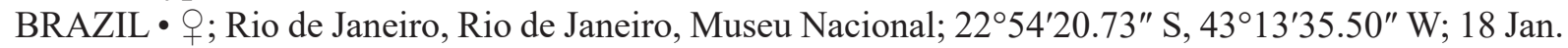
2018; G.S. Miranda, A.P.L. Giupponi, and D.R. Pedroso leg.; MNRJ 9358.

\section{Paratypes}

BRAZIL • 2 우; same collection data as for holotype; CAVAISC 1 1 ; same collection data as for holotype; 2003; A.P.L. Gupponi and R. Baptista leg.; MNRJ $9296 \bullet 1$ juv.; Museu Nacional, Carcinology Lab; MNRJ 9276 1 क; same collection data as for holotype; Oct. 2001; S.M. Ribeiro leg.; MNRJ 9032.

Additional material (examined)

BRAZIL・ 1 क; same locality as holotype; Jul. 2007; A. Kury leg.; MNRJ 9088.

\section{Description}

CARAPACE. Frontal process large, subtriangular, not visible in dorsal view (Fig. 66C). Median eyes and median ocular tubercle present (Fig. 66C); median ocular tubercle shallow, slightly higher than carapace surface, with pair of small setae. Lateral eyes well developed, pale, small seta posterior to each lateral ocular triad.

STERnUm. Tritosternum projected anteriorly into large, blunt tubercle, surpassing base of pedipalp coxae (Fig. 66B). Medial platelet (tetrasternum) and third platelet (pentasternum) forming single convex platelet, with pair of large setae anteriorly, and several small setae posteriorly. Metasternum with two anterior setae in membranous region and longitudinal row of three setae, from anterior to posterior; four setae posteriorly. 
OpISTHOSOMA. Ventral sacs and ventral sac cover absent.

Genitalia. Female gonopod with posterior margin of genital operculum slightly convex, several setae along margin and on surface (Fig. 67A-C); gonopods with small sclerotized area basally (disconnected); gonopods sucker-like with large opening (Fig. 67A, C-D); inner membranous region with gland openings (Fig. 67E); slit sense organ on lateral margin of genital operculum (Fig. 67F). Male unknown.

Chelicerae. Small, flat tooth in retrolateral row of basal segment. Prolateral surface with transverse row of more than ten small setae, from ventral to dorsal. Three setae, retrolateral, retromedial, and prolateral, on dorsodistal margin, near membranous region of claw. Claw with eleven teeth; row of setae on retrolateral surface from base to near apex (dorsal side).

PedipALPS. Coxal dorsal carina with four small setae and five setae on anterior margin of round carina. Femur with four distinct setiferous tubercles proximal to spine 1 (Fig. 66E); primary series with four dorsal spines, smaller spine between spines 2 and 3, and spines 3 and 4 (Fig. 66E); four ventral spines, small spine between spines 1 and 2, 2 and 3, and 3 and 4, the last (distal) spine half length of spine 4 (Fig. 66F); row of three small spines prolateral to ventral spines, first (proximal) spine near base of spine 1, second spine near base of spine 2, third spine near base of spine between spines 2 and 3; large ventral spine proximal to spine 1; small spine between this spine and articulation between trochanter and femur. Patella with four dorsal spines (Fig. 66E); three ventral spines decreasing in length; two or three setiferous tubercles between spine I and distal margin. Tibia with two dorsal spines, proximal spine two-thirds length of distal spine; ventral spine in distal half of tibia; prominent setiferous tubercle near its base; four long setae between spine and distal margin. Tarsus with two dorsal spines, proximal spine half length of distal spine (Fig. 66D); ventral row of cleaning brush with 25-27 setae.

Legs. Tibia of leg I with 23 articles; tarsus I with 41 articles; tarsal organ near base of claw, with three apical projections (Fig. 68A-B, D); rod sensilla with seven setae in shallow groove (69A, C); two slit sensilla near tarsal claw (Fig. 68E-F). Leg apex with small modified claw, emerging from common base, with sensilla situated ventral to it. Lateral claws smaller than medial claw. Leg IV basitibia with four pseudo-articles; trichobothrium $b t$ situated in proximal third; distal apex of basitibial pseudo-articles with dark, denticulate projection; distitibia trichobothrium $b c$ situated closer to $s b f$ than to $b f ; s c$ and $s f$ series each with six trichobothria; distitarsus with distinct white annulus distally on first article.

\section{Measurements}

See Table 4.

\section{Distribution}

Known only from the type locality.

\section{Natural history}

Occurs underneath the National Museum of Rio de Janeiro. It is unknown whether the population survived the devastating fire of 2 September 2018.

Charinus іиіи Vasconcelos \& Ferreira, 2016

Fig. 43; Table 4

Charinus іиіu Vasconcelos \& Ferreira, 2016: 190-196, figs 12-26.

Charinus iuiu - Miranda et al. 2016c: 29. 


\section{Diagnosis}

This species may be separated from other Charinus in eastern South America by means of the following combination of characters: anterior margin of carapace with six prominent, elongated setae; female gonopods sucker-like, length greater than width, opening rounded, each with posterior slit dorsally, margins with fold and small bottleneck below; male gonopods with several long lobes (LoL2 and LoL1) emerging from fistula (Fi); cheliceral claw with ten denticles; pedipalp femur with three or four dorsal spines and four or five ventral spines; pedipalp patella with five or six dorsal spines and three ventral spines; tibia of leg I with 23 articles, tarsus I with 41 articles; leg IV basitibia with four pseudo-articles; distitibia $s c$ and $s f$ series each with six trichobothria.

\section{Etymology}

Noun in apposition referring to the Iuiu Municipality, in which the type locality is situated (Vasconcelos \& Ferreira 2016).

\section{Type material}

\section{Holotype}

BRAZIL • O; Bahia, Iuiu, Lapa do Baixão; 14²3'08.13" S, 4337'35.06" W; 7 Aug. 2013; R.L. Ferreira leg.; ISLA 4097 [not examined].

\section{Paratypes}

BRAZIL - 1 O ; same locality as for holotype; 7 Aug. 2013; R.L. Ferreira leg.; ISLA 4098, ISLA 4099, ISLA4 101 [not examined] • 1 ' ; same locality as for holotype; 7 Aug. 2013; R.L. Ferreira leg.;

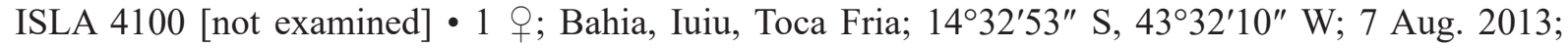

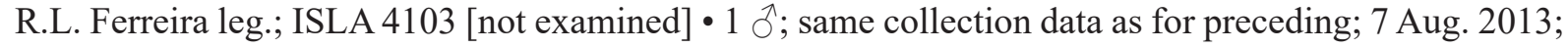
R.L. Ferreira leg.; ISLA 4102 [not examined].

\section{Measurements}

See Table 4.

\section{Distribution}

Known only from the type locality.

\section{Natural history}

Specimens were found in two caves, Lapa do Baixão and Toca Fria, which are around $18 \mathrm{~km}$ apart. Both caves are located in the Iuiu Municipality (Bahia State, Brazil), in the Caatinga biome, and belong to the Bambuí limestone group. Although other caves in the area were also surveyed, specimens were only found at the two type localities. The surroundings of the entrance to both caves are severely impacted, mainly by agricultural activities, extensive cattle and goat breeding (Vasconcelos \& Ferreira 2016).

Charinus jibaossu Vasconcelos, Giupponi \& Ferreira, 2014

Fig. 43; Table 4

Charinus jibaossu Vasconcelos et al., 2014: 156-161, figs 1-20.

Charinus jibaossu - Vasconcelos \& Ferreira 2016: 185. — Miranda et al. 2016c: 19, 29.

\section{Diagnosis}

This species may be separated from other Charinus in eastern South America by means of the following combination of characters: female gonopod sucker-like; cheliceral claw with 10-12 teeth; pedipalp 
femur with five or six dorsal spines in primary series and up to three spines in secondary series; pedipalp femur with five or six ventral spines in primary series and up to six reduced spines in secondary series; pedipalp patella with six or seven dorsal spines and three ventral spines; pedipalp tarsus with two or three dorsal spines.

\section{Etymology}

Noun in apposition taken from the Tupi-Guarani word 'jibaoçu', which means 'those with long arms' (Vasconcelos et al. 2014).

\section{Type material}

\section{Holotype}

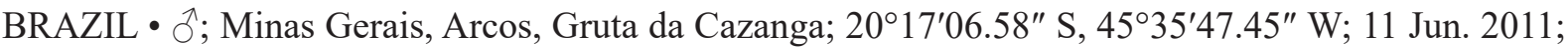
R.L. Ferreira leg.; MNRJ 9257.

\section{Paratypes}

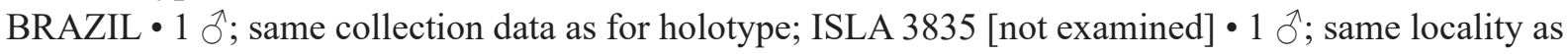
for holotype; 31 Jan. 2009; R.A. Zampaulo leg.; MNRJ 9258 • 1 ô; Minas Gerais, Arcos, Gruta Branca; $20^{\circ} 17^{\prime} 06.67^{\prime \prime} \mathrm{S}, 45^{\circ} 35^{\prime} 47.39^{\prime \prime} \mathrm{W} ; 31$ Jan. 2009, R.A. Zampaulo leg.; ISLA 483 [not examined] • 1 ô; Minas Gerais, Arcos; 10 Aug. 2008; I.G.S. Soares leg.; MNRJ 9205 • 2 q + ; Minas Gerais, Arcos; 16 Mar. 2012; I.G.S. Soares leg.; MNRJ 9206 • 1 ㅇ, 1 §ో; Minas Gerais, Arcos, Abismo Satélite cave;

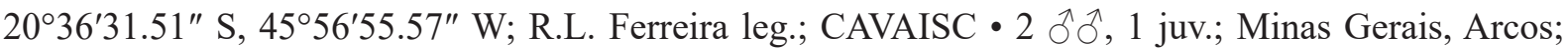
10 Oct. 2011; F. Bondezan leg.; MNRJ 9187 • 2 ㅇ; Minas Gerais, Arcos, Abrigo Caneleira I and

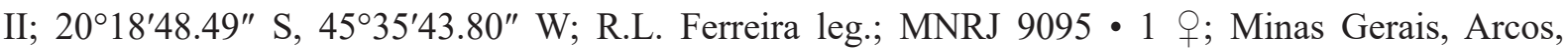

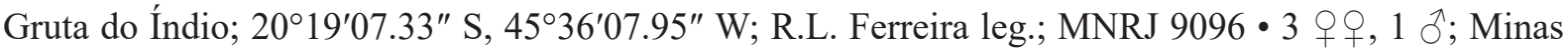
Gerais, Arcos, Meandro de Posse Grande cave; 20¹9'56.31" S, 4535'53.96" W; 11 Feb. 2006; R.L. Ferreira leg.; MNRJ 9097 • 1 đે; Minas Gerais, Arcos, Mineração Belocal, 25 Feb. 2012; MZSP 46336

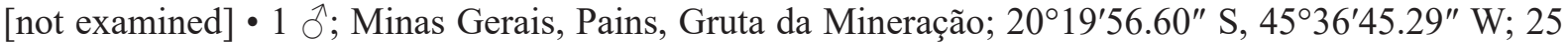
Jan. 2009; R.A. Zampaulo leg.; ISLA 480 [not examined] • 3 q 9 ; Minas Gerais, Pains, Gruta da Vila Corumbá; $20^{\circ} 19^{\prime} 55.8^{\prime \prime}$ S, $45^{\circ} 36^{\prime} 43.23^{\prime \prime}$ W; 25 Jan. 2009; R.A. Zampaulo leg.; ISLA 482 same collection data as for preceding; ISLA 3830 [not examined]; MNRJ $9217 \bullet 1$ ô; Minas Gerais, Pains, Gruta da Mineiração; MNRJ 9277.

\section{Supplementary description}

CARAPACE. Six anterior setae; frontal process triangular, not visible in dorsal view. Small granules densely scattered between ocular triads and among sulci. Median eyes present, well developed, and median ocular tubercle shallow, with pair of setae; lateral eyes well developed, pale, seta posterior to lateral ocular triad.

Sternum. Tritosternum projected anteriorly, with typical setation; other sternal platelets narrow and concave, with pair of setae anteriorly on plaque and some smaller setae posteriorly; pentasternum with eight setae anteriorly and two setae on membranous region.

Opisthosoma. Ventral sacs and ventral sac cover absent.

Genitalia. Female genital operculum with prominent setae in the ventral-posterior region and some smaller setae near margin; genital operculum with pair of sulci near posterior margin; gonopod suckerlike, tubular; gonopods unsclerotized basally. Male gonopod with base of fistula and lateral lobe unsclerotized; lateral lobe 2 fimbriate. 
Chelicerae. Small tooth projecting from retrolateral surface of basal segment, opposite to bifid tooth; retrolateral surface of claw with two patches of setae, basally and medially; claw with eleven teeth; transverse row of around nine setae on prolateral surface of basal segment; bifid tooth on basal segment with dorsal cusp larger than ventral cusp.

PeDIPALPS. Coxal dorsal carina with seta encircled by round carina and three setae on margin. Femur with five or six dorsal spines and five ventral spines; two prominent setiferous tubercles between dorsal spine 1 and proximal margin; spine between ventral spine 1 and proximal margin, and small spine between spines 1 and 2, 2 and 3, and 3 and 4. Patella with five dorsal spines in primary series; prominent setiferous tubercle distal to spine I, one-third length of spine I; four ventral spines in primary series; prominent setiferous tubercle between spine I and distal margin. Tibia with prominent setiferous tubercle proximally and ventral spine distally; three setae between spine and distal margin. Tarsus with two or three dorsal spines, proximal spine half length of distal spine; cleaning organ with 29 setae in ventral row.

LEGS. Tibia of leg I with 23 articles; tarsus I with 41 articles; first tarsal article similar in length to second article. Leg IV basitibia with four pseudo-articles, with sclerotized, denticulate margin at apex of articles; trichobothrium $b t$ situated in proximal third of pseudo-article; distitibia trichobothrium $b c$ situated closer to $s b f$ than to $b f, s c$ and $s f$ series each with six trichobothria.

\section{Measurements}

See Table 4.

\section{Distribution}

Known only from the type localities.

\section{Natural history}

Charinus jibaossu exhibits marked secondary sexual dimorphism in the length of the pedipalps. The caves where this species was collected are rather dry, unlike the humid caves inhabited by most other Brazilian species of Charinus. Most specimens were found on cave walls. Potential prey includes crickets (Eidmanacris sp. and Endecous sp.), moths, and cockroaches. The species is considered endangered due to mining activity in the area (Vasconcelos et al. 2014).

Charinus monasticus sp. nov.

urn:1sid:zoobank.org:act:5B686BD6-1303-420C-B358-2BFD15FB6C7C

Figs 43, 69-70; Table 4

\section{Diagnosis}

This species may be separated from other Charinus in eastern South America by means of the following combination of characters: metasternum without anterior setae in membranous region, but with four setae posteriorly; two small, flat teeth in retrolateral row of basal cheliceral segment; cheliceral claw with five teeth; pedipalp femur with setiferous tubercle proximal to ventral spine 1, i.e., between spine 1 and proximal margin; tibia of leg I with 21 articles, tarsus I with 37 articles; leg IV distal apex of basitibial pseudo-articles without dark, denticulate projection; distitibia with two pseudo-articles; trichobothrium $b t$ situated in proximal third.

This species resembles C. ricardoi, but differs in the count of ventral spines on the pedipalp: three ventral spines are present in C. monasticus sp. nov., compared with four in $C$. ricardoi. The male is unknown. 


\section{Etymology}

Adjective refering to a monastery; the type locality is a convent.

\section{Type material}

\section{Holotype}

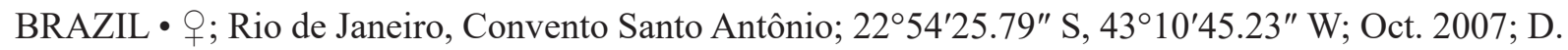
Pedroso leg.; MNRJ 9103.

\section{Paratypes}

BRAZIL• 49 + $\%$; same collection data as for holotype; MNRJ 9103.

\section{Description}

CARAPACE. Frontal process large, triangular, not visible in dorsal view (Fig. 69A). Median eyes and median ocular tubercle absent (Fig. 69C); one or two setae situated in place of median ocular tubercle. Lateral eyes reduced, pale, small seta posterior to each lateral ocular triad.

STERnUm. Tritosternum projected anteriorly into large, blunt tubercle, surpassing base of pedipalp coxae (Fig. 69B). Medial platelet (tetrasternum) and third platelet (pentasternum) forming single convex platelet, with pair of large setae anteriorly, and several small setae posteriorly. Metasternum without anterior setae in membranous region, with four setae posteriorly.

Opisthosoma. Ventral sacs and ventral sac cover absent.

Genitalia. Posterior margin of female genital operculum slightly convex, with several setae along margin and on surface (Fig. 70A-C). Gonopods with small sclerotized region basally (disconnected); gonopods cushion-like with large opening (Fig. 70A, C, E); gland openings inside gonopod atrium (Fig. 70F); posterior margin of genital operculum with smooth surface (Fig. 70D). Male unknown.

Chelicerae. Two small, flat teeth in retrolateral row of basal segment. Prolateral surface with transverse row of four small setae, from ventral to dorsal; three setae situated ventrally whereas dorsalmost seta separated from row, displaced dorsally. Two setae, retrolateral and prolateral, on dorsodistal margin, near membranous region of claw. Claw with five denticles and with two small patches of setae, basally and dorsally, on retrolateral surface.

PeDIPALPS. Coxal dorsal carina with four or five small setae and four setae on anterior margin of round carina. Femur with three distinct setiferous tubercles proximal to dorsal spine 1 (Fig. 69E); primary series with three dorsal spines (Fig. 69E); three ventral spines (one specimen with four) (Fig. 69F); one setiferous tubercle proximal to spine 1, between spine 1 and proximal margin. Patella with three dorsal spines (Fig. 69E); setiferous tubercle distal to spine I, about one-third length of spine I; two ventral spines decreasing in length (Fig. 69F); three setiferous tubercles between spine I and distal margin. Tibia with two dorsal spines, proximal spine two-thirds length of distal spine; ventral spine situated in distal half of tibia; prominent setiferous tubercle near its base; four long setae between spine and distal margin. Tarsus with two dorsal spines, distal spine half length of tarsus, proximal spine one-third length of distal spine (Fig. 69D); ventral row of cleaning brush with 39-40 setae.

LEGS. Tibia of leg I with 21 articles; tarsus I with 37 articles. Leg IV basitibia with two pseudo-articles; trichobothrium $b t$ situated in proximal third; distal apex of basitibial pseudo-articles without dark, denticulate projection. Leg IV distitibia trichobothrium $b c$ situated closer to $s b f$ than to $b f ; s f$ and $s c$ series each with five trichobothria. Leg IV tarsus with distinct white annulus distally on first article. 


\section{Measurements}

See Table 4.

\section{Distribution}

Known only from the type locality.

\section{Natural history}

Only recorded underneath a monastery in the city center of Rio de Janeiro, Brazil.

\section{Charinus montanus Weygoldt, 1972}

Figs 43; Table 4

Charinus montanus Weygoldt, 1972b: 115-122, figs 12-21, 22a.

Charinus montanus - Weygoldt 1972c: 107, fig. 17; 1974: 217-222, figs 1, 2a-c; 1975: 311; 1996a: 187, fig. 7; 1999c: 107; 2000a: 17, 98, figs 23, 208-211. - Quintero 1975: 161, figs 4-5, 7-8, 11-12. — Delle Cave 1986: 162, fig. II. - Proctor 1998: 161. - Harvey 2003: 6. - Baptista \& Giupponi 2003: 80. — Miranda \& Giupponi 2011: 66, fig. 13. — Vasconcelos et al. 2013: 495, fig. 12. — Miranda et al. 2016c: 19, 21, 27, 29, 31.

\section{Diagnosis}

This species may be separated from other Charinus in eastern South America by means of the following combination of characters: tegument covered with clavate setae; carapace and legs dark in color; leg I tarsus I with 23-28 articles with length of first tarsal article equal to combined length of subsequent ten articles.

\section{Etymology}

Although unspecified by the author, the name is a Latin adjective meaning 'of mountains', which refers to the occurrence of this species in a hilly landscape.

\section{Type material}

\section{Holotype}

BRAZIL • đ’; Espírito Santo, Domingos Martins, 50 km W of Vitória; 20¹9’36.39" S, 4050’15.03" W; MNRJ 9015.

\section{Paratypes}

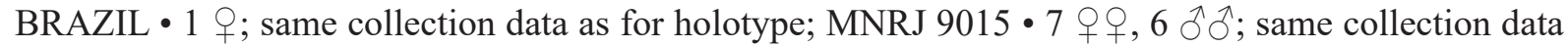
as for holotype; SMF.

\section{Additional material}

BRAZIL • 5 q 9,3 juv.; Espírito Santo, Santa Teresa, Reserva Santa Lúcia; 1956'10" S, 40³6'06" W; 15-19 Oct. 2003; Almeida, Baptista, Giupponi, Mendes and Pedroso leg.; MNRJ 9087 • 4 + $ᄋ, 1$ đ;;

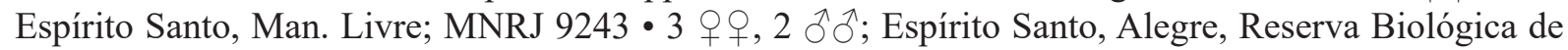
Duas Bocas; 20¹6'55.13" S, 40³0'22.97" W; MNRJ 9242.

\section{Supplementary description}

CARAPACE. Tegument covered with short, broad setae. Six anterior setae; frontal process triangular, not visible in dorsal view. Small granules densely scattered between ocular triads and among sulci. 
Median eyes present; median ocular tubercle shallow, with pair of setae. Lateral eyes well developed, seta posterior to lateral ocular triad.

STERnUm. Tritosternum projected anteriorly, with typical setation; other sternal platelets wide, flat, with pair of setae on each side of platelets and some smaller setae posteriorly; pentasternum with four setae anteriorly and three setae on membranous region.

OpISTHOSOMA. Ventral sacs and ventral sac cover absent.

Genitalia. Female genital operculum with prominent setae posteromedially and some smaller setae near margin; posterior margin of genital operculum with pair of lateral sulci; gonopod sucker-like, funnel-shaped [dissected gonopod of female (MNRJ 9087) with sulcus on anterior side, as illustrated by Weygoldt (1972b) in original description of C. brasilianus]; base of gonopods unsclerotized. Male gonopod with base of fistula and lateral lobe sclerotized; lateral lobe 2 fimbriate.

CHELICERAE. Small, flat tooth on retrolateral surface of basal segment, opposite to bifid tooth; retrolateral surface of claw with row of setae basally to medially; claw with seven teeth; transverse row of around seven setae on prolateral surface of basal segment; bifid tooth on basal segment with dorsal cusp larger than ventral cusp.

PEDIPALPS. Coxal dorsal carina with prominent seta encircled by round carina and three setae on margin. Femur with four dorsal spines and three ventral spines; three prominent setiferous tubercles between dorsal spine 1 and proximal margin; setiferous tubercle between ventral spine 1 and proximal margin. Patella with five dorsal spines in primary series; prominent setiferous tubercle distal to spine I, one-third length of spine I; four ventral spines in primary series; prominent setiferous tubercle between spine I and distal margin. Tibia with ventral spine distally and two setae between spine and distal margin. Tarsus with two dorsal spines, proximal spine half length of distal spine; cleaning organ with 26-28 setae in ventral row.

Legs. Tibia of leg I with 23 articles; tarsus I with 28 articles; length of first tarsal article equal to combined length of subsequent ten articles. Leg IV basitibia with four pseudo-articles, without sclerotized, denticulate margin projecting from apex of articles; trichobothrium $b t$ situated in distal third of pseudo-article; distitibia trichobothrium $b c$ situated closer to $s b f$ than to $b f, s c$ and $s f$ series each with six trichobothria.

\section{Measurements}

See Table 4.

\section{Distribution}

Known from several localities in the montane region of Espírito Santo, Brazil.

\section{Natural history}

Found under fallen tree trunks and stones in tropical forest.

Charinus mysticus Giupponi \& Kury, 2002

Fig. 43; Table 4

Charinus mysticus Giupponi \& Kury, 2002: 1-4, figs 1-10.

Charinus mysticus - Baptista \& Giupponi 2003: 80. — Miranda \& Giupponi 2011: 66, fig. 13. Vasconcelos et al. 2013: 496, fig. 12. — Vasconcelos \& Ferreira 2016: 185. — Miranda et al. 2016c: 19, 29. 


\section{Diagnosis}

This species may be separated from other Charinus in eastern South America by means of the following combination of characters: retrolateral surface of basal segment of chelicera with small blunt tooth; pedipalp tarsus with three spines; leg IV distitibia $s c$ and $s f$ series each with six trichobothria.

\section{Etymology}

Latin adjective, translated from the name of the type locality, which means 'charmed' (Giupponi \& Kury 2002).

\section{Type material}

\section{Holotype}

BRAZIL - ; Bahia, Cave in Encantados, Gentil do Ouro, 16 km from Santo Inácio, road to Gameleira; $11^{\circ} 25^{\prime} 58.94^{\prime \prime}$ S, 42³0'20.94" W; MNRJ 9022.

\section{Paratype}

BRAZIL • 1 +; same collection data as for holotype; MNRJ 9022.

\section{Additional material examined}

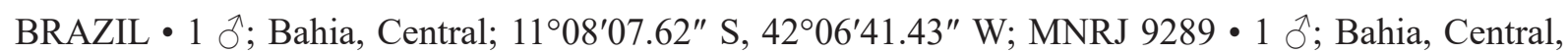
Gruta Rolling Stones; 7 Jul. 2007; M.E. Bichuette leg.; MNRJ $9291 \bullet 1$ '̇; same collection data as for preceding; MNRJ 9290.

\section{Supplementary description}

CARAPACE. Frontal process large, subtriangular, visible in dorsal view; distinct curved carina between ocular triads and margin of carapace. Median eyes and median ocular tubercle present; median ocular tubercle shallow, slightly higher than carapace surface, with pair of small setae. Lateral eyes well developed, pale, small seta posterior to each lateral ocular triad.

STERNUM. Tritosternum projected anteriorly into large, blunt tubercle, surpassing base of pedipalp coxae, and rounded posteriorly. Medial platelet (tetrasternum) and third platelet (pentasternum) forming single convex platelet, with pair of large setae anteriorly, and several small setae posteriorly; metasternum with two anterior setae at border between membranous and sclerotized region, and three setae in longitudinal row, from anterior to posterior; four to six setae posteriorly.

Opisthosoma. Ventral sacs and ventral sac cover absent.

Genitalia. Female genital operculum posterior margin slightly convex, with several setae along margin and on surface. Gonopods unsclerotized basally; gonopods sucker-like with small invagination anteriorly.

Chelicerae. Small tooth in retrolateral row of basal segment. Prolateral surface with transverse row of around six small setae, ventrally to dorsally. Four setae, retrolateral, retromedial, prolateral and promedial, on dorsodistal margin, near membranous region of claw. Claw with eleven denticles and row of setae on retrolateral surface from base to near apex (dorsal side).

PEDIPALPS. Coxal dorsal carina with two or three small setae and four setae on anterior margin of round carina. Femur with three distinct setiferous tubercles proximal to spine 1; primary series with five dorsal spines, and smaller spine between spines 2 and 3; small spine, similar in length to spine 4 (suggesting it was duplicated), present between spines 3 and 4 in holotype female (MNRJ 9022), as on sinistral pedipalp of $C$. diamantinus sp. nov.; four or five ventral spines, small spine between spines 1 and 2 , and 2 and 3; large ventral spine proximal to spine 1. Patella with five dorsal spines; large setiferous 
tubercle distal to spine I, about one-third length of spine I; four ventral spines decreasing in size; distinct setiferous tubercle between spines II and III; two or three setiferous tubercles between spine I and distal margin. Tibia with two dorsal spines, proximal spine two-thirds length of distal spine; ventral spine situated in distal half of tibia; three setiferous tubercles in row near base of spine; six or seven long setae between spine and distal margin. Tarsus with three dorsal spines; ventral row of cleaning brush with 26 or 27 setae.

Legs. Tibia of leg I with 23 articles; tarsus I with 41 articles. Leg IV basitibia with four pseudoarticles; trichobothrium $b t$ situated in proximal third; distal apex of basitibial pseudo-articles with dark, denticulate projection. Leg IV distitibia trichobothrium $b c$ situated closer to $s b f$ than to $b f ; s c$ and $s f$ each with six trichobothria; tarsus with distinct white annulus distally on first article.

\section{Measurements}

See Table 4.

\section{Distribution}

Known from two caves in the western part of the Brazilian state of Bahia.

\section{Natural history}

Holotype and paratypes were collected $8 \mathrm{~m}$ from the entrance of the cave. The behavioral repertoire of the species was studied by Tagliatela et al. (2019).

Charinus potiguar Vasconcelos, Giupponi \& Ferreira, 2013

Fig. 43; Table 4

Charinus potiguar Vasconcelos et al., 2013: 490-495, figs 1-12.

Charinus potiguar - Vasconcelos \& Ferreira 2016: 185. - Armas et al. 2016: 48. - Miranda et al. 2016c: 19, 29.

\section{Diagnosis}

Based on Vasconcelos et al. (2013), this species may be separated from other Charinus in eastern South America by means of the following combination of characters: adult body size ranging from 6.72 to 13.73 $\mathrm{mm}$; frontal process slightly longer than wide; eyes and median ocular tubercle weakly developed, seta posterior to each lateral ocular triad; male gonopod with lobus lateralis primus and secundus subdivided into several filamentous structures; female gonopod with bottleneck just prior to entrances and margin with small fold and V-neck; cheliceral claw with 9-13 denticles; pedipalp patella with three dorsal spines; leg IV basitibia with four pseudo-articles, distitibia with three basal trichobothria and fifteen distal trichobothria, metatarsus slightly longer than tarsus; tibia with 23 articles, tarsus I with 41 articles.

\section{Etymology}

Adjective used to describe the inhabitants of the state of Rio Grande do Norte (Vasconcelos et al. 2013).

\section{Type material}

\section{Holotype}

BRAZIL - J; Rio Grande do Norte, Felipe Guerra, Caverna do Buraco Redondo; 05³4'42.98" S, 37³9'04.99" W; 22 Jul. 2010; D.M. Bento leg.; MNRJ 9216. 


\section{Paratypes}

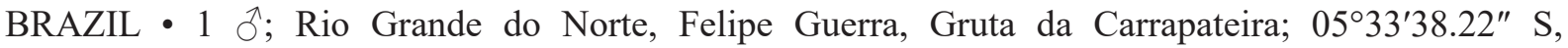
37³9'50.32" W; 24 Apr. 2007; R.L. Ferreira leg.; MNRJ 9214 • 1 q, 1 ơ; Rio Grande do Norte, Felipe Guerra, Caverna do Pau; 05³5'34.19" S, 3741'14.64" W; 8 Jan. 2007; R.L. Ferreira leg.; MNRJ 9212 • 1 q; same collection data as for preceding; ISLA 3924 [not examined] • 1 \%; Rio Grande do Norte, Felipe Guerra, Caverna Buraco da Nega; 05³1'57.16" S, 3750'40.73" W; 21 Jan. 2010; D.M. Bento leg.; ISLA 1875 [not examined] • 1 đో; Rio Grande do Norte, Felipe Guerra, Caverna da Rumana; 05³3'54.25" S, 37³9'07.13" W; 10 Jan. 2010; D.M. Bento leg.; ISLA 1890 [not examined] • 1 क; Rio Grande do Norte, Felipe Guerra, Caverna do Geilson; 05³5'53.23" S, 37²41'17.56" W; 23 Apr. 2007, D.M. Bento leg.; MNRJ 9213 • 1 q; Rio Grande do Norte, Governador Dix-Sept Rosado, Gruta Boca de Peixe; 05²9'04.45" S, 37³3'29.62" W; 7 Jan. 2010; D.M. Bento leg.; ISLA 1888 [not examined] • 1 क; same locality as for preceding; 3 Jun. 2010; D.M. Bento leg.; MNRJ 9215 • 1 ó; Rio Grande do Norte, Baraúna, Gruta da Escada; 05¹0’07.83" S, 37²4'40.98" W; 29 Jul. 2010; D.M. Bento leg.; ISLA 1894 [not examined].

\section{Supplementary description}

CARAPACE. Six anterior setae; frontal process triangular, with oval apex, not visible in dorsal view. Small granules densely scattered between ocular triads and among sulci; lateral carapace margin, ventral to lateral eyes with small carina. Median eyes present, reduced, median ocular tubercle shallow, with pair of setae; lateral eyes reduced, pale, seta posterior to lateral ocular triad.

STERnUm. Tritosternum projected anteriorly, with typical setation; other sternal platelets narrow and concave, with pair of setae anteriorly on plaque and some smaller setae posteriorly; pentasternum with 20 setae anteriorly and five setae on membranous region.

Opisthosoma. Ventral sacs and ventral sac cover absent.

GENITALIA. Female genital operculum with prominent setae posteromedially and some smaller setae near margin; gonopod sucker-like, constriction near apex, creating shape of bottleneck; gonopods markedly sclerotized basally. Male gonopod with base of fistula and lateral lobe sclerotized; lateral lobe 2 fimbriate.

CHELICERAE. Small tooth projecting from retrolateral surface of basal segment, opposite to bifid tooth; retrolateral surface of claw with two patches of setae, medially and basally; claw with thirteen teeth and transverse row of around thirteen setae on prolateral surface of basal segment; bifid tooth on basal segment with dorsal cusp larger than ventral cusp.

PediPAlps. Coxal dorsal carina with two prominent setae encircled by round carina and three setae on margin. Femur with four dorsal spines and four ventral spines; two prominent setiferous tubercles between dorsal spine 1 and proximal margin; spine between ventral spine 1 and proximal margin. Patella with three dorsal spines in primary series; prominent setiferous tubercle distal to spine I, one-third length of spine I; two ventral spines in primary series; prominent setiferous tubercle between spine I and distal margin. Tibia with ventral spine distally and five setae between spine and distal margin. Tarsus with two dorsal spines, proximal spine one-third length of distal spine; cleaning organ with 28-30 setae in ventral row.

LEGS. Tibia of leg I with 23 articles; tarsus I with 41 articles; first tarsal article same length as second article. Leg IV basitibia with four pseudo-articles, with sclerotized, denticulate margin projecting from apex of articles; trichobothrium $b t$ situated in proximal third of pseudo-article; distitibia trichobothrium $b c$ situated closer to $s b f$ than to $b f, s c$ and $s f$ series each with six trichobothria. 


\section{Measurements}

See Table 4.

\section{Distribution}

Known only from the type localities in the Brazilian state of Rio Grande do Norte.

\section{Natural history}

The localities at which C. potiguar has been recorded are situated in a karstic limestone formation, known as the Apodi group, dated to the late Cretaceous. The area is situated in the Caatinga biome, the only semi-arid biome in Brazil, with low rainfall most of the year. Charinus potiguar is widespread within the formation, but its abundance in each cave is usually low (3.9 \pm 3.4 individuals). Vasconcelos et al. (2013) suggested that caves might not be the primary habitat of the species, noting that more individuals were found in the caves during the dry season. For example, in 16 caves sampled during the dry and wet seasons, the abundance was significantly higher in the dry season than in the rainy season $(t$-value: -2.91 , $\mathrm{p}=0.007$ ), which, according to Vasconcelos et al. (2013) suggests that specimens are migrating into the caves when the outside climate is unfavourable. L.S. Carvalho (pers. com.) noted that specimens can be found under rocks at the entrance of the caves. Specimens are usually found on the cave walls, although immatures were frequently found under rocks on the floor. A schizomid, Rowlandius potiguar Santos, Ferreira \& Buzatto, 2013, and several pholcid spiders, Metagonia potiguar Ferreira, Souza, Machado \& Brescovit, 2011 and Micropholcus sp. inhabit the same caves (L.S. Carvalho, pers. com.). Potential prey species observed in the cave included crickets (Endecous sp.) and cockroaches.

\section{Charinus puri sp. nov. urn:lsid:zoobank.org:act:58C93BF8-8C3F-4120-B389-61528D8C3811}

Figs 43, 71-72; Table 4

\section{Diagnosis}

This species may be separated from other Charinus in eastern South America by means of the following combination of characters: cheliceral claw with eleven teeth; pedipalp coxa with three long setae on margin, and two distinct setae encircled by round carina; pedipalp tarsus with two subequal dorsal spines (Fig. 71C); leg IV basitibia trichobothrium $b t$ situated proximal to submedial; distitibia trichobothrium $b c$ situated closer to $s b f$ than to $b f, s c$ and $s c$ series each with six trichobothria.

This species resembles $C$. imperialis sp. nov. but possesses more spines on the pedipalp. One specimen (MNRJ 9098) exhibits a spine between dorsal spines 1 and 2 of the femur and a series of three or four small spines parallel to the primary series of dorsal spines, the first spine situated between spines 1 and 2 , the second spine ventral to spine 2 , and the third between spines 3 and 4 . These spines vary in number and position in other individuals. The male is unknown.

\section{Etymology}

Noun in apposition honoring the Puri indigenous tribe who originally inhabited the area where the type series was collected.

\section{Type material}

\section{Holotype}

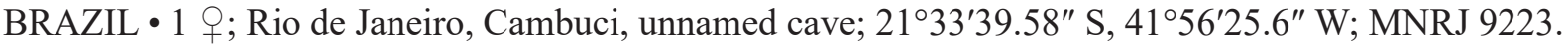

\section{Paratypes}

BRAZIL • 4 + 9 ; same collection data as for holotype; MNRJ 9223 • 2 o $\circ$; Rio de Janeiro, Gruta das Furnas or Sumidouro; 12 Nov. 2005; M.S. Silva and R.L. Ferreira leg.; MNRJ 9098. 


\section{Description}

CARAPACE. Six anterior setae (Fig. 71A); frontal process triangular. Small granules densely scattered between ocular triads and among sulci. Median eyes well developed (Fig. 71A); median ocular tubercle reduced, with pair of setae; lateral eyes well developed, seta posterior to lateral ocular triad; lateral ocular triad well separated from carapace margin.

STERnUM. Tritosternum projected anteriorly with typical setation, long, surpassing base of pedipalp coxae (Fig. 71B); other sternal platelets narrow and concave, with pair of setae anteriorly on plaque and some smaller setae posteriorly; pentasternum with eleven setae anteriorly and three setae near membranous region.

Opisthosoma. Ventral sacs and ventral sac cover absent.

Genitalia. Female genital operculum with prominent setae posteromedially and some smaller setae near margin (Fig. 72A-C); gonopod sucker-like and slightly sclerotized basally (Fig. 72A, D-E); conical, without constriction (Fig. 72A, D-E); smooth surface between gonopods and distal border of gonopod (Fig. 72B). Male unknown.

Chelicerae. Small tooth projecting from retrolateral surface of basal segment, opposite to bifid tooth; retrolateral surface of claw with continous row of setae, basally to medially; claw with eleven teeth; row of eighteen setae on prolateral surface of basal segment; bifid tooth on basal segment with dorsal cusp larger than ventral cusp.

PEDIPALPS. Coxal dorsal carina with two prominent setae encircled by round carina and three setae on margin. Femur with four dorsal spines and five ventral spines (Fig. 71D); spine between dorsal spines 2 and 3, and spines 3 and 4; four prominent setiferous tubercles between dorsal spine 1 and proximal margin; ventral spine between spine 1 and proximal margin (Fig. 71E); small spine ventral to extra spine proximal to spine 1, near articulation between femur and trochanter; spine between ventral spines 1 and 2, two spines between spines 2 and 3, and between spines 3 and 4. Patella with six dorsal spines in primary series (Fig. 71E); prominent setiferous tubercle distal to spine I, one-third length of spine I; four or five ventral spines (Fig. 71F); prominent setiferous tubercle between spine I and distal margin; small spine between spines 2 and 3. Tibia with ventral spine distally and four setae between spine and distal margin. Tarsus with two dorsal spines, distal spine twice as long as proximal spine (Fig. 71C); cleaning organ with 27-29 setae in ventral row.

LeGs. Tibia of leg I with 23 articles; tarsus I with 41 articles; first tarsal article shorter than second article. Leg IV basitibia with four pseudo-articles, with sclerotized, denticulate margin projecting from apex of articles; basitibia trichobothrium $b t$ situated proximal to submedial on pseudo-article; distitibia trichobothrium $b c$ situated closer to $s b f$ than to $b f, s c$ and $s f$ series each with six trichobothria.

\section{Measurements}

See Table 4.

\section{Distribution}

Known only from the type locality.

\section{Natural history}

Found on cave walls. 


\author{
Charinus renneri sp. nov. \\ urn:1sid:zoobank.org:act:53281423-876C-492D-B4E3-F655A80DFFFF \\ Figs 6A-B, 10I-J, 43, 73-74; Table 4
}

\title{
Diagnosis
}

This species resembles $C$. acaraje, from which it may be separated by the number spines on the pedipalp; C. renneri sp. nov. possesses four ventral spines on the femur and five dorsal spines on the patella (Fig. 73E-F), whereas $C$. acaraje possesses three ventral spines on the femur and three dorsal spines on the patella. It can be separated from the other Charinus species in eastern South America by the widely separate sucker-like female gonopods with lateral margins projecting dorsally (Fig. 6A-B).

\section{Etymology}

Patronym honoring Dr Renner L.C. Baptista for his contributions to arachnology.

\section{Type material}

\section{Holotype}

BRAZIL - O ; Bahia, Campo Formoso, Lapa do Convento; 10³0'28.07" S, 40¹9'23.12" W; 6 Nov. 2002; A.P.L. Giupponi and R. Baptista leg.; MNRJ 9198.

\section{Paratypes}

BRAZIL 1 đ̊, 1 juv.; same collection data as for holotype; MNRJ 9198.

\section{Description}

CARAPACE. Frontal process large, subtriangular, not visible in dorsal view (Fig. 73C). Median eyes and median ocular tubercle present; median ocular tubercle shallow, not higher than carapace surface, pair of small setae at base (Fig. 73C). Lateral eyes well developed, pale, small seta posterior to each lateral ocular triad (Fig. 73A).

STERnum. Tetra-segmented, all platelets markedly sclerotized (Fig. 73B). Tritosternum projected anteriorly into small, blunt tubercle, surpassing base of pedipalp coxae; medial platelet (tetrasternum) and third platelet (pentasternum) forming single convex platelet, with pair of large setae anteriorly, and several small setae posteriorly; metasternum with four setae in membranous region; two or three setae, forming longitudinal row, posteriorly.

Opisthosoma. Ventral sacs and ventral sac cover absent.

Genitalia. Female genital operculum with posterior margin slightly convex, and several setae along margin and on surface (Fig. 6A-B). Female gonopods sucker-like, sclerotized basally, with small projections from lateral margins (Fig. 6A-B). Male gonopod with distal margin of fistula and base of lateral lobes narrowly sclerotized; LoL2 fimbriate and short (Fig. 74A-D); LaM with acute projection posteriorly (Fig. 74A-D).

Chelicerae. Small tooth in retrolateral row of basal segment (Fig. 10I-J). Prolateral surface with transverse row of around ten small setae, from ventral to dorsal. Two setae, prolateral and retrolateral, on dorsodistal margin, near membranous region of claw. Claw with eight denticles and row of setae on retrolateral surface from base to near apex (dorsal side) (Fig. 10I-J); base of row with four setae, disconnected from distal row of setae (gap present between base and apex of row).

PEDIPALPS. Coxal dorsal carina with small seta and three or four setae on anterior margin of round carina. Femur with two distinct setiferous tubercles proximal to spine 1; primary series with four dorsal spines 
(Fig. 73E); small spine between dorsal spines 2 and 3 on dextral pedipalp of holotype; four ventral spines, with small spines between spines 1 and 2 and spines 2 and 3 (Fig. 73F); spine parallel to ventral spine 1, near base of spine I; spine parallel to spine 2; large ventral spine proximal to spine 1. Patella with five dorsal spines (Fig. 73F); large setiferous tubercle distal to spine I, about one-third length of spine I; three ventral spines decreasing in length; two or three setiferous tubercles between spine I and distal margin. Tibia with two dorsal spines, proximal spine two-thirds length of distal spine; ventral spine in distal half of tibia; four long setae between spine and distal margin. Tarsus with two dorsal spines (also evident in juveniles) (Fig. 73D); proximal spine half length of distal spine; ventral row of cleaning brush with $30-32$ setae.

LeGs. Tibia of leg I with 23 articles; tarsus I with 41 articles (29 or 30 in incomplete legs). Leg IV basitibia with four pseudo-articles; trichobothrium $b t$ situated in proximal third, near proximal margin; distal apex of basitibial pseudo-articles with dark, denticulate projection; distitibia trichobothrium $b c$ situated closer to $s b f$ than to $b f ; s c$ and $s f$ series each with six trichobothria; tarsus with distinct white annulus distally on first article.

\section{Measurements}

See Table 4.

\section{Distribution}

Known only from the type locality.

\section{Natural history}

This species inhabits a very wet cave. The type specimens were only found in the aphotic zone, on cave walls, close to water. Two other caves in the vicinity, which are hotter and drier, contained no amblypygids.

Charinus ruschii Miranda, Milleri-Pinto, Gonçalves-Souza, Giupponi \& Scharff, 2016

Fig. 43; Table 4

Charinus ruschii Miranda et al., 2016c: 21-28, figs 1a-g, 2a-b, 3a-f, 4.

\section{Diagnosis}

Based on Miranda et al. (2016c), this species may be separated from other Charinus in eastern South America by means of its large size, with carapace ca $80 \%$ wider than that of the closely related species, C. brasilianus and C. montanus, the unique small platelets of the sternum, the sucker-like female gonopod, the presence of ten teeth on the cheliceral claw and three spines on the pedipalp tarsus; and the similar length of the proximal article to subsequent articles of the leg I tarsus.

\section{Etymology}

Patronym honoring Adolpho Ruschi (Miranda et al. 2016c).

\section{Type material}

\section{Holotype}

BRAZIL • ' ; Espírito Santo, Santa Teresa; 1956'10" S, 40³6'06" W; T. Gonçalves-Souza and M. Milleri-Pinto leg.; MNRJ 9235. 


\section{Paratypes}

BRAZIL • 2 우; same collection data as for holotype; MNRJ 9235 4 우, 1 juv.; same collection data as for holotype; MNRJ 9237 • 1 q; Espírito Santo, Santa Teresa, Estação Biológica Santa Lúcia; 1956'13.1" S, 40³5'54.07" W; May 2005; T. Gonçalves-Souza leg.; MNRJ 9272 • 2 우; Espírito Santo, Man. Livre Div. Santa Teresa; M. Milleri-Pinto and T. Gonçalves-Souza leg.; MNRJ 9303.

\section{Measurements}

See Table 4.

\section{Distribution}

Known only from the type locality.

\section{Natural history}

See Miranda et al. (2016c) for details of the natural history of this species.

Charinus santanensis Vasconcelos \& Ferreira, 2017 Fig. 43; Table 4

Charinus satanensis Vasconcelos \& Ferreira, 2017: 283-286, figs 16-23, 29-30.

\section{Diagnosis}

Based on Vasconcelos \& Ferreira (2017), this species may be separated from other Charinus in eastern South America by means of the following combination of characters: median and lateral eyes well developed; male gonopods with processus internus and lateral lobe 1 forming several long lobes, lateral lobe 2 and dorsal lobe drop-shaped, with dorsal lobe larger than lateral lobe 2, and lamina medialis forceps-shaped; cheliceral claw with eight teeth; pedipalp femur with four or five dorsal spines and five ventral spines, patella with six dorsal spines and three or four ventral spines, and tibia with dorsal spine 2 two to three times as long as spine 1; leg IV distitibia with eighteen trichobothria, $s c$ and $s f$ series each with six trichobothria.

\section{Etymology}

Refers to Santana, the municipality in the Brazilian state of Bahia, in which the type locality is situated (Vasconcelos \& Ferreira 2017).

\section{Type material}

\section{Holotype}

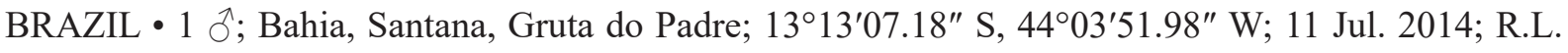
Ferreira leg.; ISLA 12777 [not examined].

\section{Paratype}

BRAZIL $・ 1$ đ̊; same collection data as for holotype; ISLA 12778 [not examined].

\section{Measurements}

See Table 4.

\section{Remarks}

See Vasconcelos \& Ferreira (2017) for more details about this species. 


\section{Distribution}

Known only from the type locality.

\section{Natural history}

Gruta do Padre Cave is one of the largest and best preserved caves in Brazil. The cave has three distinct levels and a river at the lowest level. The type specimens of $C$. santanensis were collected in a large chamber in the upper level, some $250 \mathrm{~m}$ from the entrance, on rock blocks covered by a shallow, moist layer of mud. Due to their proximity to the entrance of the cave and the lack of any troglomorphic characters, C. santanensis appears to be troglophilic, not troglobitic (Vasconcelos \& Ferreira 2017).

Charinus schirchii (Mello-Leitão, 1931)

Fig. 43; Table 4

Enantiosarax schirchii Mello-Leitão, 1931: 55, 56, figs 23-24.

Charinus schirchii - Quintero 1983: 47. - Delle Cave 1986: 162, fig. II. - Harvey 2003: 7. Baptista \& Giupponi 2003: 80. - Miranda \& Giupponi 2011: 66, fig. 13. - Vasconcelos et al. 2013: 496, fig. 12. — Vasconcelos \& Ferreira 2016: 185.

\section{Diagnosis}

Based on Mello-Leitão (1931), this species may be separated from other Charinus in eastern South America by means of the following combination of characters: lateral eyes present; tritosternum projecting anteriorly, surpassing base of pedipalp coxae; tetra- and pentasternum with small platelets with seta on each side; pedipalp femur with five dorsal spines and five ventral spines; pedipalp patella with five dorsal spines, long setiferous tubercle between spine I and distal margin, and three ventral spines; pedipalp tarsus with two dorsal spines; tibia of leg I with 23 articles.

\section{Etymology}

Patronym honoring P. Schirch (Mello-Leitão 1931).

\section{Type material}

\section{Syntypes}

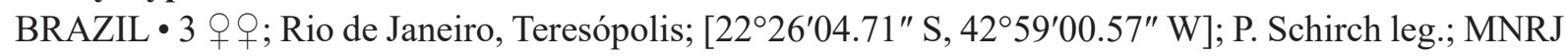
[not examined].

\section{Measurements}

See Table 4.

\section{Distribution}

Known only from the type locality.

\section{Remarks}

The syntypes are lost, hence the diagnosis is based on the original description of Mello-Leitão (1931). The median eyes were not described, but the species was collected in the Atlantic Forest and is not troglobitic; hence, it is assumed to possess a median ocular tubercle with median eyes. Mello-Leitão (1931) described six dorsal spines on the pedipalp patella, but included the long setiferous tubercle in the count; the true count of dorsal spines on the patella is five. 
Charinus spelaeus Vasconcelos \& Ferreira, 2017

Fig. 43; Table 4

Charinus spelaeus Vasconcelos \& Ferreira, 2017: 278-283, figs 1-15, 24-28.

\section{Diagnosis}

Based on Vasconcelos \& Ferreira (2017), this species may be separated from other Charinus in eastern South America by means of the following combination of characters: median eyes reduced to small eyespots with median ocular tubercle indistinct, lateral eyes reduced; second segment (tetrasternum) and third segment (pentasternum) of sternum wider than long; female gonopods sucker-like with slit in each gonopod structure opposite opercular margin; male gonopods with PI and LoL1 claw-shaped; cheliceral claw with 6-9 teeth; pedipalp femur with three or four dorsal spines and four or five ventral spines; pedipalp patella with five or six dorsal spines and three or four ventral spines; pedipalp tarsus with two dorsal spines; leg IV distitibia with 16 trichobothria, $s c$ and $s f$ series each with five trichobothria.

\section{Etymology}

Latin adjective referring to the subterranean habitat of the species (Vasconcelos \& Ferreira 2017).

\section{Type material}

\section{Holotype}

BRAZIL • ' ; Minas Gerais, Presidente Juscelino municipality, Lapa d'Água cave; $18^{\circ} 33^{\prime} 46.68^{\prime \prime}$ S, 44ํ'40.01" W; 31 Jan. 2015; R.L. Ferreira leg.; ISLA 12788 [not examined].

\section{Paratypes}

BRAZIL 1 1 ; same collection data as for holotype; ISLA 12789 [not examined] 1 1 ; same collection data as for holotype; ISLA 12791 [not examined] • 1 क ; same collection data as for holotype; ISLA 12793 [not examined] • 1 क ; same collection data as for holotype; ISLA 12795 [not examined] • 1 \%; same collection data as for holotype; ISLA 12796 [not examined] • 1 \%; same collection data as for holotype; ISLA 12797 [not examined] • 1 O ; same collection data as for holotype; ISLA 12798 [not examined] $\bullet 1$; ; same collection data as for holotype; ISLA $12790 \bullet 1 \hat{\delta}$; same collection data as for holotype; ISLA $12792 \bullet 1$ o ; same collection data as for holotype; ISLA 12794 [not examined].

\section{Measurements}

See Table 4.

\section{Remarks}

See Vasconcelos \& Ferreira (2017) for more details about this species.

\section{Distribution}

Known only from the type locality.

\section{Natural history}

Lapa d'Água is a limestone cave with a constriction in the tunnel about $50 \mathrm{~m}$ from the entrance which makes the inner part of the cave more humid and stable in temperature than the outer part. Specimens of C. spelaeus were only collected in the area beyond the constriction, becoming more abundant in deeper areas of the cave, where ca 20 specimens were observed. According to Vasconcelos \& Ferreia (2017), no specimens of $C$. spelaeus were found in five other caves in the region, suggesting that the species is restricted to Lapa d'Água Cave. The surroundings of the cave entrance are well preserved and there 
were few signs of human disturbance. Potential prey species observed in the cave included crickets (Endecous sp.), cockroaches and moths.

\author{
Charinus sooretama sp. nov. \\ urn:1sid:zoobank.org:act:8E440763-D5D2-4177-9E29-A6B533A0604A \\ Figs 7E-F, 9C-D, 43, 75; Table 4
}

\title{
Diagnosis
}

This species may be separated from other Charinus in eastern South America by means of the following combination of characters: males with secondary sexual dimorphism; despite the different lengths of the pedipalps of males and females, the spine counts are similar, except for the tarsus, as females appear to possess fewer spines, perhaps associated with smaller size; pedipalp tarsus with two or three dorsal spines (Fig. 75D).

This species resembles $C$. brasilianus, but differs in possessing three spines on the pedipalp tarsus.

\section{Etymology}

Noun in apposition referring to the type locality, the Sooretama Biological Reserve, and the Sooretama Municipality, in which it is located.

\section{Type material}

Holotype

BRAZIL・ • ; Espírito Santo, Sooretama; A.P.L. Giupponi leg.; MNRJ 9245.

\section{Paratypes}

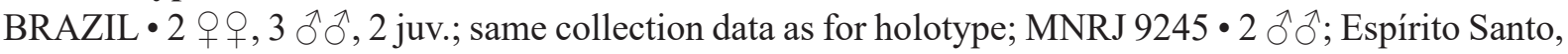
Estrada do Quirinão, Sooretama Biological Reserve; 1902'11.19" S, 4003'32.31" W; 19 Apr. 2006; Arachné Expedition leg.; MNRJ 9244.

\section{Description}

CARAPACE. Six anterior setae (Fig. 75A); frontal process triangular (Fig. 75C). Small granules densely scattered between ocular triads and among sulci. Median eyes well developed (Fig. 75C); median ocular tubercle reduced, with pair of setae; lateral eyes well developed, seta posterior to lateral ocular triad; lateral ocular triad well separated from carapace margin.

STERnUm. Tritosternum projected anteriorly with typical setation, long, surpassing base of pedipalp coxae (Fig. 75B); other sternal platelets narrow and concave, with pair of setae anteriorly on plaque and some smaller setae posteriorly; pentasternum with four setae anteriorly and pair of setae in membranous region.

Opisthosoma. Ventral sacs and ventral sac cover absent.

Genitalia. Female genital operculum with prominent setae posteromedially and some smaller setae near margin; gonopod sucker-like, sclerotized basally, with apex slightly curved outwards (Fig. 7E-F). Male gonopod with apical border of fistula and lateral lobe sclerotized; LoL2 fimbriate and LoD short (Fig. 9C-D).

CHELICERAE. Small tooth projecting from retrolateral surface of basal segment, opposite to bifid tooth; retrolateral surface of claw with continous row of setae, basally to medially; claw with seven teeth; row 
of four setae on prolateral surface of basal segment; bifid tooth on basal segment with dorsal cusp larger than ventral cusp.

PeDIPALPS. Coxal dorsal carina with prominent seta encircled by round carina and three setae on margin. Femur with five dorsal spines (one specimen with small spine between spines 2 and 3, spines 3 and 4, and distal to spine 4) and four (some females) or five ventral spines (Fig. 75E-F); two prominent setiferous tubercles between dorsal spine 1 and proximal margin; spine between spine 1 and proximal margin; long spine between ventral spines 3 and 4. Patella with five or six (one female) dorsal spines in primary series (Fig. 75E); prominent setiferous tubercle distal to spine I, one-third length of spine I; four ventral spines (Fig. 75F); prominent setiferous tubercle between spine I and distal margin. Tibia with ventral spine distally and two setae between spine and distal margin. Tarsus with three dorsal spines (only one female with three spines, others with setiferous tubercle instead), longer spines aligned in same row (Fig. 75D); third spine near base of proximal spine; among longer spines, proximal spine two-thirds length of distal spine; cleaning organ with 29-31 setae in ventral row.

LeGs. Tibia of leg I with 23 articles; tarsus I with 41 articles; first tarsal article similar in length to subsequent articles. Leg IV basitibia with four pseudo-articles, with sclerotized, denticulate margin at apex of articles; trichobothrium $b t$ situated submedial on pseudo-article; distitibia trichobothrium $b c$ situated closer to $s b f$ than to $b f, s c$ and $s f$ series each with five trichobothria.

\section{Measurements}

See Table 4.

\section{Distribution}

Known only from the type locality in the Sooretama National Park, Brazil.

\section{Natural history}

Collected under stones and fallen tree trunks.

Charinus souzai sp. nov. urn:1sid:zoobank.org:act:869B126A-1DF5-49FF-8619-851D88341869

Figs 43, 76-77; Table 4

\section{Diagnosis}

This species may be separated from other Charinus in eastern South America by means of the following combination of characters: compact habitus; reddish coloration; cheliceral claw with nine teeth; pedipalp tarsus with two spines (Fig. 76D); leg IV distitibia $s c$ and $s f$ series each with five trichobothria.

This species resembles $C$. brasilianus, but is smaller, with nine teeth on the cheliceral claw, compared with six or seven teeth in $C$. brasilianus. The male is unknown.

\section{Etymology}

Patronym honoring Dr Thiago Gonçalves-Souza for his contributions to arachnology and assistance in collecting arachnids in his home state of Espírito Santo, Brazil.

\section{Type material}

\section{Holotype}

BRAZIL • ' + Espírito Santo, Pancas, Fazenda Menezes; 19¹3'21.83" S, 4051'19.95" W; 27 May 2006; T.N. Bernabé and T.G. Souza leg.; MNRJ 9090. 
Paratypes

BRAZIL・19 9 \% ; same collection data as for holotype; MNRJ 9090.

\section{Description}

CARAPACE. Six anterior setae (Fig. 76A); frontal process triangular (Fig. 76C). Small granules densely scattered between ocular triads and among sulci. Median eyes well developed (Fig. 76C); median ocular tubercle reduced, with pair of setae; lateral eyes well developed, with seta posterior to lateral ocular triad; lateral ocular triad well separated from carapace margin.

STERnUM. Tritosternum projected anteriorly with typical setation, long, surpassing base of pedipalp coxae (Fig. 76B); other sternal platelets narrow and concave, with pair of setae anteriorly on plaque and some smaller setae posteriorly; pentasternum with four setae anteriorly and pair of setae near membranous region.

Opisthosoma. Ventral sacs and ventral sac cover absent.

Genitalia. Female genital operculum with short but prominent setae posteromedially (Fig. 77A-C); gonopod sucker-like, markedly sclerotized basally (Fig. 77A, C-D); constricted near apex, creating appearence of bottleneck (Fig. 77D); smooth border of genital operculum between gonopod and distal margin (Fig. 77E); slit sensilla on lateral margin of genital operculum (Fig. 77F). Male unknown.

CheliCERAE. Small tooth projecting slightly from retrolateral surface of basal segment, opposite to bifid tooth; retrolateral surface of chelieral claw with discontinous row of setae, extending basally to medially; claw with nine teeth; two rows of twelve setae on prolateral surface of basal segment; bifid tooth on basal segment with dorsal cusp larger than ventral cusp.

PEDIPALPS. Coxal dorsal carina with prominent setae encircled by round carina and three setae on margin. Femur with five dorsal spines and four or five ventral spines (Fig. 76E-F); spine between dorsal spines 2 and 3 in some specimens; two prominent setiferous tubercles between dorsal spine 1 and proximal margin; spine between ventral spine 1 and proximal margin. Patella with six dorsal spines in primary series (Fig. 76E); prominent setiferous tubercle distal to spine I, one-third length of spine I; four or five ventral spines (Fig. 76F); small setiferous tubercle between spine I and distal margin. Tibia with ventral spine distally and two setae between spine and distal margin. Tarsus with two dorsal spines, proximal spine half length of distal spine (Fig. 76D); cleaning organ with 29-30 setae in ventral row.

LeGs. Tibia of leg I with 23 articles; tarsus I with 41 articles; first tarsal article similar in length to subsequent articles. Leg IV basitibia with four pseudo-articles, with sclerotized, denticulate margin at apex of articles; trichobothrium $b t$ situated in proximal third of pseudo-article; distitibia trichobothrium $b c$ situated closer to $s b f$ than to $b f, s c$ and $s f$ series each with five trichobothria.

\section{Measurements}

See Table 4.

\section{Distribution}

Known only from the type localities.

\section{Natural history}

Found under stones. 
Charinus taboa Vasconcelos, Giupponi \& Ferreira, 2016

Fig. 43; Table 4

Charinus taboa Vasconcelos et al., 2016: 37-46, figs 1-23.

Charinus taboa - Miranda et al. 2016c: 29.

\section{Diagnosis}

Based on Vasconcelos et al. (2016), this species may be separated from other Charinus in eastern South America by means of the following combination of characters: median eyes reduced, with depressed median ocular tubercle; lateral eyes reduced, pale; tritosternum slightly forked anteriorly; female gonopod sucker-like, with irregular opening and margins with small fold; male gonopod with pairs of PI and LoL1 emerging from each side of Fi with narrow prolongations, and pairs of LoD and LoL2 claw-shaped, emerging from interior of upper part of Fi; pedipalps sexually dimorphic; pedipalp femur with four or (usually) five dorsal spines and five (usually) or six ventral spines; pedipalp patella with six (usually) or seven dorsal spines and four ventral spines; leg IV distitibia $s c$ and $s f$ series each with five trichobothria.

\section{Etymology}

Noun in apposition referring to the name of the cave in which most of the specimens were collected (Vasconcelos et al. 2016).

\section{Type material}

\section{Holotype}

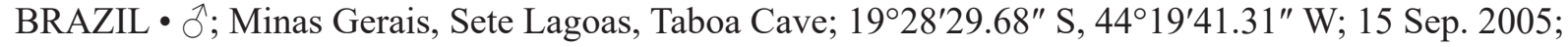
R.L. Ferreira leg.; MNRJ 9091.

\section{Paratypes}

BRAZIL • 1 q, 1 juv.; same collection data as for holotype; MNRJ 9092 [not examined] 1 1 ; same collection data as for holotype; ISLA 4019 [not examined] 11 o ; same collection data as for holotype; ISLA 4020 [not examined] 1 1 ; same collection data as for holotype; ISLA 4021 [not

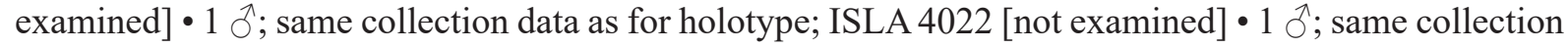
data as for holotype; ISLA 4023 [not examined] - 1 juv. ô; same collection data as for holotype; ISLA 4024 [not examined] • 1 juv. $\delta^{\lambda}$; same collection data as for holotype; ISLA 4030 [not examined] •

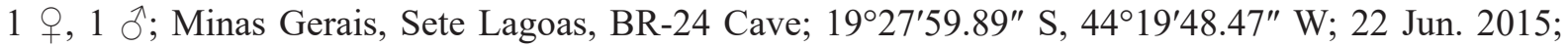
F. Bondezan leg.; CAVAISC ARAC 7 • 1 क; Minas Gerais, Sete Lagoas, BR-24 Cave; 18 Dec. 2015; F. Bondezan leg.; CAVAISC ARAC 8.

\section{Measurements}

See Table 4.

\section{Distribution}

Known only from the type localites.

\section{Natural history}

Specimens of C. taboa were found in two of the ten caves (Taboa Cave and BR-24 Cave) surveyed in the Bambui speleological group, near the city of Sete Lagoas, Minas Gerais, Brazil. The caves are located less than $500 \mathrm{~m}$ apart and likely connected by meso-caverns (Vasconcelos et al. 2016). About fifteen adults and ten juveniles were observed in Taboa Cave, all in the inner part, near a large watercourse. 
Adults were mainly found on the walls and ceiling of the cave, whereas juveniles were often under rocks. Specimens of C. taboa were only found in the deepest part of the BR-24 Cave. Six specimens were found during the dry season and only one during the rainy season. Potential prey species observed in the cave included moths and crickets. One specimen was observed preying on a noctuid moth during the day. The external native vegetation and rock outcrops surrounding these caves are severely degraded or in some cases completely destroyed by human activites, such as mining.

Charinus troglobius Baptista \& Giupponi, 2002

Fig. 43; Table 4

Charinus troglobius Baptista \& Giupponi, 2002: 106-110, figs 1-14.

Charinus troglobius - Baptista \& Giupponi 2003: 79-80. — Trajano \& Bichuette 2010: 12. — Miranda \& Giupponi 2011: 66, fig. 13. - Vasconcelos et al. 2013: 496, fig. 12. — Monte et al. 2015: 5. Torres-Contreras et al. 2015: 145-146. — Vasconcelos \& Ferreira 2016: 185. - Miranda et al. 2016c: 19, 29.

\section{Diagnosis}

Based in part on Baptista \& Giupponi (2002), this species may be separated from other Charinus in eastern South America by means of the following combination of characters: corners of anterior carapace margin produced into truncated processes; median eyes and median ocular tubercle absent; lateral eyes reduced to small whitish spot on each side of carapace, without clearly defined lens; sternal platelets narrow, convex and rounded, tritosternum small, slightly larger than tetrasternum; pedipalps articulating transversally with cephalothorax, but not horizontally; pedipalp spines longer than in other species of genus; pedipalp femur with two dorsal spines and two ventral spines; pedipalp tarsus with two long spines, second spine longer than first; proventral corners of walking legs spiniform; leg IV basitibia + distitibia with 17 trichobothria $(1+16)$; leg IV basitarsus much longer than distitarsus.

This is the most markedly troglomorphic Brazilian species of Charinus, in which the eyes are completely absent and the leg articles and pedipalp spines extremely elongated.

\section{Etymology}

Latin adjective referring to the troglobitic habitus of the species (Baptista \& Giupponi 2002).

\section{Type material}

\section{Holotype}

BRAZIL • O'; Bahia, Carinhanha, Serra do Ramalho, Gruna do ZéBastos; $14^{\circ} 16^{\prime} 53.92^{\prime \prime}$ S, 43ํ46'24.29" W; 28 Jun. 2001; R.L.C. Baptista and A.P.L. Giupponi leg.; MNRJ 9067.

\section{Paratypes}

BRAZIL 1 C; same collection data as for holotype; MNRJ $9069 \bullet 1$; same collection data as for

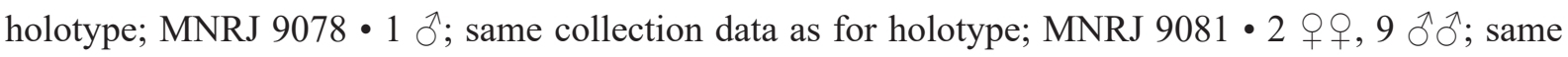
collection data as for holotype; MNRJ $9068 \bullet 1$ ㅇ, 1 त; same collection data as for holotype; IES ex MNRJ 9079 [not examined] • 1 त; same collection data as for holotype; MZSP ex MNRJ 9080 [not

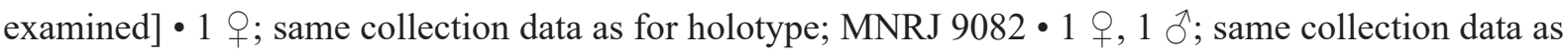
for holotype; IES 3.2972 and IES 3.2973 [not examined]. 


\section{Additional material}

BRAZIL • 1 juv.; Bahia, Serra do Ramalho, Lapa do Boqueirão; 29 Jun. 2001; R.L.C. Baptista and A.P.L. Giupponi leg.; MNRJ 9034.

\section{Supplementary description}

CARAPACE. Margin of carapace ventral to lateral eyes with rounded projection; six anterior setae; frontal process triangular, with oval apex, not visible in dorsal view. Small granules densely scattered between ocular triads and among sulci. Median eyes and median ocular tubercle absent; pair of setae in place of median ocular tubercle; lateral eyes reduced to three small, whitish lenses, with seta posterior to lateral ocular triad.

Sternum. Tritosternum short, with four long setae and several smaller setae posteriorly; other sternal platelets narrow and concave, with pair of setae anteriorly on plaque and some smaller setae posteriorly; pentasternum with four setae anteriorly and seta on membranous region.

OpISTHOSOMA. Ventral sacs and ventral sac cover absent.

Genitalia. Female genital operculum with prominent setae posteromedially and some smaller setae near margin; gonopod sucker-like and barrel shaped. Male gonopod with base of fistula and lateral lobe sclerotized; lateral lobe 2 fimbriate.

Chelicerae. Small tooth projecting from retrolateral surface of basal segment, opposite to bifid tooth; retrolateral surface of claw with continous row of setae, basally to medially; claw with ten teeth; transverse row of setae on prolateral surface of basal segment absent, with longitudinal row of dense setae, instead; bifid tooth on basal segment with dorsal cusp larger than ventral cusp.

PedipalPs. Coxal dorsal carina with six prominent setae encircled by round carina and three setae on margin. Femur with two or three (dextral pedipalp of male paratype) dorsal spines and two ventral spines; dorsal spines situated in distal third; four prominent setiferous tubercles between dorsal spine 1 and proximal margin; setiferous tubercle between ventral spine 1 and proximal margin. Patella with three dorsal spines in primary series; prominent setiferous tubercle distal to spine I, one-third length of spine I, and prominent setiferous tubercle between spines I and II, slightly shorter than first setiferous tubercle; two ventral spines in primary series; extra spine between spine I and distal margin. Tibia with ventral spine distally and three prominent setiferous tubercles proximal to ventral spine; twelve or thirteen setae between spine and distal margin. Tarsus with two dorsal spines, proximal spine one-third length of distal spine; cleaning organ with 29-31 setae in ventral row.

Legs. Tibia of leg I with 23 articles (up to 47 on regenerated legs); tarsus I with 40-42 articles (up to 62 on regenerated legs); first tarsal article shorter than second and subsequent articles. Leg IV basitibia with four pseudo-articles, with sclerotized, denticulate margin projecting from apex of articles; trichobothrium $b t$ situated in proximal third of pseudo-article; distitibia trichobothrium $b c$ situated closer to $s b f$ than to $b f, s c$ and $s f$ series each with five trichobothria.

\section{Measurements}

See Table 4.

\section{Distribution}

Known from Carinhanha in the Brazilian state of Bahia. 


\section{Natural history}

According to Baptista \& Giupponi (2002), all specimens were collected on muddy walls near water bodies, in the dark zone of caves. A troglomorphic harvestman, Giupponia chagasi Pérez \& Kury, 2002, was also found in the cave. Other taxa observed in the cave include spiders (Ctenidae Keyserling, 1877: Ctenus sp.), millipedes (Chelodesmidae Cook, 1895), crickets (Phalangopsidae Blanchard, 1845: possibly Endecous sp.), cockroaches (Epilampridae Brunner von Wattenwyl, 1865) and beetles (Cholevidae Kirby, 1837).

Charinus una sp. nov. urn:1sid:zoobank.org:act:B2646A6F-9AD9-47A1-A8A4-22B262034D8F

Figs 43, 78-79; Table 4

\section{Diagnosis}

This species may be separated from other Charinus in eastern South America by means of the following combination of characters: median and lateral eyes present (Fig. 78A); carina ventral to lateral eyes; cheliceral claw with four or five denticles and two patches of setae on retrolateral surface; secondary sexual dimorphism absent; pedipalp femur with three dorsal spines and four ventral spines (Fig. 78E-F); tibia of leg I with 23 articles, tarsus I with 41 articles; leg IV distitibia $s f$ and $s c$ series each with five trichobothria.

This species resembles $C$. acaraje, but is smaller in size, with four or five teeth on the cheliceral claw, and five trichobothria in the $s c$ and $s f$ series of the leg IV distitibia.

\section{Etymology}

Noun in apposition referring to the type locality, the Una Biological Reserve, and the Una Municipality, in which it is located.

\section{Type material}

\section{Holotype}

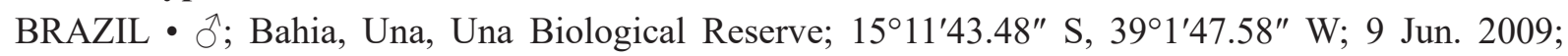
A. Chagas, Jr, A. Kury, D. Pedroso, A.P.L. Giupponi and V. Dill leg.; MNRJ 9131.

\section{Paratypes}

BRAZIL • 1 q; same collection data as for holotype; MNRJ 9131 • 1 q; Mata do Lixão; 9 Jun. 2009; A. Chagas Jr, A. Kury, D. Pedroso, A.P.L. Giupponi and V. Dill leg.; MNRJ $9298 \bullet 1$ + 1 juv.; Mata do Lixão; 9 Jun. 2009; A. Chagas, Jr, A.P.L. Giupponi, D. Pedroso and A. Kury leg.; MNRJ 9132.

\section{Additional material}

BRAZIL - 1 juv.; Bahia, Una, Una Biological Reserve, Trilha do Rio Maruim II; $15^{\circ} 10^{\prime} 05.1^{\prime \prime}$ S, 3903'52.6" W; 21 Aug. 2014; A.A. Nogueira leg.; MZSP 67527.

\section{Description}

CARAPACE. Curved carina between ocular triads and carapace margin, closer to margin than eyes, and with small transverse projection medially. Frontal process large, triangular, not visible in dorsal view (Fig. 78C). Median eyes and median ocular tubercle present (Fig. 78A); median ocular tubercle shallow, 
slightly higher than carapace surface, with pair of small setae. Lateral eyes well developed, pale, small seta posterior to each lateral ocular triad.

STERNUM. Tritosternum projected anteriorly, surpassing base of pedipalp coxae, and rounded posteriorly (Fig. 78B). Medial platelet (tetrasternum) and third platelet (pentasternum) forming single convex platelet, with pair of large setae anteriorly, and several small setae posteriorly. Metasternum with two anterior setae in membranous region and two setae posteriorly.

Opisthosoma. Ventral sacs and ventral sac cover absent.

Genitalia. Female genital operculum with posterior margin slightly convex and several setae along margin and on surface (Fig. 79A-C). Gonopods sucker-like, with large opening and small sclerotized area basally (disconnected from each other) (Fig. 79A, C-D); smooth surface between gonopods and posterior margin of genital operculum (Fig. 79E); slit sensilla on lateral margin of genital operculum (Fig. 79F). Male gonopod with LoL2 not fimbriate, slightly sclerotized.

Chelicerae. Small, flat tooth in retrolateral row of basal segment. Prolateral surface with transverse row of seven small setae, from ventral to dorsal. Claw with four or five teeth. Three setae, retrolateral, retromedial, and prolateral, on dorsodistal margin, near membranous region of claw. Retrolateral surface of claw with two small patches of setae, basally and medially.

PeDIPALPS. Coxal dorsal carina with one or two small setae and two setae on anterior margin of round carina. Femur with three distinct setiferous tubercles proximal to spine 1 (Fig. 78E); primary series with three dorsal spines; four ventral spines (Fig. 78F); large ventral spine proximal to spine 1, between spine 1 and proximal margin. Patella with three dorsal spines (Fig. 78E); setiferous tubercle distal to I and about one-third length of spine I; two ventral spines decreasing in length; setiferous tubercle between spine I and distal margin. Tibia with two dorsal spines, proximal spine two-thirds length of distal spine; ventral spine situated in distal half of tibia; prominent setiferous tubercle near base of spine; three long setae between spine and distal margin. Tarsus with two dorsal spines, distal spine one-third length of tarsus, proximal spine one-third length of distal spine (Fig. 78D); ventral row of cleaning brush with 31-32 setae.

Legs. Tibia of leg I with 23 articles; tarsus I with 41 articles. Leg IV basitibia with four pseudoarticles; trichobothrium $b t$ situated in proximal third; distal apex of basitibial pseudo-articles with dark, denticulate projection; distitibia trichobothrium $b c$ situated closer to $s b f$ than to $b f ; s c$ and $s f$ series each with five trichobothria; distitarsus with distinct white annulus distally on first article.

\section{Measurements}

See Table 4.

\section{Distribution}

Known only from the type locality.

\section{Natural history}

Found in protected and disturbed areas, in the vicinity of a dumping ground. 


\section{Key to the identification of the species of Charinus in eastern Africa}

1. Median and lateral eyes well developed (Fig. 81A); pedipalp femur with five or six dorsal spines and four ventral spines (Fig. 81); pedipalp patella with six or seven dorsal spines and five or six ventral spines (Fig. 81A); pedipalp tarsus with three dorsal spines .

C. madagascariensis Fage, 1954 (Fig. 81)

- Median and lateral eyes reduced (Fig. 82A); pedipalp femur with three dorsal spines and three ventral spines (Fig. 82E-F); pedipalp patella with four dorsal spines and three ventral spines (Fig. 82E-F); pedipalp tarsus with one dorsal spine (Fig. 82C)

C. susuwa sp. nov. (Fig. 82)

Charinus diblemma Simon, 1936, nomen dubium

Charinus diblemma Simon in Fage \& Simon, 1936: 301.

Charinus diblemma - Fage 1939: 155. — Weygoldt 1972b: 123; 1994: 244; 2000b: 340, 346. — Delle

Cave 1986: 152, fig. II (designated as nomen dubium).

\section{Etymology}

Although the etymology of the species name was unspecified, 'diblemma' refers to the presence of two eyes, from the Latin 'di-' ('two') and the Greek 'blemma' ('glance'), as Simon (1936) considered this species to possess only the median pair.

\section{Type material}

\section{Holotype}

TANZANIA • juv.; Zanzibar Island, Grotte de Haitajwa; [06 $15^{\prime} 18.92^{\prime \prime}$ S, 39¹5'31.50" E]; 24 Apr. 1912; Alluaud and Jeannel leg.; MNHN 537.

\section{Remarks}

The holotype is small and very whitish, making it difficult to see details, and the opisthosoma is missing, but some characters could be observed. In the original description, Simon (1936) mentioned that $C$. diblemma lacks lateral eyes, but small, whitish lateral eyes, were evident near the lateral margin of the carapace. The median eyes were also present. The sternum platelets were not yet formed. The cheliceral claw bears five teeth but it was impossible to observe teeth on the basal segment. Two dorsal spines and three ventral spines were evident on the pedipalp femur; three or four dorsal spines and two ventral spines were evident on the patella; and two dorsal spines on the tarsus. The tibia and tarsus of antenniform leg I comprise 21 and 37 articles, respectively. The basitibia of leg IV consists of three pseudo-articles.

The immaturity and poor preservation of the holotype renders it impossible to form an opinion regarding the taxonomic validity of $C$. diblemma until such time as adults can be collected from the vicinity of the type locality. Delle Cave (1986) designated C. diblemma as nomen dubium, not by Weygoldt (1994), as stated in Harvey $(2003,2013)$.

Charinus jeanneli Simon, 1936, nomen dubium

Charinus jeanneli Simon in Fage \& Simon, 1936: 300-301.

Charinus jeanneli - Fage 1939: 153, 156, 158, 160, fig. 2a-b; 1954: 182. — Lawrence 1969: 83, 86. Weygoldt 1972b: 123; 1994: 244; 2000b: 341, 346. — Delle Cave 1986: 152, fig. II (designated as nomen dubium). 
Non Charinus jeanneli - Fage 1946a: 260-262, fig. 2, misidentification (see Charinus madagascariensis Fage, 1954).

\section{Etymology}

Patronym honoring Dr R. Jeannel (Fage \& Simon 1936).

Type material (examined)

\section{Syntypes}

TANZANIA - 1 protonymph, 1 deutonymph; Tanga, Grotte C du Kulumuzi; [0504'34.28" S, 3902'30.40" E]; 16 Apr. 1912; Alluaud and Jeannel leg.; MNHN 536.

\section{Remarks}

The syntypes are small and whitish juveniles (protonymph and deutonymphs), as noted by Delle Cave (1986). The larger syntype is well preserved, but missing the antenniform leg I, whereas the smaller syntype is missing the opisthosoma.

The tritosternum of the larger syntype is projected anteriorly, surpassing the pedipalp coxae, and the other sternal platelets are small, rounded and concave, each with a pair of setae. The pedipalp femur bears two dorsal spines and two ventral spines and the patella bears three dorsal spines and two ventral spines. The basitibia of leg IV consists of four pseudo-articles.

The pedipalp of the smaller syntype bears two dorsal spines and two ventral spines on the femur, three dorsal spines and two ventral spines on the patella, and one dorsal spine on the tarsus. The tibia and tarsus of antenniform leg I have 23 articles and 30 articles, respectively.

In addition to these specimens, the tube contains a detached pedipalp patella and tibia, with three dorsal spines and two ventral spines on the patella, and with two dorsal spines and one ventral spine on the tibia.

The immaturity and poor preservation of the syntypes renders it impossible to form an opinion regarding the taxonomic validity of $C$. jeanneli until such time as adults can be collected from the vicinity of the type locality. Delle Cave (1986) designated C. jeanneli as nomen dubium not Weygoldt (1994), as stated by Harvey $(2003,2013)$.

Charinus madagascariensis Fage, 1954

Figs $10 \mathrm{~K}-\mathrm{L}, 80-81$; Table 5

Charinus madagascariensis Fage, 1954: 183-184, figs 1, 3.

Charinus madagascariensis - Lawrence 1969: 86. — Remillet 1973: 142. — Legendre 1972: 435. — Weygoldt 1972b: 123; 2000b: 346. — Delle Cave 1986: 157, fig. II. — Harvey 2003: 6.

Non Charinus jeanneli Simon, 1936 - Fage 1946a: 260-262, fig. 2 (misidentification).

\section{Diagnosis}

Charinus madagascariensis differs from C. africanus and C. fagei in the count of spines on the pedipalp tarsus, with three spines in $C$. madagascariensis compared with two spines in the other species. It differs from C. loko sp. nov. in the higher count of spines on the pedipalp segments, and from C. milloti and $C$. susuwa sp. nov. in the well-developed median and lateral eyes. 


\section{Etymology}

Although unspecified, the name of the species is evidently an adjective referring to Madagascar, the country in which the species was found.

\section{Type material}

\section{Syntypes}

MADAGASCAR $・ 1$ ○, 1 ठे [without gonopod], 1 adult [without gonopod], 2 juv.; Antsiranana Province, Nosy Bé Island, Réserve naturelle de Lokoubé [as Lokobe]; [1323'59.47" S, 48¹8'58.76" E]; Sep. 1947; J. Millot leg.; MNHN.

\section{Additional material}

MADAGASCAR • 1 juv.; same collection data as for syntypes; MNHN $\bullet 1 \hat{\partial}$ and 2 juv.; same collection

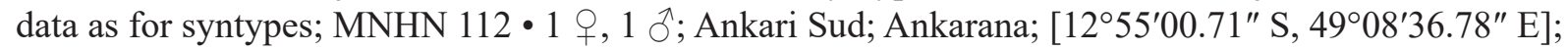

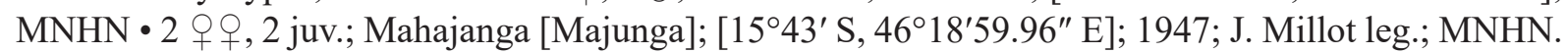

\section{Redescription}

CARAPACE. Six short anterior setae (Fig. 81A-B); frontal process long; anterolateral border of carapace slightly projected anteriorly. Small granules densely scattered between ocular triads and among sulci. Median eyes well developed, median ocular tubercle shallow, with pair of setae (Fig. 81A-B); lateral eyes well developed, seta posterior to lateral ocular triad; lateral ocular triad well separated from carapace margin.

STERnUm. Tritosternum projected anteriorly with typical setation; other sternal platelets wide, with one seta at each lateral border and some smaller setae in between; pentasternum with two setae anteriorly and pair of setae in membranous region.

Opisthosoma. Ventral sacs and ventral sac cover absent.

GeNiTALIA. Anterior margin of female genital operculum with rounded projection medially and suckerlike gonopod; genital operculum with several prominent setae ventrally, and several longer, narrower setae near margin; gonopod unsclerotized basally. Male gonopod dorsal lobe with apex projected slightly; lateral lobe 2 fimbriate

CheliCERAE. Small tooth projecting from retrolateral surface of basal segment, opposite to bifid tooth (Fig. 10L); retrolateral surface of claw with row of setae extending basally to medially; claw with five teeth (Fig. 10K-L); row of 9-11 setae on prolateral surface of basal segment; bifid tooth on basal segment with dorsal cusp larger than ventral cusp.

Pedipalps. Coxal dorsal carina with three setae on margin and without seta encircled by round carina. Femur with five or six dorsal spines (distal spine very small) and four ventral spines; small spine between dorsal spines 1 and 2, and spines 2 and 3 (Fig. 81A-B); small spines between all ventral spines of primary series; large spine proximal to ventral spine 1, one-third length of spine 1 ; three prominent setiferous tubercles between spine 1 and proximal margin, first two spines long, with geminate base. Patella with six or seven dorsal spines; prominent setiferous tubercle distal to spine I, one-third length of spine I (Fig. 81A-B); five or six ventral spines; broad spine distal to spine I, between spine I and distal margin, one-third length of spine I. Tibia with ventral spine distally and seta between spine and distal margin. Tarsus with three dorsal spines, one medially on tarsus and two near proximal margin; dorsalmost spine larger among the proximal spines, about twice length of ventralmost spine; ventralmost and distal spines aligned and subequal in length; some long, slender setae between distal spine and distal margin; cleaning organ with 28-29 setae in ventral row. 
LEGS. Tibia of leg I with 23 articles; tarsus I with 41 articles; first tarsal article almost four times length of second article (mean length of first article: $0.78 \mathrm{~mm}$; mean length of second article: $0.22 \mathrm{~mm} ; \mathrm{n}=4$ ).

Leg IV basitibia with four pseudo-articles, trichobothrium $b t$ situated in distal third of pseudo-article; distitibia trichobothrium $b c$ situated closer to $s b f$ than to $b f, s c$ and $s f$ series each with five trichobothria.

\section{Measurements}

See Table 5.

\section{Distribution}

Known from northern Madagascar.

Charinus susuwa sp. nov.

urn:lsid:zoobank.org:act:2DD78A8B-3E54-4616-9425-B62D7B360D8E

Figs 80,82 ; Table 5

\section{Diagnosis}

This species may be separated from C. madagascariensis and other African species of Charinus by means of the following combination of characters: troglobitic habitus, with pale color, elongated pedipalp spines, and eyes extremely reduced, to eyespots below tegument (Fig. 82A); pedipalp femur with long spine between dorsal spines 1 and 2 (Fig. 82E); pedipalp patella with long ventral spine between spine I and distal margin (Fig. 82F); tarsus with one dorsal spine (Fig. 82C).

The tarsus and tibia of leg I are missing from the holotype.

\section{Etymology}

Noun in apposition referring to the type locality, Mt Susuwa.

\section{Type material}

\section{Holotype}

KENYA • O; Mt. Susuwa; [01¹0’34.11" S, 36²0'55.92" E]; Mar. 1967; A.J. Sutcliffe leg.; in lava, tunnel 3 (dark zone); BMNH.

\section{Description}

CARAPACE. Six anterior setae; frontal process triangular (Fig. 82D). Small granules densely scattered between ocular triads and among sulci. Median eyes reduced to eyespots below tegument; median ocular tubercle absent (Fig. 82A); pair of setae in place of median ocular tubercle; lateral eyes extremely reduced, present only as small yellowish eyespots below tegument.

STERnUm. Tritosternum projected anteriorly with typical setation, long, greatly surpassing base of pedipalp coxae; other sternal platelets narrow and concave, with pair of setae anteriorly on plaque and some smaller setae posteriorly; pentasternum with four setae anteriorly and without seta on membranous region.

Opisthosoma. Ventral sacs and ventral sac cover absent.

GENITALIA. Female genital operculum with posterior margin straight; gonopod sucker-like with wide, rounded apex. 


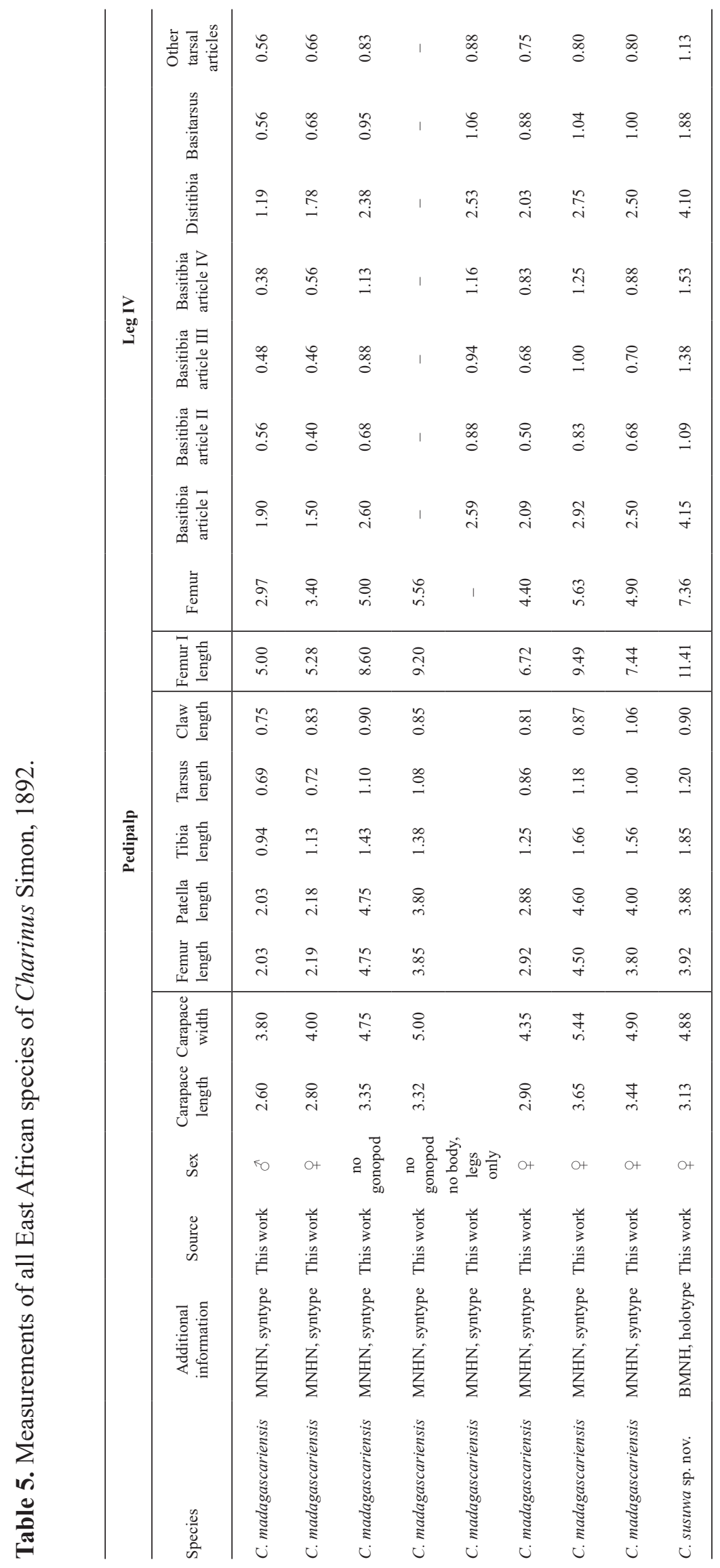


CHELICERAE. Small, flat tooth on retrolateral surface of basal segment, opposite to bifid tooth; retrolateral surface of claw with continous row of setae, basally to medially; claw with five teeth; row of twelve setae on prolateral surface of basal segment; bifid tooth on basal segment with dorsal cusp larger than ventral cusp.

PeDIPALPS. Coxal dorsal carina with four prominent setae encircled by round carina and three setae on margin. Femur with three dorsal spines and three ventral spines (Fig. 82E-F); long spine between dorsal spines 1 and 2; two prominent setiferous tubercles between dorsal spine 1 and proximal margin; long spine between ventral spine 1 and proximal margin. Patella with four dorsal spines in primary series, proximal three spines long, fourth spine shorter (Fig. 82E); prominent setiferous tubercle distal to spine I, one-fourth length of spine I; three ventral spines (Fig. 82F); prominent spine between spine I and distal margin. Tibia with ventral spine distally and two setae between spine and distal margin. Tarsus with long dorsal spine, half length of tarsus (Fig. 82C); cleaning organ with 26 setae in ventral row.

LEGS. Leg IV basitibia IV with four pseudo-articles, with sclerotized, denticulate projection at apex of articles; trichobothrium $b t$ situated submedially on pseudo-article; distitibia trichobothrium $b c$ situated closer to $s b f$ than to $b f, s c$ and $s f$ series each with five trichobothria.

\section{Measurements}

See Table 5.

\section{Distribution}

Known only from the type locality.

\section{Natural history}

This species was collected from a lava tunnel in the ancient volcano Mt Susuwa. The habitat and habitus indicate it is troglobitic. Phrynichus exophthalmus was also recorded from Mt Susuwa (Weygoldt 1998b).

\section{Key to the identification of the species of Charinus in western Africa}

1. Median and lateral eyes reduced (Fig. 93A); cheliceral claw with four teeth; pedipalp femur with five ventral spines (Fig. 93D) Charinus milloti Fage, 1939 (Fig. 93)

- Median and lateral eyes unmodified; cheliceral claw with more than four teeth; pedipalp femur with three or four ventral spines .

2. Cheliceral claw with nine teeth; pedipalp patella with four ventral spines (Fig. 89C)......

Charinus fagei Weygoldt, 1972 (Fig. 89)

- Cheliceral claw with fewer than six teeth; pedipalp patella with two or three ventral spines.....

3. Pedipalp patella with four dorsal spines and three ventral spines; pedipalp tarsus with three dorsal spines

Charinus loko sp. nov. (Figs 90-92)

- Pedipalp patella with three dorsal spines and two ventral spines; pedipalp tarsus with two dorsal spines

4. Cheliceral claw with six teeth; genital operculum with median projection

Charinus africanus Hansen, 1921 (Figs 84-88)

- Cheliceral claw with four teeth; genital operculum slightly convex but without median projection 
Charinus africanus Hansen, 1921

Figs 83-88; Table 6

Charinus africanus Hansen, 1921: 7-9, pl. 1 fig. 1a-c.

Charinus africanus - Hansen 1930: 374, pl. 14 fig. 6a. - Mello-Leitão 1931: 54. — Lawrence 1968: 2. - Weygoldt 1972b: 123; 1999c: 104; 2000b: 346; 2008: 224-226, figs 1-3. - Delle Cave 1986: 156, fig. II. - Harvey 2003: 4. - Vasconcelos et al. 2013: 488.

Charinus seychellarum Kraepelin, 1898 - Fage 1939: 154-155 (misidentification, in part, see Charinus fagei Weygoldt, 1972).

\section{Diagnosis}

This species may be separated from C. madagascariensis and other African species of Charinus by means of the following combination of characters: blackish colouration in life; female genital operculum with steep ventral flexure at about two-thirds of its length, covered with many long, prominent setae; posterior margin of genital operculum elongated medially; setae on dorsal spines of pedipalp patella situated on prominent setiferous tubercles.

This is the only species of Charinus in which the female gonopod is finger-like. Although the gonopod resembles that of Sarax, the species was placed sister to all other species of Charinus in the phylogeny (Fig. 1). All other morphological characters, as well as its distribution, are consistent with its placement in the genus Charinus.

\section{Etymology}

Although unspecified, the species name is evidently an adjective referring to the African continent where the species occurs.

\section{Type material}

Syntypes [four of six specimens mentioned by Hansen (1921) examined, others not located] EQUATORIAL GUINEA • 2 q 9 ; Annobón; [01²4'59.97" S, 05³7'59.85" E]; 400-500 m a.s.1.; May 1902; L. Fea leg.; ZMUC 24552 • 1 ô, 1 ex. missing opisthosoma; same collection data as for preceding; MNHN] - [specimen mentioned by Hansen (1921) not located]; same locality as for preceding; Apr. 1902; 0-500 m a.s.1.; L. Fea leg.

SÃO TOMÉ AND PRÍNCIPE • 1 đ [one of three specimens mentioned by Hansen (1921), others not located]; St Thome Agua Izé; [00¹3'05.76" N, 06²43'37.79" E]; 400-700 m a.s.1.; Dec. 1900; L. Fea leg.; MNHN [examined] - [Hansen (1921) mentions two specimens, but vial contains 3 o 9 ]; St Thome, Visto Alegre [as Vista Alegre]; [00 $18^{\prime} 42.96^{\prime \prime}$ N, 06 $41^{\prime} 04.60^{\prime \prime}$ E]; 200-300 m a.s.1.; Sep.-Oct. 1900; ZMUC 24545 - 7 ex. [not located]; Príncipe, Roca Infante Don Henrique; [0133'57.52" N, 07²4'17.31" E]; Jan.-Mar. 1901; 100-300 m a.s.1. [not examined].

\section{Additional material}

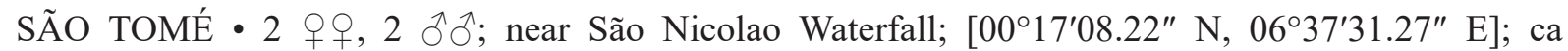
800 m a.s.1.; 8-16 Oct. 2006; S. and P. Weygoldt leg.; under stones and wood; AMCC [LP 6943].

\section{Supplementary description}

CARAPACE. Median eyes and median ocular tubercle well developed, with pair of setae; lateral eyes well developed, with seta posterior to lateral ocular triad; lateral ocular triad well separated from margin of carapace. 
STERNUM. Tritosternum projected anteriorly with typical setation; other sternal platelets each forming single small rounded sclerites, with pair of setae anteriorly; pentasternum with four setae anteriorly and without seta in membranous region.

Chelicerae. Small flattened tooth on retrolateral surface of basal segment, opposite to bifid tooth (Fig. 84A-B); retrolateral surface of claw with small row of setae subdorsally (Fig. 84C); claw setae with mop-like apex (Fig. 84I); claw with six teeth (Fig. 84D); row of thirteen setae on prolateral surface of basal segment; setae on the basal segment serrate from proximal third to apex (Fig. 84G-H); dorsal setae on basal segment acuminate (Fig. $84 \mathrm{~J}$ ); bifid tooth on basal segment with dorsal cusp larger than ventral cusp; hinge between basal segment and claw with slit sensilla (Fig. 84E-F).

OpisTHosoma. Ventral sacs and ventral sac cover absent.

GENITALIA. Female genital operculum with marked transverse ventral flexure and median elongation with prominent setae (Weygoldt 2008: 226, figs 2c, 3a); gonopods with two small cones, each terminating in small, narrow, finger-like process (Weygoldt 2008: 227, figs 2c, 3b-d); gonopod sclerotized basally, between projections extending to frontal region. Male gonopod with broad sclerotized area on margin of fistula and lateral lobes; gonopod rectangular in dorsal view (Fig. 85C), with curved median lobes (Figs 85A-B); LoD and LoL1 forming shell-like structure with spiny apex (Fig. 85A-B, F-G); LoL with fimbriate apex (Fig. 85E); processus internus slightly curved, with spiny apex (Fig. 85E). Spermatophore minute, scarcely more than $1 \mathrm{~mm}$ high; comprising stalk, small foot, and spermatophore head, with two parts: base, bent forward, where structure holding sperm sac is suspended, and apex, bent down; sperm package large, unpaired and held by two thick arm-like processes.

Pedipalps. Coxal dorsal carina with two or three setae encircled by round carina and four setae on margin. Femur with three or four dorsal spines and four ventral spines; two prominent setae and small setiferous tubercle between dorsal spine 1 and proximal margin. Patella with three dorsal spines and two prominent setiferous tubercles proximal to spine 3; prominent setiferous tubercle distal to spine I, one-third length of spine I; setae on dorsal spines of patella situated on prominent setiferous tubercle; patella with two ventral spines; setiferous tubercle between spine I and distal margin. Tibia with ventral spine distally and three setae between spine and distal margin. Tarsus with two dorsal spines, distal spine curved, long, half length of tarsus, proximal spine half length of distal spine; slit sensillae distally (Fig. 86A-B); tarsus covered with gland openings (Fig. 86C-D), and two types of setae, one smooth (Fig. 86E), other rugose (Fig. 86F); cleaning organ with 31-34 setae in ventral row; dorsal row of modified setae on cleaning organ clavate with serrate margins (Fig. 87E); ventral row of modified setae on cleaning organ acuminate with smooth margins (Fig. 87F); surface between dorsal and ventral rows of setae of cleaning organ with multiple projections (Fig. 87G-H).

LeGs. Tibia of leg I with 23 articles (up to 30 on regenerated legs); tarsus I with 41 articles (up to 45 on regenerated legs); first tarsal article 1.7 times as long as second article. Leg IV basitibia with four pseudo-articles; trichobothrium $b t$ situated submedially on pseudo-article; distitibia trichobothrium $b c$ variable in position, closer to $b f$, equidistant between $b f$ and $s b f$, or closer to $s b f, s c$ and $s f$ series each with five trichobothria (Fig. 88B-C). Arolium (Fig. 87A) with truncus presenting linearly organized microstructures (Fig. 87B), whereas labium with randomly patterned microstructure (Fig. 87C).

\section{Measurements}

See Table 6.

\section{Distribution}

Known from Equatorial Guinea and São Tomé and Príncipe. 


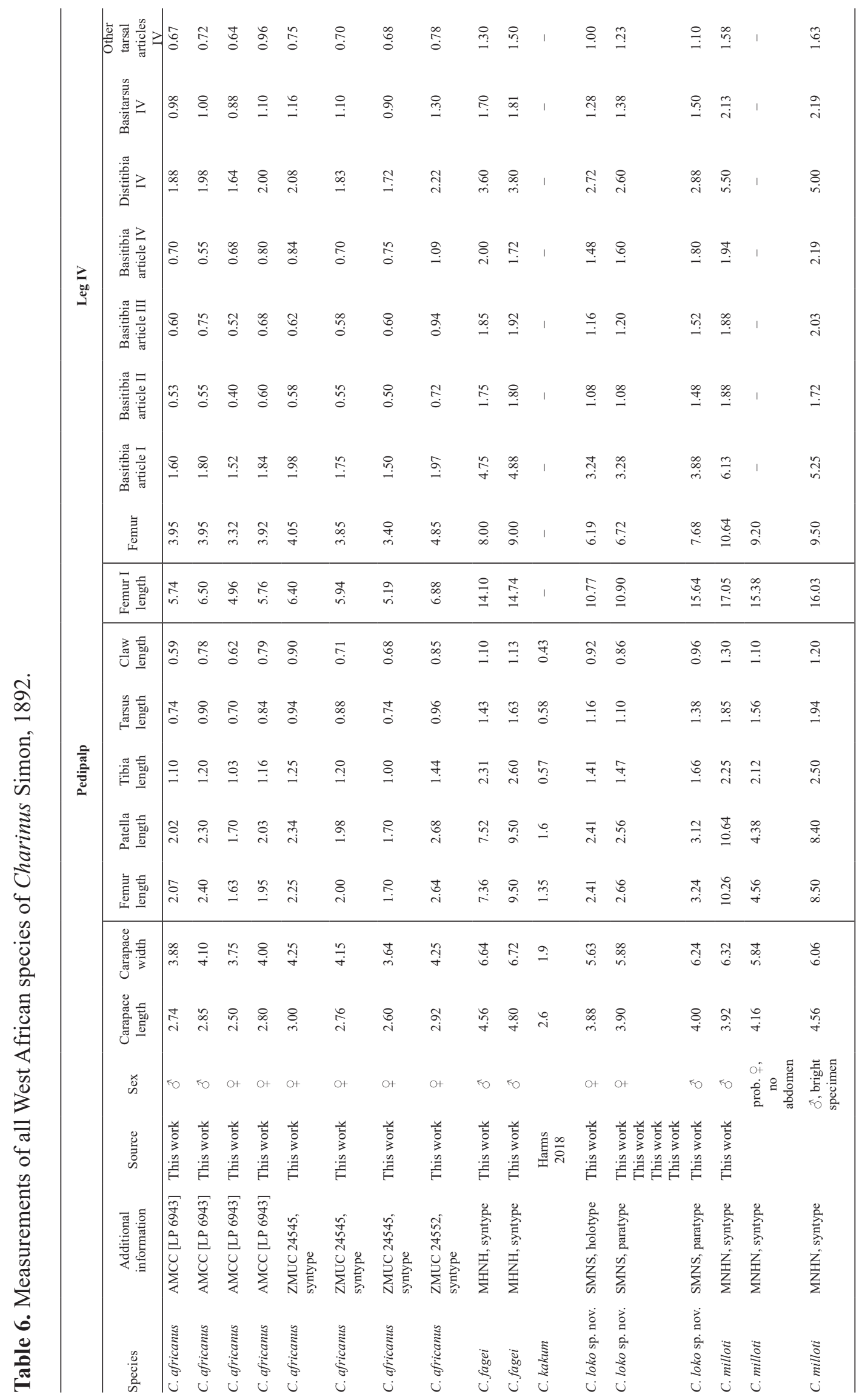




\section{Natural history}

Found under stones and fallen tree trunks. The courtship behavior of $C$. africanus was described by Weygoldt (2008).

Charinus fagei Weygoldt, 1972

Figs 83, 89; Table 6

Charinus fagei Weygoldt, 1972b: 123-128, fig. 22e.

Charinus seychellarum Kraepelin, 1898 - Fage 1939: 154-155, fig. 1a-d (misidentification, in part, see Charinus africanus).

Charinus fagei - Delle Cave 1986: 157, fig. II. — Weygoldt 1994: 244; 2000b: 346. - Harvey 2003: 5.

\section{Diagnosis}

This species may be separated from C. madagascariensis and other African species of Charinus by means of the following combination of characters: median and lateral eyes well developed; cheliceral claw with nine teeth; pedipalp tarsus with two dorsal spines. The count of nine teeth on the cheliceral claw is greater than in any other known African species of Charinus

\section{Etymology}

Although unspecified, the species name is evidently a patronym honoring Dr Louis Fage.

\section{Type material}

\section{Syntypes}

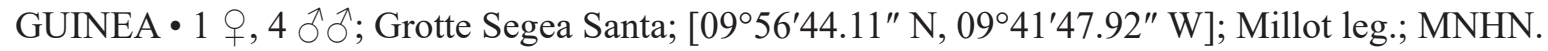

Only $2 \widehat{\partial}$ of the five syntypes listed by Weygoldt (1972) were found and examined at the MNHN. The opisthosoma of one was damaged.

\section{Redescription}

CARAPACE. Six short anterior setae (Fig. 89A); frontal process triangular. Small granules densely scattered between ocular triads and among sulci. Median eyes well developed, median ocular tubercle shallow, with pair of setae (Fig. 89A); lateral eyes well developed, seta posterior to lateral ocular triad; lateral ocular triad well separated from carapace margin.

STERNUM. Tritosternum projected anteriorly, with typical setation, short, only reaching base of pedipalp coxae; other sternal platelets narrow, with pair of setae anteriorly on plaque and some smaller setae posteriorly; pentasternum with four setae anteriorly and without seta in membranous region.

Opisthosoma. Ventral sacs and ventral sac cover absent.

Genitalia. Male gonopod with border of fistula and lateral lobe slightly sclerotized; lateral lobe 2 fimbriate.

CHELICERAE. Small, flat tooth on retrolateral surface of basal segment, opposite to bifid tooth; retrolateral surface of claw with discontinous row of setae, basally to medially; claw with nine teeth; row of seven or eight setae on prolateral surface of basal segment; bifid tooth on basal segment with dorsal cusp larger than ventral cusp. 
PeDIPALPS. Coxal dorsal carina with two setae encircled by round carina and three setae on margin. Femur with four dorsal spines, last spine very small, and four ventral spines (Fig. 89B-C); small spine between dorsal spines 2 and 3, and two or three spines distal to spine 4; two small spines between ventral spines 2 and 3, spine between spines 3 and 4, and two spines distal to spine 4; small spine proximal to ventral spine 1 (Fig. 89C); two prominent setae and two small setiferous tubercles between dorsal spine 1 and proximal margin. Patella with three dorsal spines and two prominent setiferous tubercles proximally (Fig. 89B); prominent setiferous tubercle distal to spine I, one-third length of spine I; four ventral spines, distal two spines small, slightly larger than setiferous tubercle; three or four small setiferous tubercles between spine I and distal margin. Tibia with ventral spine distally and two setae between spine and distal margin. Tarsus with two dorsal spines, distal spine half length of tarsus and proximal spine onethird length of distal spine; cleaning organ with 22-23 setae in ventral row.

LeGs. Tibia of leg I with 23 articles; first tarsal article almost half length of second article. Leg IV basitibia with four pseudo-articles, trichobothrium $b t$ situated in proximal third of pseudo-article; distitibia trichobothrium $b c$ situated closer to $s b f$ than to $b f, s c$ and $s f$ series each with five trichobothria.

\section{Measurements}

See Table 6.

\section{Distribution}

Known only from the type locality.

\section{Natural history}

Found inside caves.

Charinus kakum Harms, 2018

Fig. 83; Table 6

Charinus kakum Harms, 2018: 46-50, figs 1-5.

\section{Diagnosis}

Based in part on Harms (2018), this species may be separated from C. madagascariensis and other African species of Charinus by means of the following combination of characters: median and lateral eyes well developed; median ocular tubercle well developed; female gonopod sucker-like; cheliceral claw with five teeth; pedipalp femur with three dorsal spines and three ventral spines; pedipalp patella with three dorsal spines and two ventral spines; pedipalp tarsus with two dorsal spines; tibia of leg I with 24 articles, tarsus I with 41 articles; leg IV basitibia with three pseudo-articles; distitibia $s c$ and $s f$ series each with four trichobothria.

Charinus kakum differs from C. milloti in the number of teeth on the cheliceral claw, with five teeth in C. kakum and four teeth in C milloti, and from C. loko sp. nov. in the number of pseudo-articles in the basitibia of leg IV, with three articles in C. kakum and four articles in C. loko sp. nov. The number of teeth on the cheliceral claw also separates $C$. kakum from $C$. fagei, in which nine teeth are present. The unique shape of the genital plaque and female gonopod separate C. africanus from C. kakum.

\section{Etymology}

Noun in apposition taken from the type locality, Kakum National Park in Ghana (Harms 2018). 


\section{Type material}

\section{Holotype}

GHANA - 9 ; Central Province, Kakum National Park, track to Treehouse, under flat rock near forest floor; 05²1'21.23" N, 01²2'55.87" W; 13 Dec. 2017; D. Harms and B.K. Williams leg.; ZMH A893 [not examined].

\section{Measurements}

See Table 6.

\section{Distribution}

Known only from the type locality in Kakum National Park, Ghana.

\section{Natural history}

The holotype was collected under a rock in a small rocky outcrop near a dry creek-bed, in closed-canopy primary rainforest. The female possessed a brood sac and carried seven eggs. Harms (2018) noted that this was the smallest whip spider in western Africa and might have a preference for rocky boulders in densely vegetated areas, under which it retreats. Ricinulei (Ricinoides sp.) and unidentified schizomids were observed at the same outcrop.

Charinus loko sp. nov. urn:Isid:zoobank.org:act:FC7937C2-CB50-4FBB-ACDF-E557814D52FE

Figs $10 \mathrm{~A}-\mathrm{B}, 83,90-92$; Table 6

\section{Diagnosis}

This species may be separated from C. madagascariensis and other African species of Charinus by means of the following combination of characters: large size; tritosternum short, not reaching base of pedipalp coxae (Fig. 90B); pedipalp tarsus with three spines (Fig. 90D); tibia of leg I with 23 articles, tarsus I with 41 articles; leg IV basitibia with four pseudo-articles.

This species resembles C. africanus, but bears five teeth on the cheliceral claw, compared with six teeth in C. africanus, and a greater number of spines on the pedipalp.

\section{Etymology}

Noun in apposition honoring the Loko, an indigenous tribe that inhabit the Northern Province of Sierra Leone, particularly the Bombali and Port Loko Districts, and the vicinity of Freetown.

\section{Type material}

\section{Holotype}

SIERRA LEONE • + [leg I in vial]; Western Area, peninsula south of Freetown, Guma Trail II ca Essex

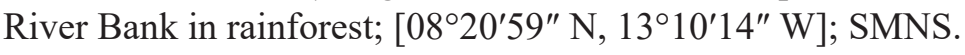

\section{Paratypes}

SIERRA LEONE • 1 +, 1 §ं; same collection data as for holotype; SMNS.

\section{Description}

CARAPACE. Lateral margin ventral to lateral eyes, markedly bent ventrally, creating appearance of projection of anterior carapace margin (Fig. 90A); six anterior setae (Fig. 90A); frontal process triangular (Fig. 90C). Small granules densely scattered between ocular triads and among sulci. Median eyes well 
developed (Fig. 90C); median ocular tubercle reduced, with pair of setae; lateral eyes well developed, seta posterior to lateral ocular triad; lateral ocular triad well separated from carapace margin.

STERNUM. Tritosternum projected anteriorly with typical setation, short, only reaching base of pedipalp coxae (Fig. 90B); other sternal platelets narrow and concave, with pair of setae anteriorly on plaque and some smaller setae posteriorly; pentasternum with four setae anteriorly and without seta in membranous region.

Opisthosoma. Ventral sacs and ventral sac cover absent.

GENITALIA. Female genital operculum with prominent setae posteromedially and some smaller setae near margin (Fig. 91A-C); gonopod cushion-like and sclerotized basally (Fig. 91A-B, D-E); apex of cushionlike gonopod serrated (Fig. 91D-E); slit sensilla on lateral margin of genital operculum (Fig. 91F). Male gonopod with apical border of fistula and lateral lobe sclerotized; LoL2 fimbriate and short (Fig. 92A, D-E); LoL1 well developed (Fig. 92A, C); LoD narrow, with denticulate surface (Fig. 92B, E).

CheliCerae. Small tooth projecting from retrolateral surface of basal segment, opposite to bifid tooth (Fig. 10B); retrolateral surface of claw with continous row of setae, basally to medially (Fig. 10B); claw with five teeth (Fig. 10A); row of more than 20 setae on prolateral surface of basal segment; bifid tooth on basal segment with dorsal cusp larger than ventral cusp (Fig. 10A-B).

PEDIPALPS. Coxal dorsal carina with five or six prominent setae encircled by round carina and three setae on margin. Femur with four dorsal spines and four ventral spines (Fig. 90E-F); long spine between ventral spine 1 and proximal margin; three prominent setiferous tubercles between dorsal spine 1 and proximal margin. Patella with four long dorsal spines in primary series (Fig. 90E); prominent setiferous tubercle distal to spine I, half length of spine I; three ventral spines (Fig. 90F); prominent setiferous tubercle between spine I and distal margin. Tibia with ventral spine distally and two setae between spine and distal margin. Tarsus with three dorsal spines, spine 1 long, one-third length of tarsus, spine 2 aligned with and half length of spine 1 (Fig. 90D); spine 3 one-third length of spine 2 and situated near its base; cleaning organ with 22-24 setae in ventral row.

Legs. Tibia of leg I with 23 articles; tarsus I with 41 articles; first tarsal article similar in length to subsequent article. Leg IV basitibia with four pseudo-articles, with sclerotized, denticulate projection at apex of articles; trichobothrium $b t$ situated submedially on pseudo-article; leg IV distitibia trichobothrium $b c$ situated closer to $s b f$ than to $b f, s c$ and $s f$ series each with five trichobothria.

\section{Measurements}

See Table 6.

\section{Distribution}

Known only from the type locality.

\section{Natural history}

Epigean, on the floor of tropical forest.

Charinus milloti Fage, 1939

Figs 11A-B, 83, 93; Table 6

Charinus milloti Fage, 1939: 156-158, fig. 3a-e. 
Charinus milloti - Millot 1949a: figs 47, 56a-b, 59a-b; 1949b: figs 318, 319a, 320, 321a-b, 322a-b, 323. — Fage 1954: 182. — Kästner 1956: fig. 544. — Janetschek 1957: fig. 8. — Cloudsley-Thompson 1968: 155, fig. 29. - Kaestner 1968: fig. 10-5; 1969: fig. 574. — Lawrence 1969a: 86. — Delle Cave 1986: 152-153, fig. II. — Barnes 1987: figs 13-37. — Dunlop 1994: figs 1-2. — Ruppert \& Barnes 1994: figs 13-33. - Weygoldt 1994: 244; 2000a: figs 1-2, 30; 2000b: 341, 346; 2002b: figs 1, 8. — Selden \& Dunlop 1998: fig. 7.1. — Ax 2001: fig. 48a-d. — Harvey 2003: 6.

\section{Diagnosis}

This species may be separated from C. madagascariensis and other African species of Charinus by means of the following combination of characters: secondary sexual dimorphism, males with longer pedipalp segments than females; cheliceral claw with four teeth; female gonopod cushion-like; three spines on pedipalp tarsus.

\section{Etymology}

Patronym honoring J. Millot (Fage 1939).

Type material (examined)

\section{Syntypes}

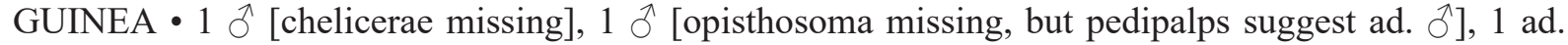
[gonopods and pedipalps missing], 2 subad. [opisthosoma missing], 1 juv. [opisthosoma missing]; Grotte Tinka, Grotte Dalaba; Millot leg.; MNHN.

\section{Redescription}

CARAPACE. Six short anterior setae (Fig. 93A); frontal process triangular. Small granules densely scattered between ocular triads and among sulci. Median eyes and median ocular tubercle reduced (Fig. 93A); pair of setae on median ocular tubercle; lateral eyes reduced, pale, seta posterior to lateral ocular triad; lateral ocular triad well separated from carapace margin.

STERnUm. Tritosternum projected anteriorly with typical setation, short, only reaching base of pedipalp coxae (Fig. 93B); other sternal platelets narrow, with pair of setae anteriorly on plaque and some smaller setae posteriorly; pentasternum with four setae anteriorly and without seta in membranous region.

OpISTHOSOMA. Ventral sacs and ventral sac cover absent.

Genitalia. Female gonopods cushion-like. Male gonopods unknown (could not be studied due to poor preservation).

CHeLICERAE. Large tooth projecting from retrolateral surface of basal segment, opposite to bifid tooth (Fig. 11B); retrolateral surface of claw with discontinous row of setae, basally to medially; claw with four teeth (Fig. 11A-B); row of twelve setae on prolateral surface of basal segment; bifid tooth on basal segment with dorsal cusp larger than ventral cusp (Fig. 11A-B).

Pedipalps. Coxal dorsal carina with six prominent setae encircled by round carina and two setae on margin. Femur with four dorsal spines and five ventral spines (Fig. 93C-D); small spine between each dorsal spine; small spine between ventral spines 1 and 2, and spines 2 and 3 (large setiferous tubercle between spines 1 and 2 in smaller specimen without gonopod); long spine proximal to ventral spine 1; long setiferous tubercle ventral to spine 1; three prominent setiferous tubercles between dorsal spine 1 and proximal margin. Patella with three long dorsal spines in primary series and row of 3-5 small spines, slightly longer than setiferous tubercle (Fig. 93C); long setiferous tubercle between spines 1 and 
2; prominent setiferous tubercle distal to spine I, half length of spine I; three ventral spines with small spine between each (Fig. 93D); large setiferous tubercle between spine I and distal margin. Tibia with one ventral spine distally and three or four setae between spine and distal margin (Fig. 93D). Tarsus with three dorsal spines, spine 1 long, half length of tarsus, spine 2 aligned and half length of spine 1, spine 3 one-third length of spine 2 and situated near its base (Fig. 93C); cleaning organ with 25-28 setae in ventral row.

Legs. Tibia of leg I with 23 articles; tarsus I with 43 articles; first tarsal article similar in length to subsequent article. Leg IV basitibia with four pseudo-articles, with sclerotized, denticulate projection at apex of articles; trichobothrium $b t$ situated in distal third of pseudo-article; distitibia trichobothrium $b c$ situated closer to $s b f$ than to $b f, s c$ and $s f$ series each with five trichobothria.

\section{Measurements}

See Table 6.

\section{Distribution}

Known only from the type locality.

\section{Natural history}

Only found inside caves.

\section{Key to the identification of the species of Charinus in Oceania}

1. Median and lateral eyes reduced (Fig. 99A, C) ........................ . longipes Weygoldt, 2006 (Fig. 99)

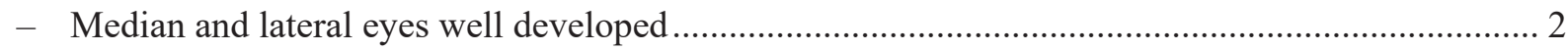

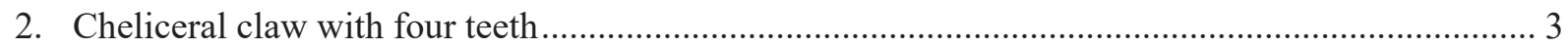

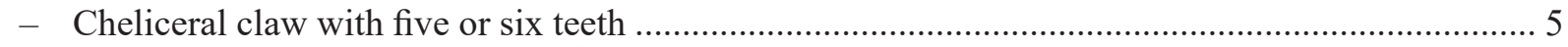

3. Pedipalp femur with three ventral spines and spine between ventral spine 1 and proximal margin; pedipalp patella with four dorsal spines

C. australianus (L. Koch, 1867)

- Pedipalp femur with four ventral spines and setiferous tubercle between ventral spine 1 and proximal margin; pedipalp patella with three dorsal spines.

4. Restricted to Papua New Guinea

C. papuanus Weygoldt, 2006

- Restricted to Australia (Queensland) C. pescotti Dunn, 1949 (Figs 101-102)

5. Carapace with distinct black markings radiating outwards from fovea ........ . pecki Weygoldt, 2006

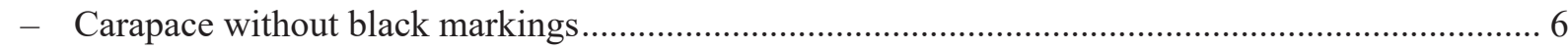

6. Chelicera with small, flat tooth opposite to bifid tooth on retrolateral surface of basal segment......... C. elegans Weygoldt, 2006 (Figs 96-98)

- Chelicera with projecting tooth opposite to bifid tooth on retrolateral surface of basal segment .... 7

7. Pedipalp coxa, rounded dorsal carina containing pair of setae, bordered by four setae

C. cavernicolus Weygoldt, 2006 (Fig. 95)

- Pedipalp coxa, rounded dorsal carina containing no setae, bordered by three setae... 
Charinus australianus (L. Koch, 1867)

Fig. 94; Table 7

Phrynus australianus L. Koch, 1867: 231-232.

Phrynus australianus - Butler 1873: 119. — Moritz \& Fischer 1980: 138.

Charon australianus - L. Koch \& Keyserling 1885: 40-41, pl. 4 fig. 1a-b. - Simon 1892: 48. Hansen 1893: 159. — Kraepelin 1895: 46-47, figs 33, 38, 41; 1899: 249, fig. 93; 1901: 264. — Börner 1904: 5. — Mello-Leitão 1931: 54. — Werner 1935: 471, fig. 176b. — Fage \& Simon 1936: 300. - Weidner 1959: 142. - Weygoldt 1972b: 123, fig. 22f; 2006a: 244, figs 3-4, 8-9; 2006b: 10-13. - Strinati \& Aellen 1983: 21. - Delle Cave 1986: 154-155, fig. II. — Quintero 1986: 207, figs 4, 7, 9. - Harvey 2003: 4. - Jocqué \& Giupponi 2012: 59.

Charon australiensis - Kästner 1932: fig. 82. - Werner 1935: figs 142-143.

Charinus australianus australianus - Weygoldt 2006b: 13-16, figs 17-21.

\section{Diagnosis}

This species may be separated from other species of Charinus in Oceania by means of the following combination of characters: prolateral surface of cheliceral basal segment with more than 20 setae in two or three parallel rows, ventrally to subdorsally; cheliceral claw with four teeth, and setae present only at base; pedipalp coxa with distinct setiferous tubercle and small spine on its side; pedipalp femur with four dorsal spines, distal spine tiny, similar in length to setiferous tubercle, but with setae inserted laterally, not apically, two setiferous tubercles proximal to spine 1 of primary series, and three ventral spines; pedipalp patella with four dorsal spines and small setiferous tubercle similar in length to other setiferous tubercles, distal to proximal spine; pedipalp tibia with three ventral spines; pedipalp tarsus with two spines.

\section{Etymology}

Although unspecified, the species name is evidently an adjective referring to the Australasian region inhabited by this species.

\section{Type material}

Holotype

SAMOA • Upolu Island; Phrynus australianus L. Koch; ZMH 2281.

\section{Additional material}

FIJI • 2 q , 1 juv.; Viti Levu, Wailotua Cave; 26 Aug. 1978; S. Peck leg.; MHNG GSM 3.

SOLOMON ISLANDS - Charinus australianus (L. Koch, 1867) [labeled as holotype, but not part of original type series; see Weygoldt (2006)]; ZMB 2505 • 1 क ; Guadalcanal, Kukum; [09²5'49.24" S,

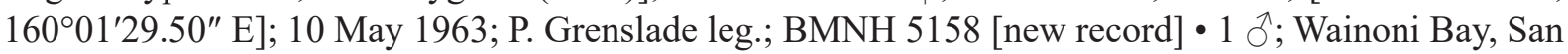
Cristobal; [10³2'35.89" S, 16148'31.47" E]; J.F.P. leg.; BMNH P3.

\section{Supplementary description}

CARAPACE. Small granules densely scattered between ocular triads and among sulci. Median eyes and median ocular tubercle well developed, with pair of setae; lateral eyes well developed, seta posterior to lateral ocular triad; lateral ocular triad well separated from carapace margin.

STERnUm. Tritosternum projected anteriorly with typical setation; other sternal platelets wide, separated into pairs, with seta on each lateral margin and some smaller setae in between; pentasternum with two setae anteriorly and without seta in membranous region. 
OPISTHOSOMA. Ventral sac and ventral sac cover absent.

Genitalia. Posterior margin of female genital operculum slightly convex; gonopod cushion-like and markedly sclerotized basally.

Chelicerae. Tooth projecting from retrolateral surface of basal segment, opposite to bifid tooth; retrolateral surface of claw with row of setae basally to medially; claw with six teeth; two or three parallel rows of more than 20 setae, ventrally to subdorsally, on prolateral surface of basal segment; bifid tooth on basal segment with dorsal cusp larger than ventral cusp.

PEDIPALPS. Coxal dorsal carina with four setae on anterior border and without seta encircled by round carina. Femur with four dorsal spines and four ventral spines; four or five prominent setiferous tubercles between dorsal spine 1 and proximal margin; prominent spine between ventral spine 1 and proximal margin. Patella with three dorsal spines and two prominent setiferous tubercles proximal to spine 3 ; prominent setiferous tubercle distal to spine I, one-third length of spine I; two ventral spines; two or three setiferous tubercles between spine I and distal margin. Tibia with one ventral spine distally and two setae between spine and distal margin. Tarsus with two dorsal spines, distal spine one-third length of tarsus, and proximal spine one-third length of distal spine; cleaning organ with 33 setae in ventral row.

LEGS. Tibia of leg I with 23 articles; tarsus I with 41 articles; first tarsal article twice length of subsequent articles. Leg IV basitibia with four pseudo-articles; denticulate sclerotized region distally on articles, but not projected; trichobothrium $b t$ situated in distal third of pseudo-article; distitibia trichobothrium $b c$ equidistant between $s b f$ and $b f, s c$ and $s f$ series each with five trichobothria.

\section{Measurements}

See Table 7.

\section{Distribution}

Known from Fiji, Samoa (Upolu Island), and the Solomon Islands.

Charinus cavernicolus Weygoldt, 2006, new rank Figs 94-95; Table 7

Charinus australianus cavernicolus Weygoldt, 2006b: 16-18, figs 1-2, 13, 23-24.

Charinus australianus cavernicolus - Seiter \& Hörweg 2013: 50.

\section{Diagnosis}

Based in part on Weygoldt (2006a), this species may be separated from other species of Charinus in New Caledonia (C. elegans, C. longipes, C. neocaledonicus and C. pecki), by means of its dull coloration, slightly smaller size, shorter legs, and different spermatophore.

\section{Etymology}

Adjective, referring to the subterranean habitat of the species (Weygoldt 2006b).

\section{Type material}

\section{Holotype}

NEW CALEDONIA • ^̊; Province Nord, Grottes de Koumac, ca 7 km E of Koumac; 13 Nov. 2004; S. Huber, S. Weygoldt and P. Weygoldt leg.; MNHN AM 1. 


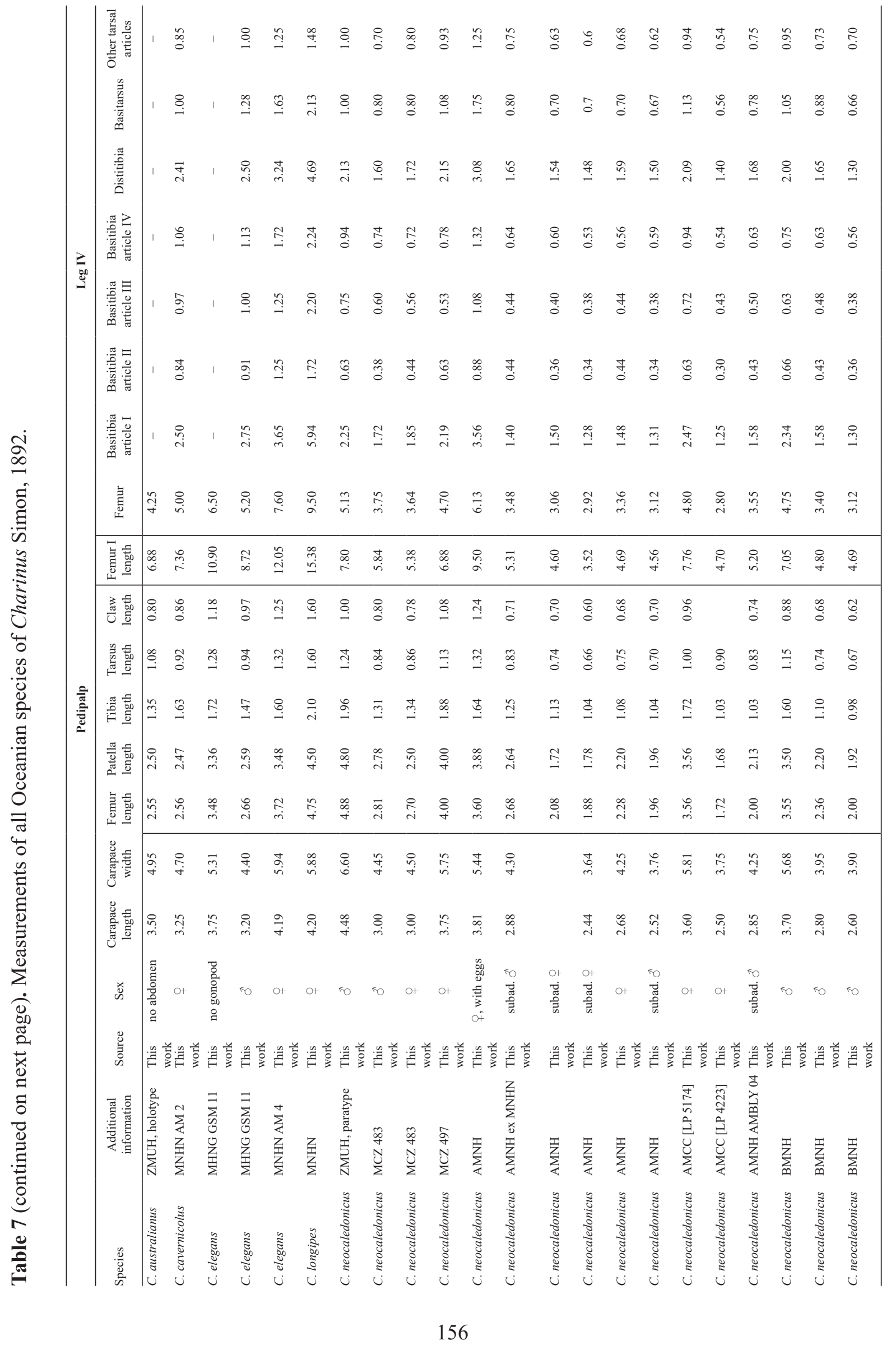




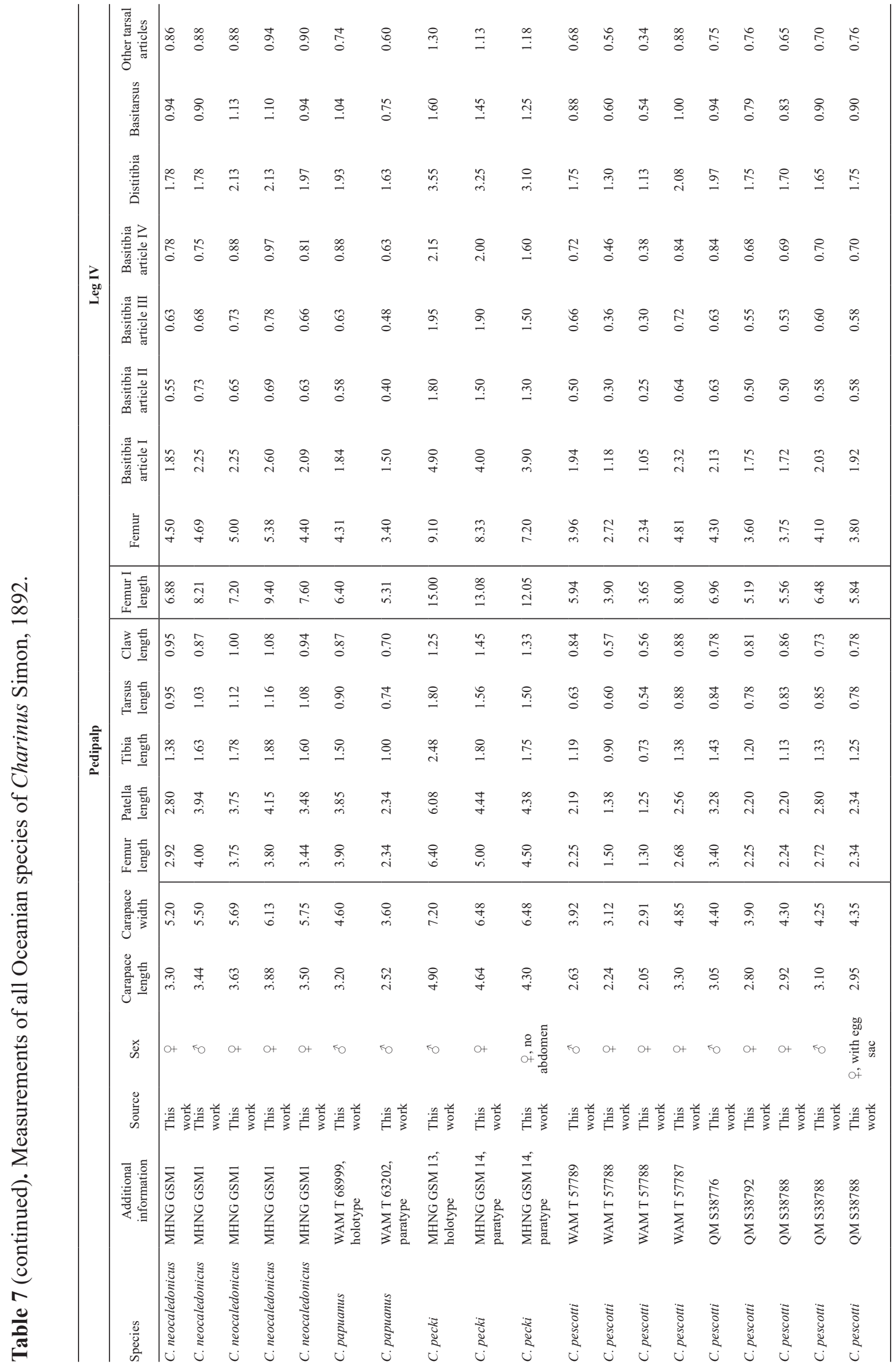




\section{Paratypes}

NEW CALEDONIA • 2 우; same collection data as for holotype; MNHN AM 2.

\section{Additional material}

NEW CALEDONIA $\bullet 2$ $q$,, 1 ô, 4 protonymphs, 1 protonymph exuvium; Province Nord, Grottes de

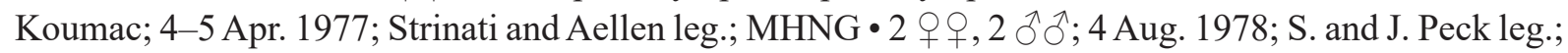
MHNG・ 5 $+q, 4$ ふึ̊, 5 juv.; 13 Nov. 2004; S. Huber, S. Weygoldt and P. Weygoldt leg.; MHNG.

\section{Supplementary description}

CARAPACE. Median eyes and median ocular tubercle well developed (Fig. 95A); pair of setae on median ocular tubercle (Fig. 95C); lateral eyes well developed, seta posterior to lateral ocular triad; lateral ocular triad well separated from margin of carapace.

STERNUM. Tritosternum projected anteriorly with typical setation (Fig. 95B); other sternal platelets divided into two pairs of small rounded plaques, each with seta anteriorly; pentasternum with two setae anteriorly and one seta in membranous region.

OpISTHOSOMA. Ventral sac and ventral sac cover absent.

GENitALIA. Posterior margin of female genital operculum slightly convex; gonopod flat cushion-like (see Weygoldt 2006b: 7, figs 1-2); unsclerotized basally. Male gonopod with border of fistula and lateral lobes sclerotized.

Chelicerae. Prominent tooth on retrolateral surface of basal segment, opposite to bifid tooth; retrolateral surface of claw with row of setae restricted to base; claw with five teeth; row of setae on prolateral surface of basal segment of chelicerae not visible; bifid tooth on basal segment with dorsal cusp larger than ventral cusp.

PeDIPALPS. Coxal dorsal carina with two setae encircled by round carina and four setae on margin. Femur with four dorsal spines and four ventral spines (Fig. 95E-F); three setiferous tubercles between dorsal spine 1 and proximal margin. Patella with three dorsal spines and prominent setiferous tubercle proximal to spine III (Fig. 95E); prominent setiferous tubercle distal to spine I, one-third length of spine I; two ventral spines (Fig. 95F); three setiferous tubercles between spine I and distal margin. Tibia with ventral spine distally and three setae between spine and distal margin; several long, slender setae prolateral to ventral spines. Tarsus with two dorsal spines, distal spine curved, long, half length of tarsus, proximal spine straight, short, one-third length of distal spine (Fig. 95D); several long, slender setae ventral to distal spine; cleaning organ with 26 setae in ventral row.

LEGS. Tibia of leg I with 23 articles; tarsus I with 41 articles; first tarsal article twice length of subsequent article (mean length of first article: $0.5 \mathrm{~mm}$; mean length of second article: $0.19 \mathrm{~mm}, \mathrm{n}=2$ ). Leg IV, basitibia with four pseudo-articles, trichobothrium $b t$ situated in proximal third of pseudo-article; distitibia trichobothrium $b c$ situated closer to $s b f$ than to $b f, s c$ and $s f$ series each with five trichobothria.

\section{Measurements}

See Table 7.

\section{Distribution}

Known from Grottes de Koumac and Île des Pins, New Caledonia. 


\section{Natural history}

Specimens were found under stones near the entrance of the cave as well as deeper, in complete darkness. No specimens were found in the forest outside the cave.

\section{Remarks}

Weygoldt (2006b) noted some differences between the specimens from Île des Pins and those from the Grottes de Koumac, such as a denser group of setae on the prolateral surface of the chelicera, and the dorsal spines of the pedipalp tarsus being unequal, the distal spine nearly four times as long as the proximal spine.

Charinus elegans Weygoldt, 2006, stat. nov.

Figs 94, 96-97; Table 7

Charinus australianus elegans Weygoldt, 2006b: 18-20, figs 3-4, 14, 22, 25-26.

\section{Diagnosis}

Based in part on Weygoldt (2006a), this species may be separated from other species of Charinus in New Caledonia by the slightly larger size, and more vivid colouration. It differs from C. cavernicolus, in particular, by the form and decoration of the male spermatophore, and the presence of a spine between ventral spine 1 and the proximal margin of the pedipalp femur.

\section{Etymology}

Latin adjective referring to the elegant appearance of the species, due to the brighter coloration and longer legs (Weygoldt 2006).

\section{Type material}

\section{Holotype}

NEW CALEDONIA • ○; Grotte d’Adio; 28 Nov. 2004; S. Huber; MNHN AM 3.

\section{Paratype}

NEW CALEDONIA • 1 ; ; same collection data as for holotype; MNHN AM 4.

\section{Additional material}

NEW CALEDONIA • 1 ô [small], 1 q exuvium; Poya, Grottes d'Adio; 2 Apr. 1977; Strinati et al. leg.

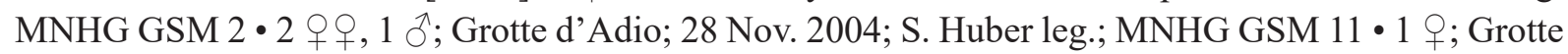
d'Adio; 28 Nov. 2004; S. Huber and P. Weygoldt leg.; cave; AMCC [LP 5175].

\section{Supplementary description}

CARAPACE. Median eyes and median ocular tubercle well developed (Fig. 96A); pair of setae on median ocular tubercle; lateral eyes well developed, seta posterior to lateral ocular triad; lateral ocular triad well separated from margin of carapace.

STERNUM. Tritosternum projected anteriorly with typical setation (Fig. 96B); other sternal platelets wide, with seta on each lateral border and some smaller setae in between; pentasternum with two setae anteriorly and without seta in membranous region.

OpISTHOSOMA. Ventral sacs and ventral sac cover absent. 
Genitalia. Posterior margin of female genital operculum slightly convex; gonopod cushion-like (see Weygoldt 2006b: figs 3-4), unsclerotized basally. Male gonopod with border of fistula and lateral lobes sclerotized; LaM long and thin (Fig. 97A); LoL2 fimbriate and short (Fig. 97B, D); LoD wide with denticulate surface (Fig. 97C); inner region of fistula with spikes (Fig. 97E).

ChELICERAE. Small, flat tooth on retrolateral surface of basal segment, opposite to bifid tooth; retrolateral surface of claw with row of setae restricted to base; claw with five teeth; row of eleven setae on prolateral surface of basal segment; bifid tooth on basal segment with dorsal cusp larger than ventral cusp.

PeDIPALPS. Coxal dorsal carina with seta encircled by round carina and four setae on margin. Femur with three or four (sinistral pedipalp of paratype) dorsal spines and four ventral spines (paratype with large spine between spines 2 and 3, and fourth spine, on sinistral pedipalp and small spine between spines 2 and 3 on dextral pedipalp) (Fig. 96E-F); three setiferous tubercles between dorsal spine 1 and proximal margin. Patella with three dorsal spines and two prominent setiferous tubercles proximal to spine 3 (Fig. 96E); prominent setiferous tubercle distal to spine I, one-third length of spine I; two ventral spines (Fig. 96F); three setiferous tubercles between spine I and distal margin. Tibia with ventral spine distally and three setae between spine and distal margin; several long, slender setae prolateral to ventral spines. Tarsus with two dorsal spines, distal spine long, more than half length of tarsus, and proximal spine onethird length of distal spine (Fig. 96D); several long, slender setae ventral to distal spine; cleaning organ with 30-33 setae in ventral row.

Legs. Tibia of leg I with 23 articles; tarsus I with 41 articles; first tarsal article slightly longer than second article (mean length of first article: $0.6 \mathrm{~mm}$; mean length of second article: $0.41 \mathrm{~mm} ; \mathrm{n}=3$ ); tarsal organ situated near the base of the claw (Fig. 98A, D-E); rod sensilla with circa of seven setae in shallow groove (Fig. 98B-C). Leg IV basitibia with four pseudo-articles, trichobothrium $b t$ situated medially on pseudo-article; distitibia trichobothrium $b c$ situated closer to $s b f$ than to $b f, s c$ and $s f$ series each with five trichobothria.

\section{Measurements}

See Table 7.

\section{Distribution}

Known only from the type locality.

\section{Natural history}

Specimens were found in a deep limestone cave with a small stream running through.

\section{Remarks}

The sex of the female paratype (MNHN AM 4) is consistent with the description of Weygoldt (2006).

Charinus longipes Weygoldt, 2006, stat. nov.

Figs 11E-F, 94, 98-99; Table 7

Charinus australianus longipes Weygoldt, 2006b: 20-22, figs 5-6, 15.

\section{Diagnosis}

Based in part on Weygoldt (2006b), this species may be separated from other species of Charinus in Oceania by the following combination of characters: median and lateral eyes reduced (Fig. 99A, C); 
long, slender legs. It differs from C. cavernicolus by the long legs and slender appearance, and from C. pecki by the long distal spine on the pedipalp tarsus.

\section{Etymology}

The species name refers to the long, thin walking legs (Weygoldt 2006).

\section{Type material}

\section{Holotype}

NEW CALEDONIA - 9 ; Taphozous Grotte near Hienghène II; 5 m a.s.l.; 25 Nov. 2004; S. Huber, S. Weygoldt and P. Weygoldt leg.; MNHN AM 5.

\section{Paratype}

NEW CALEDONIA • 1 \%; same collection data as for holotype; MNHN AM 5 [paratype was preserved in final stage of molting and is still attached to exuvium].

\section{Supplementary description}

CARAPACE. Median eyes and median ocular tubercle reduced (Fig. 99A, C); pair of setae on median ocular tubercle; lateral eyes weakly developed, pale, with seta posterior to lateral ocular triad (Fig. 99A); lateral ocular triad well separated from carapace margin.

Sternum. Tritosternum projected anteriorly with typical setation (Fig. 99B); other sternal platelets wide, with seta on each lateral border and some smaller setae in between; pentasternum with six setae anteriorly and one seta in membranous region.

Opisthosoma. Ventral sacs and ventral sac cover absent.

Genitalia. Posterior margin of female genital operculum slightly convex; gonopod cushion-like (see Weygoldt 2006b: figs 5-6), unsclerotized basally. Male unknown.

ChELICERAE. Small, flat tooth on retrolateral surface of basal segment, opposite to bifid tooth (Fig. 11F); retrolateral surface of claw with row of setae restricted to base; claw with five teeth (Fig. 11E-F); row of ten setae on prolateral surface of basal segment; bifid tooth on basal segment with dorsal cusp larger than ventral cusp (Fig. 11E-F).

PedipalPs. Coxal dorsal carina without setae encircled by round carina and with four setae on margin. Femur with four dorsal spines, last spine very small, and three ventral spines (holotype with extra spine distally on dextral pedipalp) (Fig. 99E-F); three prominent setiferous tubercles between dorsal spine 1 and proximal margin. Patella with three dorsal spines and prominent setiferous tubercle proximal to spine 3 (Fig. 99E); prominent setiferous tubercle distal to spine I, one-third length of spine I; two ventral spines (Fig. 99F); two setiferous tubercles between spine I and distal margin. Tibia with ventral spine distally and three setae between spine and distal margin; several long, slender setae prolateral to ventral spines. Tarsus with two dorsal spines, distal spine long, half length of tarsus, and proximal spine onethird length of distal spine (Fig. 99D); several long, narrow setae ventral to distal spine; cleaning organ with 32-35 setae in ventral row.

Legs. Tibia of leg I with 23 articles; tarsus I with 41 articles; first tarsal article subequal in length to subsequent articles (length of first article: $0.7 \mathrm{~mm}$; length of second article: $0.64 \mathrm{~mm}, \mathrm{n}=1$ ). Leg IV basitibia with four pseudo-articles, trichobothrium $b t$ situated in proximal third of pseudo-article; distitibia trichobothrium $b c$ situated closer to $s b f$ than to $b f, s c$ and $s f$ series with five trichobothria.

\section{Measurements}

See Table 7. 


\section{Distribution}

Known only from the type locality.

\section{Natural history}

Known only from inside caves.

Charinus neocaledonicus Kraepelin, 1895

Figs 94, 100; Table 7

Charinus neocaledonicus Kraepelin, 1895: 47.

Charinus neocaledonicus - Kraepelin 1899: 249-250; 1901: 264; 1914: 337. — Mello-Leitão 1931: 54. — Werner 1935: 471. — Fage \& Simon 1936: 300-301. — Dunn 1949: 7-8. — Weidner 1959: 142. — Kritscher 1966: 373-374. — Weygoldt 1972b: 123, fig. 22g; 2006a: 240-243, figs 1-2, 5-7, 10-11, 14; 2006b: 24-28, figs 9-10, 12, 16, 33-34. — Strinati \& Aellen 1983: 18, 24. — Delle Cave 1986: 155, fig. II. — Harvey 2003: 6. — Miranda \& Giupponi 2011: 67-68. — Wolff et al. 2015: 525; 2017: 2-3, 7, fig. 8. — Giupponi \& Miranda 2016: 27.

\section{Diagnosis}

This species may be separated from other species of Charinus in Oceania by means of the following combination of characters: slight sexual dimorphism in pedipalp length; cheliceral claw with five teeth and two patches of setae on retrolateral surface; prolateral surface of pedipalp tibia, tarsus and distal part of patella with several long, narrow setae; pedipalp femur with three or four dorsal spines and three ventral spines; pedipalp tibia with two setae between spine and distal margin; distal spine of pedipalp tarsus short; leg IV basitibia trichobothrium $b t$ situated medially; distitibia trichobothrium $b c$ situated closer to $s b f$ than to $b f$.

\section{Etymology}

Although unspecified, the species name is evidently an adjective referring to New Caledonia, the island to which this species is endemic.

\section{Type material}

\section{Holotype}

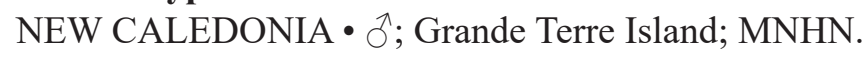

\section{Additional material}

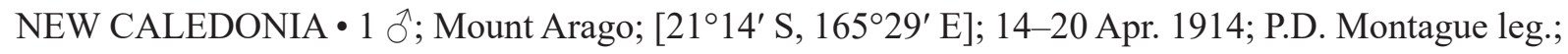

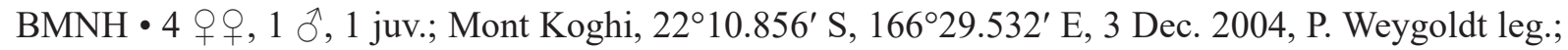
forest, under stones; MHNG • 1 đo; North Province, Mt Aoupinié; $21^{\circ} 10^{\prime} \mathrm{S}, 165^{\circ} 31^{\prime} \mathrm{E} ; 890 \mathrm{~m}$ a.s.1.; 12 Feb. 1993; N.I. Platnick, R.J. Raven and M.S. Harvey leg.; AMNH • 1 क ; Mont Koghi; 22 ${ }^{\circ} 10^{\prime} 51.36^{\prime \prime}$ S, $166^{\circ} 29^{\prime} 31.92^{\prime \prime}$ E; 3 Dec. 2004; P. Weygoldt leg.; forest, under stones; AMCC [LP 5174] • 1 9 , 6 juv.; Mount Koghi; 3 Dec. 2005; P. Weygoldt leg.; forest, under stones; AMCC [LP 4223] • 1 juv; Grande Terre, Forêt Nord, near rocky portion of track; 22¹9'20.1" S; 166 54'58.6" E; 17 Apr. 2007; 205 m a.s.1.; J. Murienne and P. Sharma leg.; rainforest, hand collected from rock; AMCC [LP 10276] • 1 o, 1 ó; North Forest; 22¹9'20.1" S, 16654'58.6" E; 205 m a.s.1.; 17 Apr. 2007; J. Murienne and P. Sharma leg.; near rocky portion of track, under rock; MCZ (DNA 104045) • 3 우, 1 गे; Riviere Blanche, forest track; $22^{\circ} 10^{\prime} 36.9^{\prime \prime}$ S, $166^{\circ} 39^{\prime} 21.8^{\prime \prime}$ E; 26 Apr. 2007; 349 m a.s.1.; J. Murienne and P. Sharma leg.; rainforest, hand collected from rock; MCZ • 1 q, 1 juv.; Riviere Blanche; $22^{\circ} 10^{\prime} 06.1^{\prime \prime} \mathrm{S}, 166^{\circ} 39^{\prime} 59.2^{\prime \prime} \mathrm{E}$; 
196 m a.s.l.; 26 Apr. 2007; J. Murienne and P. Sharma leg.; under rock; MCZ (DNA 104046) • 1 \%; South Province, Provincial parcel of Riviere Bleue; 2206' S, 166³9' E; 240 m a.s.l.; 9 Feb. 1993; N.I. Platnick, R.J. Raven and M.S. Harvey leg.; AMNH 1 \; South Province, Rivière Blanche, Provincial

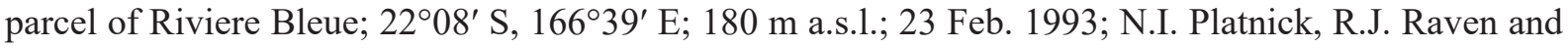

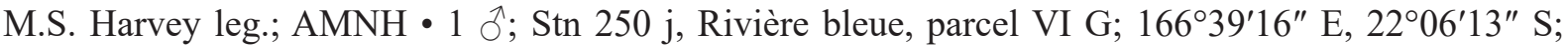

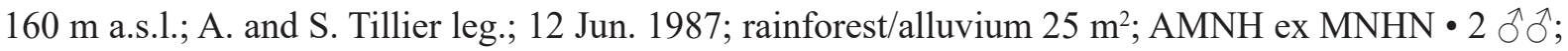
3 Apr.-16 Dec. 1894; E. Simon leg.; BMNH・2 우, 1 ơ; MNHN 4.632.

\section{Supplementary description}

CARAPACE. Six anterior setae; frontal process triangular with pointed apex. Small granules densely scattered between ocular triads and among sulci. Median eyes well developed; median ocular tubercle reduced, with pair of setae; lateral eyes well developed, seta posterior to lateral ocular triad; lateral ocular triad well separated from carapace margin.

STERnUm. Tritosternum projected anteriorly with typical setation, long, surpassing base of pedipalp coxae; other sternal platelets wide, divided, with seta on each lateral margin and some smaller setae basally; pentasternum with two setae anteriorly and without seta in membranous region.

OpISTHOSOMA. Ventral sacs and ventral sac cover absent.

Genitalia. Female genital operculum with prominent setae posteromedially and some smaller setae near margin; gonopod cushion-like (see Weygoldt 2006), slightly sclerotized basally. Male gonopod with apical border of fistula and lateral lobe sclerotized.

CheliCerae. Small tooth projecting from retrolateral surface of basal segment, opposite to bifid tooth; retrolateral surface of claw with two patches of setae, one basal, other subdorsal; claw with five teeth; row of around eight setae on prolateral surface of basal segment; bifid tooth on basal segment with dorsal cusp larger than ventral cusp.

PeDIPALPS. Coxal dorsal carina without seta encircled by round carina and with three setae on border. Femur with three or four dorsal spines and three ventral spines; spine between ventral spine 1 and proximal margin. Patella with three long dorsal spines in primary series; prominent setiferous tubercle distal to spine I, half length of spine I; two ventral spines; small setiferous tubercle between spine I and distal margin. Tibia with ventral spine distally and one or two setae between spine and distal margin; several long, narrow setae on prolateral surface. Tarsus with two dorsal spines, spine 1 short, spine 2 aligned with and half length of spine 1; cleaning organ with 23-33 setae in ventral row.

LEGS. Leg of tibia I with 23 articles; tarsus I with 41 articles; first tarsal article about 3-4 times length of second article; tarsal organ situated near base of claw (Fig. 100A, C, E); rod sensilla with five setae and in shallow groove (Fig. 100B, D). Leg IV basitibia with four pseudo-articles, without sclerotized, denticulate margin at apex of articles; trichobothrium $b t$ situated in proximal or distal third of pseudoarticle; distitibia trichobothrium $b c$ situated closer to $b f$ than to $s b f$, or vice versa; $s c$ and $s f$ series each with five trichobothria.

\section{Measurements}

See Table 7.

\section{Distribution}

Distributed across the island of New Caledonia. 


\section{Natural history}

This species may be found under stones and fallen tree trunks on the forest floor along mountain slopes. Live specimens can be recognised by their dark coloration.

\section{Remarks}

Kraepelin $(1899,1901,1914)$ attributed the discovery of C. neocaledonicus to Simon (1895), referring to the species as C. neocaledonicus Simon in litt. However, Simon did not publish a description of the species. In his revision of the world's whip spiders, Kraepelin (1895) mentions receiving material from Simon and that the specimens were named C. neocaledonicus. Consequently, the description of the species, which was based on coloration and dimensions of the carapace and leg tarsi, is attributed to Kraepelin (1895).

Delle Cave (1986: 153) was the first to cite Kraepelin (1895) as the author of C. neocaledonicus and mentioned that 'the quotation ' $C$. neocaledonicus Simon' is erroneous in accordance with the rules of zoological nomenclature.” Whereas Harvey $(2003,2013)$ and Giupponi \& Miranda (2016) erroneously listed Simon as author of the species, Weygoldt (2006a, 2006b) correctly followed Delle Cave (1986) in listing Kraepelin.

\section{Charinus papuanus Weygoldt, 2006}

Fig. 94; Table 7

Charinus papuanus Weygoldt, 2006b: 28-30, figs 35-39.

\section{Diagnosis}

This species may be separated from other species of Charinus in Oceania as follows: aside from C. papuanus, the only other charinid species in the region in which the first tarsal article of leg I is as long as the sum of the next five articles is $C$. pescotti, from which $C$. papuanus can be distinguished by the number of dorsal spines on the pedipalp femur. Charinus papuanus differs further from C. australianus and other New Caledonian species by the presence of a setiferous tubercle instead of a spine between ventral spine 1 and the proximal margin of the femur.

\section{Etymology}

Adjective referring to Papua New Guinea, the country in which the type locality is situated (Weygoldt 2006).

\section{Type material}

\section{Holotype}

PAPUA NEW GUINEA • đ'; Port Moresby, National Capital District, $6 \mathrm{~km}$ W of University of Papua New Guinea (U.P.N.G.); [09²4'28.21" S, 14707'30.14" E]; Jun. 1980; D. Black leg.; under rocks; WAM T68999.

\section{Paratypes}

PAPUA NEW GUINEA • 1 ð , 1 juv. + ; same collection data as for holotype; WAM T63202.

\section{Supplementary description}

CARAPACE. Median eyes and median ocular tubercle well developed; pair of setae on median ocular tubercle; lateral eyes well developed, seta posterior to lateral ocular triad; lateral ocular triad well separated from margin of carapace. 
STERnUm. Tritosternum projected anteriorly with typical setation; other sternal platelets wide, with seta on each lateral border and some smaller setae in between; pentasternum with two setae anteriorly and without seta in membranous region.

Opisthosoma. Ventral sacs and ventral sac cover absent.

Genitalia. Posterior margin of female genital operculum slightly convex; gonopod cushion-like and slightly sclerotized basally. Male gonopod with margin of fistula and lateral lobes sclerotized; lateral lobe 2 fimbriate.

Chelicerae. Small, flat tooth on retrolateral surface of basal segment, opposite to bifid tooth; retrolateral surface of claw with row of setae from ventral to dorsal; claw with four teeth; row of eight or nine setae on prolateral surface of basal segment; bifid tooth on basal segment with dorsal cusp larger than ventral cusp.

Pedipalps. Coxal dorsal carina without seta encircled by round carina and with four setae on margin. Femur with five dorsal spines and four ventral spines; setiferous tubercle between ventral spine 1 and proximal margin. Patella with three dorsal spines and three prominent setiferous tubercles proximal to spine III; prominent setiferous tubercle distal to spine I, one-third length of spine I; two ventral spines and small setiferous tubercle closer to spine II; three setiferous tubercles between spine I and distal margin. Tibia with ventral spine distally and two setae between spine and distal margin. Tarsus with two dorsal spines, distal spine long, about one-third length of tarsus, proximal spine one-third length of distal spine; several long setae ventral to distal spine; cleaning organ with 29 setae in ventral row.

Legs. Tibia of leg I with 23 articles; tarsus I with 41 articles; first tarsal article similar in length to sum of subsequent five articles, and second article very short (mean length of first article: $1.11 \mathrm{~mm}$; mean sum of lengths of subsequent five articles: $1.05 \mathrm{~mm}, \mathrm{n}=2$ ). Leg IV basitibia with four pseudo-articles, trichobothrium $b t$ situated on last pseudo-article; distitibia trichobothrium $b c$ situated slightly closer to $s b f$ than to $b f, s c$ and $s f$ series each with five trichobothria.

\section{Measurements}

See Table 7.

\section{Distribution}

Known only from the type locality.

\section{Natural history}

Found under rocks in disturbed areas, near human habitation.

Charinus pecki Weygoldt, 2006

Fig. 94; Table 7

Charinus pecki Weygoldt, 2006b: 22-24, figs 7-8, 11, 16, 27-32.

\section{Diagnosis}

This species may be separated from other species of Charinus in Oceania by means of the following characters: carapace with black markings radiating from fovea, cheliceral claw with five teeth, patella with three ventral spines, median and lateral eyes well developed. 


\section{Etymology}

Patronym honoring Stewart B. Peck (Weygoldt 2006).

\section{Type material}

\section{Holotype}

NEW CALEDONIA • 3 ; Hienghène, Taphozous Grotte; 3 Aug. 1978; 3 m a.s.l.; S. and J. Peck leg.; MHNG.

\section{Paratypes}

NEW CALEDONIA • 4 +, 2 juv.; same collection data as for holotype; MHNG.

\section{Supplementary description}

CARAPACE. Small granules densely scattered between ocular triads and among sulci. Median eyes and median ocular tubercle well developed; pair of setae on median ocular tubercle; lateral eyes well developed, seta posterior to lateral ocular triad; lateral ocular triad well separated from margin of carapace.

STERnUm. Tritosternum projected anteriorly with typical setation; other sternal platelets wide, with seta on each lateral border and some smaller setae posteriorly and in between; pentasternum with two setae anteriorly and one seta in membranous region.

Opisthosoma. Ventral sacs and ventral sac cover absent.

Genitalia. Posterior margin of female genital operculum slightly convex; gonopod cushion-like, unsclerotized basally. Male gonopod with border of fistula and lateral lobes sclerotized; lateral lobe 2 fimbriate.

Chelicerae. Small, flat tooth on retrolateral surface of basal segment, opposite to bifid tooth; retrolateral surface of claw with row of setae basally to medially; claw with 5 teeth; two rows of around eight setae on prolateral surface of basal segment; bifid tooth on basal segment with dorsal cusp larger than ventral cusp.

PEDIPALPS. Coxal dorsal carina with four setae encircled by round carina and four setae on margin. Femur with four dorsal spines and four ventral spines; spine between ventral spine 1 and proximal margin. Patella with three dorsal spines; prominent setiferous tubercle distal to spine I, one-third length of spine I; three ventral spines (holotype with two spines on dextral pedipalp); several setiferous tubercles between spine I and distal margin. Tibia with ventral spine distally, six long setae between spine and distal margin, and several setae throughout prolateral part of segment. Tarsus with two dorsal spines (holotype with three spines on dextral pedipalp), distal spine short, proximal spine one-third length of distal spine; several long, narrow setae ventral to distal spine; cleaning organ with 28-34 setae in ventral row.

LeGs. Tibia of leg I with 23 articles; tarsus I with 41 articles; first tarsal article similar in length to sum of subsequent 2-4 articles. Leg IV basitibia with four pseudo-articles, trichobothrium $b t$ situated medially on pseudo-article; distitibia trichobothrium $b c$ situated slightly closer to $s b f$ than to $b f, s c$ and $s f$ series each with five trichobothria.

\section{Measurements}

See Table 7. 


\section{Distribution}

Known only from the type locality.

\section{Natural history}

Known only from caves.

Charinus pescotti Dunn, 1949

Figs 94, 101-102; Table 7

Charinus pescotti Dunn, 1949: 8-11, figs 1-3.

Charinus pescotti - Monteith 1965: 87. — Baehr 1974: 101-104, fig. 1. — Harvey 1985: 157; 2003: 7. — Delle Cave 1986: 162, fig. II. — Gray \& Robinson 1986: 218-224, figs 1-16. — Quintero 1986: 208, fig. 12. - Weygoldt 2006b: 30-32, figs 40-44. - Harvey et al. 2012: 8. — Gibbons et al. 2019: 498, 500-503, figs 1f-g, 2.

\section{Diagnosis}

This species may be separated from other species of Charinus in Oceania by means of the following combination of characters: chelicerae with small tooth projecting from retrolateral surface of basal segment, opposite to bifid tooth; retrolateral surface of cheliceral claw with two patches of setae, basally and subdorsally; pedipalp coxa with seta encircled by round carina and three setae on margin; setiferous tubercle present between ventral spine 1 and proximal margin of pedipalp femur; leg I with first tarsal article similar in length to sum of subsequent four articles.

Charinus pescotti is the only species with elongated first tarsal article to have 41 articles on tarsus I. All other species with the same character, i.e., proximal tarsal article longer than the length of the subsequent three to ten articles combined (C. carvalhoi sp. nov., C. longitarsus, C. magalhaesi sp. nov., and C. montanus), have less than 40 tarsal articles.

\section{Etymology}

Patronym honoring R.T.M. Pescott (Dunn 1949).

\section{Type material}

\section{Holotype}

AUSTRALIA • +; Queensland, Barron Falls; 1923; G.F. Hill leg.; NMV [not examined].

\section{Additional material}

AUSTRALIA • $1 \hat{\jmath}, 1$ subad. $\hat{\jmath}, 1$ juv.; Freshwater Creek, at Crystal Cascades, $10 \mathrm{~km} \mathrm{~S}$ of Freshwater; $17^{\circ} 00^{\prime} \mathrm{S}, 145^{\circ} 40^{\prime} \mathrm{E} ; 12$ Jul. 1986; M.S. Harvey and P.J. Vaughan leg.; WAM T577 $89 \bullet 2$ juv. 우;

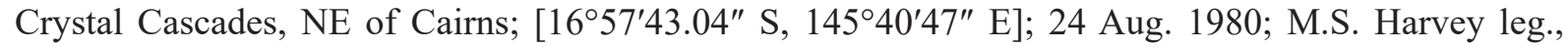

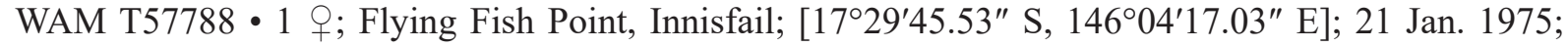
R.J. Raven leg.; WAM T57787 • 1 + juv.; Iron Range, West Claudie River; $12^{\circ} 43^{\prime} \mathrm{S}, 143^{\circ} 17^{\prime} \mathrm{E}$; 3-10 Dec. 1985; G. Monteith and D. Cook leg.; rainforest; QM S38779 • 2 juv.; West Claudie R. [river], Iron Range; 50 m a.s.1.; 3-10 Dec. 1985; G. Monteith and D. Cook leg.; rainforest; QM S38787 • 1 §ै; 2 km WNW of Cape Tribulation; [ $16^{\circ} 04^{\prime} 50.84^{\prime \prime}$ S, 145²6'38.9" E]; 23 Sep. -7 Oct. 1982; QM S38776 2 우,

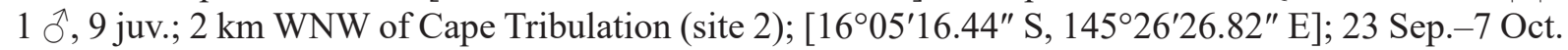
1982; Monteith, Yeates and Thompson leg.; QM S38788 • 1 \%; NeS of Pilgrim Sands, Cape Tribulation; [16 $04^{\prime} 06.68^{\prime \prime}$ S, $145^{\circ} 27^{\prime} 53.49^{\prime \prime}$ E]; 28 Aug. 1988; R. Raven, T. Churchill and J. Gallon leg.; QM

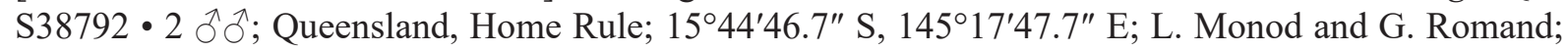
23 Jul. 2006; $191 \mathrm{~m}$ a.s.l.; walking track to waterfall, lowland rainforest, in between stones/in rock 
crevices; AMCC [LP 6367] • 1 O'; Queensland, Crystal Cascades; $16^{\circ} 57^{\prime} 58.3^{\prime \prime}$ S, $145^{\circ} 40^{\prime} 45.9^{\prime \prime}$ E; 10 Jul. 2006; $46 \mathrm{~m}$ a.s.1.; L. Monod leg.; rainforest, in rock cervices and in shallow burrows under stones, near a creek; AMCC [LP 6366].

\section{Supplementary description}

CARAPACE. Median eyes and median ocular tubercle well developed (Fig. 101A); pair of setae on median ocular tubercle; lateral eyes well developed, seta posterior to lateral ocular triad; lateral ocular triad well separated from margin of carapace; frontal process triangular (Fig. 101C).

STERnUm. Tritosternum projected anteriorly with typical setation (Fig. 101B); other sternal platelets wide, with seta on each lateral border and some smaller setae in between; pentasternum with two setae anteriorly and without seta in membranous region.

OpISTHOSOMA. Ventral sacs and ventral sac cover absent.

Genitalia. Posterior margin of female genital operculum slightly convex; gonopod cushion-like (see Weygoldt 2006: figs 41-42) and slightly sclerotized basally. Male gonopod (Fig. 102A-C) with border of fistula and lateral lobes sclerotized; lateral lobe 2 fimbriate (Fig 102E); dorsal lobe with more ventral position, situated behind lateral lobe 1 (Fig. 102D); processus internus short (Fig. 102F).

CHELICERAE. Small tooth projecting from retrolateral surface of basal segment, opposite to bifid tooth; retrolateral surface of claw with two patches of setae, basally and subdorsally; claw with four teeth; row of eleven or twelve setae on prolateral surface of basal segment; bifid tooth on basal segment with dorsal cusp larger than ventral cusp.

PEDIPALPS. Coxal dorsal carina with seta encircled by round carina and three setae on margin. Femur with four dorsal spines (one specimen with five dorsal spines on one pedipalp) and four ventral spines (Fig. 101E-F); setiferous tubercle between ventral spine 1 and proximal margin. Patella with three dorsal spines and three prominent setiferous tubercles proximal to spine III (Fig. 101E); prominent setiferous tubercle distal to spine I, one-third length of spine I; two ventral spines (one specimen with three ventral spines on one pedipalp); setiferous tubercle between spine I and distal margin. Tibia with ventral spine distally and seta between spine and distal margin. Tarsus with two dorsal spines, distal spine long, more than half length of tarsus, proximal spine one-third length of distal spine (Fig. 101D); several long, narrow setae ventral to distal spine; cleaning organ with 24-29 setae in ventral row.

Legs. Tibia of leg I with 23 articles; tarsus I with 41 articles; first tarsal article similar in length to sum of subsequent four articles, and second article very short (mean size of first article: $0.89 \mathrm{~mm}$; mean sum of subsequent four articles: $0.81, \mathrm{n}=4$ ). Leg IV basitibia with four pseudo-articles, trichobothrium $b t$ situated in distal third of pseudo-article; distitibia trichobothrium $b c$ situated closer to $s b f$ than to $b f, s c$ and $s f$ series each with five trichobothria.

\section{Measurements}

See Table 7.

\section{Distribution}

Known only from Queensland, Australia.

\section{Natural history}

Epigean, found on the forest floor. See Gray \& Robinson (1986) for a detailed study of the ecology of C. pescotti. 


\section{Remarks}

See Weygoldt (2006b) for a redescription of C. pescotti. The paratype from Savo Island, Solomon Islands, was misidentified. It is described below as Sarax dunni sp. nov.

Genus Sarax Simon, 1892

Figs 11C-D, 103-149; Tables 8-9

Sarax Simon, 1892: 43, 48 (type species: Sarax brachydactylus Simon, 1892, by original designation). Charinides Gravely, 1911: 35 (type species: Charinides bengalensis Gravely, 1911, by monotypy). Syn. nov.

Phrynichosarax Gravely, 1915b: 437 (type species: Phrynichosarax cochinensis Gravely, 1915b, by original designation (synonymized by Weygoldt 2000a: 25)).

Lindosiella Kritscher, 1959: 454 (type species: Lindosiella ioannitica Kritscher, 1959, by monotypy). Syn. nov.

Sarax - Kraepelin 1895: 45; 1899: 250. — Pocock 1900: 131. — Gravely 1915b: 441. — Mello-Leitão 1931: 55. - Werner 1935: 471. — Weygoldt 2000a: 25. - Harvey 2003: 7. — Rahmadi et al. 2010: 3. - Rahmadi \& Kojima 2010: 476.

Charinides - Gravely 1915b: 442. - Mello-Leitão 1931: 53. - Werner 1935: 471. — Quintero 1983: 27. - Weygoldt 2000a: 24.

Phrynicosarax - Mello-Leitão 1931: 52. — Werner 1935: 470.

\section{Diagnosis}

Sarax may be distinguished from the other two genera of Charinidae by the following combination of characters: lateral eyes usually close to lateral margin of carapace (Figs 105C, 112C); seta situated lateral to lateral ocular triad; dorsal carina on coxa with setiferous tubercles situated close to each other; opisthosoma with (Southeast Asian and Oceanian species) or without (species of Africa, the Middle East and South Asia) ventral sacs and ventral sac covers; female gonopod finger-like (Fig. 138), plunger-like (Fig. 106) or flat (Fig. 146); distal margin of female genital operculum with pair of projections aligned with gonopods (Fig. 121A-B); area of genital operculum between gonopods and posterior margin with denticulate projections in dorsal view (as opposed to smooth in Charinus and Weygoldtia; Fig. 115D).

\section{Etymology}

Unspecified by Simon (1892); from the Greek word for a long, flowing garment.

\section{Description}

CARAPACE. Dorsoventrally compressed, wider than long, slightly bent downwards, ventral to lateral eyes; narrow median sulcus extending from median ocular tubercle to fovea. Anterior margin rounded, with six to eight anterior setae. Frontal process large, triangular, not visible in dorsal view. Three pairs of shallow sulci laterally on carapace, first pair of sulci slightly posterior to lateral boss; no sulci reaching midline; deep, oval fovea posteromedially. Median eyes and median ocular tubercle well developed, reduced or absent, depending on the species; two setae on median ocular tubercle. Lateral eyes well developed, reduced or absent, depending on the species, pale, small seta posterior to each lateral ocular triad; lenses directed anteriorly and dorsally.

STERNUM. Tetra-segmented, all platelets markedly sclerotized. Tritosternum rounded posteriorly and projected anteriorly into large, blunt tubercle, surpassing base of pedipalp coxae, with two anterior, two median, and two posterior setae, and seta between two posterior pairs, with smaller setae posteriorly. Medial platelet (tetrasternum) with single convex platelet, with pair of large setae anteriorly, and several 
small setae posteriorly. Third platelet (pentasternum) forming single convex platelet, smaller than medial platelet, with two setae anteriorly and some setae posteriorly. Sternites separated from each other by length of third platelet. No anterior setae in membranous region and four setae posteriorly.

Opisthosoma. Oblong, tegument with nearly indistinguishable punctation. Ventral sacs and ventral sac cover present or absent, depending on the species.

Genitalia. Female genital operculum broadly sclerotized between gonopods (projections) and posteromedian margin. Female gonopods finger-like (narrow and tubular) or plunger-like (narrow and tubular with apical invagination) with wrinkled base; wide plaque of genital operculum posterior to gonopods. Male gonopods soft, as wide as long; median lobes short and narrow, not surpassing fistula, lamellar; wide, rounded apex, almost reaching apex of lateral lobe; inner surface of gonopod spinous or glabrous.

ChELICERAE. Cheliceral sulcus with four prolateral teeth; first (dorsal) tooth bifid, dorsal cusp larger than ventral cusp. Third tooth slightly narrower and shorter than second tooth. Fourth tooth one-third longer than third tooth. Prolateral surface with two parallel, transverse rows of around fifteen small setae, ventrally to dorsally. Two setae, prolateral and retrolateral, on dorsodistal border, near membranous region of claw. Retrolateral surface of claw with row of setae, basally to dorsally. Claw with three to twelve denticles.

PEDIPALPS. Coxae dorsally with rounded carina in dorsal view, with or without seta inside carina and two or three setae on anterior margin. Trochanter with large, spiniform ventral apophysis with blunt apex pointing anteriorly, bearing 11-16 large setae and several smaller setae, at posterior margin; two subequal spines, one medially in anterior row of setiferous tubercles, other at retrolateral border, dorsal to apophysis, slightly curved prolaterally. Femur with two distinct setiferous tubercles proximal to spine 1; primary series with two to four dorsal spines; three to five ventral spines; setiferous tubercle proximal to ventral spine 1, between spine 1 and proximal margin. Patella with three to five dorsal spines; setiferous tubercle distal to spine I, about one-third length of spine I; spine I with three large and several small setae in proximal third; spine II with two large and some small setae in proximal third; spine III with one seta in distal third, one medially, and one proximally; spine IV (when present) one-third length of spine III with setae medially; spine V (when present) half length of spine IV, with seta medially. Two to four ventral spines, decreasing in length; setiferous tubercle between spine I and distal margin. Tibia with two dorsal spines, proximal spine two-thirds length of distal spine; ventral spine in distal half of tibia, with prominent setiferous tubercle close to its base; long setae between spine and distal margin. Tarsus with one to three dorsal spines. Cleaning organ about half length of tarsus article; ventral row of cleaning brush with 25-34 setae. Claw with long, curved, acute apex.

LEGS. All legs setose. Femur length on leg I $>$ III $>$ II $>$ IV; ventral corner of prolateral surface of leg II-IV femora projecting into distinct spiniform process. Tibia of leg I with 21-28 articles; distal articles with two small trichobothria, dorsally and prolaterally; one trichobothrium on second, third and fourth (distal to proximal) articles, near distal margin, all situated dorsally; trichobothria absent on other articles. Leg I tarsus (basitarsus + distitarsus) with 37-41 articles covered with large number of sensilla. Leg IV basitibia with two to four pseudo-article. Leg IV distitibia with three proximal and 13-15 distal trichobothria. Leg IV basitibia-distitibia length DT $>$ BT1 $>$ BT4 $>$ BT3 $>$ BT2.

\section{Included taxa}

Sarax abbatei (Delle Cave, 1986) comb. nov.; Sarax batuensis Roewer, 1962, new status, Sarax bengalensis (Gravely, 1911) comb. nov.; Sarax bilua sp. nov.; Sarax bispinosus (Nair, 1934), stat. nov.; Sarax brachydactylus Simon, 1892; Sarax cavernicola Rahmadi, Harvey \& Kojima, 2010; Sarax cochinensis (Gravely, 1915); Sarax curioi Giupponi \& Miranda, 2012; Sarax dhofarensis (Weygoldt, 
Pohl \& Polak, 2002) comb. nov.; Sarax dunni sp. nov.; Sarax gravelyi sp. nov.; Sarax huberi Seiter, Wolff \& Hörweg, 2015; Sarax indochinensis sp. nov.; Sarax ioanniticus (Kritscher, 1959) comb. nov.; Sarax israelensis (Miranda et al., 2016) comb. nov.; Sarax javensis (Gravely, 1915); Sarax lembeh sp. nov.; Sarax mardua Rahmadi, Harvey \& Kojima, 2010; Sarax monodenticulatus Rahmadi \& Kojima, 2010; Sarax moultoni (Gravely, 1915) comb. nov., nomen dubium; Sarax newbritainensis Rahmadi \& Kojima, 2010; Sarax omanensis (Delle Cave, Gardner \& Weygoldt, 2009) comb. nov.; Sarax pakistanus (Weygoldt, 2005) comb. nov.; Sarax palau sp. nov.; Sarax rahmadii sp. nov.; Sarax rimosus (Simon, 1901); Sarax sangkulirangensis Rahmadi, Harvey \& Kojima, 2010; Sarax sarawakensis (Thorell, 1888); Sarax seychellarum (Kraepelin, 1898) comb. nov.; Sarax singaporae Gravely, 1911; Sarax socotranus (Weygoldt, Pohl \& Polak, 2002) comb. nov.; Sarax stygochthobius (Weygoldt \& Van Damme, 2004) comb. nov.; Sarax timorensis Miranda \& Reboleira, 2018; Sarax tiomanensis sp. nov.; Sarax willeyi Gravely, 1915; Sarax yayukae Rahmadi, Harvey \& Kojima, 2010,

\section{Distribution}

Cambodia, Greece, India, Indonesia, Israel, Italy, Jordan, Laos, Malaysia, Oman, Pakistan, Palau, Papua New Guinea, Philippines, Seychelles, Singapore, Solomon Islands, Somalia, Thailand, Timor-Leste, Turkey, Vietnam, Yemen.

\section{Remarks}

Ten species previously assigned to Charinus are hereby transferred to Sarax based on the phylogeny of Miranda et al. (2021). Those species share with other Sarax the position of the lateral eyes close to the carapace margin, the shape of the female gonopod (finger-like and plunger-like), and the similar shape of the posterior margin of the genital operculum with denticulate dorsal surface and ventral projections aligned with the gonopods.

\section{Key to the identification of the species of Sarax in Southeast Asia and Oceania}

1. Leg IV distitibia with six trichobothria in frontal and caudal series ............................................. 2

- Leg IV distitibia with five trichobothria in frontal and caudal series ..............................................11

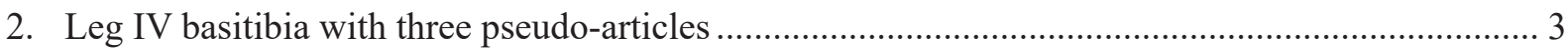

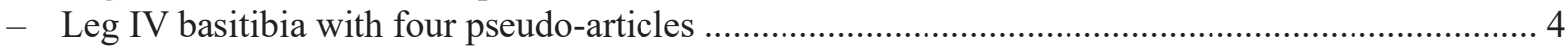

3. Leg IV distitibia, trichobothrium $b c$ situated closer to $s b f$ than to $b f$; pedipalp femur with setiferous tubercle between ventral spine 1 and proximal margin .....

S. lembeh sp. nov. (Fig. 117)

- Leg IV distitibia, trichobothrium $b c$ situated closer to $b f$ than to $s b f$; pedipalp femur with spine between ventral spine 1 and proximal margin

S. singaporae Gravely, 1911

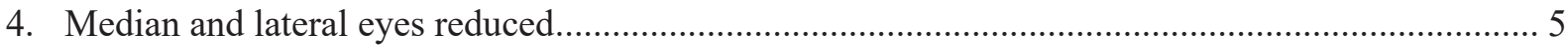

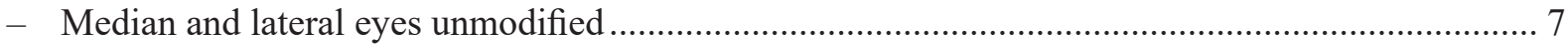

5. Two pairs of lateral eyes

S. timorensis Miranda \& Reboleira, 2018

- Three pairs of lateral eyes

6. Pedipalp femur with six dorsal spines and seven ventral spines

S. cavernicola Rahmadi, Harvey \& Kojima, 2010

- Pedipalp femur with four dorsal spines and four ventral spines

S. mardua Rahmadi Harvey \& Kojima, 2010

7. Pedipalp tarsus with one spine

S. javensis (Gravely, 1915) (Figs 115-116)

- Pedipalp tarsus with three spines (Fig. 131D)

S. yayukae Rahmadi, Harvey \& Kojima, 2010 (Figs 131-134) 
- Pedipalp tarsus with two spines.

8. Carapace anterior margin anteriorly projected ...........S. newbritainensis Rahmadi \& Kojima, 2010

- Carapace anterior margin rounded

9. Cheliceral claw with three teeth; cheliceral basal segment, retrolateral margin without tooth

- Cheliceral claw with five teeth; cheliceral basal segment, retrolateral margin with large tooth .... 10

10. Pedipalp patella with five or six dorsal spines

S. rhamadii sp. nov. (Figs 120-121)

- Pedipalp patella with four dorsal spines ... S. sangkulirangensis Rahmadi, Harvey \& Kojima, 2010

11. Cheliceral claw without teeth

S. curioi Giupponi \& Miranda, 2012

- Cheliceral claw with three to five teeth ....

12. Carapace anterior margin anteriorly projected

- Carapace anterior margin rounded

13. Pedipalp patella with five dorsal spines (Fig. 122E); leg IV basitibia with three pseudoarticles

S. rimosus (Simon, 1901) (Figs 122-124)

- Pedipalp patella with three dorsal spines (Fig. 130E); leg IV basitibia with four pseudoarticles

14. Cheliceral basal segment, retrolateral margin without tooth

- Cheliceral basal segment, retrolateral margin with tooth

15. Pedipalp femur with three dorsal spines (Fig. 125D); pedipalp patella with four dorsal spines (Fig. 125D)

S. sarawakensis (Thorell, 1888) (Fig. 125)

- Pedipalp femur with four or five dorsal spines; pedipalp patella with three dorsal spines

S. bilua sp. nov. (Figs 105-107)

16. Cheliceral claw with two teeth

S. monodenticulatus Rahmadi \& Kojima, 2010

- Cheliceral claw with three teeth

- Cheliceral claw with four teeth

- Cheliceral claw with five teeth

17. Female genital operculum concave with pair of bulges

S. tiomanensis sp. nov. (Figs 126-129)

- Female genital operculum flat

S. brachydactylus Simon, 1892 (Fig. 108)

18. Pedipalp patella with three dorsal spines

S. palau sp. nov. (Figs 118-119)

- Pedipalp patella with five dorsal spines.

19. Pedipalp tarsus with one spine

S. dunni sp. nov. (Fig. 109)

- Pedipalpl tarsus with two spines.

S. huberi Seiter, Wolff \& Horweg, 2015

20. Leg IV distitibia, trichobothrium situated $b c$ closer to $b f$ than to $s b f$.

S. batuensis Roewer, 1962 (Fig. 104)

- Leg IV distitibia, trichobothrium situated $b c$ midway between $b f$ and $s b f$.

S. indochinensis sp. nov. (Figs 112-114)

Sarax batuensis Roewer, 1962, stat. rev.

Figs 103-104; Table 8

Sarax batuensis Roewer, 1962: 519-520, fig. 3a-b. 
Sarax sarawakensis - Weygoldt 1994: 244 (from Batu caves, misidentification).

\section{Diagnosis}

This species may be separated from other species of Sarax in Southeast Asia and Oceania by the following combination of characters: sternal platelets narrow and projecting; pedipalp patella with four to six dorsal spines in primary series and two prominent setiferous tubercles distal to spine I.

\section{Etymology}

The species name refers to the caves inhabited by this species (Roewer 1962).

\section{Type material}

\section{Holotype}

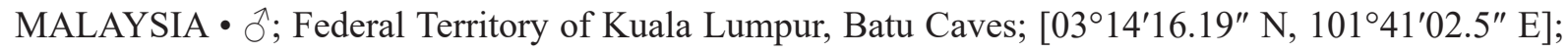
Feb.-Dec. 1959-60; H.E. McClure leg.; SMF RII/13906/51 [not examined].

\section{Paratypes}

MALAYSIA • 3 우, 5 juv.; same collection data as for holotype; SMF.

\section{Additional material}

MALAYSIA • 2 juv.; Batu caves; 2001; P. Schwendinger leg.; captive bred; AMCC [LP 1927].

\section{Redescription}

CARAPACE. Curved carina between ocular triads and carapace margin (Fig. 104A); six anterior setae (Fig. 104A); frontal process triangular. Small granules densely scattered between ocular triads and among sulci. Median eyes and median ocular tubercle well developed (Fig. 104A); pair of setae on median tubercle; lateral eyes well developed, pale, with seta lateral to lateral ocular triad; lateral ocular triad near margin of carapace.

STERnUm. Tritosternum projected anteriorly with typical setation, long, surpassing base of pedipalp coxae (Fig. 104B); other sternal platelets narrow and projected, with pair of setae anteriorly and some smaller setae posteriorly; pentasternum with four setae anteriorly and four setae near membranous region.

Opisthosoma. Ventral sacs and ventral sac cover present.

GeNITALIA. Female genital operculum with short setae posteromedially; pair of white bulges with slender setae apically, in median region; gonopod finger-like, unsclerotized basally. Male genitalia unknown.

Chelicerae. Short, broad projection on retrolateral surface of basal segment, opposite to bifid tooth; retrolateral surface of claw with row of setae basally to medially; claw with five teeth; more than two rows of several setae on prolateral surface of basal segment; bifid tooth on basal segment with dorsal cusp larger than ventral cusp.

PEDIPALPS. Coxae without seta encircled by round carina and three setae on margin. Femur with four dorsal spines and four or five ventral spines (Fig. 104C-D); three prominent setiferous tubercles between first dorsal spine and proximal margin; long spine between ventral spine 1 and proximal margin, twothirds length of spine 1; ventral spine between spines 1 and 2 (Fig. 104D). Patella with 4-6 dorsal spines in primary series (Fig. 104C); two prominent setiferous tubercles distal to spine I; three or four ventral spines; small setiferous tubercle between spine I and distal margin. Tibia with ventral spine distally and four setae between spine and distal margin. Tarsus with two dorsal spines, distal spine long, about one- 


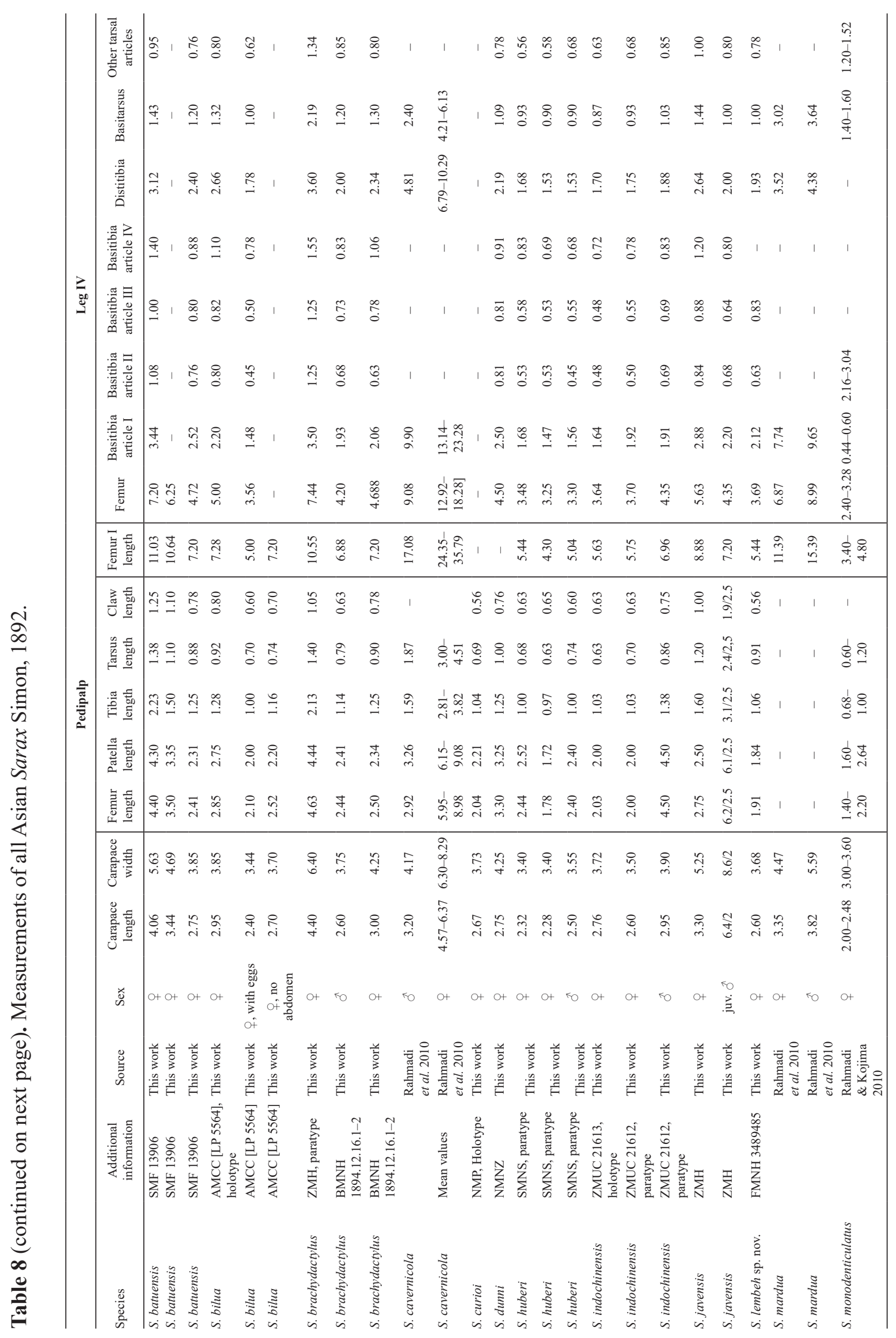




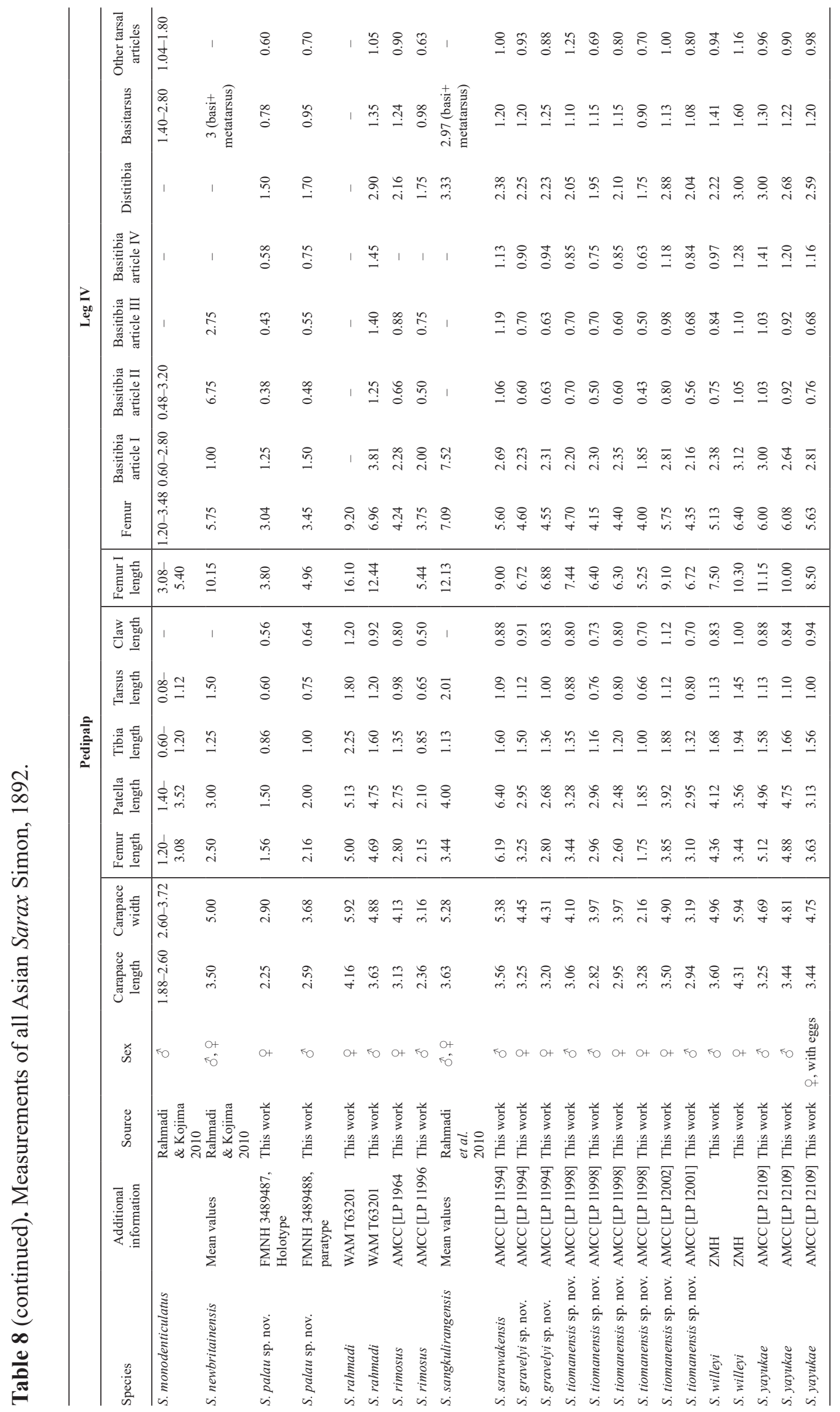


third length of tarsus, proximal spine one-third length of distal spine; cleaning organ with 29-31 setae in ventral row.

Legs. Tibia of leg I with 29 articles; tarsus incomplete; first tarsal article similar in length to second article. Leg IV basitibia with four pseudo-articles, with sclerotized, denticulate margin at apex of articles; trichobothrium $b t$ situated in proximal third of pseudo-article; distitibia trichobothrium $b c$ situated closer to $b f$ than to $s b f, s c$ and $s f$ series each with five trichobothria.

\section{Measurements}

See Table 8.

\section{Distribution}

Sarax batuensis is endemic to the Batu Caves. Previous reports of S. brachydactylus and S. sarawakensis from these caves (Fage 1929; McClure et al. 1967) are misidentifications. Only S. batuensis and S. rimosus are known from the Batu Caves.

\section{Natural history}

This troglobitic species appears to be restricted to the dark zone of the Batu Caves, as no specimens were found in other parts of the cave. Sarax rimosus occurs in the entrance of the cave.

\section{Remarks}

The vial of paratypes comprises three adult females and five juveniles, but the holotype male is missing.

The unique morphological characters of $S$. batuensis, including the large size of the adults and the basitibia of leg IV with four pseudo-articles, justify its recognition as a distinct species, as proposed by Kraus (1970). Accordingly, this species is removed from synonymy with S. buxtoni.

The vial of paratypes contains five juveniles, and three adult females, but the male holotype is missing.

Sarax bilua sp. nov.

urn:1sid:zoobank.org:act:459C6DC3-F213-40BB-A67B-3F4B0A048074

Figs 103, 105-107; Table 8

\section{Diagnosis}

This species may be separated from other species of Sarax in Southeast Asia and Oceania by the following combination of characters: chelicera without retrolateral tooth on basal segment opposite to bifid tooth; cheliceral claw with three teeth; pedipalp femur with four or five dorsal spines and four or five ventral spines (Fig. 105E-F); pedipalp patella with three dorsal spines and two ventral spines (Fig. 105E-F); leg IV basitibia with four pseudo-articles and trichobothrium $b t$ situated distally; distitibia trichobothrium $b c$ situated closer to $b f$ than to $s b f ; s c$ and $s f$ series each with five trichobothria.

This species resembles $S$. sarawakensis, but possesses fewer teeth on the cheliceral claw and more spines on the pedipalp femur.

\section{Etymology}

The species name is a noun in apposition, taken from bilua, the most common Papuan language spoken in the Solomon Islands, by the people on the island of Vella Lavella.

\section{Type material}

\section{Holotype}


SOLOMON ISLANDS • + ; Western Province, Vella Lavella Island, MBuna Poro Village; $7^{\circ} 45^{\prime} 31.56^{\prime \prime}$ S, 156 39'55" E; 25 Oct. 2004; C. Sirno, R. Wys and L. Monod leg.; rainforest, under rotten log; AMCC [LP 5564].

Paratypes

SOLOMON ISLANDS • 3 + 9 ; same collection data as for holotype; AMCC [LP 5564].

\section{Description}

CARAPACE. Six anterior setae (Fig. 105A, C); frontal process triangular (Fig. 105C). Small granules densely scattered between ocular triads and among sulci. Median eyes well developed (Fig. 105A, C); median ocular tubercle reduced; pair of setae on median ocular tubercle; lateral eyes well developed, seta lateral to lateral ocular triad; lateral ocular triad near carapace margin; curved carina between ocular triads and lateral margin of carapace (Fig. 105C).

STERnUm. Tritosternum anteriorly projected with typical setation (Fig. 105B); other sternal platelets narrow and concave, with pair of setae anteriorly on plaque and some smaller setae posteriorly; pentasternum four setae anteriorly and without seta on membranous region.

OpISTHOSOMA. Ventral sacs and ventral sac cover present.

GeNITALIA. Female genital operculum with prominent setae posteromedially and some smaller setae near margin, without bulges medially (Fig. 106A-C); gonopod with pair of short, plunger-like submedian lobes unsclerotized basally (Fig. 106A, C, F); denticulate surface between gonopod and posterior margin of genital operculum (Fig. 106D); slit sensilla on lateral margin of genital operculum (Fig. 106E). Male unknown.

Chelicerae. Basal segment without tooth on retrolateral surface, opposite to bifid tooth; retrolateral surface of claw with continuous row of setae, basally to medially; claw with three teeth; row of around ten setae on prolateral surface of basal segment; bifid tooth on basal segment with dorsal cusp larger than ventral cusp.

PeDIPALPS. Coxae with seta encircled by round carina and three setae on margin. Femur with four or five dorsal spines and four or five ventral spines (Fig. 105E-F); long spine between ventral spine 1 and proximal margin; three prominent setiferous tubercles between dorsal spine 1 and proximal margin. Patella with three dorsal spines in primary series (Fig. 105E); prominent setiferous tubercle distal to dorsal spine I, one-third length of spine I; two prominent setiferous tubercles proximal to dorsal spine III; two ventral spines; long setiferous tubercle proximal to spine II and prominent setiferous tubercle between spine I and distal margin. Tibia with ventral spine distally and three or four setae between spine and distal margin. Tarsus with one dorsal spine, one-fifth length of tarsus (Fig. 105D); cleaning organ with 30 setae in ventral row.

Legs. Tibia of leg I with 23 articles; tarsus I with 41 articles; tarsal organ situated near base of claw (Fig. 107A-C); rod sensilla with four setae in shallow groove (Fig. 107D); first tarsal article similar in length to second article. Leg IV basitibia with four pseudo-articles, without sclerotized, denticulate projection at apex of articles; trichobothrium $b t$ situated in distal third of pseudo-article; distitibia trichobothrium $b c$ situated closer to $b f$ than to $s b f ; s c$ and $s f$ series each with five trichobothria.

\section{Measurements}

See Table 8. 


\section{Distribution}

Known only from the type locality.

\section{Natural history}

The three ovigerous females are different sizes, suggesting different developmental stages. The small female does not appear to be a fully developed adult and the possession of eggs at an early stage of development suggests this species may be parthenogenetic.

\section{Sarax brachydactylus Simon, 1892}

Figs 103, 108; Table 8

Sarax brachydactylus Simon, 1892: 43-44.

Sarax brachydactylus - Kraepelin 1895: 45 (in part); 1899: 251. — Gravely 1915b: 441. — Giltay 1931: 24-25. — Mello-Leitão 1931: 55. — Werner 1935: 471. — Wolf 1938: 537. — Fage 1946b: 78-79, fig. 3b. — Bristowe 1952: 699. — Weidner 1959: 142. — Vandel 1965: 93. — Kraus 1970: 177-178, figs 1-8. - Yussof 1997: plate 27. — Weygoldt 2002c: 137-138, figs 13-15. - Harvey 2003: 7. — Dittmar et al. 2005: 224, 227. — Giupponi \& Miranda 2012: 169-171, figs 8-14. — Wolff et al. 2015: 525, 534-535, 538, figs 2d, g, 3a-b, d, 10; 2017: 2, 5, fig. 1. - Gibbons et al. 2019: fig. 1c.

\section{Diagnosis}

This species may be separated from other species of Sarax in Southeast Asia and Oceania by the following combination of characters: cheliceral claw with three teeth, basal segment with small tooth in retrolateral row, opposite to bifid tooth; pedipalp femur with four or five dorsal spines and three or four ventral spines (Fig. 108E-F); pedipalp patella with four or five dorsal spines and three ventral spines (Fig. 108E-F); leg IV basitibia with four pseudo-articles; trichobothrium $b t$ situated distally; distitibia trichobothrium $b c$ situated closer to $b f$ than to $s b f ; s c$ and $s f$ series each with five trichobothria.

\section{Etymology}

The species name is a compound adjective, derived from the Greek words 'brachy', meaning 'broad', and 'dactylus' meaning 'finger', hence 'broad-fingered'. Although unspecified, the species name, evidently refers to the appearance of the pedipalps.

\section{Type material}

\section{Syntypes}

PHILIPPINES • 1 q, 1 §’; Luzon, Grotte d'Antipolo, Grotte de San-Mateo and Grotte de Colapnitan [details unspecified in original paper, but according to Seiter et al. (2015): 7 ad.]; MNHN 14802 • 1 ad., 2 juv.; same collection data as for preceding; MNHN 14803.

\section{Additional material}

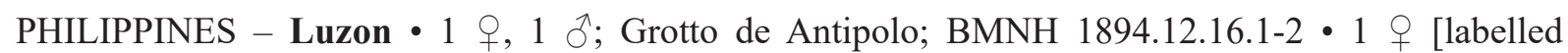
'paratype']; 17 Nov. 1894; ZMH Nr. 6 • 1 q; Laguna District, Los Banos, Hortorium; S. Huber leg.; leaf litter, under flower pots; AMCC [LP 1926] 1 ind. [without gonopod]; Los Banos Laguna, Mount Makiling; $14^{\circ} 08^{\prime} 59.2^{\prime \prime} \mathrm{N}, 121^{\circ} 13^{\prime} 34.2^{\prime \prime}$ E; 26 Feb. 2008; S. Huber leg.; AMCC [LP 9824]. - Tawi

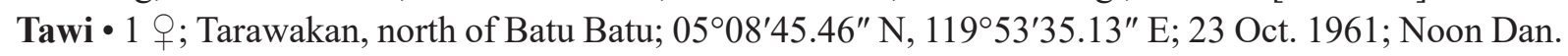
Exp. 1961-1962 leg.; ZMUC 21615; new record. 


\section{Description}

CARAPACE. Six anterior setae (Fig. 108A); frontal process triangular (Fig. 108C). Small granules densely scattered between ocular triads and among sulci. Median eyes well developed; median ocular tubercle reduced, with pair of setae; lateral eyes well developed, pale, seta lateral to lateral ocular triad; lateral ocular triad situated near carapace margin; curved carina between ocular triads and carapace margin.

STERnUm. Tritosternum projected anteriorly with typical setation, long, surpassing base of pedipalp coxae (Fig. 108B); other sternal platelets narrow and concave, with pair of setae anteriorly on plaque and some smaller setae posteriorly; pentasternum with four setae anteriorly and four setae near membranous region.

OpISTHOSOMA. Ventral sacs and ventral sac cover present.

Genitalia. Female genital operculum with short setae posteromedially; median region flat with slender setae apically; gonopod plunger-like, unsclerotized basally. Male gonopod only sclerotized at apex of lateral lobe.

Chelicerae. Small tooth on retrolateral surface of basal segment, opposite to bifid tooth; retrolateral surface of claw with row of setae basally to medially; claw with three teeth; two rows of several setae on prolateral surface of basal segment; bifid tooth on basal segment with dorsal cusp larger than ventral cusp.

Pedipalps. No secondary sexual dimorphism evident. Coxae without seta encircled by round carina and with three setae on margin. Femur with four or five dorsal spines and three or four ventral spines (Fig. 108E-F); three prominent setiferous tubercles between dorsal spine 1 and proximal margin; ventral spine between spine 1 and proximal margin, two-thirds length of spine 1. Patella with four or five dorsal spines (Fig. 108E); two prominent setiferous tubercles distal to spine I; three ventral spines. Tibia with ventral spine distally and three or four setae between spine and distal margin. Tarsus with two dorsal spines, both short, distal spine slightly longer than proximal spine (Fig. 108D); cleaning organ with 32 setae in ventral row.

Legs. Tibia of leg I with 23 articles; tarsus I with 41 articles; first tarsal article similar in length to second article. Leg IV basitibia with four pseudo-articles, without sclerotized, denticulate margin at apex of articles; trichobothrium $b t$ situated in distal third of pseudo-article; distitibia trichobothrium $b c$ situated closer to $b f$ than to $s b f ; s c$ and $s f$ series each with five trichobothria.

\section{Measurements}

See Table 8.

\section{Distribution}

Restricted to the Philippines.

\section{Natural history}

Found inside and outside caves.

\section{Remarks}

Seiter et al. (2015) examined the type material and mentioned a juvenile holotype (MNHN 14801) and seven adults (MNHN 14802), one adult and two juv. (MNHN 14803) "types” (presumably paratypes). However, Simon (1892) only mentioned a male and a female, and did not specify a holotype in the 
original description. It is unclear which of the specimens examined by Seiter et al. (2015) are the original syntypes.

Another specimen, deposited at ZMH and labelled "paratype", is unlikely to be part of the original syntype series for the following reasons. The ZMH material contains a label on which is written "E. Simon, 17 Nov. 1894", indicating the specimen was examined by Simon in 1894, two years after the publication of the species. The sinistral pedipalp and some legs are detached from the ZMH specimen, which differs from other material of $S$. brachydactylus in the following respects: pedipalp femur with large spine between dorsal spines 1 and 2, two-thirds length of spine 1, medium-sized spine between dorsal spines 2 and 3, three prominent setiferous tubercles proximal to dorsal spine 1, dorsal setiferous tubercles aligned, and large spine proximal to ventral spine 1; pedipalp patella with four ventral spines and spine between spine I and 4; pedipalp tibia with three long setae between distal spine and distal margin; leg IV basitibia trichobothrium bt situated medially.

Reports of S. brachydactylus from the Malay Peninsula (Fage 1946; McClure et al. 1967; Dittmar et al. 2005) are misidentifications. McClure et al. (1967) published a list of taxa from the Dark Cave of the Batu Caves, and reported S. brachydactylus from the deep part of the cave. At that time, S. batuensis had already been described from the same locality (the type series of $S$. batuensis was collected by McClure); hence, the report of $S$. brachydactylus from these caves, repeated by Dittmar et al. (2005), is erroneous.

Sarax cavernicola Rahmadi, Harvey \& Kojima, 2010

Fig. 103; Table 8

Sarax cavernicola Rahmadi et al., 2010: 3-6, figs 1-7, 33-34.

\section{Diagnosis}

Based in part on Rahmadi et al. (2010), this species may be separated from other species of Sarax in Southeast Asia and Oceania by the following combination of characters: large size (adult body length ca $6.2-16.2 \mathrm{~mm}$ ); yellowish-brown tegument; female gonopod plunger-like; median and lateral eyes reduced; basal segment of chelicera with one tooth in retrolateral row; six teeth on cheliceral claw; pedipalp femur with six dorsal spines and seven ventral spines; pedipalp patella with three dorsal spines and four ventral spines; pedipalp tibia with three ventral spines decreasing in length from distal to proximal; pedipalp tarsus with three dorsal spines, proximal spine shortest, distal spine longest, medial spine close to proximal spine; tibia of leg I and tarsus I with 23 and 41 segments, respectively; leg IV basitibia trichobothrium $b t$ situated close to proximal margin; leg IV distitibia with 18 trichobothria; trichobothrium $b c$ situated very close to $s b f, s c$ and $s f$ series each with six trichobothria.

This is one of few charinid species with more than one spine on the ventral surface of the pedipalp tibia (three are present), a character state otherwise found only in another cave species, Charinus diamantinus sp. nov., and in a few species of other families, including Charontidae, Phrynidae, Paracharon caecus and Xerophrynus machadoi Weygoldt, 1996.

\section{Etymology}

Latin adjective referring to the cavernicolous habitat (Rahmadi et al. 2010).

\section{Type material}

\section{Holotype}

INDONESIA • $\odot$; East Kalimantan, Pengadan Village, Sangkulirang District, Kutai Timur Regency, Gua Ambulabung (Gua Baai); KAL-110; 01 ${ }^{\circ}{ }^{\prime} 11^{\prime \prime}$ N, 117³3'59.91" E; 16 Aug. 2004; L. Deharveng leg.; MZB Ambl. 145 [not examined]. 


\section{Paratypes}

INDONESIA • 1 $\%$; same collection data as for holotype; MZB Ambl. $146 \bullet 1+$; same collection data as for holotype; MNHN Am. 8 [not examined] $11 \delta^{\top}$; same collection data as for holotype; MZB Ambl. 147

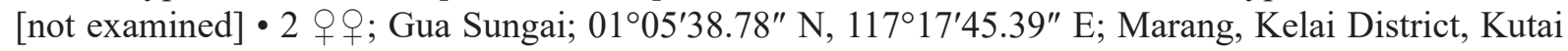
Timur Regency; 22 Aug. 2004; Y.R. Suhardjono leg.; MZB Ambl. 72, MZB Ambl. 73 [not examined] • 2 우; same locality as for preceding; 23 Aug. 2004; C. Rahmadi leg.; MZB Ambl. 91, MZB Ambl. 92 [not examined].

\section{Measurements}

See Table 8 .

\section{Distribution}

Known only from two caves, Gua Ambulabung and Gua Sungai in East Kalimantan, Indonesia.

\section{Natural history}

This troglobitic species exhibits several troglomorphies, including reduction of the eyes and elongation of the pedipalp spines. It was collected along with several other cave arthropods, including a giant cave cockroach Miroblatta baai Grandcolas \& Deharveng, 2007, and the cave millipedes Plusioglyphiulus bedosae Golovatch et al., 2009 and Plusioglyphiulus pallidior Golovatch et al., 2009.

\section{Remarks}

See Rahmadi et al. (2010) for a description of this species.

Sarax curioi Giupponi \& Miranda, 2012

Fig. 103; Table 8

Sarax curioi Giupponi \& Miranda, 2012: 166-172, figs 1-7, 14.

Sarax curioi - Seiter et al. 2015: 542, 545-547, 549-551, figs 5-6. — Wolff et al. 2017: 2-3, 5, fig. 1.

\section{Diagnosis}

Based in part on Giupponi \& Miranda (2012), this species may be separated from other species of Sarax in Southeast Asia and Oceania by the following combination of characters: median eyes and median ocular tubercle present; lateral eyes well developed and situated near lateral margin of carapace; cheliceral claw without teeth; pedipalp femur with four dorsal spines and three ventral spines; pedipalp patella with five dorsal spines and four ventral spines; pedipalp tarsus with curved and geminate spines on dorsal margin; tibia of leg I with 21 articles, tarsus I with 37 articles; leg IV basitibia with four pseudo-articles, trichobothrium $b c$ situated equidistant between $b f$ and $s b f$, and $s c$ and $s f$ series each with five trichobothria.

The absence of teeth on the cheliceral claw and presence of geminate spines on the pedipalp tarsus distinguish this species from all others in the genus.

\section{Etymology}

Patronym honoring Eberhard Curio (Giupponi \& Miranda 2012).

\section{Type material}

\section{Holotype}

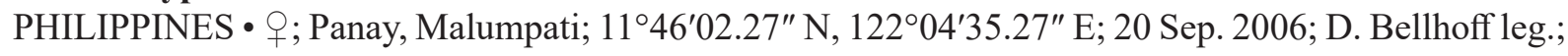
NMP. 


\section{Measurements}

See Table 8 .

\section{Distribution}

Known only from the type locality.

\section{Remarks}

See Giupponi \& Miranda (2011) for description.

Sarax dunni sp. nov. urn:lsid:zoobank.org:act:63CBC94C-F7CE-4563-80EC-29102233C553

Figs 103, 109; Table 8

Charinus pescotti Dunn, 1949: 10-11 (in part, specimens from Savo Island).

\section{Diagnosis}

This species may be separated from other species of Sarax in Southeast Asia and Oceania by the following combination of characters: cheliceral claw with four teeth and acute tooth in retrolateral row, adjacent to bifid tooth; pedipalp femur with five dorsal spines and four ventral spines (Fig. 109E-F); pedipalp patella with five dorsal spines and four ventral spines (Fig. 109E-F); leg IV basitibia with four pseudo-articles, trichobothrium $b t$ situated distally; leg IV distitibia trichobothrium $b c$ equidistant between $b f$ and $s b f, s c$ and $s f$ series each with five trichobothria.

Sarax dunni sp. nov. resembles $S$. palau sp. nov., from which it differs by the higher number of spines on the pedipalp.

\section{Etymology}

Patronym honoring R.A. Dunn for his contributions to arachnology.

\section{Type material}

\section{Holotype}

SOLOMON ISLANDS • P; Savo Island; [0907'54.17" S, 15948'42.51" E]; R.R. Forster leg.; Jan. 1944; under debris in coastal forest and coconut plantation; NMNZ.

\section{Description}

CARAPACE. Six anterior setae (Fig. 109A); frontal process triangular (Fig. 109D). Small granules densely scattered between ocular triads and among sulci. Median eyes well developed (Fig. 109A, D); median ocular tubercle reduced; pair of setae on median ocular tubercle; lateral eyes well developed, seta situated lateral to lateral ocular triad; lateral ocular triad situated near carapace margin; curved carina between ocular triads and lateral margin of carapace.

STERnUm. Tritosternum projected anteriorly with typical setation (Fig. 109B); other sternal platelets narrow and concave, with pair of setae anteriorly on plaque and some smaller setae posteriorly; pentasternum with four setae anteriorly and without seta in membranous region.

OpISTHOSOMA. Ventral sacs and ventral sac cover present.

GeNITALIA. Female genital operculum with prominent setae posteromedially and some smaller setae near margin, without bulges medially; gonopod absent (probably lost). Male unknown. 
Chelicerae. Acute tooth projecting from retrolateral surface of basal segment, opposite to bifid tooth; retrolateral surface of claw with continuous row of setae, basally to medially; claw with four teeth; row of around ten setae on prolateral surface of basal segment; bifid tooth on basal segment with dorsal cusp larger than ventral cusp.

PedipalPs. Coxae without seta encircled by round carina and with three setae on margin. Femur with five dorsal spines and four ventral spines (Fig. 109E-F); long spine between proximal margin and ventral spine 1, and between spines 1 and 2; three prominent setiferous tubercles between dorsal spine 1 and proximal margin. Patella with five dorsal spines (Fig. 109E); prominent spine distal to dorsal spine I, half length of spine I; four ventral spines (Fig. 109F; setiferous tubercle between spine I and distal margin. Tibia with ventral spine distally and three setae between spine and distal margin. Tarsus with one dorsal spine, one-tenth length of tarsus (Fig. 109D); cleaning organ with 28 setae in ventral row.

LeGs. Leg IV, basitibia with four pseudo-articles, without sclerotized, denticulate projection at apex of articles; trichobothrium $b t$ situated in distal third of pseudo-article; distitibia trichobothrium $b c$ equidistant between $b f$ and $s b f ; s c$ and $s f$ series each with five trichobothria.

\section{Measurements}

See Table 8.

\section{Distribution}

Known only from the type locality.

\section{Natural history}

Found under debris in coastal forest and coconut plantation.

\section{Remarks}

Dunn (1949) mentioned four females in the museum and his personal collection, but only one female is present at NMNZ. The specimen here described as $S$. dunni sp. nov. was a paratype of Charinus pescotti. Dunn (1949) mentioned differences in pedipalp spination between the holotype of C. pescotti and the paratypes from the Solomon Islands, but attributed these differences to developmental stages. However, the paratype from the Solomon Islands is clearly an adult female in which all spines and trichobothria are present. Although the antenniform leg I are missing from the specimen, the position of the lateral eyes situated near the carapace margin, the curved carina contacting the lateral eyes, and the presence of a ventral sac cover, unequivocally place this specimen in Sarax.

Sarax gravelyi sp. nov. urn:1sid:zoobank.org:act:AEE16A5A-147C-4814-BF11-3CC21B1B3668

Figs 103, 110-111; Table 8

Sarax buxtoni - Seiter \& Wolff 2014: 233-234, 237-238, figs 1a, 2a-d, h-j, 3a-b.

\section{Diagnosis}

This species most closely resembles $S$. batuensis and $S$. rahmadii sp. nov., from which it may be separated by the following combination of characters: brownish color with red stripes on the carapace, opisthosoma, and legs; pedipalp patella with one or two ventral spines between spine I and distal margin (Fig. 110F); two large spines dorsally on pedipalp tarsus; leg IV basitibia with four pseudo-articles, distitibia $s c$ and $s f$ series each with six trichobothria. 


\section{Etymology}

Patronym honoring Frederick H. Gravely for his contributions to arachnology.

\section{Type material}

\section{Holotype}

SINGAPORE • +; Nee Soon Swamp Forest, Old Upper Thomson Road; $01^{\circ} 23.445^{\prime}$ N, $103^{\circ} 49.077^{\prime}$ E; $46 \mathrm{~m}$ a.s.1.; 3 Jun. 2013; L. Prendini and S. Loria leg.; primary/secondary disturbed rainforest along roadside; dense canopy; sparse understorey; moderate leaf litter layer; under discarded earthen pots; LKC ex AMCC [LP 11994].

\section{Paratypes}

SINGAPORE • 4 + $\odot$; same collection data as for holotype; AMCC [LP 11994] • 1 , 1 juv.; Bukit Timah Nature Reserve, Bukit Timah; 01²1'16.85" N, 10346'34.95" E; 163 m a.s.1.; L. Prendini and S.F. Loria leg.; 3 Jun. 2013; primary rainforest on slopes of Bukit Timah [highest hill in Singapore]; dense canopy and leaf litter layer; moderate to sparse understorey; forest somewhat dry; coarse, granitic sandyloam soil; under stones; AMCC [LP 11995] • 1 क; University of Singapore, University Campus, Kent Ridge; $01^{\circ} 18^{\prime} \mathrm{N}, 103^{\circ} 47^{\prime}$ E; 6 Jan. 1991; M. Andersen, O. Martin and N. Scharff leg.; secondary forest; ZMUC 21592.

\section{Additional material}

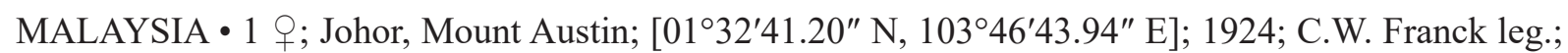
ZMUC 21611.

SINGAPORE • 3 우; Br. Timah, Singapore; Mar. 1924; BMNH 1324-25 • 2 q $q, 3$ juv.; Rifle Range Road, close to Bukit Timah; $01^{\circ} 20.789^{\prime} \mathrm{N}, 1^{\circ} 3^{\circ} 46.962^{\prime} \mathrm{E}$; $55 \mathrm{~m}$ a.s.l.; 22 Jun. 2013; P. Jäger leg.; SMF 65287.

\section{Description}

CARAPACE. Six anterior setae (Fig. 110A); frontal process triangular (Fig. 110C). Small granules densely scattered between ocular triads and among sulci. Median eyes and median ocular tubercle well developed (Fig. 110A, C); pair of setae on median tubercle; lateral eyes well developed, pale, with seta lateral to lateral ocular triad; lateral ocular triad situated near carapace margin; curved carina between ocular triads and carapace margin.

STERnUm. Tritosternum projected anteriorly with typical setation, long, surpassing base of pedipalp coxae (Fig. 110B); other sternal platelets narrow and projected, with pair of setae anteriorly on plaque and some smaller setae posteriorly; pentasternum with four setae anteriorly on plaque.

OpISTHOSOMA. Ventral sacs and ventral sac cover well developed.

Genitalia. Female genital operculum with short setae posteromedially (Fig. 111A-C); pair of white slightly bulging areas medially with slender setae apically (Fig. 111A-C); gonopod finger-like, unsclerotized basally (Fig. 111A, C, E); denticulate surface between gonopod and posterior marging of genital operculum (Fig. 111D); slit sensilla on lateral margin of genital operculum (Fig. 111F). Male unknown.

Chelicerae. Retrolateral surface of basal segment without tooth, opposite to bifid tooth; retrolateral surface of claw with row of setae basally to medially; claw with three teeth; more than two rows of several setae on prolateral surface of basal segment; bifid tooth on basal segment with dorsal cusp larger than ventral cusp. 
Pedipalps. Coxae without seta encircled by round carina and with two setae on margin. Femur with four dorsal spines and four ventral spines (Fig. 110E-F); two prominent setiferous tubercles between dorsal spine 1 and proximal margin; long spine between ventral spine 1 and proximal margin, two-thirds length of spine 1. Patella with five dorsal spines in primary series (Fig. 110E); prominent spine distal to spine I; four ventral spines; small setiferous tubercle between spine I and distal margin (Fig. 110F). Tibia with ventral spine distally and two setae between spine and distal margin. Tarsus with two dorsal spines, distal spine long, about one-third length of tarsus and proximal spine one-third length of distal spine (Fig. 110D; cleaning organ with 27-29 setae in ventral row.

LeGs. Tibia of leg I with 23 articles; tarsus I with 41 articles; first and second tarsal articles equal in length. Leg IV basitibia with four pseudo-articles, with sclerotized, denticulate margin at apex of articles; trichobothrium $b t$ situated in distal third of pseudo-article; distitibia trichobothrium $b c$ situated closer to $b f$ than to $s b f, s c$ and $s f$ series each with six trichobothria.

\section{Measurements}

See Table 8.

\section{Distribution}

Known only from Singapore.

\section{Natural history}

Found under stones and fallen tree trunks in primary and secondary rainforest.

\section{Remarks}

Three species of Sarax occur in Singapore: S. buxtoni, S. gravelyi sp. nov. and S. singaporae. Sarax buxtoni appears to be uncommon in Singapore (but abundant in peninsular Malaysia), S. gravelyi sp. nov. occurs in some restricted forested areas of Singapore, whereas S. singaporae is widespread in Singapore.

The specimen from Mount Austin, Malaysia (ZMUC 21611), near Singapore, is a female with dark coloration, perhaps due to the long time preserved in ethanol. The spines of the pedipalp tarsus are short unlike the Singaporean specimens to which the specimen is otherwise similar: the carapace has lateral carinae contacting the lateral eyes; the genital operculum is typical of Sarax, with prominent bulges; the gonopod is finger-like and unsclerotized basally; and the leg IV basitibia consists of four pseudo-articles.

Sarax huberi Seiter, Wolff \& Horweg, 2015

Fig. 103; Table 8

Sarax huberi Seiter et al., 2015: 543-548, figs 1-3.

\section{Diagnosis}

Based in part on Seiter et al. (2015), this species may be separated from the geographically closest species, S. brachydactylus and S. curioi, by the following combination of characters: six setae on anterior margin of carapace without prominent corners (as in S. curioi); margin of genital operculum with several setae; female gonopods soft, conical; cheliceral claw with teeth (absent in S. curioi); sexual dimorphism in male pedipalps, with femur and tibia elongate; pedipalp surface granular (smooth in S. brachydactylus); pedipalp tarsus with two very short, separated dorsal spines (geminate in S. curioi).

\section{Etymology}

Patronym honoring Siegfried Huber for his contributions to the study of whip spiders (Seiter et al. 2015). 


\section{Type material}

\section{Holotype}

PHILIPPINES • 9 ; Cebu, Moalboal, surroundings of Busay cave; $09^{\circ} 54^{\prime} 57.5^{\prime \prime}$ N, $123^{\circ} 26^{\prime} 13.2^{\prime \prime}$ E; Mar. 2008; S. Huber leg.; NHMW 21895 [not examined].

\section{Paratypes}

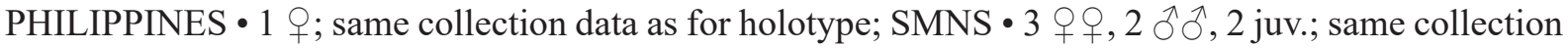
data as for holotype; NHMW 21897 [not examined] -2 웅, 2 ôj; same locality and collector as for holotype; 28 Mar. 2014; NHMW 21897 [not examined] • 1 \%; same locality and collector as for

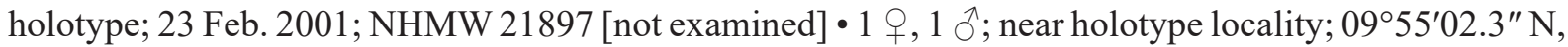
$123^{\circ} 25^{\prime} 05.8^{\prime \prime}$ E; 30 Mar. 2014; S. Huber leg.; NHMW 21897 • 1 ㅇ, 1 o'; South of Moalbaol, Kawasan Falls; 0948'20.1" N, 12322'17.7" E; 21 Feb. 2001; S. Huber leg.; SMNS [examined] • 1 \&, 1 ô, 1 juv.; same collection data as for preceding; NHMW 21896 [not examined].

\section{Additional material}

PHILIPPINES • 1 \&, 1 juv.; East slope Mt McKinley, Davao Prov., Mindanao; 3300 ft a.s.1.; 26 Sep. 1946; F.G. Werner leg.; Philippine Zool. Exped. 1946-1947 leg.; in tall stump; FMNH 3489489 • 1 \%, 1 juv.; East slope Mt McKinley, Davao Prov., Mindanao; 3000 ft a.s.l.; 10 Oct. 1946; F.G. Werner leg.; Philippine Zool. Exped. 1946-1947 leg.; debris on agricultural land; FMNH 3489491 • 1 ㅇ, 1 juv.; East slope Mt McKinley, Davao Prov., Mindanao; 4000 ft a.s.l.; 14 Aug. 1946; H. Hoogstraal leg.; Philippine Zool. Exped. 1946-1947 leg.; forest floor; FMNH 3489498.

\section{Measurements}

See Table 8.

\section{Distribution}

Known from several localities in the Philippines.

\section{Natural history}

The type series was found at the Kawasan Falls and in the vicinity of Busay Cave. Specimens were mostly under stones and in the leaf litter in front of the entrance of the cave (Seiter et al. 2015).

\section{Remarks}

See Seiter et al. (2015) for description.

Sarax indochinensis sp. nov.

urn:1sid:zoobank.org:act:20DCB29C-E29F-4F43-8BB7-40B02BCF4FF6

Figs 103, 112-114; Table 8

Sarax brachydactylus - Fage 1946b: 79 (in part).

Sarax aff. brachydactylus - Seiter et al. 2015: 545.

\section{Diagnosis}

This species may be separated from other species of Sarax in Southeast Asia and Oceania by the following combination of characters: median and lateral eyes well developed (Fig. 112A); ventral sacs and ventral sac cover well developed; female gonopod finger-like with small invagination apically (Fig. 113A); cheliceral basal segment with small tooth adjacent to bifid tooth; secondary sexual dimorphism in males with longer pedipalp segments than females; pedipalp tarsus with two short dorsal spines; leg IV basitibia with four pseudo-articles, distitibia $s c$ and $s f$ series each with five trichobothria. 
This species resembles $S$. brachydactylus, but the genital operculum is concave, with two symmetric bulges unlike that of $S$. brachydactylus, which is flat.

\section{Etymology}

The species name is an adjective derived from Indochina, the region of Southeast Asia which included Cambodia, Laos, and Vietnam, under French control between ca 1890-1950.

\section{Type material}

\section{Holotype}

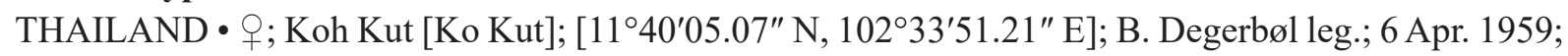
ZMUC 21613.

\section{Paratypes}

THAILAND • 3 우, $7 \widehat{\jmath}$, 1 juv.; same locality as for holotype; B. Degerbøl leg.; 5 Apr. 1959; ZMUC 21612.

VIETNAM - 1 क; Annam, Ha Tien, Kien Giang Province; Hang Trong Nguc (Da Dung mountain); $10^{\circ} 25^{\prime} 44.8^{\prime \prime}$ N, 104²8'36.6" E; 7 Jan. 2010; H. Steiner leg. (Northern Lao-European Cave Project 2010); SMF 029/10.

\section{Additional material}

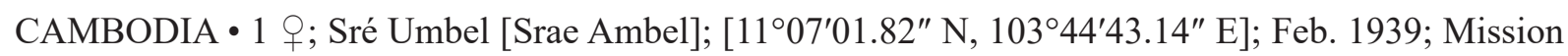
C. Dawydoff, Indochine, 1938-1939; MNHN • 1 đ’; Kampong Speu; Apr. 1939; Mission C. Dawydoff,

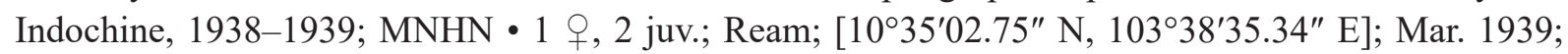

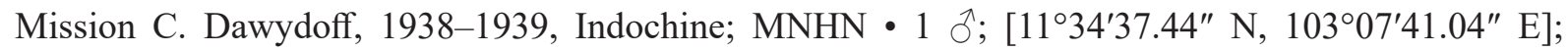
10 m a.s.1.; 3 Dec. 2014; J. Nigl leg.; NHMW 27601 • 1 juv.; Koh Chang; [12 $04^{\prime} 28.60^{\prime \prime}$ N, 102¹8'35.95" E]; under bark; 13 Jan. 1900; Th. Mortensen leg.; ZMUC 21614.

VIETNAM • 1 ठ̊; Phaurang, Tour Cham; May 1939; Mission C. Dawydoff, Indochine 1938-1939; MNHN • 1 ठ̊; Banghoi [Ba Ngôi], Indochine; May 1939; Mission C. Dawydoff; 1938-1939; MNHN • 2 juv.; Golf Du Siam [Gulf of Thailand]; Nov. 1938; P. Dama, Mission C. Dawydoff, Indochine, 1938-

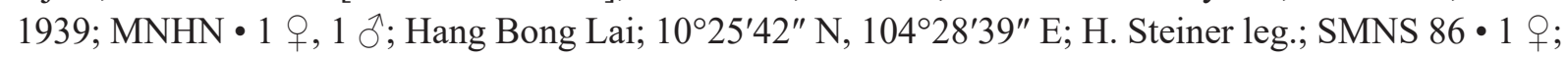
Hang 8; $10^{\circ} 25^{\prime} 45^{\prime \prime}$ N, 104²8'37.8" E; H. Steiner leg.; SMNS 87.

NO DATA • 4 juv.; MNHN • 1 q, 7 protonymphs; MNHN • 1 \&, 1 § , 1 juv.; MNHN • 2 \%; MNHN.

\section{Description}

CARAPACE. Six anterior setae (Fig. 112A); frontal process triangular (Fig. 112C). Small granules densely scattered between ocular triads and among sulci. Median eyes and median ocular tubercle well developed (Fig. 112C); pair of setae on median ocular tubercle; lateral eyes well developed, pale, seta lateral to lateral ocular triad; lateral ocular triad near carapace margin; curved carina between ocular triads and carapace margin (Fig. 112C).

STERnUm. Tritosternum projected anteriorly with typical setation, long, surpassing base of pedipalp coxae (Fig. 112B); other sternal platelets narrow, projecting, with pair of setae anteriorly on plaque and some smaller setae posteriorly; pentasternum with four setae near membranous region.

Opisthosoma. Ventral sacs cover well developed. 
Genitalia. Female genital operculum with short setae posteromedially; pair of white bulges medially and slender setae apically (Fig. 113A-C); gonopod finger-like, unsclerotized basally (Fig. 113A, C, F); denticulate margin between gonopod and posterior margin of genital operculum (Fig. 113E); slit sensilla laterally on genital operculum (Fig. 113E). Male gonopod as wide as long, wider in distal third (Fig. 114C); Lol2 fimbriate with small spines apically on projections (Fig. 114A-B, D); PI with smooth surface and acute apex (Fig. 114F); dorsal lobe short, with spines on inner margin and ventrally, and apex curved outwards (Fig. 114C, G); LaM short, not fused medially, with smooth surface (Fig. 114AB); fistula with inner spines (Fig. 114E).

Chelicerae. Retrolateral surface of basal segment with short projection, opposite to bifid tooth; retrolateral surface of claw with row of setae basally to medially; claw with five teeth; more than two rows of several setae on prolateral surface of basal segment; bifid tooth on basal segment with dorsal cusp larger than ventral cusp.

PeDIPALPS. Coxae without seta encircled by round carina and with three setae on margin. Femur with four dorsal spines and four ventral spines (Fig. 112E-F); two prominent setiferous tubercles between dorsal spine 1 and proximal margin; long spine between ventral spine 1 and proximal margin, two-thirds length of spine 1. Patella with four dorsal spines in primary series (Fig. 112E); prominent setiferous tubercle distal to spine I; three ventral spines (Fig. 112F); setiferous tubercle between spine I and distal margin. Tibia with ventral spine distally and two setae between spine and distal margin. Tarsus with two subequal dorsal spines (Fig. 112D); cleaning organ with 30-32 setae in ventral row.

Legs. Tibia of leg I with 23 articles; tarsus I with 41 articles; first and second tarsal articles equal in length. Leg IV basitibia with four pseudo-articles, with sclerotized, denticulate margin at apex of articles; trichobothrium $b t$ situated slightly closer to distal third of pseudo-article; distitibia trichobothrium $b c$ situated equidistant between $b f$ and $s b f$, and $s c$ and $s f$ series each with five trichobothria.

\section{Measurements}

See Table 8 .

\section{Distribution}

Known from Cambodia, Thailand and Vietnam. The distribution of this species overlaps that of Weygoldtia davidovi.

\section{Remarks}

Material from Cambodia (Sre Unebell, Réam) in the MNHN was misidentified as S. brachydactylus by Fage (1946).

Sarax javensis (Gravely, 1915)

Figs 103, 115-116; Table 8

Phrynichosarax javensis Gravely, 1915b: 439, fig. 3.0.

Phrynicosarax javensis - Mello-Leitão 1931: 52.

Phrynichosarax javanensis - Giltay 1931: 24-25.

Sarax javensis - Harvey 2003: 8.

\section{Diagnosis}

This species may be separated from other species of Sarax in Southeast Asia and Oceania by the following combination of characters: ventral sac cover present; female gonopod finger-like; cheliceral 
basal segment with prominent, acute tooth on retrolateral surface, adjacent to bifid tooth; pedipalp patella with two short ventral spines between spine I and distal margin; pedipalp tarsus with one dorsal spine.

\section{Etymology}

Adjective referring to the Indonesian island of Java, on which the type locality is situated.

\section{Type material}

Holotype

INDONESIA • Java, Buitenzorg [Bogor], Jawa Berat; 1 ex., Indian Museum (now the Zoological Survey of India, Calcutta) [not examined].

\section{Additional material}

INDONESIA - 1 क; Java, Gua Kokop, Pacitan; 13 Jul. 1992; Ratih Aryasari leg.; on wall; WAM T80539 • 1 q; Gua Kokop, Pacitan; J. Lowry leg.; parts of exuvia; WAM T80543 • 2 우, 2 juv.; Gua Kamidordo, Pacitan; Juguono leg.; WAM T80541 • 1 q; Leweng Jaran, Pacitan; Muksin leg.; WAM T80542 • 1 q; Gua Kendil, Pacitan; Muksin and J. Lowry leg.; WAM T80540 • 1 juv. $ð$ [misidentified as 1 9]; Jjompea; 11 Mar. 1904; ZMH; 1 क; Ichmiedekneas; 5 Aug. 1902; ZMH.

\section{Redescription}

CARAPACE. Six anterior setae; frontal process triangular. Small granules densely scattered between ocular triads and among sulci. Median eyes and median ocular tubercle well developed; pair of setae on median ocular tubercle; lateral eyes well developed, pale, seta lateral to lateral ocular triad; lateral ocular triad situated near carapace margin; curved carina between ocular triads and carapace margin, not contacting eyes.

STERnUm. Tritosternum projected anteriorly with typical setation, long, surpassing base of pedipalp coxae; other sternal platelets narrow and projected, with pair of setae anteriorly on plaque and some smaller setae posteriorly; pentasternum with four setae near posterior margin of platelet.

Opisthosoma. Ventral sac cover well developed.

GenitaLia. Female genital operculum with short setae posteromedially (Fig. 115A-C); pair of low, white bulges medially with slender setae apically (Fig. 115A-C); gonopod finger-like, unsclerotized basally (Fig. 115A, C, E); denticulate surface between gonopod and posterior margin of genital operculum (Fig. 115D). Adult male unknown (only male studied was immature).

CheliCERAE. Retrolateral surface of basal segment with short, acute projection, opposite to bifid tooth; retrolateral surface of claw with row of setae basally to medially; claw with three teeth; row of several setae on prolateral surface of basal segment; bifid tooth on basal segment with dorsal cusp larger than ventral cusp.

PEDIPALPS. Coxae without seta encircled by round carina and with two or three setae on margin. Femur with three or four dorsal spines and three or four ventral spines; two or three prominent setiferous tubercles between dorsal spine 1 and proximal margin; ventral spine between spine 1 and proximal margin; spine present or absent between ventral spines 1 and 2 , and spines 2 and 3. Patella with four or five dorsal spines in primary series; prominent setiferous tubercle distal to spine I; three ventral spines; two short spines between spine I and distal border. Tibia with ventral spine distally and three setae between spine and distal margin. Tarsus with one dorsal spine; cleaning organ with 25-29 setae in ventral row.

LEGS. Tibia of leg I with 23 articles; tarsus I with 41 articles; tarsal organ close to tarsal claw (Fig. 116AC); rod sensilla with six setae and in shallow groove (Fig. 116B, E); first and second tarsal articles equal 
in length. Leg IV basitibia with four pseudo-articles, with sclerotized, denticulate margin at apex of articles; trichobothrium $b t$ situated in medial third of pseudo-article; distitibia trichobothrium $b c$ situated closer to $s b f$ than to $b f ; s c$ and $s f$ series each with six trichobothria.

\section{Measurements}

See Table 8 .

\section{Distribution}

Known only from the Indonesian island of Java.

\section{Natural history}

Several specimens were collected in caves.

\section{Remarks}

According to Gravely (1915), the holotype was deposited at the Indian Museum (now the Zoological Survey of India, Calcutta). The types of some of Gravely's (1915) other species are deposited at SMF but the holotype of this species could not be located and may be lost.

Sarax lembeh sp. nov.

urn:lsid:zoobank.org:act:E44E0F80-EEA2-4319-AE0A-F87B32FD869C

Figs 103, 117; Table 8

\section{Diagnosis}

This species may be separated from other species of Sarax in Southeast Asia and Oceania by the following combination of characters: lateral eyes very near carapace margin; one dorsal spine on pedipalp tarsus (Fig. 117D); leg IV basitibia with trichobothrium $b t$ situated in distal third; distitibia trichobothrium $b c$ situated closer to $s b f$ than to $b f ; s c$ and $s f$ series each with six trichobothria.

The other species of Sarax with one dorsal spine on the pedipalp tibia are S. cochinensis, S. javensis, S. monodenticulatus and S. palau sp. nov., from which $S$. lembeh sp. nov. can be distinguished by its smaller body size; higher number of trichobothria in the $s c$ and $s f$ series of the leg IV distitibia (six in S. lembeh sp. nov. compared with five in S. cochinensis and S. palau sp. nov.); different number of pseudo-articles on leg IV basitibia (three in $S$. lembeh sp. nov. compared with four or two in the other species); and the arrangement of spines on the pedipalp femur and patella.

\section{Etymology}

Noun in apposition taken from the type locality, Lembeh Island.

\section{Type material}

Holotype

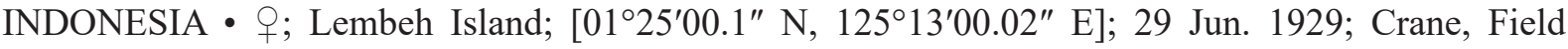
Museum Pacific Expedition 1928-1929 leg.; FMNH 3489485.

\section{Description}

CARAPACE. Six anterior setae (Fig. 117A); frontal process triangular (Fig. 117C). Median eyes and median ocular tubercle well developed (Fig. 117A, C); pair of setae on median ocular tubercle; lateral eyes well developed, pale, small seta lateral to each lateral ocular triad. 
STERnUm. Tritosternum projected anteriorly with typical setation, surpassing base of pedipalp coxae (Fig. 117B); other sternal platelets narrow and projected, with pair of setae anteriorly on plaque and some smaller setae posteriorly; without anterior setae in membranous region and four setae posteriorly.

Opisthosoma. Ventral sacs and ventral sacs cover present.

Genitalia. Female genital operculum broadly sclerotized between gonopods and posteromedian margin; posterior margin slightly convex, with several setae along margin and on surface. Female gonopod plunger-like, narrower close to apex, tubiform, unsclerotized basally. Male unknown.

CheliCERAE. Retrolateral surface of basal segment without projection opposite to bifid tooth; row of setae on retrolateral surface, basally to dorsally; prolateral surface of basal segment with two parallel, transverse rows of 15 small setae, ventrally to dorsally; claw with four teeth.

PeDIPALPS. Coxae dorsally with round carina; without small setae encircled by carina and with two or three setae on anterior margin. Femur with two distinct setiferous tubercles proximal to dorsal spine 1 (Fig. 117E); primary series with three dorsal spines; three ventral spines (Fig. 117F); setiferous tubercle proximal to ventral spine 1, between spine 1 and proximal margin. Patella with four or five dorsal spines (Fig. 117E); setiferous tubercle distal to dorsal spine I, about one-third length of spine I; three ventral spines decreasing in length (Fig. 117F); setiferous tubercle between ventral spine I and distal margin. Tibia with two dorsal spines, proximal spine two-thirds length of distal spine; ventral spine in distal half of tibia; prominent setiferous tubercle near its base; long setae between spine and distal margin. Tarsus with one dorsal spine, one-fifth length of tarsus (Fig. 117D); ventral row of setae on cleaning organ with 26-27 setae.

Legs. Tibia of leg I with 23 articles; tarsus I with 41 articles. Leg IV basitibia with three pseudoarticles; trichobothrium $b t$ situated in distal third; distal apex of basitibial pseudo-articles without dark, denticulate projection; distitibia trichobothrium $b c$ situated closer to $s b f$ than to $b f ; s f$ and $s c$ series each with six trichobothria. Tarsus with distinct white annulus distally on first article of distitarsus.

\section{Measurements}

See Table 8 .

\section{Distribution}

Known only from the type locality.

Sarax mardua Rahmadi, Harvey \& Kojima, 2010

Fig. 103; Table 8

Sarax mardua Rahmadi et al., 2010: 13-18, figs 26-32, 39-40.

\section{Diagnosis}

This species may be separated from other species of Sarax in Southeast Asia and Oceania by the following combination of characters: large body size (adult length $8.5-10.1 \mathrm{~mm}$ ); secondary sexual dimorphism, pedipalps of male longer than those of female; median ocular tubercle small and shallow, completely divided into two, each half with an ocellus; pedipalp femur with four dorsal spines and three ventral spines; pedipalp tibia with four dorsal spines and four ventral spines; leg IV basitibia trichobothrium $b t$ situated close to proximal margin; distitibia trichobothrium $b c$ situated equidistant between $b f$ and $s b f$. 


\section{Etymology}

The species name is a noun in apposition, taken from Gua Mardua, the cave in which the type material was collected (Rahmadi et al. 2010).

\section{Type material}

\section{Holotype}

INDONESIA - đ̇; East Kalimantan, Kutai Timur Regency, Sangkulirang District, Pengadan Village, Gua Mardua, near Pengadan; 01 ${ }^{\circ} 13^{\prime} 55.13^{\prime \prime}$ N, 117 $44^{\prime} 23.53^{\prime \prime}$ E; 19 Aug. 2004; L. Deharveng and A. Bedos leg.; MZB Ambl. 151 [not examined].

\section{Paratypes}

INDONESIA • 1 +, 2 juv.; same locality data as for holotype; MNHN Am. 12 [not examined].

Measurements. See Table 8.

\section{Distribution}

Known only from the type locality.

\section{Natural history}

This species was collected in a cave. It co-occurs with a mite harvestman, Stylocellus sp. (Styleyesdae Hansen \& Sørensen, 1904).

\section{Remarks}

See Rahmadi et al. (2010) for description.

Sarax monodenticulatus Rahmadi \& Kojima, 2010

Fig. 103; Table 8

Sarax monodenticulatus Rahmadi \& Kojima, 2010: 480-482, figs 1c, 4a-h.

\section{Diagnosis}

Based on Rahmadi \& Kojima (2010), this species may be separated from other species of Sarax in Southeast Asia and Oceania by the following combination of characters: small to medium sized (adult body length 2.5-6.5 mm); reddish-brown carapace; pedipalp tarsus with one spine; first article of leg I tarsus equal in length to sum of subsequent two articles; leg I tarsus with short and long articles alternating, combination present in second to eleventh tarsal articles.

\section{Etymology}

Adjective referring to the presence of one spine on the pedipalp tarsus (Rahmadi \& Kojima 2010).

\section{Type material}

\section{Holotype}

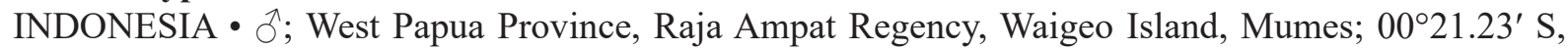
130 58.93' E; 10 Jun. 2007; C. Rahmadi leg.; under stone in limestone forest; E-Win 2007 LIPI; MZB Ambl. 135 [not examined].

\section{Paratypes}

INDONESIA • 1 क ; same collection data as for holotype; MZB Ambl. 136 [not examined] • 1 §ै; same collection data as for holotype; MNHN Am. 7 [not examined] $\cdot 2$ juv.; same collection data as for 


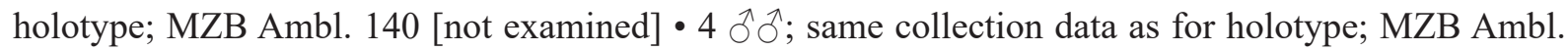
137, MZB Ambl. 138, MZB Ambl. 141, MZB Ambl. 143 [not examined] 3 우; same collection data as for holotype; MZB Ambl. 139, MZB Ambl. 142, MZB Ambl. 144 [not examined].

\section{Measurements}

See Table 8.

\section{Distribution}

Known only from the type locality.

\section{Natural history}

Found under stones in limestone forests; not found inside caves.

\section{Remarks}

See Rahmadi \& Kojima (2010) for description.

Sarax moultoni (Gravely, 1915) comb. nov., nomen dubium

Table 8

Stygophrynus moultoni Gravely, 1915b: 443-444, fig. 9.

Stygophrynus moultoni - Giltay 1931: 24-25. — Mello-Leitão 1931: 54. — Werner 1935: fig. 177a. Quintero 1986: 207, figs 2, 8. — Rahmadi \& Harvey 2008: 281-282, 286-287.

Stygophrynus Neocharon moultoni - Dunn 1949: 11. - Harvey 2003: 10. — Rahmadi et al. 2010: 1, 6, 19; 2011: 223, 225.

\section{Etymology}

Although unspecified, the name is evidently a patronym honoring Mr Moulton, who donated the holotype to Gravely (1915b).

\section{Type material}

\section{Holotype}

INDONESIA - ô; Klingkang summit [Klingkang Range], between Sarawak (Malaysia) and West Kalimantan (Indonesia); BMNH [not examined].

\section{Remarks}

In a key to the species of Stygophrynus Kraepelin, 1895, Gravely (1915b: 443) stated that the "armature of [the] hand [tibia] of S. moultoni consists of two long dorsal spines and one ventral one only" whereas, for all other species, Gravely (1915b: 443) stated that the "hand [is] armed above and below with one long spine succeeded by a series of short spines which increase in length distally". The former spine configuration is typical of Charinidae and the latter is typical of Charontidae, suggesting that S. moultoni is a charinid. Gravely (1915b: 444) further noted that $S$. moultoni possesses three dorsal spines on the pedipalp tarsus: "the finger is armed above with three-minute tooth-like spinules".

Specimens from the vicinity of the type locality of S. moultoni (e.g., AMCC [LP 12168, 12169]) exhibit characters consistent with Gravely's (1915b) diagnosis of S. moultoni, e.g., high numbers of spines on the pedipalp patella and three spines on the pedipalp tarsus, characters which are also diagnostic for S. yayukae. Therefore, S. moultoni may be a senior synonym of $S$. yayukae. Rahmadi et al. (2010) also 
suggested that $S$. moultoni might be a charinid. The holotype of $S$. moultoni must be examined to confirm the synonymy; however, Rahmadi et al. (2010) suggested it may be lost. Until that is established with certainty, it is appropriate to transfer $S$. moultoni to the genus Sarax based on the evidence available. Due to the lack of characters in the literature allowing a precise identification of the species and the lack of type material, it is suggested here that the species is a nomen dubium until further clarification of its taxonomy.

Quintero (1986) provided two SEM images of the pedipalp patella and tarsus of a specimen from Sebesi, Sumatra, Indonesia, identified as S. moultoni. However, the spination of that specimen differs considerably from what was described and illustrated by Gravely (1915b) for S. moultoni. The specimen illustrated by Quintero (1986) is congeneric with Catageus, a senior synonym of Stygophrynus, but cannot be assigned to any known species based on the characters provided.

Sarax newbritainensis Rahmadi \& Kojima, 2010

Fig. 103; Table 8

Sarax newbritainensis Rahmadi \& Kojima, 2010: 478-480, figs 1b, 3a-h.

\section{Diagnosis}

Based on Rahmadi \& Kojima (2010), this species may be separated from other species of Sarax in Southeast Asia and Oceania by the following combination of characters: large adult size (body length about 8.25-9.5 mm); pale brown tegument; carapace without distinct lateral sulci; median and lateral eyes reduced; pedipalp tarsus with two long spines, separated from each other by about twice basal diameter of spine, the proximal spine about half as long as distal spine; legs elongate; tarsus of legs II-IV longer than sum of lengths of subsequent three tarsal articles; tibia (basi- and distitibia) of leg IV with 19 trichobothria, $b t$ situated near distal margin of fourth basitibial article, and $b c$ equidistant between $b f$ and $s b f$.

\section{Etymology}

The specific name refers to the island on which the type locality is located (Rahmadi \& Kojima 2010).

\section{Type material}

\section{Holotype}

PAPUA NEW GUINEA • ${ }^{\lambda}$; East New Britain Province, New Britain Island, Resurgence Lali Bairaman; 05³9'32.59" S, 151¹2'39.91" E; 17 Feb. 2005; R. Sougeat (Expé. Papou. 2005) leg.; MNHN Am. 6 [not examined].

\section{Paratype}

PAPUA NEW GUINEA • 1 $q$; same locality data as for holotype; MZB Ambl. 134 [not examined].

\section{Measurements}

See Table 8.

\section{Distribution}

Known only from the type locality.

\section{Natural history}

This troglobitic species, with small eyes, elongate legs, and pale tegument, was collected in a cave. 


\section{Remarks}

See Ramadi \& Kojima (2010) for description.

Sarax palau sp. nov.

urn:1sid:zoobank.org:act:73538584-7F9D-4AD4-8949-A042D32298C5

Figs 103, 118-119; Table 8

\section{Diagnosis}

This species may be separated from other species of Sarax in Southeast Asia and Oceania by the following combination of characters: pedipalp tarsus with one dorsal spine and 21 setae in ventral row of cleaning organ; leg IV basitibia with four pseudo-articles, distitibia $s c$ and $s f$ series each with five trichobothria.

Sarax palau sp. nov. resembles $S$. lembeh sp. nov., also with one spine on the pedipalp tarsus, but in which the spine is situated closer to proximal margin of the tarsus. Additional differences between the two species are as follows: two ventral spines on the pedipalp patella in S. palau sp. nov. but three spines in $S$. lembeh sp. nov.; three long setae between the ventral spine and distal margin of the pedipalp tibia in $S$. palau sp. nov., but only one seta in $S$. lembeh sp. nov.; the distitibia of leg IV with four articles in $S$. palau sp. nov. but three articles in $S$. lembeh sp. nov.; $s c$ and $s f$ series of the distitibia each with five trichobothria in S. palau sp. nov. but six trichobothria in $S$ lembeh sp. nov.

\section{Etymology}

Noun in apposition referring to Palau, the country in which the type locality is situated.

\section{Type material}

\section{Holotype}

PALAU • O; Koror Island; [07²0'40.26" N, 134²9'54.15" E]; 19 Nov. 1947; H.S. Dybas (Entomological Survey of Micronesia-Pacific Science Board) leg.; FMNH 3489487.

\section{Paratypes}

PALAU 1 đं; same locality as for holotype; 26 Nov. 1947; H.S. Dybas (Entomological Survey of Micronesia-Pacific Science Board) leg.; FMNH 3489488 • 3 juv. $q$, 1 exuvium; Peleliu Island (East Coast); [0700'19.08" N, 134¹5'34.05" E]; 4 Aug. 1945; H.S. Dybas leg.; FMNH 3489497.

\section{Description}

CARAPACE. Six anterior setae (Fig. 118A); frontal process triangular (Fig. 118C). Median eyes and median ocular tubercle well developed (Fig. 118A); pair of setae on median ocular tubercle; lateral eyes well developed, pale, small seta on each lateral ocular triad; lateral ocular triad situated near lateral margin of carapace; lateral carina on lateral margin of carapace ventral to lateral eyes, with transverse line projecting from it to lateral ocular triad.

STERNUM. Tritosternum projected anteriorly with typical setation, surpassing base of pedipalp coxae (Fig. 118B); other sternal platelets narrow and projected, with pair of setae anteriorly on plaque and some smaller setae posteriorly; without anterior setae in membranous region and two setae posteriorly.

Opisthosoma. Ventral sacs and ventral sacs cover present.

Genitalia. Posterior margin of female genital operculum slightly convex, with several setae along margin and on surface. Female gonopod plunger-like, unsclerotized basally. Male gonopod damaged, lateral lobe sclerotized, but border of fistula unsclerotized. 
CheliCerae. Small, flat tooth on retrolateral surface of basal segment, opposite to bifid tooth; prolateral surface of basal segment with transverse row of six small setae, from ventral to dorsal. Retrolateral surface of cheliceral claw with row of setae, ventrally to dorsally. Claw with four teeth.

PeDIPALPS. Coxae dorsally with round carina; without small setae encircled by carina and with three setae on anterior margin. Femur with three or four dorsal spines (Fig. 118E-F); three ventral spines; setiferous tubercle proximal to ventral spine 1, between spine 1 and proximal margin. Patella with three dorsal spines (in one adult paratype spine emerges from middle of spine I) (Fig. 118E); setiferous tubercle distal to spine I, about one-third length of spine I; two ventral spines; setiferous tubercle between spine I and distal margin. Tibia with two dorsal spines; ventral spine in distal half of tibia. Tarsus with one dorsal spine (Fig. 118D); ventral row of cleaning brush with 23-25 setae.

LEGS. Tibia of leg I with 23 articles; tarsus I with 41 articles; apex with small modified claw and tarsal organ ventral to it (Fig. 118A-B); lateral claws larger than medial claw (Fig. 118B); rod sensilla with four setae in deep sulcus (Fig. 118C-D). Leg IV basitibia with four pseudo-articles; trichobothrium $b t$ situated in distal third; distal apex of basitibial pseudo-articles without dark, denticulate projection; distitibia trichobothrium $b c$ situated closer to $s b f$ than to $b f ; s f$ and $s c$ series each with five trichobothria.

\section{Measurements}

See Table 8 .

\section{Distribution}

Known only from the type localities.

\section{Natural history}

Unknown.

$$
\begin{gathered}
\text { Sarax rahmadii sp. nov. } \\
\text { urn:1sid:zoobank.org:act:307E7237-3EF2-40B4-8390-AE3EF5C03017 }
\end{gathered}
$$

Figs 103, 120-121; Table 8

\section{Diagnosis}

This species may be separated from other species of Sarax in Southeast Asia and Oceania by the following combination of characters: large size; female gonopod finger-like (Fig. 121A); basal segment of chelicera with acute tooth on retrolateral surface; cheliceral claw with five teeth; pedipalp patella with long spine between dorsal spine I and distal margin (Fig. 120E); pedipalp tarsus with two spines (Fig. 120D); tibia of leg I with 23 articles, tarsus I with 41 articles; leg IV basitibia with four pseudoarticles; distitibia $s c$ and $s f$ series each with six trichobothria.

This species resembles $S$. gravelyi sp. nov., but can be differentiated by the greater number of spines on the pedipalp.

\section{Etymology}

Patronym honoring Dr Cahyo Rahmadi for his contributions to the study of Southeast Asian whip spiders. 
MIRANDA G.S. et al., Systematic revision of Charinidae (Arachnida, Amblypygi)

\section{Type material}

\section{Holotype}

INDONESIA • + [largest]; Khom Bheng caves, Kalimantan Timut; 01 ${ }^{\circ} 01^{\prime}$ N, $116^{\circ} 59^{\prime}$ E; J. Lowy leg.; WAM T63201.

\section{Paratypes}

INDONESIA • 1 + , 1 ô, 2 juv.; same collection data as for holotype; WAM T63201.

\section{Description}

CARAPACE. Six anterior setae (Fig. 120A); frontal process triangular, visible in dorsal view (Fig. 120C). Small granules densely scattered between ocular triads and among sulci. Median eyes and median ocular tubercle well developed; pair of setae on median ocular tubercle; lateral eyes well developed, pale, seta lateral to lateral ocular triad; lateral ocular triad near carapace margin; curved carina between ocular triads and carapace margin.

STERnUm. Tritosternum projected anteriorly with typical setation, long, surpassing base of pedipalp coxae (Fig. 120B); other sternal platelets narrow and projected, with pair of setae anteriorly on plaque and some smaller setae posteriorly; pentasternum with six setae anteriorly.

Opisthosoma. Ventral sacs cover well developed.

Genitalia. Female genital operculum with short setae posteromedially (Fig. 121A-C); pair of white bulges medially with slender setae apically (Fig. 121A-C); gonopod finger-like with apical invagination (Fig. 121A, C, F); denticulate surface between gonopod and posterior margin of genital operculum (Fig. 121D); slit sensilla on lateral margin of genital operculum (Fig. 121E); unsclerotized basally. Male gonopod LoL2 with sclerotized base.

CHELICERAE. Retrolateral surface of basal segment with short projection opposite to bifid tooth; retrolateral surface of claw with row of setae basally to medially; claw with five teeth; more than two rows of several setae on prolateral surface of basal segment; bifid tooth on basal segment with dorsal cusp larger than ventral cusp.

Pedipalps. Coxae without seta encircled by round carina and with three or four setae on its margin. Femur with four dorsal spines and four ventral spines in primary series (Fig. 120E-F); four prominent setiferous tubercles between dorsal spine 1 and proximal margin; spine between dorsal spines 2 and 3 , and spines 3 and 4 ; long spine between ventral spine 1 and proximal margin, two thirds length of spine 1; spine between ventral spines 1 and 2, 2 and 3, and 3 and 4. Patella with five or six dorsal spines in primary series (Fig. 120E); prominent spine distal to spine I; four ventral spines (Fig. 120F); small spine between ventral spines 1 and 2, and spines 2 and 3; two or three small setiferous tubercles between spine I and distal border. Tibia with ventral spine distally and long setiferous tubercle proximally; three or four setae between spine and distal margin. Tarsus with two dorsal spines (Fig. 120D), distal spine long, about one-third length of tarsus, proximal spine one-third length of distal spine; cleaning organ with 30-32 setae in ventral row.

LeGs. Tibia of leg I with 23 articles; tarsus I with 41 articles; first and second tarsal articles equal in length. Leg IV basitibia with four pseudo-articles, without sclerotized, denticulate border at apex of articles; trichobothrium $b t$ situated in distal third of pseudo-article; distitibia trichobothrium $b c$ situated closer to $s b f$ than to $b f, s c$ and $s f$ series each with six trichobothria. 


\section{Measurements}

See Table 8 .

\section{Distribution}

Known only from the type localities.

\section{Natural history}

Exclusively found in caves; troglomorphic characters include large size and long spines on pedipalp.

Sarax rimosus (Simon, 1901)

Figs 103, 122-124; Table 8

Catagaeus rimosus Simon, 1901: 77.

Phrynichosarax buxtoni Gravely, 1915b: 439-440, fig. 4. Syn. nov.

Sarax mediterraneus Delle Cave, 1986: 161. Syn. nov.

Phrynichosarax rimosus - Gravely 1915b: 440-441, fig. 6.

Sarax sarawakensis - Fage 1929: 357 (misidentification). — Bristowe 1952: 699. — Weygoldt 1994: 244. - Moseley et al. 2012: 89.

Phrynicosarax ramosus - Mello-Leitão 1931: 53.

Phrynichosarax buxtoni - Mello-Leitão 1931: 52. — Speijer 1937: 173. — Weygoldt 1994: 244.

Sarax brachydactylus - McClure et al. 1967: 415 (misidentification). — Moseley et al. 2012: 89.

Sarax buxtoni - Weygoldt 2002c: 135-137, figs 9-12 (misidentification). - Harvey 2003: 8.

Sarax rimosus - Harvey 2003: 8.

Sarax mediterraneus - Seiter \& Wolff 2014: 233. — Seiter et al. 2015: 548-549.

\section{Diagnosis}

This species may be separated from other species of Sarax in Southeast Asia and Oceania by the following combination of characters: tegument covered in clavate setae; short, acute projection on retrolateral surface of cheliceral basal segment; pedipalp tarsus with three short spines, proximal spine subequal to middle spine, and two-thirds the length of distal spine (Fig. 122D).

\section{Etymology}

Although uspecified in the original description, the Latin word 'rimosus' means 'full of cracks' and may refer to the species or the habitat in which the holotype was collected.

Type material (examined)

\section{Holotype}

MALAYSIA • $q$ [holotype of Catageus rimosus] [with egg sac, opisthosoma detached]; Kuala Aring, Kelantan; Sep. 1899; Skeat Expedition leg.; CUMZ I.48100.

\section{Addtitional type material}

GREECE $\bullet 1$ ㅇ [holotype of Sarax mediterraneus]; Rhodos, Lindos, in Mauerspalten und Felsritzen der Stütz- und Unterbauten der Johanniterburg [in crevices in foundations of Johanniterburg castle]; 27 Apr. 1964; V. Helversen and Pieper leg.; SMF 35614 • 1 \&, 1 juv. ㅇ [paratypes of Sarax mediterraneus]; same collection data as for preceding; SMF 35614.

MALAYSIA - 1 ad. [holotype of Phrynichosarax buxtoni] [sex unspecified], 1 juv. O+; Kubang Tiga Cave, Perlis; B.H. Buxton leg.; Indian Museum [currently at SMF]. 


\section{Additional material}

MALAYSIA • 1 ㅇ; Selangor, Bukit Malawati, Kuala Selangor; $03^{\circ} 20.351^{\prime} \mathrm{N}, 101^{\circ} 14.692^{\prime}$ E; L. Prendini and S.F. Loria leg.; 9 Jun. 2013; 8-12 m a.s.l.; secondary forest on slope of small hill (Bukit Malawati), old Chinese graveyard, granitic outcrops under moderate canopy, under stones and old concrete blocks around graves; AMCC [LP 11996] • 1 क ; Bukit Takun, Taman Templer (Templer Park); 03 $18.082^{\prime}$ N, 10138.386' E; L. Prendini and S.F. Loria leg.; 9 Jun. 2013; 129 m a.s.1.; primary rainforest on steep slopes at base of large limestone mountain (Bukit Takun), dense canopy and moderate to dense understory, scattered limestone and granite boulders, under stone on soil; AMCC [LP 11997].

\section{Redescription}

Tegument covered in clavate setae.

CARAPACE. Projected anteriorly; six anterior setae (Fig. 122A); frontal process triangular (Fig. 122C). Small reddish-brown granules covered by small black tubercles, densely scattered between ocular triads and among sulci. Median eyes and median ocular tubercle well developed (Fig. 122C); one pair of setae on median tubercle; lateral eyes well developed, pale, seta lateral to lateral ocular triad; lateral ocular triad situated near carapace margin; curved carina between ocular triads and carapace margin.

STERnUm. Tritosternum projected anteriorly with typical setation, long, surpassing base of pedipalp coxae (Fig. 122B); other sternal platelets narrow and projected, with pair of setae anteriorly on plaque and some smaller setae posteriorly; pentasternum with four setae near membranous region.

CHelicerae. Short, acute projection on retrolateral surface of basal segment, opposite to bifid tooth; retrolateral surface of claw with row of setae basally to medially; claw with three teeth; more than two rows of several setae on prolateral surface of basal segment; bifid tooth on basal segment with dorsal cusp larger than ventral cusp.

OpISTHOSOMA. Ventral sacs and ventral sacs cover present.

Genitalia. Female genital operculum with short setae posteromedially; pair of white bulges medially with slender setae apically; gonopod plunger-like, unsclerotized basally. Male gonopod as wide as long, wider in distal third (Fig. 123C); Lol2 fimbriate with small spines apically on projections (Fig. 123A-B, D); PI with smooth surface and acute apex (Fig. 123F); dorsal lobe short, with spines on inner margin and ventrally and apex curved laterally (Fig. 123B-C, E); LaM short, not fused medially and with smooth surface (Fig. 123B); fistula with inner spines (Fig. 123G).

PEDIPALPS. Coxae without seta encircled by round carina and with two prominent setae on margin. Femur with three or four dorsal spines and four ventral spines (Fig. 122E-F); two prominent setiferous tubercles between dorsal spine 1 and proximal margin; spine between ventral spine 1 and proximal margin, twothirds length of spine 1. Patella with four or five dorsal spines in primary series (Fig. 122E-F); two prominent setiferous tubercles distal to spine I; three or four ventral spines (Fig. 122F); large setiferous tubercle between spine I and distal margin. Tibia with ventral spine distally and two setae between spine and distal margin. Tarsus with two short dorsal spines (Fig. 122D); cleaning organ with 31 setae in ventral row.

LEGS. Tibia of leg I with 23 articles; tarsus I with 41 articles; first and second tarsal articles equal in length; tarsal organ close to base of tarsal claw (Fig. 124B-D); slit sensillae located on lateral of tip segment of tarsus I (Fig. 124A); rod sensilla with five seate in deep groove (Fig. 124A, E). Leg IV basitibia with three pseudo-articles, with sclerotized, denticulate border at apex of articles; trichobothrium $b t$ situated 
in distal third of pseudo-article; distitibia trichobothrium $b c$ situated closer to $b f$ than to $s b f ; s c$ and $s f$ series each with five trichobothria.

\section{Measurements}

See Table 8.

\section{Distribution}

Known from peninsular Malaysia and Singapore.

\section{Natural history}

Found under stones on the floor of primary and secondary forests, as well as disturbed habitats (e.g., graveyards).

\section{Remarks}

Sarax rimosus has been overlooked since its description. Few papers covered this species, perhaps due to the complex taxonomy of Sarax and because several species have been described in and around the Malay Peninsula, e.g., S. batuensis, S. buxtoni, S. rimosus, S. sarawakensis and S. singaporae. Reassessment of the morphological characters and phylogenetic analysis based on morphology and DNA sequences (Miranda et al. 2021) led to the following conclusions.

1) Sarax sarawakensis is a large, sexually dimorphic species occurring on the islands of Indonesia and Malaysia, characterized by two small spines on the pedipalp tarsus; the basitibia of leg IV consisting of four pseudo-articles; and the distitibia of leg IV consisting of five trichobothria in the $s c$ and $s f$ series.

2) Sarax rimosus occurs only in peninsular Malaysia and is characterized by brownish coloration; two dorsal spines on the pedipalp tarsus; the basitibia of leg IV consisting of three pseudo-articles; and the distitibia of leg IV with five trichobothria in the $s c$ and $s f$ series. Although the type material of $S$. buxtoni was not examined, a large number of topotypes were studied, and no differences were obserbed between $S$. buxtoni and S. rimosus. Therefore, S. buxtoni is newly synonymized with S. rimosus.

3) Sarax batuensis is restricted to the dark zone of the Batu Caves in peninsular Malaysia and characterized by the basitibia of leg IV with four pseudo-articles; and the distitibia of leg IV with five trichobothria in the $s c$ and $s f$ series.

4) Sarax singaporae is a brown colored species, endemic to Singapore, characterized by a small pair of dorsal spines on the pedipalp tarsus; the basitibia of leg IV with three pseudo-articles (Gravely (1915b) mentions one specimen of the type series in which the basitibia of leg IV consisting of four pseudo-articles); and the distitibia of leg IV with six trichobothria in the $s c$ and $s f$ series.

5) Sarax gravelyi sp. nov. is a new species from Singapore characterized by prominent reddish bands on the carapace; two relatively long spines on the pedipalp tarsus, the distal spine longer than the proximal spine; the basitibia of leg IV consisting of four pseudo-articles; and the distitibia of leg IV with six trichobothria in the $s c$ and $s f$ series.

The male gonopods of $S$. rimosus are similar to those of $S$. indochinensis sp. nov. Weygoldt (2002c: 136, fig. 12) illustrated the female genitalia of a specimen identified as $S$. buxtoni, but that gonopod is quite different from what was observed in other species of the genus. It more closely resembles the sucker-like structures of Charinus than the finger-like structures of Sarax. The apex of the finger-like projection of 
the specimen studied by Weygoldt (2002) may have collapsed, giving the impression of a sucker-like gonopod.

Seiter et al. (2015) synonymized $S$. mediterraneus with $S$. buxtoni based on a combination of seven characters, but their characters "i" (number of setae on the anterior margin of the carapace), "ii" (in part; number of teeth on the basal segment of the chelicera) and " $v$ " (number of segments of the tibia of legs II and III) are not informative at any level in Amblypygi. Most Charinidae possess six setae on the anterior margin of the carapace, a character common to all species of Sarax. The same holds true for the number of teeth in the prolateral row of the cheliceral basal segment: all Charinidae possess four teeth. The tibia of legs II and III are not divided in any Charinidae. All other characters of $S$. mediterraneus are shared with $S$. rimosus: three teeth on the cheliceral claw; pedipalp patella with four or five dorsal spines; basitibia of leg IV with three pseudo-articles. Therefore, $S$. mediterraneus is here synonymized with $S$. rimosus. Seiter et al. (2015: 550) also stated that the three females in the vial identified as $S$. mediterraneus "belong most probably to the $S$. batuensis types originating from the Batu caves in Malaysia", but there is no evidence supporting this statement as the type material of $S$. batuensis is deposited at the SMF.

Sarax sangkulirangensis Rahmadi, Harvey \& Kojima, 2010

Fig. 103; Table 8

Sarax sangkulirangensis Rahmadi et al., 2010: 11-13, figs 21-25, 37-38.

\section{Diagnosis}

Based on the original description (Rahmadi et al. 2010), this species may be separated from other species of Sarax in Southeast Asia and Oceania by the following combination of characters: relatively small size (adult body length 5.9-9.8 mm); sexual dimorphism absent; pedipalp tarsus with two spines, proximal spine about half as long as distal spine; leg IV tibia with 19 trichobothria, $b t$ situated medially on fourth basitibial article, and $b c$ situated closer to $b f$ than to $s b f$.

\section{Etymology}

Adjective derived from the Sangkulirang Karst formation in Indonesia, where the species occurs (Rahmadi et al. 2010).

\section{Type material}

\section{Holotype}

INDONESIA • $q$ [ovigerous]; East Kalimantan, Gua Ke 4; 01²8'13.23" N, 117³9'28.14" E; Tabalar Ulu District, Berau Regency; 9 Aug. 2004; C. Rahmadi leg.; MZB Ambl. 70 [not examined].

\section{Paratypes}

INDONESIA - 1 ते; Gua Danum Tengen, near Tebo Lake, Merapun Village, Kelai District, Berau Regency; 01³1'28.5" N, 117²2'4.9" E; 2 Sep. 2004; Y.R. Suhardjono leg.; MZB Ambl. 150 [not examined] • 1 juv.; Tabalar Ulu, Gua Louwading, Tabalar Ulu District, Berau Regency, 11 Aug. 2004, L. Deharveng and A. Bedos leg.; KAL-059; MNHN Am. 10 [not examined] - 1 ô; Gua Ampanas; $01^{\circ} 12^{\prime} 01.46^{\prime \prime} \mathrm{N}, 117^{\circ} 44^{\prime} 03.58^{\prime \prime}$ E; Pengadan Village, Sangkulirang District, Kutai Timur Regency; 8 Aug. 2004; L. Deharveng and A. Bedos leg.; KAL-113 • 1 万ै; same collection data as for preceding; MNHN Am. 11 [not examined].

\section{Measurements}

See Table 8 . 


\section{Distribution}

Known from only the type localities in Indonesia.

\section{Natural history}

Found in caves in three different limestone hills in the northern part of the Sangkulirang Karst formation, including Tabalar Ulu, a small limestone area with several underground rivers, the Tebo area, where an isolated karst lake is located, and Gua Ampanas (Rahmadi et al. 2010).

\section{Remarks}

See Rahmadi et al. (2010) for a description.

\section{Sarax sarawakensis (Thorell, 1888)}

Figs 103, 125; Table 8

Charon sarawakensis Thorell, 1888: 354-358.

Sarax sarawakensis - Simon 1892: 48. — Pocock 1898: 100; 1900: 131, fig. 43a-c. - Kraepelin 1901: 264. — Arldt 1908: 441. — Gravely 1915b: 441-442, fig. 8. — Giltay 1931: 24-25. — Werner 1935: 471, fig. 175. — Fage 1946b: 77, fig. 3c. — Millot 1949b: figs 337, 340-343. — Klingel 1963: 456-459, figs 10-13. — Vandel 1965: 93. — Kaestner 1968: 123. — Schaller 1971: 423-425. — Delle Cave 1986: 160-161. — Weygoldt 1994: 242; 1996a: 190, fig. 35; 1999c: 106-107, figs 4-5; 2000a: 50, figs 104, 204-205. — Harvey 2003: 8. — Rahmadi et al. 2010: 10, figs 16-20. — Wolff et al. 2015: 525.

Sarax saravakensis - Kraepelin 1895: 45-46, fig. 40 (in part); 1899: 251. — Börner 1904: 5. — MelloLeitão 1931: 55. - Wolf 1938: 537.

Sarax sarawakensis sarawakensis - Gravely 1911: 357.

\section{Diagnosis}

This species may be separated from other species of Sarax in Southeast Asia and Oceania by the following combination of characters: carapace lateral margin slightly sinuous ventral to lateral eyes (Fig. 125A); sternal platelets formed by single segments (Fig. 125B); males with secondary sexual dimorphism on the pedipalp (Fig. 125D-E); basal segment of chelicerae without tooth on retrolateral margin; cheliceral claw with four teeth; pedipalp tarsus with two small spines (Fig. 125C); leg IV basitibia with four pseudo-articles.

\section{Etymology}

Although unspecified, the species name is evidently an adjective referring to the Malaysian state of Sarawak, in which the holotype was collected.

\section{Type material}

\section{Holotype}

MALAYSIA • O; Sarawak; Viag. Doria and Beccari leg.; MCSG [not examined].

\section{Additional material}

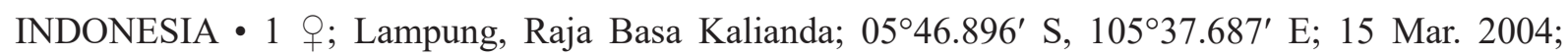
$1255 \mathrm{~m}$ a.s.1.; A. Riedel leg.; MZB Ambl. 149 [not examined] • 1 đ̇; Bali, Candidasa, Tenagan; 08²8'16.2" S, 115³4'08.4" E; 17 Mar. 2009; S. Huber leg.; AMCC [LP 11594] • Nusa Tenggara Barat, Sumbawa, Batoedoelang; 1927; Rensch, Sunda Exped. leg.; SMF 17.393 • 1 +; CUMZ I.46520. 
MIRANDA G.S. et al., Systematic revision of Charinidae (Arachnida, Amblypygi)

PAPUA NEW GUINEA・1 ô; Ralm [Ralum, New Britain]; 28 Jul. 1896; ZMB 8045.

\section{Measurements}

See Table 8.

\section{Distribution}

Recorded from Indonesia, Malaysia and Papua New Guinea.

\section{Remarks}

Sarax sarawakensis was the first species of the genus to be described. Specimens collected across Southeast Asia were initially identified as this species over the course of many years. For example, Fage (1929), followed by others (e.g., Bristowe 1952; Weygoldt 1994), erroneously reported S. sarawakensis from the Batu Caves, in peninsular Malaysia, at a time when three other species, S. buxtoni, S. rimosus and $S$. singaporae, were already known from the vicinity. Delle Cave (1986) cited the presence of $S$. sarawakensis in Singapore, probably also a misidentification (three other species, S. gravelyi sp. nov., S. rimosus and S. singaporae, are currently recorded from Singapore).

See Rahmadi et al. (2010) for a redescription and discussion on the taxonomic history of S. sarawakensis.

Sarax singaporae Gravely, 1911

Fig. 103; Table 8

Sarax sarawakensis singaporae Gravely, 1911: 37-38.

Phrynichosarax singapurae - Gravely 1915b: 440, fig. 5. - Buxton 1917: 3.

Phrynicosarax singapurae - Mello-Leitão 1931: 53.

Sarax singaporae - Harvey 2003: 8. — Seiter \& Wolff 2014: 233.

\section{Diagnosis}

This species may be separated from other species of Sarax in Southeast Asia and Oceania by the following combination of characters: uniform coloration without distinct stripes; female genital plaque flattened posteromedially; basal segment of chelicera with tooth on retrolateral surface, opposite to bifid tooth; leg IV basitibia with three pseudo-articles.

Sarax singaporae differs from $S$. gravelyi sp. nov. in the color and the number of pseudo-articles in the basitibia of leg IV.

\section{Etymology}

Refers to Singapore, the island state in which the species was first collected.

\section{Type material}

\section{Syntypes}

SINGAPORE • 2 우; Singapore Botanical Garden; 1910; H.H. Ridley leg.; SMF 64594 [examined].

\section{Additional material}

SINGAPORE • 2 q ㅇ ; Jurong Bird Park; S. Huber leg.; 17 Nov. 1999; leaf litter; AMCC [LP 1964A] • 1 juv.; Bukit Timah Nature Reserve; $1.355^{\circ} \mathrm{N}, 103.78^{\circ} \mathrm{E}$; 9 May 2005; W. Maddison, D. Li, I. Agnarsson and J.X. Zhang leg.; beating vegetation; AMCC [LP 4761]. 


\section{Redescription}

CARAPACE. Tegument dark brown; six anterior setae; frontal process short and triangular. Small granules densely scattered between ocular triads and among sulci; median eyes and median ocular tubercle well developed; pair of setae on median ocular tubercle; lateral eyes well developed, pale, with seta lateral to lateral ocular triad; lateral ocular triad near carapace margin; curved carina between ocular triads and carapace margin.

STERnUm. Tritosternum projected anteriorly with typical setation, long, surpassing base of pedipalp coxae; other sternal platelets narrow and projected, with pair of setae anteriorly on plaque and some smaller setae posteriorly; pentasternum with six setae near anterior region of plaque.

Opisthosoma. Ventral sacs and ventral sacs cover well developed.

Genitalia. Female genital operculum with short setae posteromedially; medial region flat with slender setae apically; gonopod finger-like with small invagination apically, unsclerotized basally. Male genitalia unknown.

Chelicerae. Retrolateral surface of basal segment with short tooth opposite to bifid tooth; retrolateral surface of claw with row of setae basally to medially; claw with two or three teeth; more than two rows of several setae on prolateral surface of basal segment; bifid tooth on basal segment with dorsal cusp larger than ventral cusp.

Pedipalps. Coxae without seta encircled by round carina and with two setae on margin. Femur with four or five dorsal spines and four ventral spines; two prominent setiferous tubercles between dorsal spine 1 and proximal margin; long spine between ventral spine 1 and proximal margin, two-thirds length of spine 1. Patella with five dorsal spines in primary series; prominent spine distal to spine I; four ventral spines; two small setiferous tubercles between spine I and distal margin. Tibia with ventral spine distally and two or three setae between spine and distal margin. Tarsus with two dorsal spines, distal spine longer, about one-fifth length of tarsus, proximal spine half length of distal spine; cleaning organ with 26 or 27 setae in ventral row.

LEGS. Tibia of leg I with 23-27 articles; tarsus I with 41 articles; first and second tarsal articles equal in length. Leg IV basitibia with three pseudo-articles, with sclerotized, denticulate border at apex of articles; trichobothrium $b t$ situated in proximal third of pseudo-article; distitibia trichobothrium $b c$ situated closer to $b f$ than to $s b f, s c$ and $s f$ series each with six trichobothria.

\section{Measurements}

See Table 8 .

\section{Distribution}

Known only from Singapore.

\section{Natural history}

Type series found under bricks in the leaf litter (Gravely 1911).

\section{Remarks}

Gravely (1911) examined several specimens, including two ovigerous females, but only one female syntype was located at SMF. The whereabouts of the other specimens is unknown. 
Sarax timorensis Miranda \& Reboleira, 2019

Fig. 103; Table 8

Sarax timorensis Miranda \& Reboleira, 2019: 4-8, figs 1-4.

\section{Diagnosis}

Based in part on Miranda \& Reboleira (2019), this species may be separated from other species of Sarax in Southeast Asia and Oceania by the following combination of characters: large size (total length 12.82 $\mathrm{mm}$ ); eight anterior setae; only two pairs of lateral eyes; cheliceral claw with six teeth; male gonopod with base of fistula, dorsal lobe and lateral lobe II sclerotized; pedipalp tarsus with two dorsal spines; leg basitibia with four pseudo-articles; leg IV distitibia $s c$ and $s f$ series each with six trichobothria.

The presence of only two pairs of lateral eyes is a unique character state among Amblypygi, otherwise known only in a few extinct species, e.g., Kronocharon longicalcaris Wunderlich, 2015 and Paracharonopsis cambayensis Engel \& Grimaldi, 2014. Sarax timorensis differs from these species by its much larger size and the number of spines on the pedipalp. The female is unknown.

\section{Etymology}

Adjective referring to the island of Timor, on which the species is found.

Type material (examined)

\section{Holotype}

TIMOR-LESTE • O’; Lautém District, Puropoko Cave; 08³2'37.7952" S, 12703'58.374" E; 6-12 Sep. 2016; A.S.P.S. Reboleira leg.; ZMUC.

\section{Distribution}

Known only from the type locality.

\section{Natural history}

The cave in which the type material was collected is on the border of Ira Lalaro Lake, a large closed karst depression in the eastern part of Timor Island. The temperature in the cave is constant at about $32^{\circ} \mathrm{C}$ and a stream runs through it. A large bat colony contributes extensive guano deposits, resulting in high densities of cockroaches throughout the cave.

\section{Remarks}

See Miranda \& Reboleira (2019) for description.

Sarax tiomanensis sp. nov. urn:1sid:zoobank.org:act:7E64F7E1-1D3E-4586-9873-7CC190630783

Figs 103, 126-129; Table 8

\section{Diagnosis}

This species may be separated from other species of Sarax in Southeast Asia and Oceania by the following combination of characters: median and lateral eyes well developed (Fig. 126A); median ocular tubercle shallow; secondary sexual dimorphism, males with longer pedipalp segments than females; pedipalp tarsus with three spines (two on dextral pedipalp of holotype male) (Fig. 126D); leg IV basitibia with four pseudo-articles; distitibia trichobothrium $b c$ situated closer to $b f$ than to $s b f ; s c$ and $s f$ series each with five trichobothria. 
Sarax tiomanensis sp. nov. resembles Sarax yayukae in having secondary sexual dimorphism, pedipalp segments longer in males; the presence of three ventral spines on the pedipalp patella and two or three dorsal spines on the pedipalp tarsus; and the position of trichobothria $b t$ and $b c$ on the tibia leg IV. It differs in the number of dorsal spines on the pedipalp femur (three to five spines in adults and immatures of $S$. tiomanensis sp. nov. compared with three spines in adults and two or three in immatures of $S$. yayukae); five ventral spines on the pedipalp femur in adults and immatures (three spines in S. yayukae); five (immatures) or six (adults) dorsal spines on the pedipalp patella (three in immatures and four in adults of S. yayukae); 17 trichobothria on leg IV tibia (19 trichobothria in S. yayukae). Sarax tiomanensis sp. nov. exhibits a prominent carina ventral to the lateral eyes, extending to the anterior margin of the carapace, which resembles that of Weygoldtia davidovi, but is shorter.

\section{Etymology}

Adjective referring to Tioman Island, Malaysia, to which this species appears to be endemic.

\section{Type material}

\section{Holotype}

MALAYSIA - '; Pahang, Pulau Tioman, trail from Juara to Tekek, closer to Tekek; $02^{\circ} 49.301^{\prime}$ N, 104 ${ }^{\circ} 10.183^{\prime}$ E; $135 \mathrm{~m}$ a.s.1.; 15 Jun. 2013; L. Prendini and S.F. Loria leg.; secondary forest/old plantation with many rubber trees; relatively dry; moderately open canopy; many granite outcrops; AMCC [LP 12001].

\section{Paratypes}

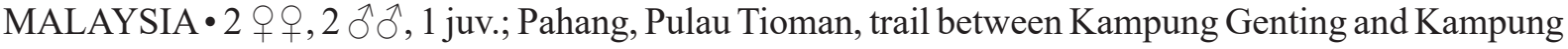
Paya; $02^{\circ} 46.427^{\prime} \mathrm{N}, 104^{\circ} 07.198^{\prime} \mathrm{E}-02^{\circ} 47.009^{\prime} \mathrm{N}, 1^{\circ} 04^{\circ} 07.113^{\prime} \mathrm{E}$; 11 Jun. 2013; 35-41 m a.s.l.; L. Prendini and S.F. Loria leg.; primary rainforest close to seashore; moderately open canopy; sparse understorey; moderate leaf litter layer; many large granite boulders, often with exfoliating flakes; brownish-orange, clayey granitic loam; under rocks; AMCC [LP 11998] • 1 q, 1 juv.; Pahang, Pulau Tioman, trail from Air Batang to Salang via Monkey Bay; 02 $51.151^{\prime}$ N, $104^{\circ} 09.077^{\prime}$ E; 13 Jun. 2013; 48 m a.s.1.; L. Prendini and S.F. Loria leg.; primary rainforest close to seashore, moderately open canopy, sparse understorey, moderate leaf litter layer, many large granite boulders, often with exfoliating flakes, brownish-orange, clayey granitic loam; under rocks; AMCC [LP 11999] - 2 $+\%$; Pahang, Pulau Tioman, trail from Juara to Tekek; $02^{\circ} 48.622^{\prime} \mathrm{N}, 1^{\circ} 4^{\circ} 10.745^{\prime} \mathrm{E}$; 15 Jun. 2013; 301-305 m a.s.1.; L. Prendini and S.F. Loria leg.; primary rainforest in interior of Tioman Island, closed canopy, moderate to dense leaf litter layer, limestone rocks on summit, becoming sandstone and then granite lower down, under log, AMCC [LP 12000] - 1 '̊; Pahang, Pulau Tioman, trail from Juara to Tekek, closer to Tekek; $02^{\circ} 49.301^{\prime} \mathrm{N}$, $104^{\circ} 10.183^{\prime}$ E; 15 Jun. 2013; 135 m a.s.1.; L. Prendini and S.F. Loria; secondary forest/old plantation with many rubber trees, relatively dry, moderately open canopy, many granite outcrops, AMCC [LP 12001] • 1 +, 2 subad. + q, 2 juv.; Pahang, Pulau Tioman, trail from Salang to Air Batang via Monkey Bay; $02^{\circ} 51.09^{\prime} \mathrm{N}, 104^{\circ} 09.221^{\prime} \mathrm{E}-02^{\circ} 52.322^{\prime} \mathrm{N}, 1^{\circ} 4^{\circ} 09.14^{\prime} \mathrm{E}$; 14 Jun. 2013 ; $33-36$ m a.s.1.; L. Prendini and S.F. Loria leg.; primary rainforest close to seashore; moderately open canopy; sparse understorey; moderate leaf litter layer; many large granite boulders, often with exfoliating flakes; brownish-orange, clayey granitic loam; under logs and stones; AMCC [LP 12002].

\section{Description}

CARAPACE. Frontal process large, triangular, slightly curved anteriorly (Fig. 126A). Median eyes well developed and median ocular tubercle shallow (Fig. 126C); pair of setae on median ocular tubercle, aligned one after another, posterior to eyes; lateral eyes well developed, seta situated lateral to each lateral ocular triad 
STERnUm. Tritosternum projected anteriorly, with typical setation, except one medial seta instead of two, surpassing base of pedipalp coxae (Fig. 126B); metasternum not paired, formed by single platelet, with pair of setae posteriorly.

Opisthosoma. Ventral sacs and ventral sacs cover well developed.

GeNITALIA. Female genital operculum with pair of bulges near apex and medial invagination, with several setae along margin (Fig. 127A-C); pair of glands laterally on bulges (Fig. 127F). Gonopods finger-like with small invagination apically and wrinkled base (Fig. 127E); gonopods well separated from margin of genital operculum (genital operculum with wide margin); denticulate surface between gonopods and posterior margin of genital operculum (Fig. 127D). Male gonopod as wide as long, wider in distal third (Fig. 128C); Lol2 fimbriate, projections short (Fig. 128A-B, D); PI with spiny surface and acute apex (Fig. 128E); dorsal lobe short, surface covered with spines and apex curved laterally (Fig. 128C, F-G); LaM short, not fused medially, with smooth surface (Fig. 128A-B, D); fistula without inner spines.

Chelicerae. Small tooth on retrolateral surface, opposite to bifid tooth; prolateral surface of basal segment with vertical row of several large setae; claw with three denticles.

PediPAlPs. Coxae with three setae on margin of round carina. Femur with 3-5 dorsal spines; small, extra spine between dorsal spines 1 and 3, closer to spine 3, may be present (Fig. 126E); two prominent setiferous tubercles proximal to spine 1; five ventral spines (Fig. 126F); extra spine, distal to spine 5, may be present; prolateral spine near base of spine I; prolateral row of spines, with three small spines, present in one specimen (adult female, AMCC [LP 12002]). Patella with five dorsal spines (Fig. 126E); two spines between spine I and distal margin; three ventral spines, decreasing in length (extra spine proximally may be present) (Fig. 126F); small spine between spine I and distal margin, one-third length of spine I. Tibia with two dorsal spines; ventral spine in distal half, two-thirds length of proximal dorsal spine. Tarsus with two or three dorsal spines (Fig. 126D); holotype with two spines on dextral pedipalp, proximal spine two-thirds length of distal spine, and three spines on sinistral pedipalp, two distal spines subequal, proximal spine two-thirds length of distal spine; cleaning organ with 28-33 setae in ventral brush.

LEGS. Tibia of leg I with 23 articles; tarsus I with 41 articles; modified claw and tarsal organ at apex of leg (Fig. 129D-E); leg covered with bristles and clavate sensilla (Fig. 129A-E). Leg IV basitibia with four pseudo-articles, trichobothrium $b t$ situated submedially on distal pseudo-article; apex of basitibia with strong sclerotized mark; distitibia trichobothrium $b c$ situated mid-way to $b f$ and $s b f ; s c$ and $s f$ series each with five trichobothria; tarsus with weakly developed white annulus on second article.

\section{Measurements}

See Table 8.

\section{Distribution}

Known only from the type localities on Tioman Island, Malaysia.

\section{Natural history}

Collected under logs and stones in moderately open to closed canopy, primary rainforest with moderate to dense leaf litter layer. 
Sarax willeyi Gravely, 1915

Figs 3G-H, 4G-H, 103, 130; Table 8

Sarax willeyi Gravely, 1915b: 441, fig. 7.

Sarax willeyi - Mello-Leitão 1931: 55. — Werner 1935: 471. — Kraus 1970: figs 10-11. — Harvey 2003: 9. — Rahmadi \& Kojima 2010: 476, figs 1a, 2a-g.

\section{Diagnosis}

This species may be separated from other species of Sarax in Southeast Asia and Oceania by the following combination of characters: small size (adult body length about 4.0-6.2 $\mathrm{mm}$ ); carapace projected anteriorly (Fig. 130A); sternum projected anteriorly with typical setation (Fig. 130B); frontal process triangular, short (Fig. 130C); female gonopod plunger-like; cheliceral claw with three teeth; pedipalp femur with four dorsal spines (dextral pedipalp with five dorsal spines due to presence of additional spine distally, and equal in length, to spine 4 ) and four ventral spines (spine 4 very small on dextral pedipalp) (Figs $3 \mathrm{G}-$ $\mathrm{H}, 130 \mathrm{E}-\mathrm{F}$ ); pedipalp patella with three dorsal spines, large spine distal to dorsal spine 3, and three ventral (Figs 4G-H, 130E-F); pedipalp tarsus with two short spines (Fig. 130D), tarsal cleaning organ with 23 (sinistral) or 26 (dextral) setae in ventral row of setae; tibia of leg I with 23 articles, tarsus I with 41 articles; leg IV basitibia with four pseudo-articles.

\section{Etymology}

Although unspecified, the name is evidently a patronym honoring the collector, Dr Willey.

\section{Type material}

\section{Syntypes}

PAPUA NEW GUINEA • 1 ㅇ, 1 §̊; New Britain; Dr Willey leg.; SMF 64589 [examined].

\section{Additional material (examined)}

PAPUA NEW GUINEA • 1 ð, 6 juv.; New Britain, S. Küst; 5-8 Feb. 1909; G. Duncker leg.; Hamburg. Südsee Exped.; ZMH • 1 q [opisthosoma detached]; Ralum [Ralum, New Britain]; 21 Oct. 1896; L. Dahl leg.; ZMH.

\section{Measurements}

See Table 8.

\section{Distribution}

Known from the island of New Britain, Papua New Guinea.

\section{Natural history}

Found under stones, fallen trees and rotten logs on the forest floor.

\section{Remarks}

The holotype is dismembered, and the dextral pedipalp is missing. See Rahmadi \& Kojima (2010) for redescription.

Sarax yayukae Rahmadi, Harvey \& Kojima, 2010

Figs 103, 131-134; Table 8

Sarax yayukae Rahmadi et al., 2010: 6-10, figs 8-15, 35-36. 


\section{Diagnosis}

Based on Rahmadi et al. (2010), this species may be separated from other species of Sarax in Southeast Asia and Oceania by the following combination of characters: medium-sized with adult body length about 8.8-11.8 mm; frontal process triangular (Fig. 131C); tritosternum projected anteriorly (Fig. 131B). Female gonopod plunger-like (Fig. 132A, C-D, G) with bulging area on posteriormost region of genital operculum (Fig. 132A-C); slit sensilla laterally on genital operculum (Fig. 132E); deep invagination posteriomedially on genital operculum (Fig. 132E). Male gonopod triangular (Fig. 133C), with dorsal lobe and LoL1 denticulate (Fig. 133E-F); LoL2 fimbriate and short (Fig. 133D); inner surface of fistula smooth (Fig. 133G). Secondary sexual dimorphism, male with long, slender pedipalp whereas female pedipalp shorter and stouter; pedipalp femur with three dorsal spines and three ventral spines (Fig. 131E-F); pedipalp patella with four dorsal spines (Fig. 131E); pedipalp tarsus with three dorsal spines in adults (Fig. 131D); juveniles with two spines on pedipalp tarsus; rod sensilla in deep groove with five setae (Fig. 134B, D); tarsal organ close to basis of claw (Fig. 134A-B, E); leg IV tibia with 19 trichobothria and trichobothrium $b c$ much closer to $s b f$ than to $b f$; leg IV with trichobothrium $b t$ situated near distal margin of fourth article.

\section{Etymology}

Patronym honoring Yayuk R. Suhardjono who collected the type material and for his contribution to the knowledge on cave biology in Indonesia (Rahmadi et al. 2010).

\section{Type material}

\section{Holotype}

INDONESIA • ${ }^{\top}$; Central Kalimantan, Liang Puruk, 00²7'45. $0^{\prime \prime}$ N, $115^{\circ} 00^{\prime} 55.5^{\prime \prime}$ E, Tumbang Topus, Murung Raya Regency, 9 Jun. 2004, C. Rahmadi, Y.R. Suhardjono and D. Silam leg., MZB Ambl. 56 [not examined].

\section{Paratypes}

INDONESIA -2 우, 1 juv.; Central Kalimantan, Liang Puruk, 00²7'45" N, 115 00'55.5" E; 9 Jun. 2004; C. Rahmadi, Y.R. Suhardjono and D. Silam leg.; MZB Ambl. 57-59 [not examined] • 1 q; same collection data as for preceding; MNHN Am. 9 [not examined] • $1{ }^{\lambda}$; Central Kalimantan, Liang Hajuq;

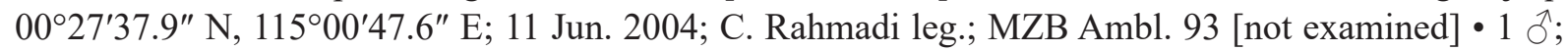
West Kalimantan, Gua Kelasi in buffer zone, Bukit Raya-Bukit Baka National Park, Menukung, Melawi; 00³0'25.66" S, 112¹7'44.97" E; 7 Aug. 2008; K.P.G. Himakova leg.; MZB Ambl. 148 [not examined].

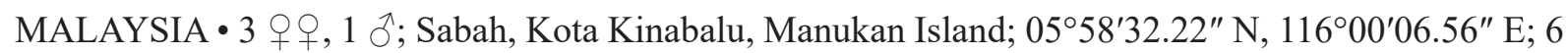
May 2006; T. Briggs leg.; under logs in forest; CASENT 9036127 [not examined] • 1 juv.; Sabah, Kota Kinabalu, Manukan Island; 6 May 2006; H. Tu and T. Briggs leg.; jogging track on leaf litter, under logs; CASENT 9036126 [not examined].

\section{Additional material}

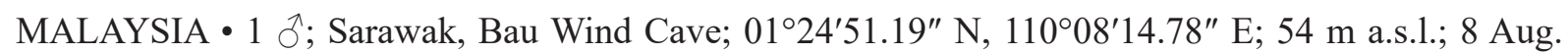
2013; J. Huff, A. Ang and L. Qie leg.; under limestone in dark part of cave; AMCC [LP 12169] • 1 \%, 2 juv.; Sarawak, 8 Jalan Ong Kwan Hin; 01³2'49.1" N, 110²0'44.6" E; 29 m a.s.1.; Kuching; 6 Aug. 2013; J. Huff and A. Ang leg.; in backyard under rocks and debris; AMCC [LP 12168] • 1 q, 1 \%; Sarawak, Kuching; Mjóhesg leg.; AMNH 1 juv. Sarawak, Gunung Mulu National Park, Cave of the Winds; 0403'39.9" N, 11449'49.6" E; 54 m a.s.l.; 30 Jul. 2013; S.F. Loria, J. Huff and A. Ang leg.; AMCC [LP 12123] - 3 우, 3 ふ̊ग, 3 juv.; Sarawak, Gunung Mulu National Park, Racer Cave; 0403'25.9" N, 114²49'36.8" E; 34 m a.s.l.; 2-3 Aug. 2013; L. Qie, J. Huff, L. Kumpang, M. Peter and A. Ang leg.; AMCC [LP 12152] 1 q juv.; Sarawak, Batu Song Mt. and Apoh River, Baram District; 


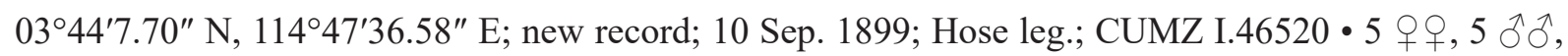
4 juv.; Sabah, Tunku Abdul Rahman National Park; Pulau Gaya; 0600'44.8" N, 116 00'34.8" E; 2 m a.s.1.; 25-28 Jul. 2013; S.F. Loria and J. Huff leg.; AMCC [LP 12109] 2 웅, 2 ふ઼ , 2 juv.; Sabah, Myne Resort, Kampung Bilit, Kinabatangan, near Kinabatangan River; 05²9'23.3' N, 118 13'38.1" E; 22-23 Jul. 2013; 20-66 m a.s.l.; S.F. Loria and J. Huff leg.; AMCC [LP 12119] • 1 đ;; Sandakan, British N. Borneo; 8 Jul. 1929; K.P. Schmidt leg.; FMNH 3489490.

\section{Measurements}

See Table 8.

\section{Distribution}

Widely distributed in Sabah and Sarawak, Malaysia.

\section{Natural history}

Large species with secondary sexual dimorphism of the pedipalp. Found inside caves and outside, under rocks and other debris on the ground.

\section{Remarks}

See Rahmadi et al. (2010) for description.

\section{Sarax sp.}

\section{Diagnosis}

This undescribed species may be separated from other species of Sarax in Southeast Asia and Oceania by the following combination of characters: juveniles with distinct dark bands on carapace and legs; median and lateral eyes well developed; lateral eyes near lateral margin of carapace; carapace lateral carina present; pentasternum with four setae; ventral sacs cover well developed; male gonopod with base of LoL2 sclerotized; cheliceral claw with three or four teeth; basal segment without tooth on retrolateral surface; pedipalp femur with four dorsal spines, three ventral spines, and spine between ventral spine 1 and proximal margin; pedipalp patella with four dorsal spines, long spine between dorsal spine I and distal margin, three ventral spines, setiferous tubercle between ventral spine I and distal margin; pedipalp tibia with two setae between ventral spine and distal margin; pedipalp tarsus with two short, subequal dorsal spines, cleaning brush with 29-31 setae; tibia of leg I with 23 articles, tarsus I with 41 articles; leg IV basitibia with four pseudo-articles; trichobothrium $b t$ situated in medial third; distitibia trichobothrium $b c$ situated closer to $b f$ than to $s b f ; s c$ and $s f$ series each with six setae, proximal two trichobothria displaced from row.

\section{Material examined}

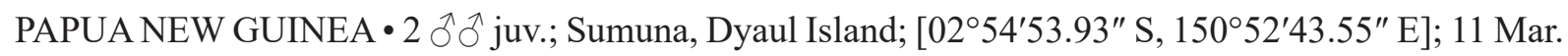
1962; Noona Dan. Eksp. 1961-1962 leg.; new record; ZMUC 21617.

\section{Remarks}

Although these immature specimens are not formally described and illustrated, a short list of diagnostic characters is provided for future research.

\section{Key to the identification of the species of Sarax in Africa, the Middle East, and South Asia}

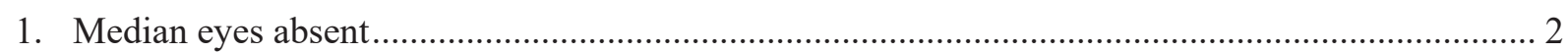

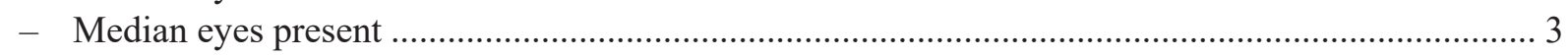


2. Lateral eyes reduced; tibia of leg I with more than 28 articles; leg I tarsus with more than 58 articles

S. omanensis (Delle Cave, Gardner \& Weygoldt, 2009) comb. nov.

- Lateral eyes absent; tibia of leg I with 21 articles; leg I tarsus with 35 articles

S. stygochthobius (Weygoldt \& Van Damme, 2004) comb. nov. (Fig. 149)

3. Pedipalp tarsus with one spine

- Pedipalp tarsus with two spines.

4. Pedipalp femur with three dorsal spines; pedipalp patella with five dorsal spines; female gonopods finger-like.

S. cochinensis (Gravely, 1915) (Fig. 141)

- Pedipalp femur with four dorsal spines; pedipalp patella with four dorsal spines; female gonopods plunger-like. S. dhofarensis (Weygoldt, Pohl \& Polak, 2002) comb. nov.

5. Cheliceral claw with twelve teeth; leg IV basitibia with two pseudo-articles

S. socotranus (Weygoldt, Pohl \& Polak, 2002) comb. nov. (Fig. 148)

- Cheliceral claw with fewer than ten teeth; leg IV basitibia with three or four pseudo-articles.......... 6

6. Leg IV basitibia with three pseudo-articles 7

- Leg IV basitibia with four pseudo-articles

7. Cheliceral claw with four teeth; tibia of leg I with 23 articles; leg I tarsus with 39 articles

- Cheliceral claw with more than four teeth; tibia of leg I with fewer than 23 articles; leg I tarsus with fewer than 39 articles

8. Pedipalp patella with two ventral spines S. abbatei (Delle Cave, 1986) (Fig. 136) comb. nov.

- Pedipalp patella with three ventral spines 9

9. Median and lateral eyes well developed S. bengalensis (Gravely, 1911) comb. nov.

- Median and lateral eyes reduced. S. pakistanus (Weygoldt, 2005) comb. nov. (Fig. 144)

10. Pedipalp patella with four dorsal spines; ventral sac cover absent; female gonopod 'absent' (flat). S. seychellarum (Kraepelin, 1898) (Figs 145-147) comb. nov.

- Pedipalp patella with five dorsal spines; ventral sac cover present; female gonopods finger-like...11

11. Pedipalp femur with five dorsal spines and five ventral spines

S. ioanniticus (Kritscher, 1959) comb. nov. (Figs 142-143)

- Pedipalp femur with four dorsal spines and four ventral spines

S. israelensis (Miranda et al., 2016) comb. nov.

Sarax abbatei (Delle Cave, 1986) comb. nov.

Figs 135-136; Table 9

Charinus abbatei Delle Cave, 1986: 148-150, figs I (1-7), II.

Charinus n. sp. - Messana et al. 1985: 334.

Charinus abbatei - Vanni et al. 1988: 376. — Weygoldt 1994: 244; 2000b: 346; 2005: 8-10, figs 16-18.

- Harvey 2003: 4. 


\section{Diagnosis}

Based on Weygoldt (2005), this species may be separated from other species of Sarax in Africa, the Middle East and South Asia by the following combination of characters: small size; female genital operculum rounded posteriorly, pointed medially, with group of setae posteriorly, gonopods small, cone shaped, plunger-like; bifid tooth on basal segment of chelicera with ventral cusp larger than dorsal cusp; leg IV basitibia with three articles. It shares this character with $S$. bengalensis comb. nov., S. bispinosus comb. nov. and S. pakistanus comb. nov. from which it may be distinguished by the thick, plunger-like gonopods of the female genitalia and by leg IV basitibia trichobothrium $b c$ situated near $s b f$.

\section{Etymology}

Patronym honoring Ernesto Abbate (Delle-Cave 1986).

\section{Type material}

\section{Holotype}

SOMALIA • +; Campione 12, Tratto 20, Grotta do Showli Berdi; [02¹8'51.78" N, 42¹6'56.53" E]; Bardera; 15 Mar. 1984; Spedizione Biologica in Somalia del Centro di Studio per la Faunistica ed Ecologia Tropicali del C.N.R. (Florence) leg.; MZUF 1896-167.

\section{Supplementary description}

CARAPACE. Six anterior setae (Fig. 136A); frontal process triangular (Fig. 136C). Small granules densely scattered between ocular triads and among sulci. Median eyes reduced; median ocular tubercle very shallow with pair of setae; lateral eyes reduced, situated near carapace margins, seta posterior to lateral ocular triad.

STERnUm. Tritosternum projected anteriorly, short, reaching base of pedipalp coxae (Fig. 136B); with typical setation; other sternal platelets narrow and projected, pair of setae situated anteriorly on plaque; pentasternum with two setae posteriorly.

Opisthosoma. Ventral sac cover absent.

Genitalia. Female genital operculum with short setae posteromedially; projected posteromedially; gonopod plunger-like; markedly sclerotized border posterior to gonopod projections. Male genitalia unknown.

CHELICERAE. Retrolateral surface of basal segment without projection, opposite to bifid tooth; retrolateral surface of claw with row of setae basally to medially; claw with four teeth; bifid tooth on basal segment with ventral cusp larger than dorsal cusp.

Pedipalps. Coxae without seta encircled by round carina and two setae at margin. Femur with three or four dorsal spines and four ventral spines (Fig. 136E-F); three prominent setiferous tubercles between dorsal spine 1 and proximal margin; ventral spine between spine 1 and proximal margin. Patella with three dorsal spines in primary series (Fig. 136E); prominent tubercle distal to spine I; two ventral spines (Fig. 136F); two small setiferous tubercles between spine I and distal margin. Tibia with ventral spine distally and two setae between spine and distal margin. Tarsus with two small dorsal spines, distal spine slightly larger than proximal spine, near cleaning brush (Fig. 136D); cleaning brush with 29 or 30 setae.

LEGs. Tibia of leg I with 22 articles; tarsus I with 36 articles (Delle-Cave 1986). Leg IV basitibia with three pseudo-articles (Delle-Cave 1986); trichobothrium $b t$ situated medially on pseudo-article; distitibia trichobothrium $b c$ situated closer to $s b f$ than to $b f ; s c$ and $s f$ series each with six trichobothria. 


\section{Measurements}

See Table 9.

\section{Distribution}

Known only from the type locality.

\section{Natural history}

The holotype was collected in Showli Berd Cave, in the middle of the desert, surrounded by xerophilic vegetation outside (Messana et al. 1985). Another arthropod described from the same cave showed no adaptation to subterranean life (Taiti \& Ferrara 1985). However, S. abbatei comb. nov. exhibits characters, such as reduced eyes, which suggest it may be restricted to the cave.

\section{Remarks}

The holotype is a small, pale specimen, missing the first pair of legs. It was originally described in the genus Charinus. Delle-Cave (1986) noted that the combination of characters of S. abbatei comb. nov. is unusual and contemplated proposing a new genus to accommodate it. Weygoldt (2005) redescribed the species. It is hereby transferred to Sarax based on the phylogenetic analyses of Miranda et al. (2021).

Sarax bengalensis (Gravely, 1911) comb. nov.

Fig. 135; Table 9

Charinides bengalensis Gravely, 1911: 35-36, fig. $2 \mathrm{~b}$.

Charinides bengalensis - Gravely 1912: cxxiv; 1915a: 526, fig. 29; 1915b: 442. — Buxton 1917: 3. — Mello-Leitão 1931: 53. - Werner 1935: 471, fig. 176a. — Weidner 1959: 142. — CloudsleyThompson 1968: 156, 158, 160. — Quintero 1983: 27, 29, 47; 1986: 207, fig. 5. — Delle Cave 1986: 158-160, fig. I-8. - Weygoldt 1999c: 104. — Torres-Contreras et al. 2015: 146, 148.

Charinus bengalensis - Delle Cave 1986: 161, figs I-8, II. - Weygoldt 2005: 5-6, figs 7-9. — Harvey 2003: 4. — Jocqué \& Giupponi 2012: 59.

\section{Diagnosis}

This species may be separated from other species of Sarax in Africa, the Middle East and South Asia by the following combination of characters: sexual dimorphism in male pedipalp length; carapace anterior margin projected; female gonopod finger-like; female genital plate markedly sclerotized posteriorly, with median projection; leg IV basitibia with three pseudo-articles; distitibia with trichobothrium $b c$ situated near $b f$ and both situated near proximal margin of article; $s c$ and $s f$ series each with five trichobothria, proximal two displaced from series.

The female gonopod and trichobothria of leg IV resemble those of S. ioanniticus comb. nov., S. israelensis comb. nov., and S. socotranus comb. nov. The median projection of the female genital plate resembles that of Charinus africanus, but is shorter. The markedly sclerotized posterior margin of the genital plate in dorsal view resembles that of $S$. abbatei comb. nov., in which the leg IV basitibia consists of an equal number of articles.

\section{Etymology}

Although unspecified, the species name evidently refers to the Bengal region of India in which the type locality is situated. 


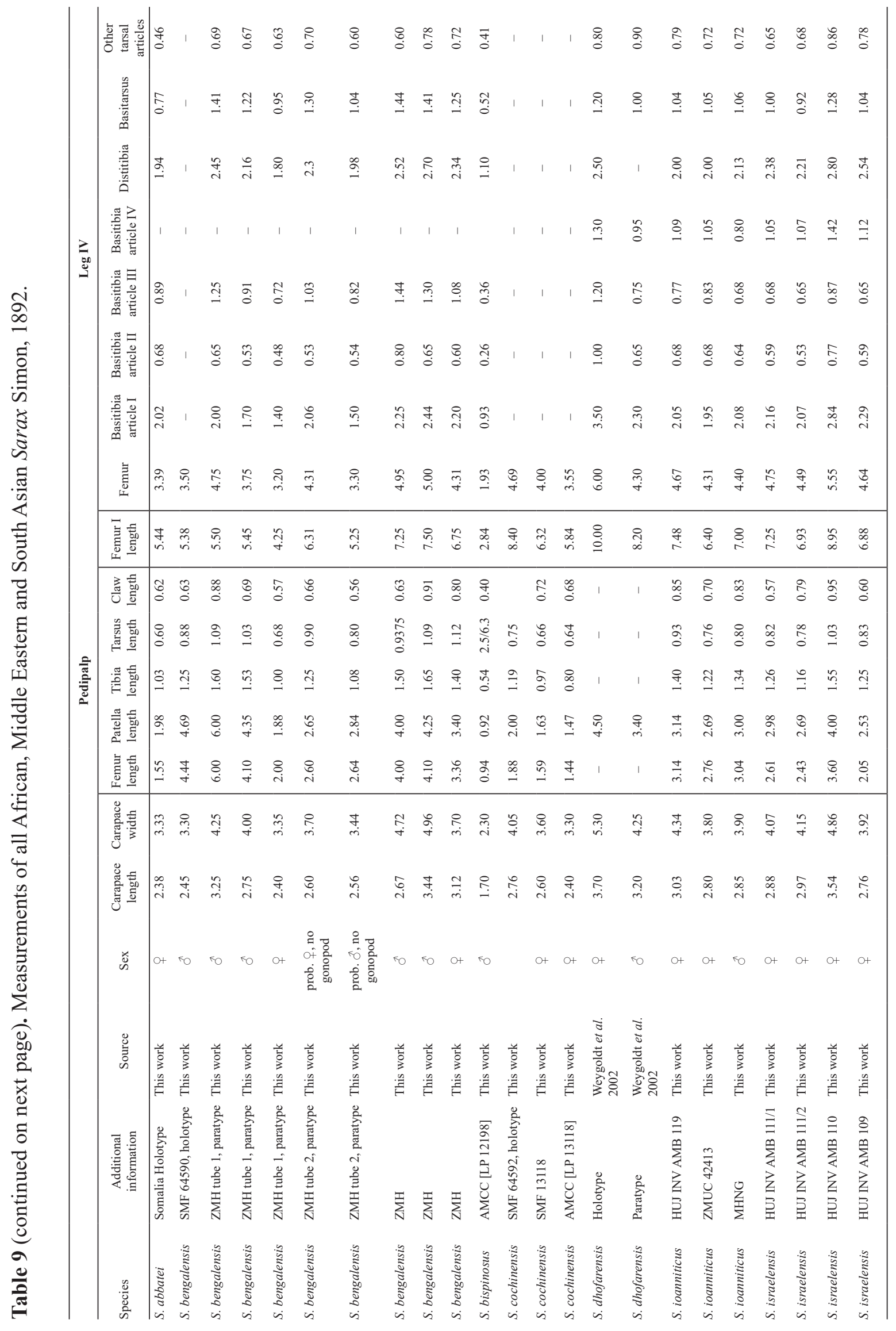




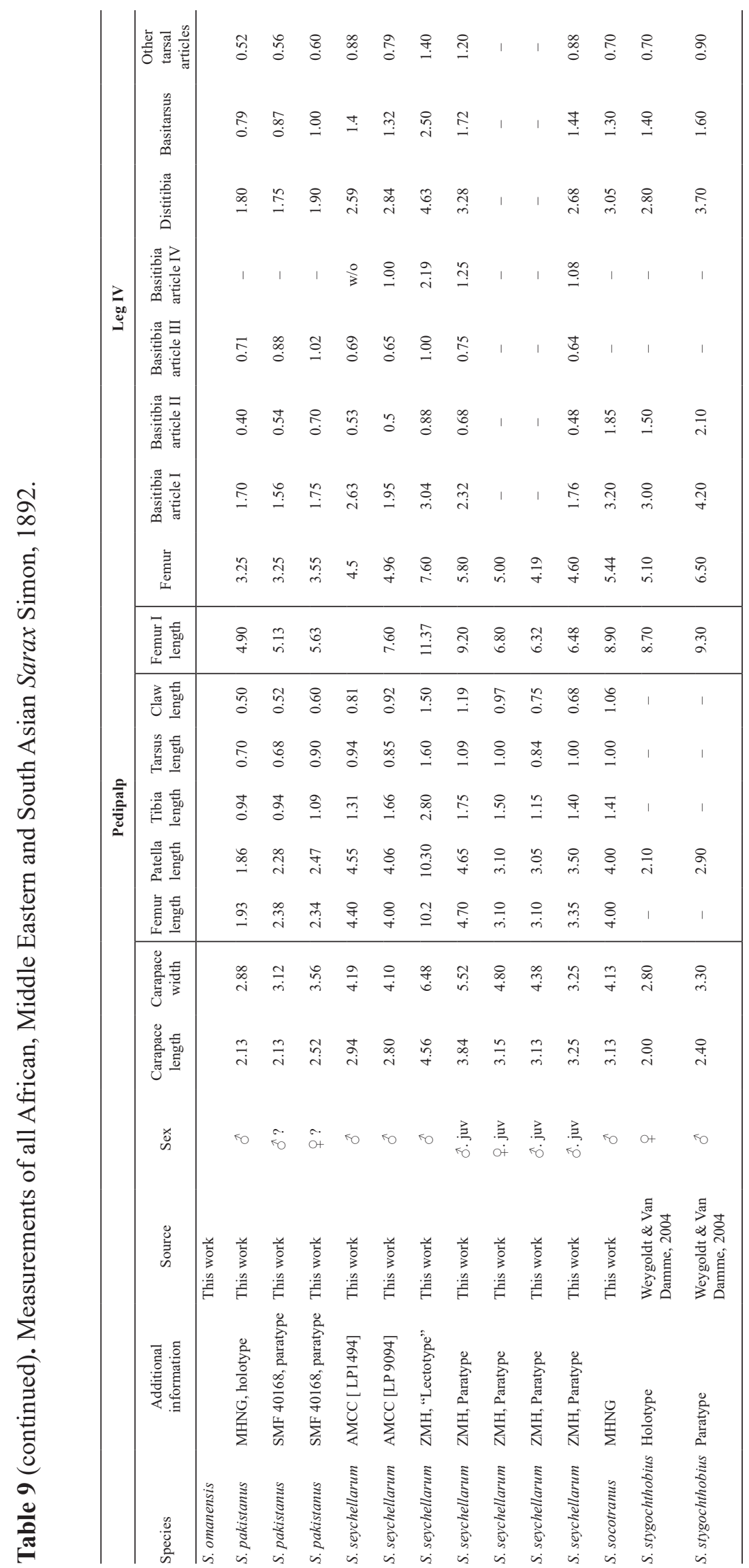




\section{Type material}

Holotype

INDIA • ${ }^{\lambda}$; West Bengal, Calcutta; SMF 64590.

Paratypes

INDIA • 6 ex.; Mus. Calcutta, Calcutta; Jun. 1911; Zool. Mus. Hamburg. Typenkatalog Nr. 1; ZMH.

\section{Additional material}

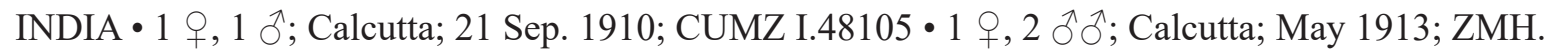

\section{Description}

CARAPACE. Six anterior setae; anterior margin projected; frontal process triangular. Small granules densely scattered between ocular triads and among sulci. Median eyes and median ocular tubercle well developed; pair of setae on median ocular tubercle; lateral eyes well developed, pale, seta lateral to lateral ocular triad; lateral ocular triad situated near carapace margin.

STERnum. Tritosternum projected anteriorly with typical setation, long, surpassing base of pedipalp coxae; other sternal platelets narrow and projected, with pair of setae anteriorly on plaque and some smaller setae posteriorly; pentasternum with two setae posteriorly.

Opisthosoma. Ventral sac cover absent.

Genitalia. Female genital operculum with short setae posteromedially; median region projected posteriorly; gonopod finger-like, unsclerotized basally; markedly sclerotized margin posterior to fingerlike projections.

CHELICERAE. Retrolateral surface of basal segment without projection opposite to bifid tooth; retrolateral surface of claw with row of setae basally to medially; claw with seven or eight teeth; bifid tooth on basal segment with dorsal cusp larger than ventral cusp.

PEDIPALPS. Coxae without seta encircled by round carina and with two setae on margin. Femur with three or four dorsal spines and three or four ventral spines; two prominent setiferous tubercles between dorsal spine 1 and proximal margin; setiferous tubercle between ventral spine 1 and proximal margin. Patella with four dorsal spines in primary series; prominent setiferous tubercle distal to spine I; three ventral spines; small setiferous tubercle between spine I and distal margin. Tibia with ventral spine distally and two setae between spine and distal margin. Tarsus with two dorsal spines, distal spine long, about onethird length of tarsus, proximal spine one-third length of dista spine; cleaning brush with 34 setae.

LeGs. Tibia of leg I with 21 articles; tarsus I with 35 articles; first tarsal article similar in length to second article. Leg IV basitibia with three pseudo-articles; trichobothrium $b t$ situated in proximal third of pseudo-article; distitibia trichobothrium $b c$ situated closer to $b f$ than to $s b f$, with first two closer the proximal end of article and $s b f$ in medial on article; $s c$ and $s f$ series each with five trichobothria, closest two displaced from series and situated close together.

\section{Measurements}

See Table 9.

\section{Distribution}

Known only from Calcutta, India. 


\section{Natural history}

This epigean species is found in under bricks in shady places in the city of Calcutta (Weygoldt, 2005a).

\section{Remarks}

The jar containing the paratypes contains two detached legs, leg II or III and leg IV, and three vials: one with 2 subad., 1 juv.; another with $2 \hat{\jmath}, 1$ juv. O+; and another with two chelicerae and one gonopod.

Charinides bengalensis is the type species of Charinides by monotypy. The genus was synonymized with Charinus by Delle Cave (1986). Here, C. bengalensis is transferred to Sarax based on the phylogenetic analyses of Miranda et al. (2021), resulting in the synonymy of Charinides with Sarax. All other species once placed in Charinides (C. acosta, C. bordoni, C. camachoi, C. cubensis, C. decu, C. pardillalensis, C. tronchonii, and C. wanlessi) remain in Charinus.

Sarax bispinosus (Nair, 1934), stat. nov. Figs 3E-F, 4E-F, 135, 137-140; Table 9

Phrynichosarax cochinensis var. bispinosus Nair, 1934: 475, fig. b.

Sarax cochinensis bispinosus - Harvey 2003: 8.

\section{Diagnosis}

This species may be separated from other species of Sarax in Africa, the Middle East and South Asia by the following combination of characters: median eyes present; median ocular tubercle shallow (Fig. 137A); chelicera with short, acute tooth on retrolateral surface of basal segment, opposite to bifid tooth; cheliceral claw with four teeth; pedipalps sexually dimorphic, male pedipalps with longer segments than female pedipalps; tibia of leg I with 23 articles, tarsus I with 39 articles; leg IV basitibia with three pseudo-articles; distitibia trichobothrium $b c$ situated medially and closer to $b f$ than to $s b f ; s c$ and $s f$ series each with five trichobothria.

This species differs from its congeners in the number of articles on the tarsus of leg I.

\section{Etymology}

Adjective referring to two spines on the pedipalp tarsus (Nair 1934).

\section{Type material}

\section{Syntypes}

INDIA • 2 ex.; Kallar, 30 miles E of Trivandrum, Tamil Nadu; [08 42'35.41" N, 7707'44.77" E]; $2000 \mathrm{ft}$ a.s.1.; Mar. 1933; K.B. Nair leg.; [repository unspecified] [not examined] • many specimens; Mookunni Hill, near Trivandrum; [08 $32^{\prime} 51.76^{\prime \prime}$ N, 76 59'28.26" E]; $842 \mathrm{ft}$ a.s.1.; K.B. Nair leg.; damp places adhering to undersurface of stones and fallen timber; [repository unspecified] [not examined].

Additional material (examined)

SRI LANKA - 2 우, 2 $\delta^{\lambda}$; North Central Province, Anuradhapura District, Kodigala Mountain; 08 $06^{\prime} 34^{\prime \prime}$ N, 80³9'24" E; new record; 6 Feb. 2014; L. Prendini and P. Horsley leg.; under stones on summit and rocky upper slopes, many large granitic outcrops, moderate to thick leaf litter layer, dense canopy cover with sparse understorey below summit; forest shorter and drier at summit; AMNH Ambly 90 • 1 o juv.; same collection data as for preceding; AMCC [LP 12298]. 


\section{Description}

CARAPACE. Six anterior setae (Fig. 137A); frontal process triangular, not visible in dorsal view (Fig. 137C). Small granules densely scattered between ocular triads and among sulci. Median eyes and median ocular tubercle well developed; pair of setae on median ocular tubercle; lateral eyes well developed, pale, with seta lateral to lateral ocular triad; lateral ocular triad situated near carapace margin; curved carina between ocular triads and carapace margin.

STERnUm. Tritosternum projected anteriorly with typical setation, long, surpassing base of pedipalp coxae (Fig. 137B); other sternal platelets narrow and projected, with 6-8 setae anteriorly on plaque and 6-8 setae posteriorly; pentasternum with two or three setae medially on plaque.

Opisthosoma. Ventral sac cover well developed.

GeNITALIA. Female genital operculum with short setae posteromedially; median region with pair of white bulges and slender setae apically (Fig. 138A-C); gonopod finger-like with small invagination apically (Fig. 138A-B, E); base of gonopods unsclerotized; slit sensilla on lateral margin of genital operculum (Fig. 138E). Male genitalia with LoL1 wrinkled (Fig. 139A, E); LoL2 fimbriate (Fig. 139D); LoD not projected or surpassing LaM (Fig. 139A, C); wth small spiny projections on border of LaM (Fig. 139AB); spiny projections inside fistula (Fig. 139G); short PI (Fig. 139D); border of fistula and base of LoL2 sclerotized.

CHELICERAE. Retrolateral surface of basal segment with short, acute projection opposite to bifid tooth on basal segment; retrolateral surface of claw with row of setae basally to medially; claw with four teeth; two transverse rows of several setae on prolateral surface of basal segment; bifid tooth on basal segment with dorsal cusp larger than ventral cusp.

PEDIPALPS. Coxae without seta encircled by round carina, two setae on margin with sockets near each other. Femur with four or five dorsal spines and four or five ventral spines (Figs 3E-F, 137E-F); two or three prominent setiferous tubercles between dorsal spine 1 and proximal margin; short setiferous tubercle between ventral spine 1 and proximal margin. Patella with five dorsal spines in primary series (Figs 4E-F, 137E-F); two prominent setiferous tubercles distal to spine I; three ventral spines decreasing in length from distal to proximal; two small setiferous tubercles between spine I and distal margin. Tibia with two dorsal spines, distal spine similar in length to tibia, proximal spine one-third length of distal spine; ventral spine distally and two setae between spine and distal margin. Tarsus with two dorsal spines, distal spine long (Fig. 137D), about half length of tarsus, proximal spine short, emerging from base of longer spine; cleaning organ with 30-32 setae in ventral row.

Legs. Tibia of leg I with 23 articles; tarsus I with 39 articles; first tarsal article same length as second article; tarsal organ close to base of tarsal claw (Fig. 140A-B, D); rod sensilla in deep groove (Fig. 140C). Leg IV basitibia with three pseudo-articles, with sclerotized, denticulate margin at apex of articles; trichobothrium $b t$ situated in proximal third of pseudo-article; distitibia trichobothrium $b c$ situated closer to $b f$ than to $s b f, s c$ and $s f$ series each with five trichobothria.

\section{Measurements}

See Table 9.

\section{Distribution}

Known from India and Sri Lanka. 


\section{Natural history}

Specimens were collected under stones in primary forest.

\section{Remarks}

The distinctive morphology of S. bispinosus justifies its elevation to the rank of species.

Sarax cochinensis (Gravely, 1915)

Figs 11C-D, 135, 141; Table 9

Phrynichosarax cochinensis Gravely, 1915b: 438-439, fig. 2.

Phrynicosarax cochinensis - Mello-Leitão 1931: 52.

Phrynichosarax cochinensis - Nair 1934: 475, fig. a. - Werner 1935: 470.

Sarax cochinensis - Harvey 2003: 8.

Sarax cochinensis cochinensis - Harvey 2003: 8.

\section{Diagnosis}

This species may be separated from other species of Sarax in Africa, the Middle East and South Asia by the following combination of characters: lateral eyes contacting lateral curved carina; ventral sac cover well developed; female gonopod finger-like; cheliceral claw with three denticles (Fig. 11C-D); pedipalp patella dorsal with two spines between spine I and distal margin (Fig. 141E); pedipalp tarsus with one spine, one-third length of tarsus (Fig. 141D); tibia of leg I and tarsus I with 23 and 41 articles, respectively.

This species resembles $S$. dhofarensis comb. nov., from which it differs in the higher number of dorsal spines on the pedipalp patella: four spines are present in $S$. dhofarensis comb. nov., compared with five in S. cochinensis.

\section{Etymology}

Although unspecified, the name is evidently an adjective referring to the city of Cochin, in the vicinity of the type locality.

\section{Type material}

\section{Holotype}

INDIA • O; Kerala, near Trichur, Cochin State Forest Tramway, between miles 10-14; 0-91 m a.s.1.; F.H. Gravely leg.; 28-29 Sep. 1914; SMF 64592.

\section{Paratype}

INDIA • 1 q; Kerala, Kavalai, Cochin State Forest Tramway; 396-914 m a.s...; F.H. Gravely leg.; 24-27 Sep. 1914; SMF 64593.

\section{Additional material}

INDIA • 1 क; Kerala, Thrissur Distr., Attoor, Asurankundu Dam, near dam wall; $10^{\circ} 41^{\prime} \mathrm{N}, 7^{\circ} 18^{\prime} \mathrm{E}$; $118 \mathrm{~m}$ a.s.1.; 25 Nov. 2004; S. Basi leg.; under stone in tropical lowland swamp forest with dense canopy, many sandstone outcrops; moderate to sparse leaf litter layer; AMCC [LP 13118]. 


\section{Description}

CARAPACE. Frontal process large, triangular, not visible in dorsal view, rounded apically (Fig. 141C). Median eyes and median ocular tubercle well developed; seta on median ocular tubercle and another seta posterior to it (Fig. 141A, C); lateral eyes well developed, seta situated lateral to each lateral ocular triad.

STERNUM. Tritosternum projected anteriorly, surpassing base of pedipalp coxae, with typical setation (Fig. 141B); metasternum not paired, forming single platelet, with pair of setae on elevated surface medially on plaque.

Opisthosoma. Ventral sacs and ventral sac cover well developed. Region of plaque where ventral sac cover present with dark margin.

GenitaLia. Female gonopod with posterior margin slightly curved. Elevated surface, covered with setae, extending from midpoint to posterior margin; first third of elevated surface pale, resembling membranous structure. Gonopods finger-like. Male gonopod with PI short, visible in dorsal view; LoL2 lanceolate, long, reaching LaM; LoL1 short, fimbriate; LaM long, reaching LoL2. Fistula curved, unsclerotized.

Chelicerae. Small tooth on retrolateral surface of basal segment, opposite to bifid tooth (Fig. 11D). Prolateral surface with longitudinal row of eight setae. Claw with three denticles (Fig. 11C-D).

PEDIPALPS. Coxae without seta encircled by round carina and with two or three setae on anterior margin. Femur with three dorsal spines and two prominent setiferous tubercles proximal to spine 1 (Fig. 141E); four ventral spines (female with three ventral spines) with small setiferous tubercle proximal to spine 1 (Fig. 141F). Patella with five dorsal spines; two spines distal to spine I, proximal spine about half length of spine I, distal spine one-fifth length of proximal spine. Patella with three ventral spines; second spine half length of first spine. Tibia with two dorsal spines, proximal spine two-thirds length of distal spine; ventral spine in distal half, two-thirds length of proximal dorsal spine. Tarsus with large, curved dorsal spine (Fig. 141D); cleaning brush with 24-27 setae ventrally.

LeGs. Tibia of leg I with 23 articles; tarsus I with 41 articles; proximal article subequal to subsequent articles. Leg IV basitibia with one or two pseudo-articles; trichobothria unknown; distitibia trichobothrium $b c$ situated closer to $s b f$ than to $b f ; s c$ and $s f$ series each with 5 trichobothria; tarsus unknown (missing in material examined).

\section{Measurements}

See Table 9.

\section{Distribution}

Known only from the state of Kerala, India.

\section{Natural history}

One specimen collected under stone in dense canopy tropical lowland swamp forest with many sandstone outcrops and moderate to sparse leaf litter layer.

\section{Remarks}

Leg IV was missing from the material examined, preventing the position of the trichobothria or the number of pseudo-articles in the basitibia to be assessed. However, Gravely (1915) noted that the basitibia of leg IV could be undivided, i.e., with one pseudo-article, or divided, i.e., with two pseudoarticles. 
Sarax dhofarensis (Weygoldt, Pohl \& Polak, 2002) comb. nov.

Fig. 135; Table 9

Charinus dhofarensis Weygoldt et al., 2002: 292-295, figs 1-7.

Charinus dhofarensis - Miranda et al. 2016c: 29.

\section{Diagnosis}

Based on Weygoldt et al. (2002), this cavernicolous species may be separated from other species of Sarax in Africa, the Middle East and South Asia as follows: it differs from S. omanensis comb. nov., S. socotranus comb. nov. and S. stygochthobius comb. nov., in having a plunger-like female gonopod and not possessing a slender, tubular female gonopod and the convex genital operculum, without an acuminate apex. Sarax dhofarensis comb. nov. also differs from S. omanensis comb. nov., S. socotranus and S. stygochthobius comb. nov. in the curved carina between the lateral eyes and lateral margin of the carapace.

\section{Etymology}

Adjective referring to Dhofar, the southern province of Oman, where the species occurs (Weygoldt et al. 2002).

\section{Type material}

Holotype

OMAN • O; Tawi Atayr Waterhole, Tawi Atayr; 1706'45" N, 54²2'20" E; S. Polak leg.; ONHM 2969 [not examined].

\section{Paratypes}

OMAN $1 \delta^{\lambda}$; same collection data as for holotype; ONHM 2970 [not examined] $\bullet 1 \%$; same collection data as for holotype; SMNS [not examined] • 1 O ; Tawi Atayr, Pop Cave; $17^{\circ} 06^{\prime} 45^{\prime \prime}$ N, 54 $33^{\prime} 30^{\prime \prime}$ E; 2 Nov. 1997; S. Polak leg.; ONHM [not examined] • 1 q, 1 §̊; Quanaf, Blown Gasket Cave; $17^{\circ} 06^{\prime} 45^{\prime \prime} \mathrm{N}$,

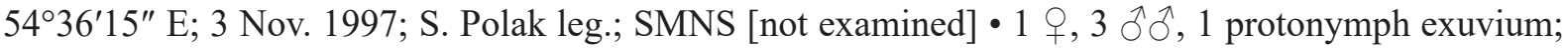
same collection data as for preceding; BFUL [not examined].

\section{Measurements}

See Table 9.

\section{Distribution}

Known only from the type locality in the Dhofar Province of Oman.

\section{Natural history}

According to Weygoldt et al. (2002), the species occurs in three deep limestone caves in a large karst plateau. The caves are sinkholes of usually dry rivers that occasionally flow during the rainy monsoon season, and all have water in the deeper parts. Sarax dhofarensis comb. nov. is found in the aphotic zone in deeper parts of the caves, between 150 and $1000 \mathrm{~m}$ from the entrance. Individuals were observed sitting on the roof, on the cave walls or on bat guano deposits on the cave floor. The temperature in the caves is about $23^{\circ} \mathrm{C}$.

\section{Remarks}

The type material was not deposited in the SMNS. 
This species was originally described in the genus Charinus and is hereby transferred to Sarax based on the phylogenetic analyses of Miranda et al. (2021). See Weygoldt et al. (2002) for a description of this species.

Sarax ioanniticus (Kritscher, 1959) comb. nov.

Figs 135, 142-143; Table 9.

Lindosiella ioannitica Kritscher, 1959: 454-457, figs 1-4.

Lindosiella ioannitica - Kraus 1961: 491.

Charinus sp. - Rosin \& Shulov 1960: 167-168, unnumbered fig.

Charinus ioanniticus - Weygoldt 1972b: 123, fig. 22c; 2002b: 469; 2005: 2-5, figs 1-6; 2006a: 246, fig. 12; 2007: 81-82. — Delle Cave 1986: 150-151, fig. II. — Kovař́́k \& Vlasta 1996: 57-58. — ElHennawy 2002: 452-453, figs 1-2. — Harvey 2003: 6. — Seyyar \& Demir 2007: 109-111, figs 1-4. — Seiter \& Hörweg 2013: 49-51, fig. 3. - Seiter \& Wolff 2014: 233. — Torres-Contreras et al. 2015: 146, 148. — Blick \& Seiter 2016: 586-588, figs 1-2, 6. — Teruel \& Friedrich 2016: 22. Miranda et al. 2016a: 31. - Agapakis \& Miranda 2019: 13-15. - Shakhatreh et al. 2020: 35-37. — Colla et al. 2020: 642-645, 647, figs 1-3, 6-9. — Gainett et al. 2020: 4-5, 7, 10-13, figs 1b, 3.

\section{Diagnosis}

This species may be separated from other species of Sarax in Africa, the Middle East and South Asia by the following combination of characters: trichobothria $b c$ and $b f$ situated close to each other at the proximal end of the leg IV distitibia and $s b f$ is situated about midway between these two trichobothria and the distal $s c$ and $s f$ series. It may be further distinguished from $S$. israelensis comb. nov. by the smaller number of ventral spines on the pedipalp patella.

\section{Etymology}

The species name is an adjective referring to the type locality, the Johanniter castle, built in Rhodos (Greece) in 1309 after the First Crusade.

\section{Type material}

\section{Syntypes}

GREECE - 1 क; Island of Rhodos, Lindos, below castle; 15-16 Apr. 1959; E. Kritscher leg.; NHMW $19138 \bullet 5$ o 9 ; same collection data as for preceding; NHMW $19137 \bullet 2$ juv.; same collection data as for preceding; NHMW 1427.

\section{Additional material}

GREECE • 2 q 9,3 juv.; Rhodos, O. Bechtold leg.; MHNG • 1 q; Dodekanes, Rhodos, Rhodos City; Jun. 1978; N. Polemikos leg.; SMF 56704 • 6 ㅇ; Rhodos, Lindos, castle of Johannites [Monolithos]; 27 Apr. 1964; V. Helversen and H. Pieper leg.; in wall and rock fissures of substructure; SMF 17319 • 4 우; same collection data as for preceding; SMF 17392 • 6 q 9 ; Kos, bunker of castle; 30 Apr. 1965; H. Piepper leg.; SMF 17391•1 q; Rhodos, town of Lindos, Krichter leg., SMF 11895/1 • 7 $\uparrow$, 4 juv., 4 exuvia; under ancient city Rhódos; 3 Sep. 2003; P. and S. Weygoldt leg.; in subterranean tunnels; SMNS - 2 q 9 ; Rhodos; 3 Sep. 2003; P. and S. Weygoldt leg.; in subterranean tunnels under ancient city; AMCC [LP 2843].

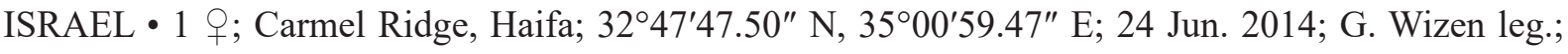
HUJ INV AMB 100 • 1 \%; Haruba cave; 9 Mar. 2014; Aharon and Gavish-Regev leg.; HUJ INV AMB $119 \bullet$ 
Khirbet Roma, near Rumana, Beit Netofa Lower Galilee; 3247'20.39" N, 35¹7'35.18" E; 178 m a.s.l.; 21 Mar. 2015; O. Segev leg.; HUJ INV AMB 120 • 1 क; Jerusalem, Rosin leg.; 4 May 1960; SMF 12126/1 • 1 क ; same collection data as for preceding; SMF 12127/1.

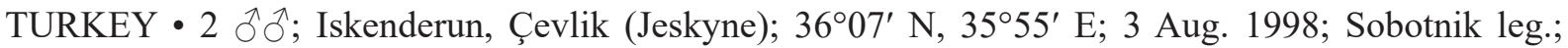
MHNG • 1 ठ; Adana, 12 km N of Kozan; 300 m a.s.1.; 5 May 1967; C. Besuchet leg.; under rock; MHNG • 1 क; Yalan Dünya Cave, Beyrebucak Village, Gazipaşa District, Antalya Province; 36 $13^{\prime} 16.92^{\prime \prime}$ N, 32²4'4.43" E; 5 Dec. 2013; K.B. Kunt and Y.M. Marusik leg.; ZMUC 2413.

\section{Description}

CARAPACE. Six anterior setae (Fig. 142A); frontal process triangular (Fig. 142C). Small granules densely scattered between ocular triads and among sulci. Median eyes and median ocular tubercle reduced; pair of setae on median ocular tubercle; lateral eyes reduced, pale, with seta lateral to lateral ocular triad; lateral ocular triad situated near carapace margin.

STERnUm. Tritosternum projected anteriorly with typical setation, long, surpassing base of pedipalp coxae (Fig. 142B); other sternal platelets narrow and projected, with pair of setae anteriorly on plaque and some smaller setae posteriorly; pentasternum with posteromedial depression and four setae posteriorly.

Opisthosoma. Ventral sacs present, withour ventral sac cover.

Genitalia. Female genital operculum with short setae posteromedially; median region with setae; gonopod finger-like, unsclerotized basally. Male gonopod sclerotized dorsally and in distal part of fistula (difficult to interpret structures due to transparency of gonopod).

CHELICERAE. Acute projection on retrolateral surface of basal segment, opposite to bifid tooth; retrolateral surface of claw with row of setae basally to medially; claw with eight teeth; row of six setae on prolateral surface of basal segment; bifid tooth on basal segment with dorsal cusp smaller than ventral cusp.

PeDIPALPS. Coxae without seta encircled by round carina and with three setae on margin. Femur with five dorsal spines and five ventral spines (Fig. 142E-F); two prominent setiferous tubercles between first dorsal spine and proximal margin; setiferous tubercle between ventral spine 1 and proximal margin. Patella with five dorsal spines in primary series (Fig. 142E); two prominent setiferous tubercles distal to spine I; three or four ventral spines (Fig. 142F); small setiferous tubercle between spine I and distal margin. Tibia with ventral spine distally and two setae between spine and distal margin. Tarsus with two dorsal spines, distal spine long, about one-third length of tarsus, proximal spine one-third length of distal spine (Fig. 142D); cleaning organ with 25-28 setae in ventral row.

Legs. Tibia of leg I with 21 articles; tarsus I with 37 articles; first tarsal article similar in length to second article. Leg IV basitibia with four pseudo-articles; trichobothrium $b t$ situated in proximal third of pseudo-article; distitibia trichobothrium $b c$ situated closer to $b f$ than to $s b f, s c$ and $s f$ series each with five trichobothria.

\section{Measurements}

See Table 9.

\section{Distribution}

The extensive distribution of this species includes records from Egypt, Greece, Jordan, Israel, Italy and Turkey. 


\section{Natural history}

This synanthropic species inhabits caves in disturbed areas. Its broad distribution may be associated with parthenogenetic reproduction (Fig. 143A-C).

\section{Remarks}

This species is closely related to $S$. israelensis comb. nov., which overlaps its distribution. It was originally described in the genus Lindosiella and is hereby transferred to Sarax based on the phylogenetic analyses of Miranda et al. (2021). The morphological characters that support its placement in Sarax include the lateral eyes situated near the lateral margin of the carapace, the presence of a seta lateral to the lateral ocular triad, and the finger-like female gonopod. See Miranda et al. (2016a) for more details about S. ioanniticus comb. nov.

Sarax israelensis (Miranda, Aharon, Gavish-Regev, Giupponi \& Wizen, 2016) comb. nov. Fig. 135; Table 9

Charinus israelensis Miranda et al., 2016a: 4-12, figs 1-6.

Charinus israelensis - Torres et al. 2019: 15, 18. — Gainett et al. 2020: 4-7, 11-13, figs 1c, 3.

\section{Diagnosis}

This species may be separated from other species of Sarax in Africa, the Middle East and South Asia by the following combination of characters: 6-8 anterior setae on carapace; median eyes extremely reduced; median ocular tubercle absent; lateral eyes very reduced.

It differs from S. ioanniticus comb. nov. as follows: reduction of the median and lateral eyes; number of spines on the pedipalp, the femur with four dorsal spines and four ventral spines in S. israelensis comb. nov. compared with five dorsal spines and five ventral spines in S. ioanniticus comb. nov.; shape of the carapace, with anterior margin rounded in S. israelensis comb. nov. but projected anteriorly in S. ioanniticus comb. nov.; and the shape of the frontal process, which is acute in S. israelensis comb. nov. but rhomboid in $S$. ioanniticus comb. nov.

\section{Etymology}

The name refers to the country of the type locality (Miranda et al. 2016).

\section{Type material}

\section{Holotype}

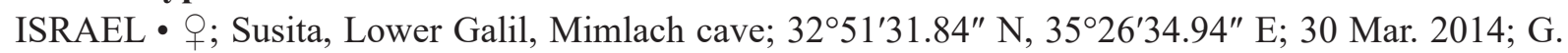
Wizen leg.; HUJ INV AMB 111A.

\section{Paratypes}

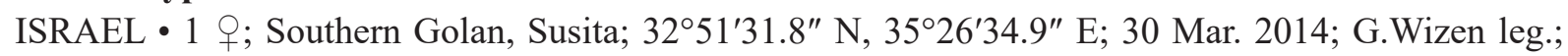
HUJ INV AMB 111B • 2 q 9 , 1 juv.; same locality as for preceding; $32^{\circ} 46^{\prime} 46.2^{\prime \prime} \mathrm{N}, 35^{\circ} 39^{\prime} 28.5^{\prime \prime} \mathrm{E} ; 2$ May 2013; G. Wizen leg.; HUJ INV AMB 109・1 ; same collection data as for preceding; 13 Jul. 2013; G. Wizen leg.; HUJ INV AMB 110.

\section{Measurements}

See Table 9. 


\section{Distribution}

Known only from the type locality.

\section{Natural history}

This troglobitic species is restricted to a cave in a semi-arid region.

\section{Remarks}

This species is closely related to $S$. ioanniticus comb. nov., which overlaps its distribution. It was originally described in the genus Charinus and is hereby transferred to Sarax based on the phylogenetic analyses of Miranda et al. (2021). The morphological characters that support its placement in Sarax include the lateral eyes situated near the lateral margin of the carapace, the presence of a seta lateral to the lateral ocular triad, and the finger-like female gonopod. See Miranda et al. (2016a) for more details about $S$. israelensis comb. nov.

Sarax omanensis (Delle Cave, Gardner \& Weygoldt, 2009) comb. nov.

Fig. 135; Table 9

Charinus omanensis Delle Cave et al., 2009: 130-132, figs 1-7.

\section{Diagnosis}

Based in part on Delle Cave et al. (2009), this small troglomorphic species most closely resembles S. stygochthobius comb. nov., from which it differs in the slightly larger size; the presence of vestigial lateral eyes; the finger-like female gonopod with wrinkled base, well separated from the margin of the genital operculum; the long dorsal lobe of the male gonopod, projecting forward and surpassing all other lobes; larger numbers of pedipalp spines, and leg IV basitibia with three pseudo-articles.

\section{Etymology}

Although unspecified, the species name is evidently an adjective referring to Oman, the country in which the species occurs.

\section{Type material}

\section{Holotype}

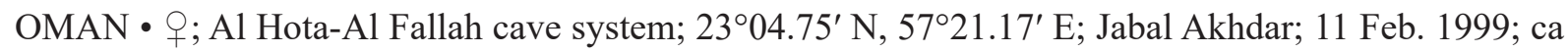
$730 \mathrm{~m}$ a.s.l.; A.S. Gardner leg.; ONHM [not examined].

\section{Paratypes}

OMAN $\bullet 1$; same collection data as for holotype; ONHM [not examined] $\bullet 1$ \% ; same collection data as for holotype; MZUF 213 [not examined] • 1 क ; same collection data as for holotype; MZUF 2015 [not

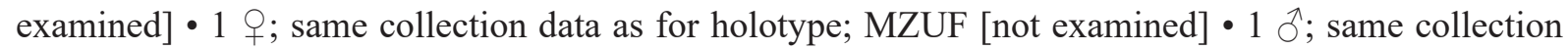
data as holotype; MZUF 214 [not examined].

\section{Measurements}

See Table 9.

\section{Distribution}

Known only from the type locality. 


\section{Natural history}

Inhabits a cave in an arid region.

\section{Remarks}

This species was originally described in the genus Charinus and is hereby transferred to Sarax based on the phylogenetic analyses of Miranda et al. (2021). The female genitalia are consistent with its placement in Sarax. See Delle Cave et al. (2009) for a description of this species.

Sarax pakistanus (Weygoldt, 2005) comb. nov. Figs 135, 144; Table 9

Charinus pakistanus Weygoldt, 2005: 6-8, figs 10-15.

Charinus pakistanus - Blick \& Seiter 2016: 590.

\section{Diagnosis}

This species may be separated from other species of Sarax in Africa, the Middle East and South Asia by the following combination of characters: distal margin of female genital operculum with small median projection; ventral sac cover absent; female gonopod finger-like, with slender apex; sexual dimorphism in pedipalps apparently absent; pedipalp patella with large dorsal spine, not setiferous tubercle, distal to spine I, two-thirds length of spine I, two ventral spines, and one seta between spine I and distal margin (Fig. 144E-F); pedipalp tibia with base of two dorsal spines situated very close to each other; leg IV basitibia with three articles.

Sarax pakistanus comb. nov. resembles S. bengalensis comb. nov. but bears more teeth on the cheliceral claw, more spines on the pedipalp, and the eyes are not as developed, than the latter.

\section{Etymology}

An adjective referring to Pakistan, the country in which the type locality is situated (Weygoldt 2005).

\section{Type material}

\section{Holotype}

PAKISTAN - đ; Malkandi, between Kawai and Mahandri, Kaghan Valley, Mansehra District;

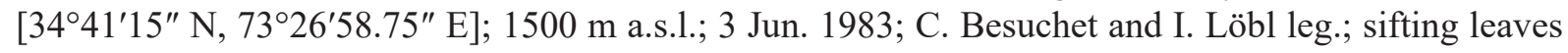
and old stumps in hardwood forest; MHNG.

\section{Paratypes}

PAKISTAN • 3 우, 2 o $\delta^{\wedge}$; Khyber Pakhtunkhwa [former North-West Frontier Province], ca $1.5 \mathrm{~km} \mathrm{~N}$ of Islamabad; $33^{\circ} 44.3^{\prime} \mathrm{N}, 73^{\circ} 03^{\prime} \mathrm{E}$; ca $800 \mathrm{~m}$ a.s.1.; $10 \mathrm{Jul}$. 2003; S.V. Ovchinnikov leg.; forest, under stones; SMF 40168.

\section{Supplementary description}

CARAPACE. Median eyes and median ocular tubercle reduced (Fig. 144A); frontal process with rounded apex (Fig. 144C); one seta, not pair, posterior to median eyes; lateral eyes well developed, one seta posterior to lateral ocular triad; lateral ocular triad well separated from margin of carapace.

STERnum. Tritosternum projected anteriorly with typical setation (Fig. 144B); other sternal platelets small, rounded and convex, with pair of setae anteriorly; pentasternum with two setae anteriorly and without seta in membranous region. 
OpISTHOSOMA. Ventral sacs and ventral sac cover absent.

Genitalia. Posterior margin of female genital operculum with small median projection; gonopod fingerlike, with slender apex, unsclerotized basally. Male gonopod sclerotized along entire margin of fistula and ventrally, near margin of genital operculum; lateral lobe 1 sclerotized apically; lateral lobe 2 not fimbriate.

CHELICERAE. Small, flat tooth projecting from retrolateral surface of basal segment, opposite to bifid tooth; retrolateral surface of claw with two patches of setae, basally and subdorsally; claw with eight teeth; row of eight setae on prolateral surface of basal segment; bifid tooth on basal segment with dorsal cusp larger than ventral cusp.

PedipalPs. Coxae with seta encircled by round carina and four setae on margin. Femur with four dorsal spines and four ventral spines (Fig. 144E-F); two setiferous tubercles between spine 1 and proximal margin. Patella with three dorsal spines and two prominent setiferous tubercles proximal to spine 3; large spine distal to spine I, two-thirds length of spine I; three ventral spines; prominent setiferous tubercle between spine I and distal margin. Tibia with base of two dorsal spines situated very close to each other; three ventral spines distally and seta between spine and distal margin. Tarsus with two dorsal spines, distal spine long, more than half length of tarsus, proximal spine two-thirds length of distal spine (Fig. 144D); cleaning organ with 30-34 setae in ventral row.

Legs. Tibia of leg I with 21 articles; tarsus I with 35 articles; first tarsal article slightly longer than second (mean length of first article: $0.32 \mathrm{~mm}$; mean length of second article: $0.22 \mathrm{~mm}, \mathrm{n}=3$ ). Leg IV basitibia with three pseudo-articles, trichobothrium $b t$ situated in proximal third of pseudo-article; distitibia trichobothrium $b c$ situated closer to $b f$ than to $s b f, s c$ and $s f$ series with five trichobothria; proximal-most trichobothria of $s c$ and $s f$ aligned.

\section{Measurements}

See Table 9.

\section{Distribution}

Known only from the type localities.

\section{Natural history}

The known specimens were collected under stones and tree stumps, and by sifting leaf litter in forest.

\section{Remarks}

The specimen labeled "holotype" in the vial is male not female, as indicated in the original description by Weygoldt (2005), and the paratypes are $3 ㅇ ㅜ, 2 \hat{\jmath} \widehat{d}$, again contrary to the original description.

This species was originally described in the genus Charinus and is hereby transferred to Sarax based on the phylogenetic analyses of Miranda et al. (2021).

The male gonopod of S. pakistanus comb. nov. is completely different from all other species in the family. Detailed SEM images are needed for comparison with the genitalia of other charinids.

Sarax seychellarum (Kraepelin, 1898) comb. nov.

Figs 135, 145-147; Table 9

Charinus seychellarum Kraepelin, 1898: 3. 
Charinus seychellarum - Kraepelin 1899: 250. - Börner 1904: 5, fig. 10, 41d, 86, 93-94. - Arldt 1908: 441. — Gravely 1911: 36, fig. 2a; 1915b: 442. — Hirst 1913: 34. — Mello-Leitão 1931: 54. — Werner 1935: 471, figs 28, 68c. — Fage \& Simon 1936: 300. — Fage 1954: 182. — Weidner 1959: 142. — Lawrence 1969: 86. — Weygoldt 1972b: 123, fig. 22d, 1999b: 49-52, 59-61, figs 1-5; 1999c: 107, figs 11-12; 2000a: 24, 99, figs 45-46, 213-217. — Benoit 1979: 458-459. — Moritz \& Fischer 1980: 139. — Delle Cave 1986: fig. II. — Harvey 2001: 691; 2003: 7.

Non Charinus seychellarum - Fage 1939: 154-155, fig. 1a-d (misidentification, see Charinus africanus and Charinus fagei).

\section{Diagnosis}

This species may be separated from all other Amblypygi by the following combination of characters: slender female gonopod, considered absent in the literature (Fig. 146A, C-D); secondary sexual dimorphism, with male pedipalp segments longer than females; pedipalp patella with long ventral spine between spine 1 and distal margin (Fig. 145F).

\section{Etymology}

Although unspecified, the species name is evidently an adjective referring to the Seychelles, where the species occurs.

\section{Type material}

\section{Syntypes}

SEYCHELLES • 1 क , 2 juv.; ZMB 15745-A-E; ZMH.

\section{Additional material}

SEYCHELLES - 1 ô, "lectotypus"; Insel Silhoueten [Silhouette Island]; Brauer leg.; 5 Aug. 1896; [see Remarks]; ZMH • 3 우, 1 juv.; Long Island, Percy Staden Trust Expedition; Jul. 1904;

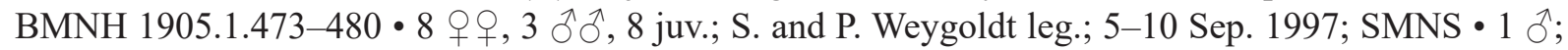
S. and P. Weygoldt leg.; 15 Sep. 1997; AMCC [LP 1494] • 1 đ̊; Praslin, Vallée de Mai; 18 Jul. 2008; L. Monod leg.; coco de mer forest, under stones; AMCC [LP 9074] • 2 q+ ; Mahé, Morne Seychellois National Park, Mare aux Cachons walking trail; 04³7'42.8" S, 55²4'51.4" E; 340 m a.s.1.; 15 Jul. 2008; L. Monod leg.; rainforest with lot of granitic boulders, in rock crevices; AMCC [LP 9075].

\section{Redescription}

CARAPACE. Frontal process large, triangular, not visible in dorsal view (Fig. 146C). Median eyes and median ocular tubercle well developed (Fig. 146A); median eyes situated anteriorly; without seta posterior to median eyes. Lateral eyes well developed, with seta situated on tubercle of lateral ocular triad, between posterior eyes (indistinct in syntype male labeled as lectotype); lateral eyes well separated from carapace margin; lenses directed anteriorly and dorsally.

STERnUm. Tritosternum projected anteriorly with typical setation (Fig. 146B). Metasternum with subtle white suture medially, with pair of setae near posterior margin.

Opisthosoma. Ventral sacs absent.

Genitalia. Female genital operculum with posterior margin straight (Fig. 146A-C). Female gonopod with slender soft cuticle with folded apex directed anteriorly (Fig. 146A, C-D); gonopod sclerotized basally (for details, see Weygoldt 1999b). Male gonopod and spermatophore described by Weygoldt (1999b); margin of third sternite bent ventrally posteromedially. 
ChELICERAE. Retrolateral surface of basal segment with projection opposite to bifid tooth; claw with eight teeth; retrolateral row of setae from base to near apex of claw.

PeDIPALPS. Coxae dorsally with round carina; five setae close to each other on margin of dorsal carina; without seta inside round protuberance. Femur with 3-5 dorsal spines in primary series (Fig. 145E); three prominent setiferous tubercles proximal to spine 1; secondary series with four spines, first spine situated between 2 and 3, other three spines distal to 3; four ventral spines in primary series (Fig. 145F); secondary series with three small spines distal to spine 4 of primary series. Patella with four dorsal spines in primary series (Fig. 145E); two small, subequal spines, forming secondary series, proximally; invagination below dorsal spine 3 of primary series extending to curve at distal margin of tibia; secondary series with five spines, first spine between spines 2 and 3, last four spines distal to spine 3; three ventral spines; large spine between spine I and distal margin. Tibia with two dorsal spines, proximal spine two-thirds length of distal spine; ventral spine in distal half, two-thirds length of proximal dorsal spine. Tarsus with two small, slightly curved dorsal spines (Fig. 145D); 26-27 setae in ventral row of cleaning brush.

Legs. Tibia of leg I with 21 articles; tarsus I with 37 articles; tarsal organ close to tarsal claw base (Fig. 147A-B); rod sensilla with five setae in shallow groove (Fig. 147A, C-D). Leg IV basitibia with four pseudo-articles, trichobothrium near proximal margin of distalmost pseudo-article; distitibia trichobothrium $b c$ situated equidistant between $b f$ and $s b f ; s f$ and $s c$ series each with five trichobothria.

\section{Measurements}

See Table 9.

\section{Distribution}

Endemic to the Seychelles.

\section{Natural history}

Collected under stones and in rock crevices in granitic boulders, in rainforest.

\section{Remarks}

The ZMH collection contains a vial with four protonymphs and four larger specimens, none of which appear to be adult, as they are much smaller (Table 9). Kraepelin (1898) did not designate any types, hence all specimens mentioned in the original description are syntypes. One specimen is labelled "lectotype" but this was not published, hence this vial is considered a syntype.

Almost all species of Charinus, Sarax and Weygoldtia exhibit some sort of projection (cushion-like, sucker-like, finger-like or plunger-like) of the female gonopod. Sarax seychellarum comb. nov. is unique in exhibiting a flat layer of cuticle without any projection. Weygoldt (1999b: 52) considered S. seychellarum comb. nov. to "not carry anything resembling gonopods" because he was unsure how to homologize the thin layer of cuticle to the gonopod projections of other charinids.

This species was originally described in the genus Charinus and is hereby transferred to Sarax based on the phylogenetic analyses of Miranda et al. (2021). As suggested by Weygoldt (1999b) and confirmed by Miranda et al. (2021), the presence of ventral sacs and ventral sac covers are not synapomorphic for Sarax and their absence in some species may be a secondary loss, as in the species of Charinus transferred to Sarax. 
Sarax socotranus (Weygoldt, Pohl \& Polak, 2002) comb. nov.

Figs 135, 148; Table 9

Charinus socotranus Weygoldt et al., 2002a: 295-298, figs 8-16.

\section{Diagnosis}

Based on Weygoldt et al. (2002a), this species may be separated from other species of Sarax in Africa, the Middle East and South Asia by the following combination of characters: large size; uniquely high number of cheliceral teeth (12); leg IV basitibia IV with only two articles.

Sarax socotranus comb. nov. is most similar to $S$. bengalensis comb. nov. from which it differs in larger size, the number of articles on the tibia of leg IV, and the second tarsomere with a marked annulus.

\section{Etymology}

Adjective, referring to the island of Socotra, where the type locality is situated (Weygoldt et al. 2002a).

\section{Type material}

\section{Holotype}

YEMEN • `’; Socotra Island, Hoq; 12³6' N, 54²1’ E; 400 m a.s.1.; 6 Feb. 1999; H. Pohl leg.; limestone cave; HLMD EA-45-HT [not examined].

\section{Paratypes}

YEMEN • 2 우, 4 ठぇં; same collection data as for holotype; HLMD EA-46-PT1-PT6 [not examined] • 1 †, $4 \hat{\jmath} \partial^{\lambda}$; same collection data as for holotype; NHCY [not examined] • 1 \%; Socotra Island, Momi; $12^{\circ} 33^{\prime} \mathrm{N}, 54^{\circ} 18^{\prime} \mathrm{E} ; 12$ Feb. 2000; W. Wranik leg.; cave; NHCY [not examined].

Additional material (examined)

YEMEN • 1 đ̊; Socotra Island, Ghiniba Cave; 9 Jan. 2004; K. van Damme leg.; MHNG GSM 5.

\section{Supplementary description}

CARAPACE. Six anterior setae (Fig. 148A); frontal process triangular (Fig. 148C). Small granules densely scattered between ocular triads and among sulci. Median eyes and median ocular tubercle present; median ocular lenses directed anteriorly, not dorsally; lateral eyes well developed, with seta posterior to each lateral ocular triad; lateral ocular triad well separated from margin of carapace.

STERnUm. Tritosternum projected anteriorly, long, surpassing base of pedipalp coxae (Fig. 148); other sternal plaques small, rounded, forming unique platelets, with pair of setae on lateral margins; pentasternum with two setae anteriorly and without seta near membranous region.

Opisthosoma. Ventral sacs and ventral sac cover absent.

GenitaLia. Female genital operculum with slender setae posteromedially and some smaller setae near margin; genital operculum with small projection medially; gonopod finger-like, long, slender projection with wrinked base (Weygoldt et al. 2002a). Male gonopod compact, with apex of fistula and base of lateral lobe 2 markedly sclerotized.

Chelicerae. Small, flat tooth on retrolateral surface of basal segment, opposite to bifid tooth; without row of setae on retrolateral surface of claw; claw with twelve teeth; row of around six setae on prolateral surface of basal segment; bifid tooth on basal segment with dorsal cusp larger than ventral cusp. 
Pedipalps. Coxal dorsal carina with seta encircled by round carina and five setae on anterior margin. Femur with four dorsal spines and five ventral spines (Fig. 148D-E); three prominent dorsal setiferous tubercles between spine 1 and proximal margin; ventral setiferous tubercle between spine 1 and proximal margin. Patella with three dorsal spines (Fig. 148E); prominent spine and small spine distal to spine I, longest setiferous tubercle one-third length of spine I; two ventral spines and long setiferous tubercle proximal to spine III; two setiferous tubercles between spine I and distal margin. Tibia with ventral spine distally and two setae between spine and distal margin. Tarsus with two dorsal spines, proximal spine half length of distal spine, distal spine half length of tarsus; cleaning organ with 33 setae in ventral row.

Legs. Tibia of leg I with 21 articles; tarsus I with 35 articles; first tarsal article similar in length to second article. Leg IV basitibia with two pseudo-articles, without sclerotized denticulation projecting from distal margin of articles; trichobothrium $b t$ situated in proximal third of pseudo-article; distitibia trichobothrium $b c$ situated much closer to $b f$ than to $s b f$, and $s b f$ displaced medially on article; $s c$ and $s f$ series each with five trichobothria, and two distal trichobothria displaced from row.

\section{Measurements}

See Table 9.

\section{Distribution}

Known only from the type localities.

\section{Natural history}

Collected from caves in an arid region. Sympatric with S. stygochthobius comb. nov. in Ghiniba Cave.

\section{Remarks}

The median ocular lenses are directed anteriorly, not dorsally. The male specimen studied exhibits theratogeny of the pedipalp, i.e., the tarsus has two geminate ventral spines proximal to the cleaning organ.

This species was originally described in the genus Charinus and is hereby transferred to Sarax based on the phylogenetic analyses of Miranda et al. (2021).

Sarax stygochthobius (Weygoldt \& Van Damme, 2004) comb. nov.

Figs 135, 149; Table 9

Charinus stygochthobius Weygoldt \& Van Damme, 2004: 328-331, figs 1-8.

\section{Diagnosis}

Based on Weygoldt \& Van Damme (2004), this small species resembles $S$. socotranus comb. nov. in the similar genitalia, the leg basitibia with only two articles, and the similar arrangement of trichobothria on leg IV. It differs from $S$. socotranus comb. nov. in the extreme level of troglomorphism, including complete loss of eyes (Fig. 149A, C), elongate legs and structures such as the trochanter apophysis (Fig. 149A, E). The sternum setation is typical (Fig. 149B). The pedipalps of preserved specimens are turned upwards, with the femora held almost vertically.

\section{Etymology}

The species name is combination of the Greek words 'stygo', referring to the Styx, the main river of the underworld, according to the Greek mythology, 'ochthy', meaning 'riverbank', and 'bios', meaning 'life', all together meaning 'living on the banks of the river Styx' (Weygoldt \& Van Damme 2004). 


\section{Type material}

\section{Holotype}

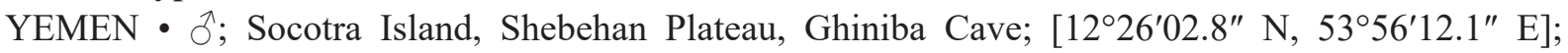
400 m a.s.1.; K. van Damme leg.; HLMD EA-172-HT [not examined].

\section{Paratypes}

YEMEN • 2 우, 1 § ; same collection data as for holotype; HLMD-EA-172-PT1-PT3 [not examined] • $1 \mathrm{\delta}$; same collection data as for holotype; NHCY [not examined].

\section{Measurements}

See Table 9.

\section{Distribution}

Known only from the type locality.

\section{Natural history}

Inhabits a cave in an arid region.

\section{Remarks}

This species was originally described in the genus Charinus and is hereby transferred to Sarax based on the phylogenetic analyses of Miranda et al. (2021). See Weygoldt \& Van Damme (2004) for description.

\section{Genus Weygoldtia Miranda, Giupponi, Prendini \& Scharff, 2018}

Figs 150-153; Table 10

\section{Type species}

Weygoldtia davidovi (Fage, 1946), by original designation.

\section{Diagnosis}

Weygoldtia may be distinguished from the other two genera of Charinidae by the presence of a straight carina anterior to the lateral eyes (Fig. 151A), as well as the following combination of characters: tritosternum projected anteriorly with pair of prominent setae near anterior pair of setae; pedipalp tarsus with one or two setae at base of ventral row of cleaning organ; leg IV distitibia with seven to nine trichobothria in $s c$ and $s f$ series.

\section{Etymology}

Patronym honoring Dr Peter Weygoldt for his contributions to arachnology in general and Amblypygi in particular.

\section{Remarks}

The number of articles on the tibia and tarsus of leg I in Weygoldtia is similar to that in species of Catageus, but the two genera may be distinguished by the dorsal spines on the pedipalp trochanter of Catageus, which are absent in Weygoldtia; the different numbers of trichobothria in the frontal and caudal rows of the distitibia in Catageus, which are equal in Weygoldtia; the absence of a straight carina anterior to the lateral eyes, a synapomorphy of Weygoldtia; and spines between dorsal spine 1 and the proximal margin of the pedipalp femur. 
Weygoldtia belongs to the family Charinidae (Miranda et al. 2021), not Charontidae, due to the following characters: spines absent on pedipalp trochanter; small dorsal spines and ventral spines absent from pedipalp tibia; pedipalp tibia with two dorsal spines, distal spine longer than proximal, instead of one long spine proximally, with small spine close to its base, followed by smaller spines; pedipalp tibia ventral spine situated distally, near distal margin of tibia, instead of proximally; only one seta, instead of several, at base of cleaning organ on pedipalp tarsus; equal number of trichobothria in $s c$ and $s f$ series of leg IV distitibia.

\section{Key to the identification of the species of Weygoldtia (Fig. 150)}

1. Pedipalp femur with five dorsal spines; pedipalp patella with six dorsal spines; cheliceral claw with 7-9 teeth; leg IV distitibia with six or seven $s c$ trichobothria and seven or eight $s f$ trichobothria......

Weygoldtia davidovi (Fage, 1946)

- Pedipalp femur with four dorsal spines; pedipalp patella with five dorsal spines; cheliceral claw with six teeth; leg IV distitibia with nine $s c$ and $s f$ trichobothria

Weygoldtia consonensis sp. nov. (Figs 151-153)

Weygoldtia davidovi (Fage, 1946)

Fig. 150; Table 10

Sarax davidovi Fage, 1946b: 76-77, figs 2, 3a, 4.

Sarax davidovi - Harvey 2003: 8. - Miranda et al. 2018a: 24-25, 31.

Weygoldtia davidovi - Miranda et al. 2018a: 25-27, figs 2-4.

\section{Diagnosis}

Based on Miranda et al. (2018a), W. davidovi may be separated from $W$. consonensis sp. nov. by the following combination of characters: prominent carina ventral to lateral eyes; ventral sac cover present; straight carina projecting anteriorly from lateral carina; pedipalp femur with two or three large setiferous tubercles anterior to spine 1; pedipalp tibia with spine between spine I and distal margin; tibia of leg I with 25 articles, tarsus I with 45 articles (unique among Charinidae); leg IV distitibia with six or seven trichobothria in $s c$ series and seven or eight trichobothria in $s f$ series.

\section{Etymology}

Patronym honoring Konstantin Davidoff (Fage 1946b).

\section{Type material}

\section{Syntypes}

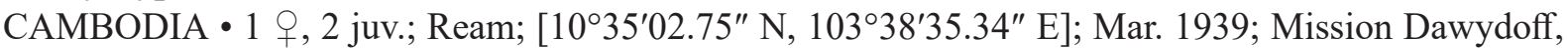
1938-39 leg.; MNHN.

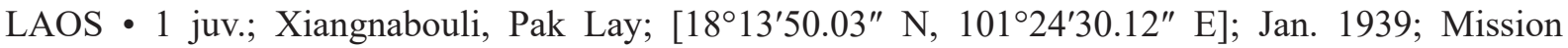
Dawydoff, 1938-39 leg.; MNHN.

VIETNAM [as Annam] • 3 đ̂̃; PhanRang; Mar.-Apr. 1939; Mission Dawydoff, 1938-39 leg.; MNHN •

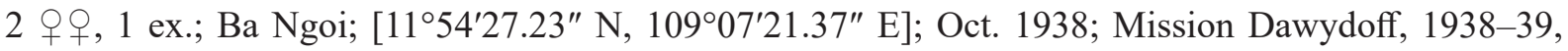

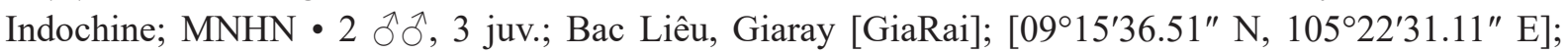
Dec. 1938-Mar.1939; Mission Dawydoff, 1938-39 leg.; MNHN • 1 ð̊; Sóc Traeng; [09³6'09.01" N, 10558'25.95" E]; Nov. 1938; Mission Dawydoff, 1938-39 leg.; MNHN. 


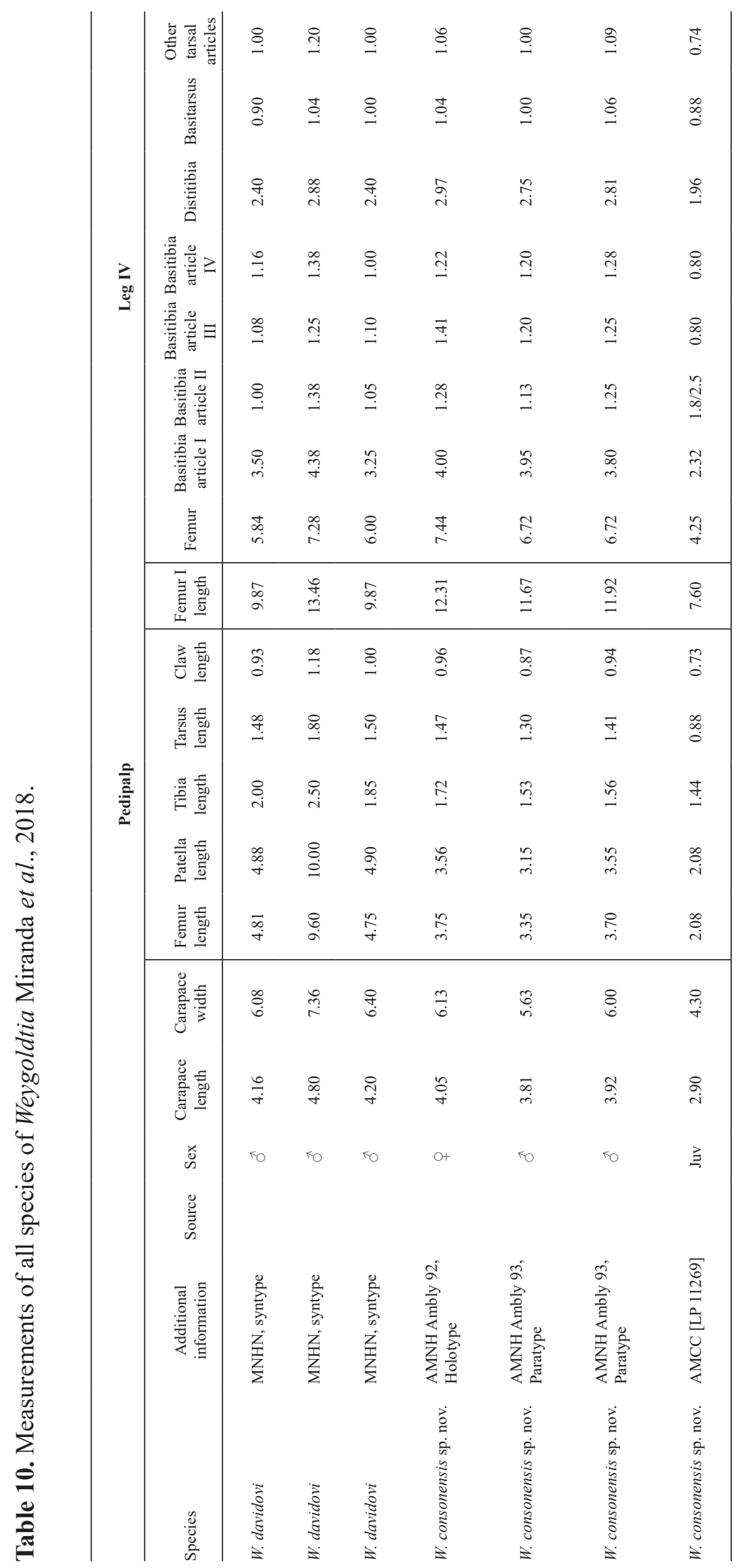




\section{Additional material}

VIETNAM • 1 क; Khan Hoa Province, Ninhoa [Ninh Hòa]; [12³0'38.89" N, 10909'52.35" E]; Mar. 1939; Mission Dawydoff, 1938-39 leg.; MNHN • 3 juv.; Khanh Hoa Province, Nhatrang [Nha Trang]; [12¹4'20.28" N, 109¹1'12.49" E]; Jun. 1939; Mission Dawydoff, 1938-39 leg.; MNHN • 1 q; same

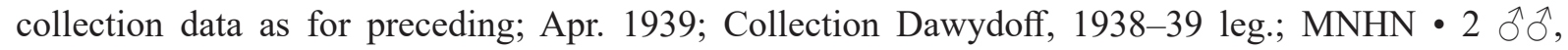
2 우; Vung Ro Bay, at the foot of [Cape] Varella; [1252'48.29" N, 109²6'39.29" E]; Jun. 1939; Mission Dawydoff, 1938-39 leg.; MNHN • 1 o ; Bin Thuan Province, Ham Thuan Nam District, Ta Kou Mountain Nature Reserve, Ta Kou Mountain (Nui Ta Kou), trail above pagoda; $10^{\circ} 49^{\prime} 01.9^{\prime \prime}$ N, $107^{\circ} 53^{\prime} 49.3^{\prime \prime}$ E; $592 \mathrm{~m}$ a.s.1.; 23 Jun. 2012; L. Prendini and S.F. Loria leg.; rocky ravine on opposite side of summit, primary rainforest with dense stands of bamboo in rocky ravine below summit of inselberg surrounded by farmland, moderate to dense canopy with sparse to moderate understorey, brownish-grey sandy/clayey-loam soil with sandstone outcrops and scattered boulders, moderate leaf litter layer, moist soil, specimen taken from under stone; AMCC [LP 11375] • 1 juv.; Bin Thuan Province, Ham Thuan Nam District, Ta Kou Mountain Nature Reserve, Ta Kou Mountain (Nui Ta Kou), trail below guesthouse and upper cable station; $10^{\circ} 48^{\prime} 47.1^{\prime \prime} \mathrm{N}, 107^{\circ} 53^{\prime 2} 24.7^{\prime \prime} \mathrm{E}$; 23 Jun. 2012; $356 \mathrm{~m}$ a.s.1.; L. Prendini and S.F. Loria leg.; primary rainforest with bamboo, moderate canopy cover with sparse to moderate understorey, many sandstone outcrops, dense leaf-litter layer on steep slope alongside path, greyish sandy-loam soil, UV light detection on cool, still, dark, humid night, specimen taken in burrow of Heterometrus silenus (Simon, 1884); AMCC [LP 11376] • 1 کे; Ninh Thuan Province, Ninh Hai District, Nui Chua National

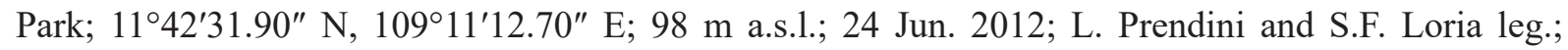
dry deciduous forest on rocky granite/sandstone hills near coast, dry, coarse granitic sandy-loam soil, specimen collected under stone; AMCC [LP 11377].

\section{Description}

See Miranda et al. (2018a).

\section{Measurements}

See Table 10.

\section{Distribution}

Known from Cambodia, Laos and Vietnam.

\section{Natural history}

Found under rocks and fallen tree trunks in tropical rainforest.

\section{Remarks}

The species was recently redescribed by Miranda et al. (2018a).

Weygoldtia consonensis sp. nov. urn:1sid:zoobank.org:act:D91A12A4-FE1A-4BC1-99B5-BB293ECD2FBA

Figs 150-153; Table 10

\section{Diagnosis}

Weygoldtia consonensis sp. nov. may be separated from $W$. davidovi by the following combination of characters: ventral sac cover present, but reduced; retrolateral surface of basal cheliceral segment with tooth; pedipalp coxae round carina with three setae on frontal margin but without seta encircled 
by carina; trochanter ventral apophysis with long, swollen seta near apex; pedipalp femur with four dorsal spines, including spine between spines 2 and 3, four ventral spines, including prominent spine near distal margin; pedipalp patella with five dorsal spines, including spine between spines 4 and 5 , and four ventral spines; pedipalp tarsus with three dorsal spines, cleaning organ with 24 well spaced setae in ventral row, and seta situated proximal to row; tibia of leg I with 25 articles, tarsus I with 45 articles; leg IV basitibia with four pseudo-articles, with denticulate margin, trichobothrium $b t$ situated in distal third; leg IV distitibia trichobothrium $b c$ situated closer to $s b f$ than to $b f ; s c$ and $s f$ series each with nine trichobothria.

Weygoldtia consonensis sp. nov. resembles $W$. davidovi, but differs in the number of spines on the cheliceral claw, the number of spines on the pedipalp femur and patella, and the number of trichobothria on the distitibia of leg IV.

\section{Etymology}

Latin verb derived from the name of Con Son Island, Vietnam, where the type locality is situated.

\section{Type material}

\section{Holotype}

VIETNAM • + ; Ba Ria-Vung Tau Province, Con Dao District, Con Dao Archipelago, Con Son Island, Con Dao National Park, Plot 58, Hunynh Thuc Khang Road; 0841'13.92" N, 106³5'42.66" E; 14 Feb. 2012; L. Prendini, H.T. Luu and H.S. Le leg.; degraded coastal forest in lowlands behind minor urban area, closed canopy forest with moderate understorey, granite outcrops and boulders with smaller stones on greyish-brown clayey-loam soil, moderate to thick leaf-litter layer, specimens under stones; AMNH.

\section{Paratypes}

VIETNAM $\bullet 1$ s subadult; same collection data as for holotype; AMNH $\bullet 1$ juv., same collection data

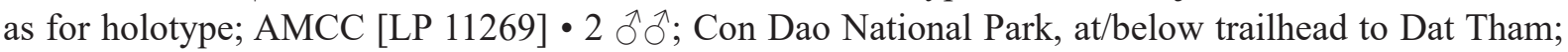
$08^{\circ} 42^{\prime} 10.5^{\prime \prime} \mathrm{N}, 106^{\circ} 35^{\prime} 43.8^{\prime \prime}$ E; 124 m a.s.1.; 13 Feb. 2012; L. Prendini and H.T. Luu leg.; coastal forest along rocky ravine just below summit of main mountain range in NW part of island; canopy thick with diverse plant species, sparse understorey; granite boulders and outcrops with smaller stones on grayish clayey-loam and moderate leaf-litter layer; specimens uncommon under stones; AMNH • 1 के; Con Dao town, $1.5 \mathrm{~km} \mathrm{SW}$ of intersection with road to Doc Ong Tong on road to Bem Dam; 08 $40^{\prime} 49.74^{\prime \prime} \mathrm{N}$, 106 $36^{\prime} 13.32^{\prime \prime}$ E; ca 15 m a.s.1.; 13-14 Feb. 2012; L. Prendini and H.T. Luu leg.; coastal forest on moderate to steep rocky slope and ravine opposite seashore on SE side of island; closed canopy with fairly sparse understorey, granite boulders and smaller stones on clayey-loam soil with moderate to thick leaf-litter layer; specimens collected under stones; AMNH.

\section{Description}

CARAPACE. Corners of anterior carapace margin extending ventrally in wide, roundish boss (Fig. 151A); curved carina between ocular triads and carapace margin, and straight carina anterior to lateral eyes; six short, narrow anterior setae; frontal process rectangular. Small granules densely scattered between ocular triads and among sulci. Median eyes and median ocular tubercle well developed; pair of setae on median ocular tubercle; lateral eyes well developed, seta posterior to lateral ocular triad; lateral ocular triad situated near carapace margin.

STERnUm. Tritosternum projected anteriorly with pair of prominent setae near anterior pair of setae, long, surpassing base of pedipalp coxae (Fig. 151B); other sternal platelets narrow and concave, with pair of setae anteriorly and some smaller setae posteriorly; pentasternum with four setae anteriorly and without seta near membranous region. 
Opisthosoma. Ventral sacs and short ventral sac cover present.

Genitalia. Female genital operculum with small projection and short setae posteromedially; median region flat; gonopod short, broad, tubular, and markedly sclerotized basally. Male genitalia with distal border of fistula and base of lateral lobe markedly sclerotized; lateral lobe 2 fimbriate, with short projections (Fig. 152A-B, D).

ChELICERAE. Short projection on retrolateral surface of basal segment, opposite to bifid tooth; retrolateral surface of claw with row of setae basally to medially; claw with six teeth; more than two rows of 16 setae on prolateral surface of basal segment; bifid tooth on basal segment with dorsal cusp larger than ventral cusp.

PediPALPS. Coxal dorsal carina with three setae on anterior margin and with seta encircled by round carina. Trochanter with long, swollen seta near apex of ventral apophysis. Femur with four dorsal spines and four or five ventral spines; males with small spine between spines 2 and 3, and spines 3 and 4; two dorsal spines and prominent setiferous tubercle between spine 1 and proximal margin; short ventral spine between spines 1 and 2 (Fig. 151E-F); long ventral spine between spine 1 and proximal margin. Patella with five dorsal spines; short spine between spines 3 and 4; prominent spine distal to spine I, half length of spine I; three or four ventral spines; small spine between each spine of primary series; long, straight spine between spine I and distal margin. Tibia with ventral spine distally and seta between spine and distal margin. Tarsus with three short, equal dorsal spines; short seta near base of cleaning organ (Fig. 151C); ventral row of cleaning organ with 24-30 setae in ventral row.

Legs. Tibia of leg I with 25 articles ( 28 on regenerated legs); tarsus I with 45 articles ( 48 on regenerated legs); first tarsal article similar in length to subsequent article; rod sensilla with multiple setae (Fig. 153AB). Leg IV basitibia with four pseudo-articles, with sclerotized, denticulate margin projecting from apex of articles; trichobothrium $b t$ situated in distal third of pseudo-article; distitibia trichobothrium $b c$ situated closer to $s b f$ than to $b f, s c$ and $s f$ series each with nine trichobothria.

\section{Measurements}

See Table 10.

\section{Distribution}

Known only from Con Son Island.

\section{Natural history}

The type specimens were collected under stones in primary and secondary coastal forest.

\section{Discussion}

\section{Troglomorphism in Charinidae}

The cosmopolitan family Charinidae is the most diverse in Amblypygi and currently comprises three genera and 132 species distributed in the tropics and the eastern Mediterranean. The genus Charinus comprises 94 species, Sarax 36 and Weygoldtia two. Although inhabiting mostly epigean environments, charinids are also commonly found inside caves, habitats that provide a stable environment, abundance of prey arthropods and protection from potential predators (for trogloxene or troglophile species). A few taxa, however, are troglophites and can only survive in subterranean environments. 
Many charinids, including some epigean taxa, take advantage of cavernicolous environments with their stable temperature and humidity to thrive. This is the case for C. cavernicolus, C. elegans and C. longipes in New Caledonia; these three species are commonly found in subterranean environments but also observed outside caves. Other charinids inhabit areas in which caves constitute the only suitable habitat for their survival, such as the deserts inhabited by Sarax dhofarensis comb. nov. and S. omanensis comb. nov. Only a few charinids are obligately troglobitic, however, possessing troglomorphies such as depigmentation (e.g., C. susuwa sp. nov.), elongation of leg and pedipalp segments, and pedipalp spines (e.g., C. troglobius), and complete loss of eyes (e.g., C. tronchonii).

\section{Sexual dimorphism}

The behavior of charinids is not well studied in general, but some advances have been made in the understanding of reproduction strategies of some species (Armas 2000b; Seiter et al. 2017; Seiter \& Wolff 2014; Weygoldt 1999b, 2002c, 2005, 2006a, 2007, 2008) with evidence mounting for parthenogenesis in Charinus and Sarax. It is also known that some morphological features might be the result of sexual selection due to competition for mates by males (Weygoldt 2000a).

Secondary sexual dimorphism, in which males exhibit longer pedipalp segments than females, is common in Amblypygi and recorded in 27 charinid species, i.e., 18 species of Charinus and nine of Sarax. According to Teruel \& Questal (2011), the carapace and genital operculum are narrower in the male than in the female of $C$. bruneti, but this remains to be confirmed in a larger sample size and with morphometric analysis. Differences between the sexes are probably ancestral (inherited by all groups, but lost in some) and, following the pattern in Amblypygi, secondary sexual dimorphism is more common in the Neotropics and closer to the equator, areas of the globe in which more amblypygid taxa exhibit longer pedipalps in males than females (McArthur et al. 2018).

\section{Regional diversity and endemism}

Diversity is unequally distributed across the planet, and this holds true for charinids. The eastern part of Brazil, encompassing the Atlantic forest, is the world hotspot for Charinidae, containing 30 species of Charinus, more than recorded in any other country, similar to what is observed in many other taxa, including butterflies, lizards, frogs and plants (Carnaval et al. 2014; Thomé et al. 2020). The highest number of species of Sarax occurs in Indonesia, and much of the larger islands, such as Borneo and Sumatra, still need to be better sampled, which suggests that the true diversity of the genus might be higher than currently known. The genus Weygoldtia is only known from Cambodia, Laos, Thailand and Vietnam. Although found mostly on the continent ( $W$. davidovi has the wider distribution, while $W$. consonensis sp. nov. is known from Con Son Island only), collecting efforts focused on more continental areas and on islands in the South China Sea might reveal a greater diversity.

\section{Acknowledgments}

The authors acknowledge the following friends and colleagues for assistance with fieldwork and/ or donations of material used in the study: A. Ang, S. Basi, E.F. Bezerra Lima, L.A. Esposito, O.F. Francke, E. Gavish-Regev, A. Gluesenkamp, E. González, P. Horsley, S. Huber, J.H. Huff, K.B. Kunt, A. Kury, J. Lazell, S.F. Loria, H.T. Luu, W. Maddison, C. Magalhães, Y.M. Marusik, L. Monod, J. Murienne, J.A. Ochoa, F. Réveillon, C. Savvas, S. Schoenbrun, P. Schwendinger, M. Seiter, L. Sousa de Carvalho, P. Sprouse, P. \& S. Weygoldt, R. Wickramarachchi, G. Wizen, H. Yamaguti; the following curators for loaning specimens studied in this revision and their care and/or assistance during our visits: J. Beccaloni (BMNH), E.F. Bezerra Lima (CHNUFPI), M. Lowe (CUMZ), M.C.L. Peres (ECOA), P. Sierwald (FMNH), C. Whitehill (FSCA), E. Gavish-Regev (HUJ), A. Brescovit (IBSP), C. Magalhães (INPA), L. Baert (RBINS), G. Giribet (MCZ), M. Judson (MNHN), P. Schwendinger (MNHG), A.B. Kury (MNRJ), A.B. Bonaldo (MPEG), R. Pinto-da-Rocha (MZSP), S. Whitman (MZUF), C. Hörweg 
(NHMW), P. Sirvid (NMNZ), E. Curio (NMP), R. Raven (QM), P. Jäger (SMF), H. Höfer (SMNK), J. Holstein (SMNS), H. Wood (USNM), M.S. Harvey (WAM), J. Dunlop (ZMB), and M. Glaubrecht (ZMH); A. Schulze, L. Betz and J. Köhler from the Hessisches Landesmuseum Darmstadt for providing photos of the type material of Charinus socotranus and C. stygochthobius; P.A. Ali and K.B. Kunt for assistance with the identification of localities in Pakistan and Turkey, respectively. We are also greatful to L.F. de Armas, H. Enghoff, R. Gillespie, and M.S. Harvey for revising early versions of the manuscript. GSM acknowledges the Coordenação de Aperfeiçoamento de Pessoal de Nível Superior (CAPESBrazil; www.capes.gov.br) for a Science Without Borders Ph.D. scholarship (process number 8922-136). GSM is currently funded by a GGI Peter Buck Postdoctoral Fellowship (Smithsonian Institution). This research received support from the SYNTHESYS Project http://www.synthesys.info, financed by European Community Research Infrastructure Action under the FP7 "Capacities" Program (DE-TAF-6158 and FR-TAF-5129). GSM and NS acknowledge the Danish National Research Foundation for support to the Center for Macroecology, Evolution and Climate (grant number DNRF96). Field collections and DNA sequencing involving AMNH staff and students were supported by the following awards to LP: US National Science Foundation grants DEB 0413453, DEB 0640219, DEB 1655050, DEB 2003382, DEC 0910091, DEC 0910147, DEC 1310855 and EAR 0228699; a grant from the Richard Lounsbery Foundation; and three Constantine S. Niarchos Expedition grants from the Stavros Niarchos Foundation.

\section{References}

Agapakis G. \& Miranda G.S. 2019. First record of Charinus ioanniticus (Arachnida, Amblypygi, Charinidae) from continental Europe. Arachnologische Mitteilungen/Arachnology Letters 58: 13-15. https://doi.org/10.30963/aramit5805

Arldt T. 1908. Die Ausbreitung einiger Arachnidenordnung (Mygalomorphen, Skorpione, Pedipalpen, Solifugen, Palpigraden). Archiv für Naturgeschichte 74: 389-458.

Armas L.F. 2000a. La artropodofauna cavernicola de las Antillas Mayores. Boletín de la Sociedad Entomológica Aragonesa 27: 134-138.

Armas L.F. 2000b. Parthenogenesis in Amblypygi (Arachnida). Avicennia 12/13: 133-134.

Armas L.F. 2004. Arácnidos de República Dominicana. Palpigradi, Schizomida, Solifugae y Thelyphonida (Chelicerata: Arachnida). Revista Ibérica de Aracnología 2: 1-64.

Armas L.F. 2005. Notas sobre la biología reproductiva del amblipígido partenogenético Charinus acosta (Quintero, 1983) (Amblypygi: Charinidae). Boletín de la Sociedad Entomológica Aragonesa 36: 271-273.

Armas L.F. 2006a. Nueva especie de Charinus Simon, 1892 (Amblypygi: Charinidae) de Cuba central. Revista Ibérica de Aracnología 13: 167-170.

Armas L.F. 2006b. Sinopsis de los amblipígidos antillanos (Arachnida: Amblypygi). Boletín Sociedad Entomológica Aragonesa 38: 223-245.

Armas L.F. 2010. Nuevos arácnidos de Puerto Rico (Arachnida: Amblypygi, Araneae, Opiliones, Parasitiformes, Schizomida, Scorpiones). Boletín de la Sociedad Entomológica Aragonesa 47: 55-64.

Armas L.F. 2013a. Los amblipigios cavernícolas de Cuba (Arachnida: Amblypygi). Revista Ibérica de Aracnología 22: 15-19.

Armas L.F. 2013b. Pedipalpi (Arachnida: Amblypygi, Schizomida, Thelyphonida) de Cuba Occidental. Revista Ibérica de Aracnología 22: 91-94.

Armas L.F. 2014. Los amblipigios de Cuba (Arachnida: Amblypygi). Revista Ibérica de Aracnología 24: 29-51. 
Armas L.F. 2017. Charinus victori Armas, 2010 is a synonym of Charinus aguayoi Moyá-Guzman, 2009 (Amblypygi: Charinidae). Revista Ibérica de Aracnología 31: 113-114.

Armas L.F. \& Abud Antun A.J. 2000. El alacrán en la cultura de República Dominicana. Revista Ibérica de Aracnología 1: 77-79.

Armas L.F. \& Alayón García G. 1984. Sinopsis de los arácnidos cavernícolas de Cuba (excepto ácaros). Poeyana 276: 1-25.

Armas L.F. \& Alayón García G. 2014. Aracnofauna del Archipiélago de los Canarreos. Revista Cubana de Ciencias Biológicas 3:41-52.

Armas L.F. \& Ávila Calvo A. 2000. Dos nuevos amblipígidos de Cuba, con nuevos sinónimos y registros (Arachnida: Amblypygi). Anales de la Escuela Nacional de Ciencias Biologicas, Mexico 46: 289-303.

Armas L.F. \& Maes J.-M. 2000. Los amblipígidos de Nicaragua (Arachnida: Amblypygi). Revista Ibérica de Aracnología 1: 39-44.

Armas L.F. \& Pérez A. 2001. Los amblipígidos de República Dominicana (Arachnida: Amblypygi). Revista Ibérica de Aracnología 3: 47-66.

Armas L.F. \& Teruel R. 1997. A new Charinus (Amblypygi: Charontidae) from St. John, U.S. Virgin Islands. Avicennia 6/7: 43-46.

Armas L.F., García G.A. \& Hernández J.M.R. 2009. Aracnofauna (excepto Acari) del Macizo Guamuhaya, Cuba Central. Primera Aproximación. Boletín Sociedad Entomológica Aragonesa 45: 135-146.

Armas L.F., Chiriví D.J., Botero-Trujillo R., Cortés G.P.C. \& García-Hernández S. 2012. Presencia en Colombia de la familia Charinidae (Arachnida: Amblypygi). Boletín de la Sociedad Entomológica Aragonesa 50: 321-322.

Armas L.F., Palomino-Cárdenas A.C. \& Castillo-Espinoza M.d. 2016. Amblipigios de los Departamentos Cusco y Madre de Dios, Perú, con la descripción de un nuevo Charinus (Amblypygi: Charinidae, Phrynidae). Revista Ibérica de Aracnología 28: 45-50.

Armas L.F., Trujillo R.E. \& Agreda E.O. 2018. Sinopsis de los amblipigios de Guatemala (Arachnida: Amblypygi). Revista Ibérica de Aracnología 32: 55-72.

Ávila Calvo A. \& Armas L.F. 1997. Lista de los amblipigidos (Arachnida: Amblypygi) de México, Centroamérica y las Antillas. Cocuyo 6: 31-32.

Ax P. 2001. Multicellular Animals: The Phylogenetic System of the Metazoa. Springer-Verlag, Berlin.

Baehr M. 1974. Wiederfund der einzigen bekannten australischen Geisselspinne Charinus pescotti Dunn 1949 (Chelicerata, Arachnida, Amblypygi). Entomologische Zeitschrift 84: 101-105.

Baert L. \& Mahnert V. 2015. The distribution of the non-Araneae and non-Acari arachnids of Galápagos. Belgian Journal of Entomology 28: 1-76.

Baert L., Maelfait J.-P. \& Desender K. 1996. Distribution of the arachnid species of the orders Scorpiones, Solifugae, Amblypygi, Schizomida, Opiliones and Pseudoscorpiones in Galápagos. Bulletin de l'Institut royal des Sciences naturelles de Belgique, Entomologie 65: 5-19.

Ballón-Estacio R.J. \& Armas L.F. 2019. Una especie nueva de Charinus (Amblypygi: Charinidae) del Departamento de Huánuco, Perú. Revista Ibérica de Aracnología 35: 15-19.

Banks N. 1902. Papers from the Hopkins Stanford Galapagos Expedition, 1898-1899. VII. Entomological results (6), Arachnida, part 1. Proceedings of the Washington Academy of Sciences 4: 49-70.

Baptista R.L.C. \& Giupponi A.P.L. 2002. A new troglomorphic Charinus from Brazil (Arachnida: Amblypygi: Charinidae). Revista Ibérica de Aracnología 6: 105-110. 
Baptista R.L.C. \& Giupponi A.P.L. 2003. A new troglomorphic Charinus from Minas Gerais State, Brazil (Arachnida: Amblypygi: Charinidae). Revista Ibérica de Aracnología 7: 79-84.

Barnes R.D. 1987. Invertebrate Zoology. Saunders College Publishing, Philadelphia.

Barrows W.M. 1925. Modification and development of the arachnid palpal claw, with special reference to spiders. Annals of the Entomological Society of America XVIII: 483-516. https://doi.org/10.1093/aesa/18.4.483

Benoit P.L.G. 1979. Contributions à l'étude de la faune terrestre des îles granitiques de l'archipel des Séchelles. (Mission P.L.G. Benoit - J.J. van Mol 1972. Amblypygi et Scorpiones). Revue de Zoologie africaine 93: 458-460.

Blick T. \& Seiter M. 2016. Whip spiders (Amblypygi, Arachnida) of the Western Palaearctic - a review. Zootaxa 4161 (4): 586-592. https://doi.org/10.11646/zootaxa.4161.4.11

Börner C. 1904. Beiträge zur Morphologie der Arthropoden. I. Ein Beitrag zur Kenntnis der Pedipalpen. Zoologie 42: 1-174. https://doi.org/10.5962/bhl.title.59544

Bristowe W.S. 1952. The arachnid fauna of the Batu Caves in Malaya. Annals and Magazine of Natural History 12: 697-707. https://doi.org/10.1080/00222935208654340

Butler A.G. 1873. A monographic revision of the genus Phrynus, with descriptions of four remarkable new species. Annals and Magazine of Natural History, Serie 4 12: 117-125.

https://doi.org/10.1080/00222937308680723

Buxton B.H. 1917. Notes on the anatomy of arachnids. Journal of Morphology 29: 1-31. https://doi.org/10.1002/jmor.1050290102

Caporiacco L. di. 1947. Diagnosi preliminari di specie nuove di aracnidi della Guiana Britannica raccolte dai Professori Beccari e Romiti. Monitore Zoologico Italiano 56: 20-34.

Caporiacco L. di. 1948. Arachnida of British Guiana collected in 1931 \& 1936 by Professors Beccari and Romiti. Proceedings of the Zoological Society of London 118: 607-747.

https://doi.org/10.1111/j.1096-3642.1948.tb00402.x

Carnaval A.C., Waltari E., Rodrigues M.T., Rosauer D., VanDerWal J., Damasceno R., Prates I., Strangas M., Spanos Z., Rivera D., Pie M.R., Firkowski C.R., Bornschein M.R., Ribeiro L.F. \& Moritz C. 2014. Prediction of phylogeographic endemism in an environmentally complex biome. Proceedings of the Royal Society B 281 (1792): 20141461. https://doi.org/10.1098/rspb.2014.1461

Chapin K.J. \& Hebets E.A. 2016. The behavioral ecology of amblypygids. Journal of Arachnology 44: 1-14. https://doi.org/10.1636/v15-62.1

Cloudsley-Thompson J.L. 1968. Spiders, Scorpions, Centipedes \& Mites, Revised Edition. Pergamon Press, New York. https://doi.org/10.1016/B978-0-08-012322-6.50015-8

Colla A., Legittimo C.M., Castellucci F., Simeon E. \& Miranda G.S. 2020. First record of Amblypygi from Italy: Charinus ioanniticus (Charinidae). Arachnologische Mitteilungen/Arachnology Letters 18: 642-648. https://doi.org/10.13156/arac.2020.18.6.642

Cope E.D. 1886a. An analytical table of the genera of snakes. Proceedings of the American Philosophical Society 23: 479-499.

Cope E.D. 1886b. Three problematical genera of Mexican boaeform snakes. American Naturalist 20: 293-294.

Delle Cave L. 1986. Biospeleology of the Somaliland Amblypygi (Arachnida, Chelicerata) of the caves of the Showli Berdi and Mugdile (Bardera, Somaliland). Redia 69: 143-170. 
Delle Cave L., Gardner A.S. \& Weygoldt P. 2009. A new troglomorphic whip spider of the genus Charinus from the Sultanate of Oman (Amblypygi: Charinidae). Fauna of Arabia 24: 129-134.

Dittmar K., Porter M.L., Price L., Svenson G. \& Whitling M.F. 2005. A brief survey of invertebrates in caves of Peninsular Malaysia. Malayan Nature Journal 57: 221-233.

Dunlop J.A. 1994. An Upper Carboniferous amblypygid from the Writhlington Geological Nature Reserve. Proceedings of the Geologists' Association 105: 245-250.

https://doi.org/10.1016/S0016-7878(08)80177-0

Dunlop J.A. \& Martill D.M. 2002. The first whipspider (Arachnida: Amblypygi) and three new whipscorpions (Arachnida: Thelyphonida) from the Lower Cretaceous Crato Formation of Brazil. Transactions of the Royal Society of Edinburgh, Earth Sciences 92: 325-334.

https://doi.org/10.1017/S0263593300000262

Dunn R.A. 1949. New Pedipalpi from Australia and the Solomon Islands. Memoirs of the National Museum of Victoria 16: 7-15. https://doi.org/10.24199/j.mmv.1949.16.01

El-Hennawy H.K. 2002. The first record of Amblypygi from Egypt. Journal of Arachnology 30: 452453. https://doi.org/cpm8fj

Engel M.S. \& Grimaldi D.A. 2014. Whipspiders (Arachnida: Amblypygi) in amber from the Early Eocene and mid-Cretaceous, including maternal care. Novitates Paleoentomologicae 9: 1-17. https://doi.org/10.17161/np.v0i9.4765

Fage L. 1929. Fauna of the Batu Caves, Selangor. X. Arachnida: Pedipalpi (part) and Araneae. Journal of the Federated Malay States Museums 14: 356-364.

Fage L. 1939. Les Pédipalpes africains du genre Charinus à propos d'une espèce nouvelle du FoutaDjalon: Charinus milloti, n. sp. Bulletin de la Société entomologique de France 44: 153-160.

Fage L. 1946a. Complément à la faune des arachnides de Madagascar. Bulletin du Muséum national d'histoire naturelle, Paris 2: 256-267.

Fage L. 1946b. Scorpions et pédipalpes de l'Indochine Française. Annales de la Société entomologique de France 113: 71-81.

Fage L. 1954. Remarques sur la distribution géographique des pédipalpes amblypyges africains, accompagnées de la description d'une espèce nouvelle de Madagascar: Charinus madagascariensis, nov. sp. Annales du Musée du Congo belge, Sciences zoologiques 1: 180-184.

Fage L. \& Simon E. 1936. Mission scientifique de 1'Omo, Tome III. - Fascicule 30. Arachnida III. Pedipalpi, Scorpiones, Solifuga et Araneae ( $1^{\text {re }}$ partie). Mémoires du Muséum national d'histoire naturelle, Paris 4: 293-340.

Gainett G., Ballesteros J.A., Kanzler C.R., Zehms J.T., Zern J.M., Aharon S., Gavish-Regev E. \& Sharma P.P. 2020. Systemic paralogy and function of retinal determination network homologs in arachnids. BMC Genomics 21: 811. https://doi.org/10.1186/s12864-020-07149-x

Galán C. \& Herrera F.F. 2006. Fauna cavernícola de Venezuela: Una Revisión. Boletín de la Sociedad Venezolana de Espeleología 40: 39-57.

Garwood R.J., Dunlop J.A., Knecht B.J. \& Hegna T.A. 2017. The phylogeny of fossil whip spiders. BMC Evolutionary Biology 17: 105. https://doi.org/10.1186/s12862-017-0931-1

Gaubert P. 1892. Recherches sur les organes des sens et sur les systemes tegumentaires, glandulaires et musculaires des appendices des Arachnides. Annales des Sciences naturelles, Zoologie et Paléontologie 7: $31-184$. 
Gibbons A.T., Idnurm A., Seiter M., Paul S. Dyer M.K., Goodacre S.L., Gorb S.N. \& Wolff J.O. 2019. Amblypygid-fungal interactions: The whip spider exoskeleton as a substrate for fungal growth. Fungal Biology 123: 497-506. https://doi.org/10.1016/j.funbio.2019.05.003

Giltay L. 1931. Scorpions et Pédipalpes. In: Résultats scientifiques du voyage aux Indes orientales néerlandaises de LL. AA. RR. le Prince et la Princesse Léopold de Belgique. Mémoires du Musée royal d'Histoire naturelle de Belgique 3: 1-28.

Giupponi A.P.L. \& Baptista R.L.C. 2003. A case of homonymy in Charinus Simon, 1892 (Amblypygi: Charinidae). Revista Ibérica de Aracnología 7: 173-174.

Giupponi A.P.L. \& Kury A.B. 2002. A new species of Charinus Simon, 1892 from northeastern Brazil (Arachnida, Amblypygi, Charinidae). Boletim do Museu Nacional 477: 1-7.

Giupponi A.P.L. \& Kury A.B. 2013. Two new species of Heterophrynus Pocock, 1894 from Colombia with distribution notes and a new synonymy (Arachnida: Amblypygi: Phrynidae). Zootaxa 3647: 329342. https://doi.org/10.11646/zootaxa.3647.2.5

Giupponi A.P.L. \& Miranda G.S. 2012. A new species of Sarax Simon, 1892 from the Philippines (Arachnida: Amblypygi: Charinidae). Anais da Academia Brasileira de Ciências 84: 165-173. https://doi.org/10.1590/S0001-37652012000100017

Giupponi A.P.L. \& Miranda G.S. 2016. Eight new species of Charinus Simon, 1892 (Arachnida: Amblypygi: Charinidae) endemic for the Brazilian Amazon, with notes on their conservational status. PLoS One 11: e0148277. https://doi.org/10.1371/journal.pone.0148277

Gonçalves-Souza T., Giupponi A.P.L. \& Hernandes F.A. 2014. A rare finding of mites (Arachnida: Acari: Leeuwenhoekiidae) parasitising a whip spider (Arachnida: Amblypygi: Charinidae). Folia Parasitologica 61:182-184.

González-Sponga M.A. 1998. Arachnida of Venezuela. Two new species of the genus Charinides Gravely, 1911 (Amblypygi: Charontidae). Acta Biologica Venezuelica 18: 1-8.

Goodnight C.J. \& Goodnight M.L. 1946. A new species of pedipalp from South America. Transactions of the American Microscopical Society 65: 323-327. https://doi.org/10.2307/3223544

Gravely F.H. 1911. Notes on Pedipalpi in the collection of the Indian Museum. I. New Pedipalpi from Calcutta. II. A preliminary note on a new Sarax from Singapore. Records of the Indian Museum 6: 33-38. Available from https://www.biodiversitylibrary.org/page/11135481 [accessed 2 Jul. 2021].

Gravely F.H. 1912. Exhibition of living Pedipalpi, with remarks on the distribution of the order. Proceedings of the Asiatic Society of Bengal: cxxiii-cxxv.

Gravely F.H. 1915a. Notes on the habits of Indian insects, myriapods \& arachnids. Records of the Indian Museum 11: 483-539.

Gravely F.H. 1915b. A revision of the Oriental subfamilies of Tarantulidae (order Pedipalpi). Records of the Indian Museum 11: 433-455.

Gray M.R. \& Robinson M.L. 1986. Observations on the behaviour and taxonomy of the Australian tailless whipscorpion Charinus pescotti Dunn (Amblypygi: Charontidae). Proceedings of the Linnean Society of New South Wales 108: 217-224.

Hansen H.J. 1893. Organs and characters in different orders of arachnids. Entomologiske Meddelelser 4: $135-251$.

Hansen H.J. 1921. The Pedipalpi, Ricinulei, and Opiliones (exc. Op. Laniatores) collected by Mr. Leonardo Fea in tropical West Africa and adjacent islands. Studies on Arthropoda 1: 1-55. Gyldendalske Boghandel, Copenhagen. 
Hansen H.J. 1930. On the comparative morphology of the appendages in the Arthropoda. B. Crustacea (supplement), Insecta, Myriopoda, and Arachnida. Studies on Arthropoda 3: 1-376. Gyldendalske Boghandel, Copenhagen.

Harms D. 2018. A new species of Charinus (Amblypygi: Charinidae) from Ghana, with notes on West African whip spiders. Evolutionary Systematics 2: 45-53. https://doi.org/10.3897/evolsyst.2.24505

Harvey M.S. 1985. Amblypygi. In: Walton D.W. (ed.) Zoological Catalogue of Australia 3: 156-157.

Harvey M.S. 1992. The phylogeny and classification of the Pseudoscorpionida (Chelicerata: Arachnida). Invertebrate Taxonomy 6 (6): 1373-1435. https://doi.org/10.1071/IT9921373

Harvey M.S. 2001. The Schizomida (Arachnida) of the Seychelle Islands. Invertebrate Taxonomy 15: 681-693. https://doi.org/10.1071/IT01006

Harvey M.S. 2002a. The neglected cousins: What do we know about the smaller arachnid orders? Journal of Arachnology 30: 357-372. https://doi.org/d6443q

Harvey M.S. 2002b. Nomenclatural notes on Solifugae, Amblypygi, Uropygi and Araneae (Arachnida). Records of the Western Australian Museum 20: 449-459.

Harvey M.S. 2002c. The first Old World species of Phrynidae (Amblypygi): Phrynus exsul from Indonesia. Journal of Arachnology 30: 470-474.

Harvey M.S. 2003. Catalogue of the Smaller Arachnid Orders of the World. Amblypygi, Uropygi, Schizomida, Palpigradi, Ricinulei and Solifugae. CSIRO Publishing, Collingwood, Australia. https://doi.org/10.1071/9780643090071

Harvey M.S. 2013. Whip Spiders of the World, version 1.0. Western Australian Museum, Perth. Available from http://museum.wa.gov.au/catalogues-beta/whip-spiders [accessed 2 Jul. 2021].

Harvey M.S. \& West P.L.J. 1998. New species of Charon (Amblypygi, Charontidae) from northern Australia and Christmas Island. Journal of Arachnology 26: 273-284.

Available from https://www.jstor.org/stable/3706233 [accessed 26 Mar. 2021].

Harvey M.S., Rahmadi C. \& Aland K. 2012. The first record of whip spiders (Amblypygi) in Western Australia. Australasian Arachnology 84: 8-9.

Haupt J. 2009. Chelicerae of arachnids: Facts and fiction. Arthropoda Selecta 18: 17-19.

Hernández Pacheco J.J., Izquierdo Zamora I. \& Oromi Masoliver P. 1992. Catálogo espeleológico de las Islas Galápagos. Resultados Cientificos del Proyecto Galápagos: Patrimonio de la Humanidad TMFC 2: $71-180$.

Hirst S. 1913. Second report on the Arachnida - The scorpions, Pedipalpi, and supplementary notes on the Opiliones and pseudoscorpions. Transactions of the Linnean Society of London, Zoology 2: 31-37. https://doi.org/10.1111/j.1096-3642.1914.tb00122.x

Igelmund P. 1987. Morphology, sense organs, and regeneration of the forelegs (whips) of the whip spider Heterophrynus elaphus (Arachnida, Amblypygi). Journal of Morphology 193: 75-89.

https://doi.org/10.1002/jmor.1051930108

Janetschek H. 1957. Das seltsamste Tier Tirols. Palpenläufer (Arachn., Palpigradida): Stellung, Verbreitung, Arten, Bibliographie. Schlern-Schriften 158: 190-214.

Jiménez M.-L. \& Llinas-Gutiérrez J. 2005. Description of male Phrynus asperatipes (Amblypygi, Phrynidae) from Baja California Sur, Mexico. Journal of Arachnology 33: 862-865.

https://doi.org/10.1636/h03-42.1 
Jocqué M. \& Giupponi A.P.L. 2012. Charinus bromeliaea sp. n. (Amblypygi: Charinidae); a new species of bromeliad inhabiting whip spider from French Guyana. Zootaxa 3158 (2): 53-59.

https://doi.org/10.11646/zootaxa.3158.1.4

Kästner A. 1932. Ordnung der Arachnida: Pedipalpi Latreille=Geissel-Scorpione. In: Kükenthal W. (ed.) Handbuch der Zoologie: 1-75. Walter de Gruyter und Co., Berlin.

Kästner A. 1956. Wirbellose. Lehrbuch der Speziellen Zoologie. Gustav Fischer, Jena.

Kaestner A. 1968. Arthropod Relatives, Chelicerata, Myriapoda. Invertebrate Zoology Vol. II. John Wiley and Sons, New York.

Kaestner A. 1969. Wirbellose. Lehrbuch der Speziellen Zoologie. Gustav Fischer, Stuttgart.

Klingel H. 1963. Paarungsverhalten bei Pedipalpen (Telyphonus [sic] caudatus L., Holopeltidia, Uropygi und Sarax sarawakiensis Simon, Charontiinae, Amblypygi. Verhandlungen der Deutschen Zoologischen Gesellschaft 26: 452-459.

Kovařík F. \& Vlasta D. 1996. First report of Amblypygi (Charinidae: Charinus ioanniticus) from Turkey. Klapalekiana 32: 57-58.

Kraepelin K. 1895. Revision der Tarantuliden Fabr. Verhandlungen des Naturwissenschaftlichen Vereins in Hamburg 13: 3-53.

Kraepelin K. 1898. Neue Pedipalpen und Scorpione des Hamburger Museums. Mitteilungen aus dem Naturhistorischen Museum in Hamburg 15: 1-6.

Kraepelin K. 1899. Scorpiones und Pedipalpi. In: Dahl F. (ed.) Das Tierreich 8: i-xviii, 1-265.

Kraepelin K. 1901. Catalogue des Pédipalpes des collections du Muséum d'Histoire Naturelle de Paris. Bulletin du Muséum national d'histoire naturelle 7: 263-264.

Kraepelin K. 1914. Die Skorpione und Pedipalpen von Neu-Caledonien und den benachbarten Inselgruppen. In: Sarasin F. \& Roux J. (eds) Nova Caledonia, Zoologie 1: 327-337. C.W. Kreidals Verlag, Wiesbaden.

Kraus O. 1961. Charontidae aus Israel, ein zoogeographisch bemerkenswertes Vorkommen (Arach., Pedipalpi - Amblypygi). Senckenbergiana Biologica 42: 491-493.

Kraus O. 1970. Genitalmorphologie und Systematik der Amblypygi (Arachnida). Bulletin du Muséum national d'histoire naturelle 2: 176-180.

Kritscher E. 1959. Ergebnisse der von Dr. O. Paget und Dr. E. Kritscher auf Rhodos durchgeführten zoologischen Exkursionen. II. Pedipalpi (Amblypygi). Annalen des Naturhistorischen Museums in Wien 63: 453-457.

Kritscher E. 1966. Die Pedipalpen- und Araneenausbeute der Österreichischen NeukaledonienExpedition 1965. Annalen des Naturhistorischen Museums in Wien 69: 373-391.

Koch L. 1867. Beschreibungen neuer Arachniden und Myriapoden. Verhandlungen der KaiserlichKöniglichen Zoologischen-Botanischen Gesellschaft in Wien 17: 173-250.

Available from https://www.biodiversitylibrary.org/page/26724654 [accessed 30 May 2021].

Koch L. \& Keyserling E. 1885. Die Arachniden Australiens nach der Natur beschrieben und abgebildet. Bauer und Raspe, Nürnberg. Available from https://www.biodiversitylibrary.org/page/51908653 [accessed 30 May 2021].

Lawrence R.F. 1968. The structure of the cleaning brush on the pedipalps of some African Amblypygi (Arachnida). Journal of Zoology, London 153: 1-8. 
Lawrence R.F. 1969. A collection of African Amblypygi with keys to the subfamilies, genera and species of the Ethiopian fauna. Revue de Zoologie et de Botanique africaine 80: 80-87.

Legendre R. 1972. Les arachnides de Madagascar. In: Battistini R. \& Richard-Vindard G. (eds) Biogeography and Ecology in Madagascar: 427-457. W. Junk, The Hague.

McArthur I.W., Miranda G.S., Seiter M. \& Chapin K.J. 2018. Global patterns of sexual dimorphism in Amblypygi. Zoologischer Anzeiger 273: 56-64. https://doi.org/10.1016/j.jcz.2018.02.005

McClure H.E., Lim B.-L. \& Winn S.E. 1967. Fauna of the Dark Cave, Batu Caves, Kuala Lumpur, Malaysia. Pacific Insects 9: 399-428.

Mello-Leitão C. 1931. Pedipalpos do Brasil e algumas notas sobre a ordem. Archivos do Museu Nacional 33: 7-72.

Messana G., Chelazzi L. \& Baccetti N. 1985. Biospeleology of Somalia. Mugdile and Showli Berdi Caves. Monitore Zoologico Italiano, n.s., Supplemento 20: 325-340.

https://doi.org/10.1080/03749444.1985.10736702

Millot J. 1949a. Classe de Arachnides (Arachnida). I. - Morphologie générale et anatomie interne. In: Grassé P.-P. (ed.) Traité de zoologie, Vol. 6: 263-319. Masson et Cie, Paris.

Millot J. 1949b. Ordre des Amblypyges. In: Grassé P.-P. (ed.) Traité de zoologie, Volume 6: 563-558. Masson et Cie, Paris.

Miranda G.S. \& Giupponi A.P.L. 2011. A new synanthropic species of Charinus Simon, 1892 from Brazilian Amazonia and notes on the genus (Arachnida: Amblypygi: Charinidae). Zootaxa 2980: 61-68. https://doi.org/10.11646/zootaxa.2980.1.5

Miranda G.S. \& Reboleira A.S.P.S. 2019. Amblypygids of Timor-Leste: First records of the order from the country with the description of a remarkable new species of Sarax (Arachnida, Amblypygi, Charinidae). ZooKeys 820: 1-12. https://doi.org/10.3897/zookeys.820.30139

Miranda G.S., Aharon S., Gavish-Regev E., Giupponi A.P.L. \& Wizen G. 2016a. A new species of Charinus Simon, 1892 (Arachnida: Amblypygi: Charinidae) from Israel and new records of C. ioanniticus (Kritscher, 1959). European Journal of Taxonomy 234: 1-17. https://doi.org/10.5852/ejt.2016.234

Miranda G.S., Giupponi A.P.L. \& Wizen G. 2016b. Two new species of whip spider (Amblypygi): an epigean and a cave dwelling Charinus Simon, 1892 from Belize. Zootaxa 4098 (3): 545-559.

https://doi.org/10.11646/zootaxa.4098.3.7

Miranda G.S., Milleri-Pinto M., Gonçalves-Souza T., Giupponi A.P.L. \& Scharff N. 2016c. A new species of Charinus Simon, 1892 (Amblypygi, Charinidae) from Brazil, with notes on behavior. ZooKeys 621: 15-36. https://doi.org/10.3897/zookeys.621.9980

Miranda G.S., Giupponi A.P., Prendini L. \& Scharff N. 2018a. Weygoldtia, a new genus of Charinidae Quintero, 1986 (Arachnida, Amblypygi) with a reappraisal of the genera in the family. Zoologischer Anzeiger 273: 23-32. https://doi.org/10.1016/j.jcz.2018.02.003

Miranda G.S., Kury A.B. \& Giupponi A.P.L. 2018b. Review of Trichodamon Mello-Leitão 1935 and phylogenetic placement of the genus in Phrynichidae (Arachnida, Amblypygi). Zoologischer Anzeiger 273: 33-55. https://doi.org/10.1016/j.jcz.2018.02.006

Miranda G.S., Giupponi A.P., Scharff N. \& Prendini L. 2021. Phylogeny and biogeography of the pantropical whip spider family Charinidae (Arachnida: Amblypygi). Zoological Journal of the Linnean Society. https://doi.org/10.1093/zoolinnean/zlaa101 
Monte B.G.O. do, Gallão J.E., Schimonsky D.M. von \& Bichuette M.E. 2015. New records of two endemic troglobitic and threatened arachnids (Amblypygi and Opiliones) from limestone caves of Minas Gerais state, southeast Brazil. Biodiversity Data Journal 3: e5260. https://doi.org/10.3897/BDJ.3.e5260

Monteith G.M. 1965. Notes on the order Amblypygi (Arachnida) in Australia. Journal of the Entomological Society of Queensland 4: 87. https://doi.org/10.1111/j.1440-6055.1965.tb00663.x

Moritz M. \& Fischer S.-C. 1980. Die Typen der Arachniden-Sammlung des Zoologischen Museums Berlin. Mitteilungen aus dem Zoologischen Museum in Berlin 56: 137-154.

Morrone J.J. 2006. Biogeographic areas and transition zones of Latin America and the Caribbean Islands based on panbiogeographic and cladistic analysis of the entomofauna. Annual Review of Entomology 51: 467-494. https://doi.org/10.1146/annurev.ento.50.071803.130447

Moseley M., Lim T.W. \& Lim T.T. 2012. Fauna reported from Batu caves, Selangor, Malaysia: Annotated checklist and bibliography. Cave and Karst Science 39: 77-92.

Moyá-Guzmán S. 2009. Taxonomía de los guabás (Arachnida: Amblypygi) en Puerto Rico y la descripción de una nueva especie de Charinus Gravely. Ceiba 8: 68-78.

Muchmore W.B. 1993. List of terrestrial invertebrates of St. John, U.S. Virgin Islands (exclusive of Acarina and Insecta), with some records of freshwater species. Caribbean Journal of Science 29: 30-38.

Nair K.B. 1934. On a new sub-species of Phrynichosarax cochinensis Gravely (Pedipalpi: Tarantulidae). Records of the Indian Museum 36: 475-476.

Peck S.B. \& Kukalova-Peck J. 1986. Preliminary summary of the subterranean fauna of the Galapagos Islands, Ecuador. Part I. Introduction and non-insect invertebrates. Proceedings of the $9^{\text {th }}$ International Congress of Speleology, Barcelona 2: 164-166.

Peck S.B. \& Peck J. 1986. The Galapagos Islands. Volcanic caves and cave fauna of the Galapagos Islands. Canadian Cavernicolous 18: 42-49.

Pérez Y. \& Teruel R. 2004. La fauna de arácnidos de dos localidades de Cuba oriental (Arachnida: Scorpiones, Amblypygi, Schizomida, Ricinulei). Revista Ibérica de Aracnología 10: 167-178.

Pike N. 1872. A visit to the Seychelles Islands. Transactions of the Royal Society of Arts and Sciences of Mauritius series B 6: 83-142.

Pinto-da-Rocha R., Machado G. \& Weygoldt P. 2002. Two new species of Charinus Simon, 1892 from Brazil with biological notes (Arachnida; Amblypygi; Charinidae). Journal of Natural History 36: 107118. https://doi.org/10.1080/00222930110110152

Pocock R.I. 1893. On some points in the morphology of the Arachnida (s.s.), with notes on the classification of the group. Annals and Magazine of Natural History, Ser. 611: 1-19. https://doi.org/10.1080/00222939308677457

Pocock R.I. 1898. Scorpions, Pedipalpi, and spiders from the Solomon Islands. Annals and Magazine of Natural History, Ser. 7 1: 457-475. https://doi.org/10.1080/00222939808678002

Pocock R.I. 1900. The Fauna of British India, Including Ceylon and Burma. Arachnida. Taylor \& Francis, London.

Proctor H.C. 1998. Indirect sperm transfer in arthropods: Behavioral and evolutionary trends. Annual Review of Entomology 43: 153-174. https://doi.org/10.1146/annurev.ento.43.1.153

Pyron R.A., Reynolds R.G. \& Burbrink F.T. 2014. A taxonomic revision of boas (Serpentes: Boidae). Zootaxa 3846: 249-260. https://doi.org/10.11646/zootaxa.3846.2.5 
Quintero D., Jr. 1975. Scanning electron microscope observations on the tarsi of the legs of the amblypygids (Arachnida, Amblypygi). In: Proceedings of the $6^{\text {th }}$ International Arachnological Congress: 161-163. Free University of Amsterdam, The Netherlands.

Quintero D.J. 1981. The amblypygid genus Phrynus in the Americas (Amblypygi, Phrynidae). Journal of Arachnology 9: 117-166.

Quintero D.J. 1983. Revision of the amblypygid spiders of Cuba and their relationships with the Caribbean and continental American amblypygid fauna. Studies on the Fauna of Curaçao \& other Caribbean Islands 65: 1-54.

Quintero D., Jr. 1986. Revision de la clasification de Amblypygidos pulvinados: Creacion de subordenes, una neuva familia y un nuevo genero con tres nuevas especies (Arachnida: Amblypygi). In: Eberhard, W.G, Lubin, Y.D. \& Robinson B.C. (eds) Proceedings of the $9^{\text {th }}$ International Congress of Arachnology, Panama 1983: 203-212. Smithsonian Institution Press, Washington D.C.

Quintero D.J. \& Shear W.A. 2016. Charinidae Gray 1849 (Reptilia, Squamata, Serpentes): Proposed suppression. Bulletin of Zoological Nomenclature 73: 25-29. https://doi.org/10.21805/bzn.v73i1.a21

Rahmadi C. \& Harvey M.S. 2008. A first epigean species of Stygophrynus Kraepelin (Amblypygi: Charontidae) from Java and adjacent island, Indonesia with notes on S. dammermani Roewer, 1928. Raffles Bulletin of Zoology 56: 281-288.

Rahmadi C. \& Kojima J.-i. 2010. Whip spiders of the genus Sarax in the Papuan region, with description of two new species (Amblypygi: Charinidae). Journal of Arachnology 38: 475-484. https://doi.org/10.1636/Ha09-95.1

Rahmadi C., Harvey M.S. \& Kojima J.-i. 2010. Whip spiders of the genus Sarax Simon 1892 (Amblypygi: Charinidae) from Borneo Island. Zootaxa 2612: 1-21. https://doi.org/10.11646/zootaxa.2612.1.1

Rahmadi C., Harvey M.S. \& Kojima J.-i. 2011. The status of the whip spider subgenus Neocharon (Amblypygi: Charontidae) and the distribution of the genera Charon and Stygophrynus. Journal of Arachnology 39: 223-229. https://doi.org/10.1636/ca10-77.1

Ravelo P.O. 1975. Speleophrynus tronchonii, nuevo género y especie de amblipigios de la familia Charontidae, en una cueva de Venezuela. Boletín de la Sociedad Venezolana de Espeleología 6: 77-85.

Ravelo P.O. 1977. Speleophrynus bordoni nuevo especie de amblipigios de la familia Charontidae, en una cueva de Venezuela (Arachnida: Amblypygy). Boletín de la Sociedad Venezolana de Espeleología 8: $17-25$.

Ray J.M. \& Ruback P. 2015. Updated checklists of snakes for the provinces of Panamá and Panamá Oeste, Republic of Panama. Mesoamerican Herpetology 2: 168-188.

Remillet M. 1973. Aperçu de la faune souterraine à Madagascar. In: Livre du cinquantenaire de L'Institut de Spéologie "Émile Racovitza": 135-160. Editura Academiei Republicii Socialiste România, Bucharest.

Réveillion F. \& Maquart P.O. 2015. A new species of Charinus Simon, 1892 (Amblypygi, Charinidae) from termite nests in French Guiana. Zootaxa 4032: 190-196. https://doi.org/10.11646/zootaxa.4032.2.3

Rodríguez-Cabrera T.M. \& Teruel R. 2016. Distribution, conservation status and taxonomic update of the Cuban endemic whip-spider Charinus tomasmicheli Armas, 2006 (Amblypygi: Charinidae). Revista Ibérica de Aracnología 29: 1-8.

Roewer C.F. 1962. Einige Arachniden aus den Batu Caves in Malaya. Pacific Insects 4: 517-520.

Rosin R. \& Shulov A. 1960. Representatives of the order Amblypygi (Arachnida) found in Israel. Bulletin of the Research Council of Israel 9B: 167-168. 
Roth V.D. \& Craig P.R. 1970. Arachnida of the Galápagos Islands (excluding Acari). Résultats scientifiques de la Mission zoologique belge aux îles Galapagos et en Ecuador (N. et J. Leleup, 19641965) 2: 107-124. Royal Museum for Central Africa, Tervuren.

Ruppert E.E. \& Barnes R.D. 1994. Invertebrate Zoology. Saunders College Publishers, Fort Worth, Texas.

Schaller F. 1971. Indirect sperm transfer by soil arthropods. Annual Review of Entomology 16: 407-446. https://doi.org/10.1146/annurev.en.16.010171.002203

Segovia J.M.G., Neco L.C. \& Willemart R.H. 2018. On the habitat use of the Neotropical whip spider Charinus asturius (Arachnida: Amblypygi). Zoologia 35: e12874.

https://doi.org/10.3897/zoologia.35.e12874

Segovia J.M.G., Gainett G. \& Willemart R.H. 2020. Predatory behavior and sensory morphology of the whip spider Charinus asturius (Arachnida: Amblypygi). Journal of Ethology 38: 273-280.

https://doi.org/10.1007/s10164-020-00648-0

Seiter M. \& Hörweg C. 2013. The whip spider collection (Arachnida, Amblypygi) held in the Natural History Museum Vienna, Austria. Arachnologische Mitteilungen 46: 47-53.

https://doi.org/10.5431/aramit4606

Seiter M. \& Wolff J. 2014. Description of Sarax buxtoni (Gravely 1915) (Arachnida: Amblypygi: Charinidae) and a new case of parthenogenesis in Amblypygi from Singapore. Journal of Arachnology 42: 233-239. https://doi.org/10.1636/Ha14-13.1

Seiter M., Wolff J. \& Hörweg C. 2015. A new species of the South East Asian genus Sarax Simon, 1892 (Arachnida: Amblypygi: Charinidae) and synonymization of Sarax mediterraneus Delle Cave, 1986. Zootaxa 4012 (3): 542-552. https://doi.org/10.11646/zootaxa.4012.3.8

Seiter M., Lanner J. \& Karolyi F. 2017. Mating behaviour and spermatophore morphology of four Cuban whip spiders (Arachnida, Amblypygi, Phrynidae) - Taxonomic relevance and evolutionary trends. Zoologischer Anzeiger: 117-126. https://doi.org/10.1016/j.jcz.2017.08.006

Seiter M., Schramm F.D. \& Schwaha T. 2018. Description of a new Charinus species (Amblypygi: Charinidae) from the Monseñor Nouel province, Dominican Republic. Zootaxa 4438: 349-361.

https://doi.org/10.11646/zootaxa.4438.2.9

Selden P.A. \& Dunlop J.A. 1998. Fossil taxa and relationships of Chelicerata. In: Edgecombe G. (ed.) Arthropod Fossils and Phylogeny: 303-331. Columbia University Press, New York.

Seyyar O. \& Demir H. 2007. A new locality for Charinus ioanniticus (Kritscher, 1959) (Amblypygi: Charinidae) in Turkey. Serket 10: 109-111.

Shakhatreh M.R., Miranda G.S., Bader-Katbeh A., Baker M.A.A. \& Amr Z.S. 2020. Charinus ioanniticus (Amblypygi: Charinidae), first record of a whip spider from Jordan. Arachnologische Mitteilungen/ Arachnology Letters 59: 35-37. https://doi.org/10.30963/aramit5906

Shear W.A., Selden P.A., Rolfe W.D.I., Bonamo P.M. \& Grierson J.D. 1987. New terrestrial arachnids from the Devonian of Gilboa, New York (Arachnida, Trigonotarbida). American Museum Novitates 2901: 1-74.

Shultz J.W. 1989. Morphology of locomotor appendages in Arachnida: Evolutionary trends and phylogenetic implications. Zoological Journal of the Linnean Society 97: 1-56.

https://doi.org/10.1111/j.1096-3642.1989.tb00552.x 
Simon E. 1892. Arachnides. In: Raffray A., Bolivar I., Simon E. (eds) Etude sur les Arthropodes cavernicoles de l'île de Luzon, Voyage de M. E. Simon aux îles Philippines (mars et avril 1890). 4̀ mémoire. Annales de la Société entomologique de France 61: 35-52.

Simon E. 1901. On the Arachnida collected during the "Skeat Expedition" to the Malay Peninsula, 1899-1900. Proceedings of the Zoological Society of London 71: 45-84.

https://doi.org/10.1111/j.1469-7998.1901.tb08164.x

Snodgrass R.E. 1902. Papers from the Hopkins Stanford Galapagos Expedition, 1898-1899. VII. Entomological results (6). Arachnida, part 2. Field notes on species described in part I. Proceedings of the Washington Academy of Sciences 4: 71-80.

Available from https://www.biodiversitylibrary.org/page/8666034\#page/87/mode/1up [ accessed 2 Jul. 2021].

Snodgrass R.E. 1948. The feeding organs of Arachnida, including mites and ticks. Smithsonian Miscellaneous Collection 110: 1-93.

Speijer E.A.M. 1937. A collection of pedipalps from the Raffles Museum. Bulletin of the Raffles Museum 13: 171-175.

Stockton W.D. 1976. Amblypygi. In: Leleup N. (ed.) Mission zoologique belge aux îles Galapagos et en Ecuador (N. et J. Leleup, 1964-1965): 55-65. Royal Museum for Central Africa, Brussels.

Strinati P. \& Aellen V. 1983. Voyage biospéologique autour du monde. Memoires du Speléo-Club de Paris 9: 1-29.

Tagliatela J., Gallao J.E. \& Bichuette M.E. 2019. Behavioral repertoire of Charinus mysticus Giupponi \& Kury 2002. Espeleo-Tema 29: 57-63.

Taiti S. \& Ferrara F. 1985. Biospeleology of Somalia. Two new species of terrestrial Isopoda (Crustacea Oniscidea) from Mugdile and Showli Berdi Caves. Monitore Zoologico Italiano 20: 341-349. https://doi.org/10.1080/03749444.1985.10736703

Teruel R. 2011. Nuevos registros de Charinus acosta (Quintero, 1983) en Cuba (Amblypygi: Charinidae). Boletín de la Sociedad Entomológica Aragonesa 49: 345-346.

Teruel R. 2016. The genus Charinus Simon, 1892 (Amblypygi: Charinidae) on the Island of Hispaniola, Greater Antilles. Revista Ibérica de Aracnología 28: 3-12.

Teruel R. \& Coulis M. 2017. First record of the genus Charinus Simon, 1892 from Martinique, Lesser Antilles, with description of a new species (Amblypygi: Charinidae). Ecologica Montenegrina 13: 3036. https://doi.org/10.37828/em.2017.13.3

Teruel R. \& Friedrich S. 2016. Unusual observation of a whip spider in Germany (Arachnida, Amblypygi). Spixiana 39: 22.

Teruel R. \& Questel K. 2011. A new species of Charinus Simon 1892 (Amblypygi: Charinidae) from the Leeward Islands, Lesser Antilles. Boletín de la Sociedad Entomológica Aragonesa 49: 15-18.

Teruel R. \& Questel K. 2015. A new species of Charinus Simon, 1892 (Amblypygi: Charinidae) from Guadeloupe, Lesser Antilles. Revista Ibérica de Aracnología 26: 43-47.

Teruel R. \& Rodríguez-Cabrera T.M. 2016. Actualización de la distribución conocida de Charinus acosta (Quintero, 1983) en Cuba (Amblypygi: Charinidae). Revista Ibérica de Aracnología 28: 135-136.

Teruel R., Armas L.F. \& Rodríguez T.M. 2009. Nuevos datos sobre la distribución geográfica y ecología de los amblipígidos de Cuba (Arachnida: Amblypygi). Boletín de la Sociedad Entomológica Aragonesa 44: 201-211. 
Thomé M.T.C., Lyra M.L., Lemes P., Teixeira L.S., Carnaval A.C., Haddad C.F.B. \& Canedo C. 2020. Outstanding diversity and microendemism in a clade of rare Atlantic Forest montane frogs. Molecular Phylogenetics and Evolution 149: 106813. https://doi.org/10.1016/j.ympev.2020.106813

Thorell T. 1888. Pedipalpi e scorpioni dell'Arcipelago Malese conservati nel Museo Civico di Storia Naturale di Genova. Annali del Museo Civico di Storia Naturale di Genova 26: 327-428.

Torres-Contreras R., García D.M.Á. \& Armas L.F. 2015. Una especie nueva de Charinus Simon, 1892 (Amblypygi: Charinidae) del Caribe Colombiano. Revista Ibérica de Aracnología 27: 145-148.

Torres-Contreras R.A., Arroyo-Pérez W. \& Alvarez-Garcia D.M. 2019. Charinus rocamadre (Amblypygi, Charinidae): Description of the female, ultrastructure of the male and female gonopods, and mitochondrial DNA sequences. Zootaxa 4664: 129-141. https://doi.org/10.11646/zootaxa.4664.1.6

Trajano E. \& Bichuette M.E. 2010. Diversity of Brazilian subterranean invertebrates, with a list of troglomorphic taxa. Subterranean Biology 7: 1-16.

Vandel A. 1965. Biospeleology: The Biology of Cavernicolous Animals. Pergamon Press, Edinburgh.

Van der Hammen L. 1986. Comparative studies in Chelicerata. IV. Apatellata, Arachnida, Scorpionida, Xiphosura. Zoölogische Verhandelingen (Leiden) 226: 1-52.

Vanni S., Bartolozzi L. \& Whitman-Mascherini S. 1988. Cataloghi del Museo Zoologico 'La Specola'. 6. Arachnida, Solifugae e Amblypygi: Tipi. Atti della Società Toscana di Scienze Naturali, Memorie B 94: 373-377.

Vasconcelos A.C.O. \& Ferreira R.L. 2016. Description of two new species of Charinus Simon, 1892 from Brazilian caves with remarks on conservation (Arachnida: Amblypygi: Charinidae). Zootaxa 4072 (2): 185-202. https://doi.org/10.11646/zootaxa.4072.2.3

Vasconcelos A.C.O. \& Ferreira R.L. 2017. Two new species of cave-dwelling Charinus Simon, 1892 from Brazil (Arachnida: Amblypygi: Charinidae). Zootaxa 4312: 277-292.

https://doi.org/10.11646/zootaxa.4312.2.4

Vasconcelos A.C., Giupponi A.P.L. \& Ferreira R.L. 2013 . A new species of Charinus Simon, 1892 from northeastern Brazil with comments on the potential distribution of the genus in Central and South Americas (Arachnida:Amblypygi:Charinidae).Zootaxa 3737:488-500.https://doi.org/10.11646/zootaxa.3737.4.9

Vasconcelos A.C.O., Giupponi A.P.L. \& Ferreira R.L. 2014. A new species of Charinus from Minas Gerais State, Brazil, with comments on its sexual dimorphism (Arachnida: Amblypygi: Charinidae). Journal of Arachnology 42: 155-162. https://doi.org/10.1636/H14-01.1

Vasconcelos A.C.O., Giupponi A.P.L. \& Ferreira R.L. 2016. Description of a new troglomorphic species of Charinus Simon, 1892 from Brazil (Arachnida, Amblypygi, Charinidae). ZooKeys 600: 35-52. https://doi.org/10.3897/zookeys.600.8580

Víquez C., Miranda R. \& Armas L.F 2012. First record of the genus Charinus (Amblypygi: Charinidae) from Panama. Revista Iberica de Aracnologia 21: 56-58.

Víquez C., Chiriví D.J., Moreno-González J.A. \& Christensen J.A. 2014. Heterophrynus armiger Pocock, 1902 (Amblypygi: Phrynidae): First record from Colombia, with notes on its historic distribution records and natural history. Check List 10: 457-460.

Weidner H. 1959. Die Entomologischen Sammlungen des Zoologischen Staatsinstituts und Zoologischen Museums Hamburg. I. Teil. Pararthropoda und Chelicerata I. Mitteilungen aus dem Hamburgischen Zoologischen Museum und Institut 57: 89-142.

Werner F. 1935. Klasse: Arachnoidea, Spinnentiere. Pedipalpen. In: Bronn H.G. (ed.) Klassen und Ordnungen des Tierreichs: 317-490. Akademische Verlagsgesellschaft, Leipzig. 
Weygoldt P. 1972a. Charinus koepckei n. sp. aus Peru (Amblypygi: Charontidae). Senckenbergiana Biologica 53: 281-286.

Weygoldt P. 1972b. Charontidae (Amblypygi) aus Brasilien. Zoologische Jahrbücher, Abteilung für Systematik, Ökologie und Geographie der Tiere 99: 107-132.

Weygoldt P. 1972c. Geisselskorpione und Geisselspinnen (Uropygi und Amblypygi). Zeitschrift des Kölner Zoo 15: 95-107.

Weygoldt P. 1972d. Spermatophorenbau und Samenübertragung bei Uropygen (Mastigoproctus brasilianus C.L. Koch) und Amblypygen (Charinus brasilianus Weygoldt und Admetus pumilio C.L. Koch) (Chelicerata, Arachnida). Zeitschrift für Morphologie und Ökologie der Tiere 71: 23-51. https://doi.org/10.1007/BF00282139

Weygoldt P. 1974. Kampf und Paarung bei Geisselspinne Charinus montanus Weygoldt (Arachnida, Amblypygi, Charontidae). Zeitschrift für Tierpsychologie 34: 217-223.

Weygoldt P. 1975. Die indirekte Spermatophorenübertragung bei Arachniden. Verhandlungen der Deutschen Zoologischen Gesellschaft: 308-313.

Weygoldt P. 1994. Amblypygi. In: Juberthie C. \& Decu V. (eds) Encyclopaedia Biospeologica: 241247. Société de Biospéologie, Moulis and Bucarest.

Weygoldt P. 1996a. Evolutionary morphology of whip spiders: towards a phylogenetic system (Chelicerata: Arachnida: Amblypygi). Journal of Zoological Systematics and Evolution Research 34: 185-202. https://doi.org/10.1111/j.1439-0469.1996.tb00825.x

Weygoldt P. 1996b. The relationships of the south east African whip spiders Hemiphrynus machadoi Fage, 1951 and Phrynichus scullyi Purcell, 1901: Introduction of the new generic names Xerophrynus and Phrynichodamon (Chelicerata: Amblypygi). Zoologischer Anzeiger 235: 117-130.

Weygoldt P. 1998a. The identity of Oligacanthophrynus guianensis di Caporiacco, 1947 (Arachnida: Amblypygi: Charinidae). Bulletin of the British Arachnological Society 11: 72.

Weygoldt P. 1998b. Revision of the species of Phrynichus Karsch, 1879 and Euphrynichus Weygoldt, 1995 (Chelicerata, Amblypygi). Zoologica, Stuttgart 147: 1-65.

Weygoldt P. 1999a. Revision of the genus Damon C. L Koch, 1850 (Chelicerata: Amblypygi: Phrynichidae). Zoologica, Stuttgart 150: 1-45.

Weygoldt P. 1999b. Sperm transfer, spermatophore morphology, and female genitalia of three species of whip spiders: Charinus seychellarum Kraepelin, 1898, Damon medius (Herbst, 1797), and Phrynichus scaber (Gervais, 1844) (Chelicerata, Amblypygi). Zoologica, Stuttgart 150: 47-64.

Weygoldt P. 1999c. Spermatophores and the evolution of female genitalia in whip spiders (Chelicerata, Amblypygi). Journal of Arachnology 27: 103-116.

Weygoldt P. 2000a. Whip spiders (Chelicerata: Amblypygi). Their Biology, Morphology and Systematics. Apollo Books, Stenstrup.

Weygoldt P. 2000b. African whip spiders. Synopsis of the Amblypygi (Chelicerata: Arachnida) reported from Africa. Memorie della Società Entomologica Italiana 78: 339-359.

Weygoldt P. 2002a. Amblypygi. In: Adis J. (ed.) Amazonian Arachnida and Myriapoda: 293-302. Pensoft Publishers, Moscow.

Weygoldt P. 2002b. Chelicerata, Spinnentiere. In: Rieger R. (ed.) Spezielle Zoologie: 449-497. Heidelberg, Berlin. 
MIRANDA G.S. et al., Systematic revision of Charinidae (Arachnida, Amblypygi)

Weygoldt P. 2002c. Sperm transfer and spermatophore morphology of the whip spiders Sarax buxtoni, S. brachydactylus (Charinidae), Charon cf. grayi, and Stygophrynus brevispina nov. spec. (Charontidae) (Chelicerata, Amblypygi). Zoologischer Anzeiger 241: 131-148.

https://doi.org/10.1078/s0044-5231(04)70069-8

Weygoldt P. 2005. Biogeography, systematic position, and reproduction of Charinus ioanniticus (Kritscher, 1959) with the description of a new species from Pakistan (Chelicerata, Amblypygi, Charinidae). Senckenbergiana Biologica 85: 1-14.

Weygoldt P. 2006a. Courtship and sperm transfer in Charinus neocaledonicus Kraepelin, 1895 and Charinus australianus (L. Koch, 1867) (Arachnida, Amblypygi, Charinidae). Zoologischer Anzeiger 244: 239-247. https://doi.org/10.1016/j.jcz.2006.01.002

Weygoldt P. 2006b. New Caledonian whip spiders: Notes on Charinus australianus, Charinus neocaledonicus and other south-western Pacific species of the Charinus australianus species group (Chelicerata, Amblypygi, Charinidae). Verhandlungen des Naturwissenschaftlichen Vereins in Hamburg 42: 5-37.

Weygoldt P. 2007. Parthenogenesis and reproduction in Charinus ioanniticus (Kritscher, 1959) (Chelicerata, Amblypygi, Charinidae). Bulletin of the British Arachnological Society 14: 81-82. https://doi.org/10.13156/arac.2007.14.2.81

Weygoldt P. 2008. Spermatophores, female genitalia, and courtship behaviour of two whip spider species, Charinus africanus and Damon tibialis (Chelicerata: Amblypygi). Zoologischer Anzeiger 247: 223-232. https://doi.org/10.1016/j.jcz.2007.12.002

Weygoldt P. \& Van Damme K. 2004. A new troglomorphic whip spider of the genus Charinus (Amblypygi: Charinidae) from Socotra Island. Fauna of Arabia 20: 327-334.

Weygoldt P., Weisemann A. \& Weisemann K. 1972. Morphologisch-histologische Untersuchungen an den Geschlechtsorganen der Amblypygi unter besonderer Berücksichtigung von Tarantula marginemaculata C.L. Koch (Arachnida). Zeitschrift für Morphologie und Ökologie der Tiere 73: 209247. https://doi.org/10.1007/BF00297206

Weygoldt P., Hans P. \& Polak S. 2002. Arabian whip spiders: four new species of the genera Charinus and Phrynichus (Chelicerata: Amblypygi) from Oman and Socotra. Fauna of Arabia 19: 289-309.

Wolf B. 1938. Animalium cavernarum Catalogus. W. Junk, The Hague.

Wolfe J.M., Daley A.C., Legg D.A. \& Edgecombe G.D. 2016. Fossil calibrations for the arthropod Tree of Life. Earth-Science Reviews 160: 43-110. https://doi.org/10.1016/j.earscirev.2016.06.008

Wolff J.O., Seiter M. \& Gorb S.N. 2015. Functional anatomy of the pretarsus in whip spiders (Arachnida, Amblypygi). Arthropod Structure \& Development 44: 524-540.

https://doi.org/10.1016/j.asd.2015.08.014

Wolff J.O., Schwaha T., Seiter M. \& Gorb S.N. 2016. Whip spiders (Amblypygi) become water-repellent by a colloidal secretion that self-assembles into hierarchical microstructures. Zoological Letters 2: 23. https://doi.org/10.1186/s40851-016-0059-y

Wolff J.O., Seiter M. \& Gorb S.N. 2017. The water-repellent cerotegument of whip-spiders (Arachnida: Amblypygi). Arthropod Structure \& Development 46: 116-129.

https://doi.org/10.1016/j.asd.2016.10.010

Yussof S. 1997. The Natural and Other Histories of Batu Caves. Malaysian Nature Society, Kuala Lumpur. 
Manuscript received: 10 December 2020

Manuscript accepted: 24 March 2021

Published on: 24 September 2021

Topic editor: Rudy Jocqué

Desk editors: Kristiaan Hoedemakers and Natacha Beau

Printed versions of all papers are also deposited in the libraries of the institutes that are members of the EJT consortium: Muséum national d'histoire naturelle, Paris, France; Meise Botanic Garden, Belgium; Royal Museum for Central Africa, Tervuren, Belgium; Royal Belgian Institute of Natural Sciences, Brussels, Belgium; Natural History Museum of Denmark, Copenhagen, Denmark; Naturalis Biodiversity Center, Leiden, the Netherlands; Museo Nacional de Ciencias Naturales-CSIC, Madrid, Spain; Real Jardín Botánico de Madrid CSIC, Spain; Zoological Research Museum Alexander Koenig, Bonn, Germany; National Museum, Prague, Czech Republic. 


\section{Appendix}

Table 1. List of published works using the name Charinidae Quintero, 1986 for whip spiders, in chronological order.

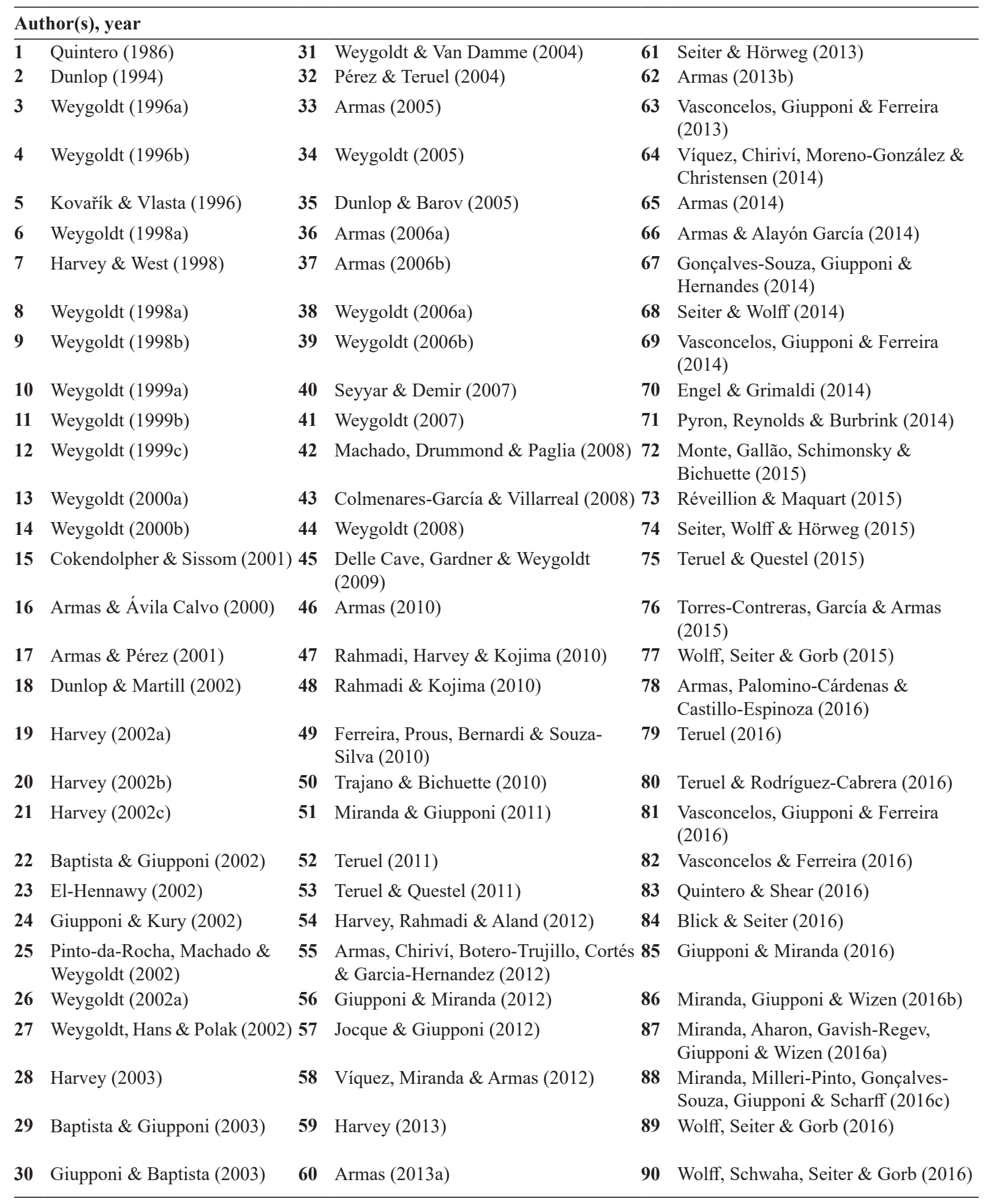


Table 2. List of published papers and books using the name Charinidae Gray, 1849 for snakes, in chronological order.

\section{Author(s), year}

1 Cope (1886a)

2 Cope (1886b)

3 Gilmore (1938)

4 Pyron, Reynolds \& Burbrink (2014)

5 Solís, Wilson \& Townsend (2014)

6 Sunyer (2014)

7 Head (2015)

8 Ray \& Ruback (2015)

9 Quintero \& Shear (2016)

\section{References}

This list of references contains only those cited in the tables above, but not in the main text.

Cokendolpher J.C. \& Sissom W.D. 2001. A new troglobitic Paraphrynus from Oaxaca, Mexico (Amblypygi, Phrynidae). Texas Memorial Museum, Speleological Monographs 5: 17-23.

Colmenares-García P.A. \& Villarreal O.M. 2008. Una nueva especie de Phrynus Lamarck, 1801 (Amblypygi: Phrynidae), de la Sierra de Perijá, Venezuela. Boletín de la Sociedad Entomológica Aragonesa 43: 89-93.

Dunlop J.A. \& Barov V. 2005. A new fossil whip spider (Arachnida: Amblypygi) from the Crato Formation of Brazil. Revista Iberica de Aracnologia 12: 53-62.

Ferreira R.L., Prous X., Bernardi L.F.O. \& Souza-Silva M. 2010. Fauna subterrânea do Estado do Rio Grande do Norte: Caracterização e impactos. Revista Brasileira de Espeleologia 1 (1): 25-51.

Gilmore C.W. 1938. Fossil snakes of North America. Geological Society of America Special papers 9: 1-93. https://doi.org/10.1130/SPE9-p1

Head J.J. 2015. Fossil calibration dates for molecular phylogenetic analysis of snakes 1: Serpentes, Alethinophidia, Boidae, Pythonidae. Palaeontologia Electronica 18.1.6FC: 1-17. https://doi.org/10.26879/487

Machado A.B.M., Drummond G.M. \& Paglia A.P. 2008. Livro Vermelho da Fauna Brasileira Ameaçada de Extinção. Fundação Biodiversitas, Belo Horizonte, MG.

Solís J.M., Wilson L.D. \& Townsend J.H. 2014. An updated list of the amphibians and reptiles of Honduras, with comments on their nomenclature. Mesoamerican Herpetology 1 (1): 123-144.

Sunyer J. 2014. An updated checklist of the amphibians and reptiles of Nicaragua. Mesoamerican Herpetology 1 (1): 186-202. 


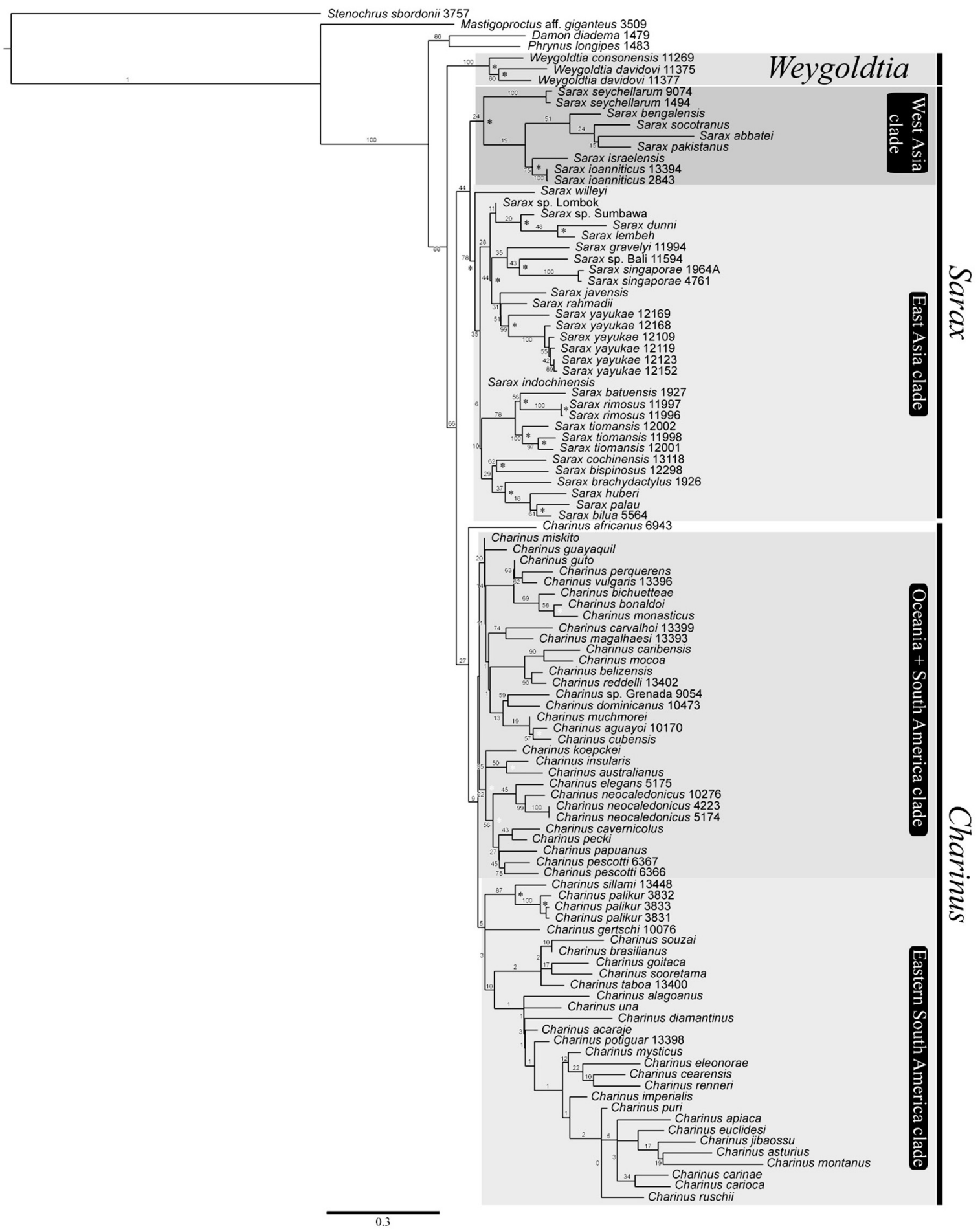

Fig. 1. Phylogeny of the whip spider family Charinidae Quintero, 1986 with proposed group names for major clades, based on Miranda et al. (2021). Bootstrap values above clades. 


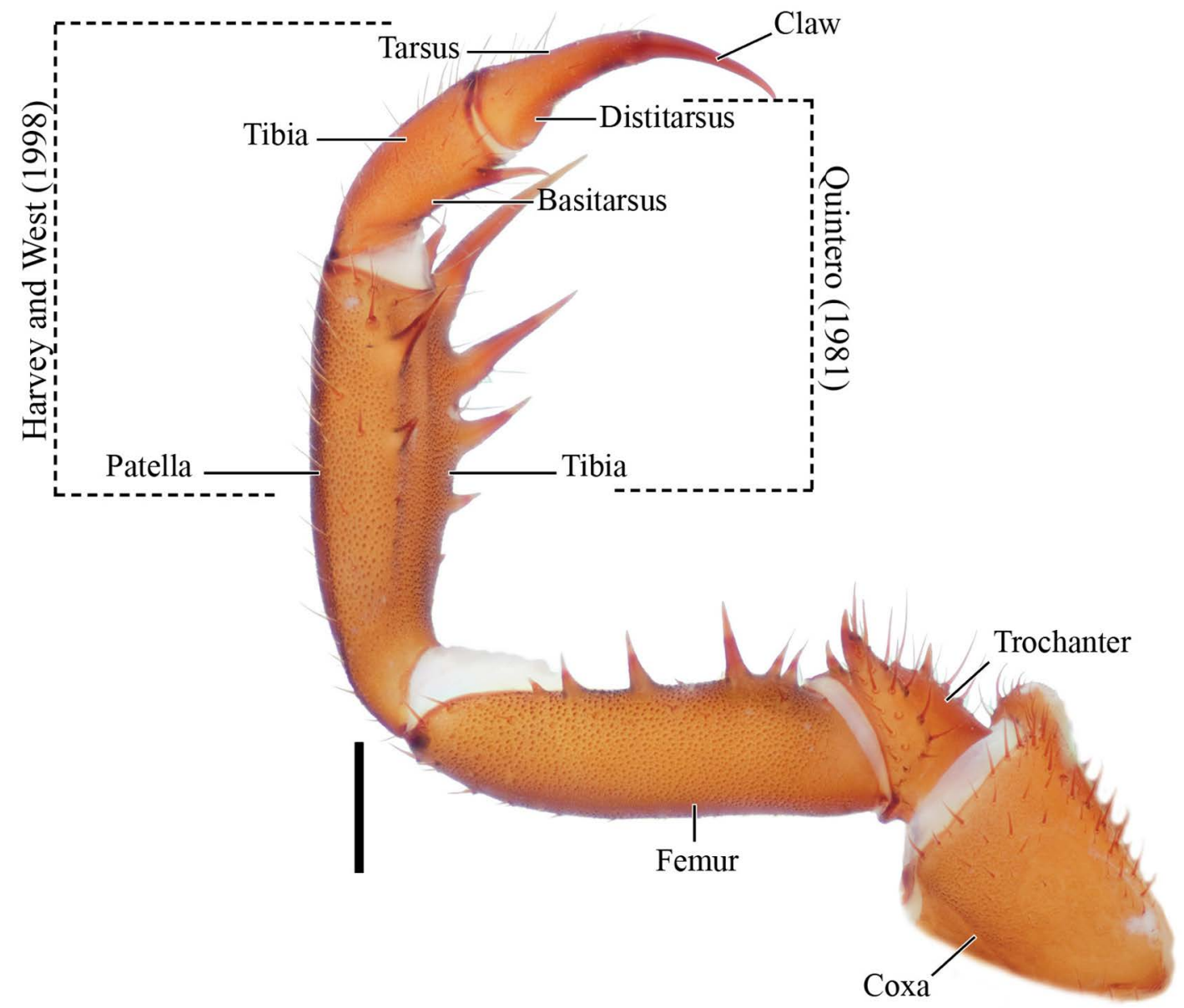

Fig. 2. Charinus insularis Banks, 1902 (RBINS), dextral pedipalp, ventral view, illustrating nomenclature for pedipalp segments. Scale bar: $1 \mathrm{~mm}$. 

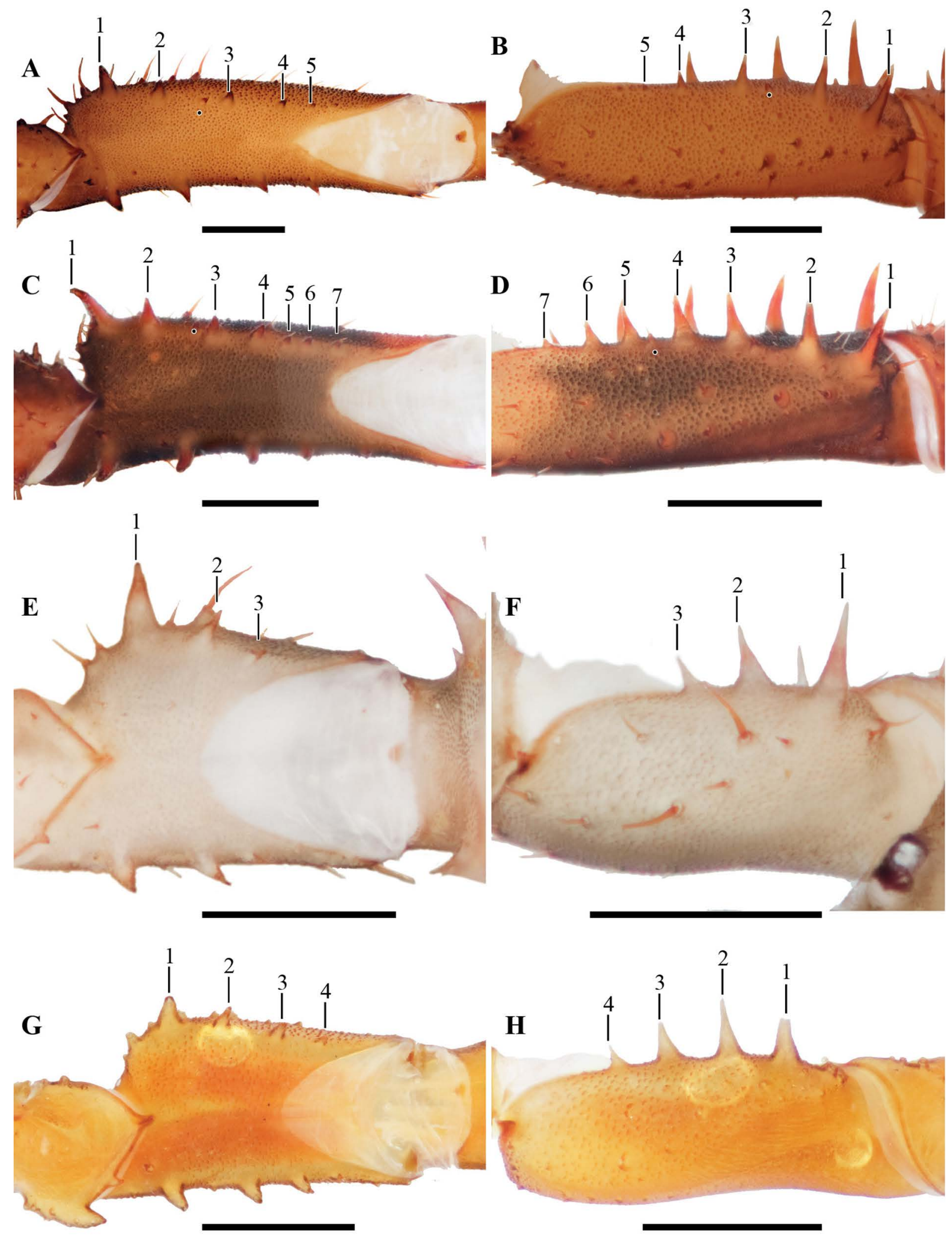

Fig. 3. Charinidae Quintero, 1986, pedipalp femur, prolateral and dorsal views. A-B. Charinus carinae sp. nov. (MNRJ 9293). C-D. Charinus gertschi Goodnight \& Goodnight, 1946 (AMCC [LP 10076]). E-F. Sarax bispinosus (Nair, 1934) (AMCC [LP 12298]). G-H. Sarax willeyi Gravely, 1915 (SMF). Scale bars: A-D, G-H $=1 \mathrm{~mm}$; E-F $=0.5 \mathrm{~mm}$. 

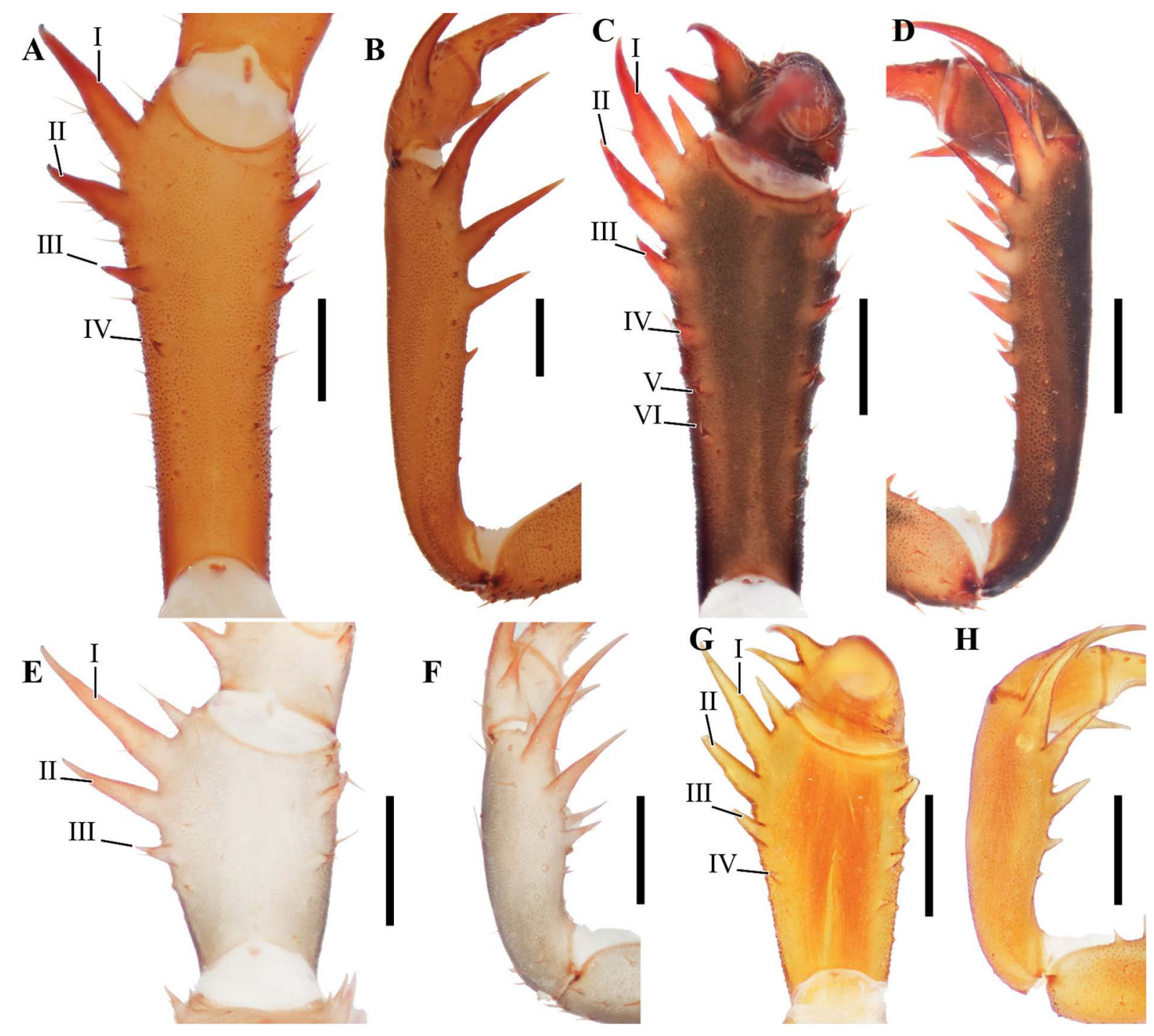

Fig. 4. Charinidae Quintero, 1986, pedipalp patellar articles, dorsal and prolateral views. A-B. Charinus carinae sp. nov. (MNRJ 9293). C-D. Charinus gertschi Goodnight \& Goodnight, 1946 (AMCC [LP 10076]). E-F. Sarax bispinosus (Nair, 1934) (AMCC [LP 12298]). G-H. Sarax willeyi Gravely, 1915 (SMF). Scale bars: A-D, G-H = $1 \mathrm{~mm}$; E-F = $0.5 \mathrm{~mm}$. 

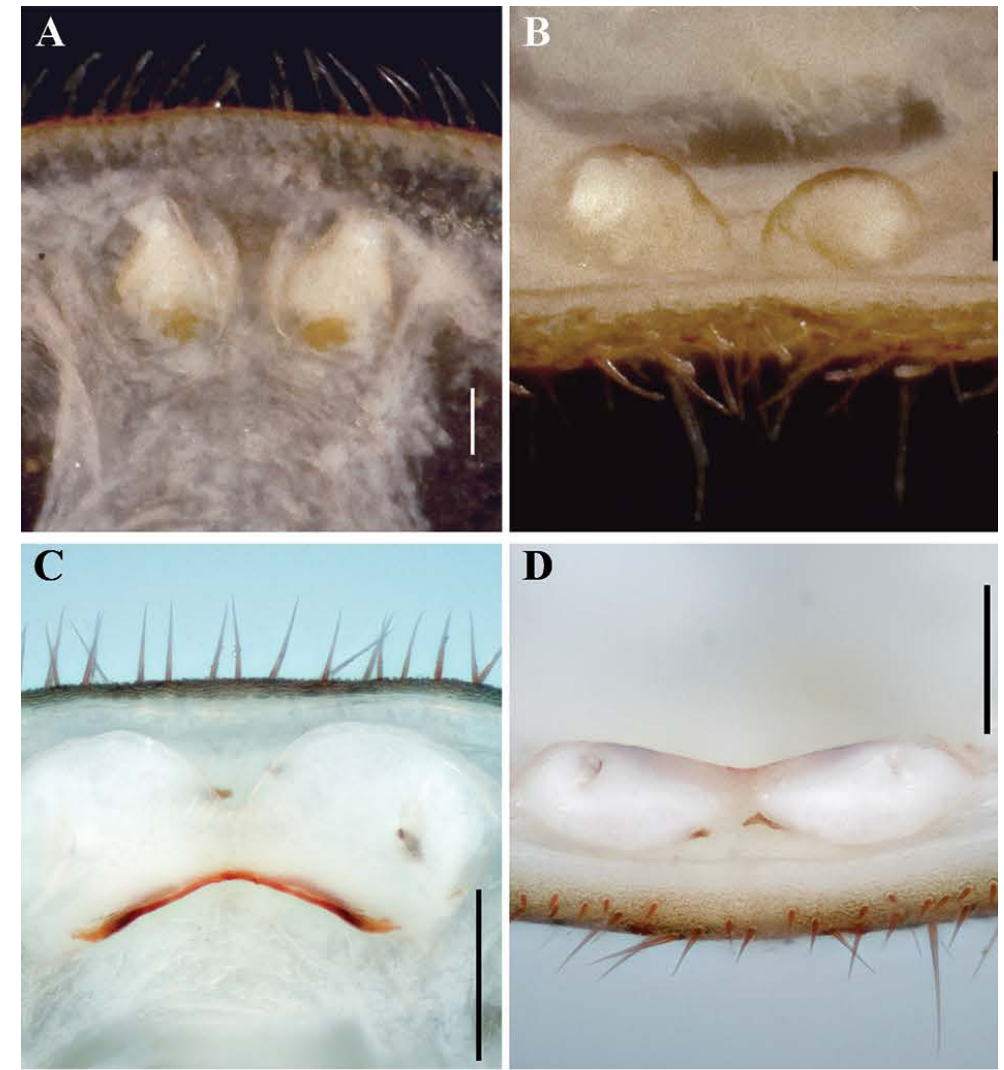

D
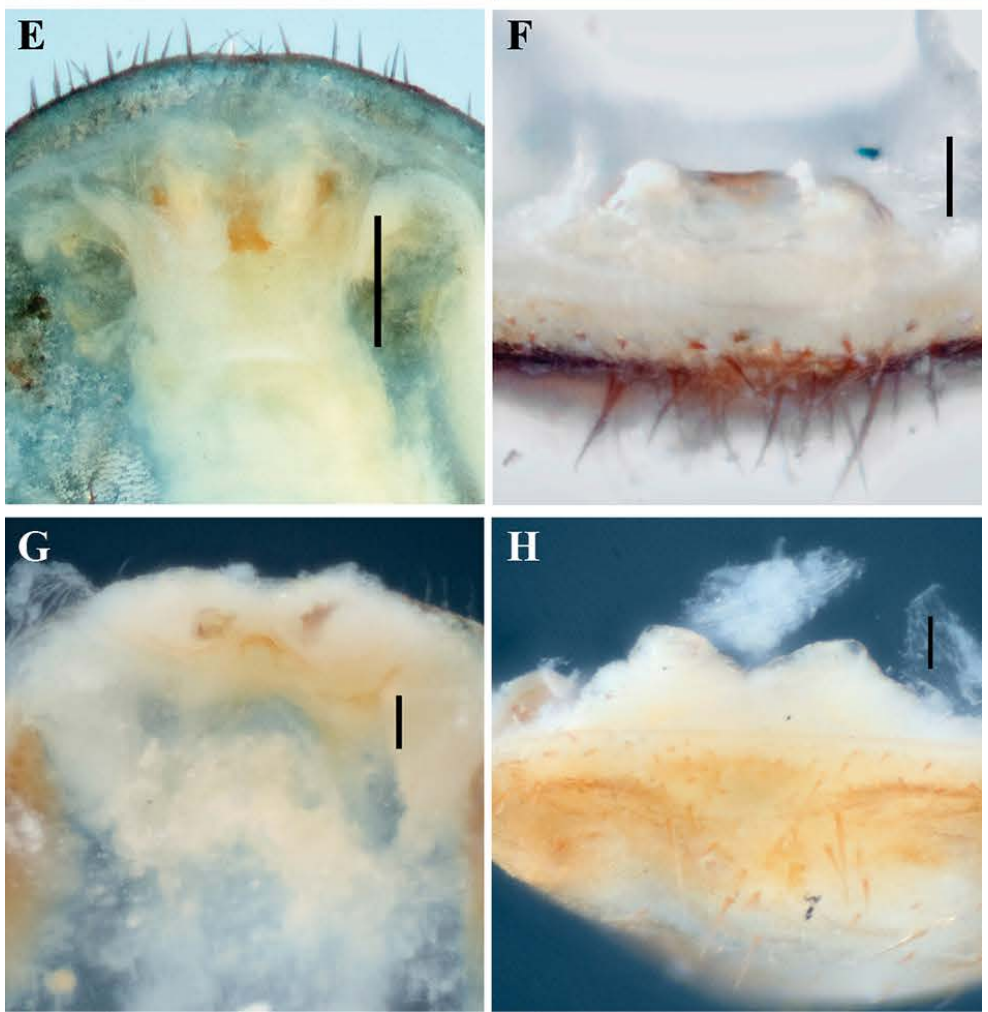

Fig. 5. Charinus Simon, 1892, female gonopods, dorsal (left column) and posterior (right column) views. A-B. Charinus apiaca sp. nov. (MNRJ 9286). C-D. Charinus gertschi Goodnight \& Goodnight, 1946 (AMCC [LP 10076]). E-F. Charinus miskito sp. nov. (SMNS). G-H. Charinus mocoa sp. nov. (SMF 68). Scale bars: A-B, F-H $=0.1 \mathrm{~mm}$; C-E, I-L $=0.25 \mathrm{~mm}$. 

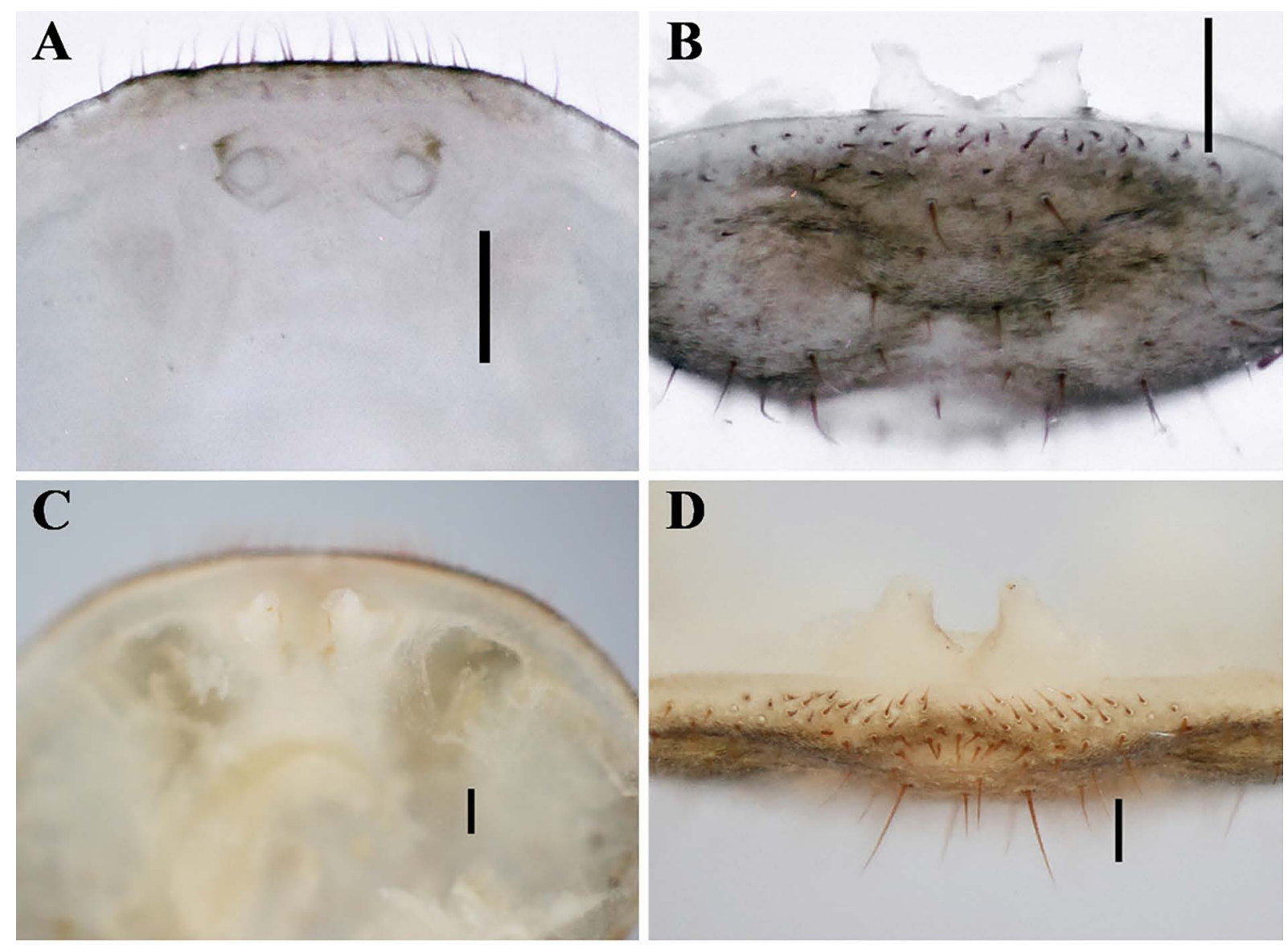

\section{D}
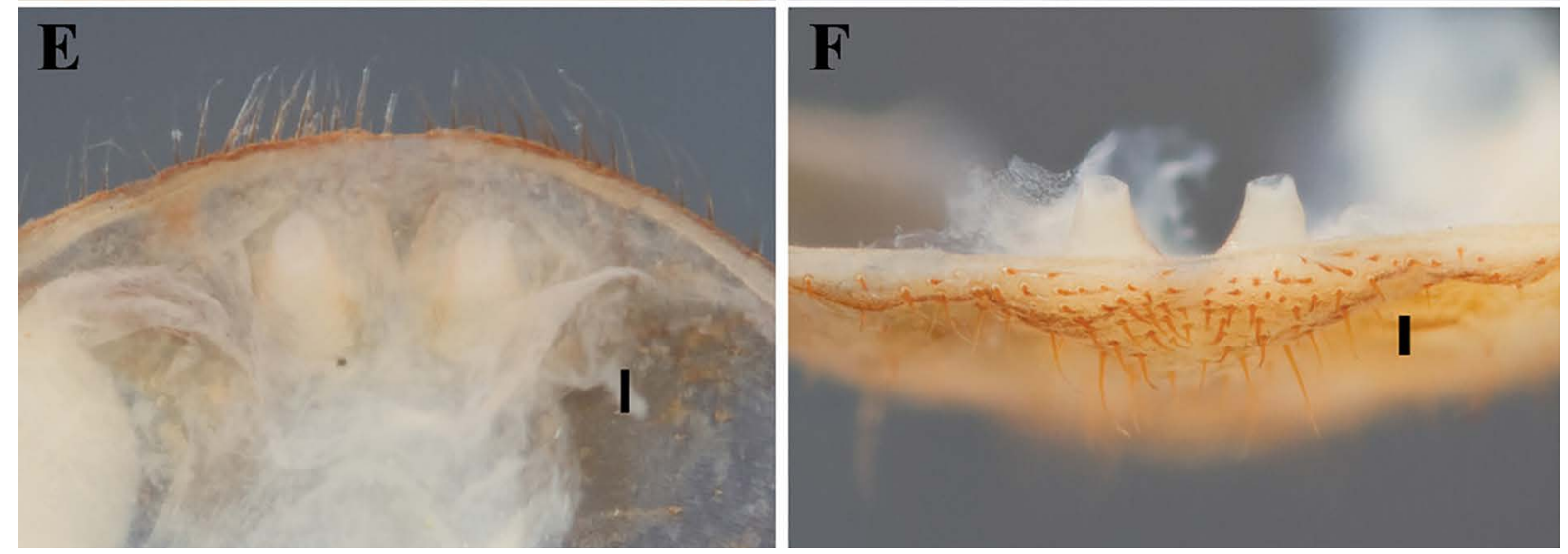

Fig. 6. Charinus Simon, 1892, female gonopods, dorsal (left column) and posterior (right column) views. A-B. Charinus renneri sp. nov. (MNRJ 9198). C-D. Charinus euclidesi sp. nov. (MNRJ 9099). E-F. Charinus carioca sp. nov. (MNRJ 9201). Scale bars: A-D $=0.25 \mathrm{~mm}$; E-F $=0.1 \mathrm{~mm}$. 
MIRANDA G.S. et al., Systematic revision of Charinidae (Arachnida, Amblypygi)
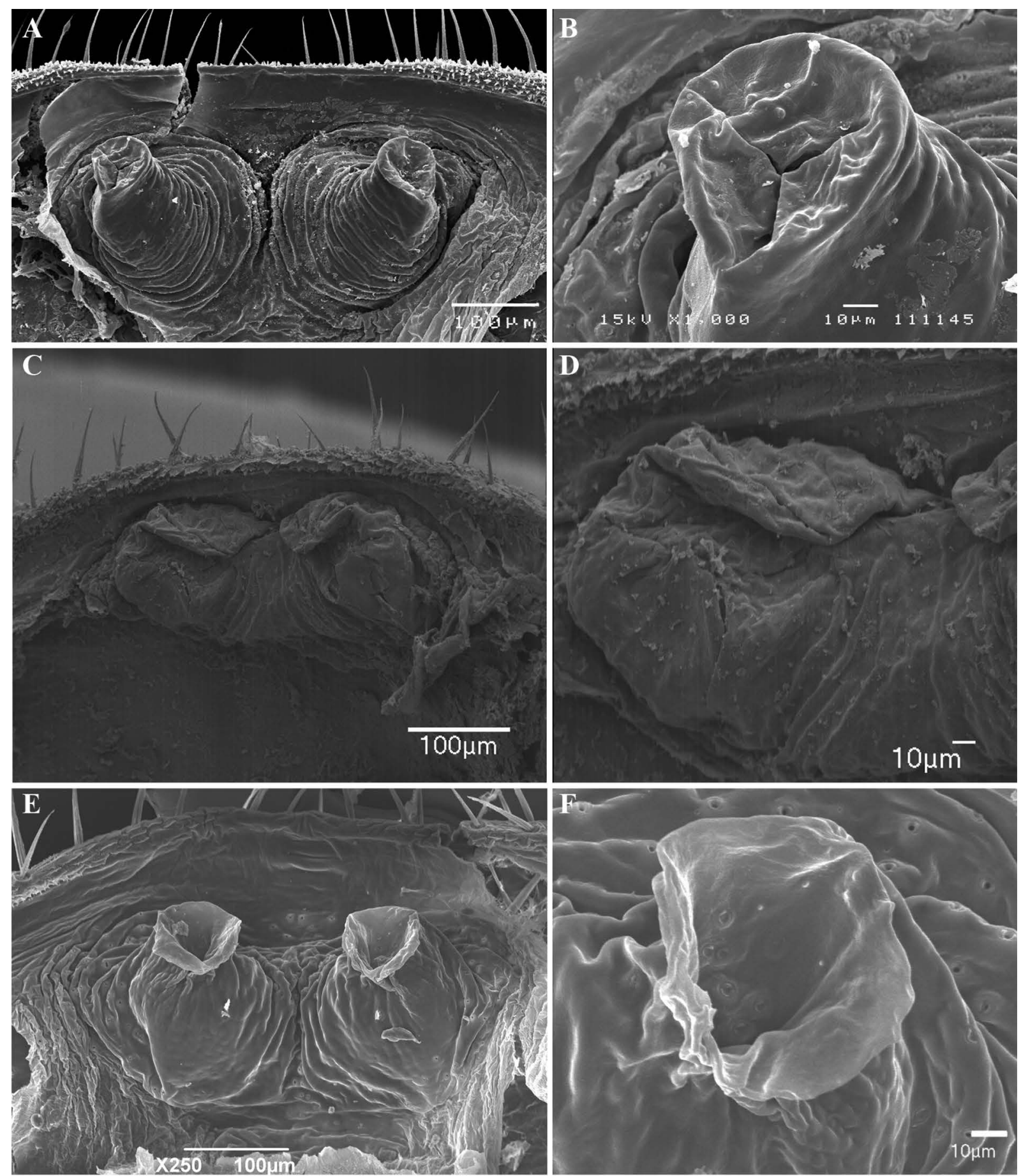

Fig. 7. Charinus Simon, 1892, female gonopods, dorsal view (left column) and detail (right column). A-B. Charinus acaraje Pinto-da-Rocha, Machado \& Weygoldt, 2002 (MNRJ 9297). C-D. Charinus palikur sp. nov. (AMCC [LP 3831]) E-F. Charinus sooretama sp. nov. (MNRJ 9245). 

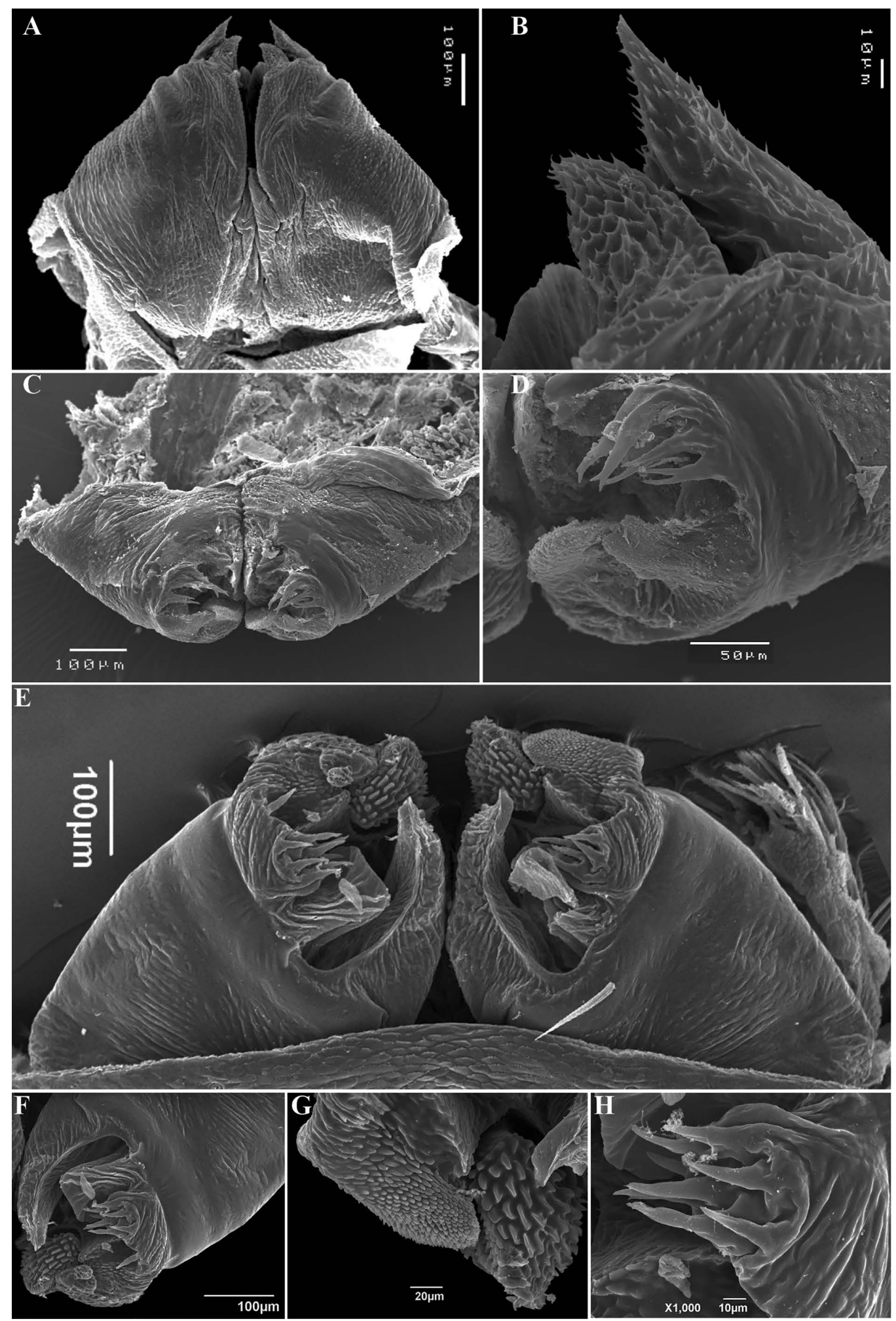

Fig. 8. Charinus Simon, 1892, male gonopods. A-B. Charinus acaraje Pinto-da-Rocha, Machado \& Weygoldt, 2002 (MNRJ 9297), ventral view (A) and detail of dorsal lobe (LoD) and lateral lobe 1 (LoL1). C-D. Charinus brasilianus Weygoldt, 1972 (MNRJ 9226), posterior view (C) and detail of lateral lobes 1 and 2 (LoL1, 2), dorsal lobe (LoD) and lamina medialis (LaM) (D). E-H. Charinus carajas Giupponi \& Miranda, 2016 (MZSP 29126), ventral view of gonopod (E), detail of sinistral side of gonopod (F), detail of LoL1 and LoD (G), and detail of LoL2 (H). 

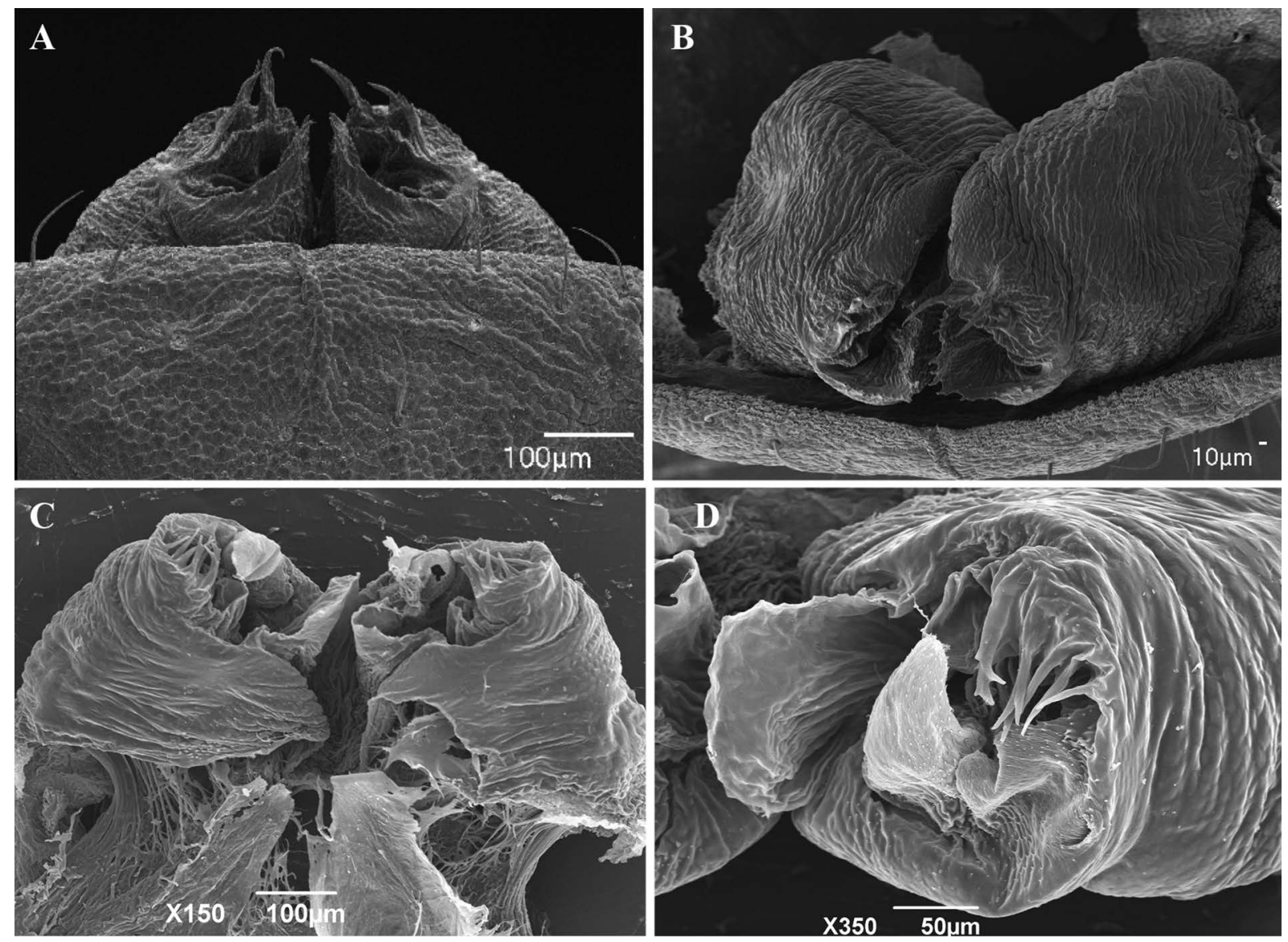

Fig. 9. Charinus Simon, 1892, male gonopods. A-B. Charinus euclidesi sp. nov. (MNRJ 9099), ventral view (A), posterior view (B). C-D. Charinus sooretama sp. nov. (MNRJ 9245), ventral view (B), detail of sinistral side showing lamina medialis, lateral lobe 1 and 2, and dorsal lobe (D). 

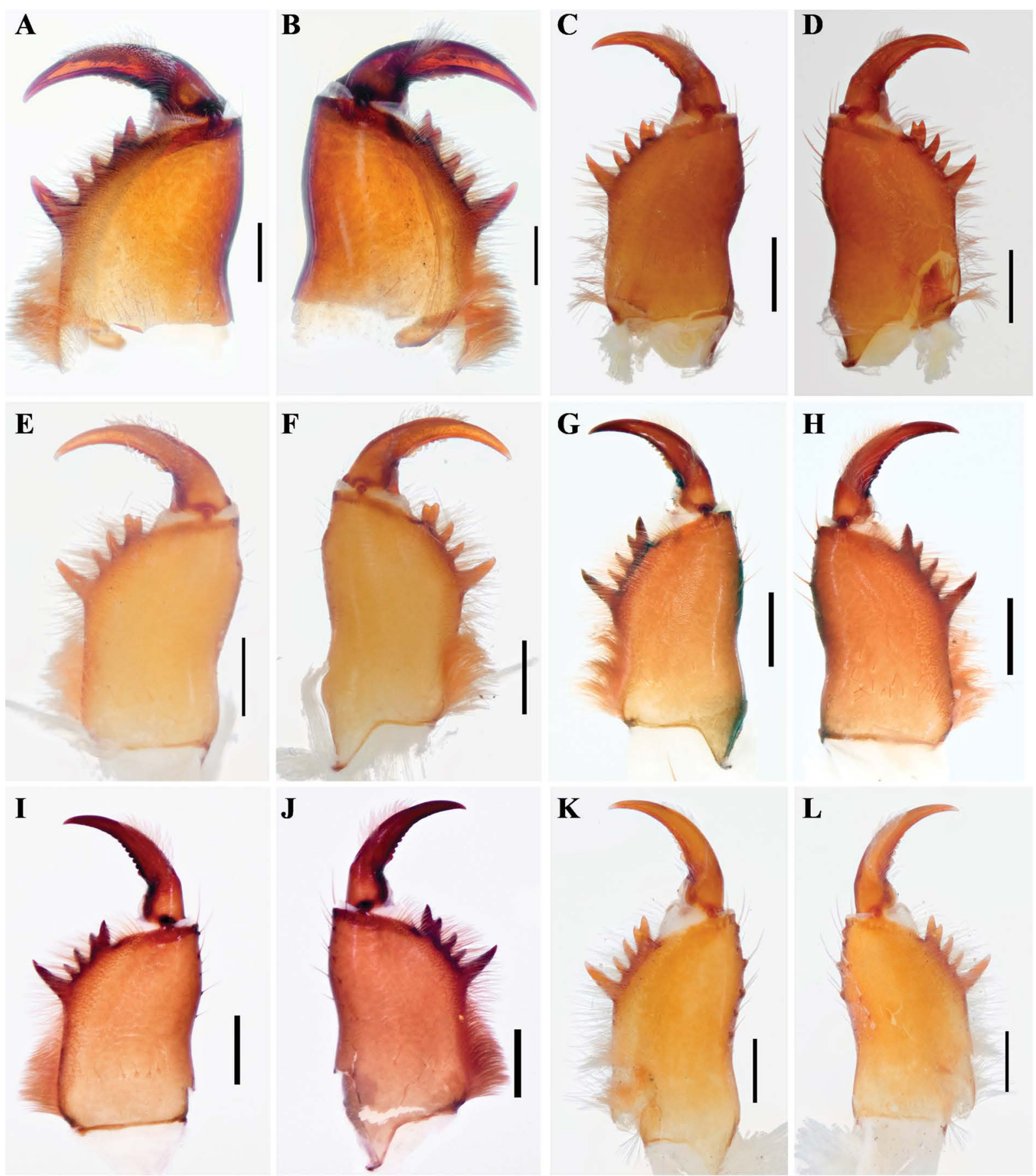

Fig. 10. Charinus Simon, 1892, chelicerae, prolateral and retrolateral views. A-B. Charinus loko sp. nov. (SMNS). C-D. Charinus miskito sp. nov. (SMNS). E-F. Charinus mocoa sp. nov. (SMF 68). G-H. Charinus alagoanus sp. nov. (MNRJ 9295). I-J. Charinus renneri sp. nov. (MNRJ 9198). K-L. Charinus madagascariensis Fage, 1954 (MNHN). Scale bars: 0.5 mm. 
A

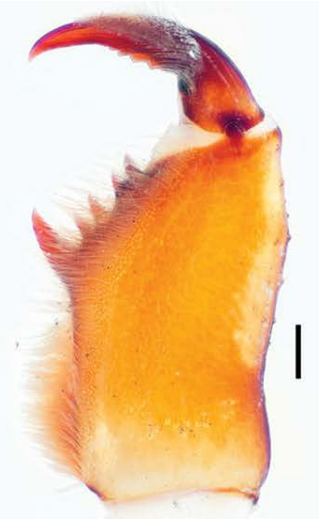

C

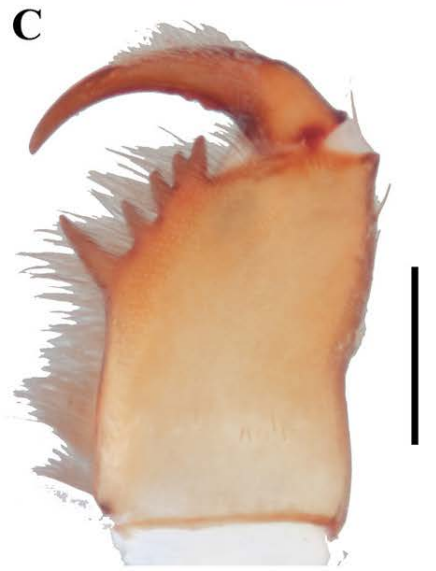

$\mathbf{E}$

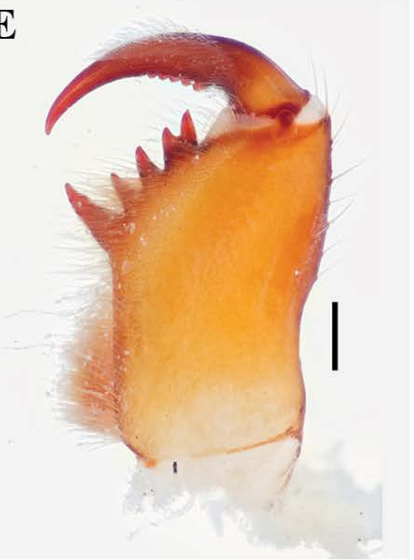

B

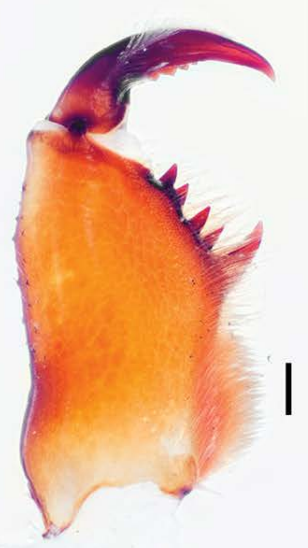

D

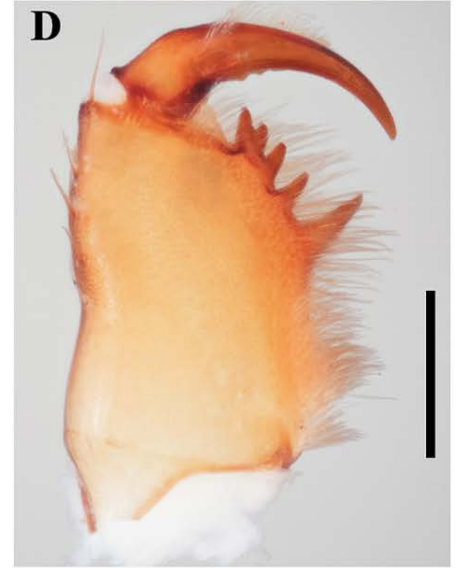

F

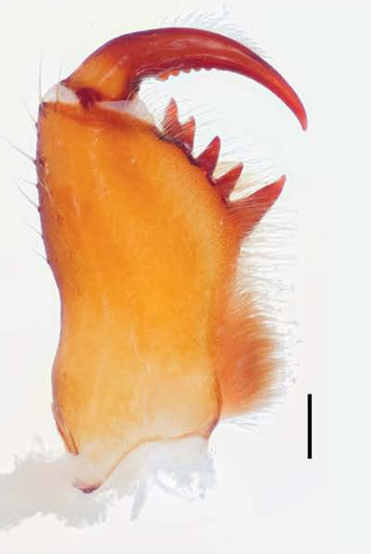

Fig. 11. Charinidae Quintero, 1986, chelicerae, prolateral and retrolateral views. A-B. Charinus milloti Fage, 1939 (MNHN). C-D. Sarax cochinensis (Gravely, 1915) (AMCC [LP 13118]). E-F. Charinus longipes Weygoldt, 2006 (MNHN). Scale bars: $0.5 \mathrm{~mm}$. 


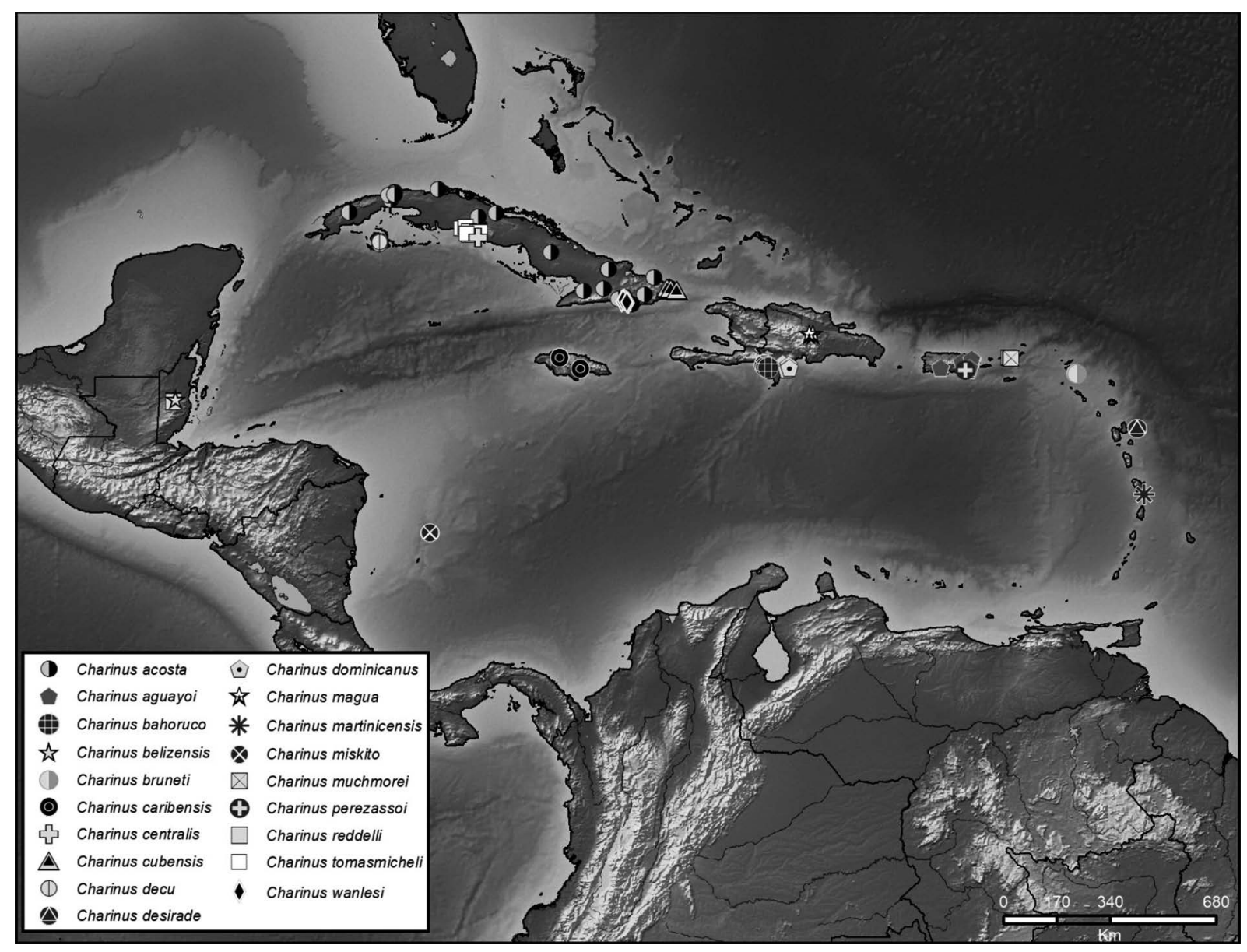

Fig. 12. Map plotting known distributions of species of Charinus Simon, 1892 in the Caribbean and Central America. 

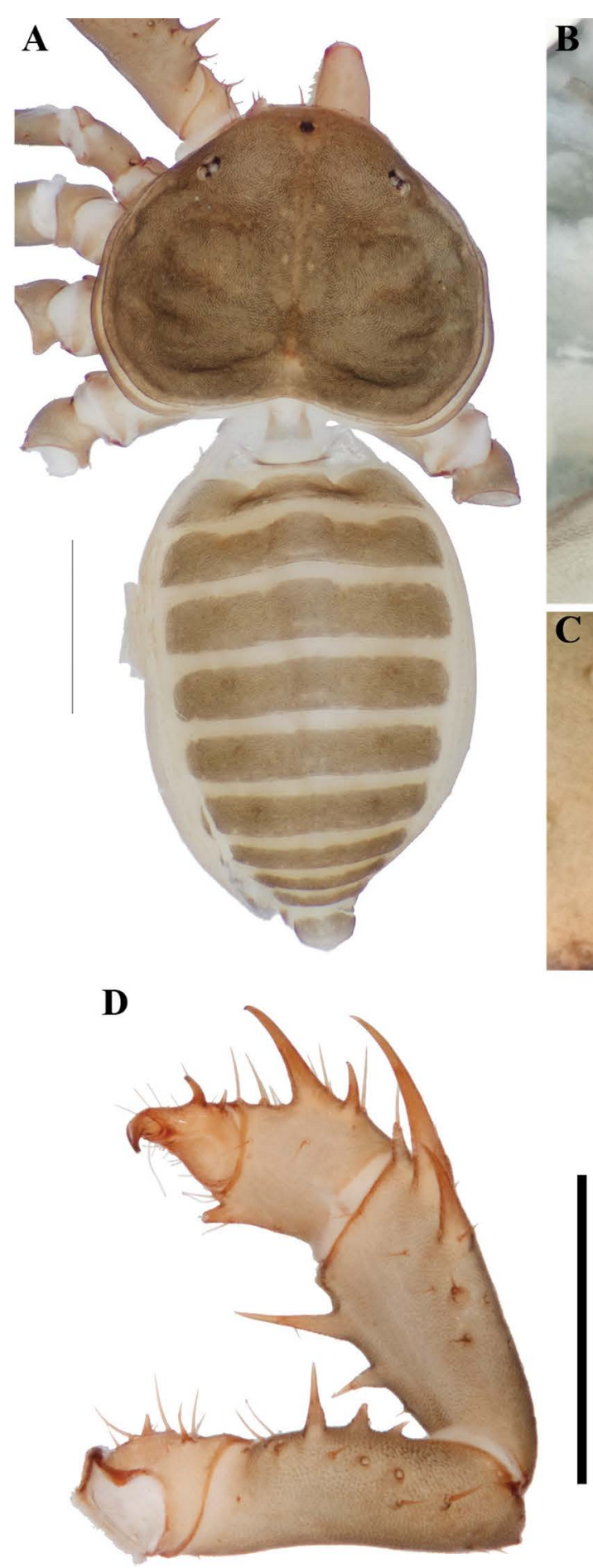
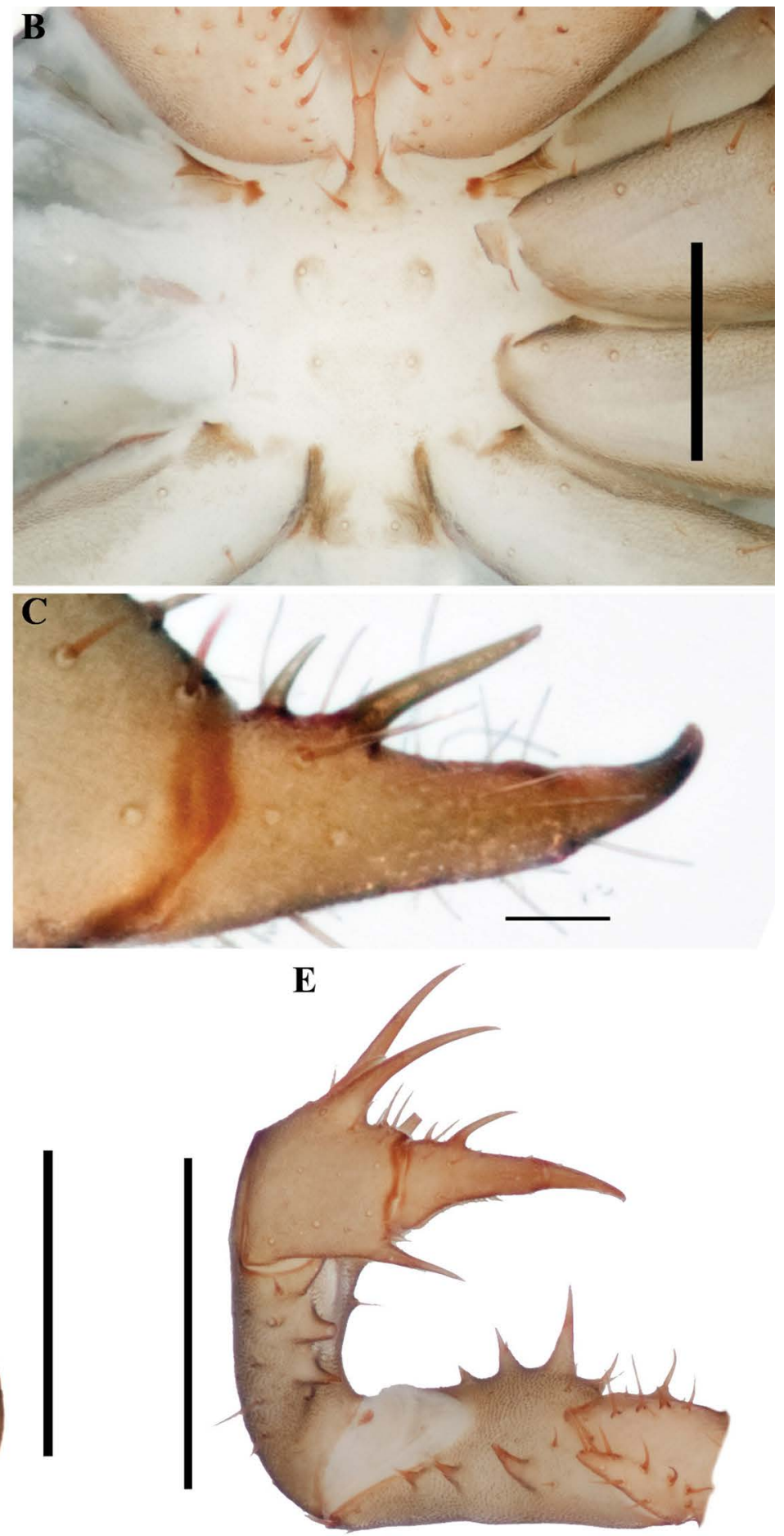

Fig. 13. Charinus aguayoi Moyá-Guzman, 2009 (USNM 782825), general morphology, ô. A. Carapace, dorsal view. B. Sternum, ventral view. C. Pedipalp tarsus, frontal view. D. Pedipalp, dorsal view. E. Pedipalp, ventral view. Scale bars: A, E-F $=1 \mathrm{~mm} ; \mathrm{B}=0.5 \mathrm{~mm} ; \mathrm{C}=0.1 \mathrm{~mm}$. 

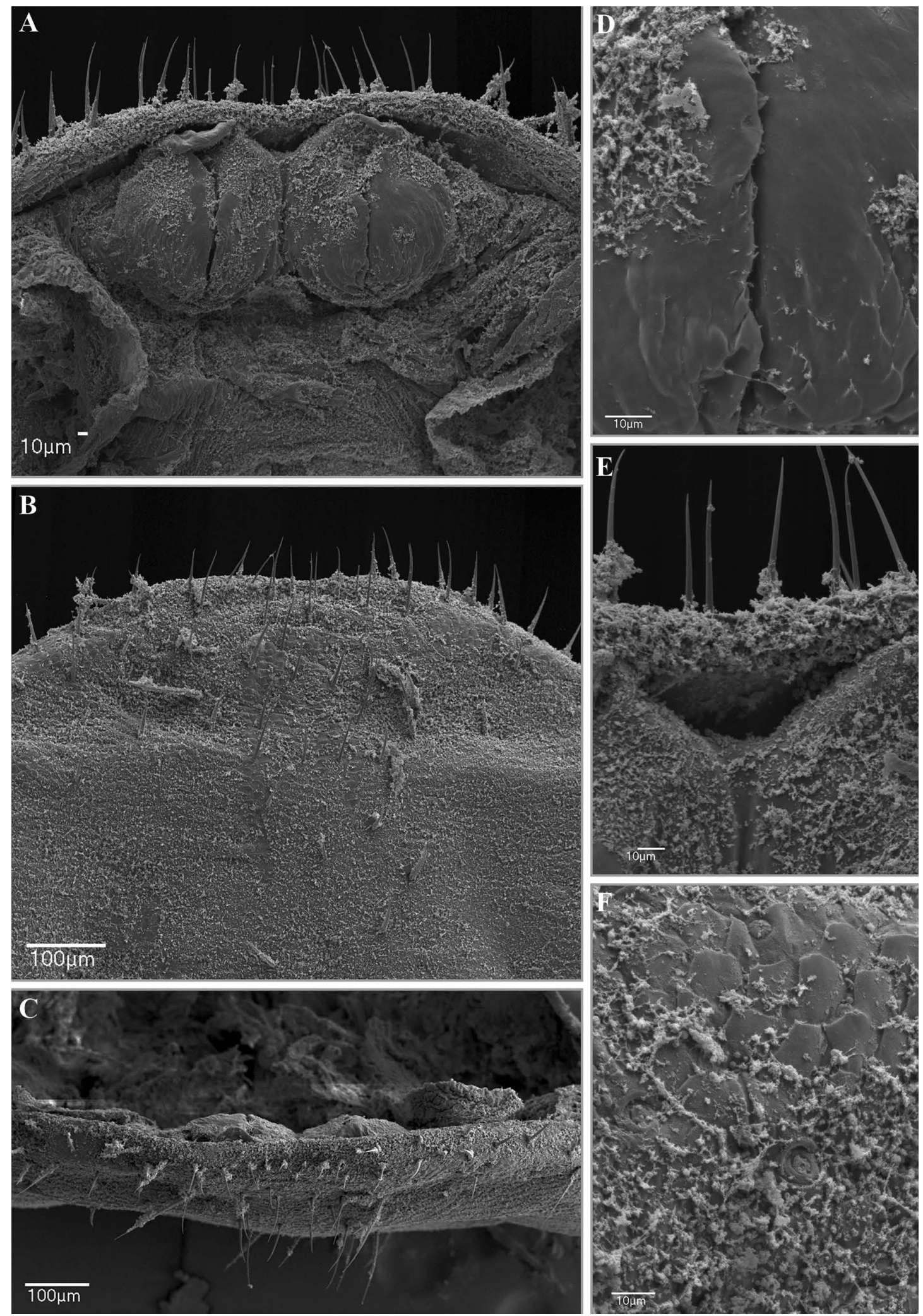

Fig. 14. Charinus aguayoi Moyá-Guzman, 2009 (CarBio), female gonopod and genital operculum. A. Gonopod, dorsal view. B. Genital operculum, ventral view. C. Gonopod and genital operculum, posterior view. D. Dextral gonopod, dorsal view. E. Genital operculum between gonopods, dorsal view. F. Gland on genital operculum, ventral view. 

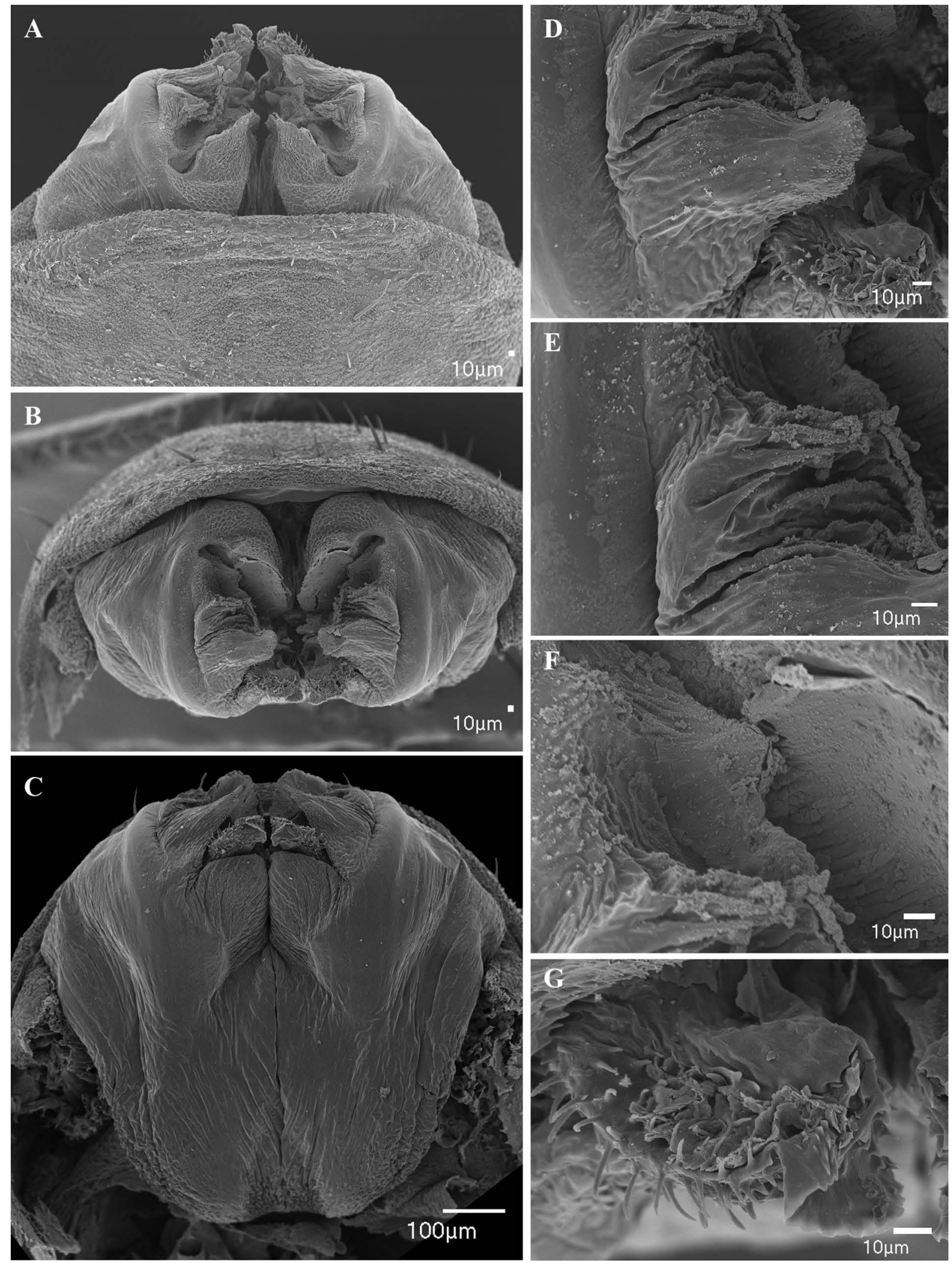

Fig. 15. Charinus aguayoi Moyá-Guzman, 2009 (USNM 392988), male gonopod. A. Ventral view. B. Posterior view. C. Dorsal view. D. Detail of lateral lobe 1. E. Detail of lateral lobe 2. F. Detail of processus internus. G. Detail of apex of dorsal lobe. 


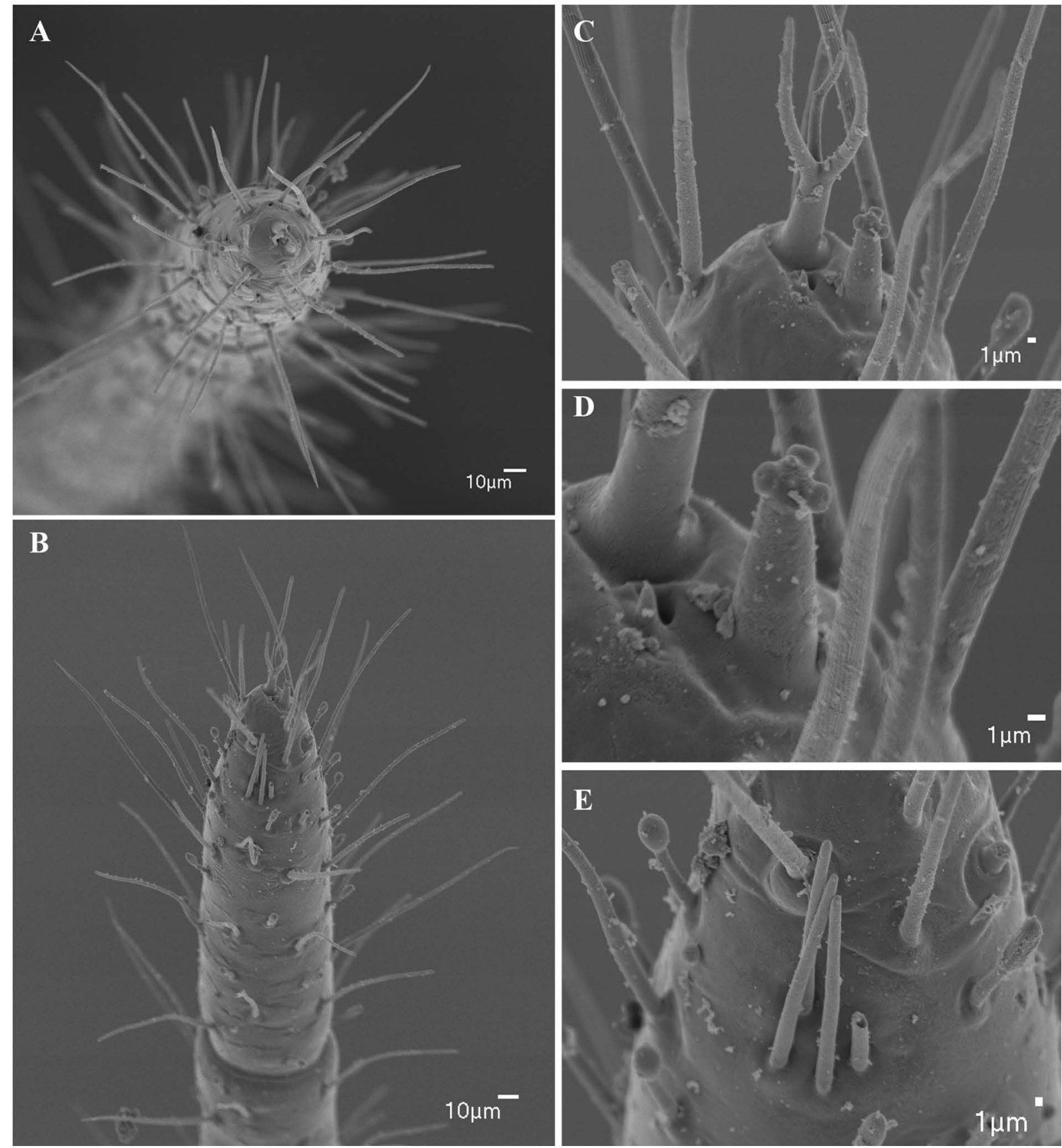

Fig. 16. Charinus aguayoi Moyá-Guzman, 2009 (USNM 785110), antenniform leg I, q. A. Apex of distal article. B. Distal segment of tarsus, lateral view. C. Apex of distal article of tarsus showing claw and tarsal organ. D. Detail of tarsal organ. E. Rod sensilla and olfactory setae. 
MIRANDA G.S. et al., Systematic revision of Charinidae (Arachnida, Amblypygi)
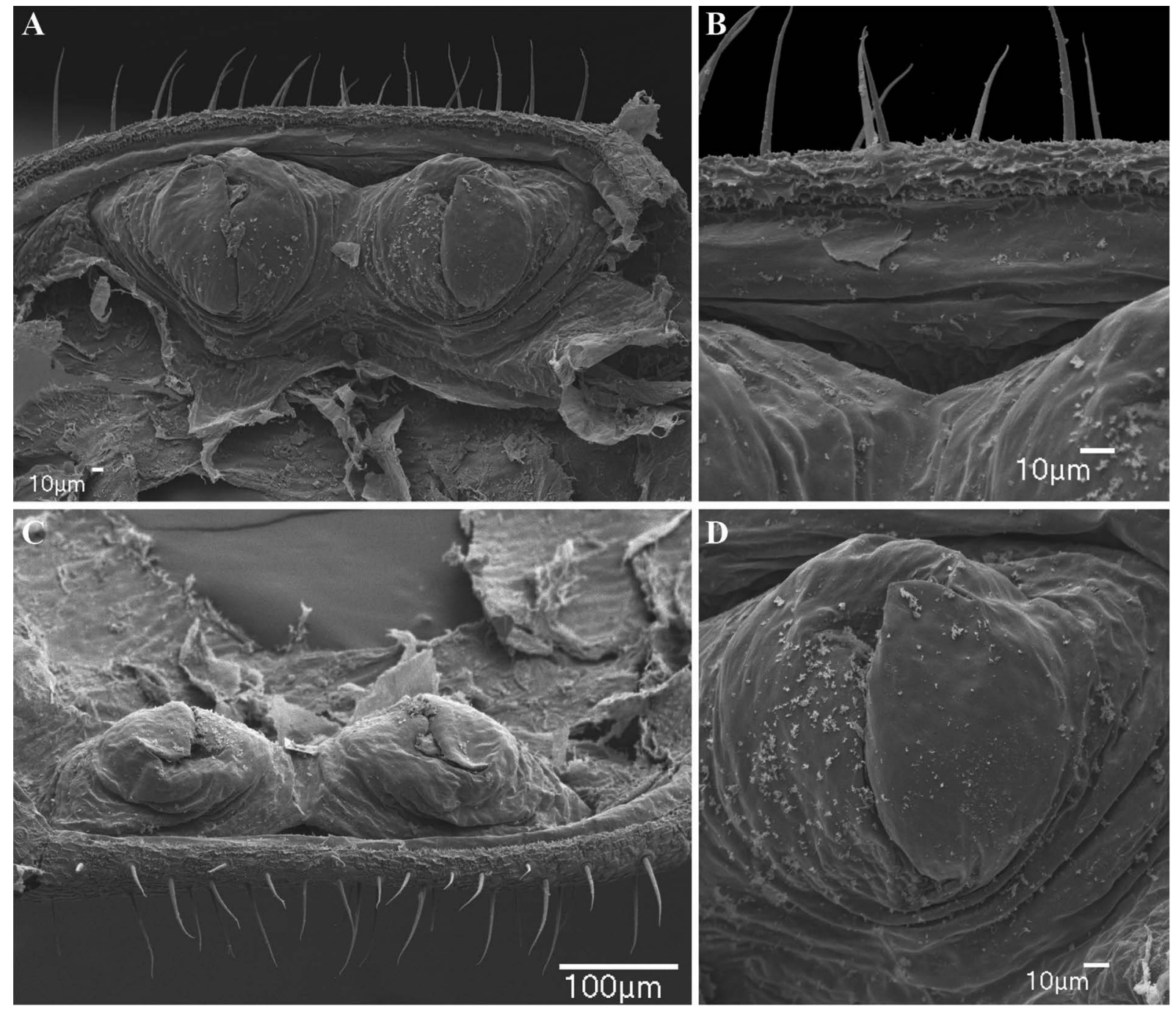

Fig. 17. Charinus caribensis (Quintero, 1986) (SMNS), female gonopod. A. Gonopod, ventral view. B. Genital operculum between gonopods. C. Gonopod, posterior view. D. Sinistral gonopod. 

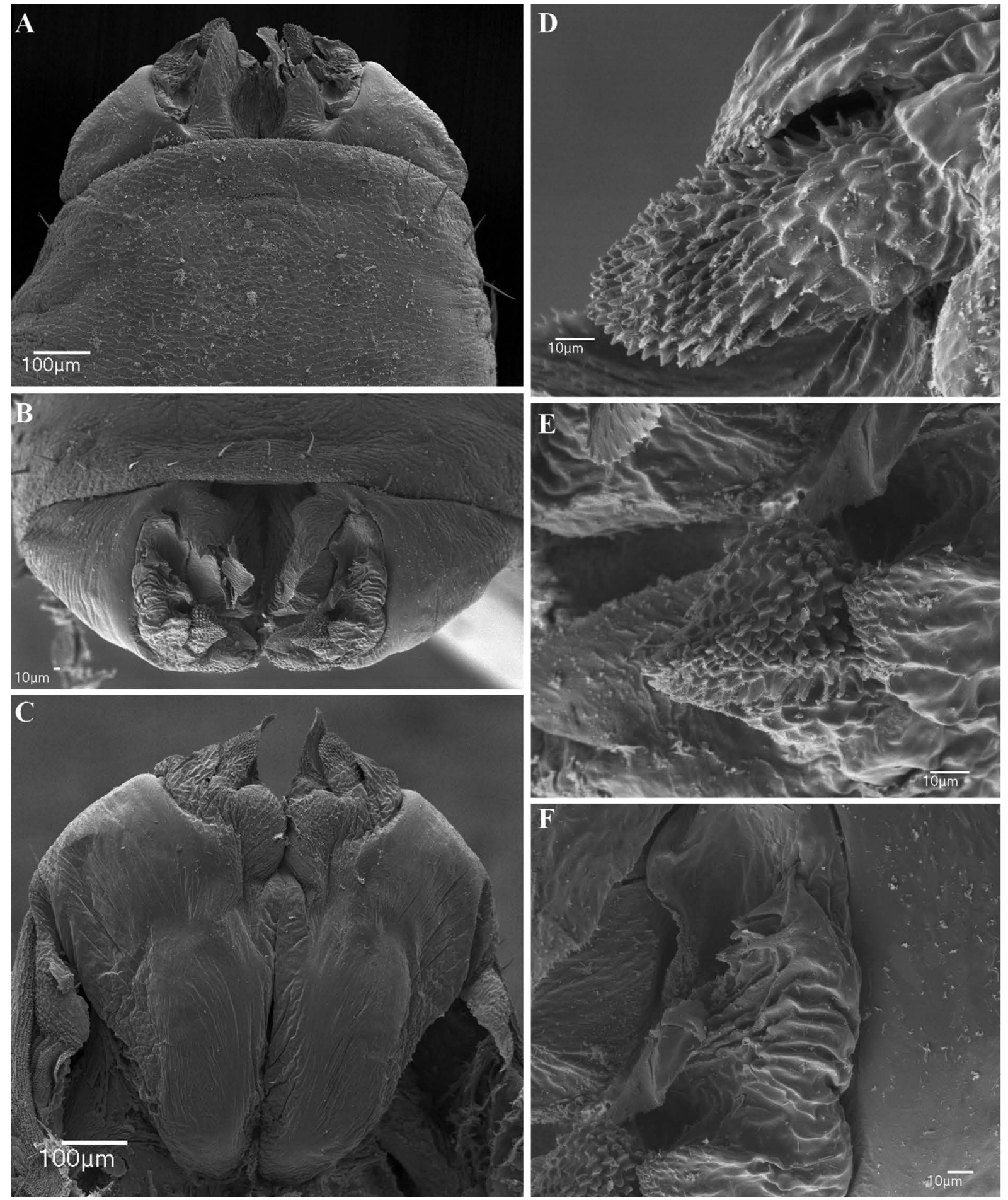

Fig. 18. Charinus caribensis (Quintero, 1986) (SMNS), male gonopod. A. Ventral view. B. Posterior view. C. Dorsal view. D. Dorsal lobe. E. Lateral lobe 1 and dorsal lobe. F. Lateral lobe 2. 


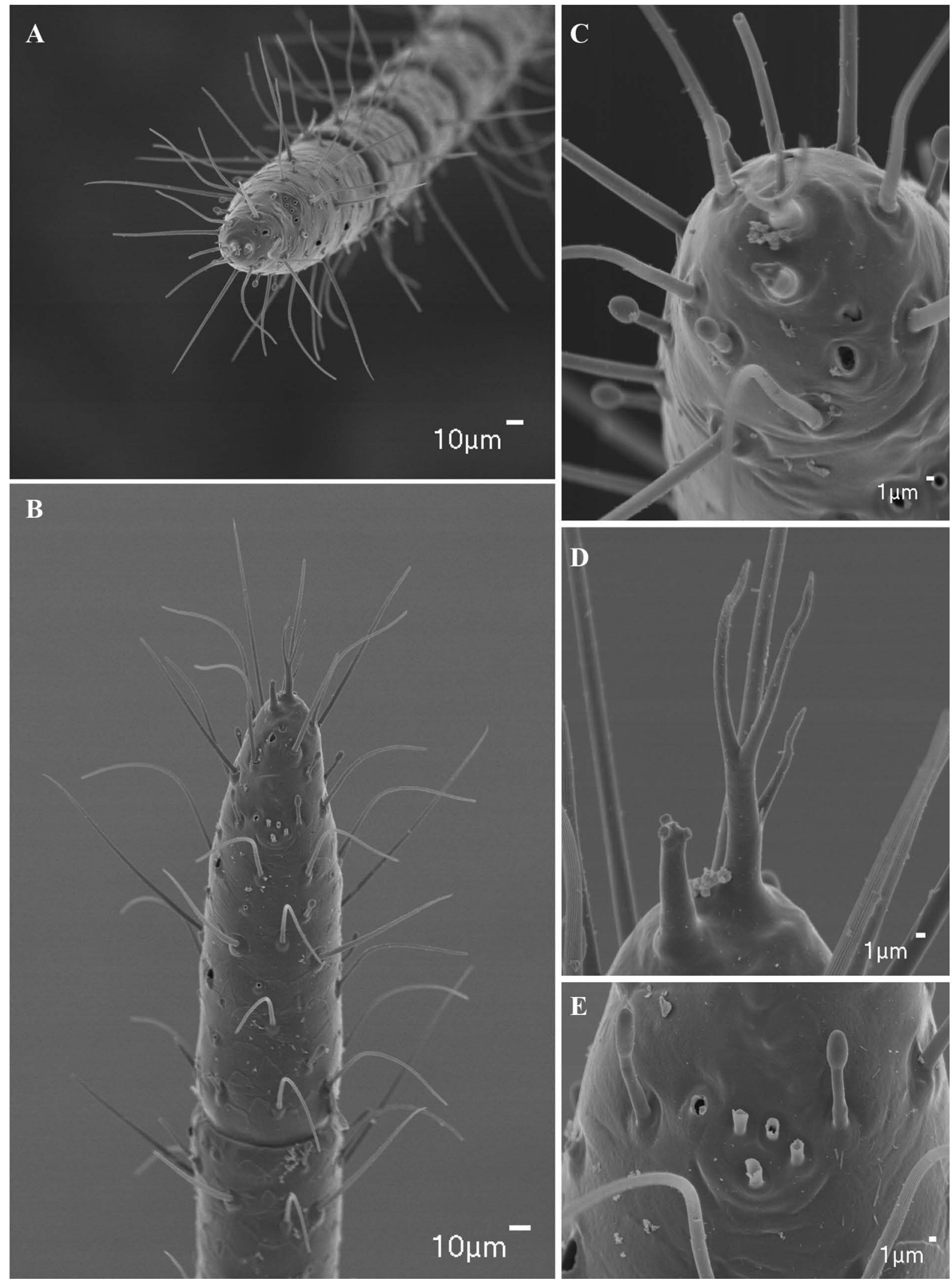

Fig. 19. Charinus caribensis (Quintero, 1986) (SMNS), antenniform leg I. A. Apex of distal article. B. Distal segment of tarsus, lateral view. C. Apex of distal article of tarsus showing claw and tarsal organ. D. Detail of claw tarsal organ. E. Rod sensilla and part of olfactory setae. 


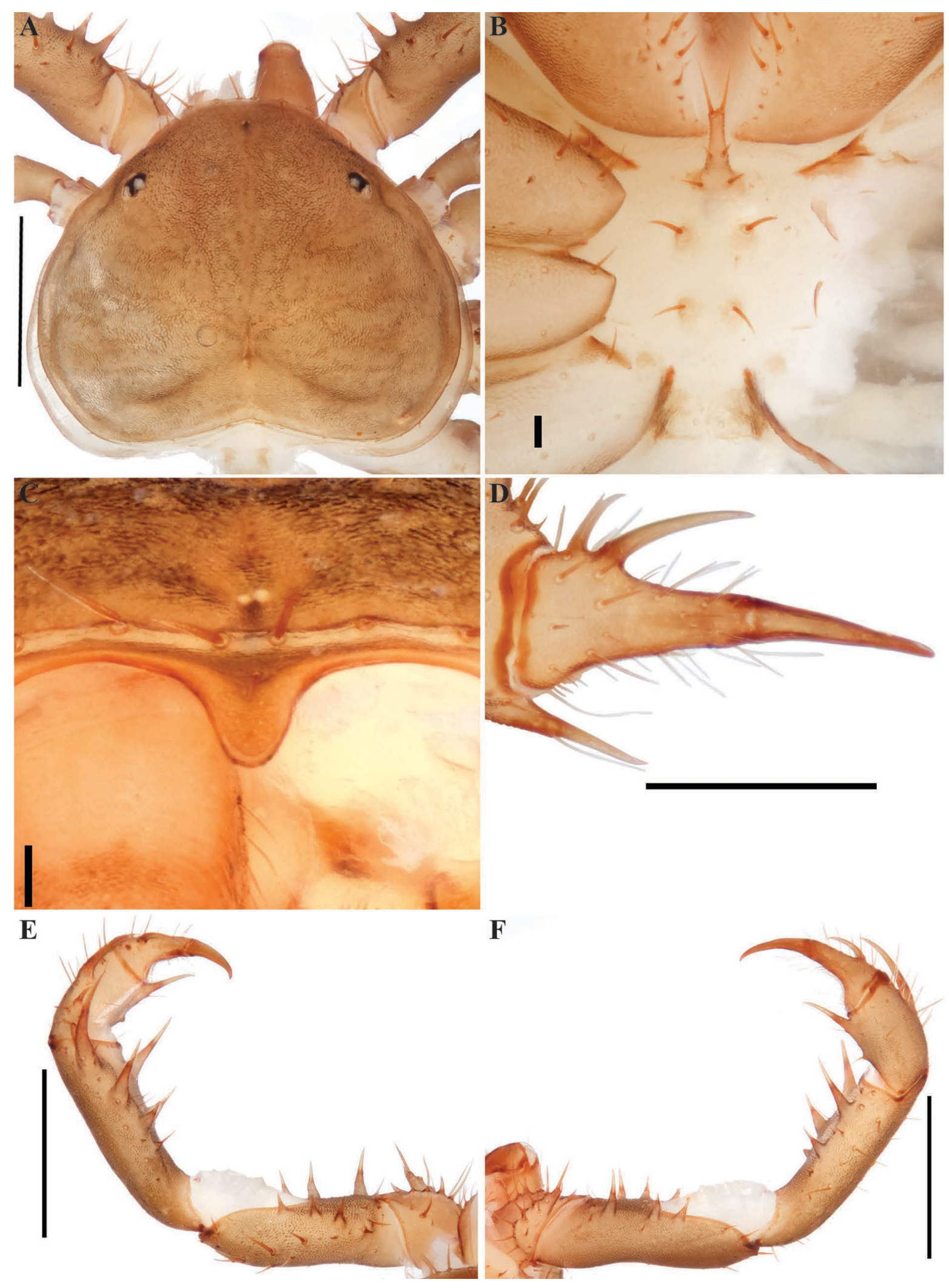

Fig. 20. Charinus cubensis (Quintero, 1983) (USNM 784407), general morphology, ๆ. A. Carapace, dorsal view. B. Sternum, ventral view. C. Frontal process. D. Pedipalp tarsus, frontal view. E. Pedipalp, dorsal view. F. Pedipalp, ventral view. Scale bars: A, E-F $=1 \mathrm{~mm} ; \mathrm{B}=0.1 \mathrm{~mm}$; $\mathrm{C}-\mathrm{D}=0.5 \mathrm{~mm}$. 

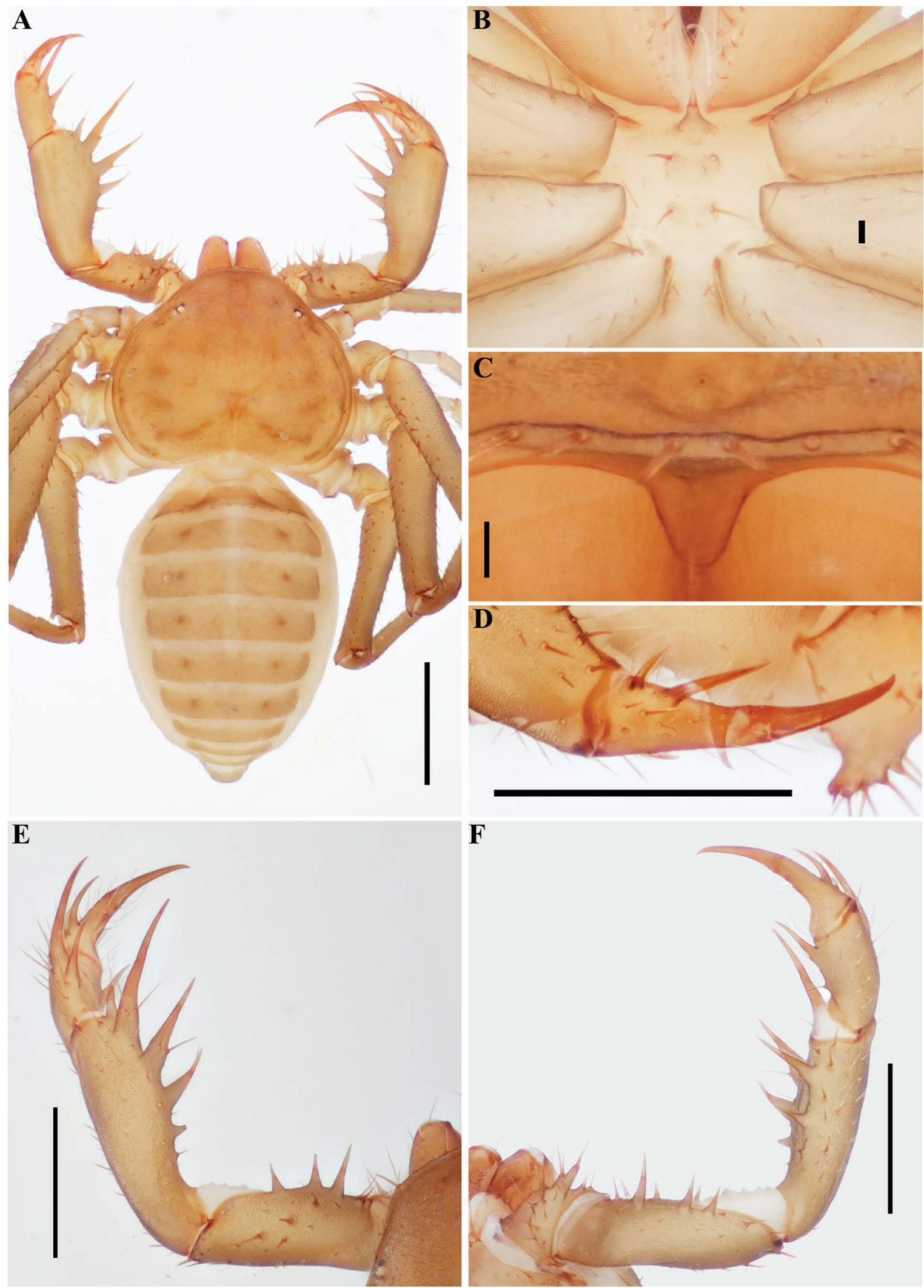

Fig. 21. Charinus dominicanus Armas \& Perez, 2001 (AMCC [LP 10473]), general morphology, Õ. A. Habitus, dorsal view. B. Sternum, ventral view. C. Frontal process. D. Pedipalp tarsus, frontal view. E. Pedipalp, dorsal view. F. Pedipalp, ventral view. Scale bars: A, D-F $=1 \mathrm{~mm}$; $-\mathrm{C}=0.1 \mathrm{~mm}$. 

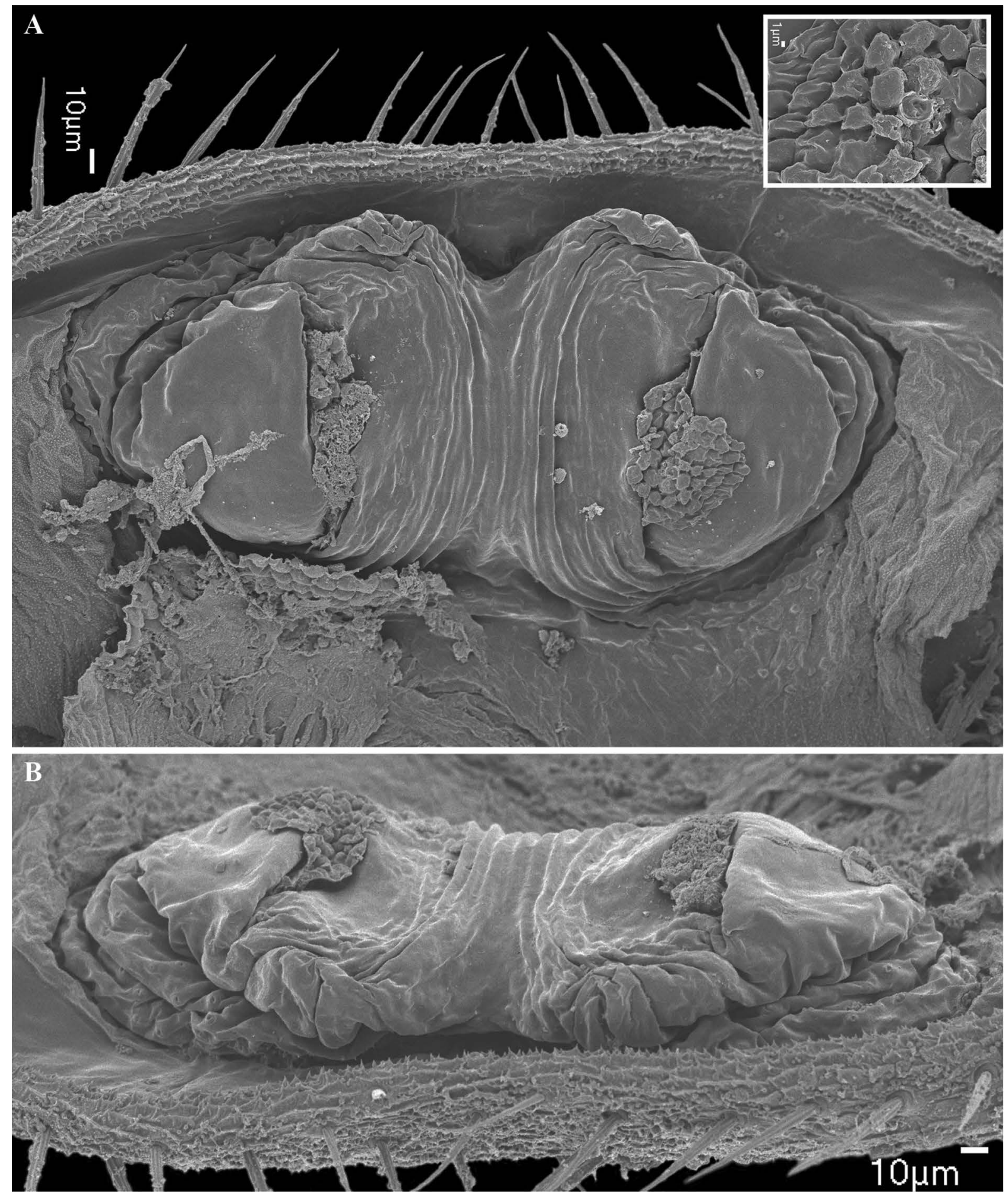

Fig. 22. Charinus dominicanus Armas \& Perez, 2001 (AMNH), female gonopod. A. Dorsal view. Inset: sperm sac attached to atrium entrance. B. Posterior view. 

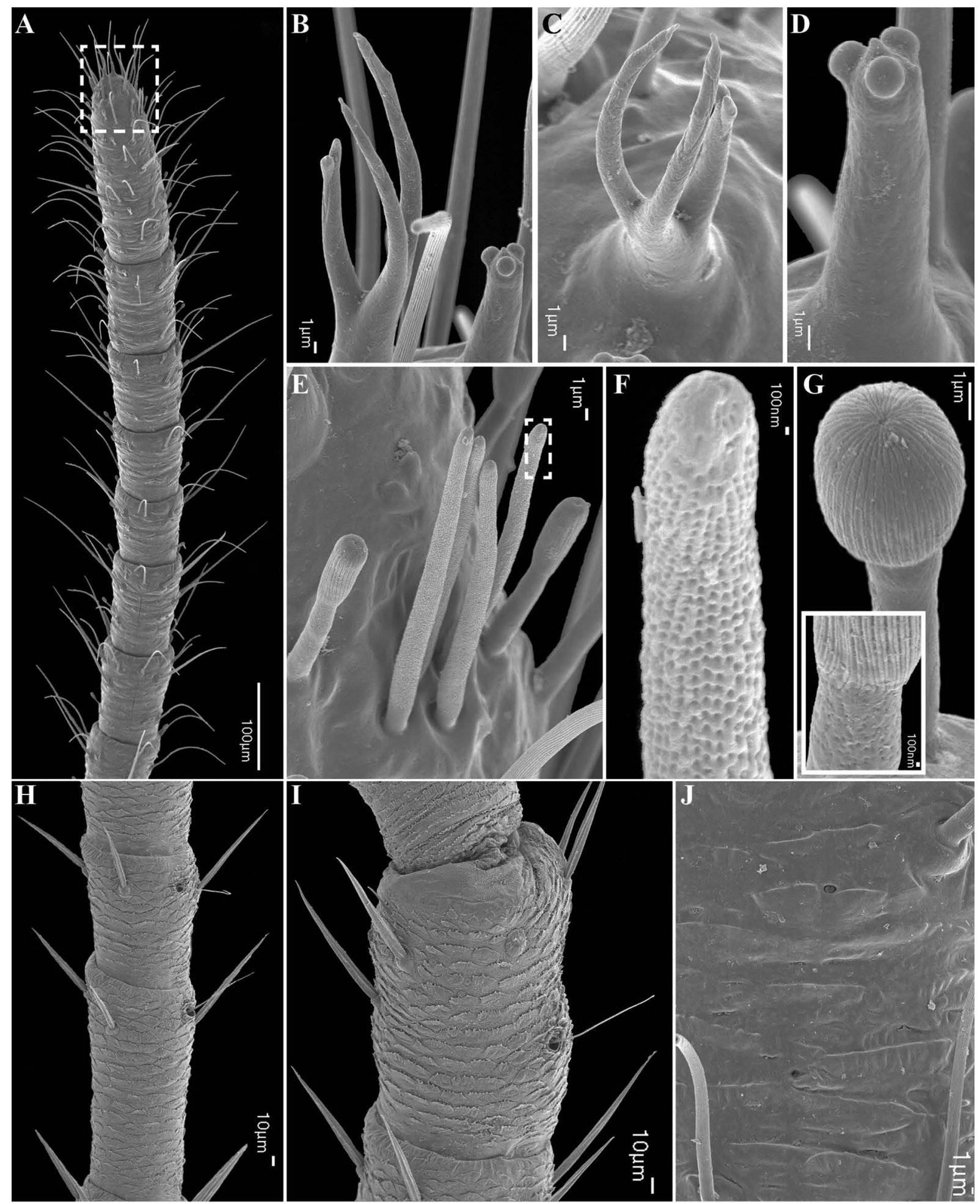

Fig. 23. Charinus dominicanus Armas \& Perez, 2001 (AMNH), antenniform leg I, . . A. Distal tarsal articles. B. Apex of distal article showing modified claw and tarsal organ. C. Claw. D. Tarsal organ. E. Rod sensilla with olfactory setae. F. Apex of olfactory seta. G. Clavate setae. Inset: small punctures at setal base. H. Trichobothria on distal articles of tibia of leg I. I. Trichobothria on last article of tibia of leg I. J. Sensory gland opening on tarsal article 13. 
A

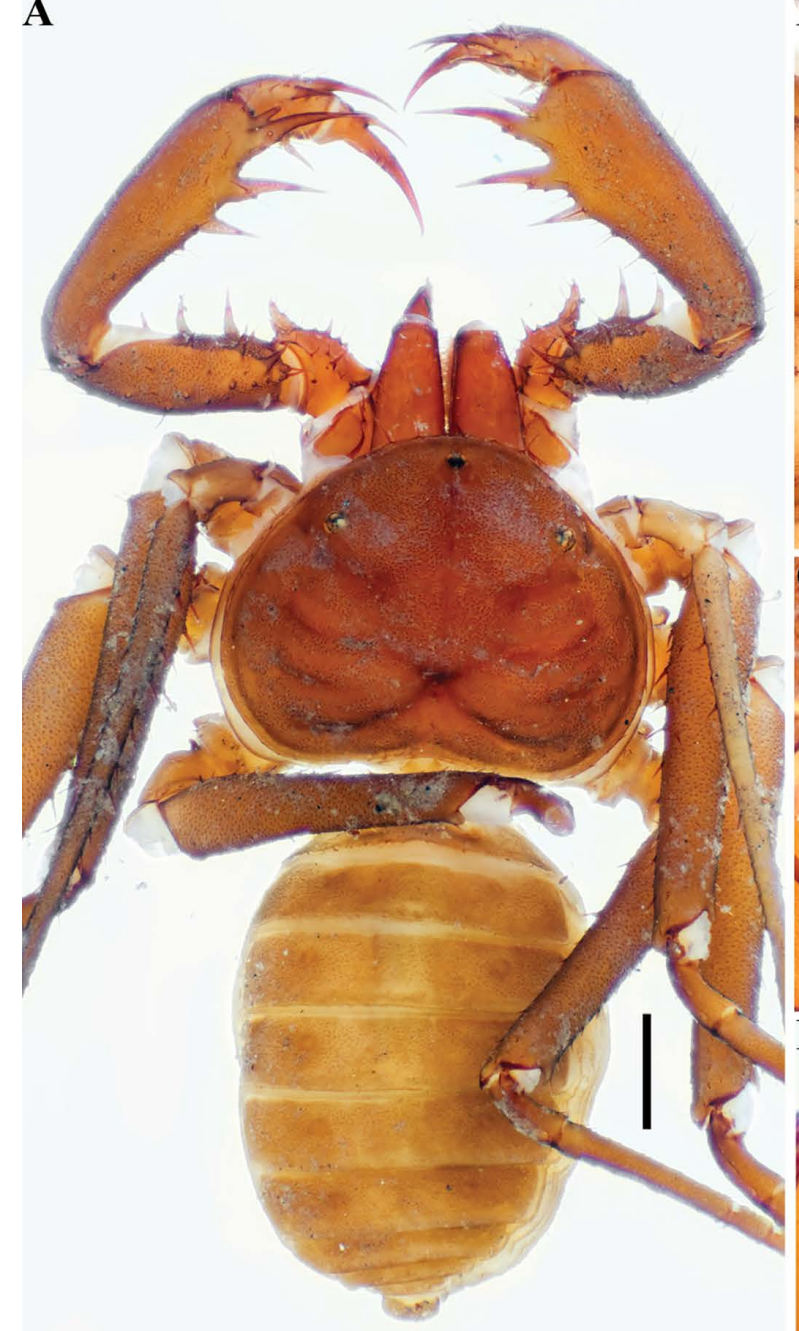

$\mathbf{E}$

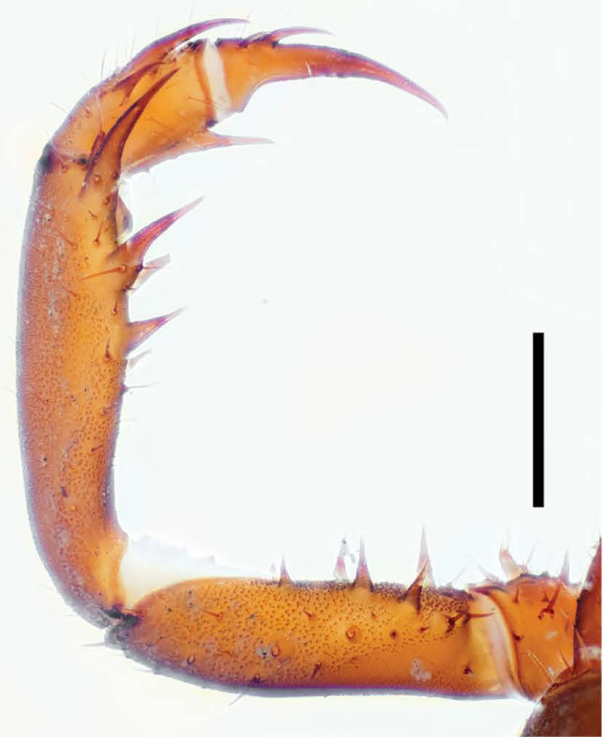

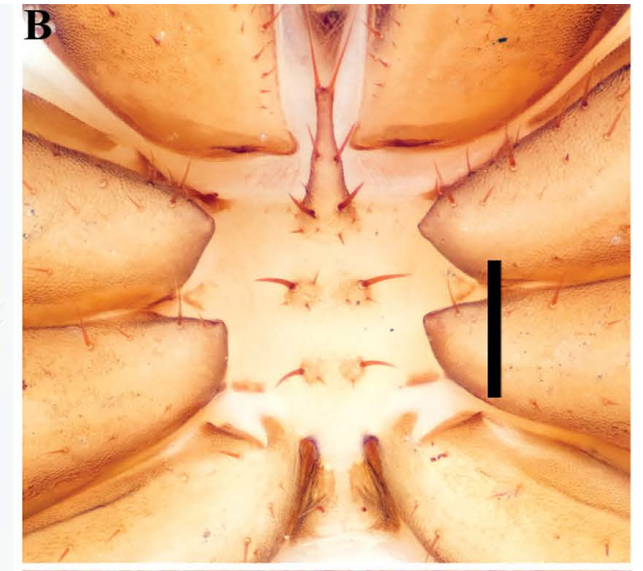
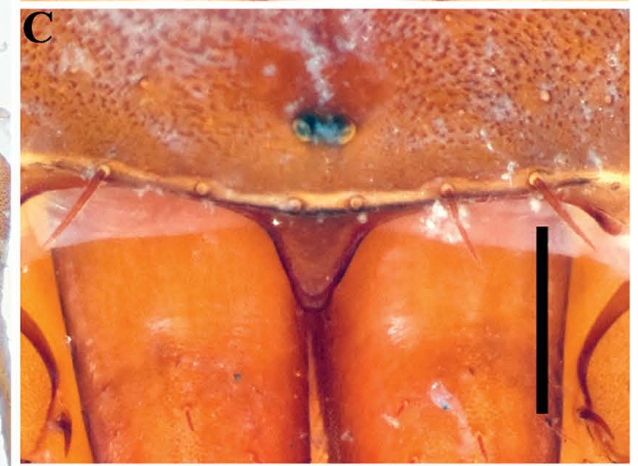

D

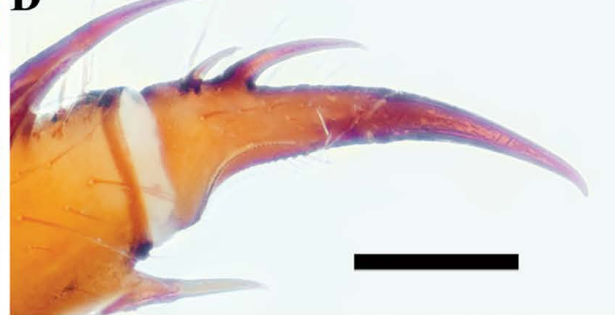

$\mathbf{F}$

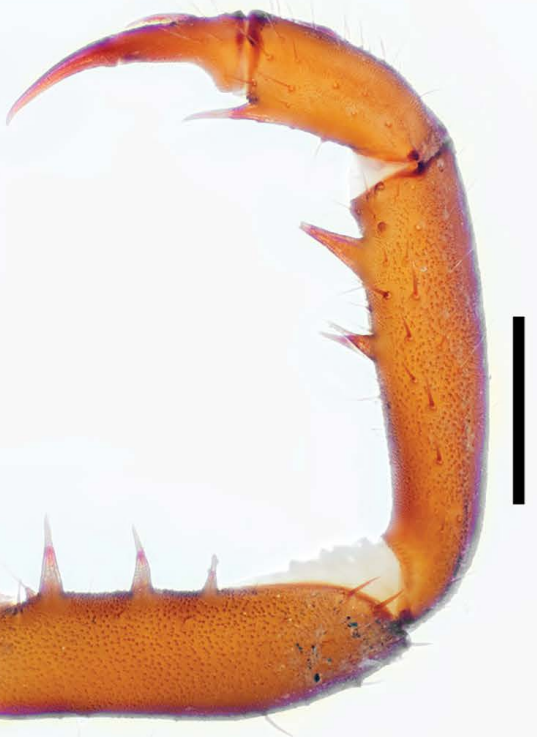

Fig. 24. Charinus miskito sp. nov. (SMNS), general morphology, + . A. Habitus, dorsal view. B. Frontal process. C. Sternum, ventral view. D. Pedipalp tarsus, frontal view. E. Pedipalp, dorsal view. F. Pedipalp, ventral view. Scale bars: A, E-F $=1 \mathrm{~mm}$; $B-D=0.5 \mathrm{~mm}$. 

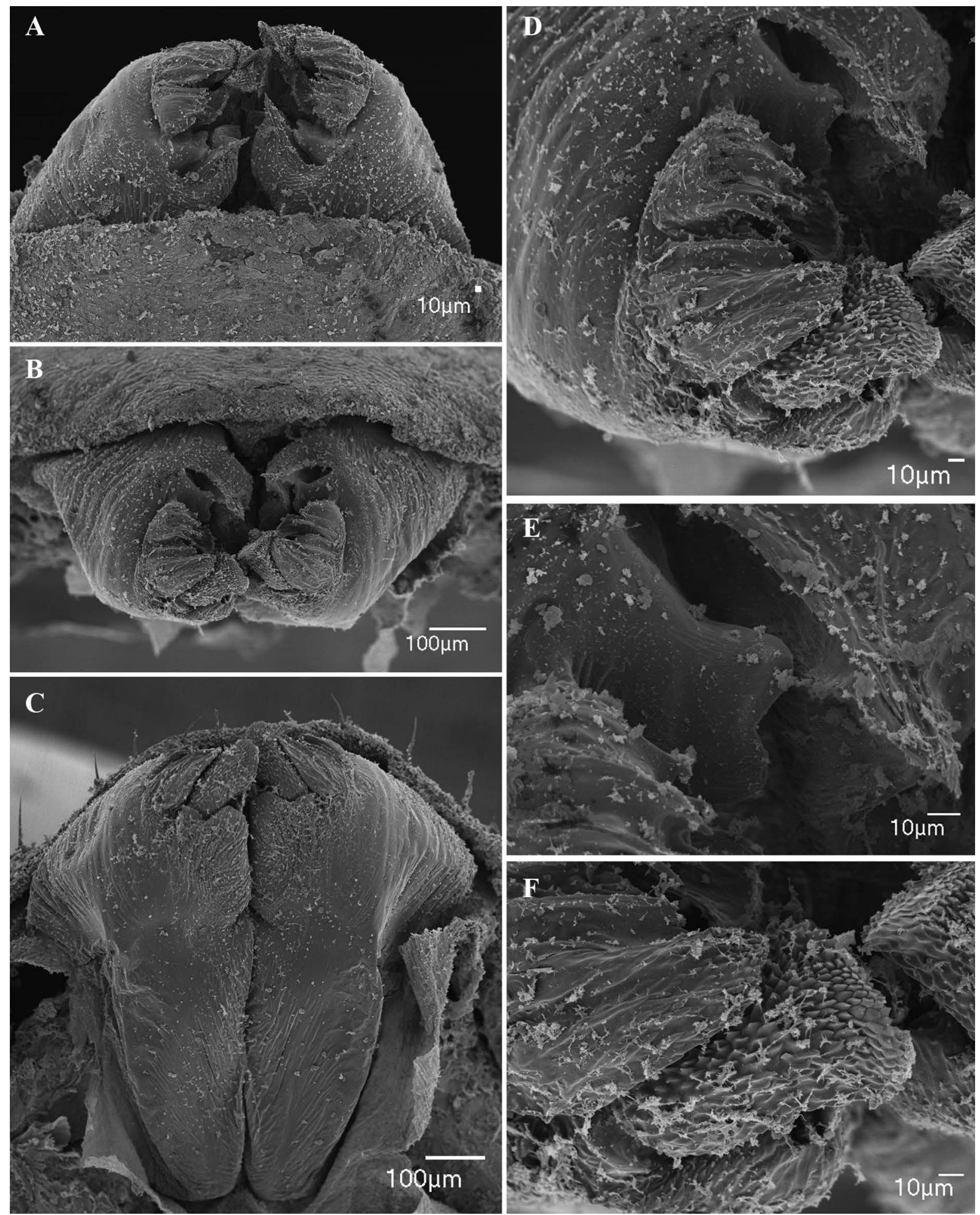

Fig. 25. Charinus miskito sp. nov. (SMNS), male gonopod. A. Ventral view. B. Posterior view. C. Dorsal view. D. Detail of the lateral lobe 2. E. Detail of processus internus. F. Detail of lateral lobe 1 and dorsal lobe. 

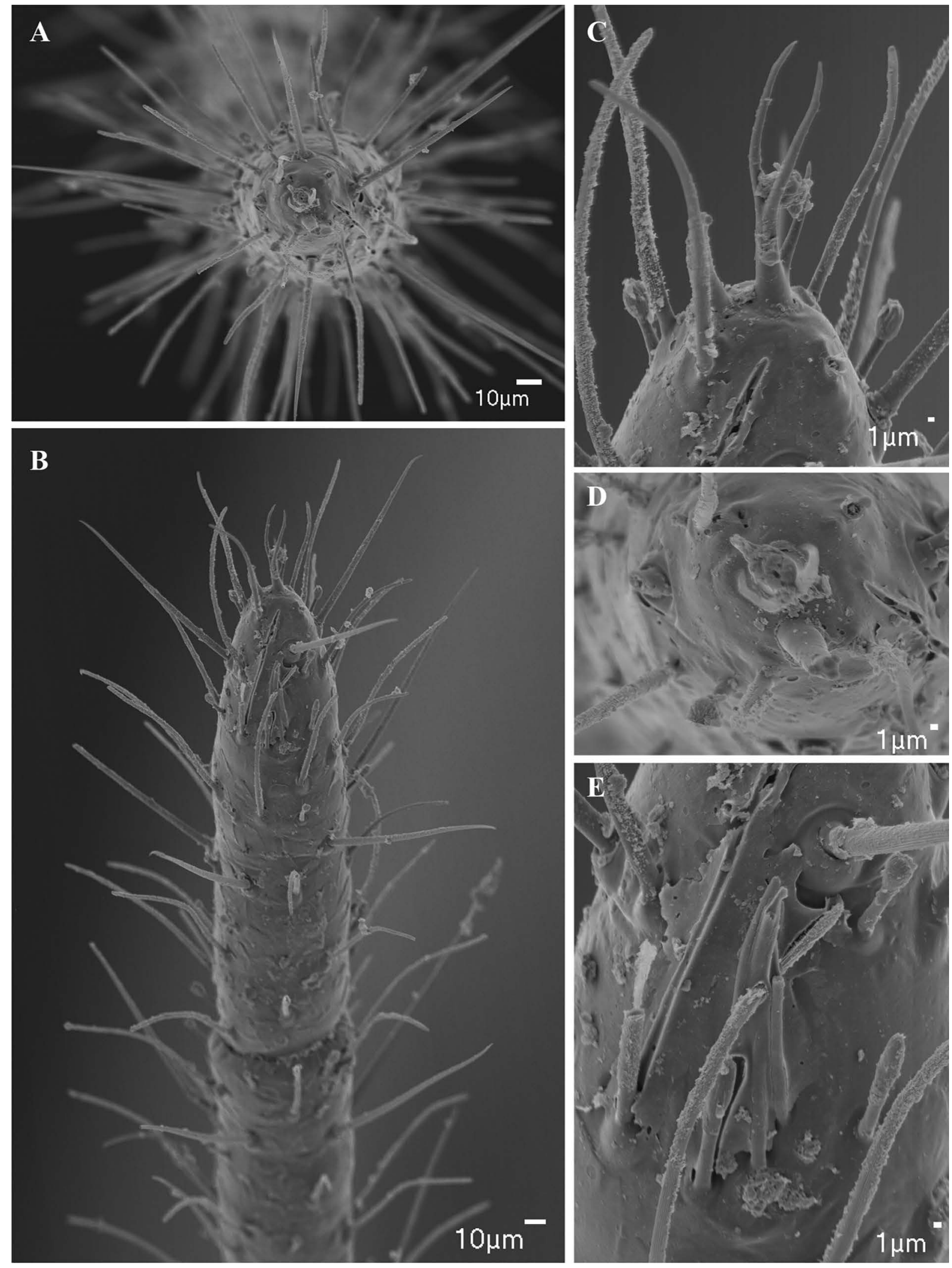

Fig. 26. Charinus miskito sp. nov. (SMNS), antenniform leg I, §. A. Apex of distal article. B. Distal segment of tarsus, lateral view. C. Apex of distal article of tarsus showing claw and tarsal organ. D. Detail of claw tarsal organ. E. Rod sensilla and olfactory setae. 
MIRANDA G.S. et al., Systematic revision of Charinidae (Arachnida, Amblypygi)

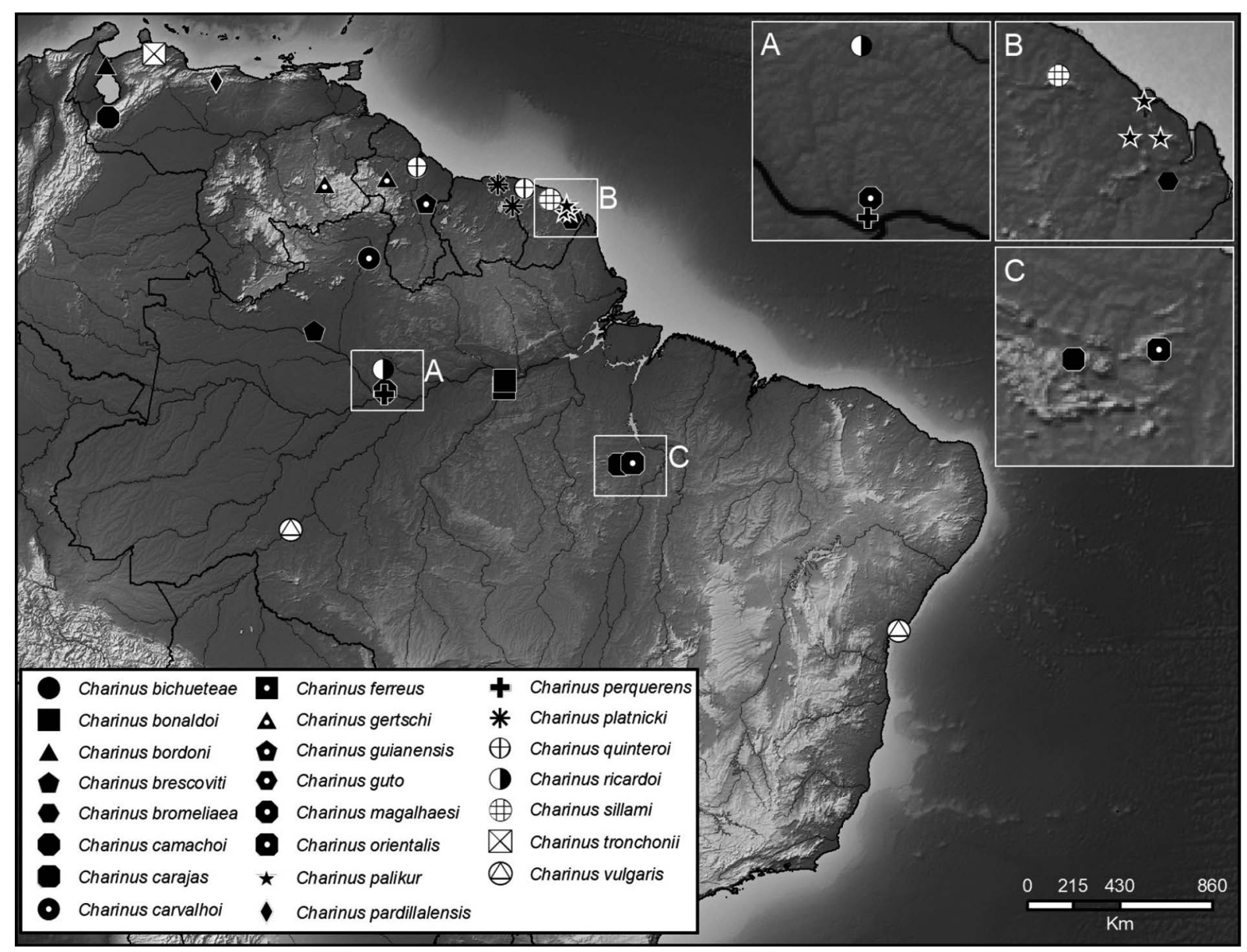

Fig. 27. Map plotting known distributions of species of Charinus Simon, 1892 in northern South America. 


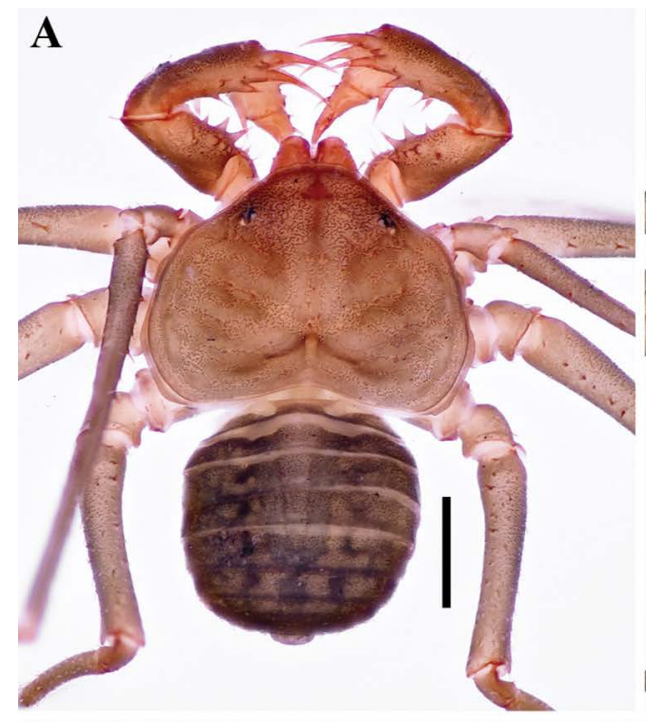

$\mathbf{E}$
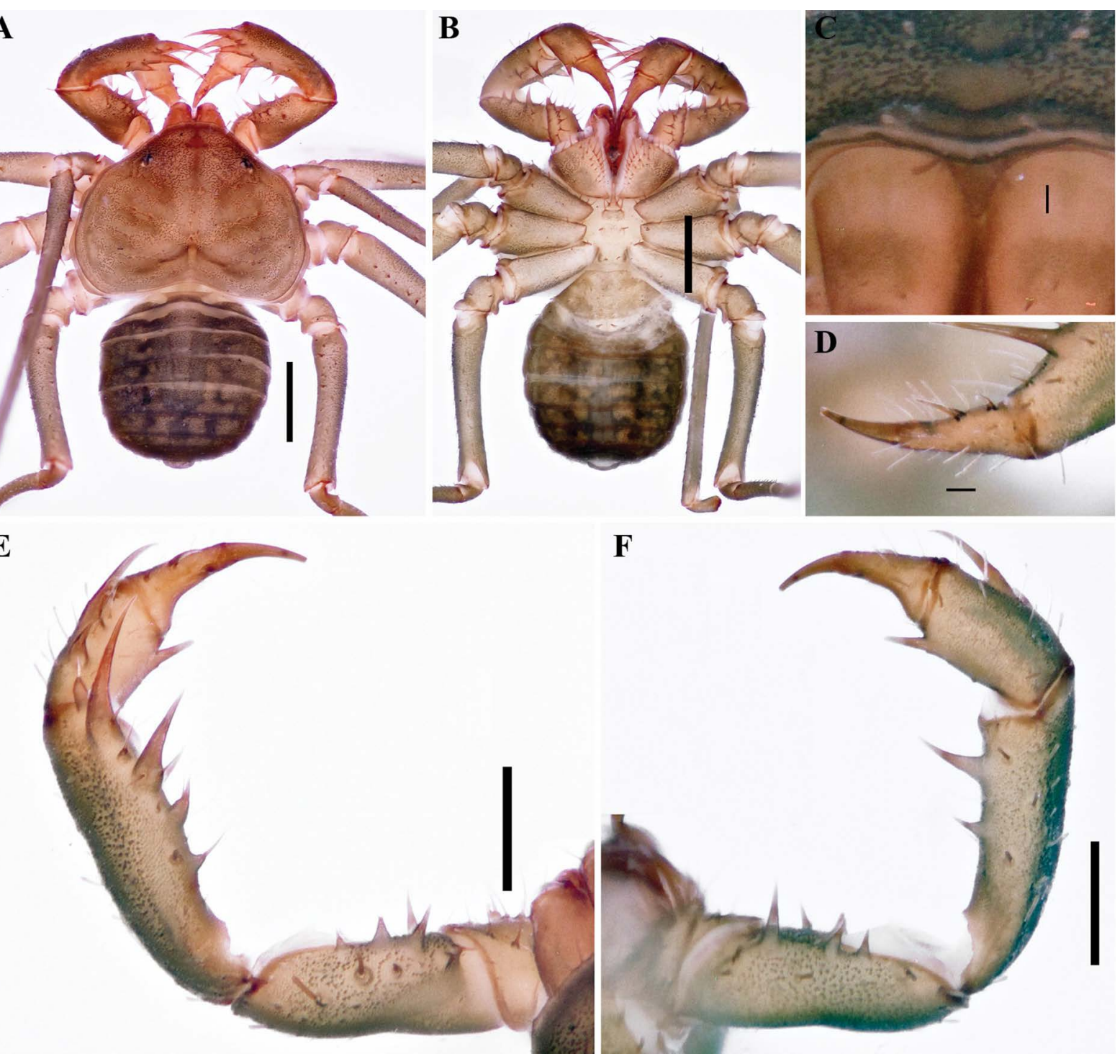

\section{$\mathbf{F}$}
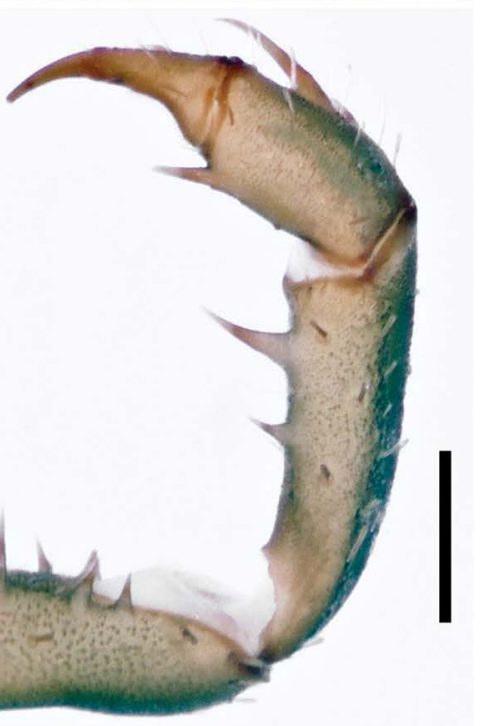

Fig. 28. Charinus carvalhoi sp. nov. (CHNUFPI 1324), general morphology, $q$. A. Habitus, dorsal view. B. Habitus, ventral view. C. Frontal process. D. Pedipalp tarsus, frontal view. E. Pedipalp, dorsal view. F. Pedipalp, ventral view. Scale bars: $A-B=1 \mathrm{~mm}$; $-D=0.1 \mathrm{~mm}$; E-F $=0.5 \mathrm{~mm}$. 

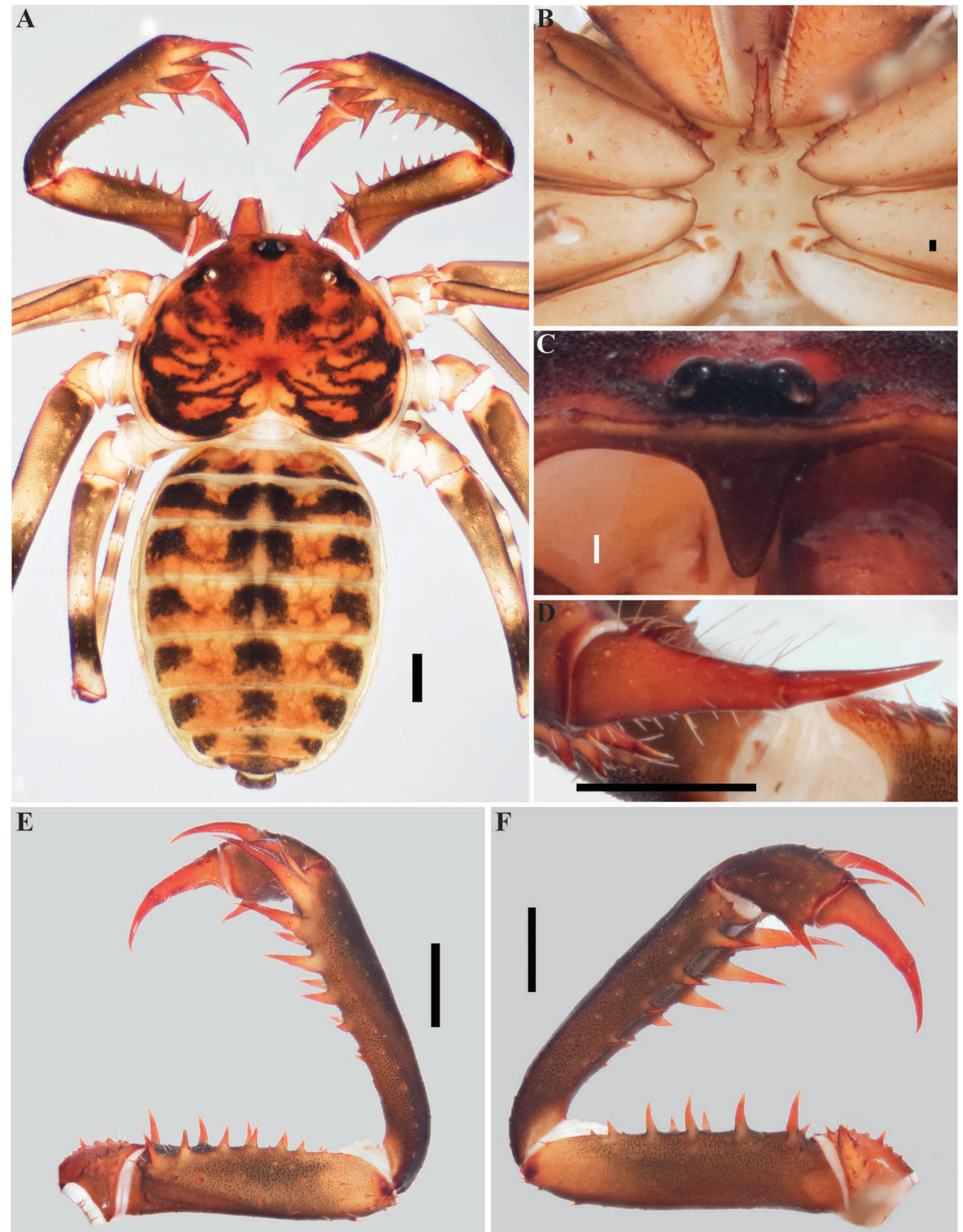

Fig. 29. Charinus gertschi Goodnight \& Goodnight, 1946 (AMCC [LP 10076]), general morphology, . A. Habitus, dorsal view. B. Sternum, ventral view. C. Frontal process. D. Pedipalp tarsus, frontal view. E. Pedipalp, dorsal view. F. Pedipalp, ventral view. Scale bars: A, D-F $=1 \mathrm{~mm}$; B-C $=0.1 \mathrm{~mm}$. 

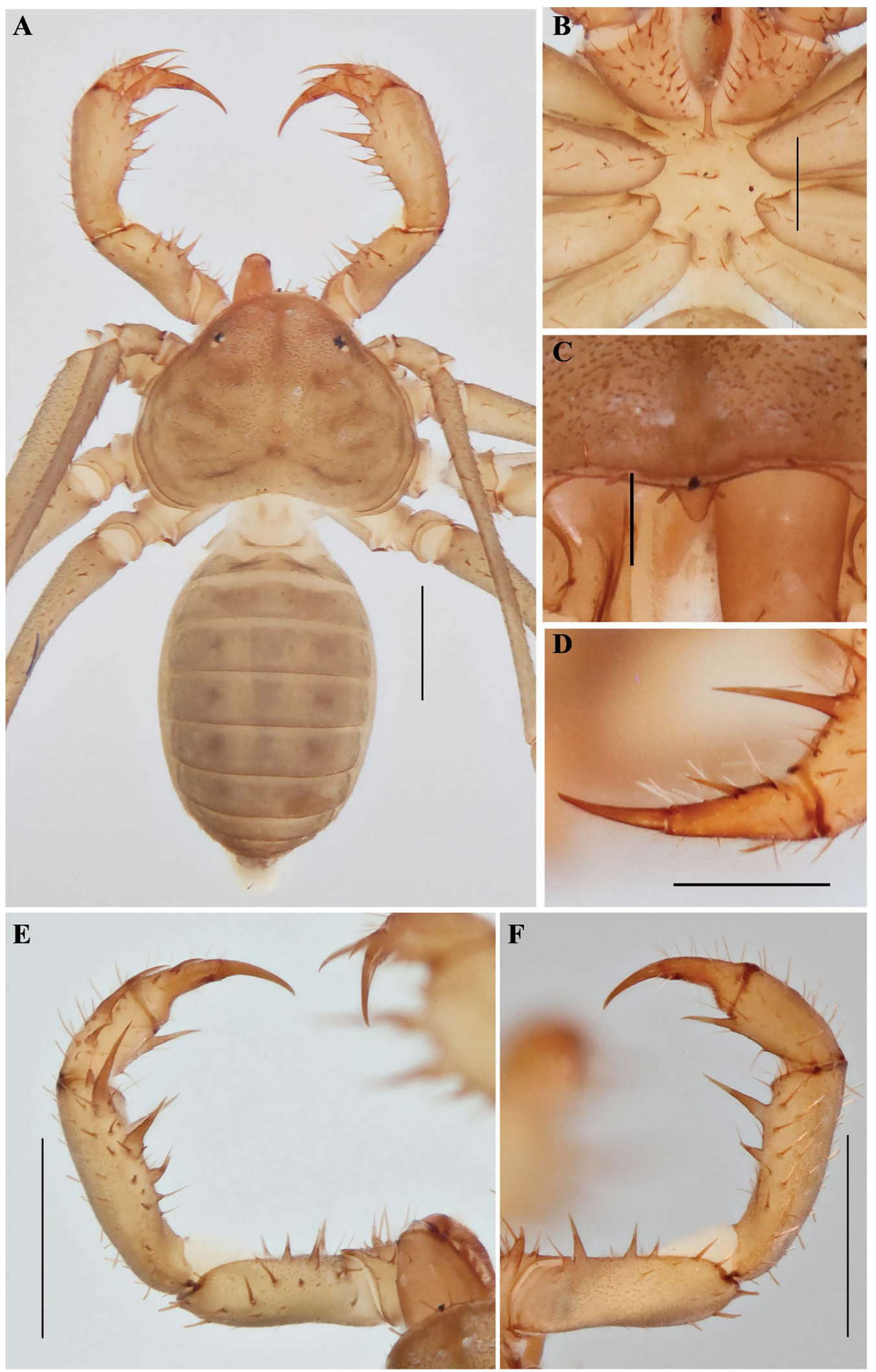

Fig. 30. Charinus magalhaesi sp. nov. (MNRJ 9285), general morphology,. A. Habitus, dorsal view. B. Sternum, ventral view. C. Frontal process. D. Pedipalp tarsus, frontal view. E. Pedipalp, dorsal view. F. Pedipalp, ventral view. Scale bars: A, E-F $=1 \mathrm{~mm} ; \mathrm{B}, \mathrm{D}=0.5 \mathrm{~mm} ; \mathrm{C}=0.25 \mathrm{~mm}$. 

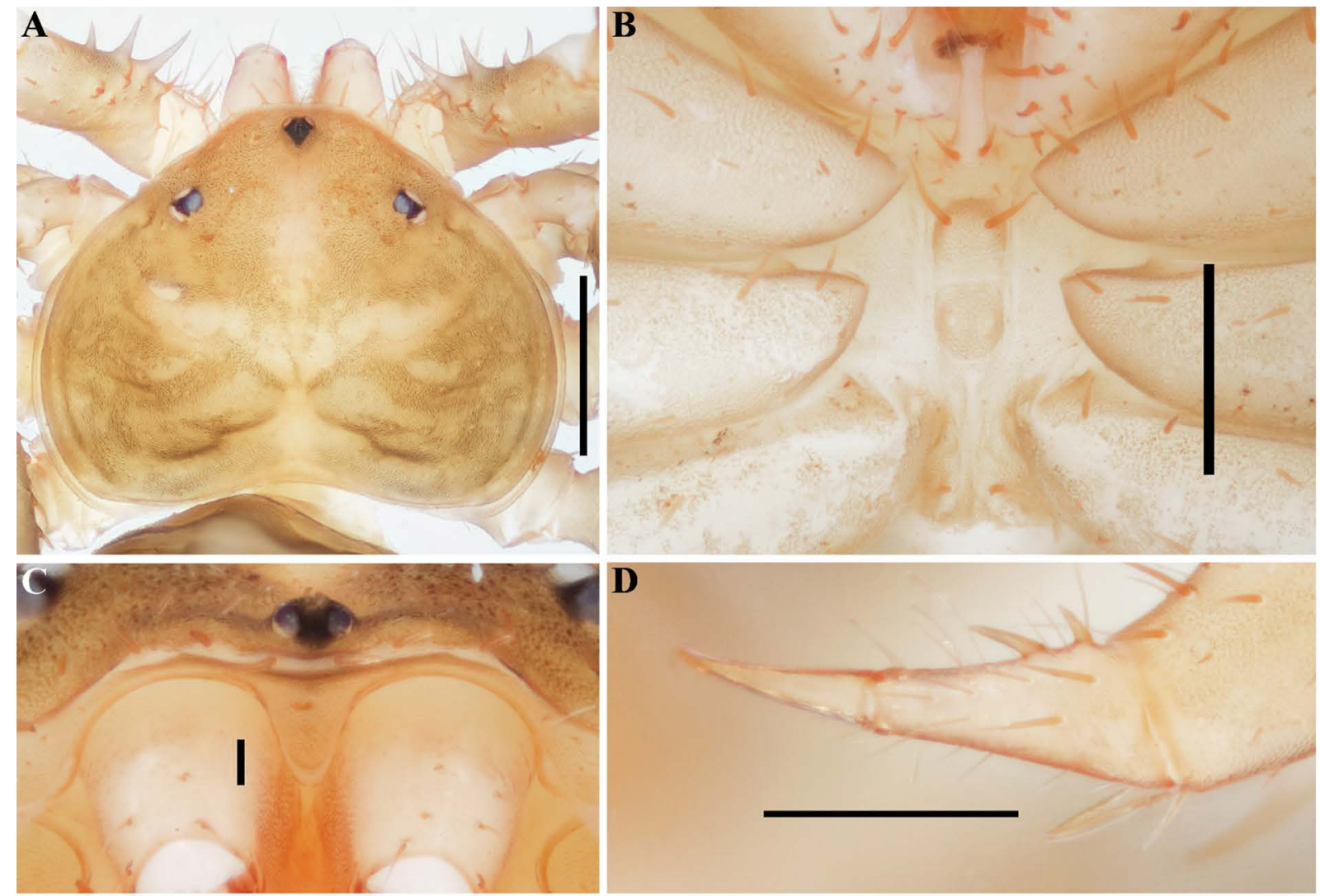

$\mathbf{E}$

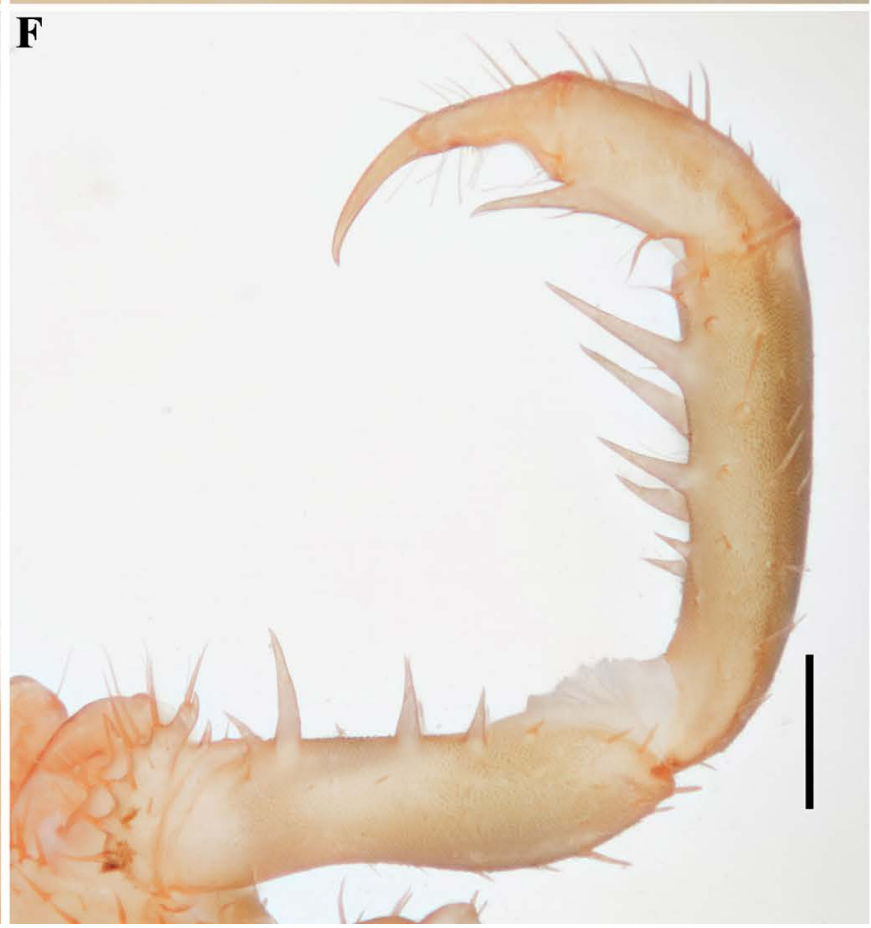

Fig. 31. Charinus palikur sp. nov. (AMCC [LP 3832]), general morphology, $\widehat{\jmath}$. A. Carapace, dorsal view. B. Sternum, ventral view. C. Frontal process. D. Pedipalp tarsus, frontal view. E. Pedipalp, dorsal view. F. Pedipalp, ventral view. Scale bars: $A=1 \mathrm{~mm} ; B, D-F=0.5 \mathrm{~mm} ; C=0.1 \mathrm{~mm}$. 


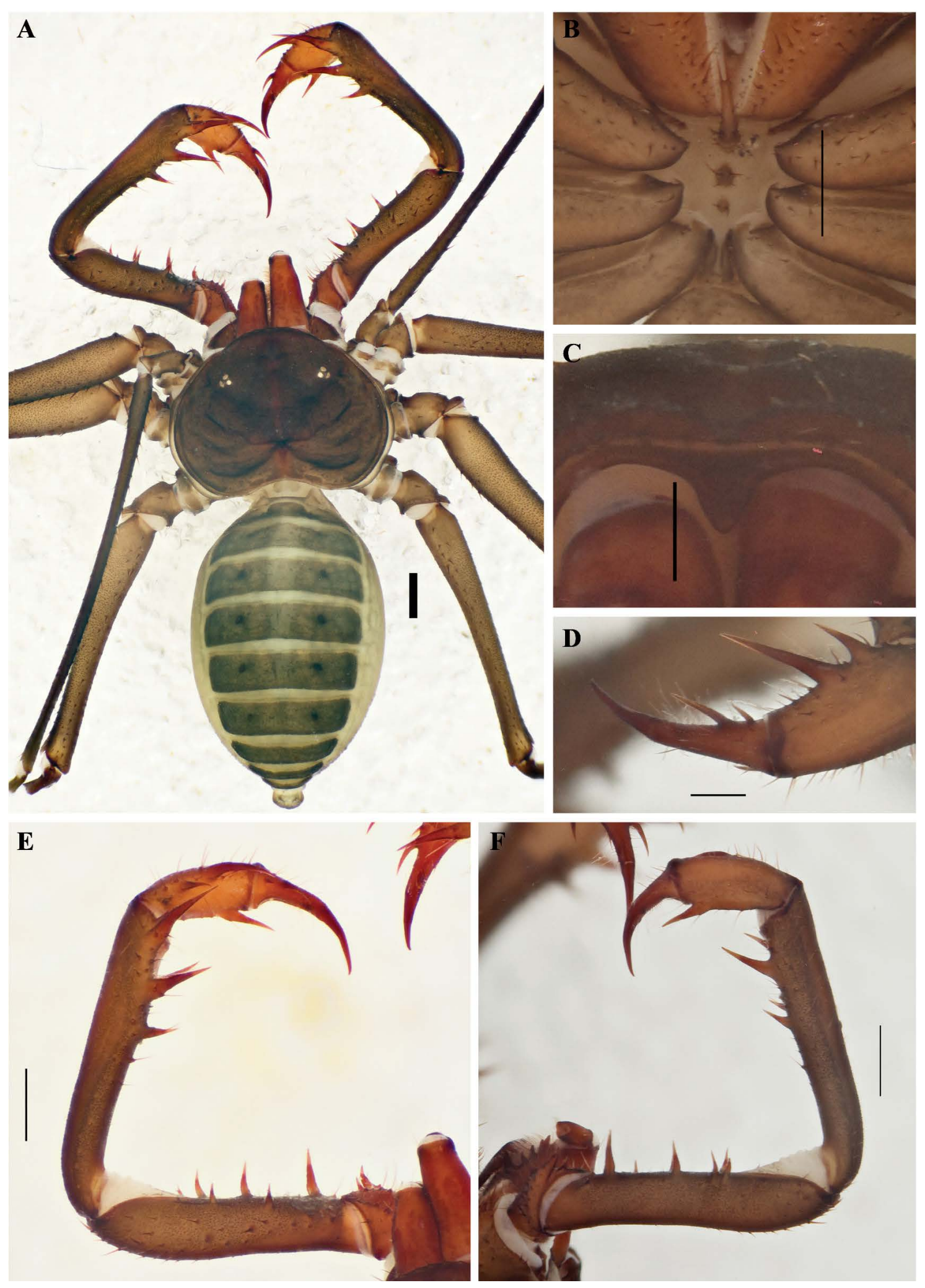

Fig. 32. Charinus perquerens sp. nov. (MNRJ 9283), general morphology, ${ }$. A. Habitus, dorsal view. B. Sternum, ventral view. C. Frontal process. D. Pedipalp tarsus, frontal view. E. Pedipalp, dorsal view. F. Pedipalp, ventral view. Scale bars: A-B, E-F $=1 \mathrm{~mm} ; \mathrm{C}-\mathrm{D}=0.5 \mathrm{~mm}$. 
$\mathbf{A}$

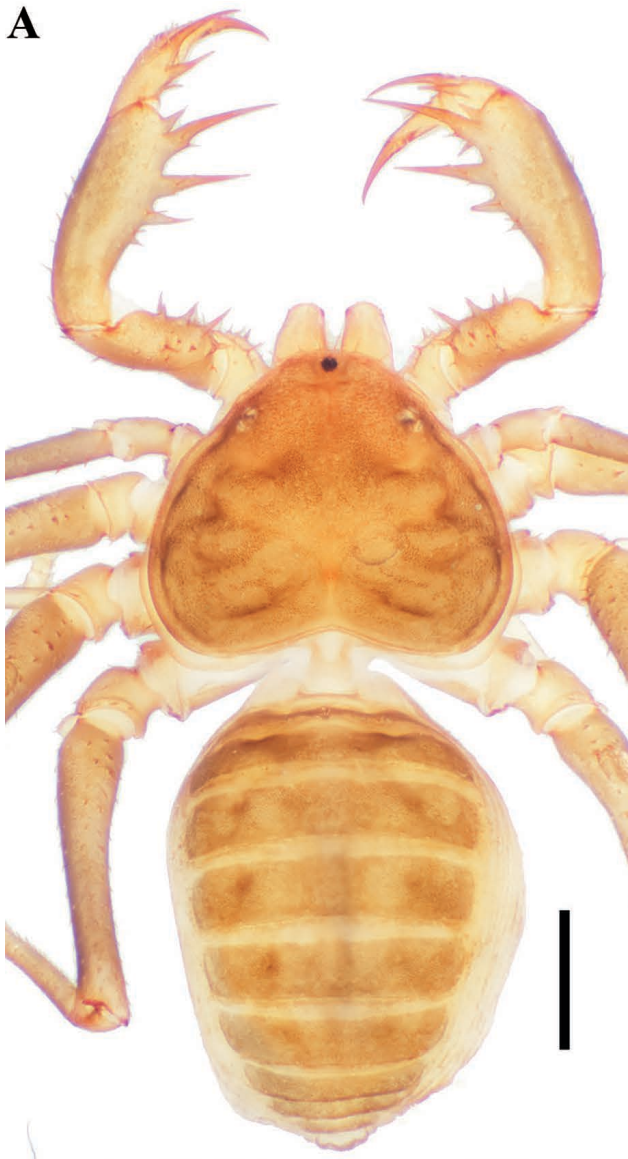

$\mathbf{E}$

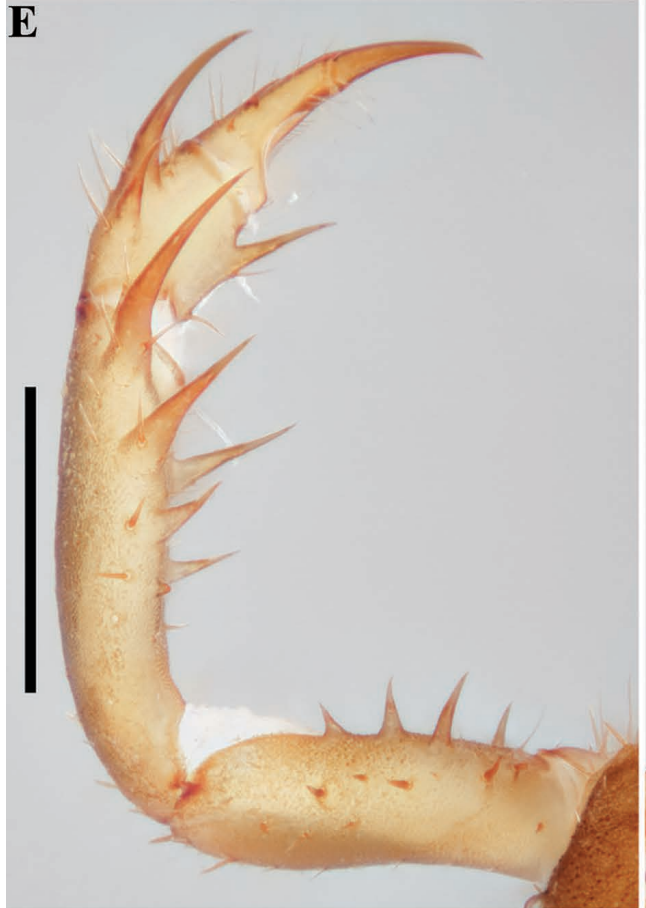

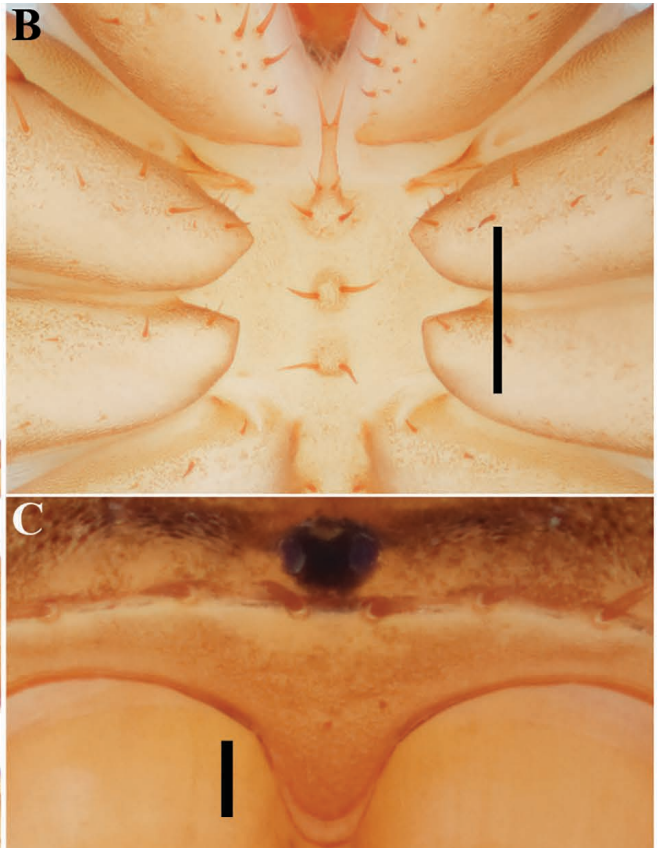

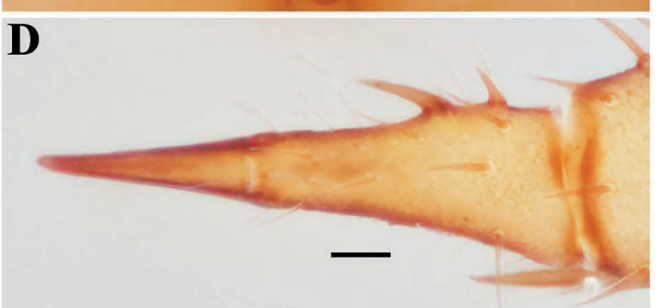

$\mathbf{F}$

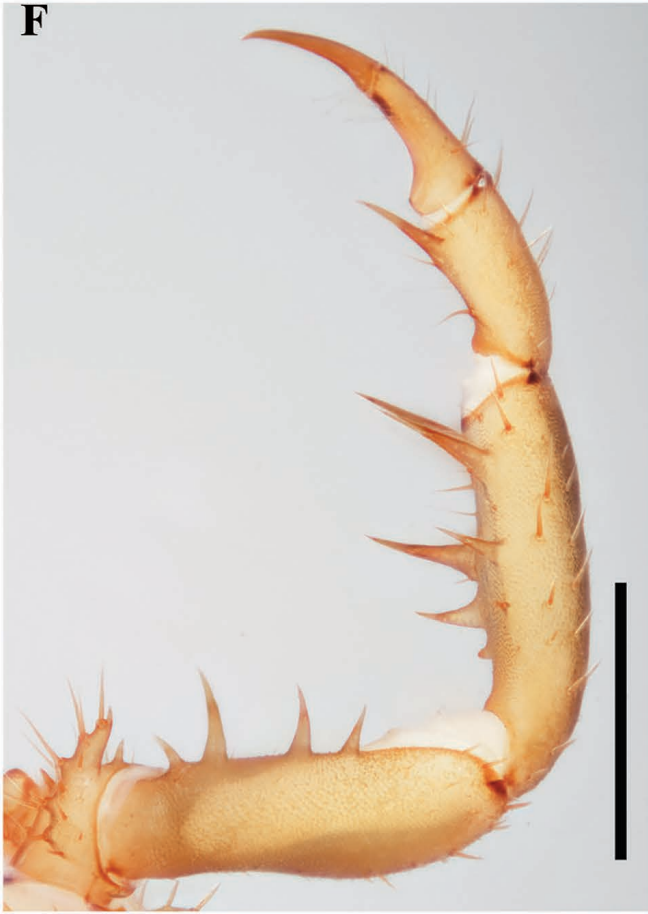

Fig. 33. Charinus sillami Réveillion \& Maquart, 2015 (AMCC [LP 13448]), general morphology, + A. Habitus, dorsal view. B. Sternum, ventral view. C. Frontal process. D. Pedipalp tarsus, frontal view. E. Pedipalp, dorsal view. F. Pedipalp, ventral view. Scale bars: A, E-F $=1 \mathrm{~mm}$; B $=0.5 \mathrm{~mm}$; $\mathrm{C}-\mathrm{D}=$ $0.1 \mathrm{~mm}$. 


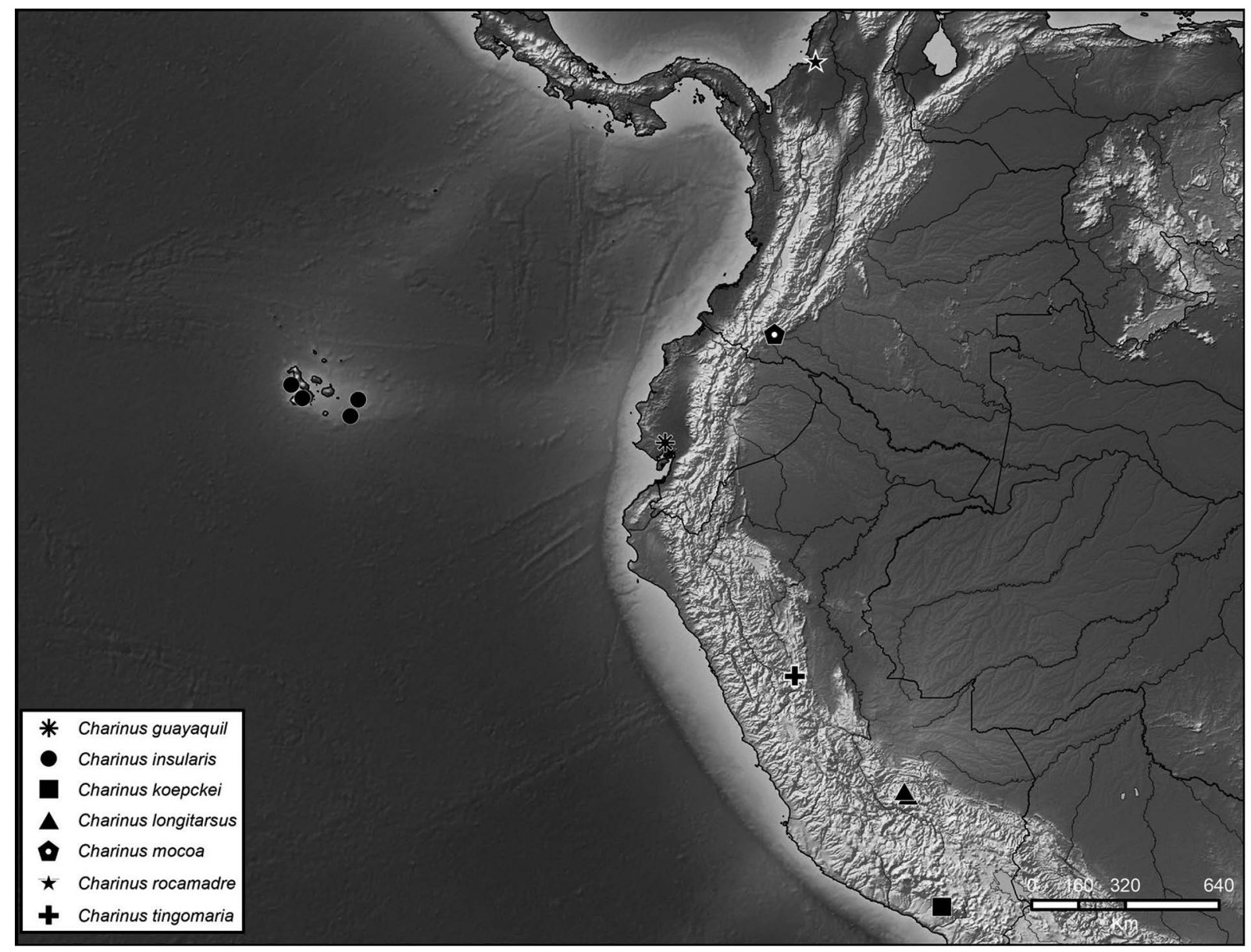

Fig. 34. Map plotting known distributions of species of Charinus Simon, 1892 in western South America. 

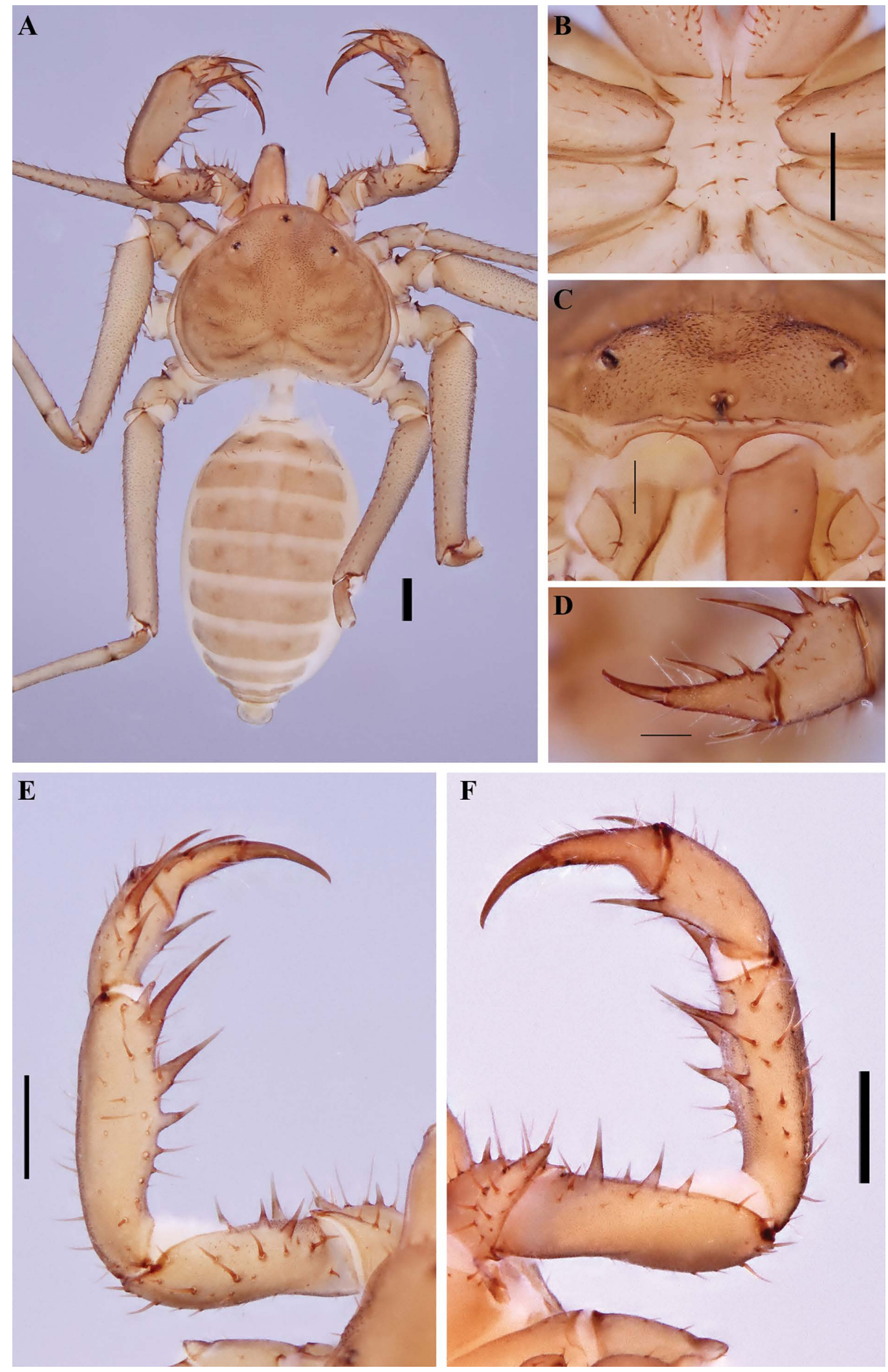

Fig. 35. Charinus guayaquil sp. nov. (MNRJ 9302), general morphology, +. A. Habitus, dorsal view. B. Sternum, ventral view. C. Frontal process. D. Pedipalp tarsus, frontal view. E. Pedipalp, dorsal view. F. Pedipalp, ventral view. Scale bars: A-B, E-F $=1 \mathrm{~mm} ; \mathrm{C}-\mathrm{D}=0.5 \mathrm{~mm}$. 

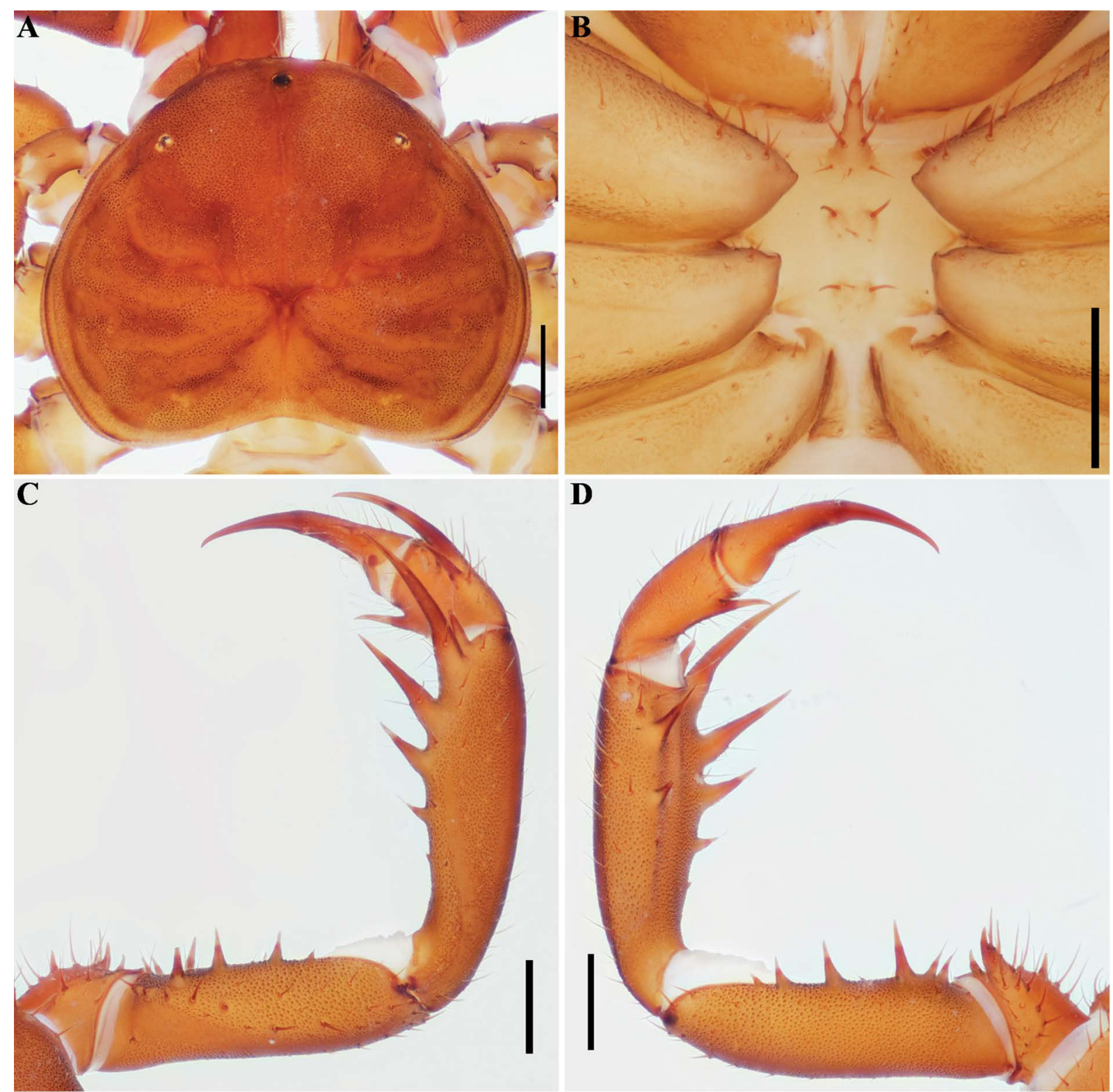

Fig. 36. Charinus insularis Banks, 1902 (RBINS), general morphology, . . A. Carapace, dorsal view. B. Sternum, ventral view. C. Pedipalp, dorsal view. D. Pedipalp, ventral view. Scale bars: $1 \mathrm{~mm}$. 

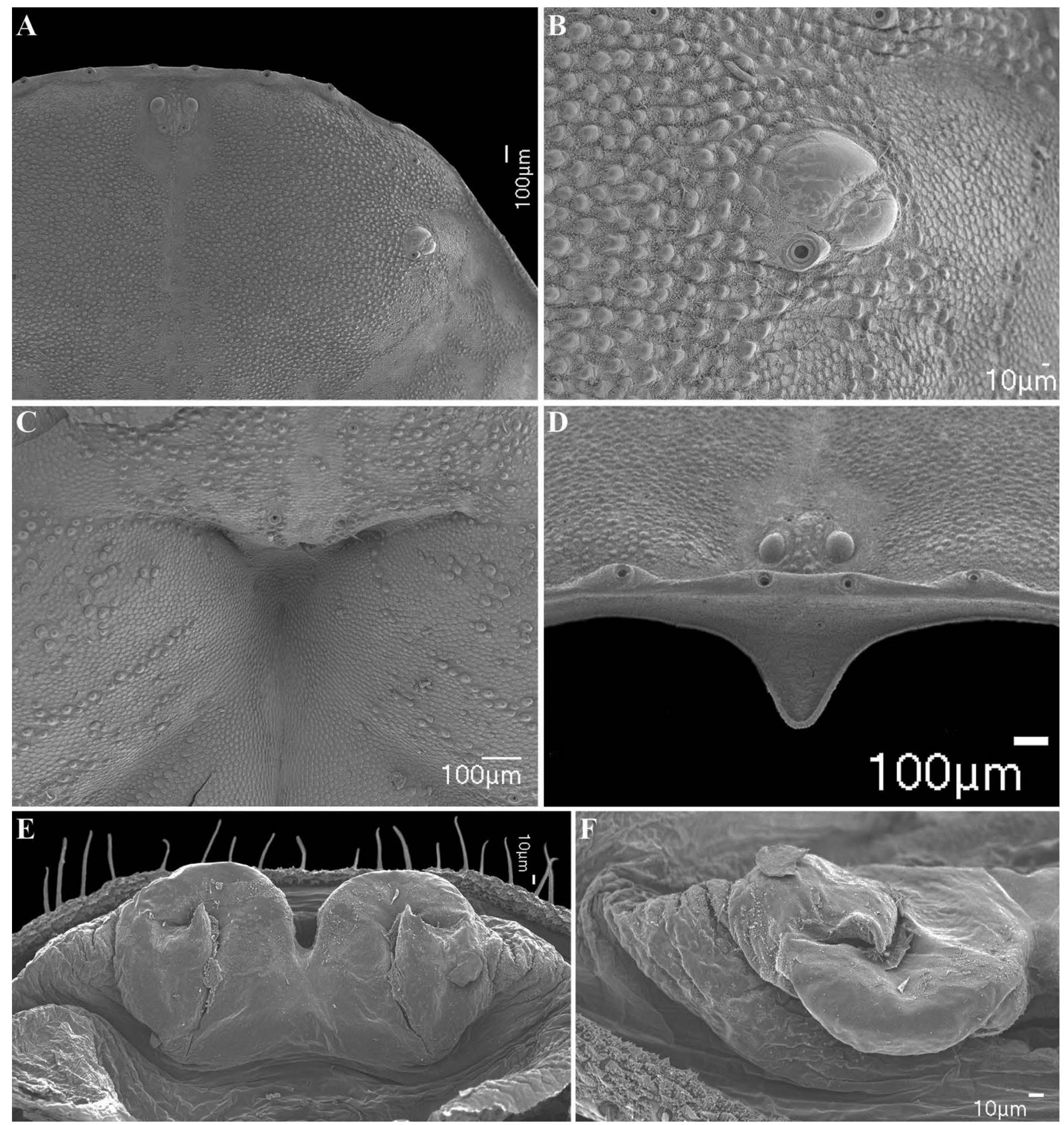

Fig. 37. Charinus insularis Banks 1902 (RBINS), carapace and female gonopod. A. Carapace, anterior part illustrating granular macrosculpture. B. Lateral ocular triad, setal socket and carapace macrosculpture. C. Fovea and granules. D. Frontal process. E. Female gonopod, dorsal view. F. Female gonopod, sinistral side. 

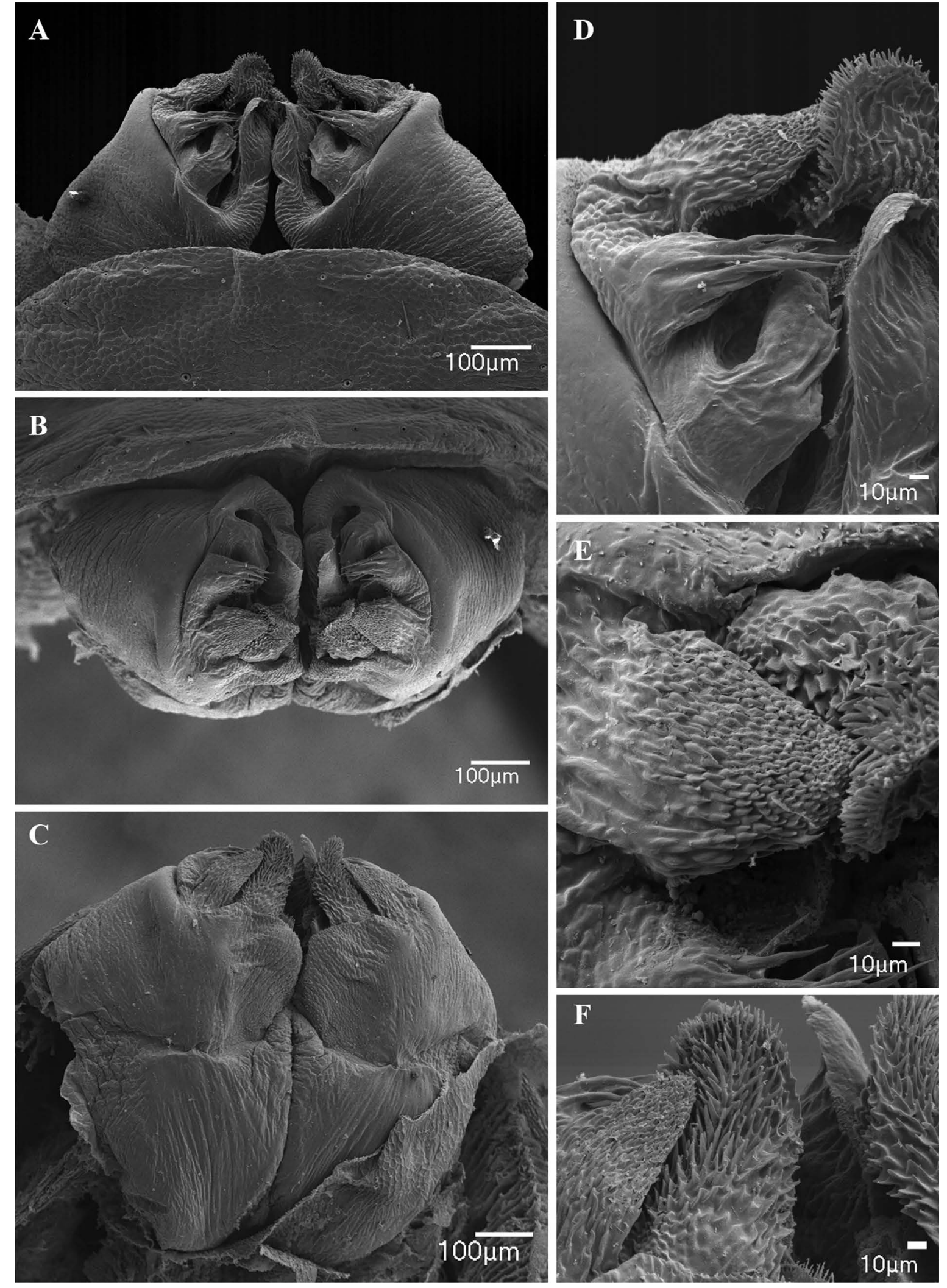

Fig. 38. Charinus insularis Banks 1902 (RBINS), male gonopod. A. Ventral view. B. Posterior view. C. Dorsal view. D. Detail of lateral lobe 1 and processus internus. E. Detail of lateral lobe I. F. Detail of lateral dorsal lobe. 


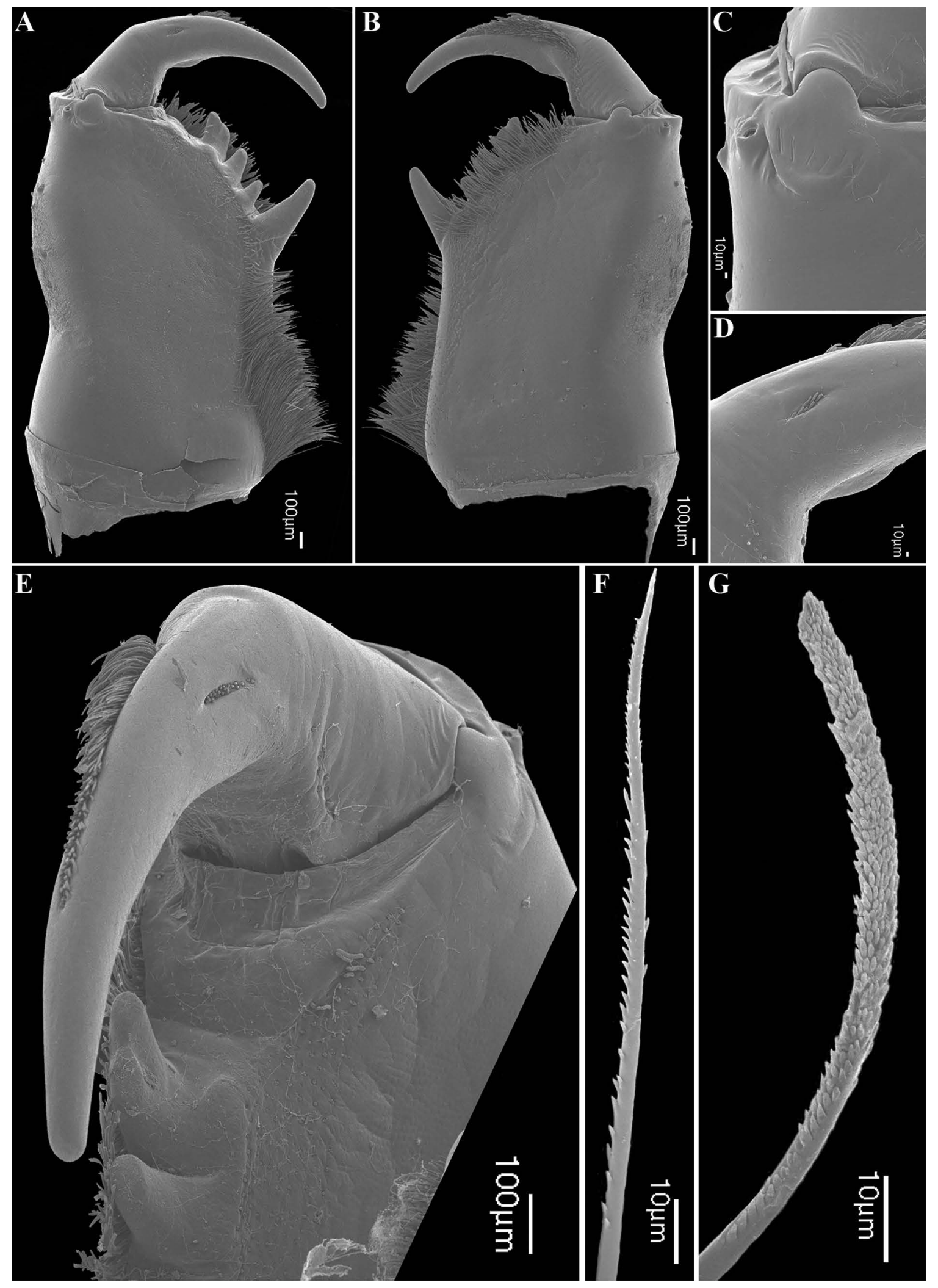

Fig. 39. Charinus insularis Banks 1902 (RBINS), chelicerae. A. Retrolateral view. B. Prolateral view. C. Slit sensillae on lateral surface of basal segment. D. Dorsal patch of setae on claw. E. Cheliceral claw and proximal teeth of basal segment, frontal view. F. Seta on basal segment. G. Seta on prolateral surface of cheliceral claw. 


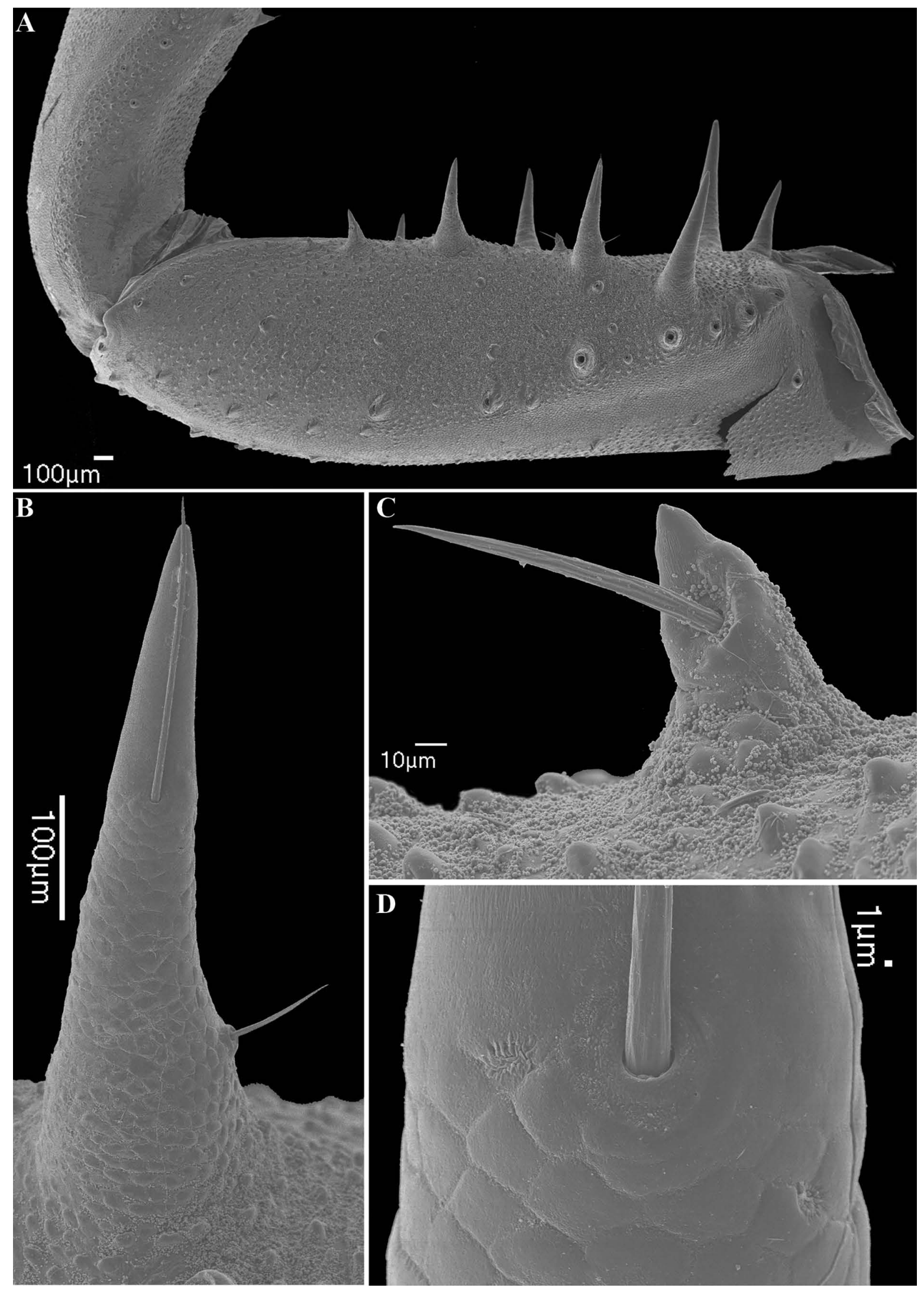

Fig. 40. Charinus insularis Banks, 1902 (RBINS), pedipalp. A. Dorsal view. B. Spine of primary series. C. Small spine. D. Base of seta and glandular/sensory opening of spine in primary series. 

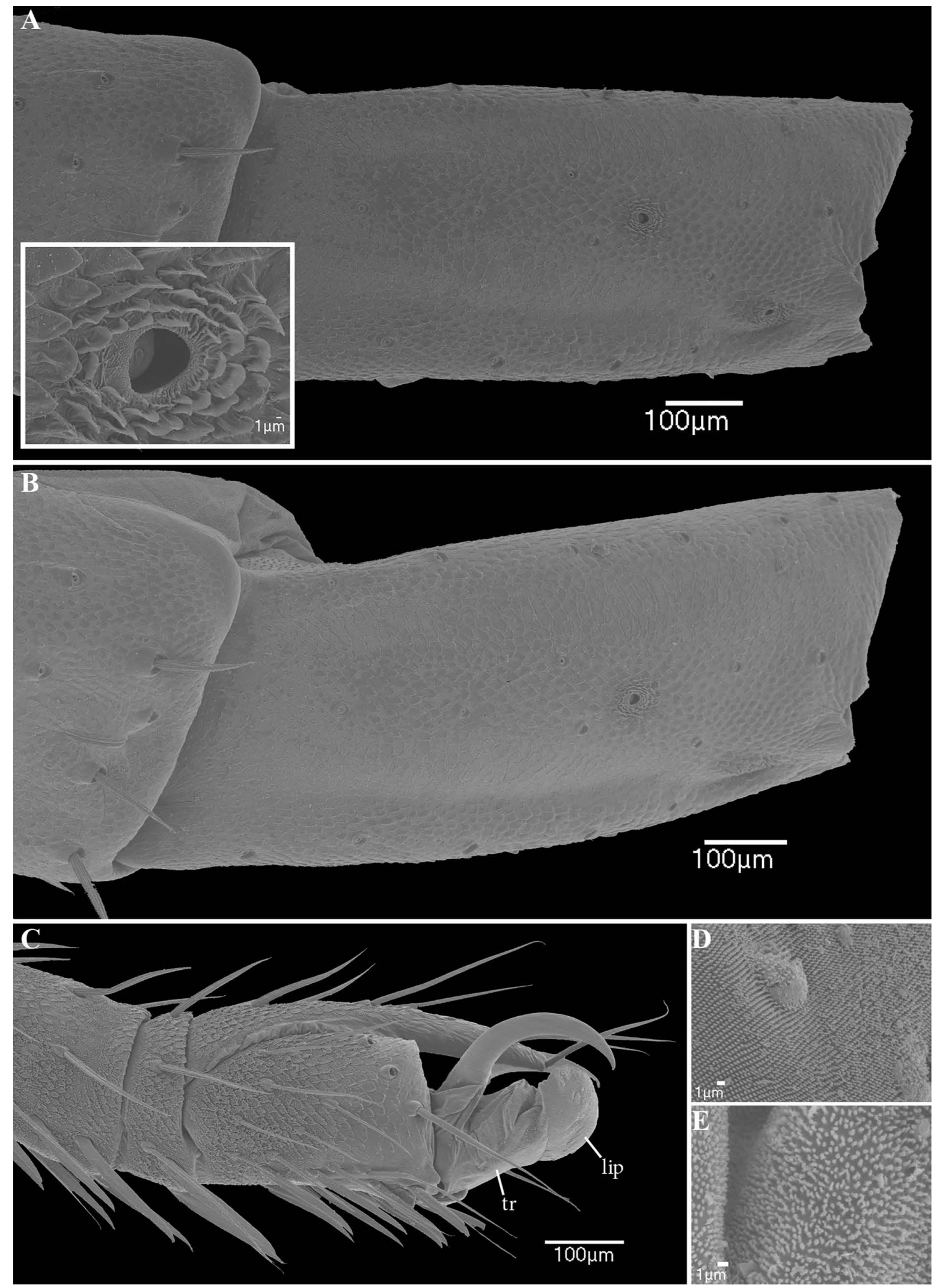

Fig. 41. Charinus insularis Banks, 1902 (RBINS), leg IV. A. Patella, dorsal view showing trichobothrial insertion. B. Patella, lateral view. C. Tarsus, lateral view. D. Aroliar lip. E. Aroliar truncus. Abbreviations: lip $=$ aroliar lip; $\operatorname{tr}=$ truncus. 


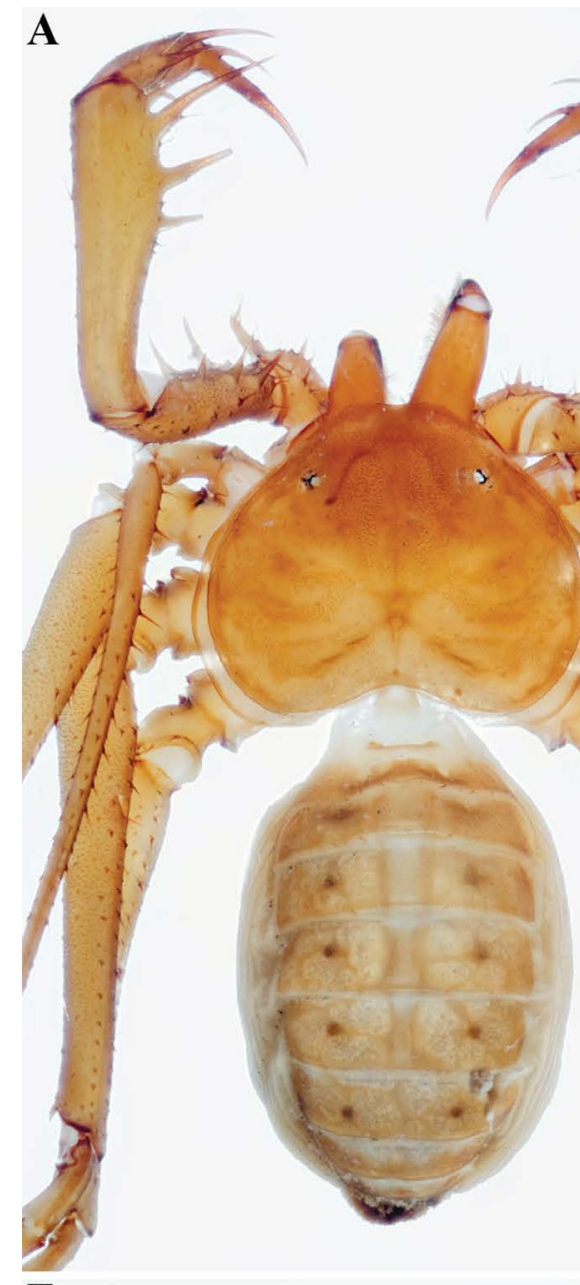

$\mathbf{E}$

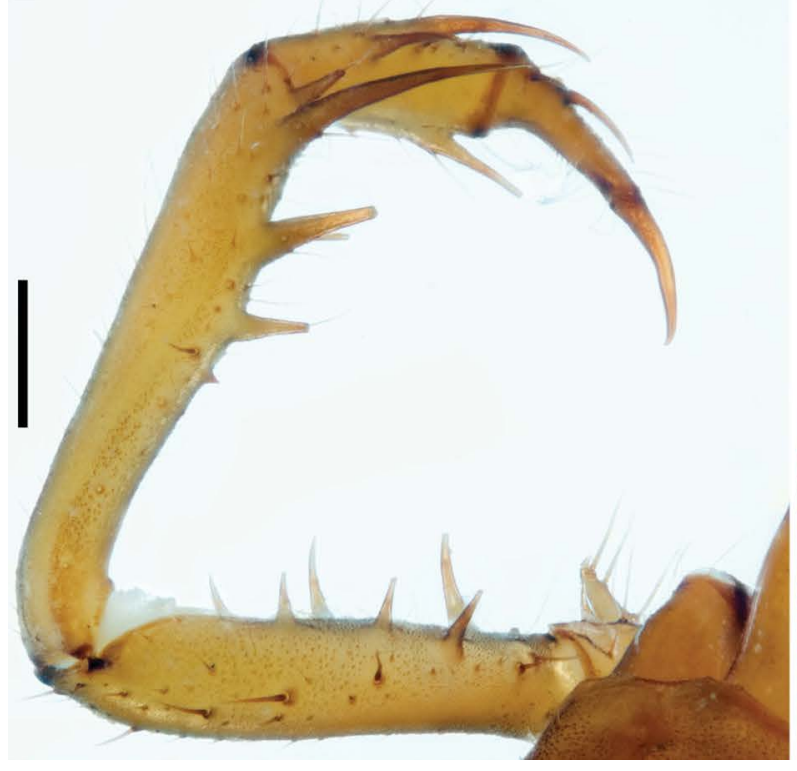

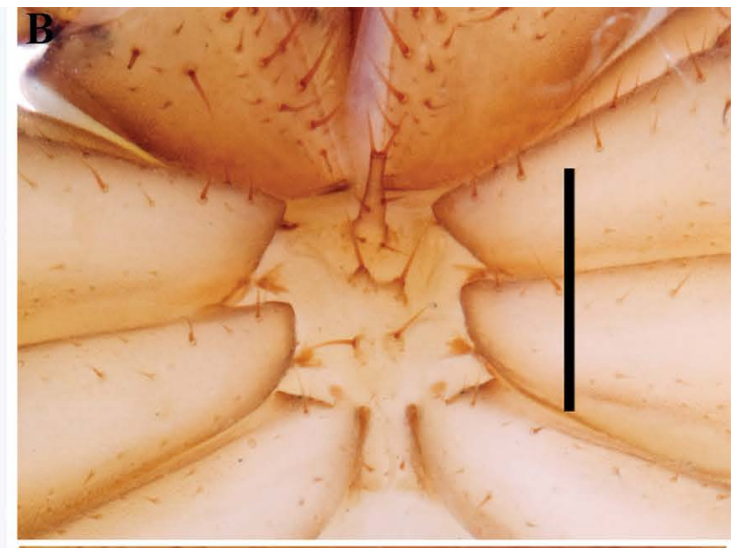
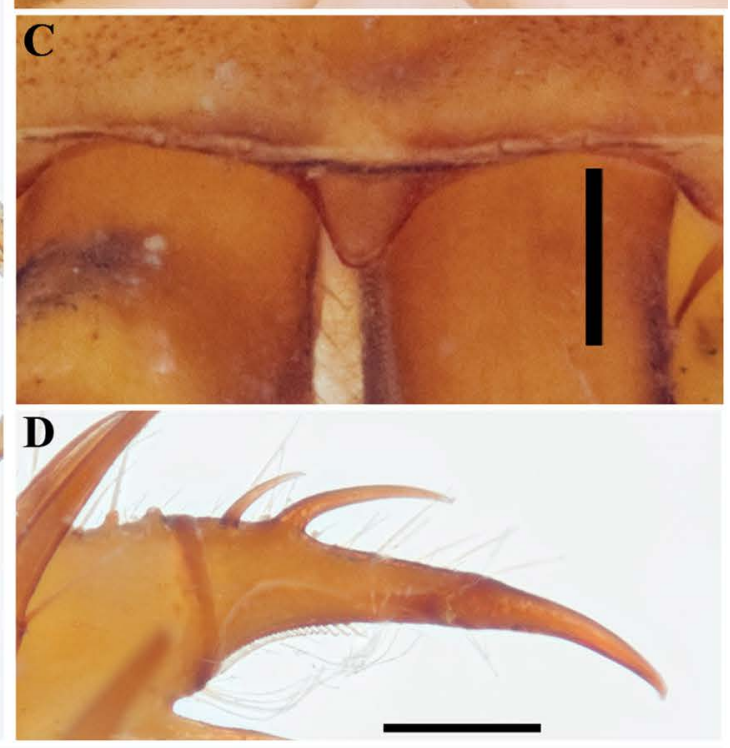

$\mathbf{F}$

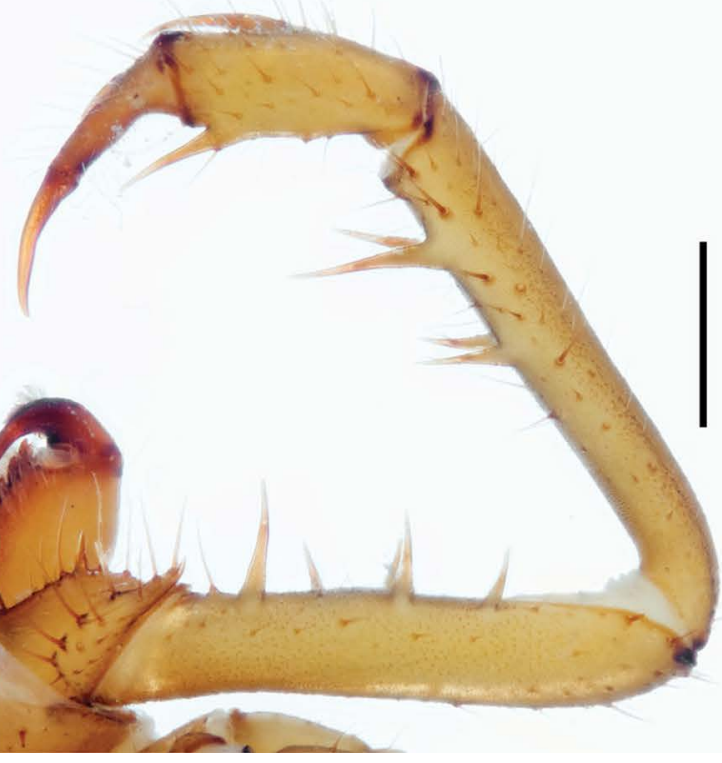

Fig. 42. Charinus mocoa sp. nov. (SMF 68), general morphology, +. A. Habitus, dorsal view. B. Sternum, ventral view. C. Frontal process. D. Pedipalp tarsus, frontal view. E. Pedipalp, dorsal view. F. Pedipalp, ventral view. Scale bars: A-B, E-F $=1 \mathrm{~mm}$; $\mathrm{C}-\mathrm{D}=0.5 \mathrm{~mm}$. 
MIRANDA G.S. et al., Systematic revision of Charinidae (Arachnida, Amblypygi)

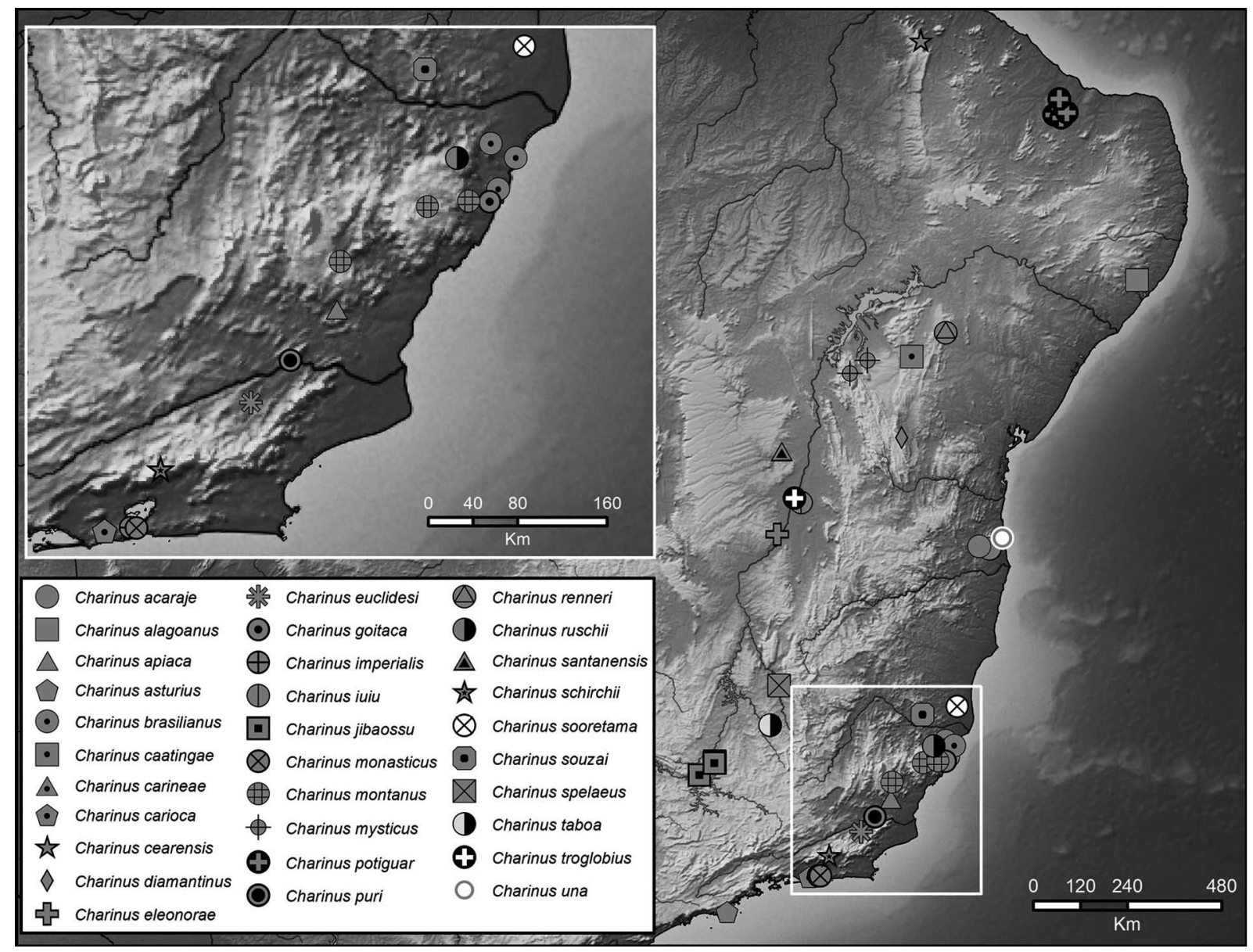

Fig. 43. Map plotting known distributions of species of Charinus Simon, 1892 in eastern South America, with inset for southeastern Brazil. 


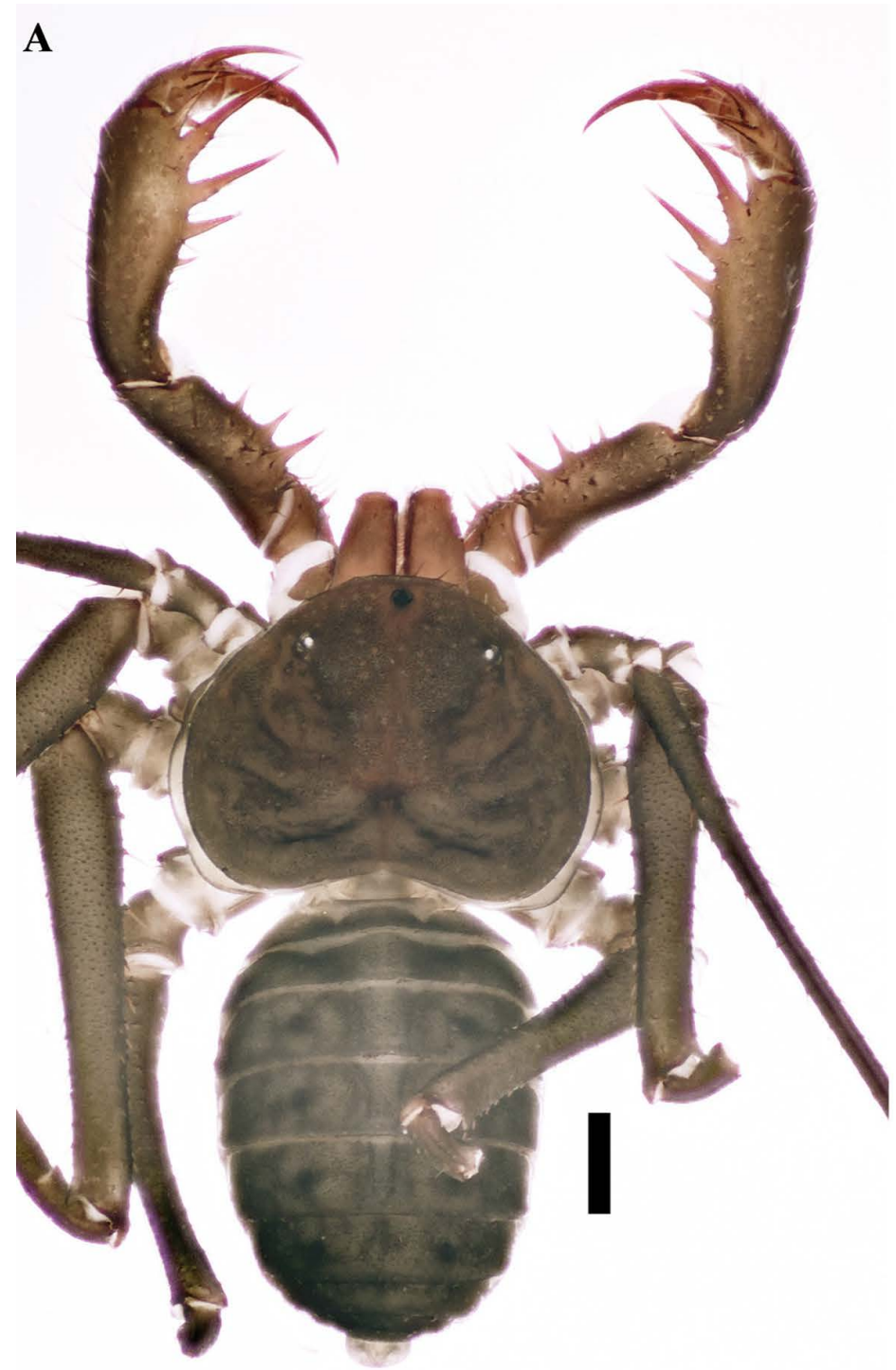

$\mathbf{E}$

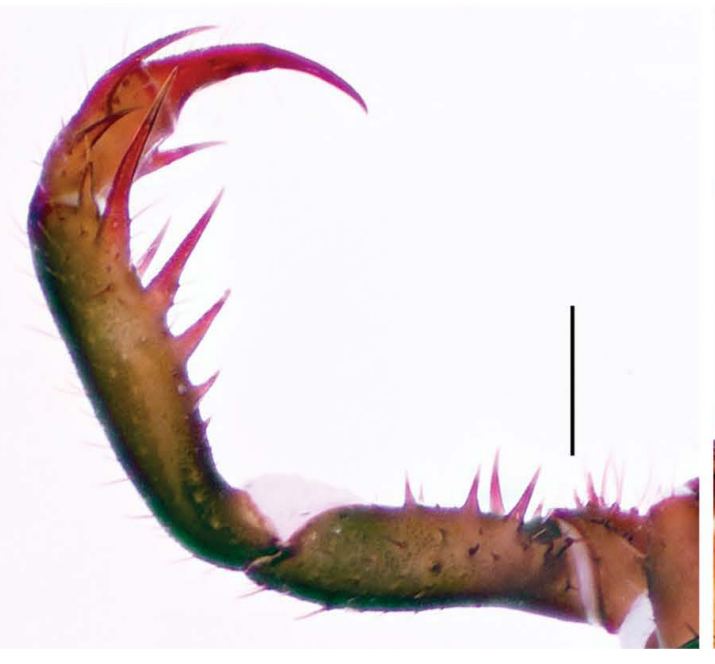

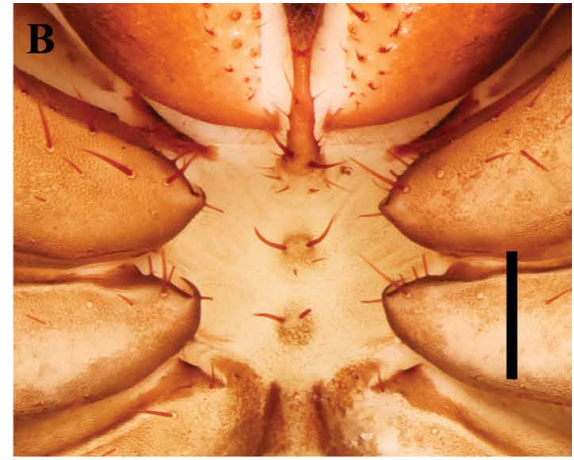
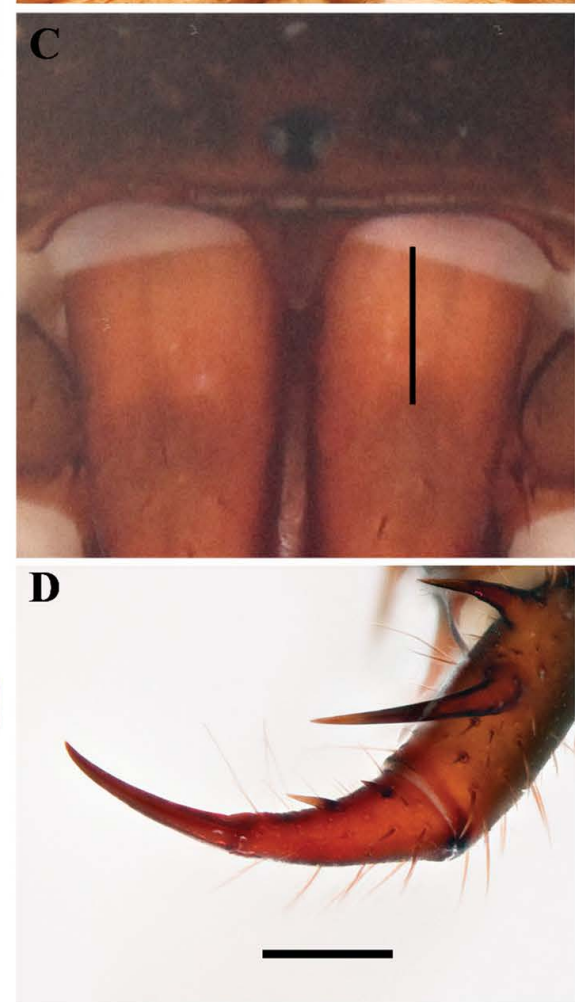

$\mathbf{F}$

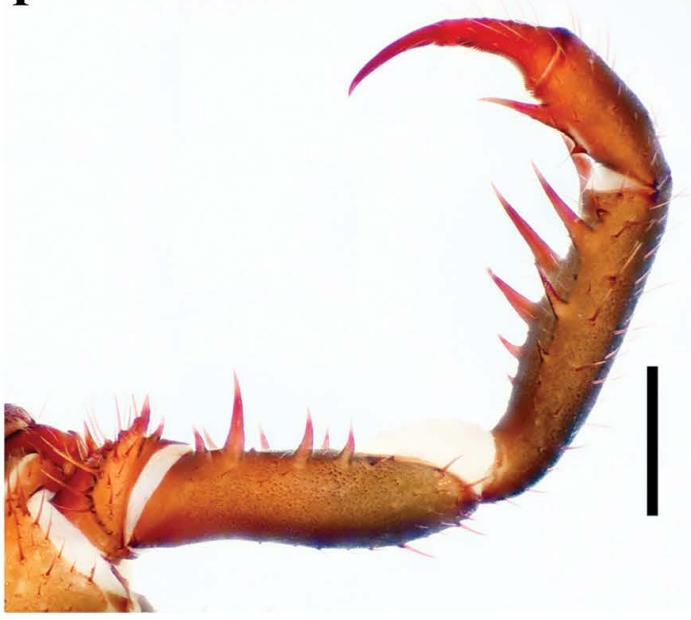

Fig. 44. Charinus alagoanus sp. nov. (MNRJ 9294), general morphology, + . A. Habitus, dorsal view. B. Sternum, ventral view. C. Frontal process. D. Pedipalp tarsus, frontal view. E. Pedipalp, dorsal view. F. Pedipalp, ventral view. Scale bars: A, E-F $=1 \mathrm{~mm}$; $B, D=0.5 \mathrm{~mm} ; C=0.25 \mathrm{~mm}$. 

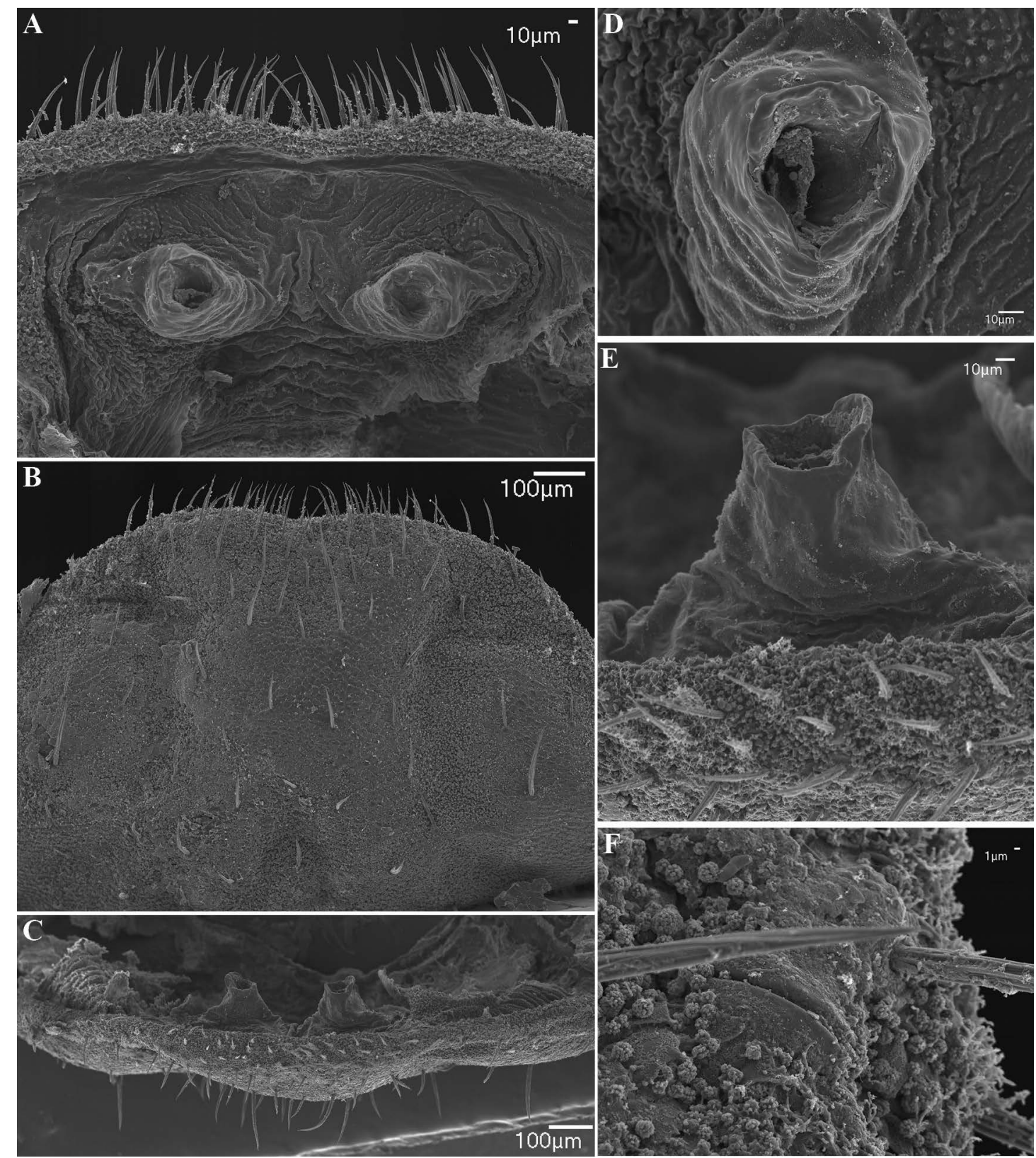

Fig. 45. Charinus alagoanus sp. nov. (MNRJ 9295), female gonopod and genital operculum. A. Suckerlike gonopod, dorsal view. B. Genital operculum, ventral view. C. Gonopods, posterior view. D. Aperture on sinistral side of sucker-like gonopod, dorsal view. E. Projection on sinistral side of sucker-like gonopod, posterior view. F. Gland opening near lateral margin of genital operculum. 


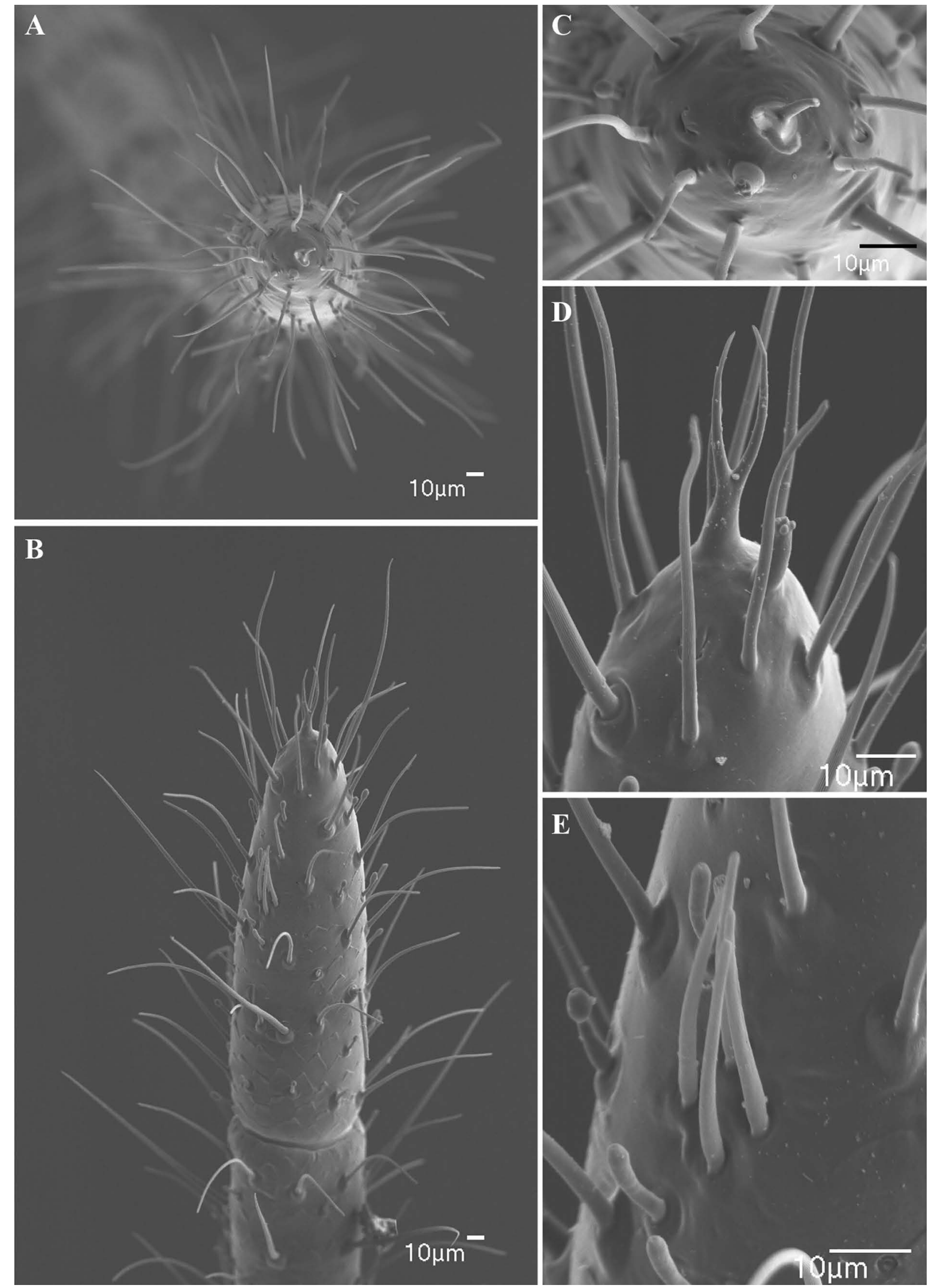

Fig. 46. Charinus alagoanus sp. nov. (MNRJ 9295), antenniform leg I, + . A. Apex of distal article. B. Distal segment of tarsus, lateral view. C. Apex of distal article of tarsus showing claw and tarsal organ. D. Detail of claw and tarsal organ. E. Rod sensilla and olfactory setae. 


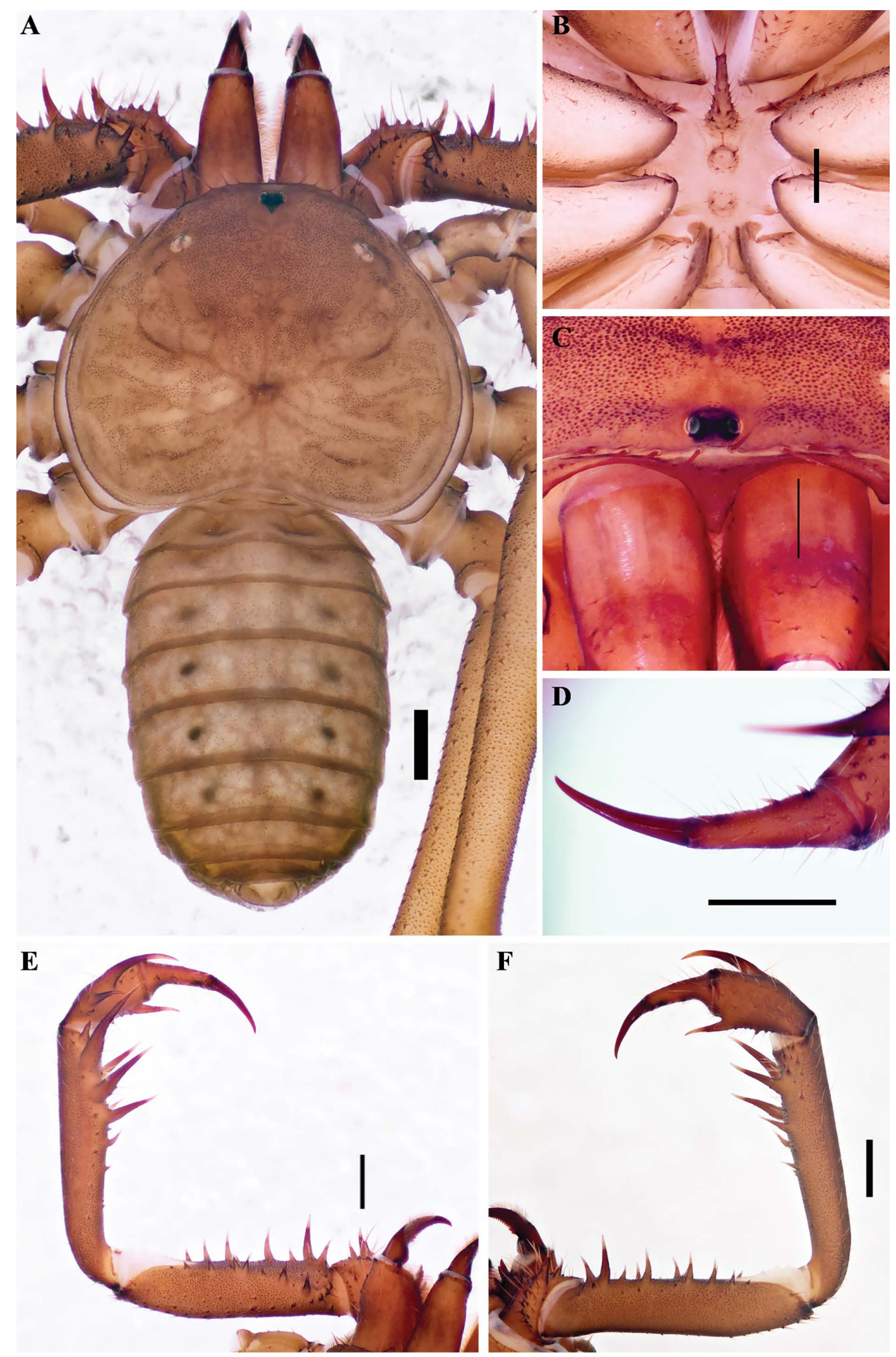

Fig. 47. Charinus apiaca sp. nov. (MNRJ 9286), general morphology, +. A. Habitus, dorsal view. B. Sternum, ventral view. C. Frontal process. D. Pedipalp tarsus, frontal view. E. Pedipalp, dorsal view. F. Pedipalp, ventral view. Scale bars: A, D-F $=1 \mathrm{~mm}$; B-C $=0.5 \mathrm{~mm}$. 


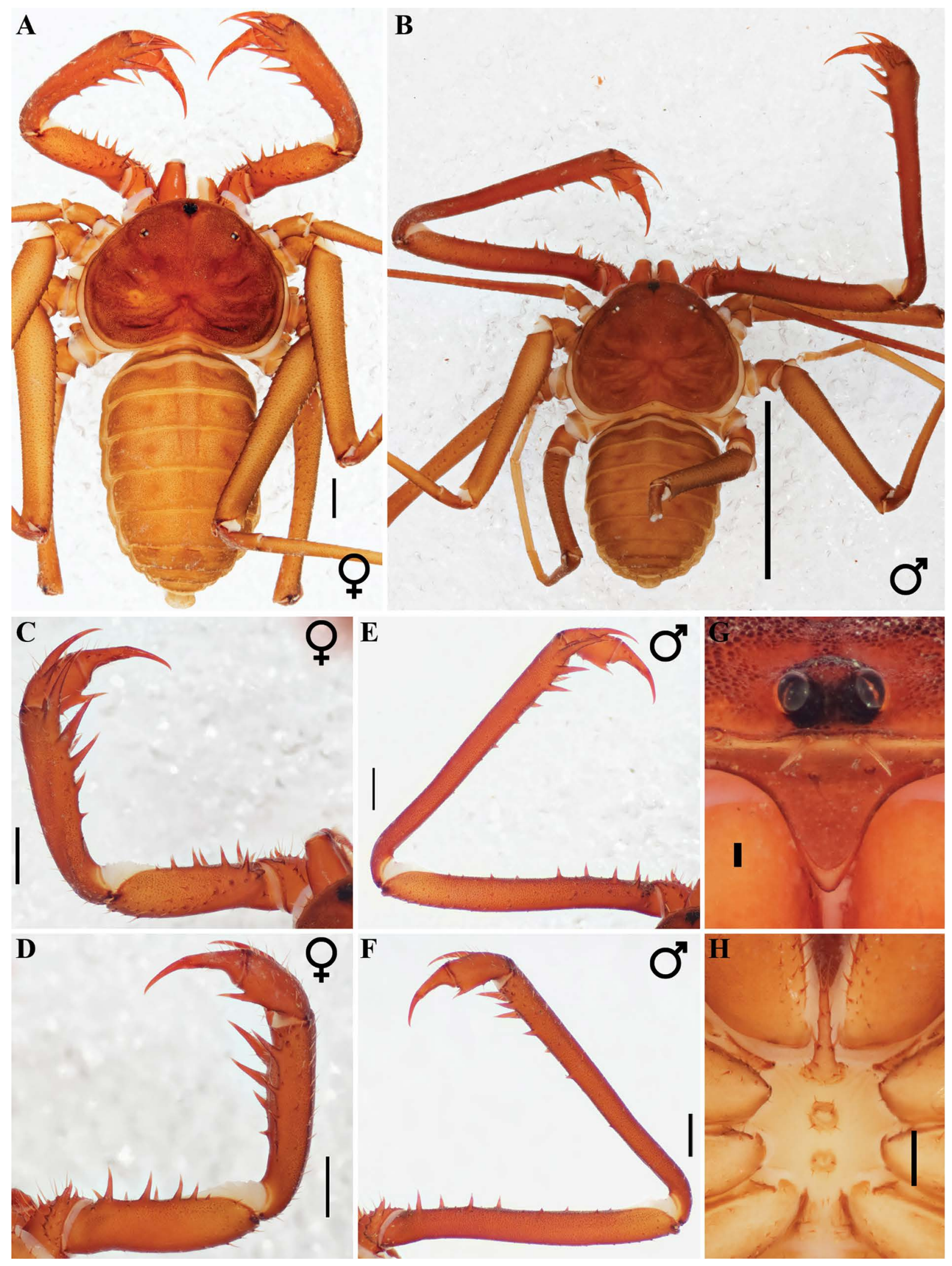

Fig. 48. Charinus brasilianus Weygoldt, 1972, general morphology (MNRJ 9271). A. Female habitus, dorsal view. B. Male habitus, dorsal view. C. Female pedipalp, dorsal view. D. Female pedipalp, ventral view. E. Male pedipalp, dorsal view. F. Male pedipalp, ventral view. G. Frontal process. H. Sternum, ventral view. Scale bars: A, $C-F=1 \mathrm{~mm} ; B=5 \mathrm{~mm} ; \mathrm{G}=0.1 \mathrm{~mm} ; \mathrm{H}=0.5 \mathrm{~mm}$. 


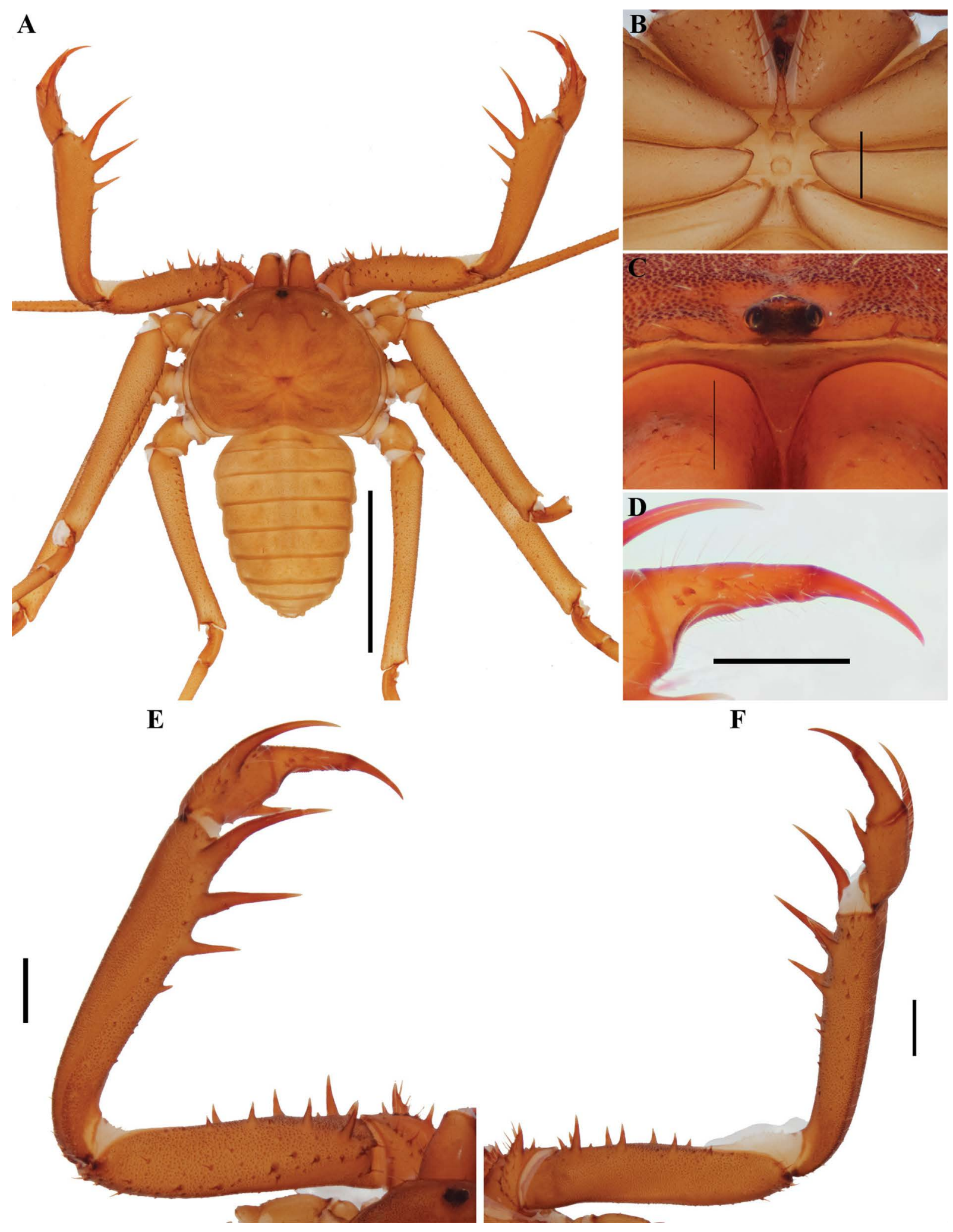

Fig. 49. Charinus carinae sp. nov. (MNRJ 9293), general morphology, $\widehat{\partial}$. A. Habitus, dorsal view. B. Sternum, ventral view. C. Frontal process. D. Pedipalp tarsus, frontal view. E. Pedipalp, dorsal view. F. Pedipalp, ventral view. Scale bars: $A=5 \mathrm{~mm} ; \mathrm{B}, \mathrm{D}-\mathrm{F}=1 \mathrm{~mm} ; \mathrm{C}=0.5 \mathrm{~mm}$. 

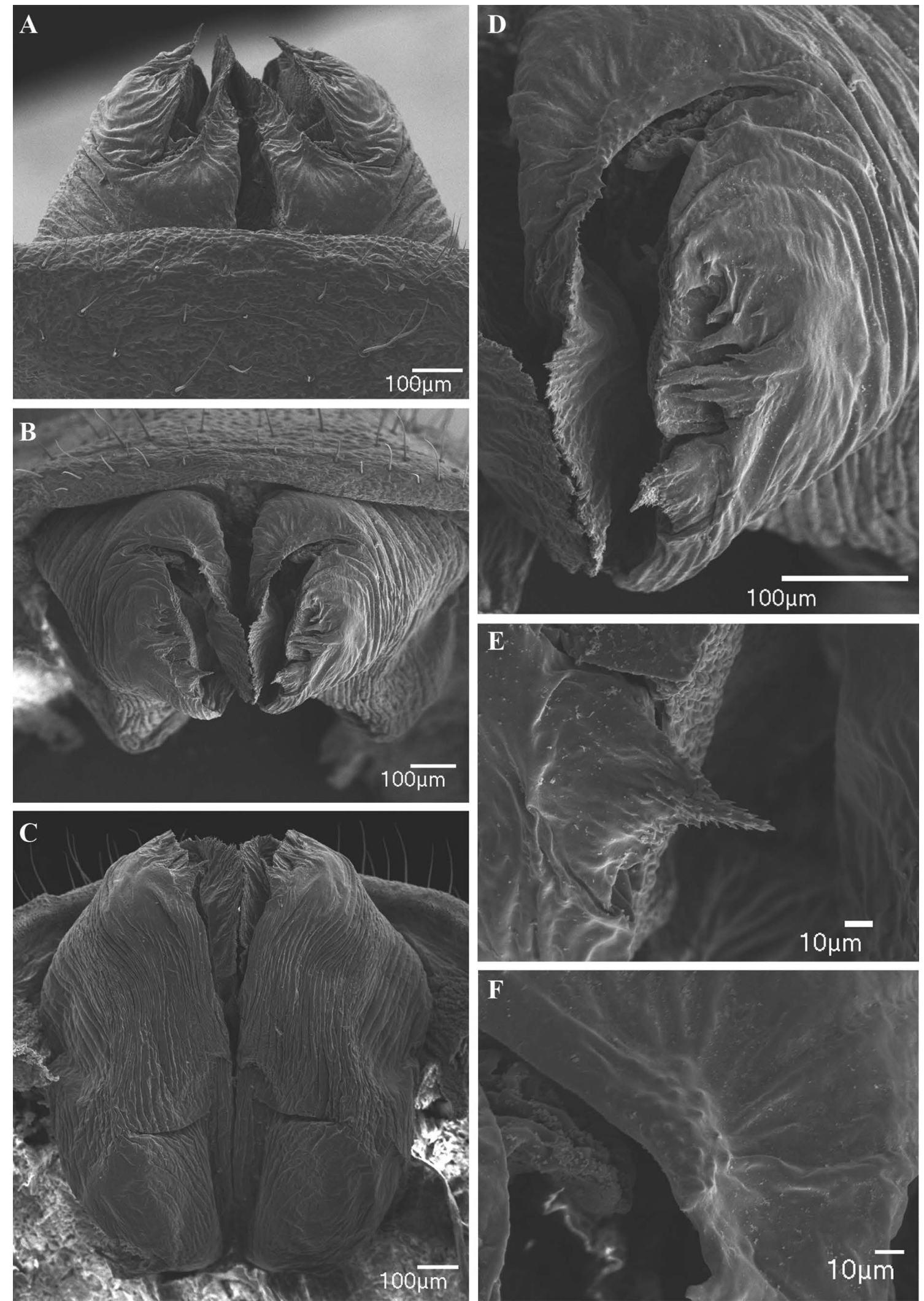

Fig. 50. Charinus carinae sp. nov. (MNRJ 9199), male gonopod. A. Ventral view. B. Posterior view. C. Dorsal view. D. Sinistral side of gonopod. E. Lateral lobe 1. F. Globular projection on dorsal margin of fistula. 

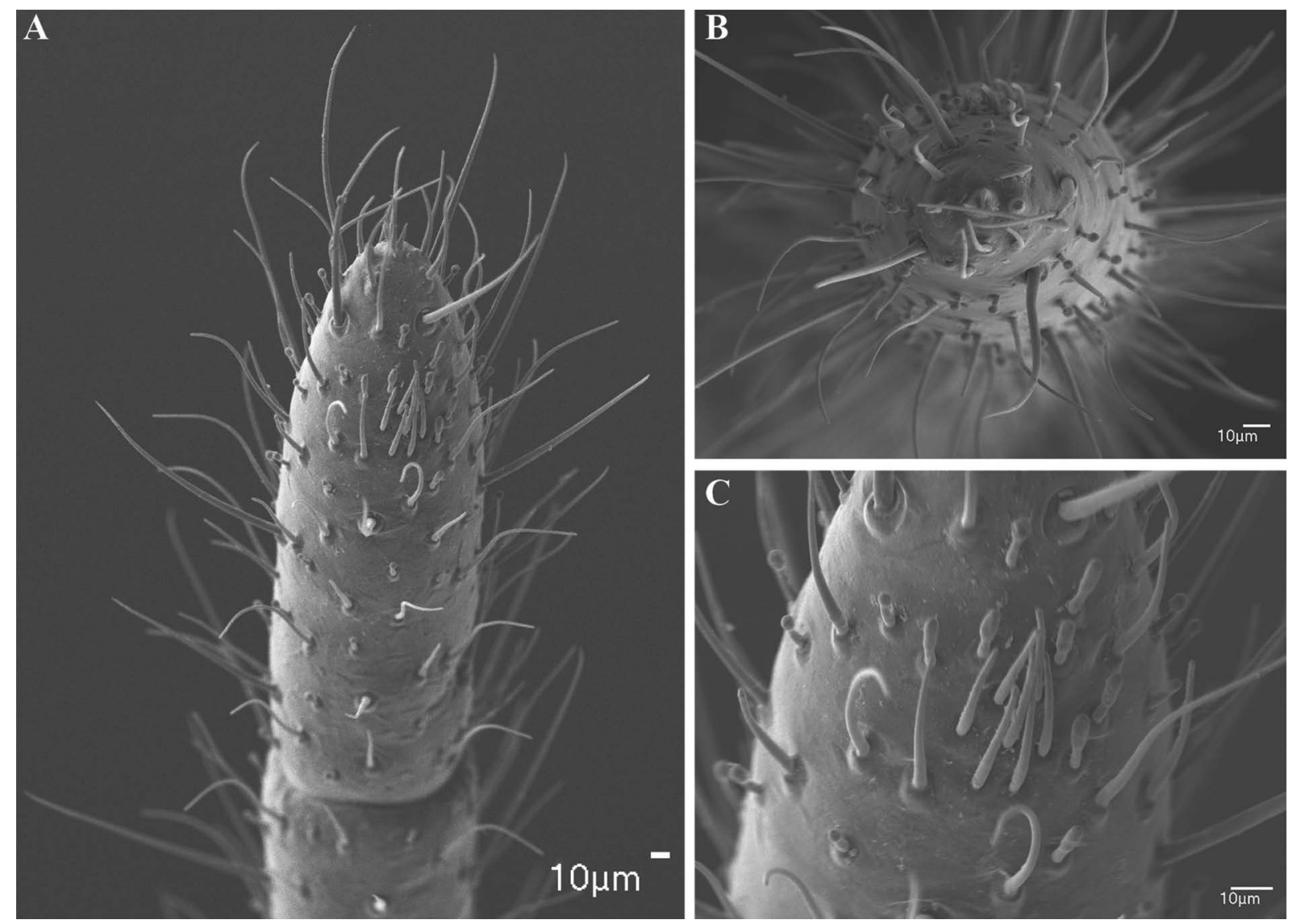

Fig. 51. Charinus carinae sp. nov. (MNRJ 9199), antenniform leg I, ふૈ. A. Apex, ventral view. B. Apex, frontal view. C. Rod sensilla with olfactory setae. 


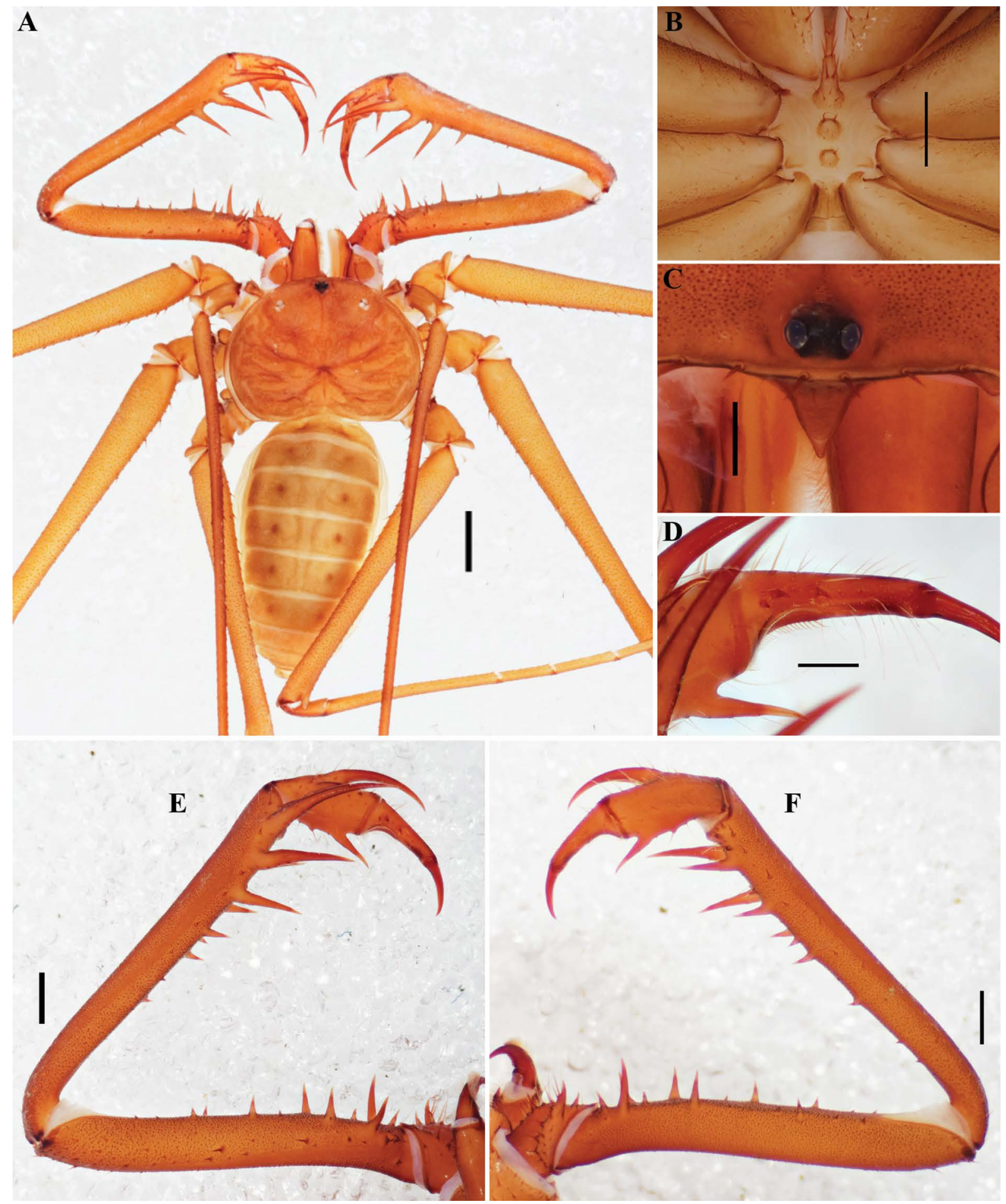

Fig. 52. Charinus carioca sp. nov. (MNRJ 9021), general morphology, $\widehat{\jmath}$. A. Habitus, dorsal view. B. Sternum, ventral view. C. Frontal process. D. Pedipalp tarsus, frontal view. E. Pedipalp, dorsal view. F. Pedipalp, ventral view. Scale bars: A-B, E-F $=1 \mathrm{~mm} ; \mathrm{C}-\mathrm{D}=0.5 \mathrm{~mm}$. 


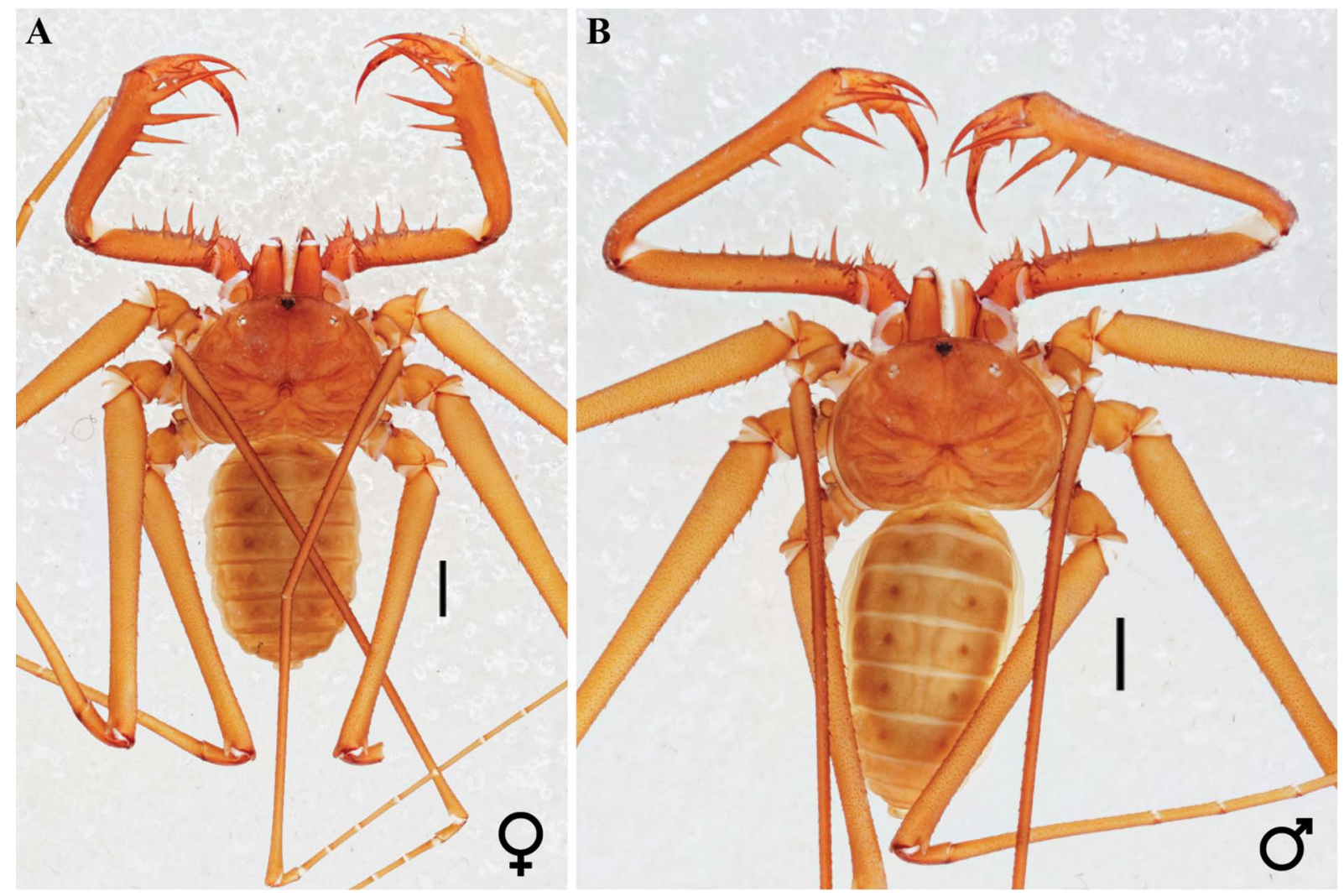

Fig. 53. Charinus carioca sp. nov. (MNRJ 9021), habitus, dorsal view illustrating secondary sexual

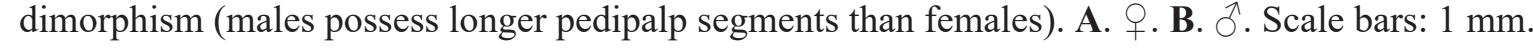



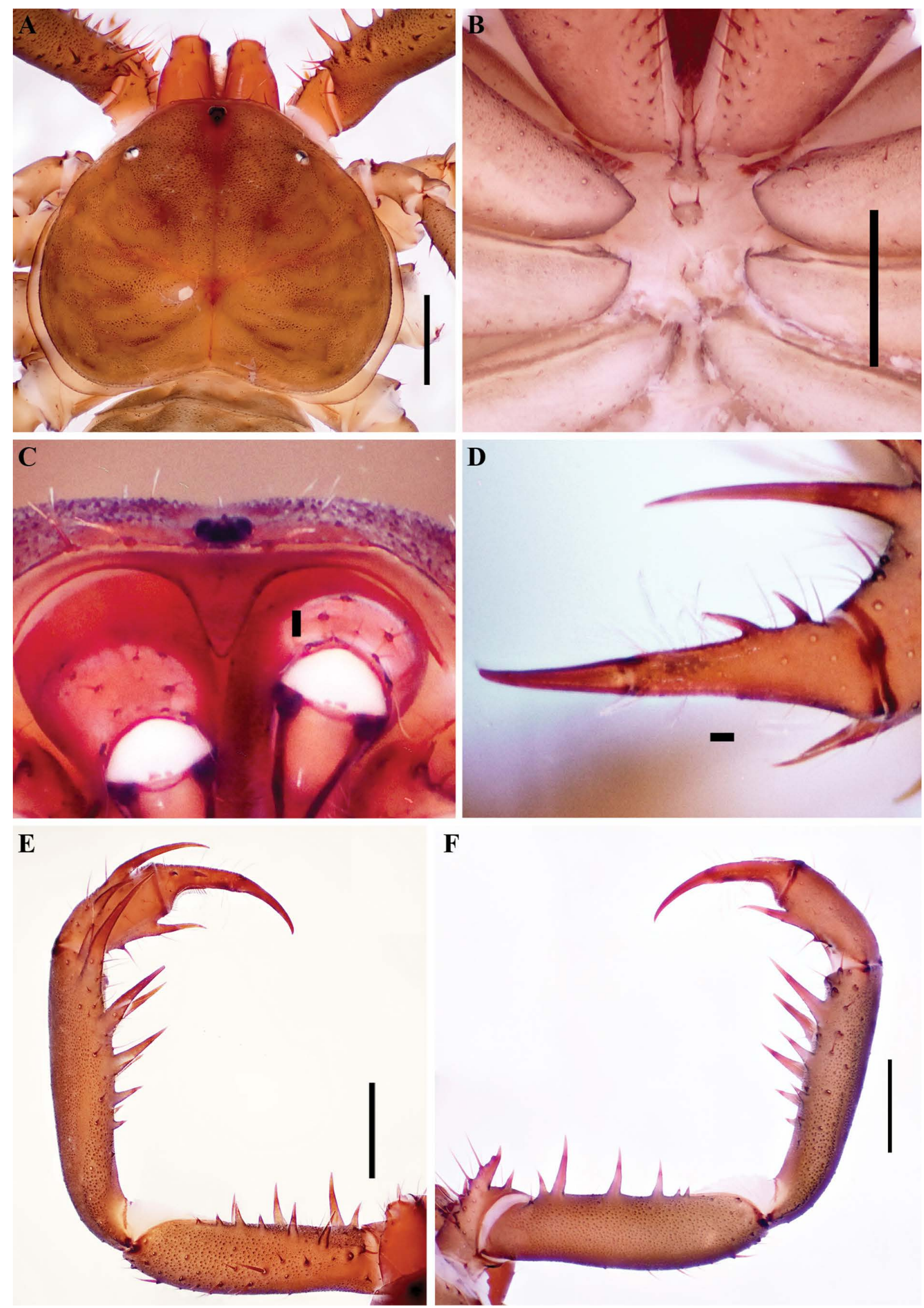

Fig. 54. Charinus cearensis sp. nov. (CHNUFPI 1255), general morphology, ${ }^{\circ}$. A. Carapace, dorsal view. B. Sternum, ventral view. C. Frontal process. D. Pedipalp tarsus, frontal view. E. Pedipalp, dorsal view. F. Pedipalp, ventral view. Scale bars: A-B $=0.5 \mathrm{~mm} ; \mathrm{C}-\mathrm{D}=0.1 \mathrm{~mm}$; E-F $=1 \mathrm{~mm}$. 

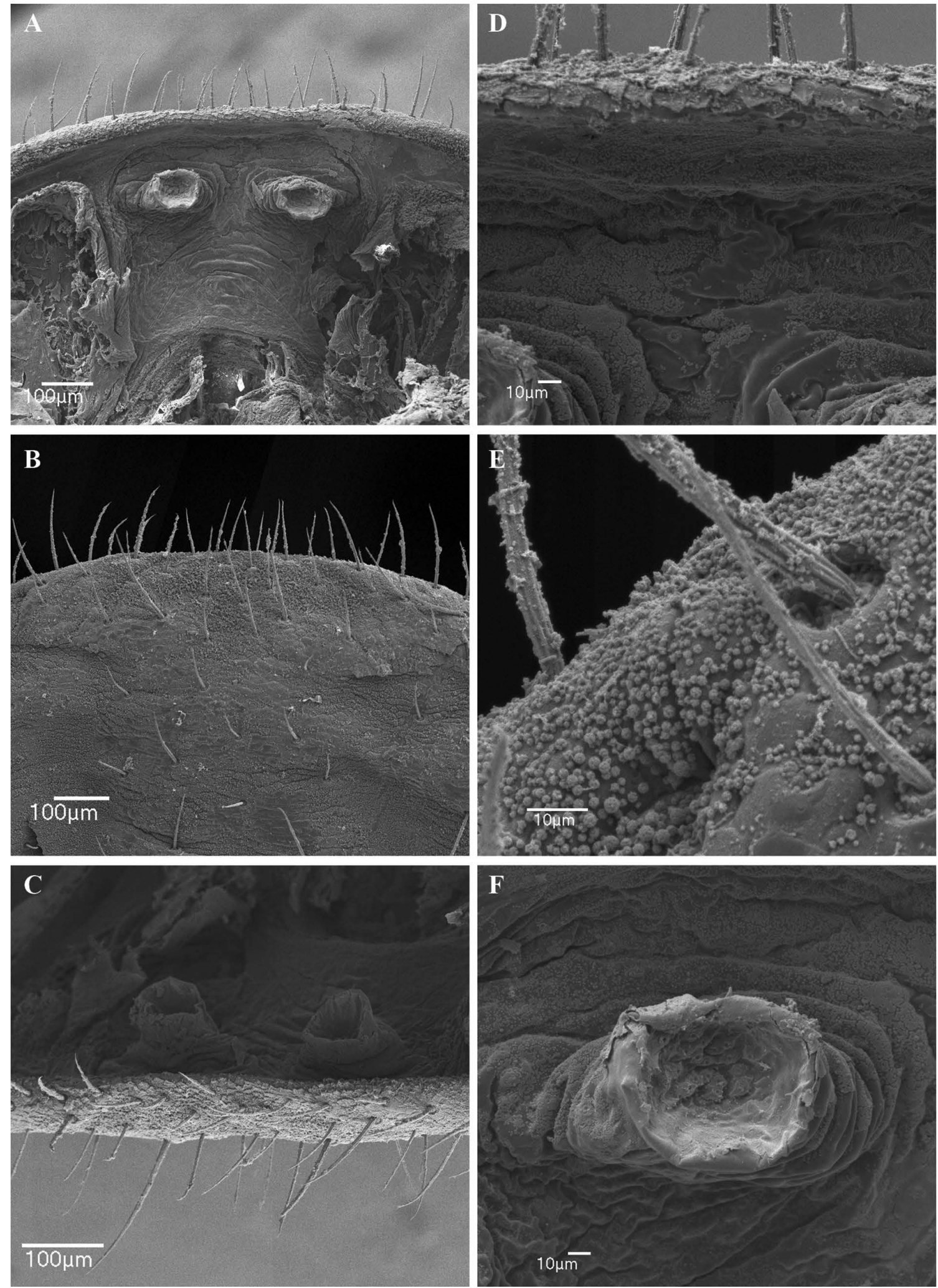

Fig. 55. Charinus cearensis sp. nov. (CHNUFPI 1255), female gonopod. A. Sucker-like gonopod, dorsal view. B. Genital operculum, ventral view. C. Gonopods, posterior view. D. Genital operculum, between gonopods, dorsal view. E. Gland opening near lateral margin of genital operculum. F. Sinistral side of sucker-like gonopod, dorsal view. 

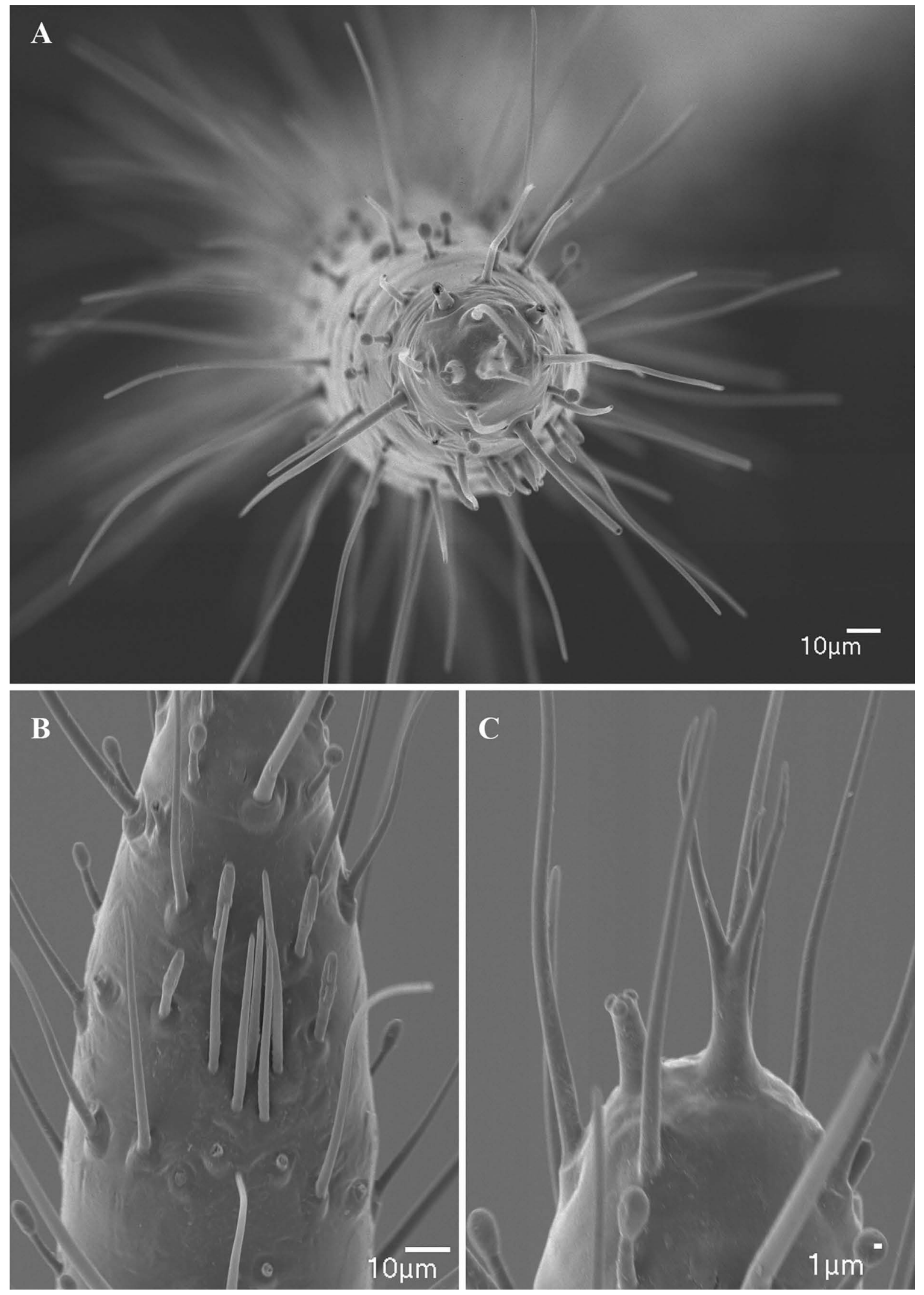

Fig. 56. Charinus cearensis sp. nov. (CHNUFPI 1255), antenniform leg I, ㅇ. A. Apex of distal article. B. Rod sensilla and olfactory setae. C. Apex of distal article of tarsus showing claw and tarsal organ. 


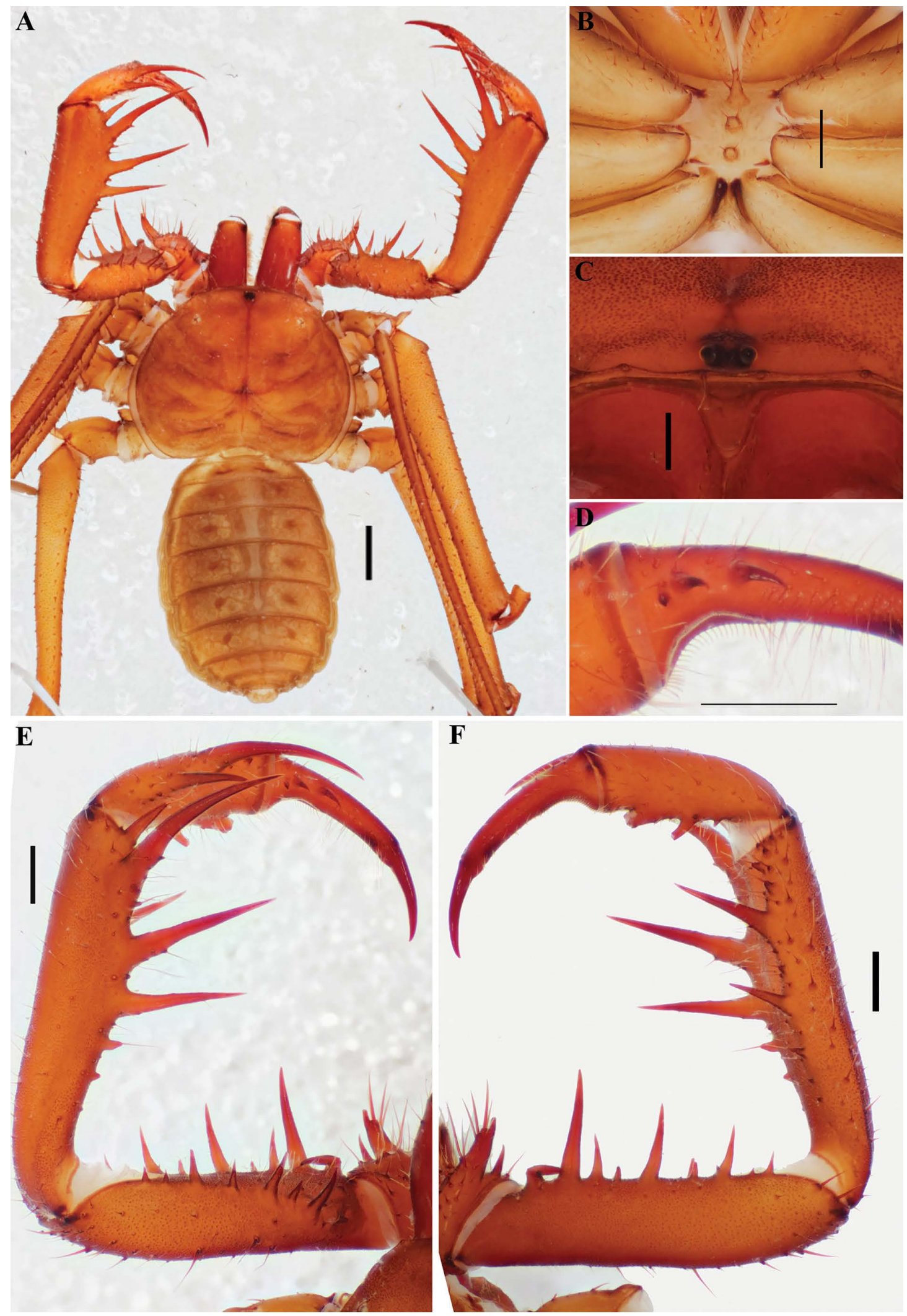

Fig. 57. Charinus diamantinus sp. nov. (MNRJ 9299), + , general morphology. A. Habitus, dorsal view. B. Sternum, ventral view. C. Frontal process. D. Pedipalp tarsus, frontal view. E. Pedipalp, dorsal view. F. Pedipalp, ventral view. Scale bars: A-B, D-F $=1 \mathrm{~mm} ; \mathrm{C}=0.5 \mathrm{~mm}$. 

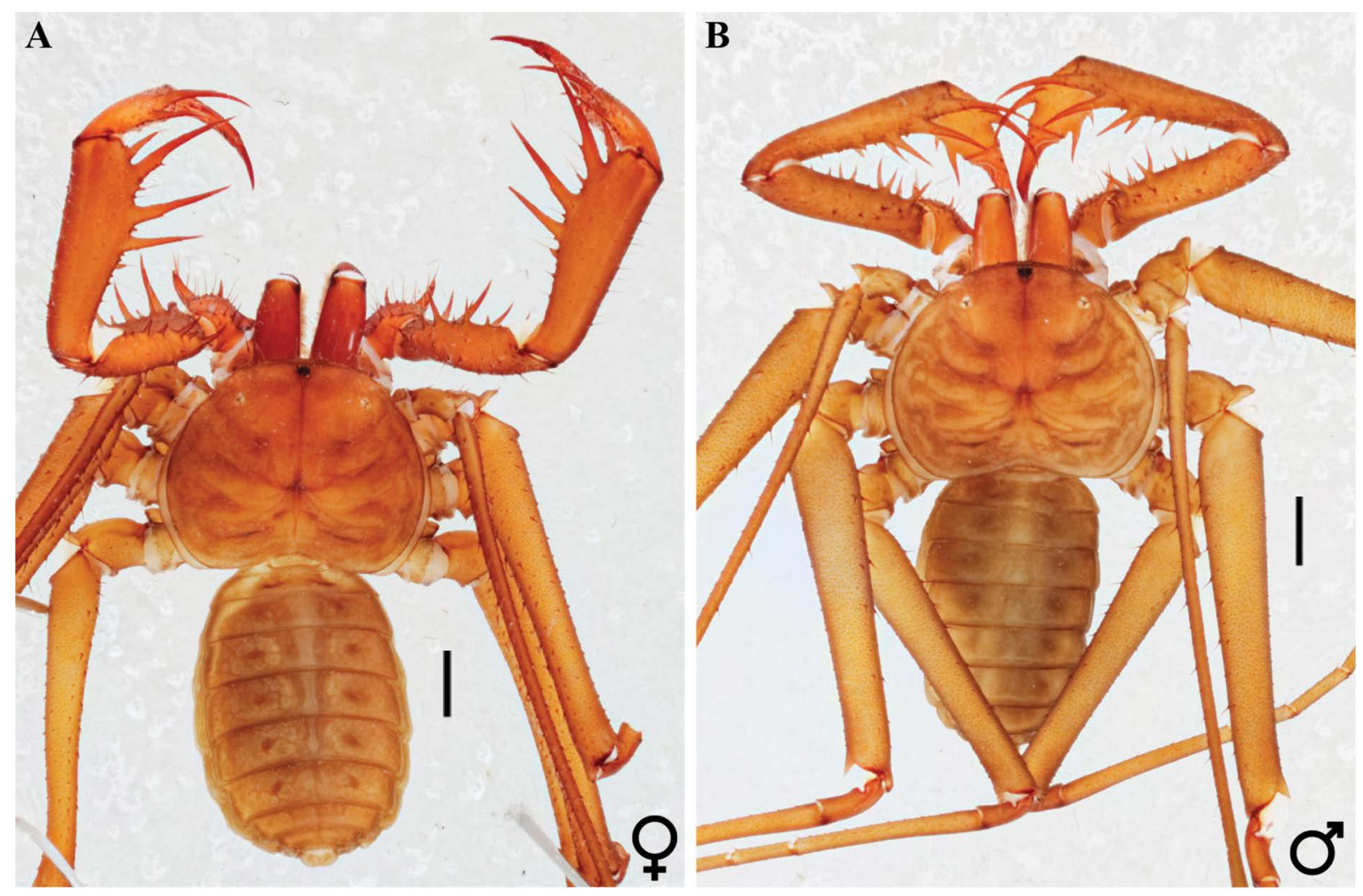

Fig. 58. Charinus diamantinus sp. nov., habitus, dorsal view illustrating secondary sexual dimorphism (males possess longer pedipalp segments than females). A. ㅇ (MNRJ 9299). B. ô (MNRJ 9190). Scale bars: $0.1 \mathrm{~cm}$. 

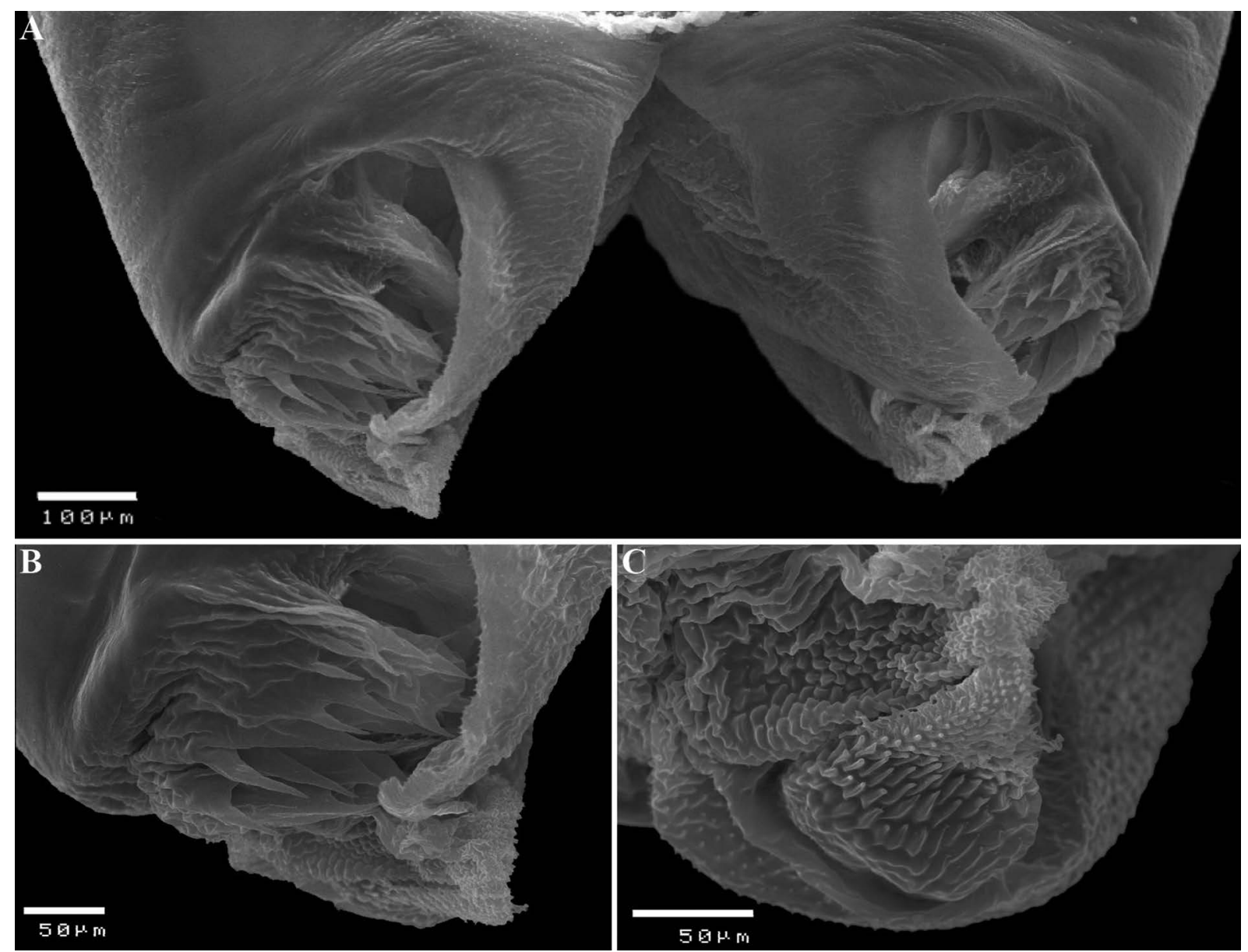

Fig. 59. Charinus diamantinus sp. nov. (MNRJ 9189), male gonopod. A. Gonopod with long and curved lamina medialis (LaM), ventral view. B. Sinistral side of gonopod showing lobus lateralis 2 (LoL2). C. Dorsal lobe (LoD). 


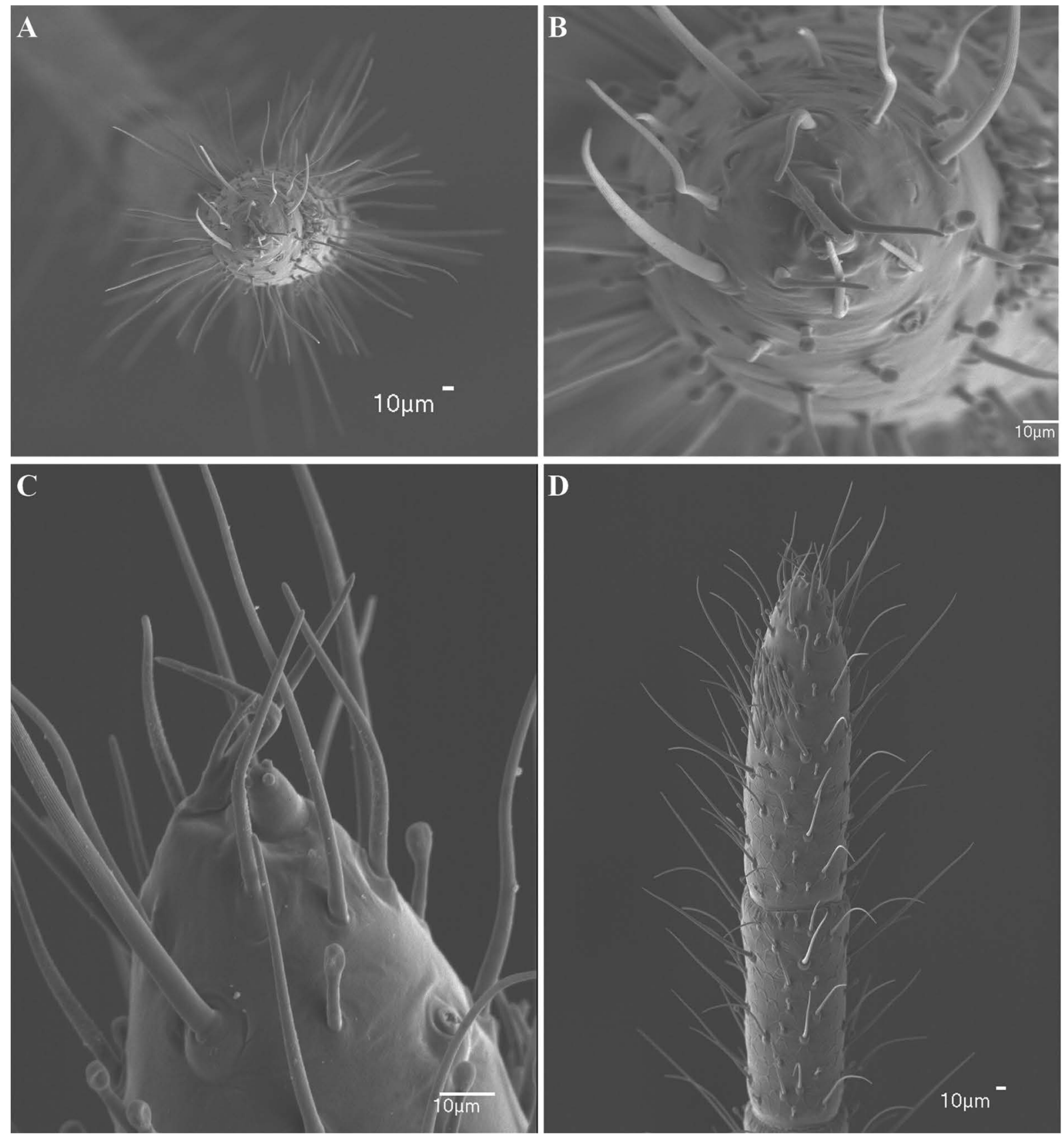

Fig. 60. Charinus diamantinus sp. nov. (MNRJ 9189), antenniform leg I, $q$. A. Frontal view. B. Apex showing claw. C. Claw and tarsal organ, lateral view. D. Rod sensilla lateral view. 


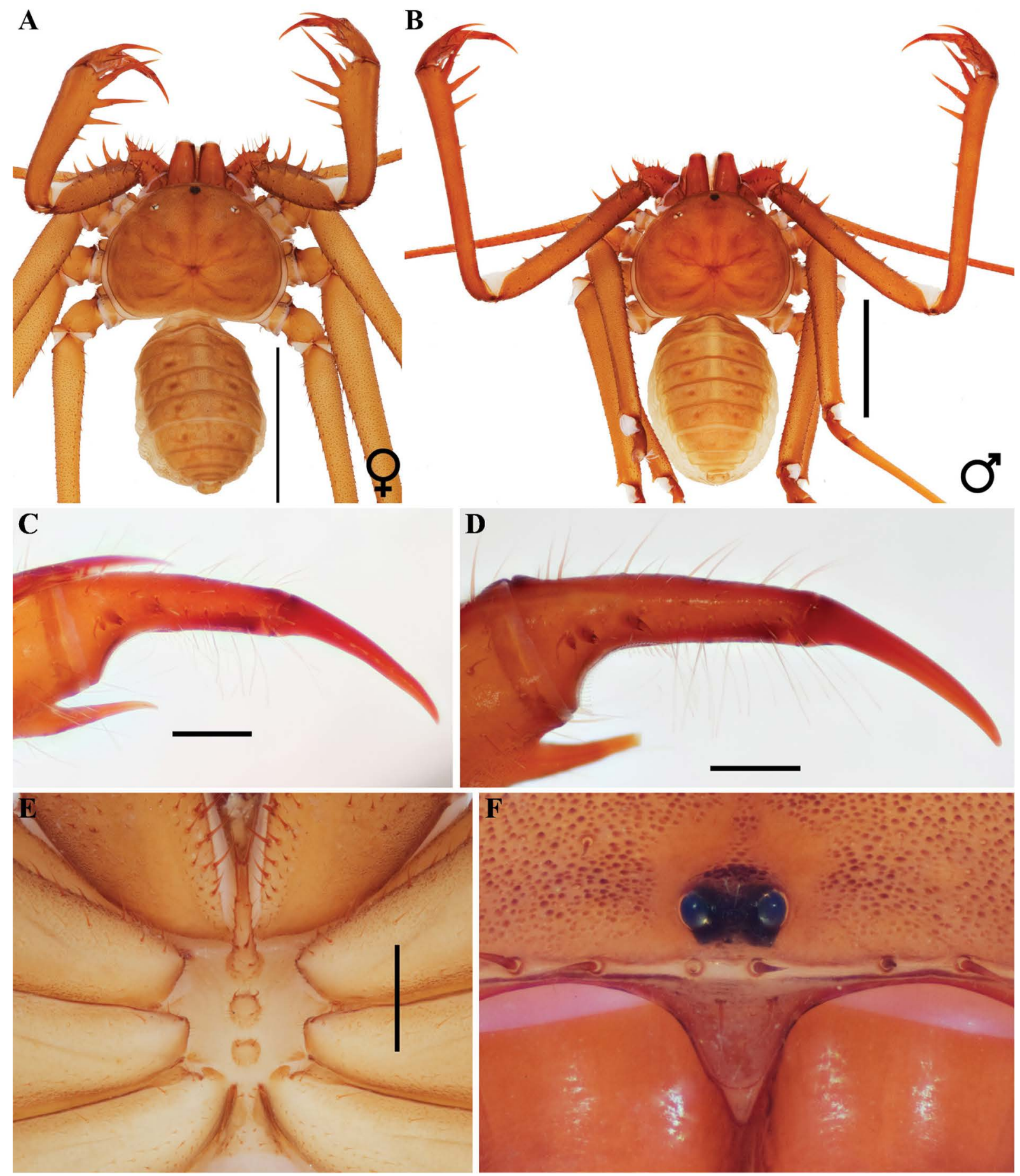

Fig. 61. Charinus euclidesi sp. nov. (MNRJ 9099), general morphology. A. Female habitus, dorsal view. B. Male habitus, dorsal view. C. Female pedipalp tarsal spines, dorsal view. D. Male pedipalp tarsal spines, dorsal view. E. Female sternum, ventral view. F. Male frontal process. Scale bars: $A-B=0.5 \mathrm{~cm}$; $\mathrm{C}-\mathrm{D}=0.5 \mathrm{~mm} ; \mathrm{E}=1 \mathrm{~mm} ; \mathrm{F}=0.1 \mathrm{~mm}$. 


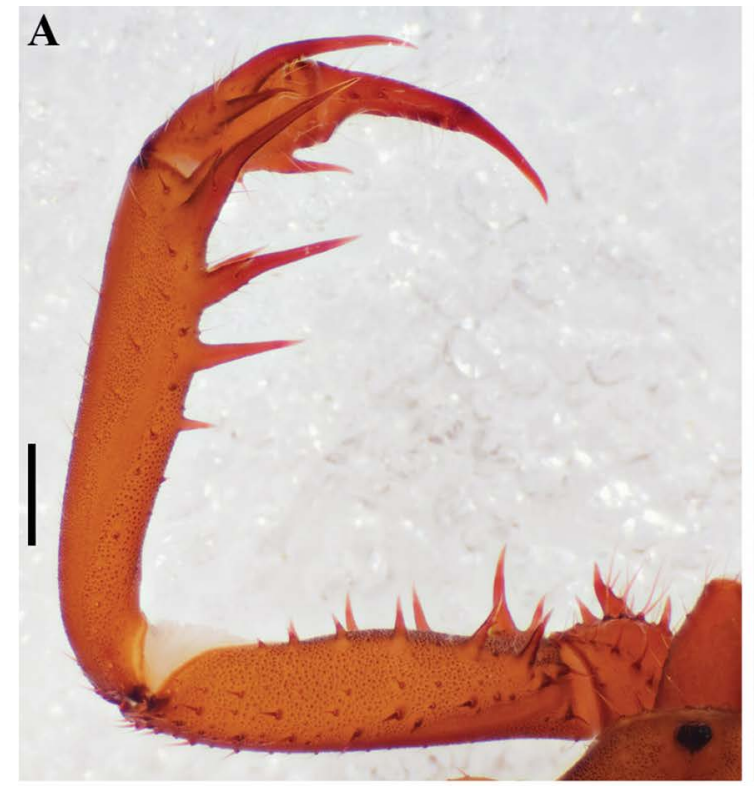

C

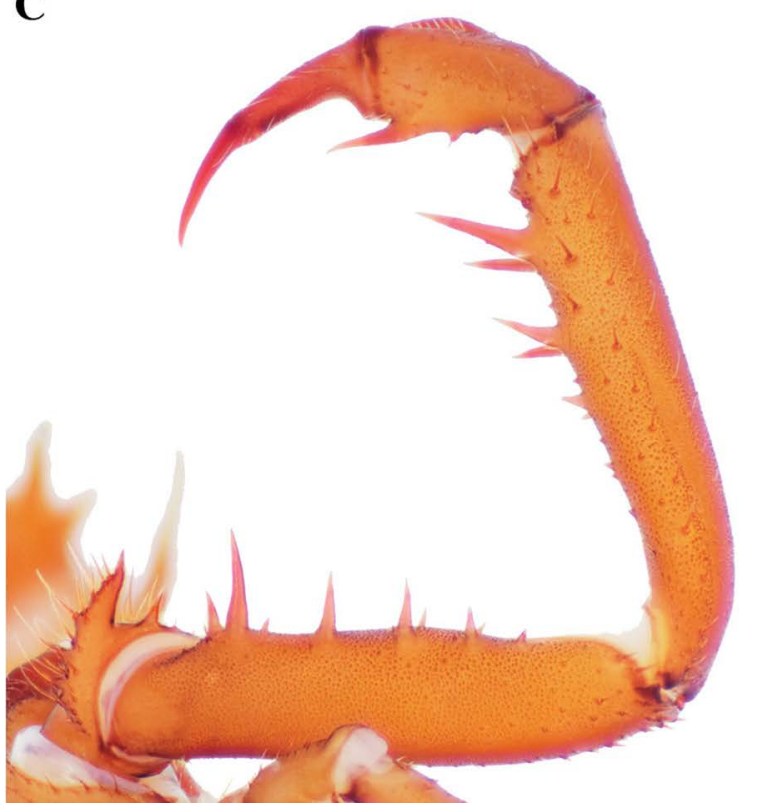

B

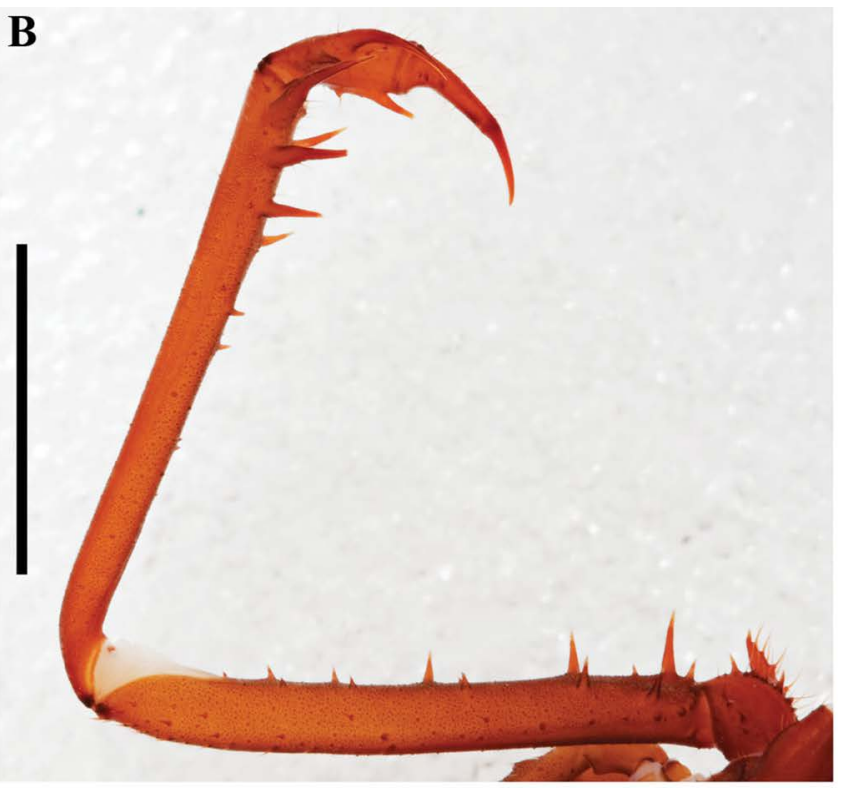

D

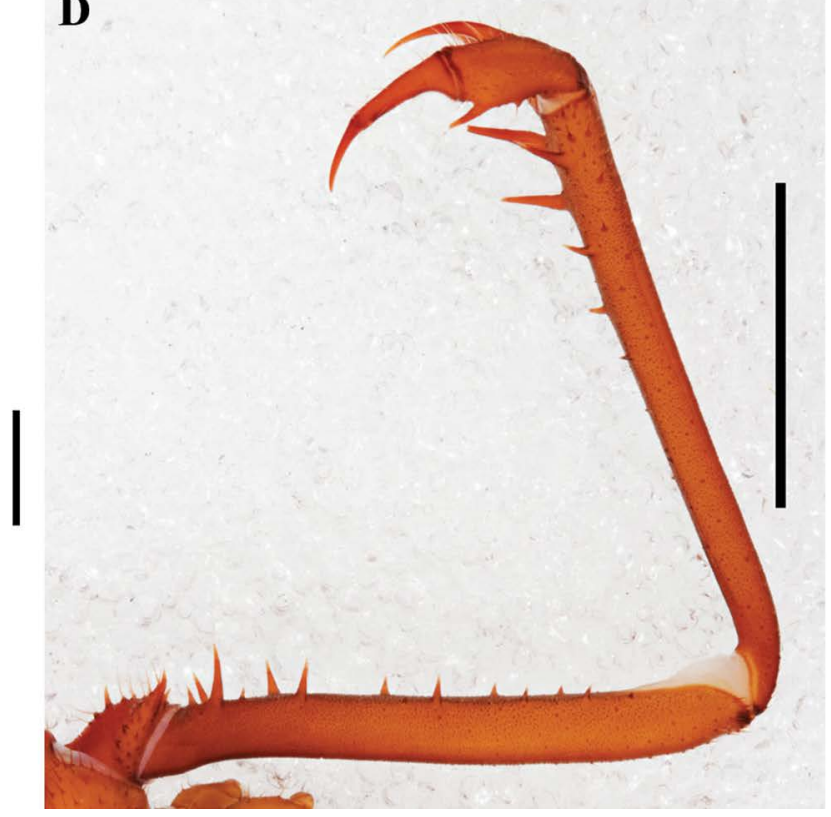

Fig. 62. Charinus euclidesi sp. nov. (MNRJ 9099), pedipalp. A. Female pedipalp, dorsal view. B. Male pedipalp, dorsal view. C. Female pedipalp, ventral view. D. Male pedipalp, ventral view. Scale bars: A, $\mathrm{C}=1 \mathrm{~mm} ; \mathrm{B}, \mathrm{D}=0.5 \mathrm{~cm}$. 

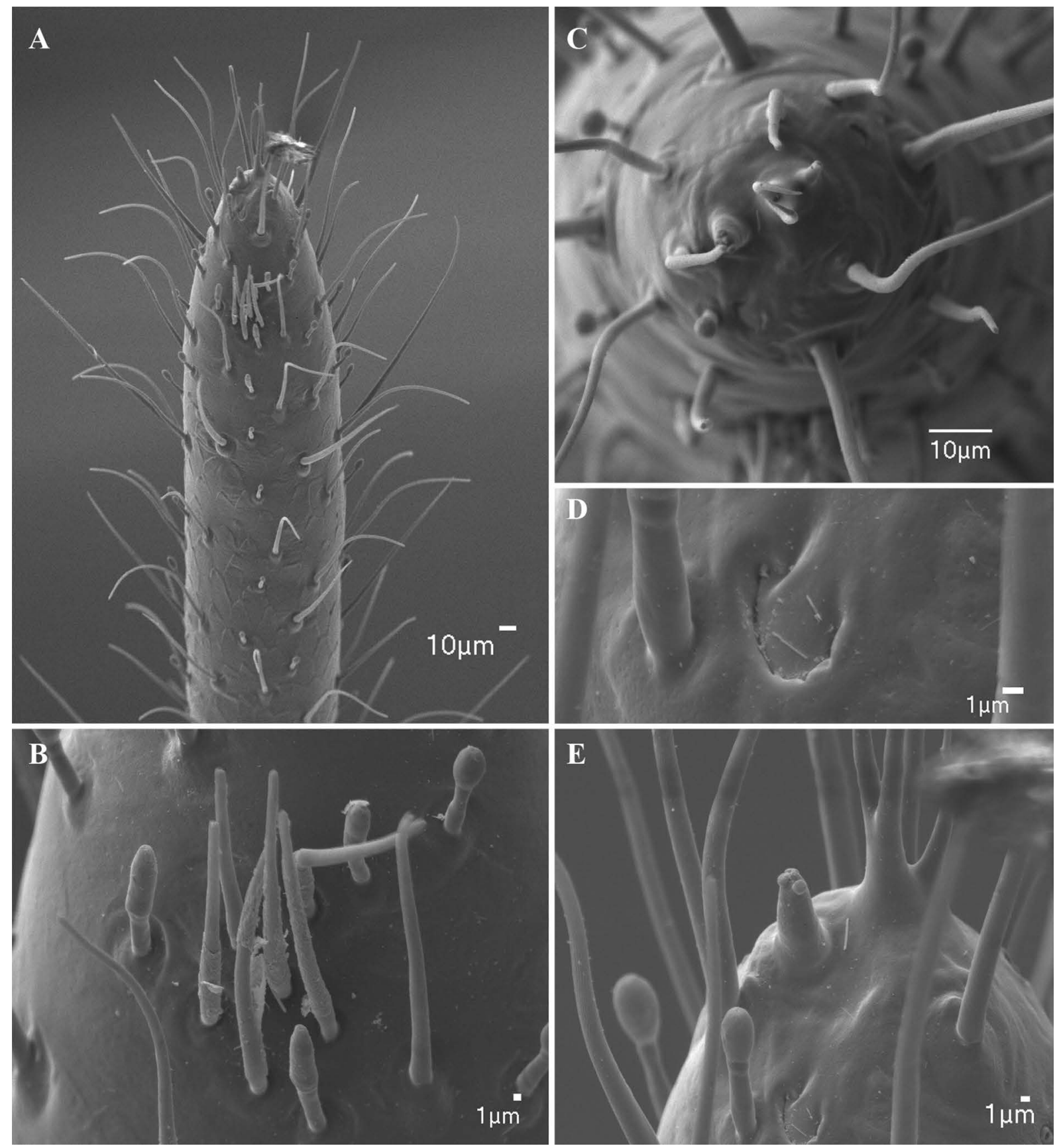

Fig. 63. Charinus euclidesi sp. nov. (MNRJ 9099), antenniform leg I. A. Apex of distal article. B. Rod sensilla and olfactory setae. C. Apex of distal article of tarsus showing claw and tarsal organ. D. Detail of slit sensilla. E. Distal segment of tarsus, lateral view. 


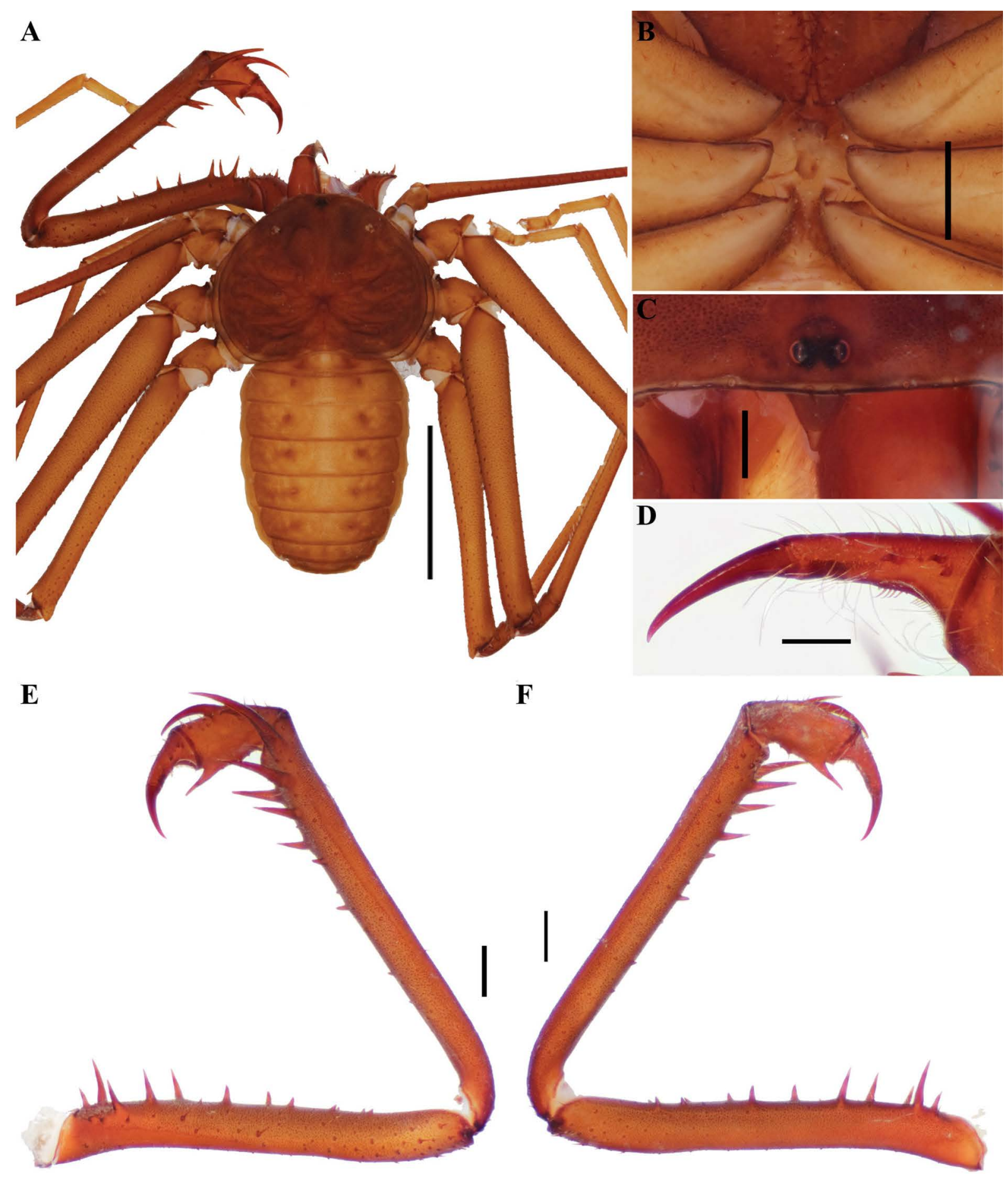

Fig. 64. Charinus goitaca sp. nov. (MNRJ 9224), general morphology, $\widehat{\partial}$. A. Habitus, dorsal view. B. Sternum, ventral view. C. Frontal process. D. Pedipalp tarsus, frontal view. E. Pedipalp, dorsal view. F. Pedipalp, ventral view. Scale bars: $A=0.5 \mathrm{~cm} ; \mathrm{B}, \mathrm{E}-\mathrm{F}=1 \mathrm{~mm}$; $\mathrm{C}-\mathrm{D}=0.5 \mathrm{~mm}$. 
MIRANDA G.S. et al., Systematic revision of Charinidae (Arachnida, Amblypygi)
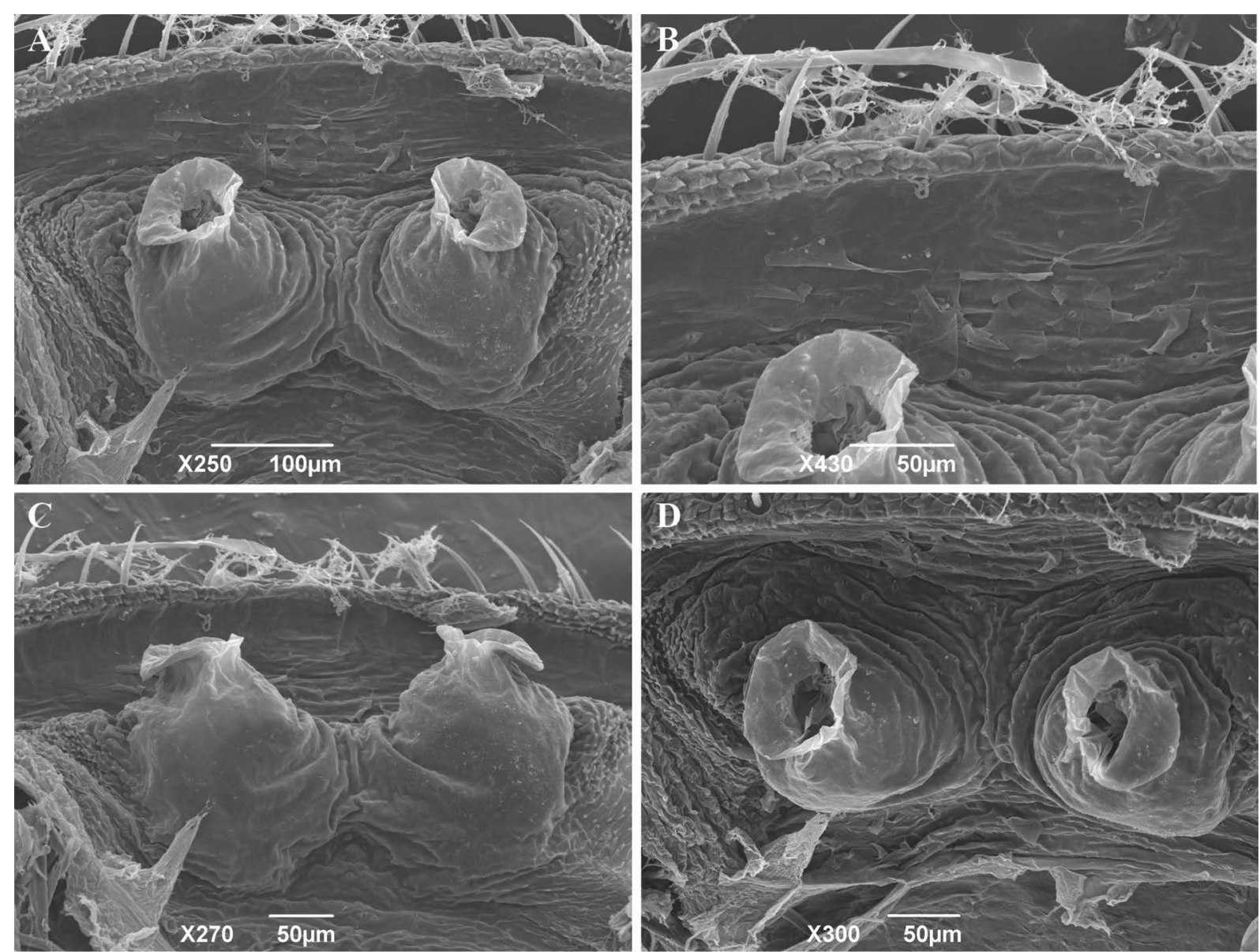

Fig. 65. Charinus goitaca sp. nov. (MNRJ 9360), female gonopod and genital operculum. A. Suckerlike gonopod, dorsal view. B. Genital operculum between gonopods. C. Gonopods, anterior view. D. Gonopods aperture. 


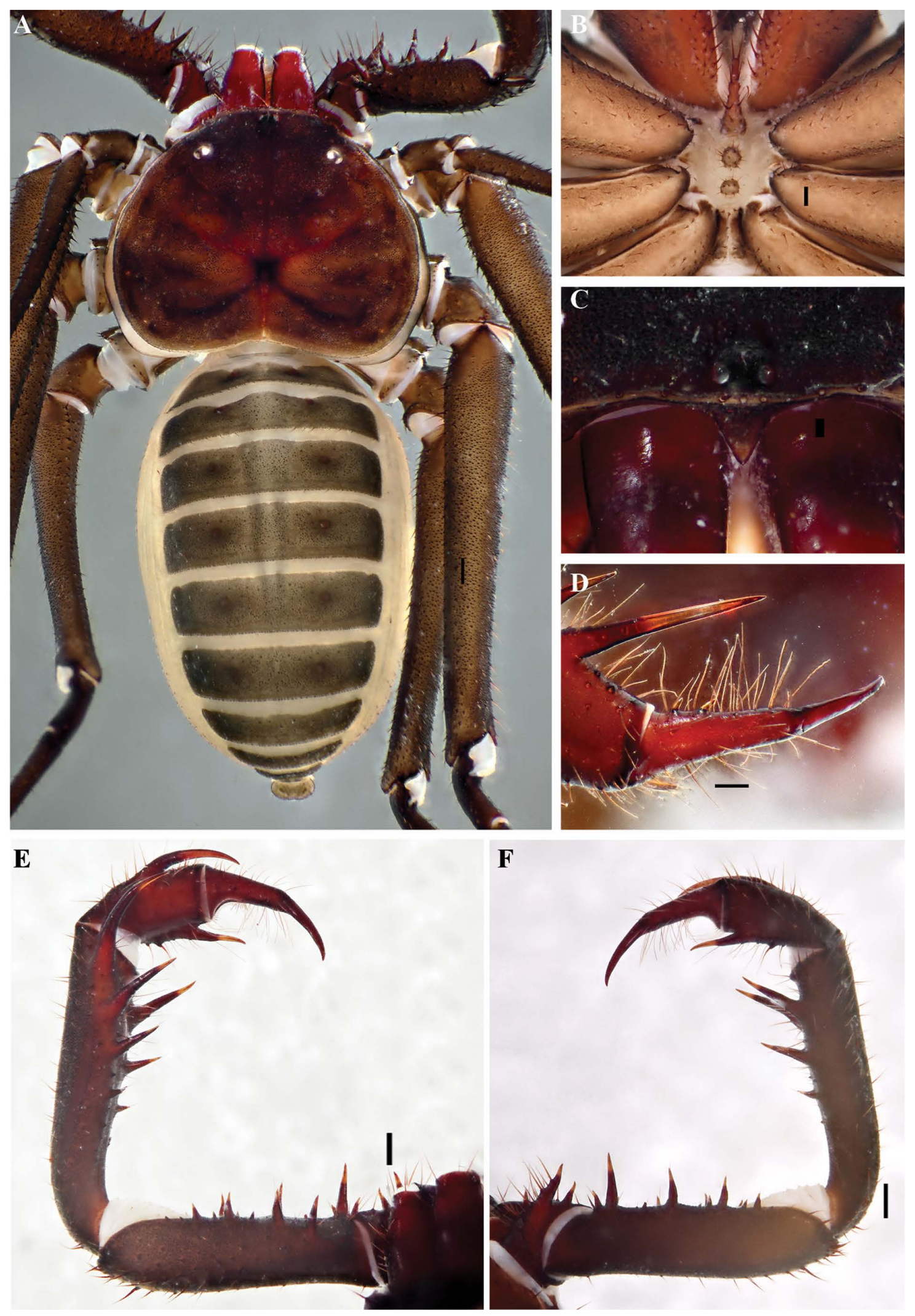

Fig. 66. Charinus imperialis sp. nov. (MNRJ 9358), general morphology. A. Habitus, dorsal view. B. Sternum, ventral view. C. Frontal process. D. Pedipalp tarsus, frontal view. E. Pedipalp, dorsal view. F. Pedipalp, ventral view. Scale bars: A, E-F $=1 \mathrm{~mm}$; B-D $=0.5 \mathrm{~mm}$. 

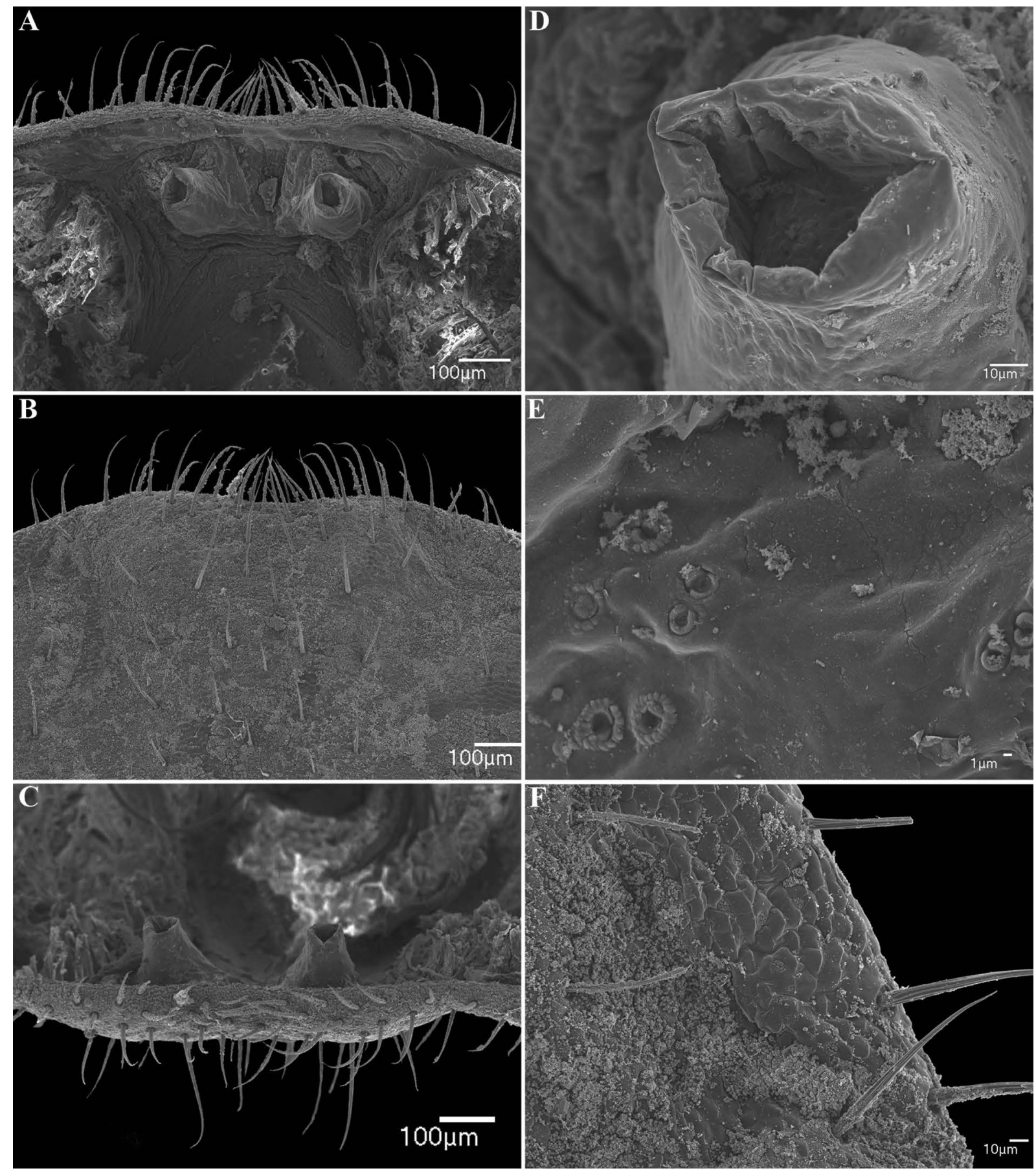

Fig. 67. Charinus imperialis sp. nov. (MNRJ 9032), female gonopod and genital operculum. A. Suckerlike gonopod, dorsal view. B. Posterior margin of genital operculum, ventral view. C. Gonopods, posterior view. D. Dextral sucker-like projection. E. Glandular openings at base of gonopods. F. Slit sensilla on lateral margin of genital operculum. 

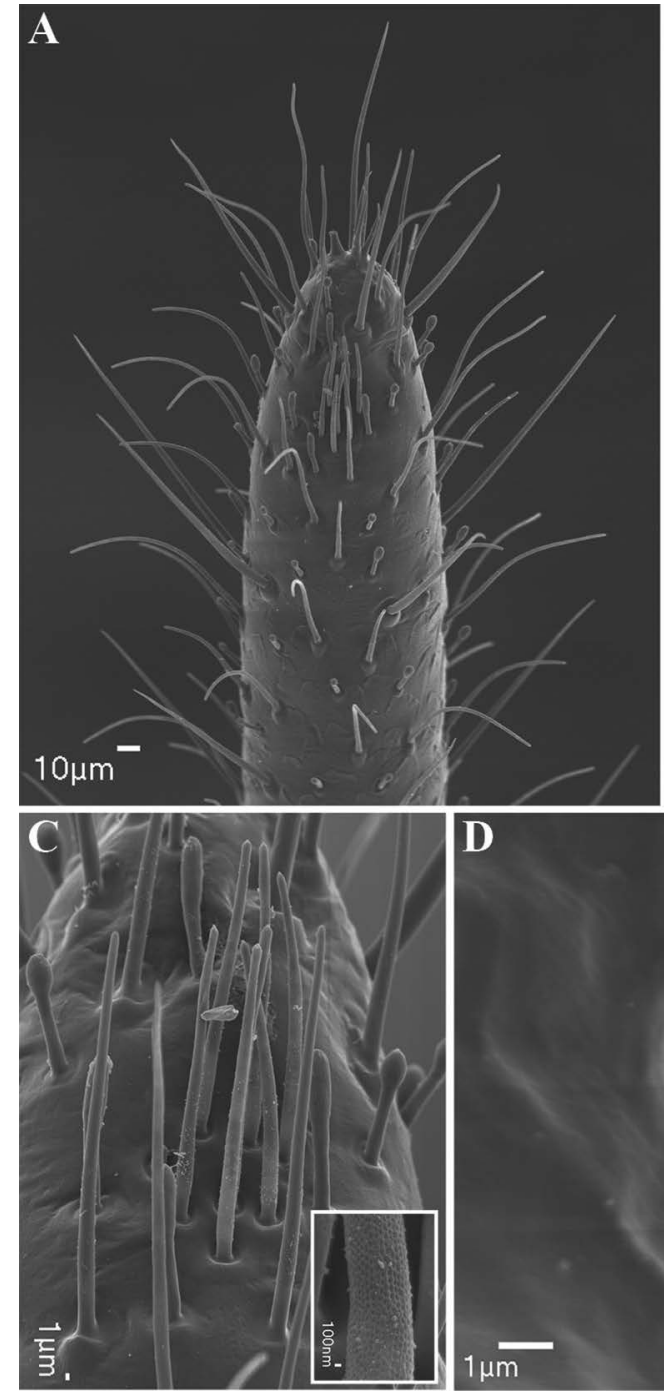

B

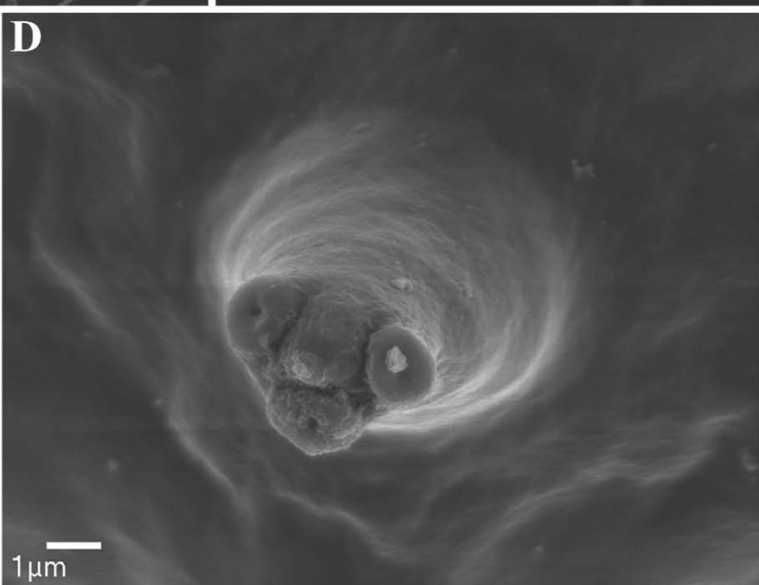

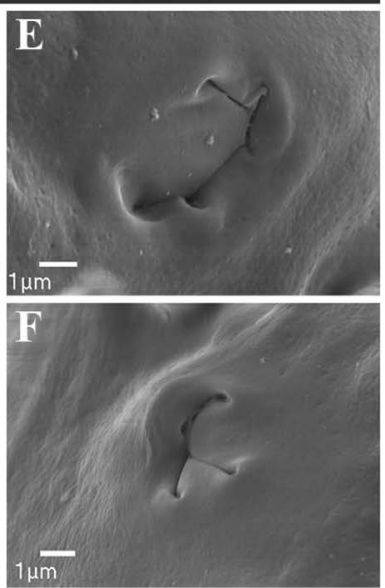

Fig. 68. Charinus imperialis sp. nov. (MNRJ 9032), leg I tarsus, $q$. A. Tarsus, apex of distal article. B. Tarsus, distal article, frontal view. C. Olfactory setae ventrally on last segment of tarsus. D. Tarsal organ near claw of tarsus. E. Slit sensilla near base of tarsal organ. F. Another slit sensilla on opposite side of article. 
$\mathbf{A}$

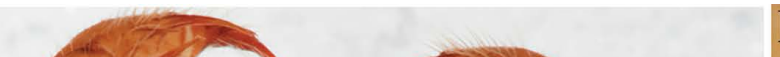

240 B

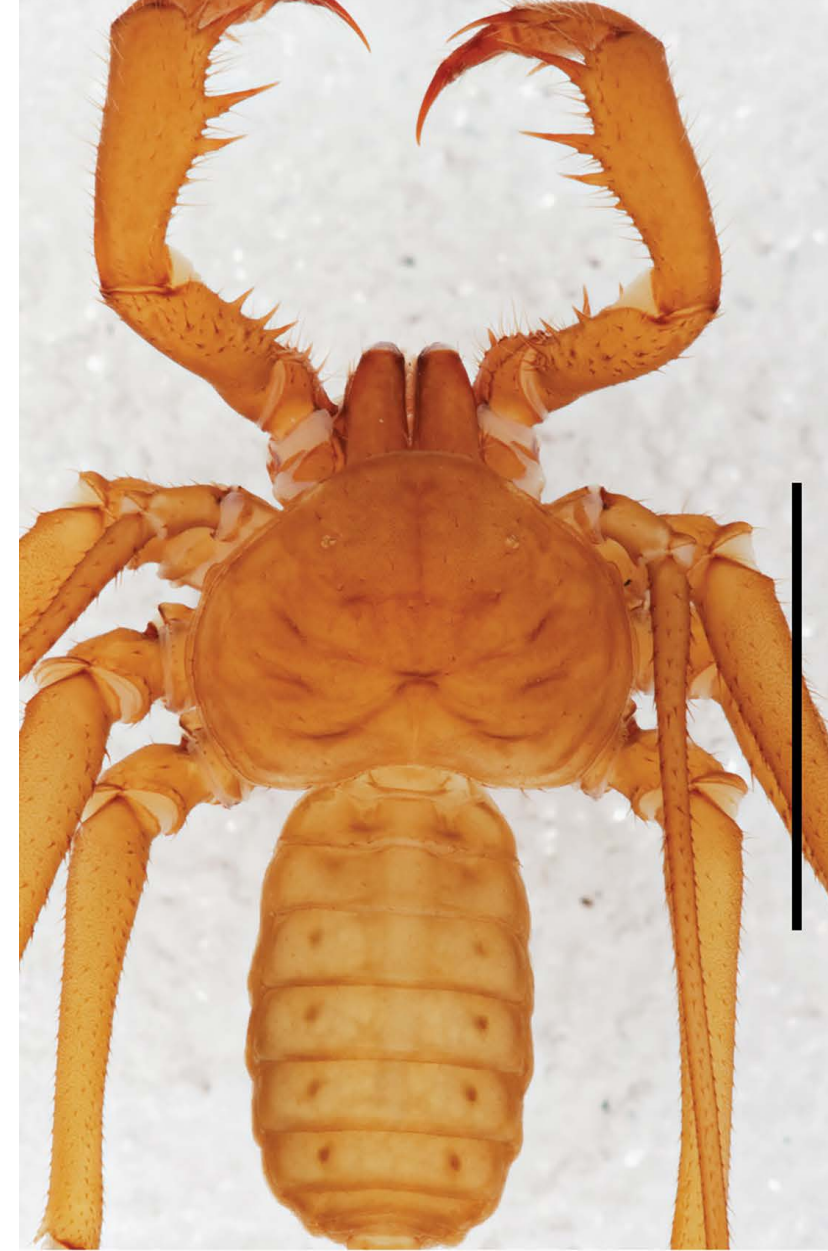

$\mathbf{E}$

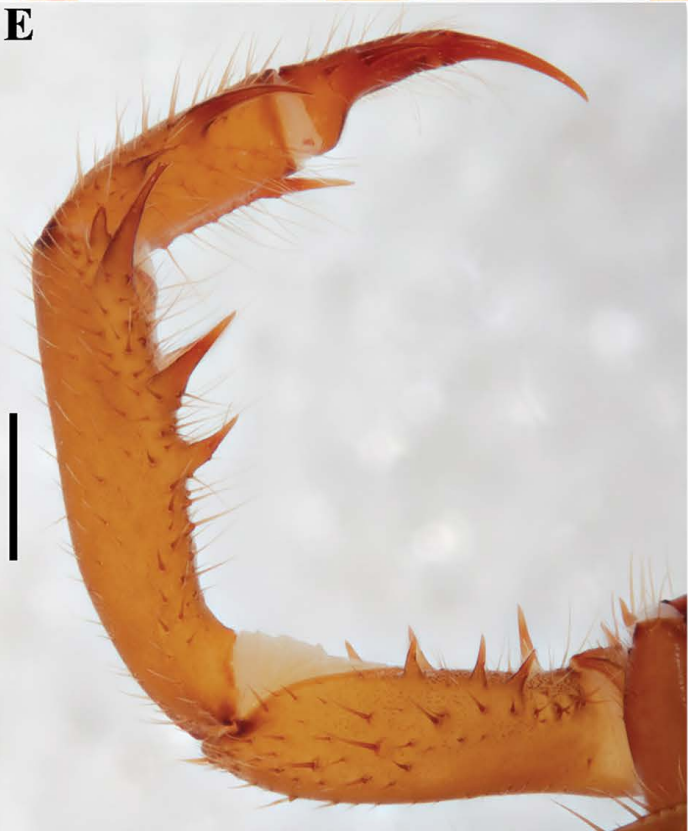

B

F

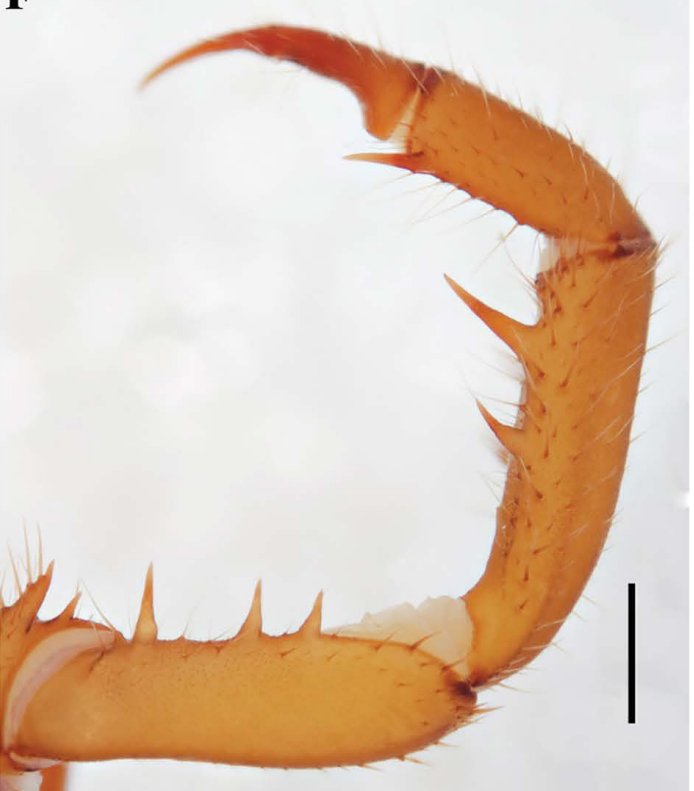

Fig. 69. Charinus monasticus sp. nov. (MNRJ 9103), general morphology. A. Habitus, dorsal view. B. Sternum, ventral view. C. Frontal process. D. Pedipalp tarsus, frontal view. E. Pedipalp, dorsal view. F. Pedipalp, ventral view. Scale bars: $A=0.5 \mathrm{~cm} ; \mathrm{B}, \mathrm{E}-\mathrm{F}=1 \mathrm{~mm} ; \mathrm{C}-\mathrm{D}=0.5 \mathrm{~mm}$. 

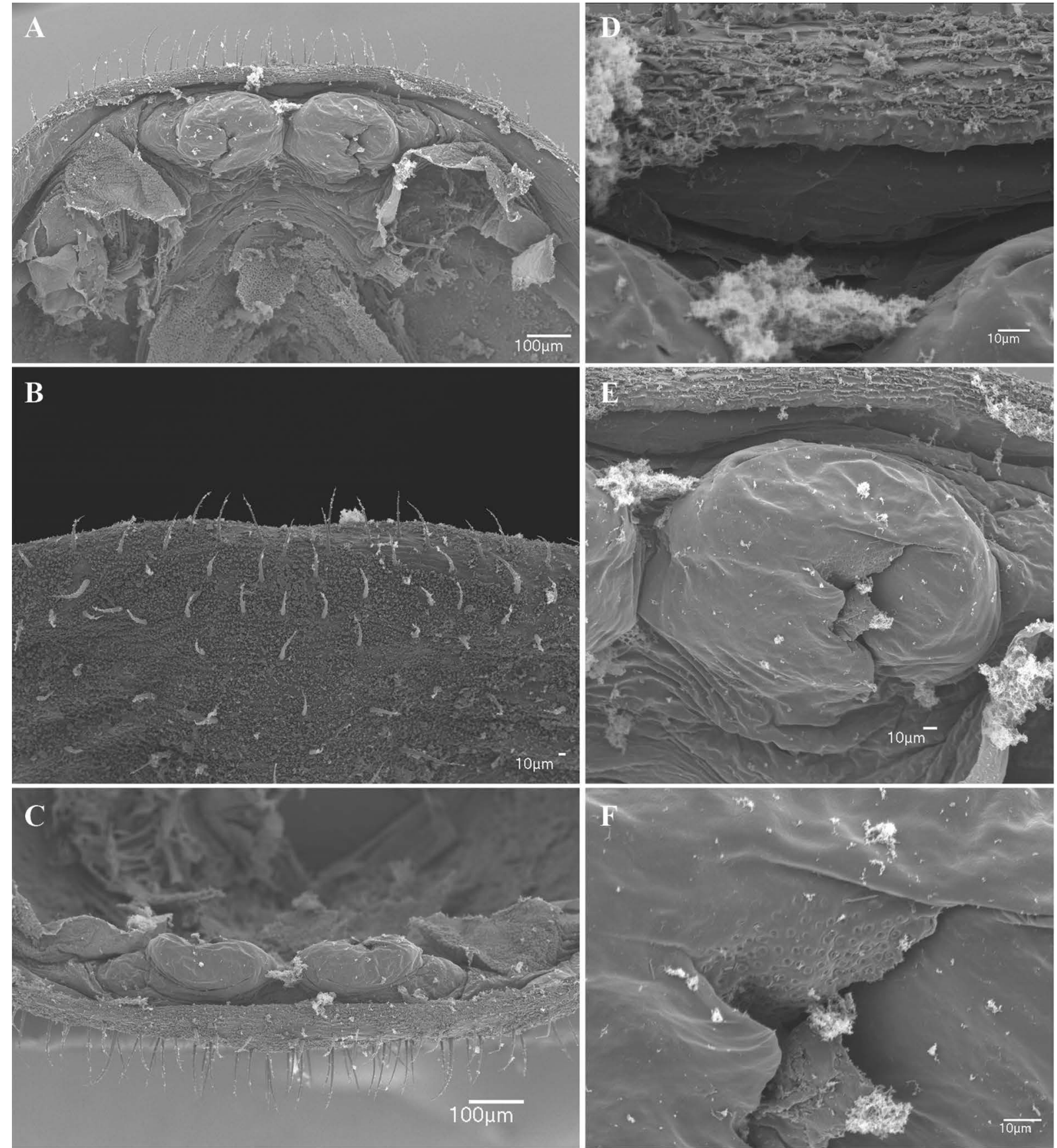

Fig. 70. Charinus monasticus sp. nov. (MNRJ 9103), female gonopod and genital operculum. A. Cushionlike gonopod, dorsal view. B. Posterior margin of genital operculum, ventral view. C. Gonopods, posterior view. D. Genital operculum between gonopods. E. Dextral gonopod and gonopore. F. Glandular openings inside gonopod projection. 


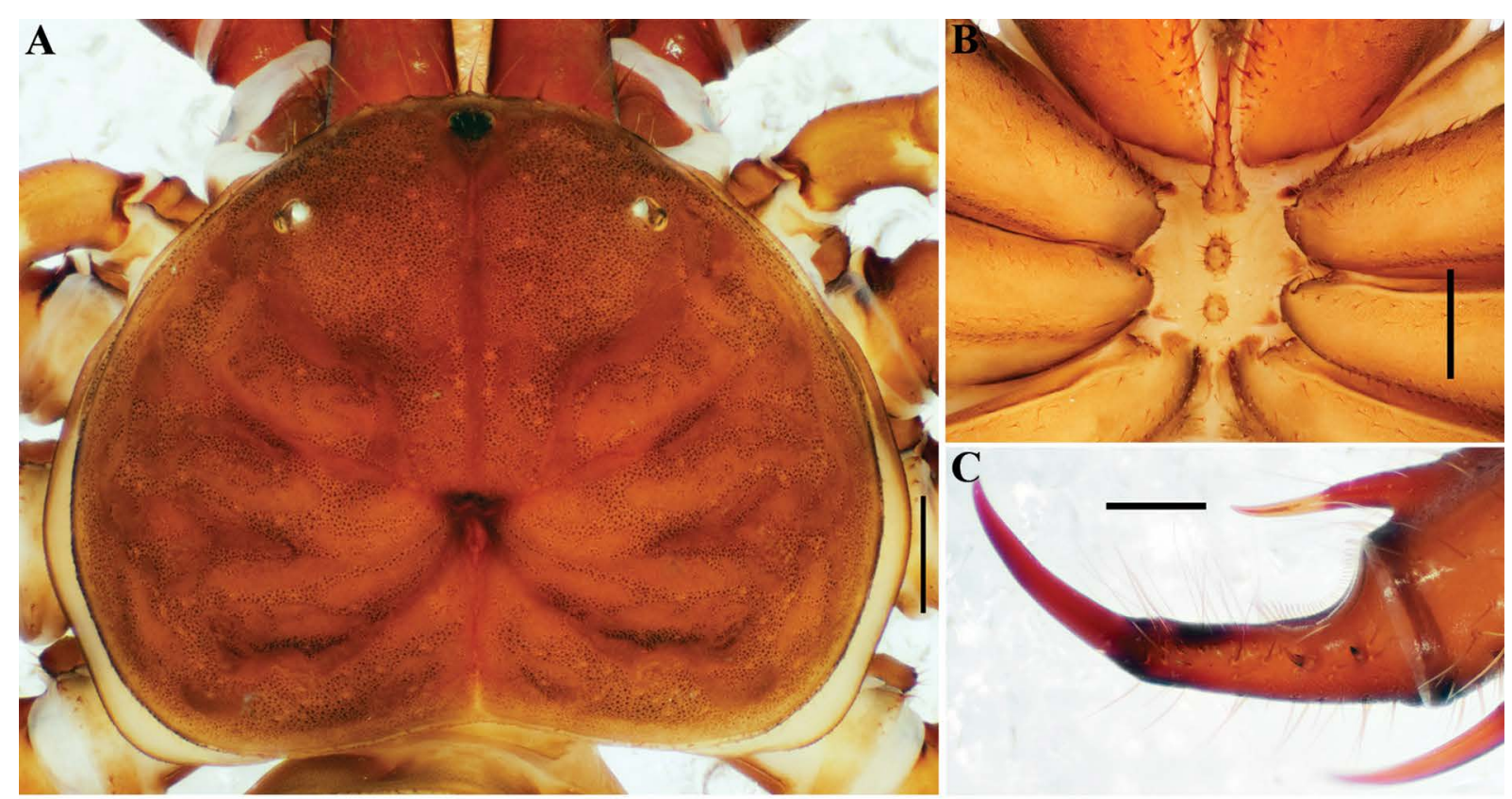

D

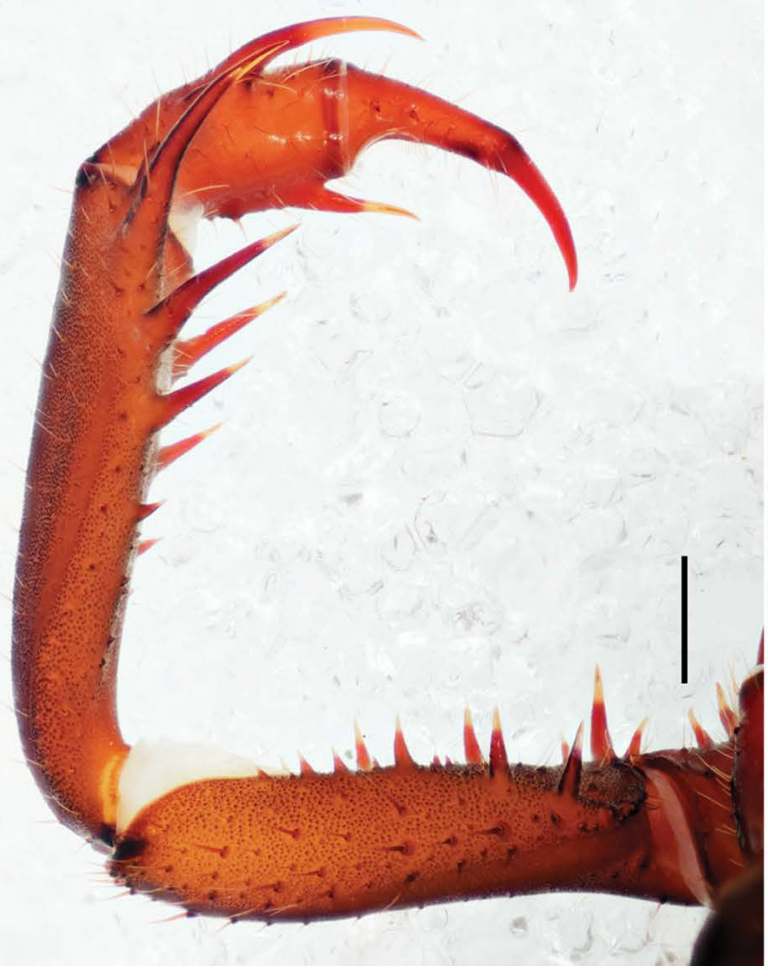

E
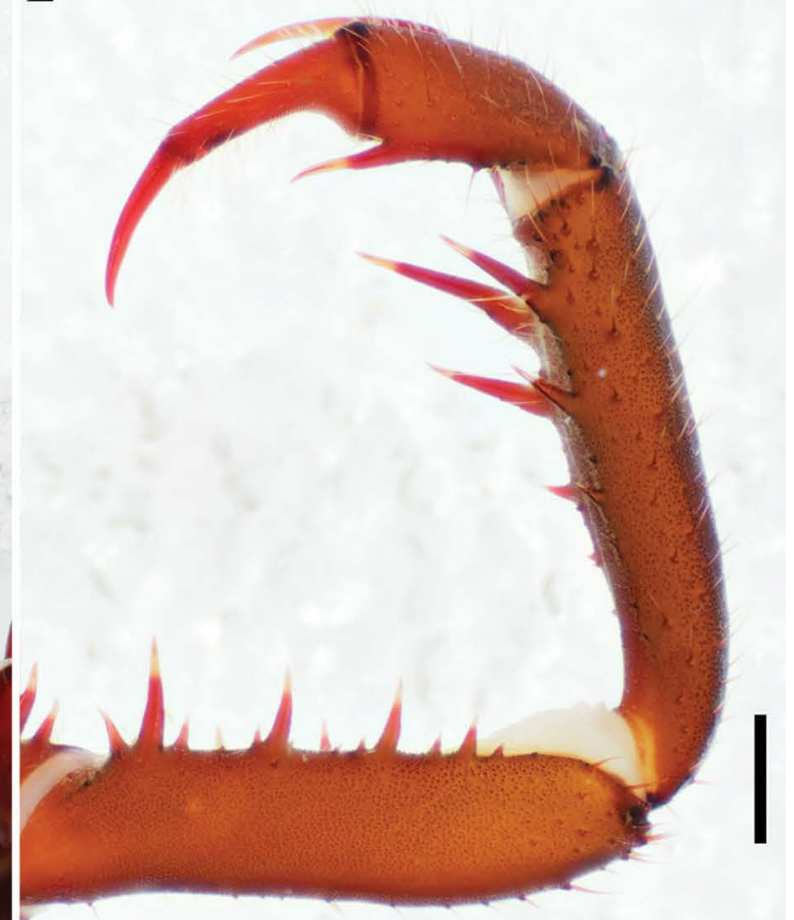

Fig. 71. Charinus puri sp. nov. (MNRJ 9223), general morphology. A. Carapace, dorsal view. B. Sternum, ventral view. C. Pedipalp tarsus, frontal view. D. Pedipalp, dorsal view. E. Pedipalp, ventral view. Scale bars: A-B, D-E $=1 \mathrm{~mm}$; $\mathrm{C}=0.5 \mathrm{~mm}$. 

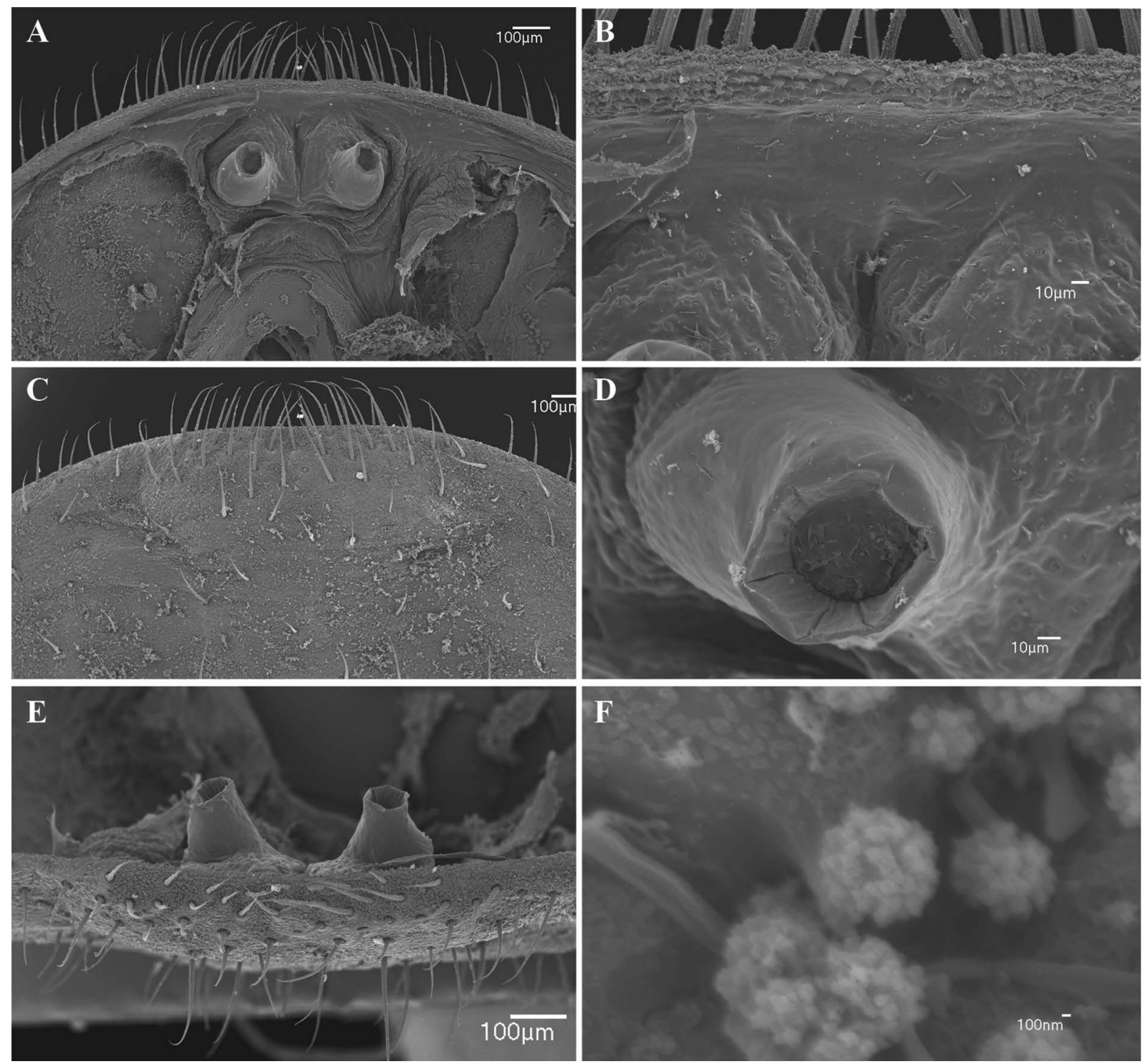

Fig. 72. Charinus puri sp. nov. (MNRJ 9223), female gonopod and genital operculum. A. Sucker-like gonopod, dorsal view. B. Genital operculum, ventral view. C. Gonopods, posterior view. D. Posterior margin of genital operculum, ventral view. F. Cerotegument. 


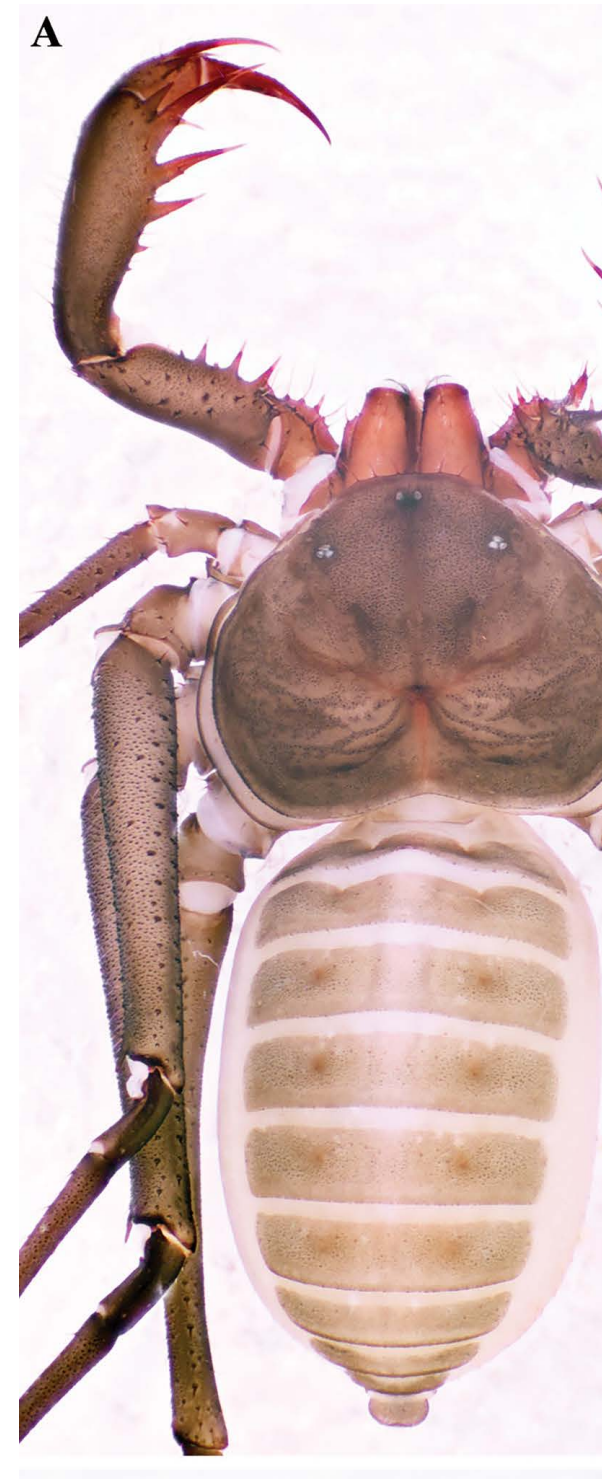

$\mathbf{E}$

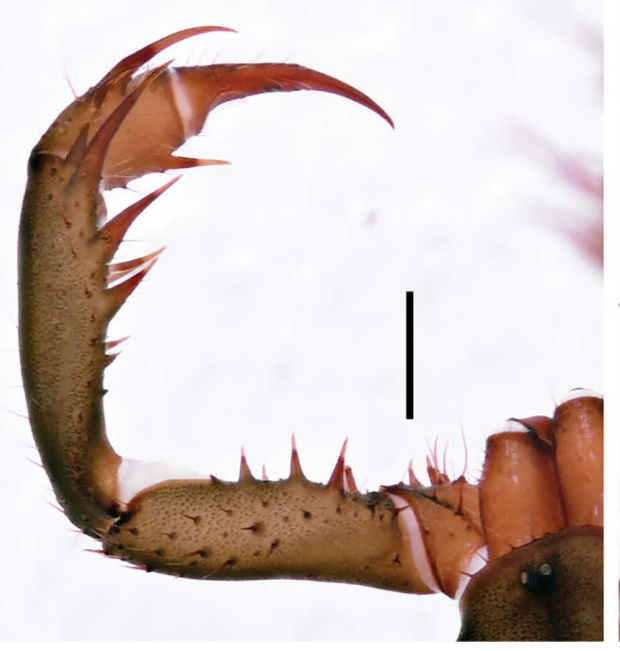

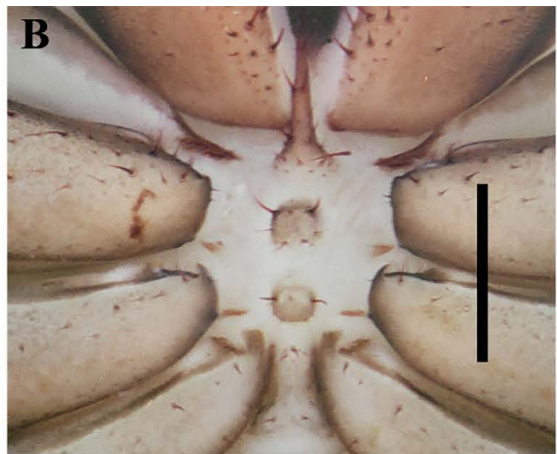
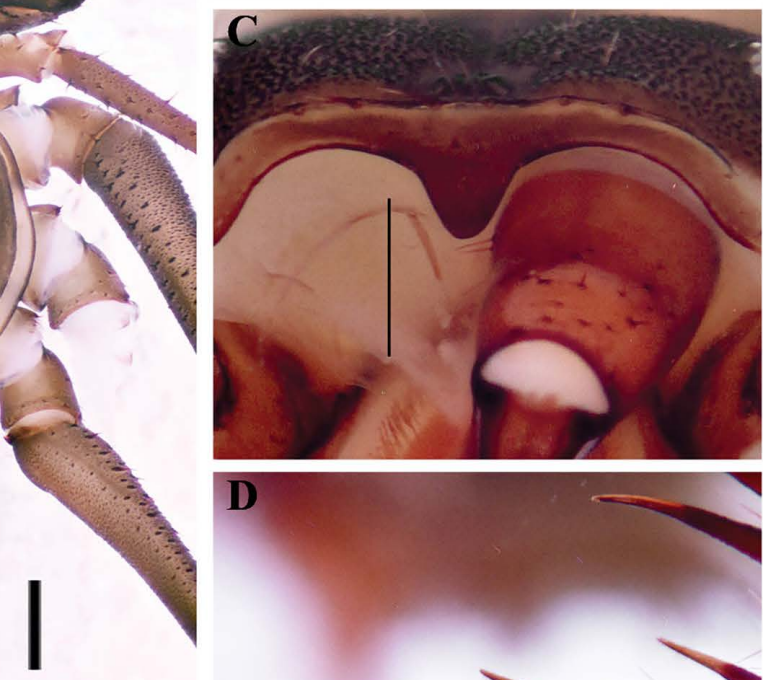

$\mathbf{F}$

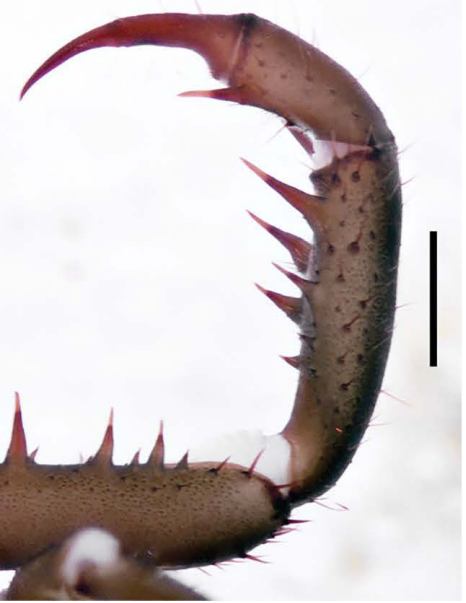

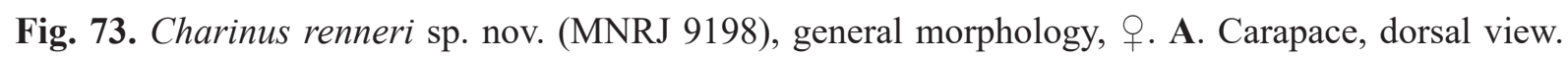
B. Sternum, ventral view. C. Frontal process. D. Pedipalp tarsus, frontal view. E. Pedipalp, dorsal view. F. Pedipalp, ventral view. Scale bars: A-B, E-F $=1 \mathrm{~mm} ; \mathrm{C}-\mathrm{D}=0.5 \mathrm{~mm}$. 

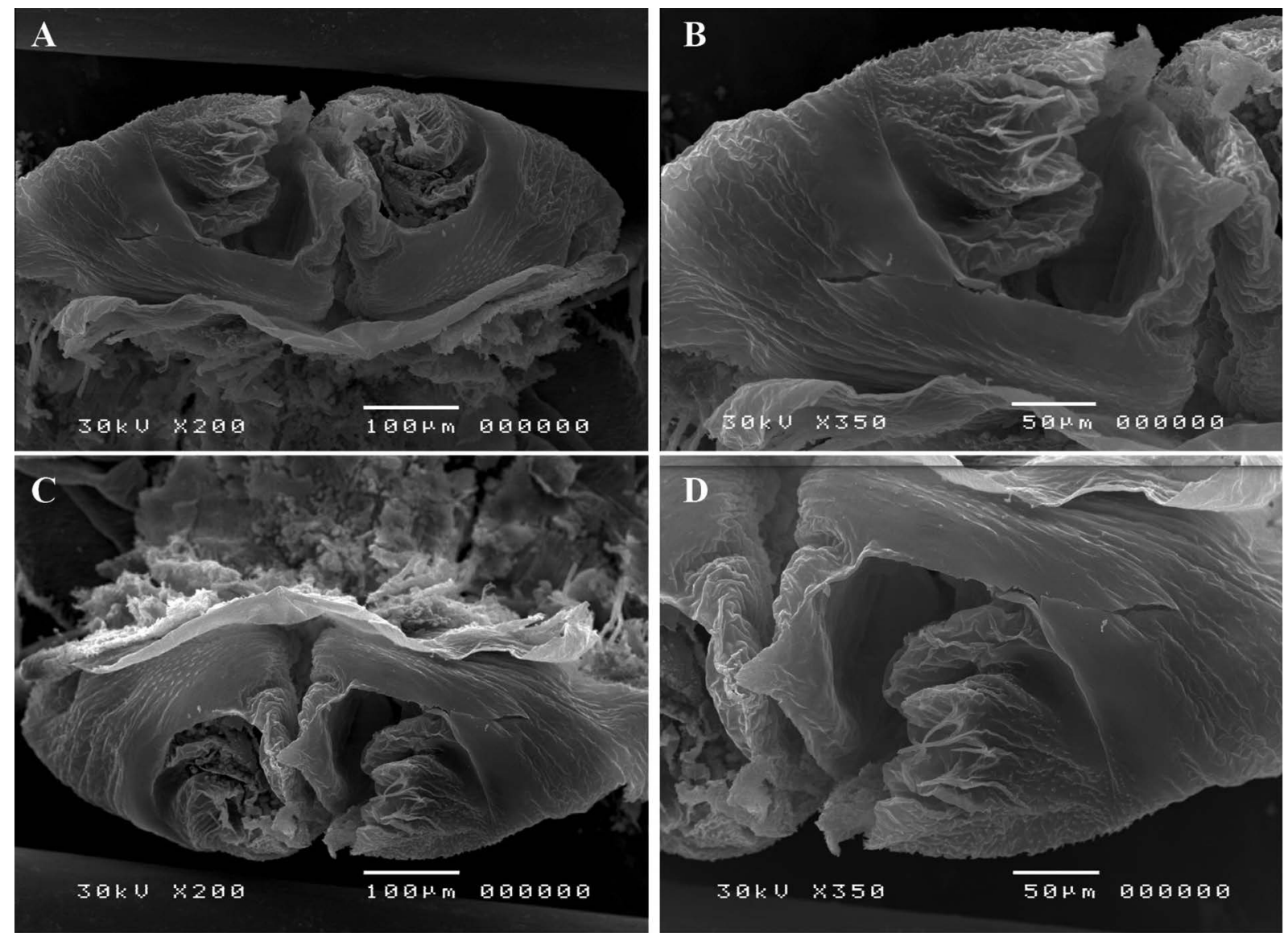

Fig. 74. Charinus renneri sp. nov. (MNRJ 9198), male gonopod. A. Ventral view. B. Lateral lobe 2, lamina medialis, processus internus and fistula. C. Posterior view. D. Lateral lobe 2, lamina medialis, processus internus and fistula. 


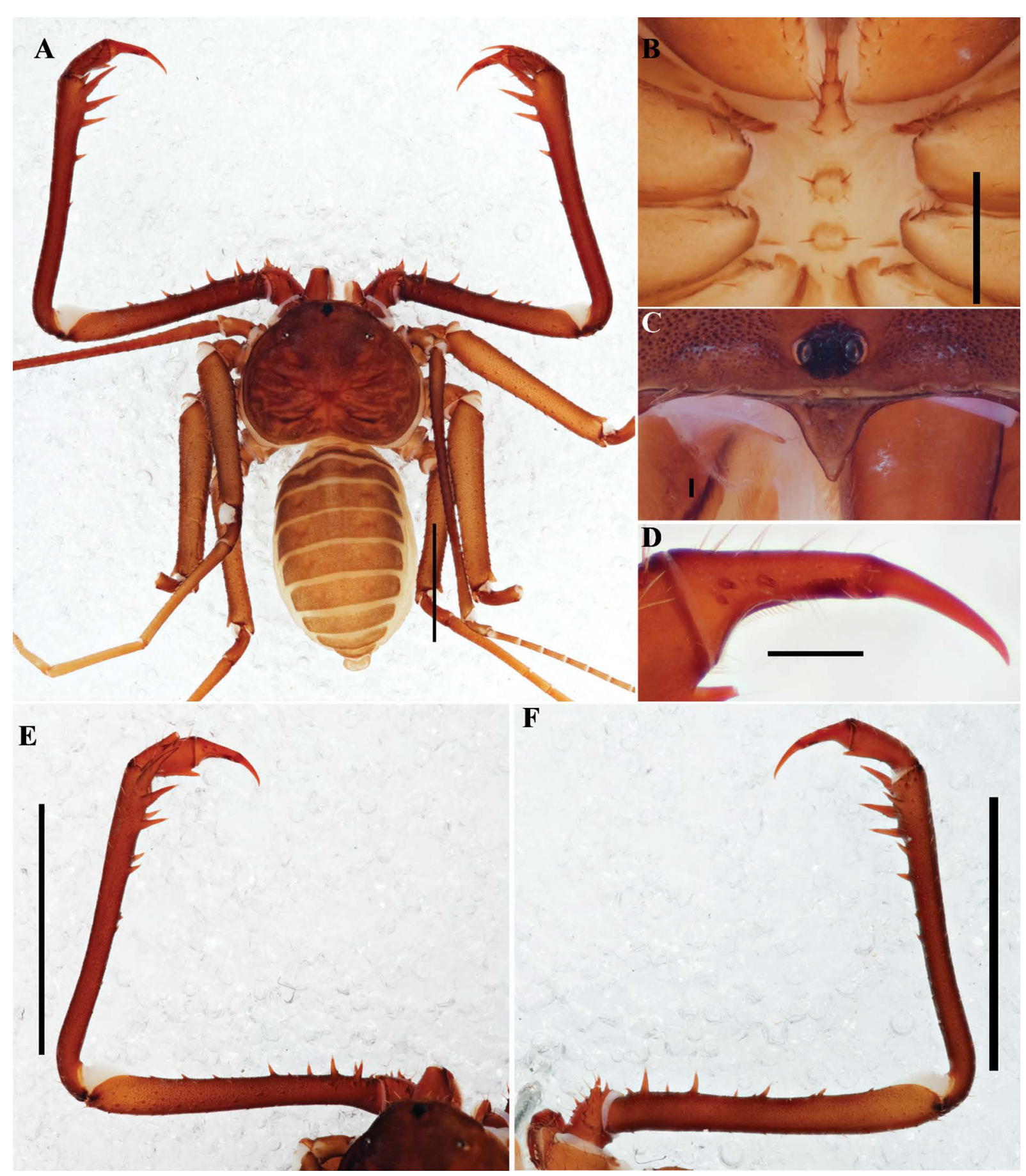

Fig. 75. Charinus sooretama sp. nov. (MNRJ 9245), general morphology, $\circ$. A. Habitus, dorsal view. B. Sternum, ventral view. C. Frontal process. D. Pedipalp tarsus, frontal view. E. Pedipalp, dorsal view. F. Pedipalp, ventral view. Scale bars: $A=1 \mathrm{~cm} ; B=1 \mathrm{~mm} ; C=0.1 \mathrm{~mm} ; \mathrm{D}=0.5 \mathrm{~mm} ; \mathrm{E}-\mathrm{F}=0.5 \mathrm{~cm}$. 


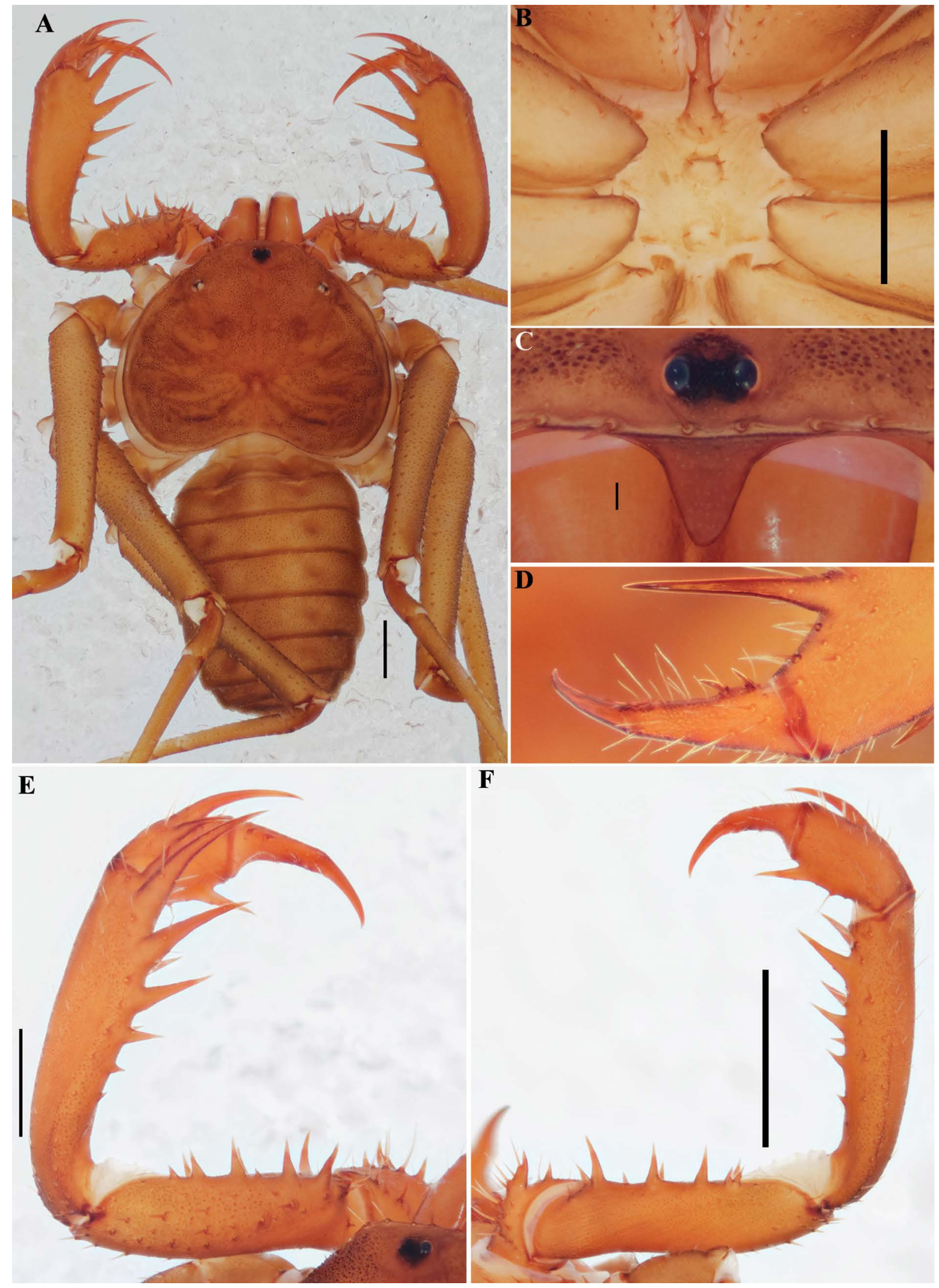

Fig. 76. Charinus souzai sp. nov. (MNRJ 9090), general morphology, . A. Habitus, dorsal view. B. Sternum, ventral view. C. Frontal process. D. Pedipalp tarsus, frontal view. E. Pedipalp, dorsal view. F. Pedipalp, ventral view. Scale bars: A-B, E-F $=1 \mathrm{~mm} ; \mathrm{C}=0.1 \mathrm{~mm} ; \mathrm{D}=0.5 \mathrm{~mm}$. 

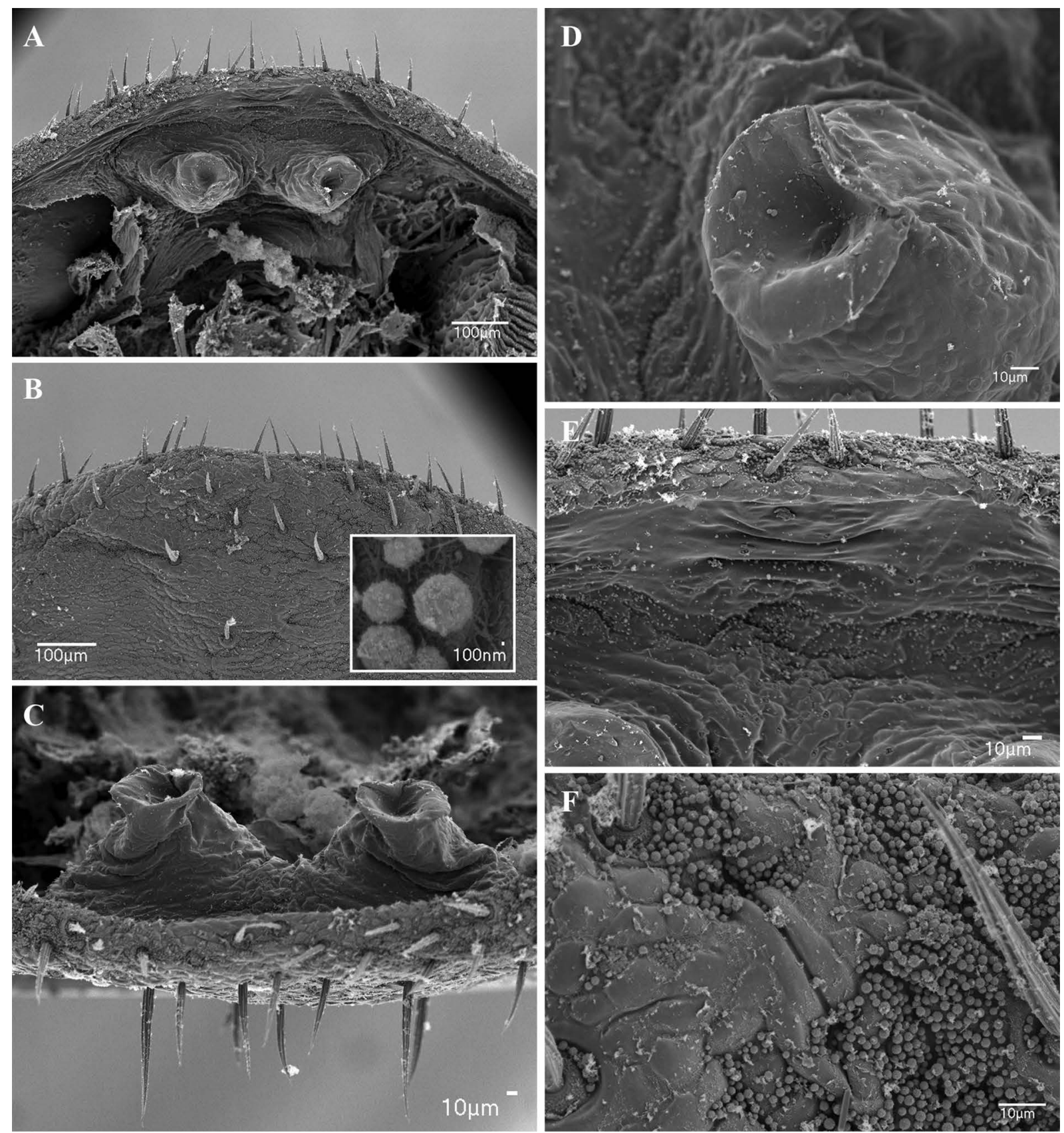

Fig. 77. Charinus souzai sp. nov. (MNRJ 9245), female gonopod and genital operculum. A. Sucker-like gonopod, dorsal view. B. Genital operculum, ventral view. Inset: cerotegument. C. Gonopods, posterior view. D. Aperture on sinistral side of sucker-like gonopod, dorsal view. E. Posterior margin of genital operculum. F. Gland opening near lateral margin of genital operculum. 


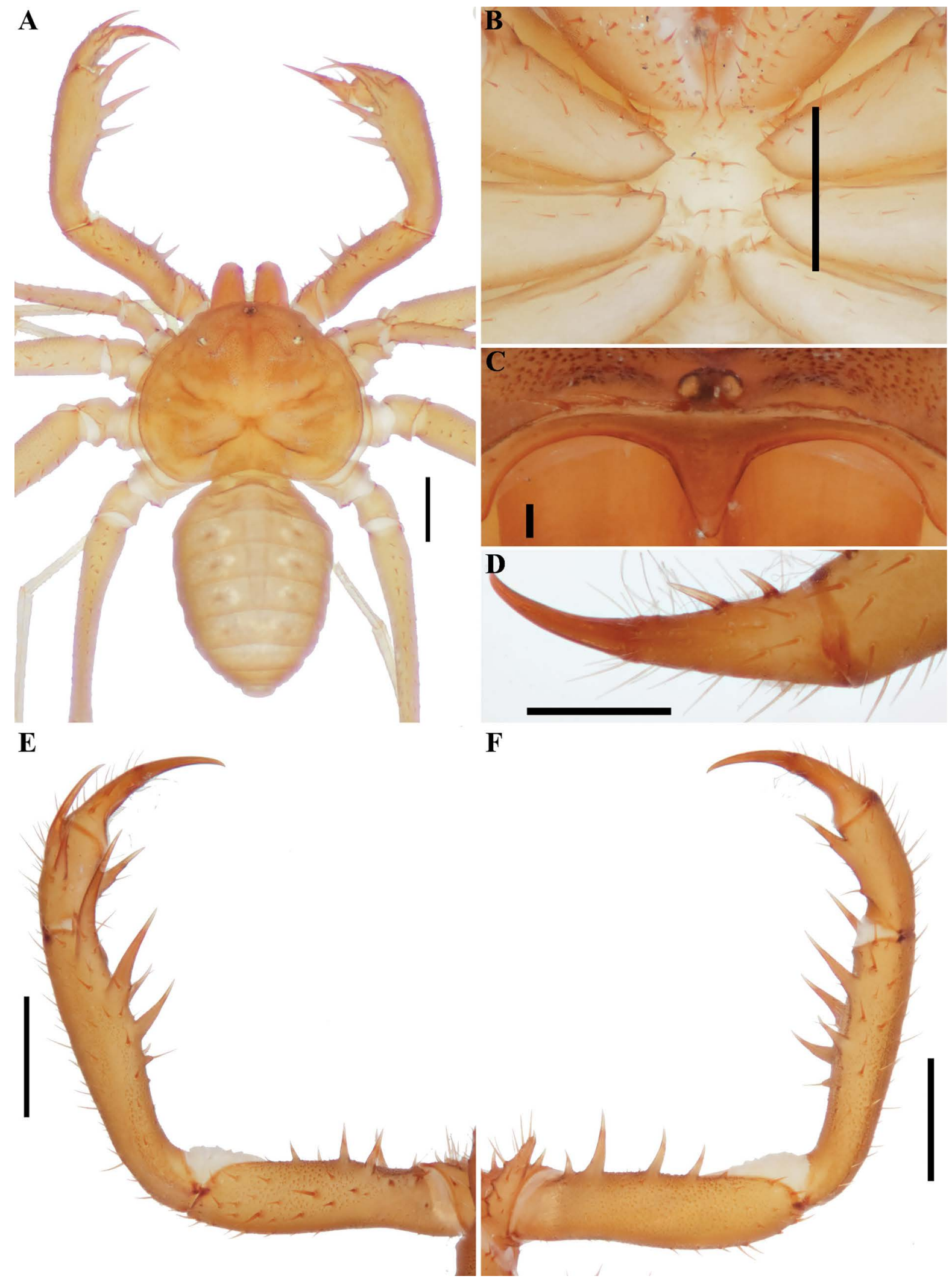

Fig. 78. Charinus una sp. nov. (MNRJ 9131), general morphology, $\widehat{\partial}$. A. Habitus, dorsal view. B. Sternum, ventral view. C. Frontal process. D. Pedipalp tarsus, frontal view. E. Pedipalp, dorsal view. F. Pedipalp, ventral view. Scale bars: A-B, E-F $=1 \mathrm{~mm} ; \mathrm{C}=0.1 \mathrm{~mm} ; \mathrm{D}=0.5 \mathrm{~mm}$. 

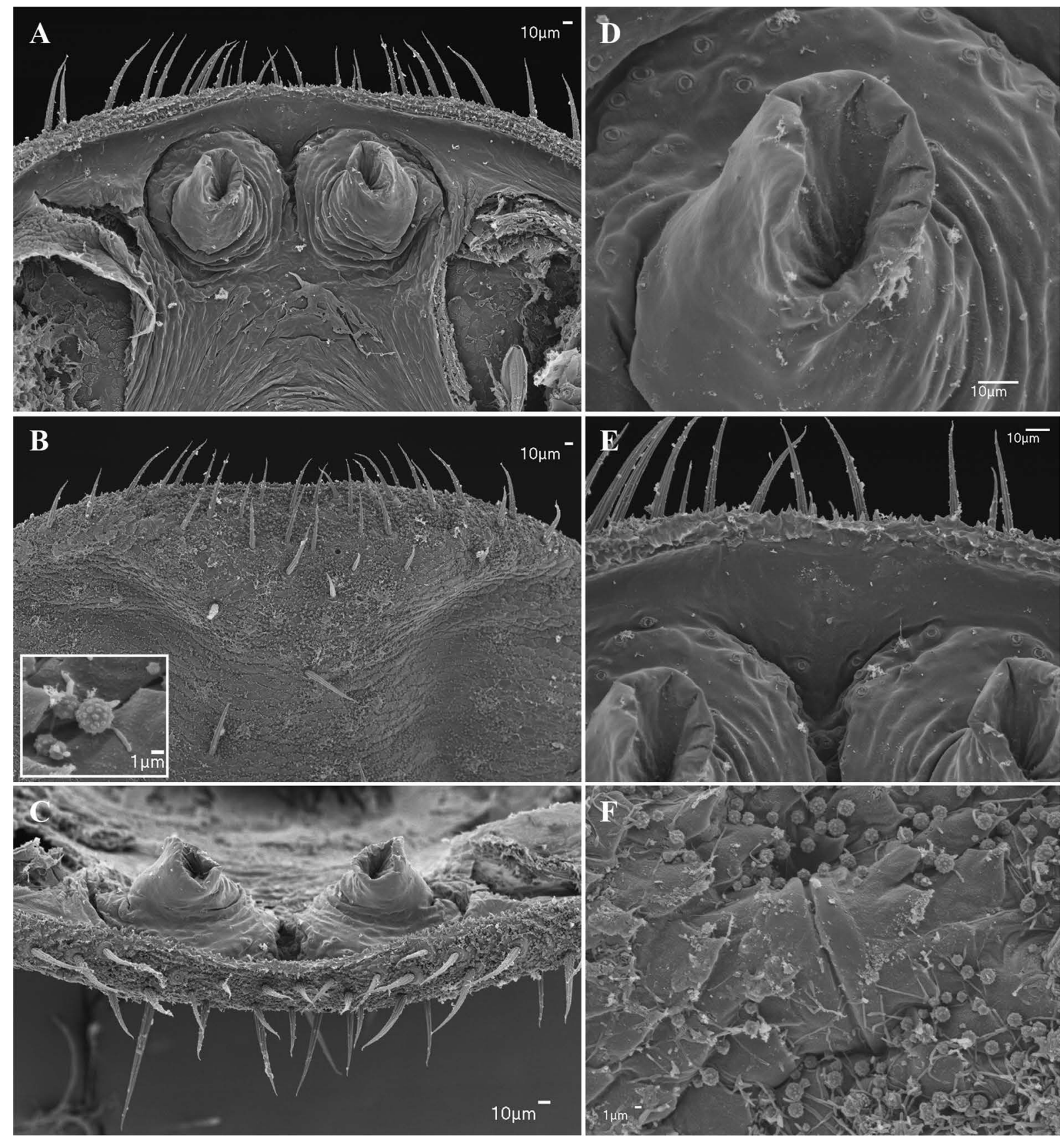

Fig. 79. Charinus una sp. nov. (MNRJ 9131), female gonopod and genital operculum. A. Sucker-like gonopod, dorsal view. B. Genital operculum, ventral view. Inset: cerotegument. C. Gonopods, posterior view. D. Aperture on sinistral side of sucker-like gonopod, dorsal view. E. Posterior margin of genital operculum. F. Gland opening near lateral margin of genital operculum. 


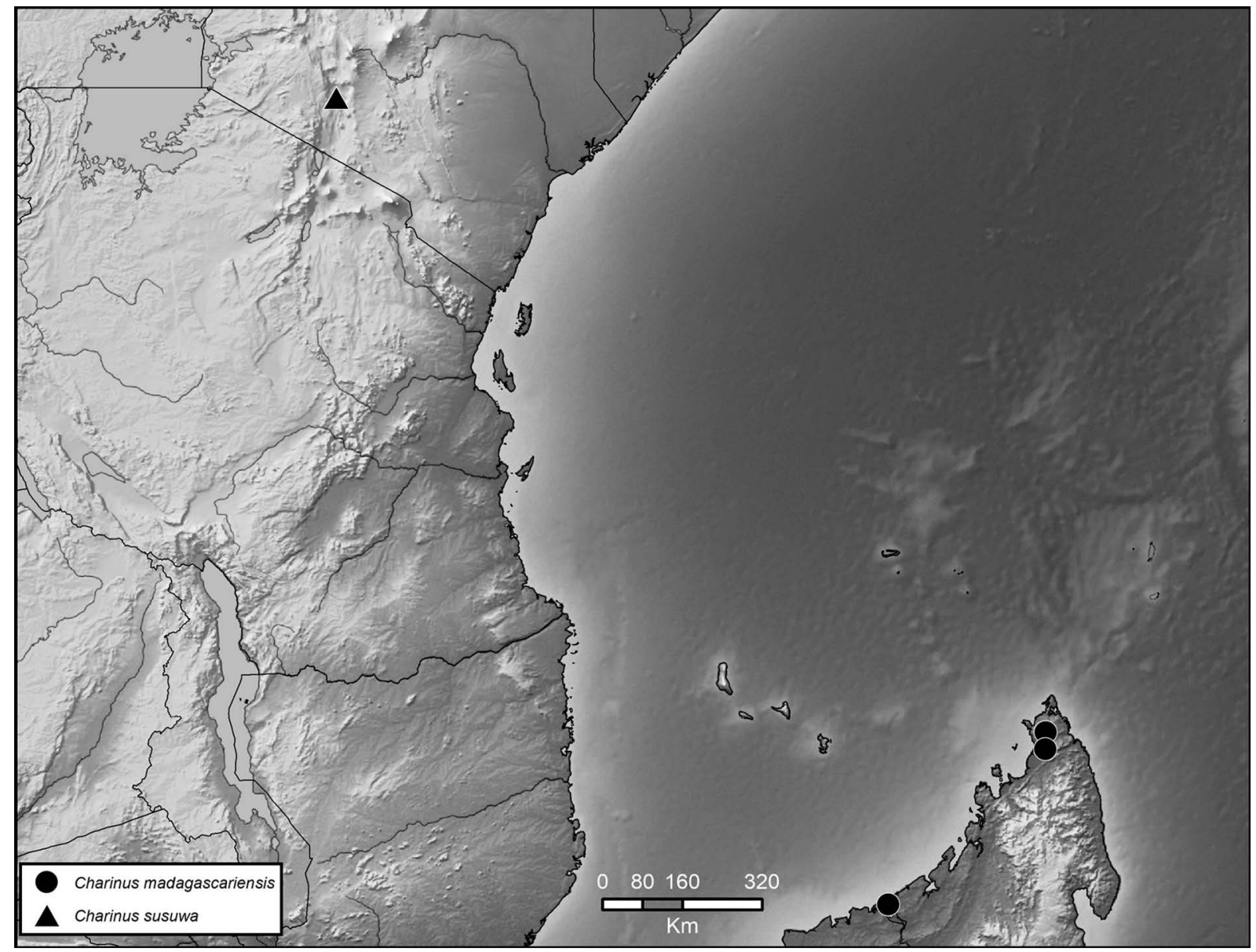

Fig. 80. Map plotting known distributions of species of Charinus Simon, 1892 in eastern Africa and northern Madagascar. 


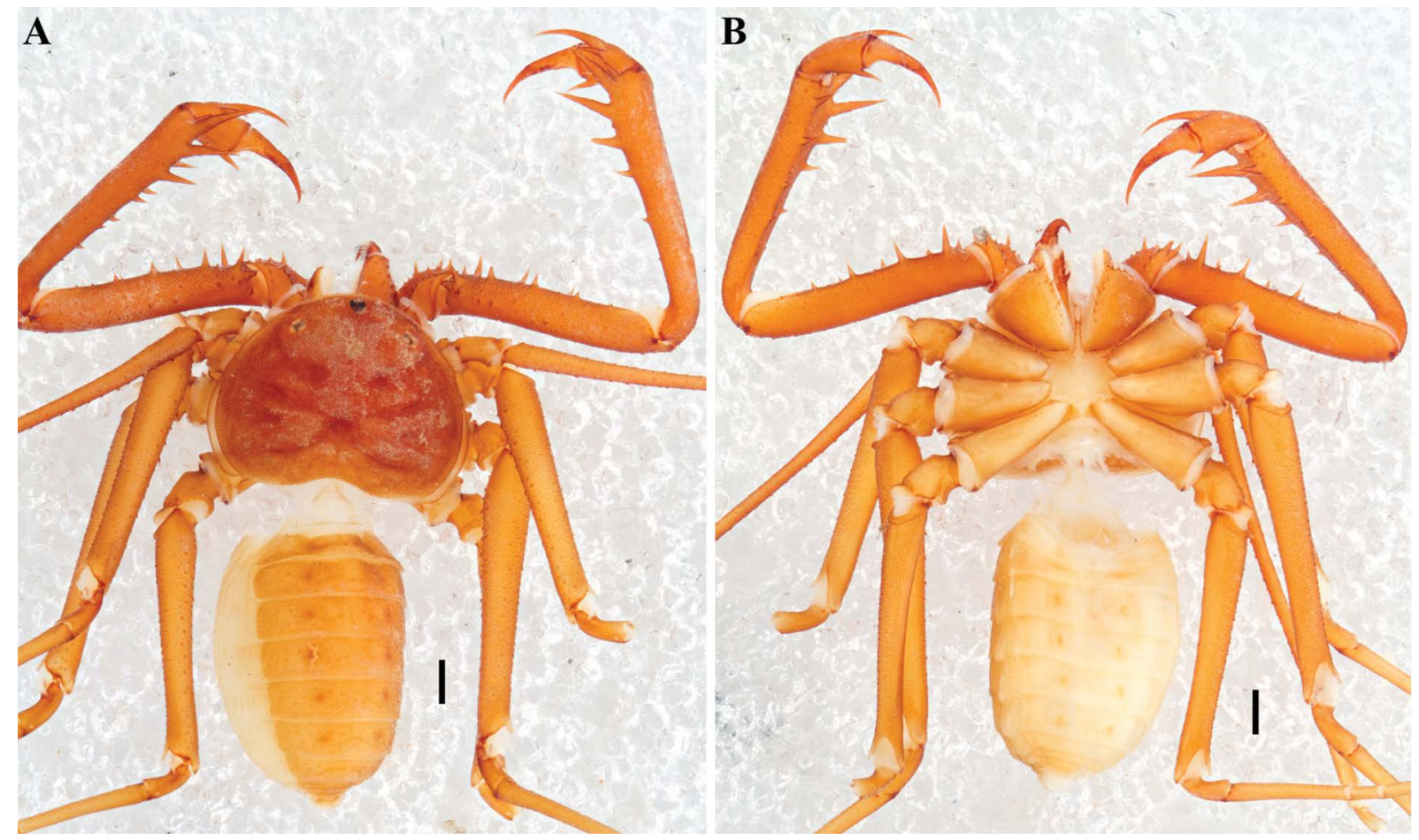

Fig. 81. Charinus madagascariensis Fage, 1954 (MNHN), habitus, ô. A. Dorsal view. B. Ventral view. Scale bars: $1 \mathrm{~mm}$. 


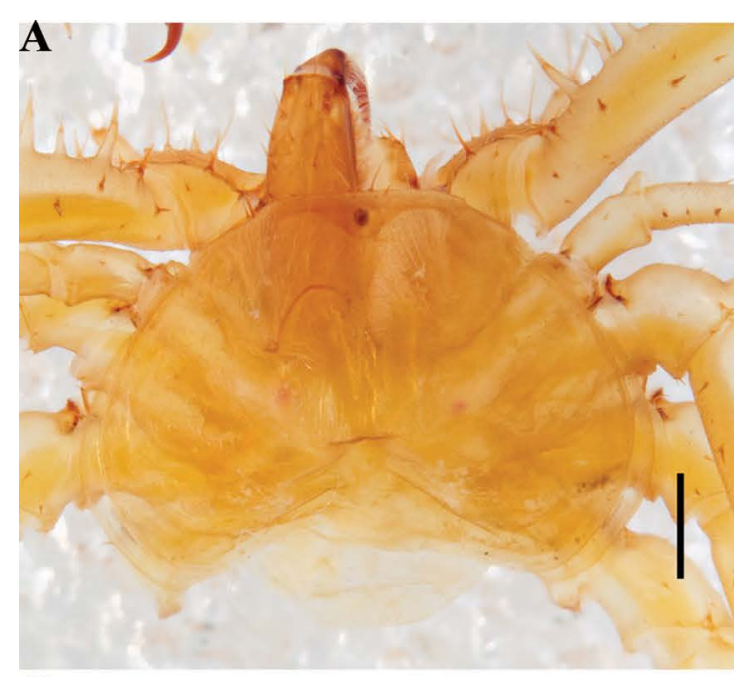

C

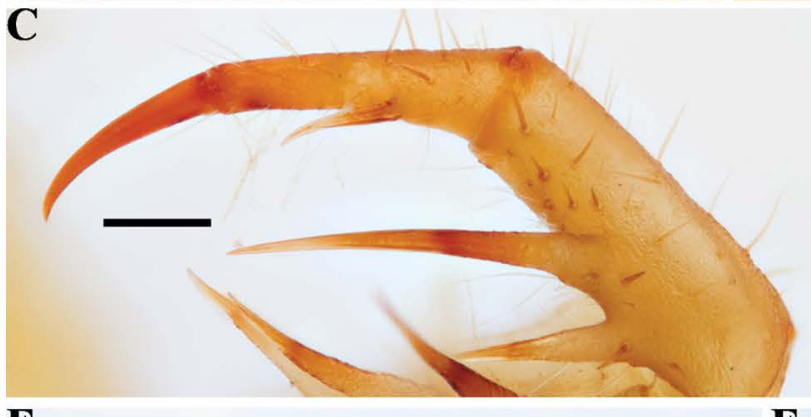

$\mathbf{E}$

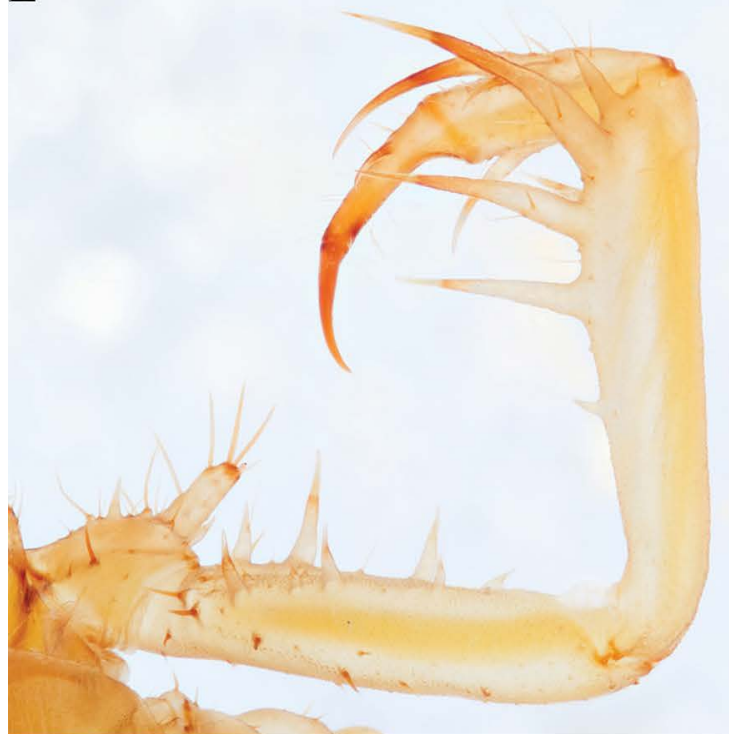

$\mathbf{F}$
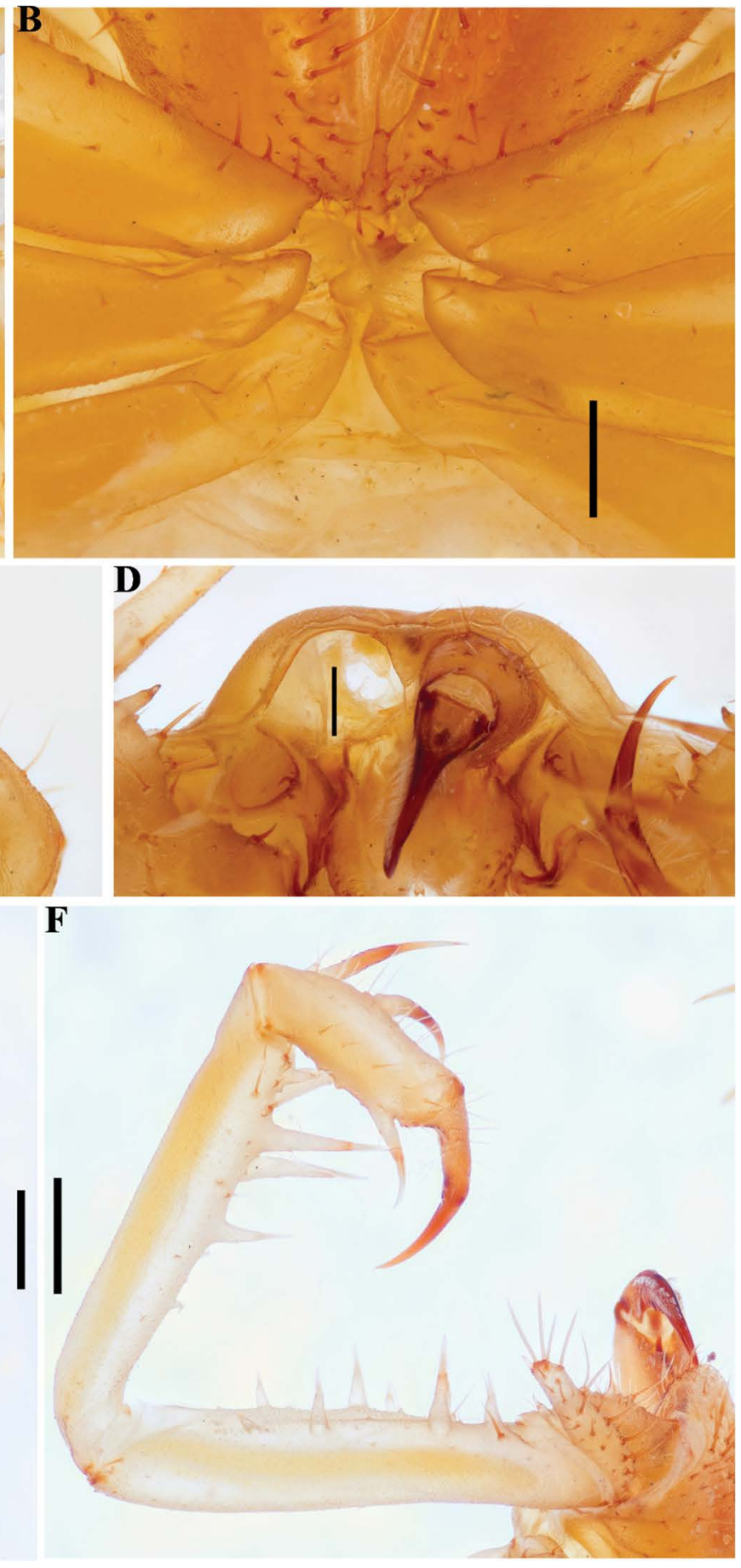

Fig. 82. Charinus susuwa sp. nov. (BMNH), general morphology, + . A. Carapace, dorsal view. B. Sternum, ventral view. C. Pedipalp tarsus, frontal view. D. Frontal process. E. Pedipalp, dorsal view. F. Pedipalp, ventral view. Scale bars: A, E-F $=1 \mathrm{~mm}$; B-D $=0.5 \mathrm{~mm}$. 
MIRANDA G.S. et al., Systematic revision of Charinidae (Arachnida, Amblypygi)

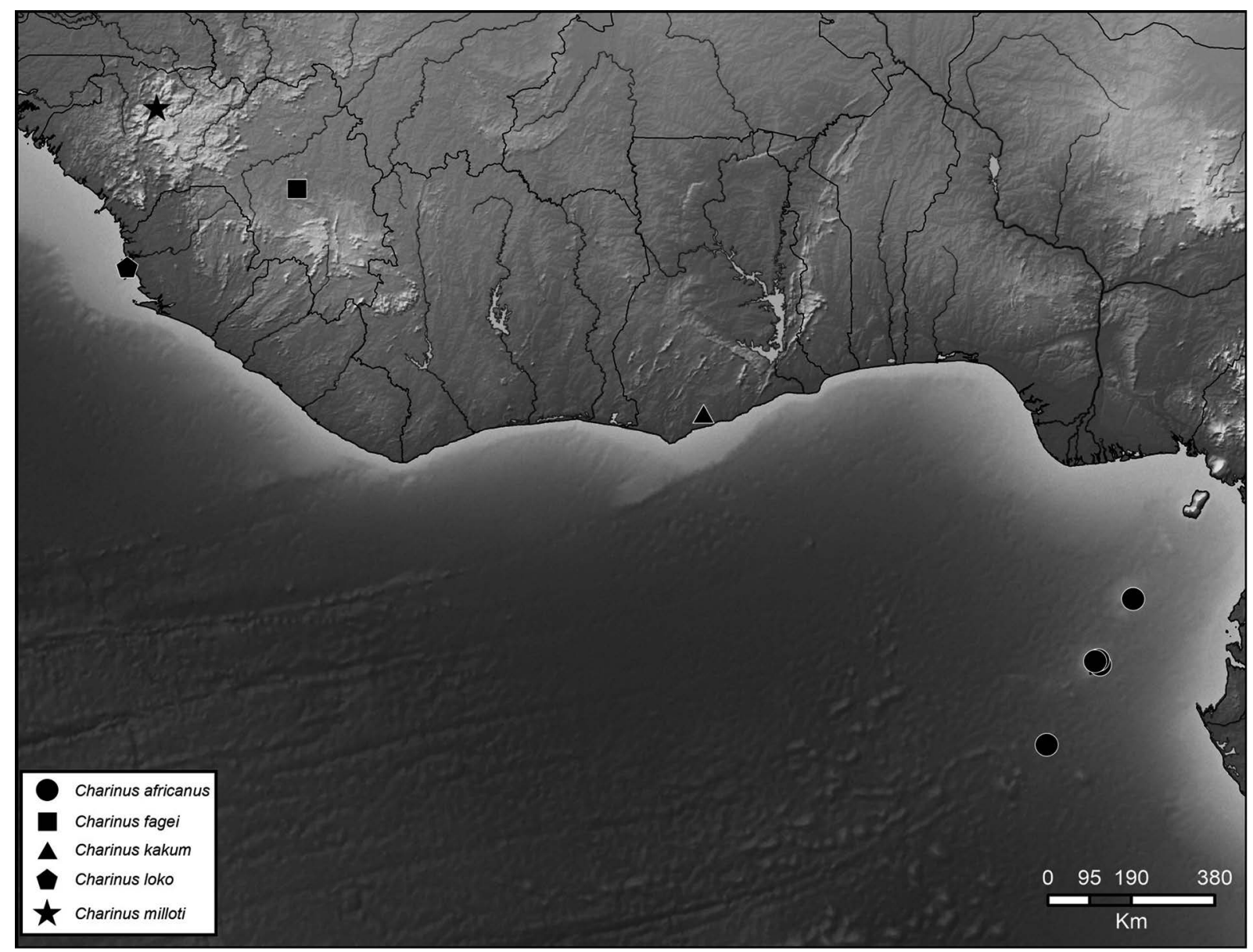

Fig. 83. Map plotting known distributions of species of Charinus Simon, 1892 in western Africa. 


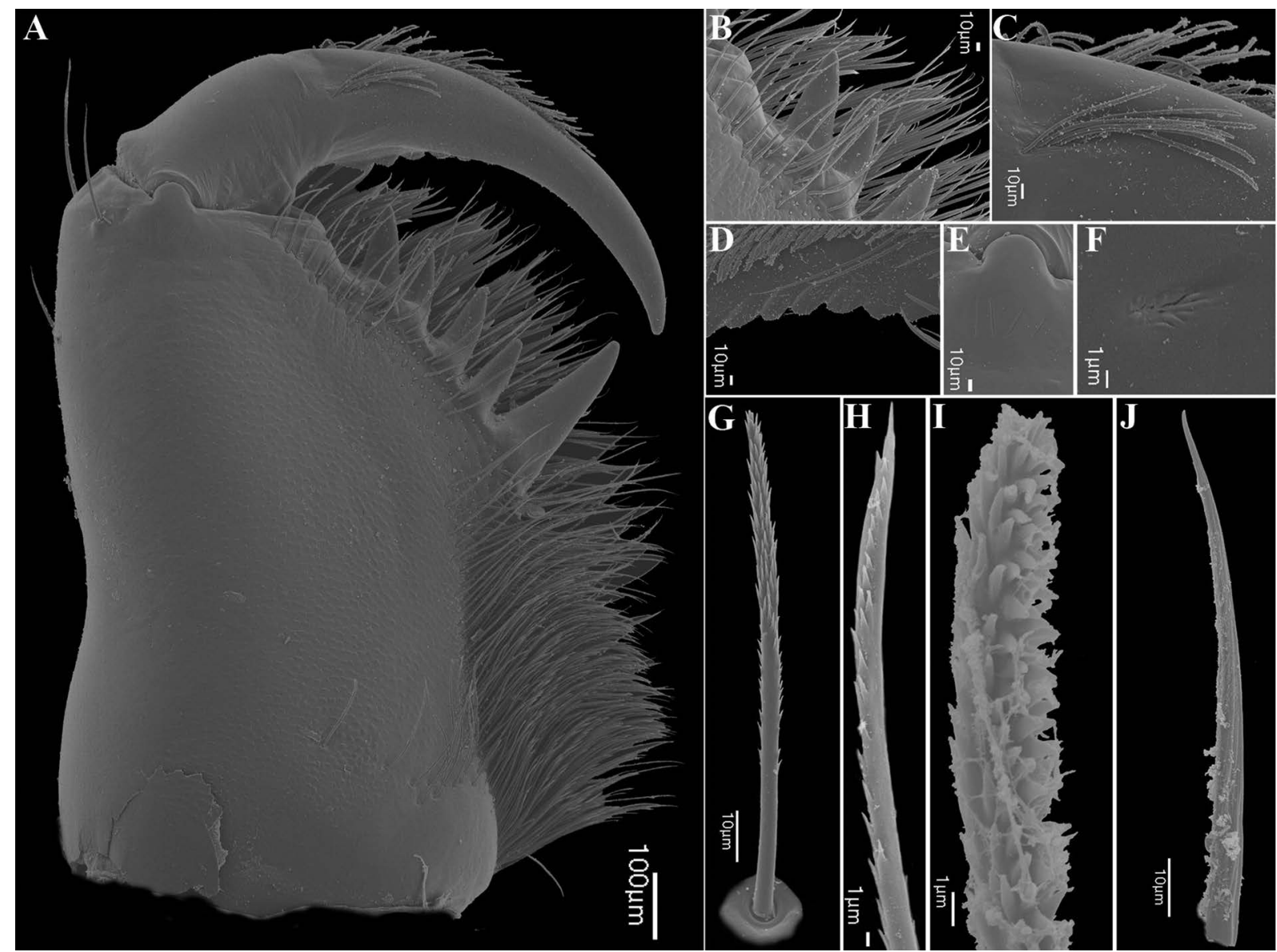

Fig. 84. Charinus africanus Hansen, 1921 (AMCC [LP 6943]), chelicera, . . A. Prolateral view. B. Retrolateral projection, opposite to bifid tooth. C. Setal row on cheliceral claw. D. Cheliceral claw teeth. E. Position of gland on joint between basal segment and cheliceral claw. F. Gland. G. Seta on cheliceral basal segment. H. Apex of basal segment seta. I. Seta on cheliceral claw. J. Setae on dorsal surface of cheliceral basal segment. 


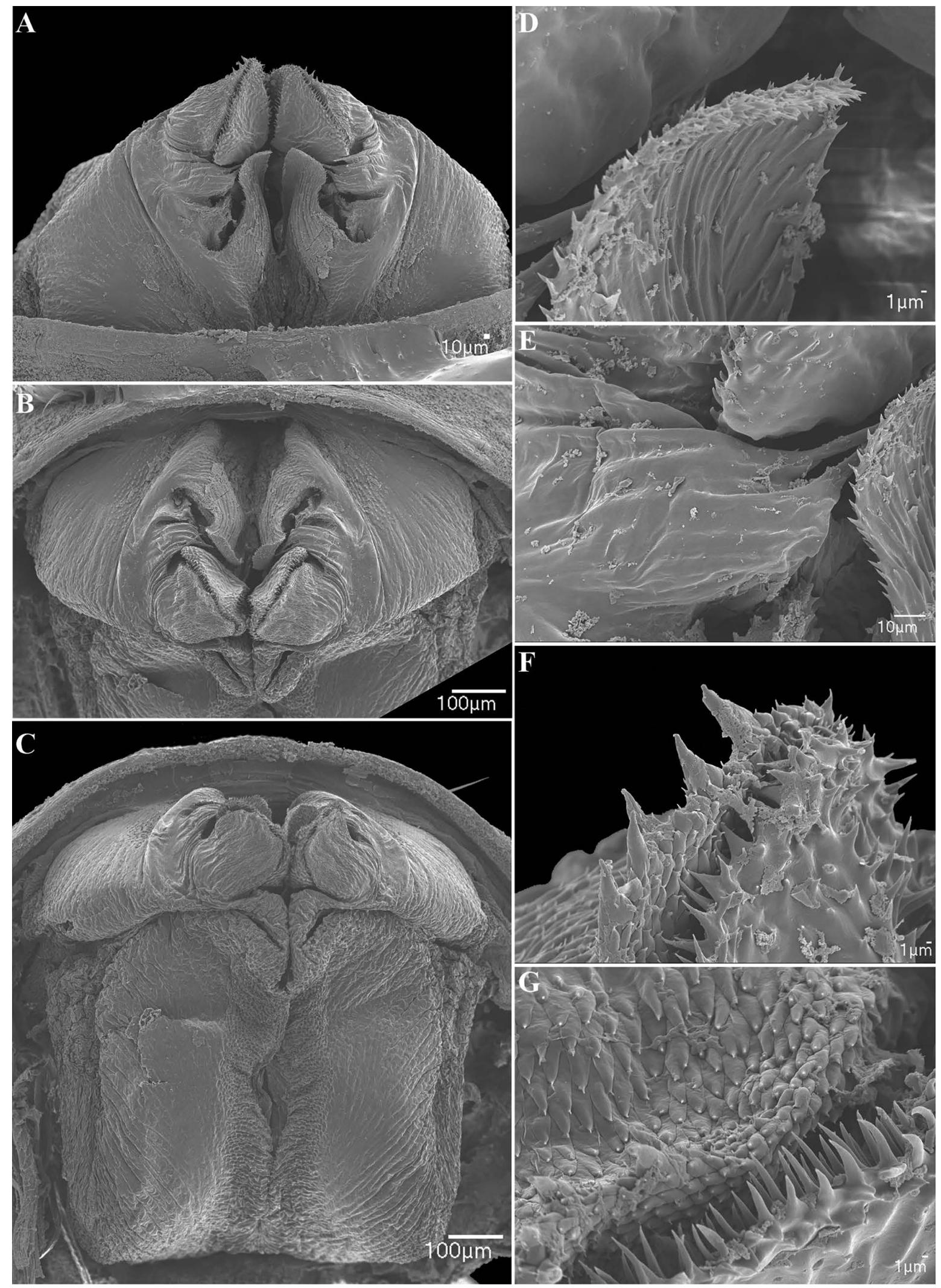

Fig. 85. Charinus africanus Hansen, 1921 (AMCC [LP 6943]), male gonopod. A. Ventral view. B. Posterior view. C. Dorsal view. D. Lamina medialis. E. Lateral lobe 2. F. Junction between dorsal lobe and lateral lobe 1. G. As F, frontal view. 

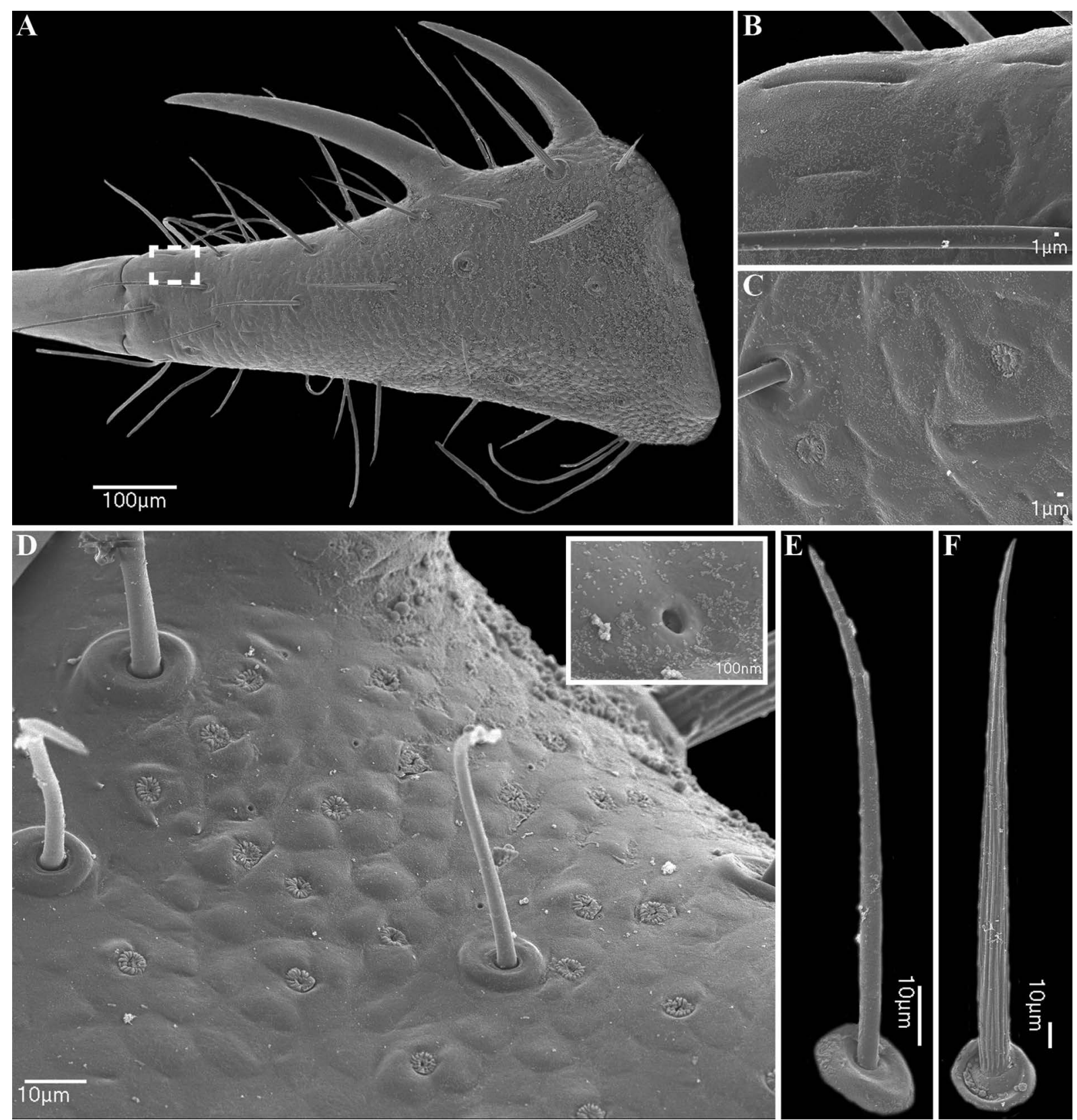

Fig. 86. Charinus africanus Hansen, 1921 (AMCC [LP 6943]), pedipalp tarsus, +. A. Tarsus. B. Slit sense organs on tarsus. C. Gland openings on tarsus. D. Multiple gland openings on tarsus. E. Type I setae on tarsus. F. Type II setae on tarsus. 

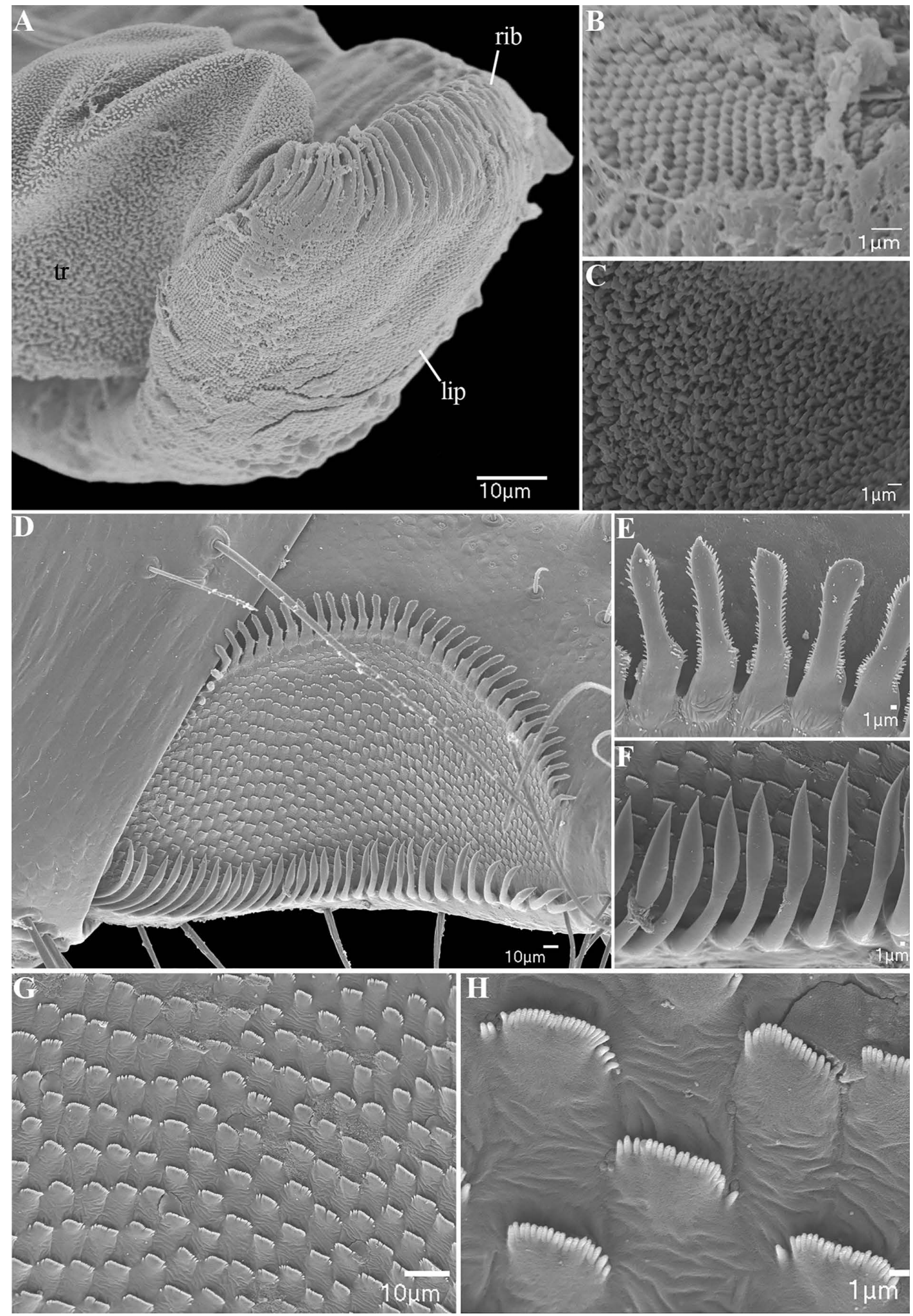

Fig. 87. Charinus africanus Hansen, 1921 (AMCC [LP 6943]), leg IV arolium and pedipalp cleaning brush, . . A. Truncus, lip and ribs of arolium, lateral view. B. Aroliar truncus. C. Aroliar lip. D. Cleaning brush of pedipalp tarsus. E. Dorsal row of setae. F. Ventral row of setae. G. Surface between setal rows. H. Small projections on surface between setal rows of cleaning brush on pedipalp tarsus. Abbreviations: lip = distal aroliar lip; rib = ribs of aroliar lip; $\operatorname{tr}=$ truncus. 

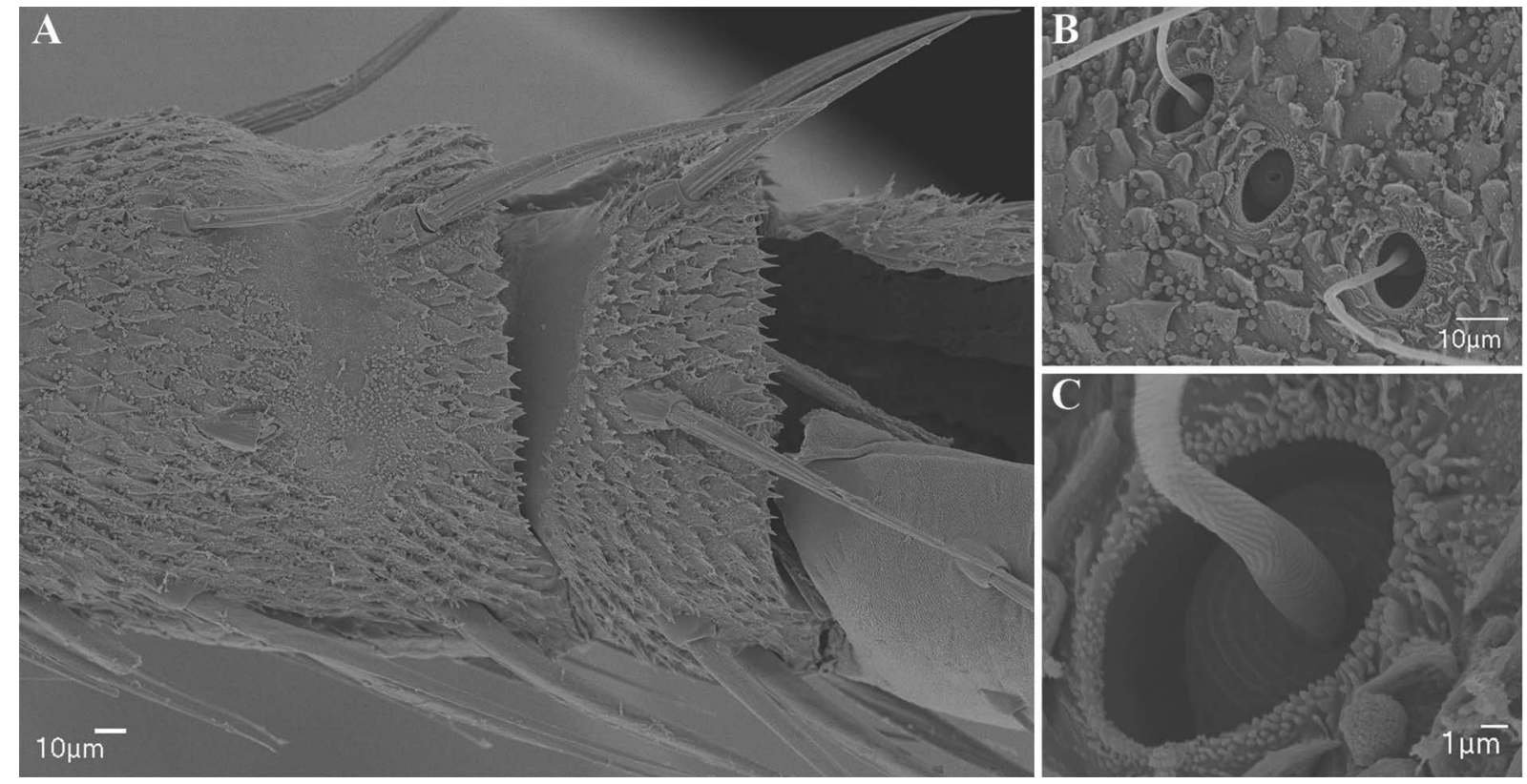

Fig. 88. Charinus africanus Hansen, 1921 (AMCC [LP 6943]), tarsus, ․ . A. Tarsus showing region of white ring. B. Trichobothria on distitarsus of leg IV. C. Trichobothrial socket. 

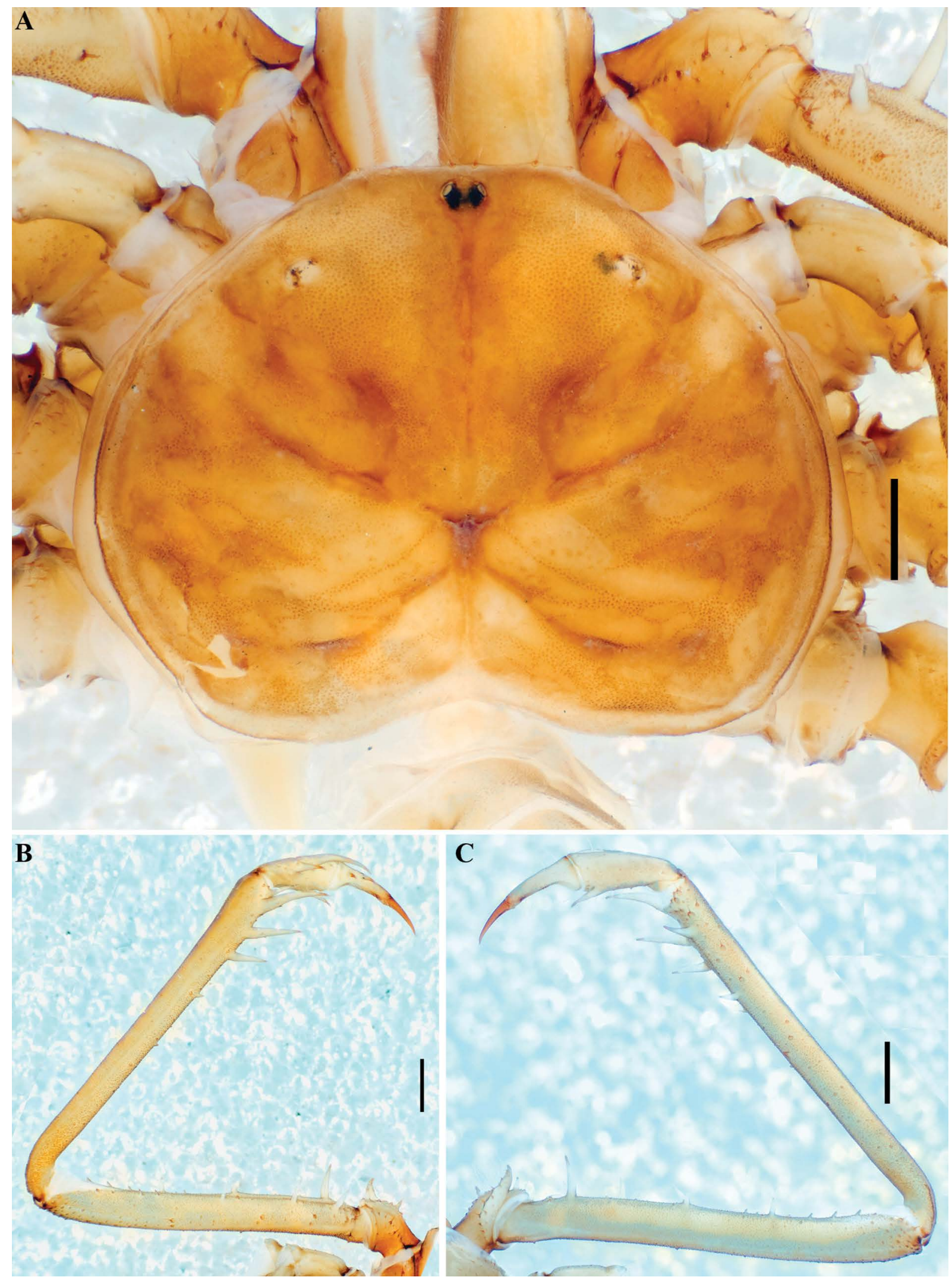

Fig. 89. Charinus fagei Weygoldt, 1972 (MNHN), general morphology, §̊. A. Carapace, dorsal view. B. Pedipalp, dorsal view. C. Pedipalp, ventral view. Scale bars: $1 \mathrm{~mm}$. 


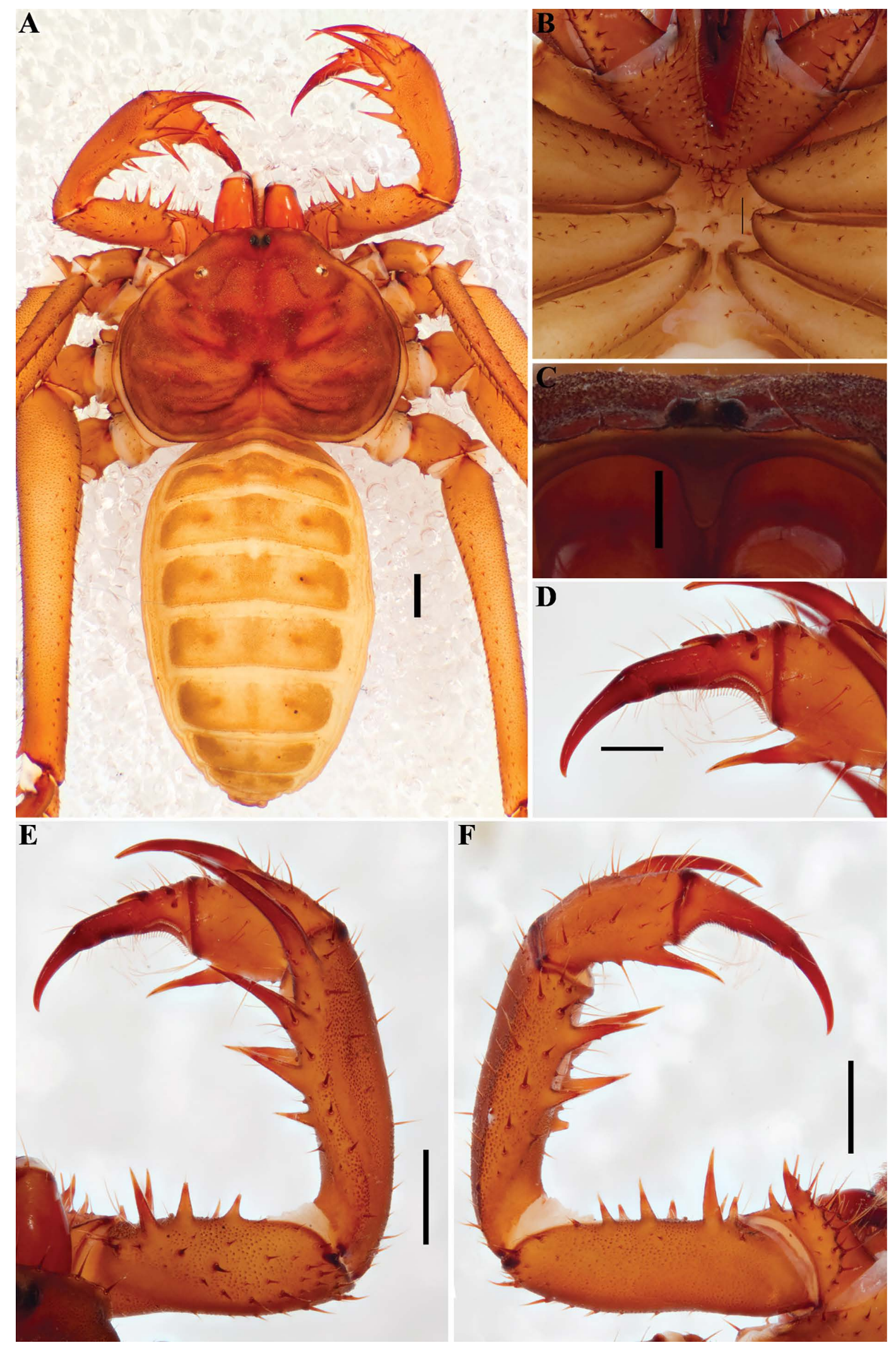

Fig. 90. Charinus loko sp. nov. (SMNS), general morphology, ․ . A. Habitus, dorsal view. B. Sternum, ventral view. C. Frontal process. D. Pedipalp tarsus, frontal view. E. Pedipalp, dorsal view. F. Pedipalp, ventral view. Scale bars: A, E-F $=1 \mathrm{~mm}$; $\mathrm{B}-\mathrm{D}=0.5 \mathrm{~mm}$. 

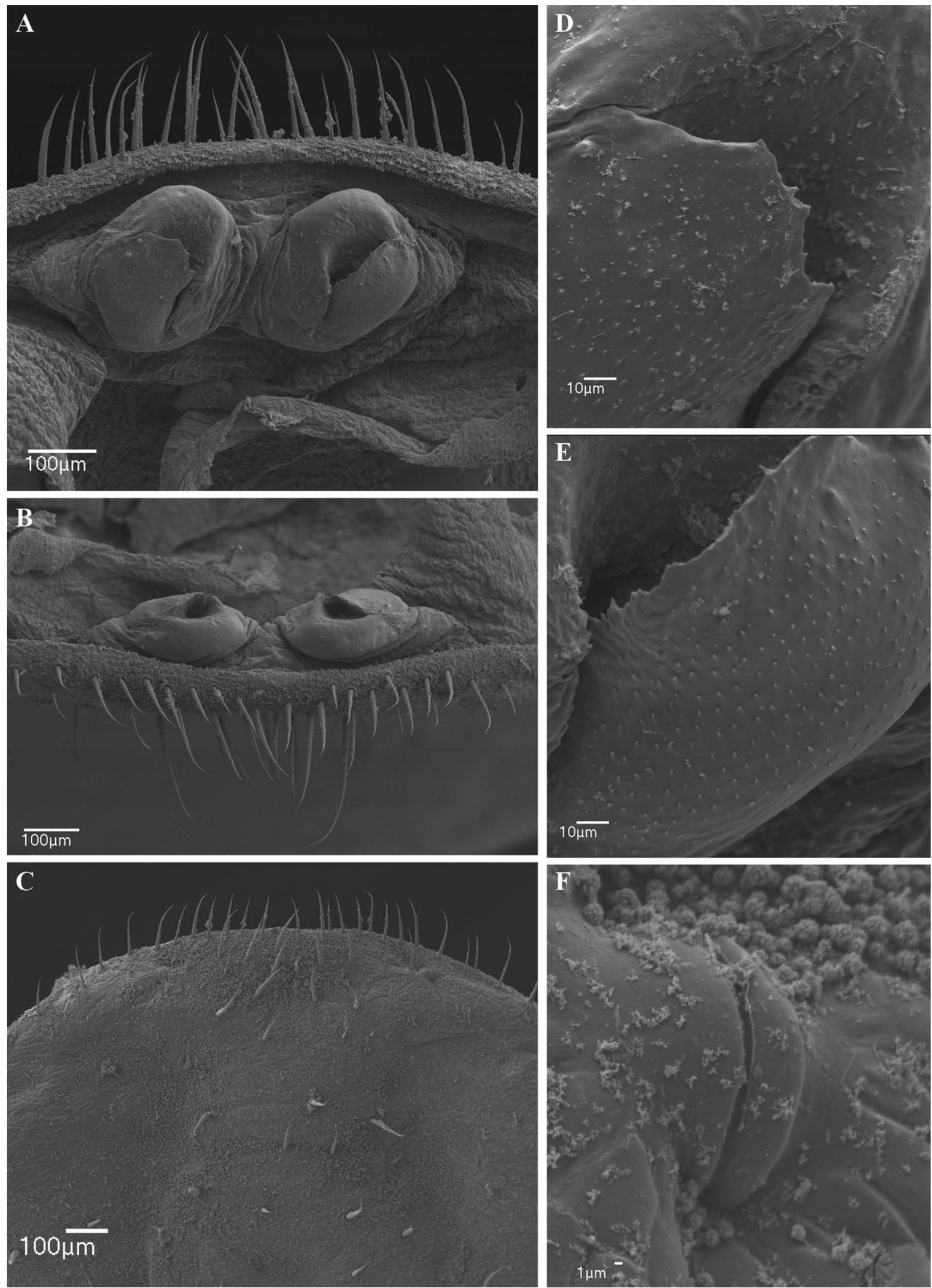

Fig. 91. Charinus loko sp. nov. (SMNS), female gonopod and genital operculum. A. Cushion-like gonopod, dorsal view. B. Gonopods, posterior view. C. Posterior margin of genital operculum, ventral view. D. Apex of projection on sinistral gonopod. E. Apex of projection on dextral gonopod. F. Glandular opening on margin of genital operculum, ventral view. 


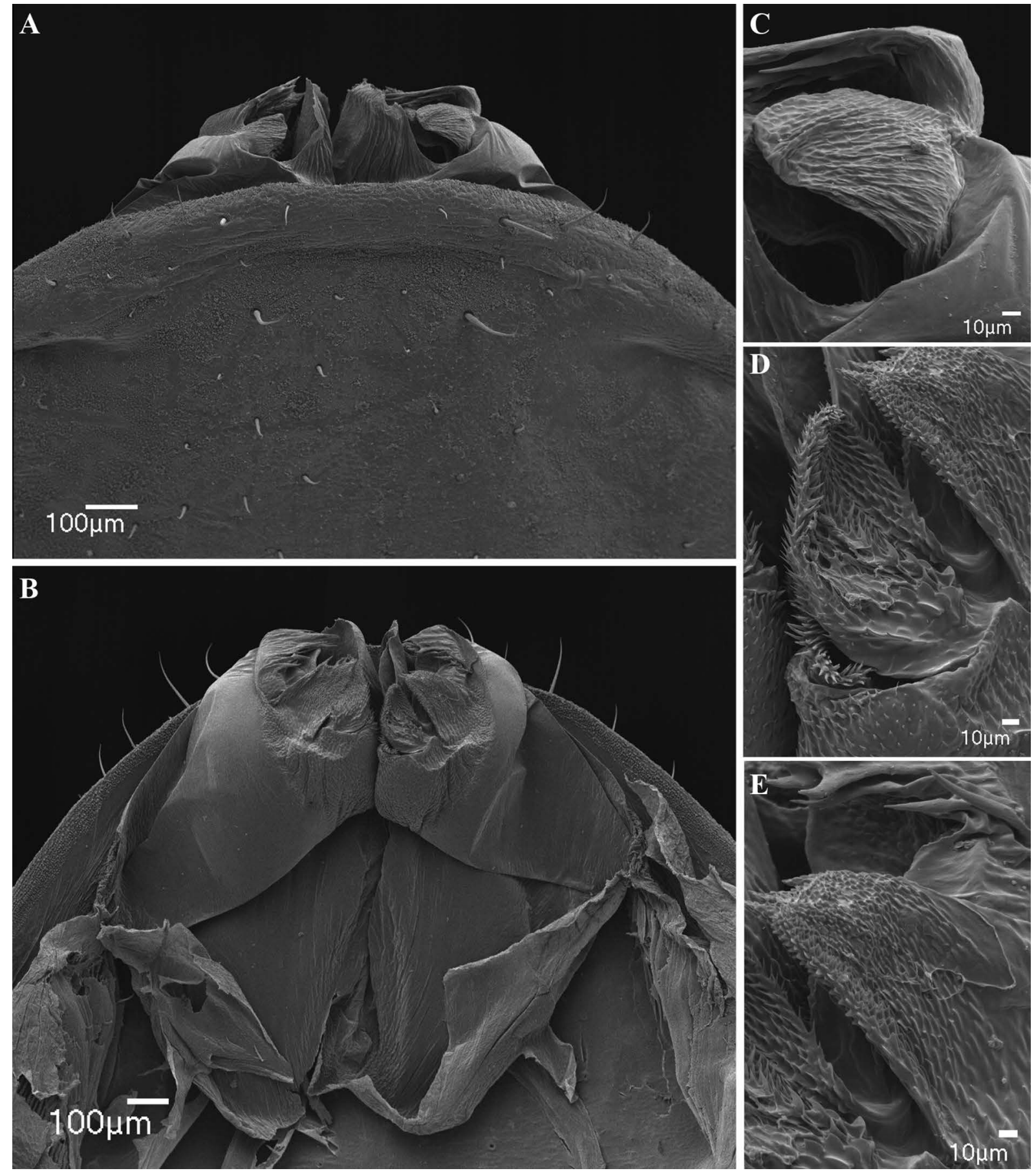

Fig. 92. Charinus loko sp. nov. (SMNS), male gonopod. A. Ventral view. B. Dorsal view. C. Dextral side of gonopod. D. Lateral lobe 1. E. Dorsal lobe. 

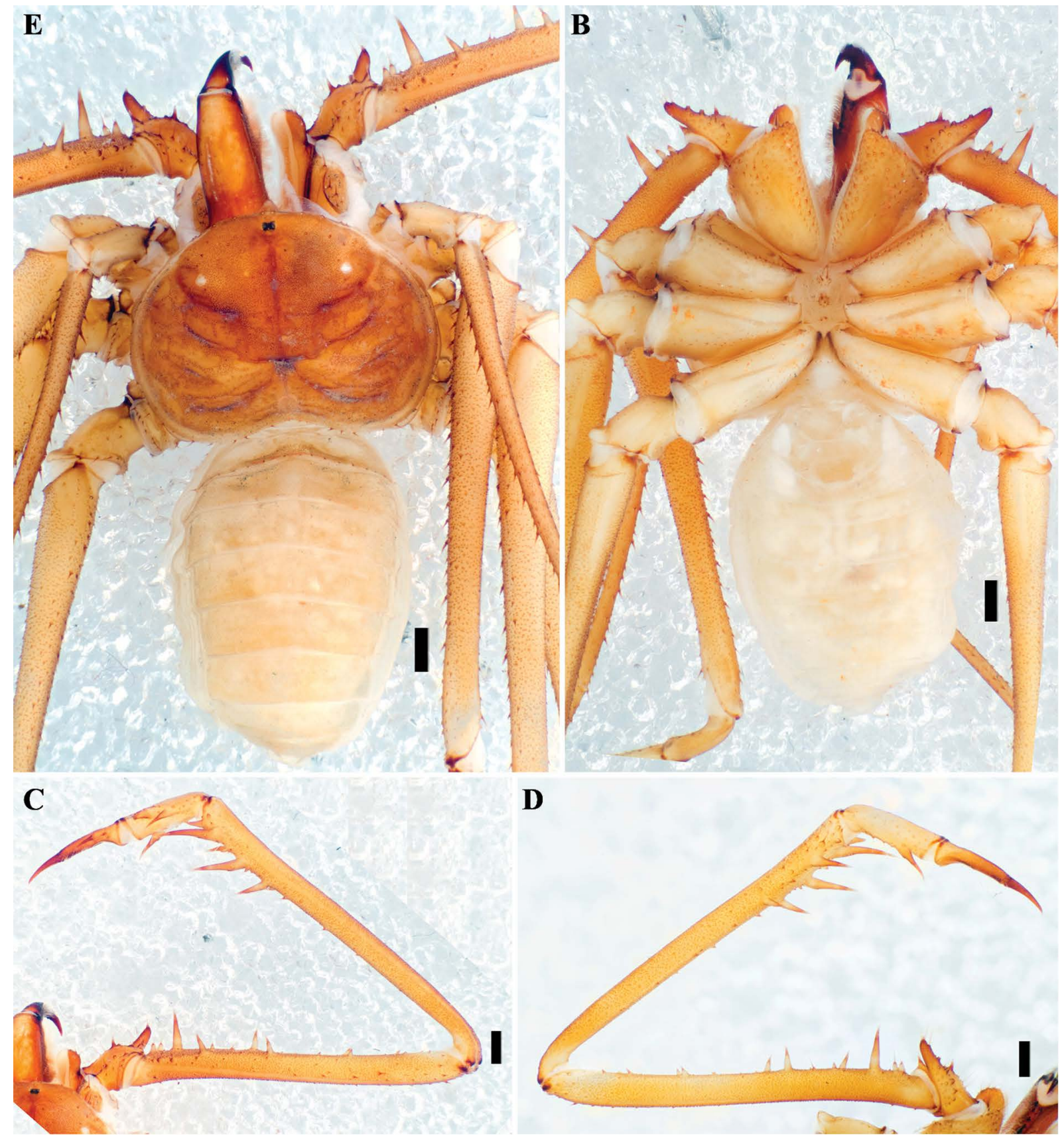

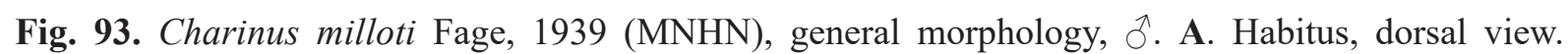
B. Habitus, ventral view. C. Pedipalp, dorsal view. D. Pedipalp, ventral view. Scale bars: $1 \mathrm{~mm}$. 


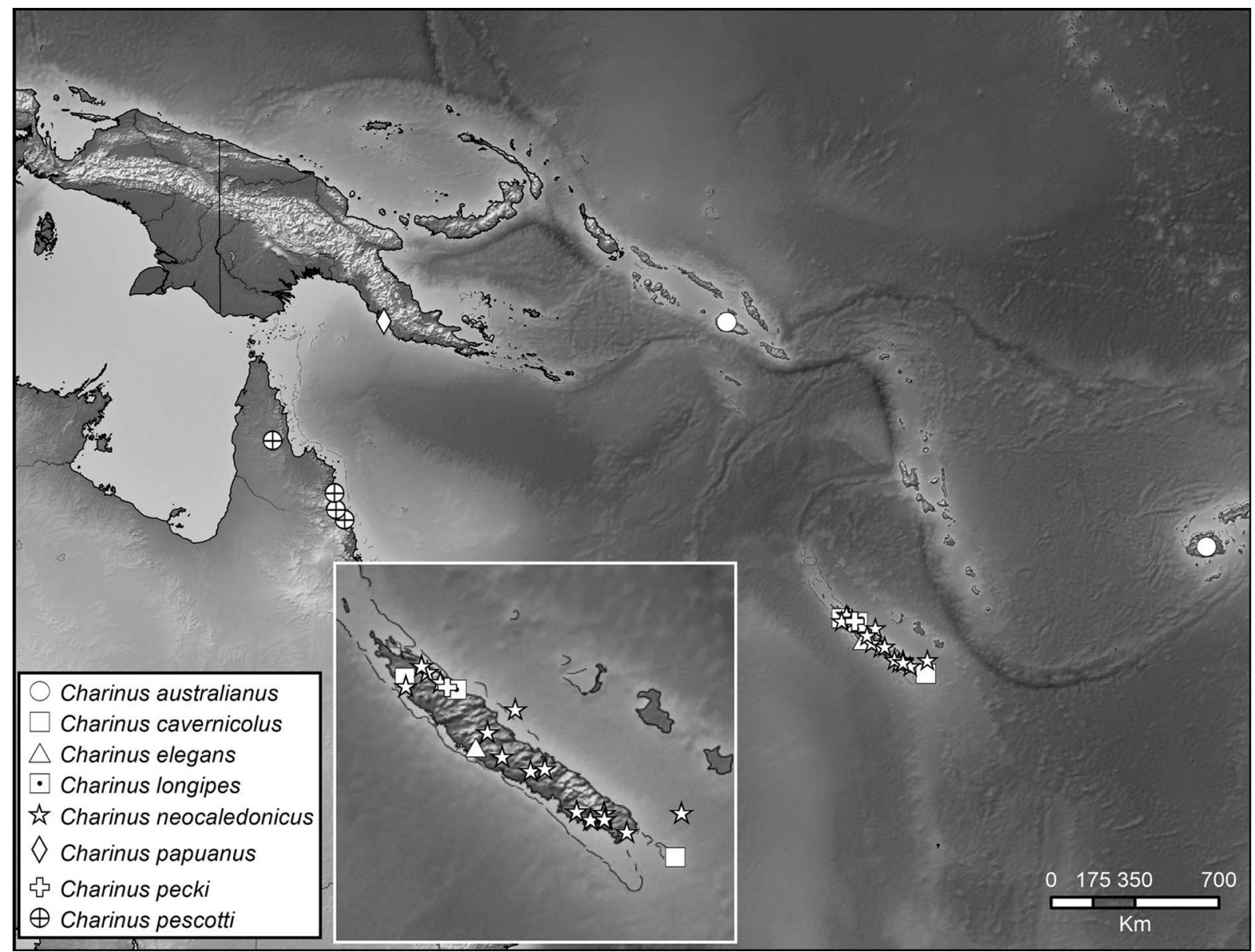

Fig. 94. Map plotting known distributions of species of Charinus Simon, 1892 in Oceania, with inset for New Caledonia. 


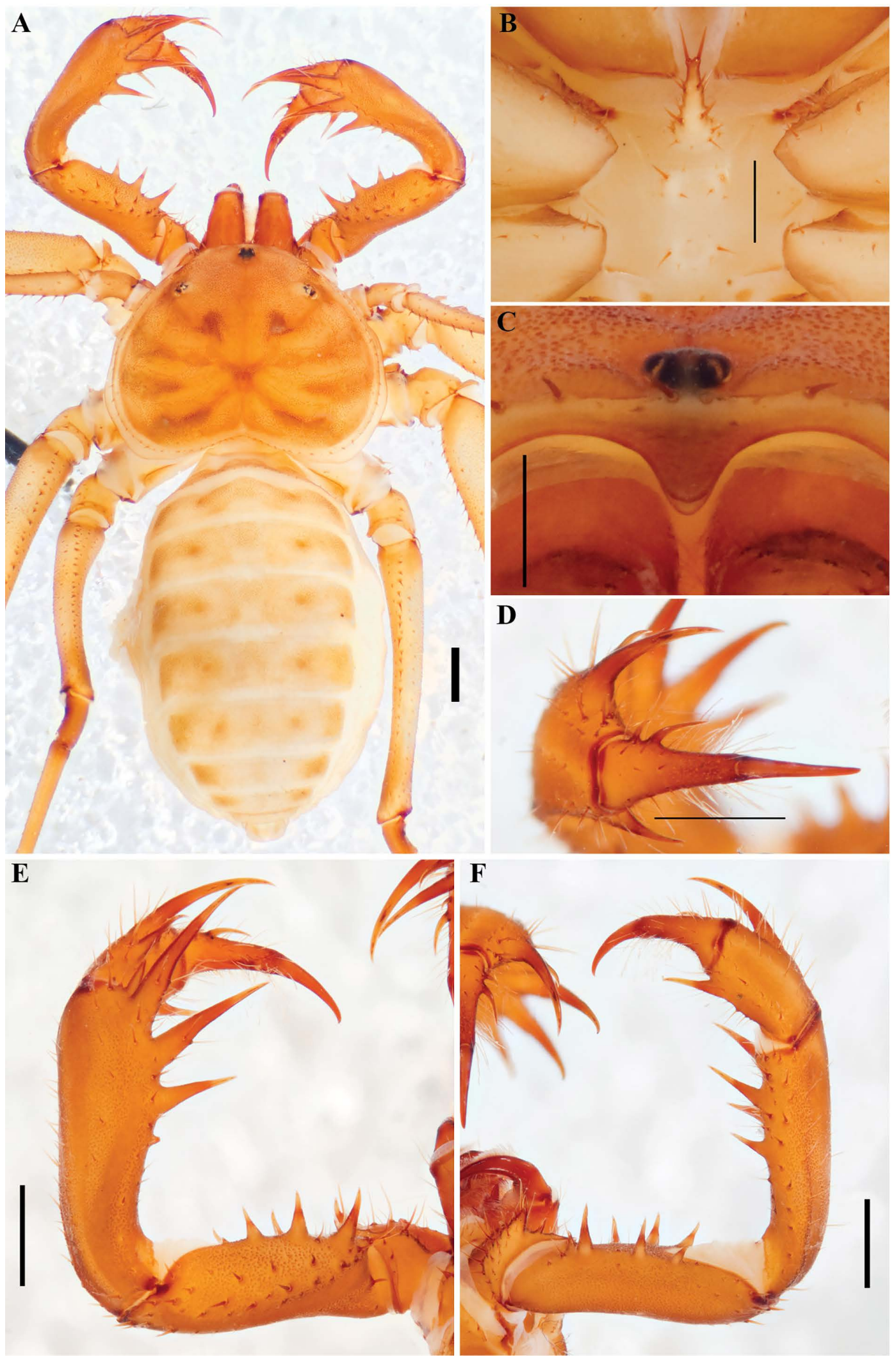

Fig. 95. Charinus cavernicolus Weygoldt, 2006 (MNHN), general morphology, ${ }^{\circ}$. A. Habitus, dorsal view. B. Sternum, ventral view. C. Frontal process. D. Pedipalp tarsus, frontal view. E. Pedipalp, dorsal view. F. Pedipalp, ventral view. Scale bars: A, $E-F=1 \mathrm{~mm}$; $B-D=0.5 \mathrm{~mm}$. 


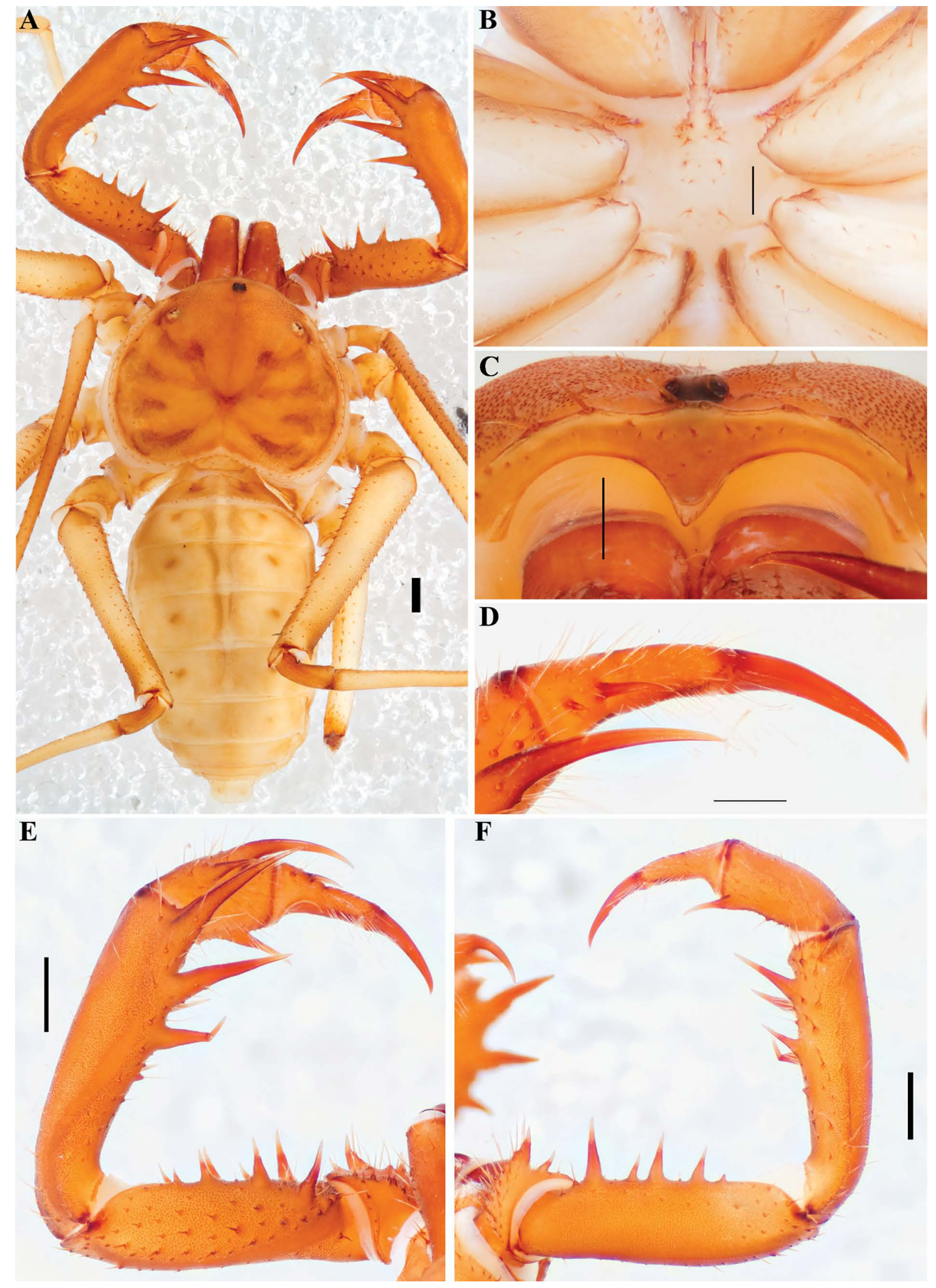

Fig. 96. Charinus elegans Weygoldt, 2006 (MNHN), general morphology, $q$. A. Habitus, dorsal view. B. Sternum, ventral view. C. Frontal process. D. Pedipalp tarsus, frontal view. E. Pedipalp, dorsal view. F. Pedipalp, ventral view. Scale bars: A, E-F $=1 \mathrm{~mm}$; B-D $=0.5 \mathrm{~mm}$. 

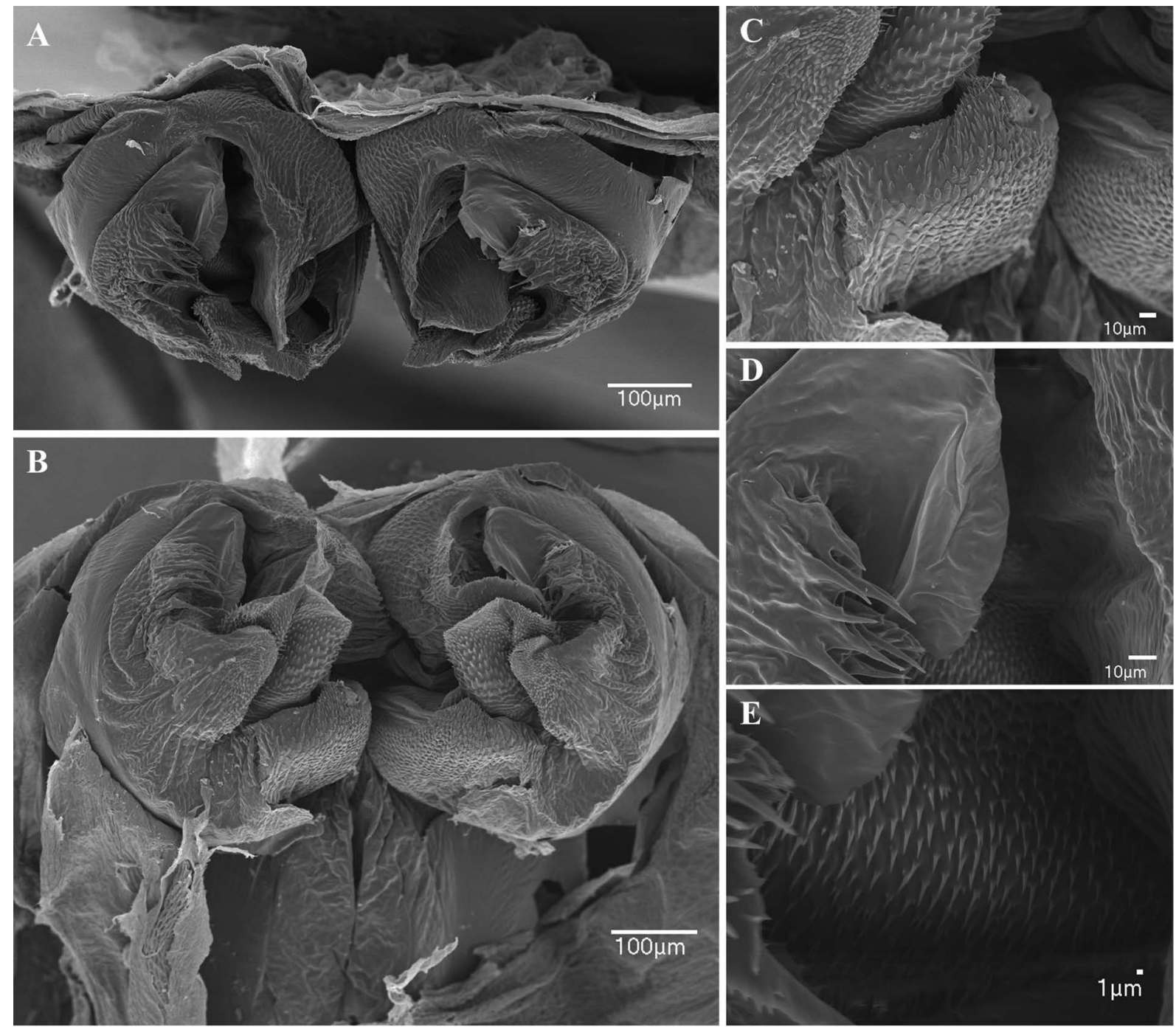

Fig. 97. Charinus elegans Weygoldt, 2006 (MHNG), male gonopod. A. Ventral view. B. Posterior view. C. Dorsal lobe. D. Lateral lobe 2 and processus internus. E. Inner region of fistula (behind PI) showing spiny surface. F. Pedipalp, ventral view. Scale bars: A, E-F $=1 \mathrm{~mm}$; B-D $=0.5 \mathrm{~mm}$. 

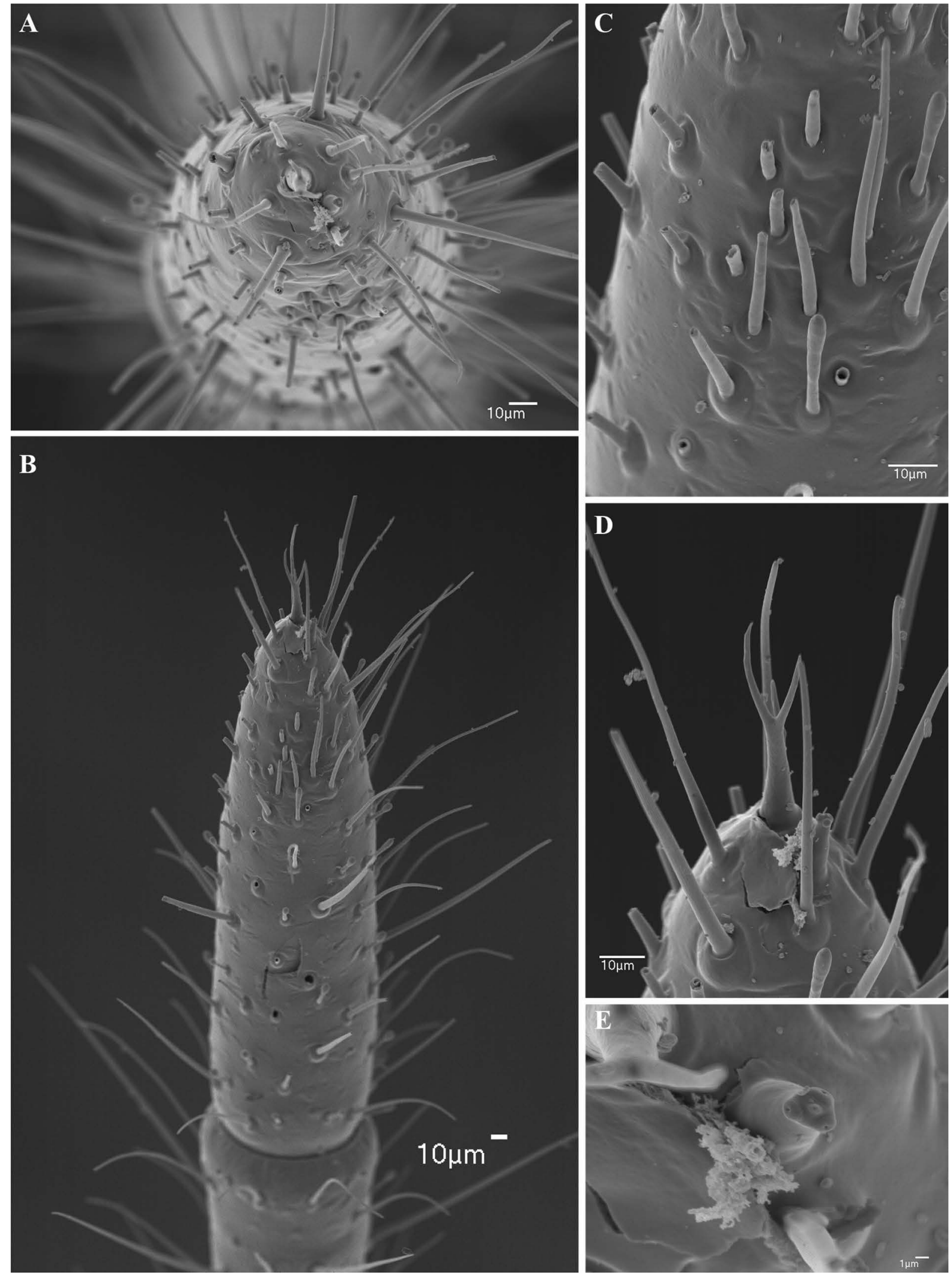

Fig. 98. Charinus elegans Weygoldt, 2006 (MHNG), antenniform leg I, Ô. A. Apex of distal article. B. Distal segment of tarsus, lateral view. C. Rod sensilla and olfactory setae. D. Apex of distal article of tarsus showing claw and tarsal organ. E. Detail of tarsal organ. 

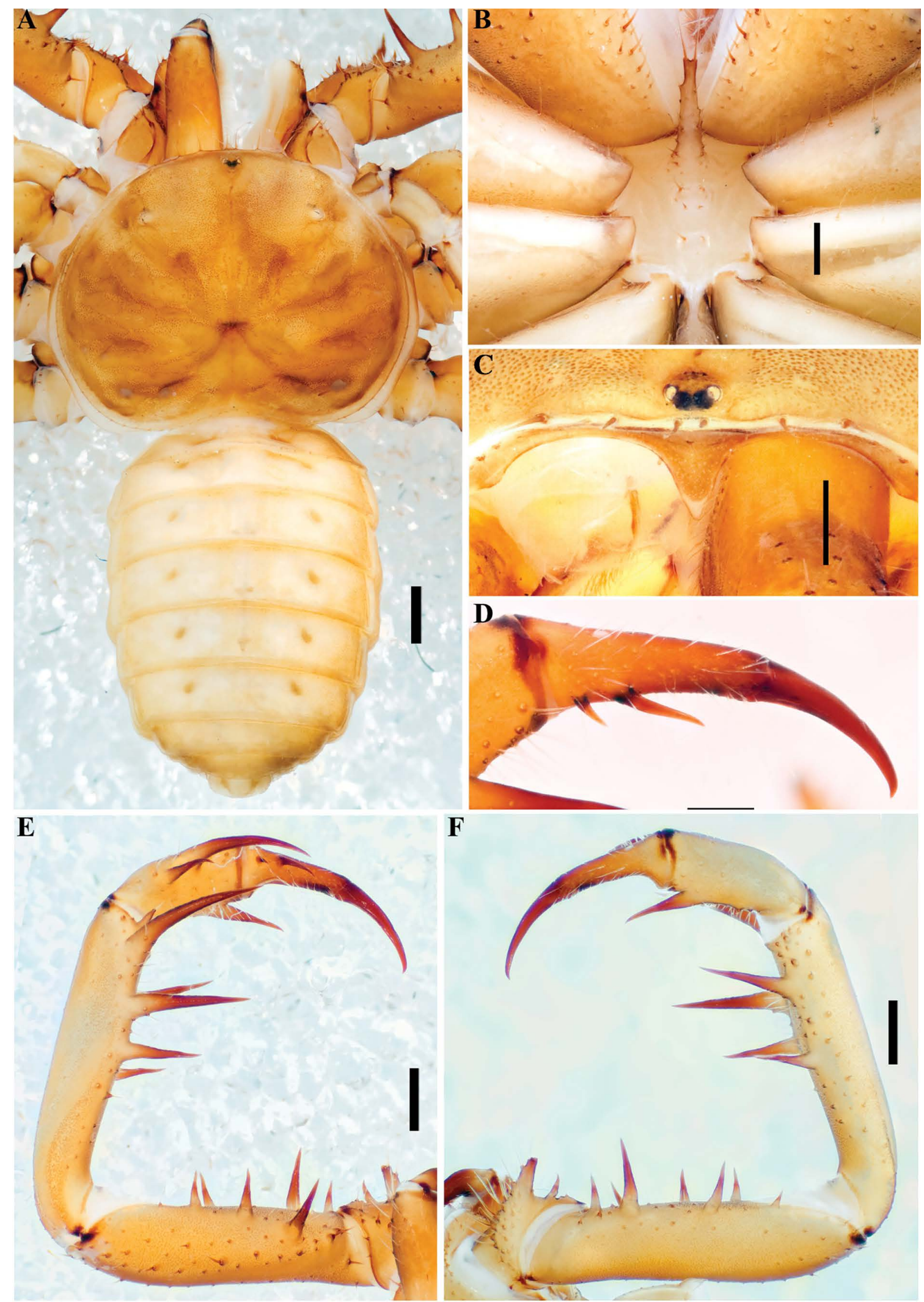

Fig. 99. Charinus longipes Weygoldt, 2006 (MNHN), general morphology, $\uparrow$. A. Habitus, dorsal view. B. Sternum, ventral view. C. Frontal process. D. Pedipalp tarsus, frontal view. E. Pedipalp, dorsal view. F. Pedipalp, ventral view. Scale bars: A, E-F $=1 \mathrm{~mm}$; B-D $=0.5 \mathrm{~mm}$. 

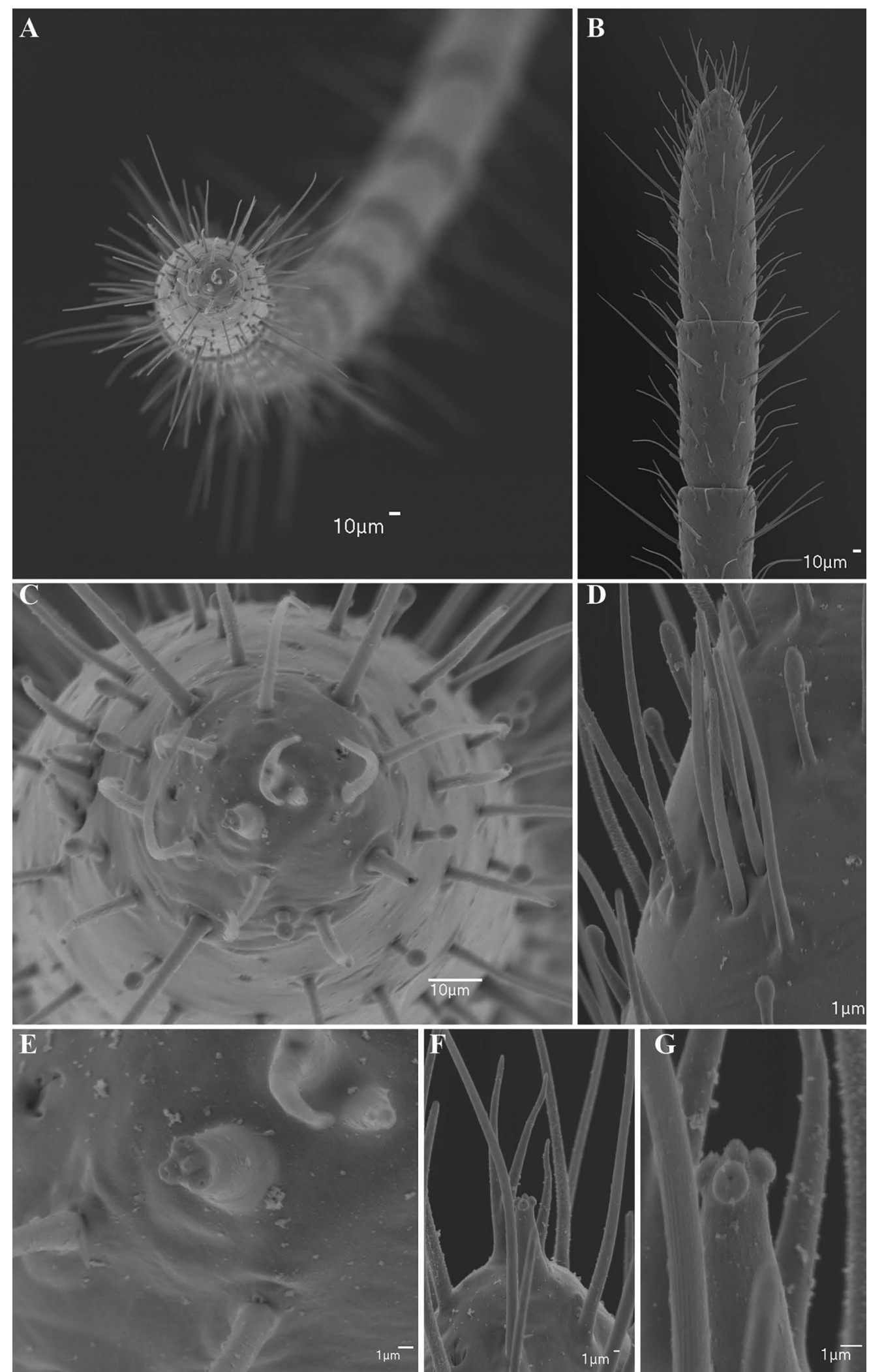

Fig. 100. Charinus neocaledonicus Kraepelin, 1895 (AMNH), antenniform leg I, ․ A. Apex of distal article of tarsus. B. Two distalmost articles, lateral view. C. Distal article of tarsus, frontal view. D. Olfactory setae ventral surface of last article of tarsus. E. Tarsal organ near tarsal claw. F. Claw and tarsal organ, lateral view. F. Tarsal organ, lateral view. 

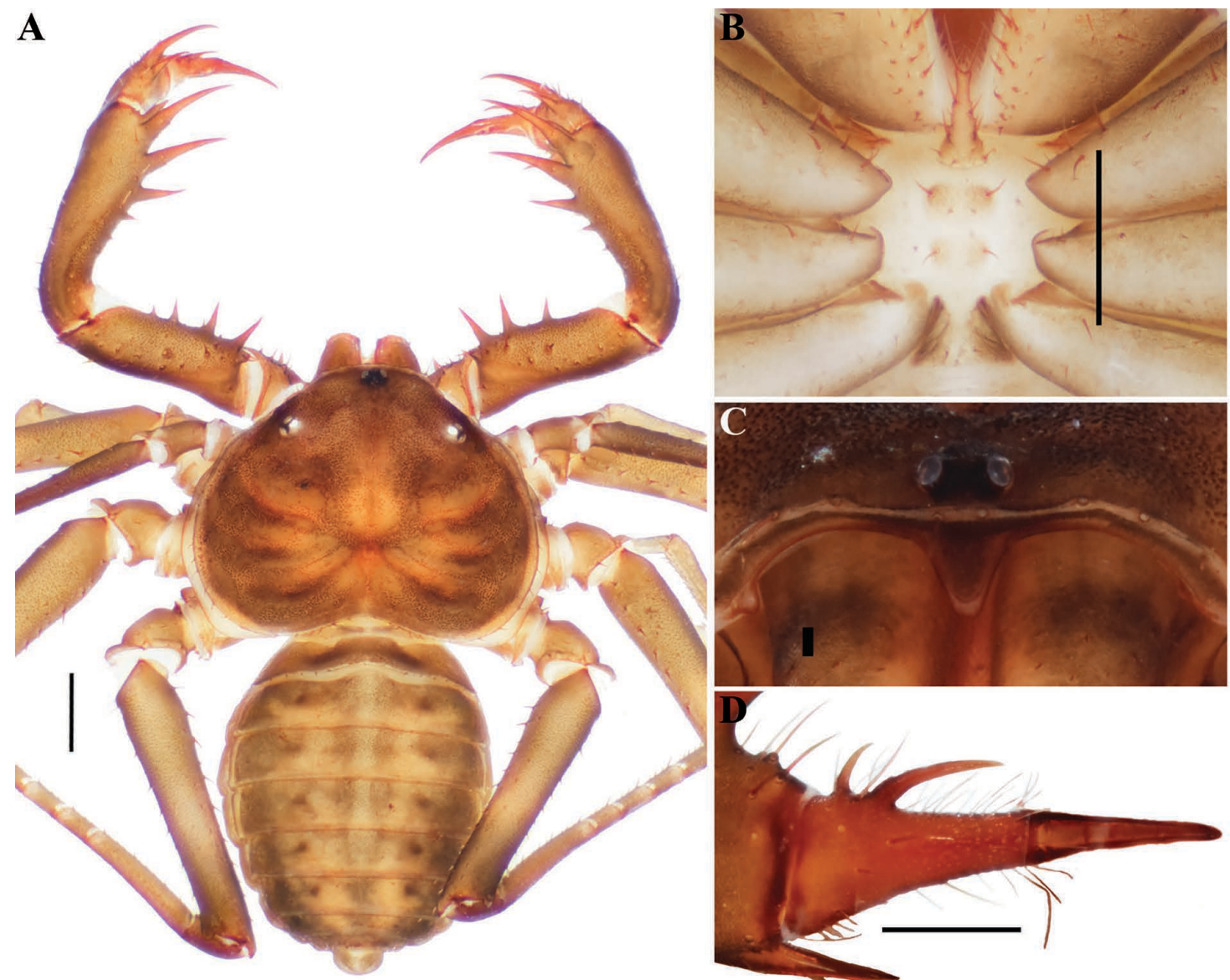

$\mathbf{E}$

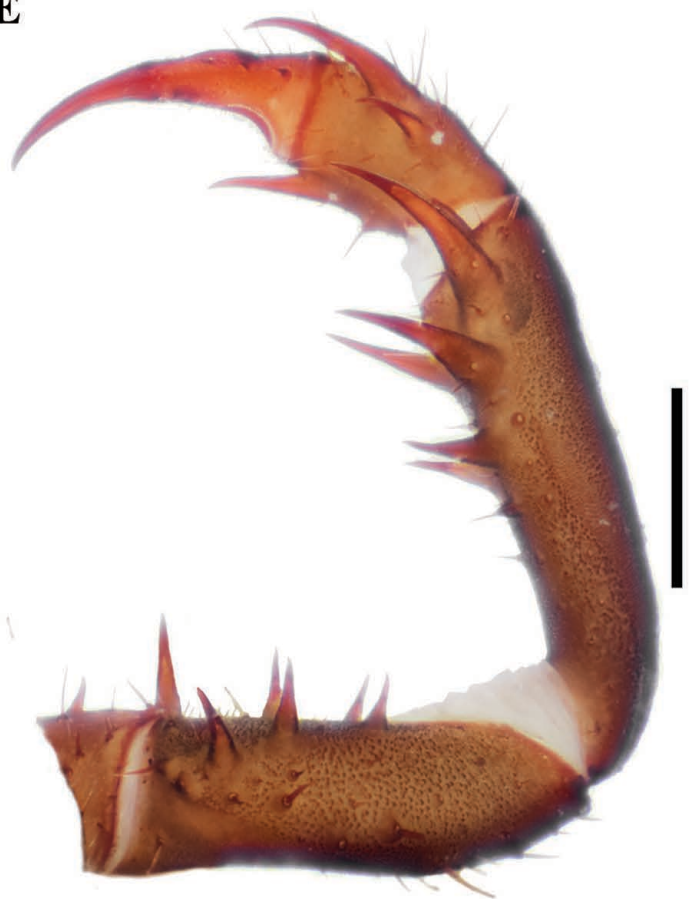

$\mathbf{F}$

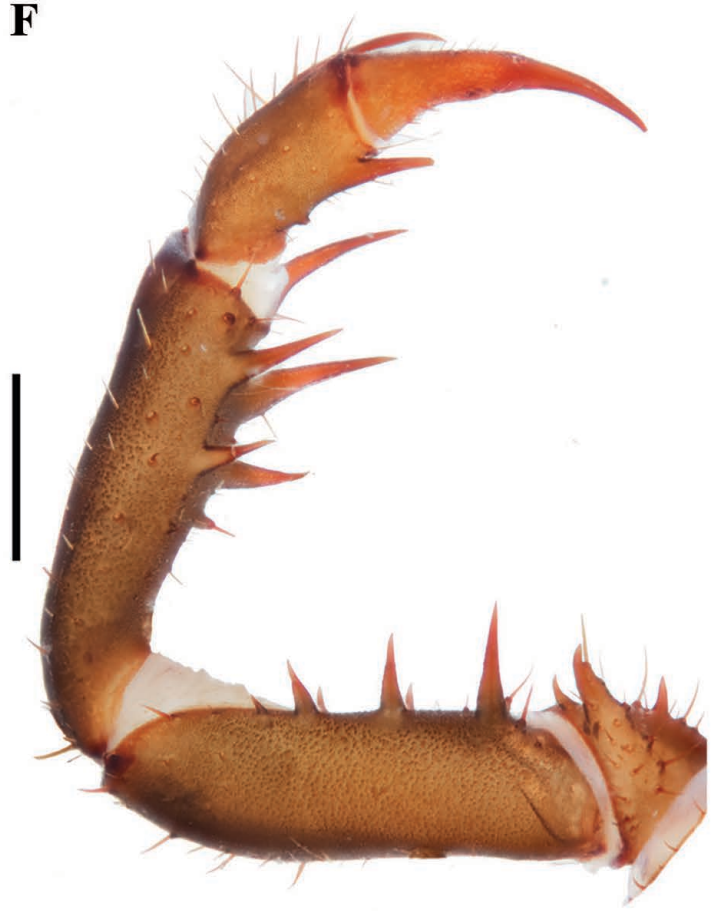

Fig. 101. Charinus pescotti Dunn, 1949 (AMCC [LP 6367]), general morphology, $\widehat{\jmath}$. A. Habitus, dorsal view. B. Sternum, ventral view. C. Frontal process. D. Pedipalp tarsus, frontal view. E. Pedipalp, dorsal view. F. Pedipalp, ventral view. Scale bars: $A-B, E-F=1 \mathrm{~mm} ; C=0.1 \mathrm{~mm} ; \mathrm{D}=0.5 \mathrm{~mm}$. 

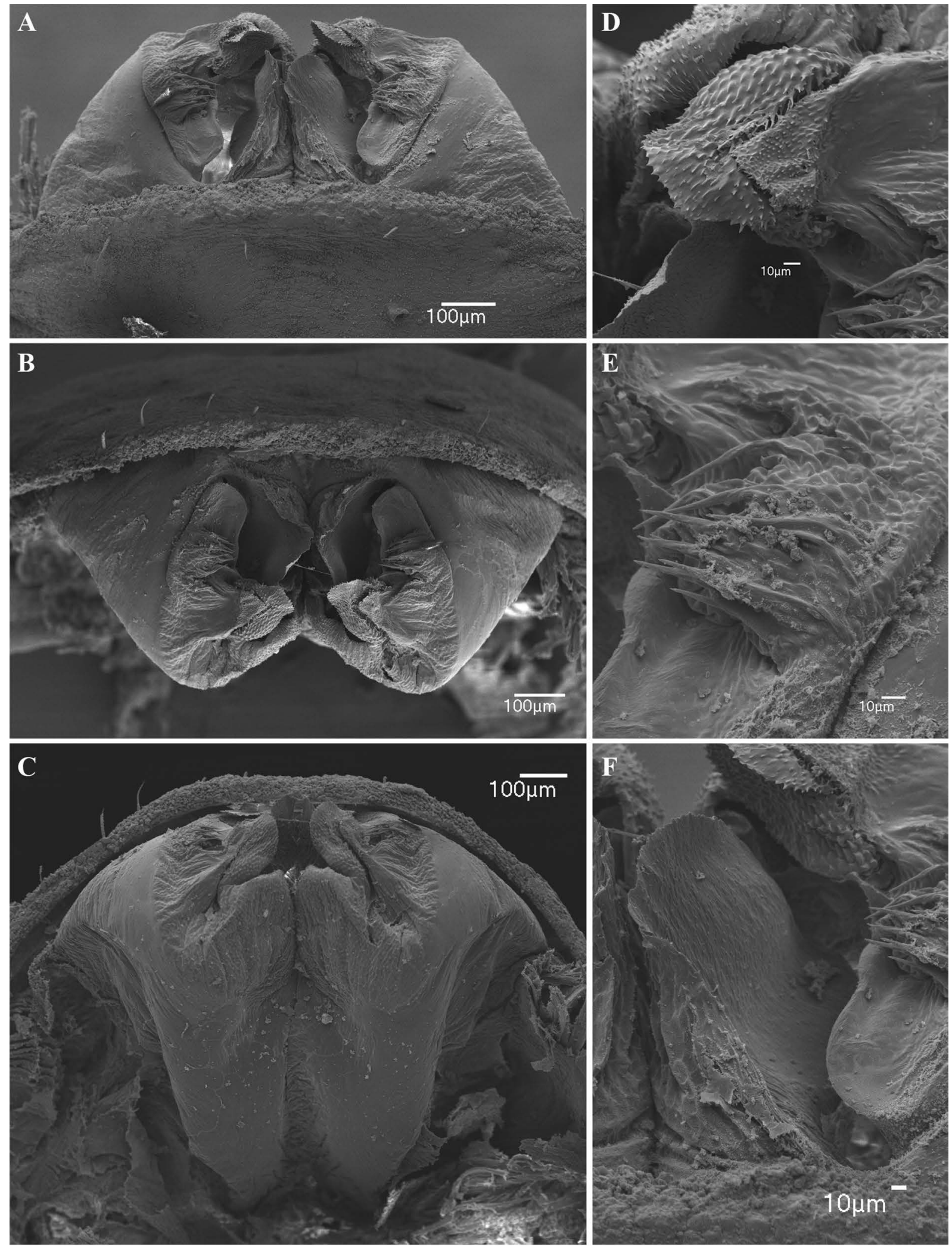

Fig. 102. Charinus pescotti Dunn, 1949 (AMCC [LP 6367]), male gonopod. A. Ventral view. B. Posterior view. C. Dorsal view. D. Lateral lobe 1 and dorsal lobe. E. Lateral lobe 2. F. Lamina medialis and processus internus. 


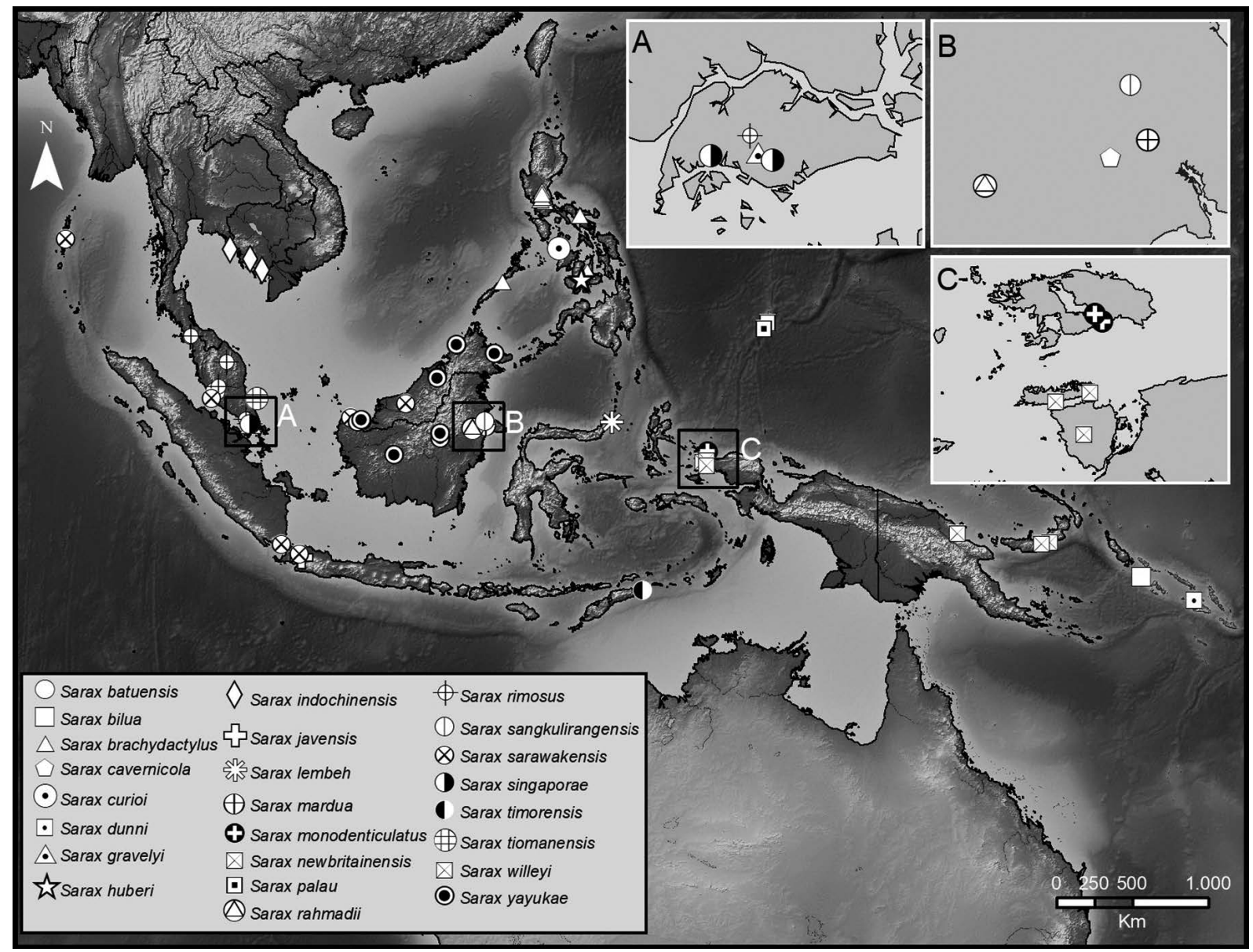

Fig. 103. Map plotting known distributions of species of Sarax Simon, 1892 in Southeast Asia and Oceania, with insets for Singapore (A), eastern Borneo (B), and western West Papua (C). 


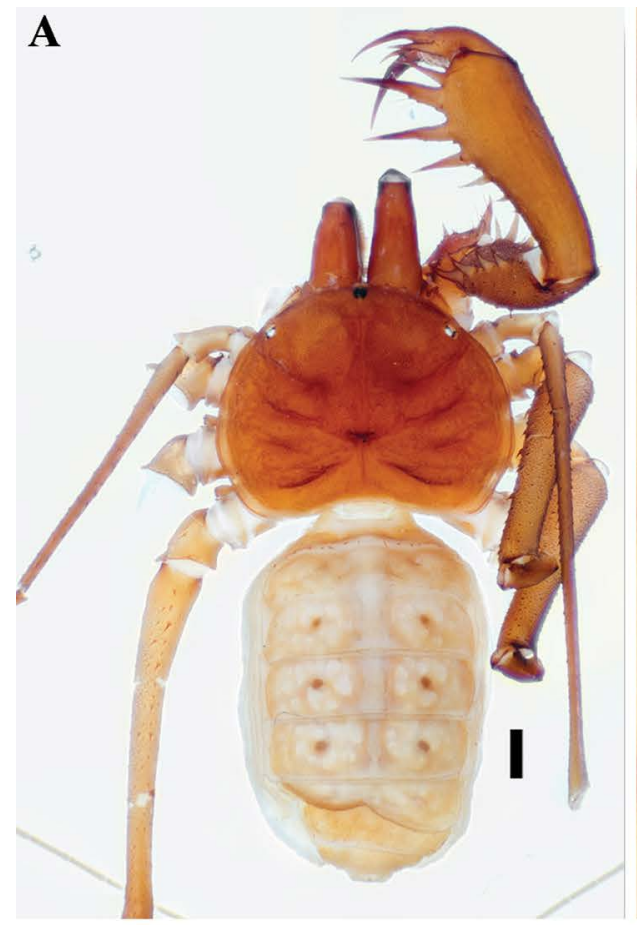

C

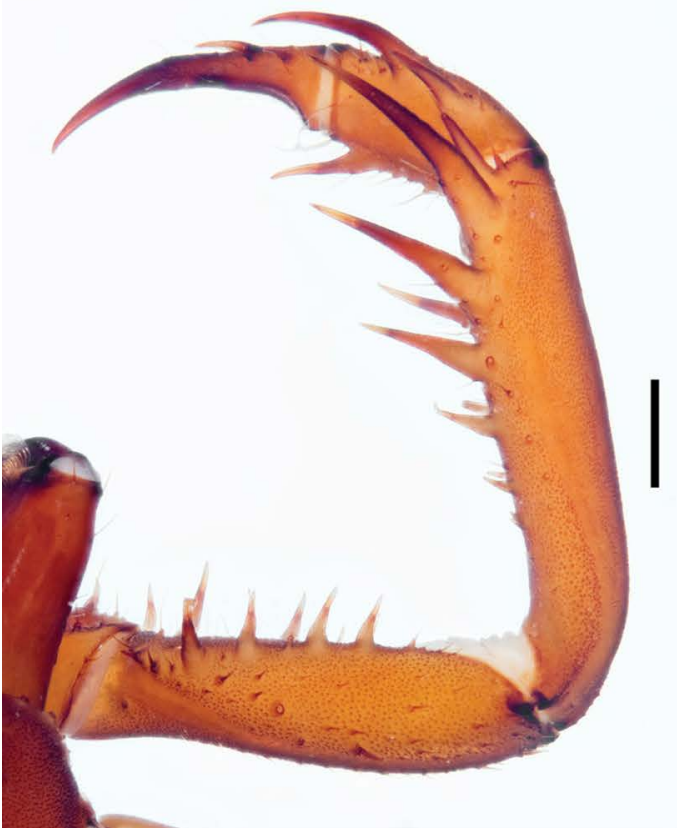

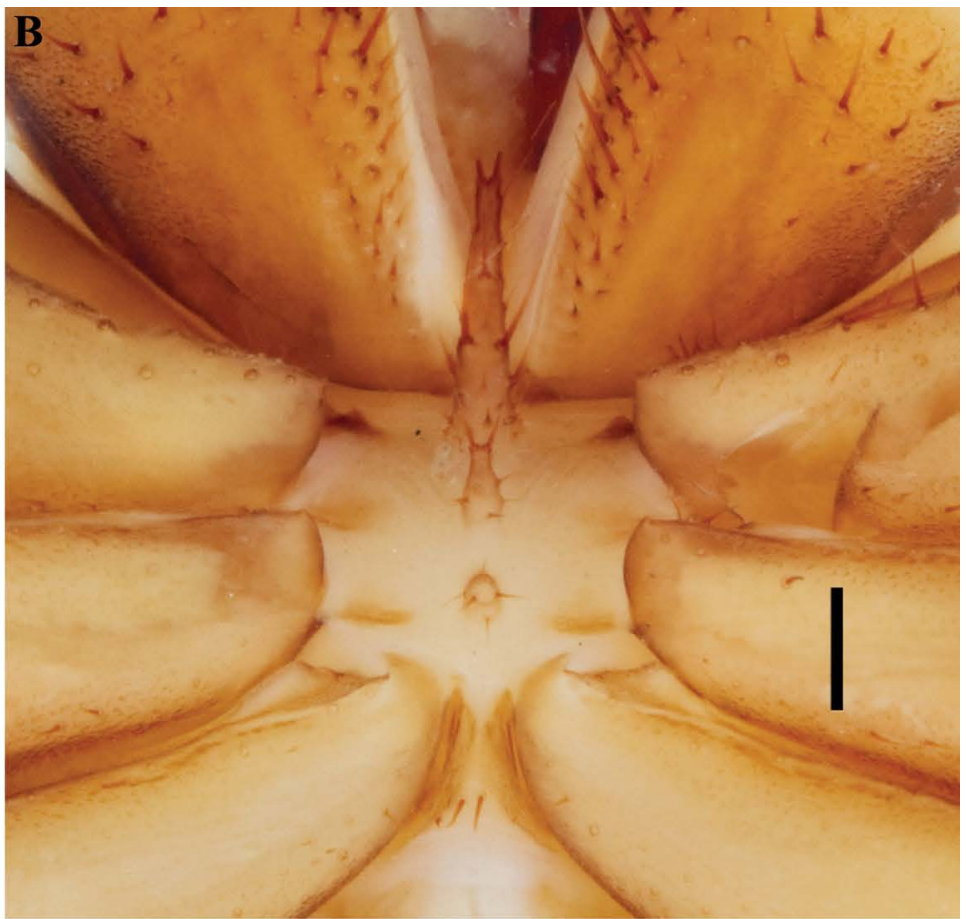

D

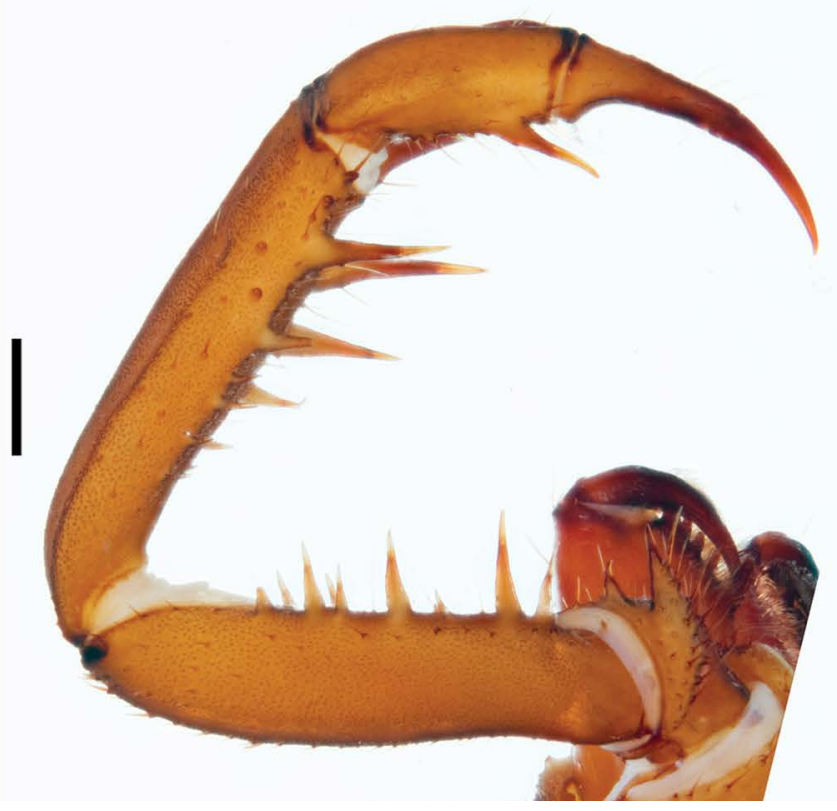

Fig. 104. Sarax batuensis Roewer (1962) (SMF), general morphology, $q$. A. Habitus, dorsal view. B. Sternum, ventral view. C. Pedipalp, dorsal view. D. Pedipalp, ventral view. Scale bars: A, C-D = $1 \mathrm{~mm} ; \mathrm{B}=0.5 \mathrm{~mm}$. 
A

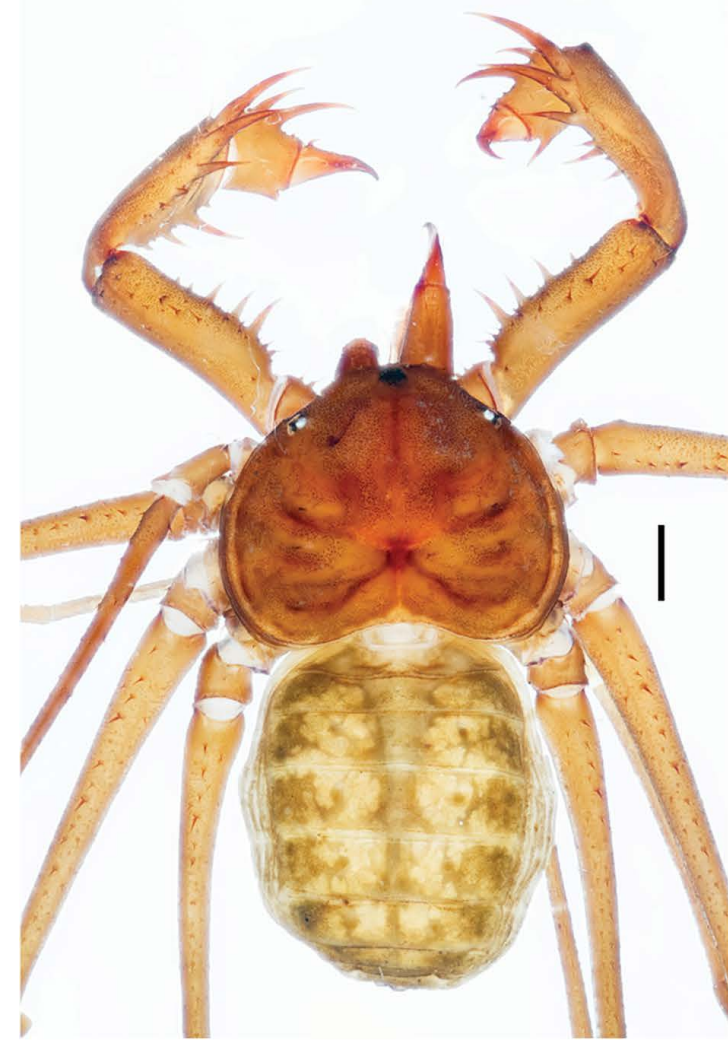

$\mathbf{E}$

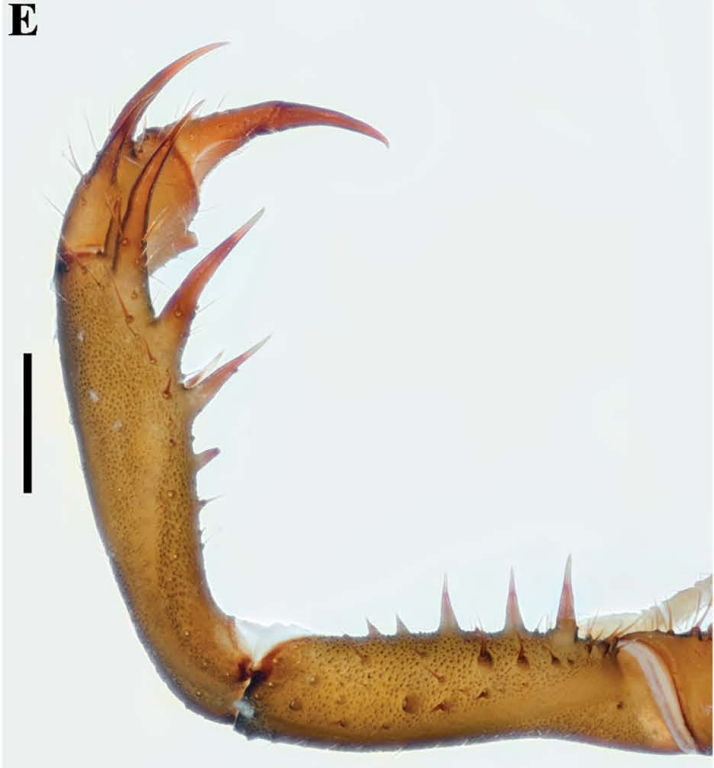

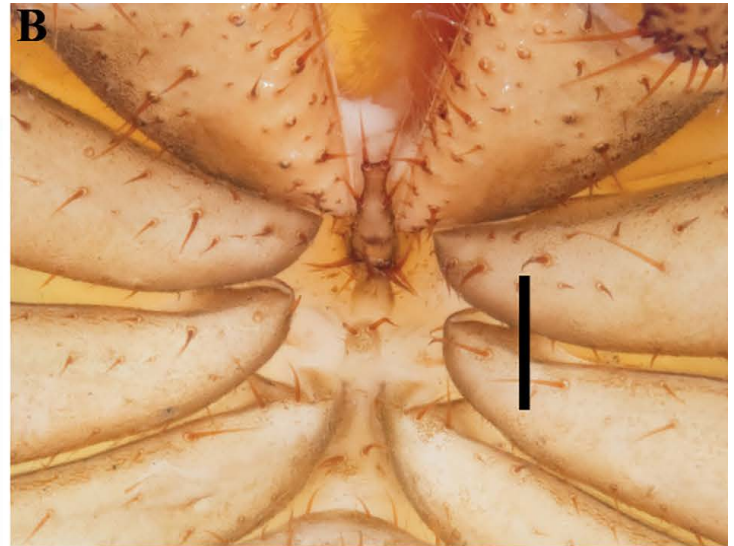

C
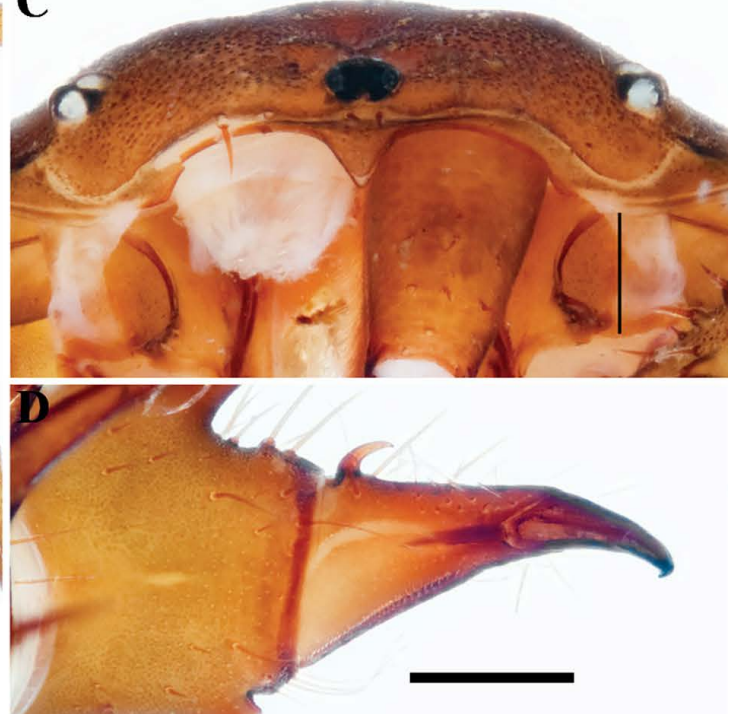

$\mathbf{F}$

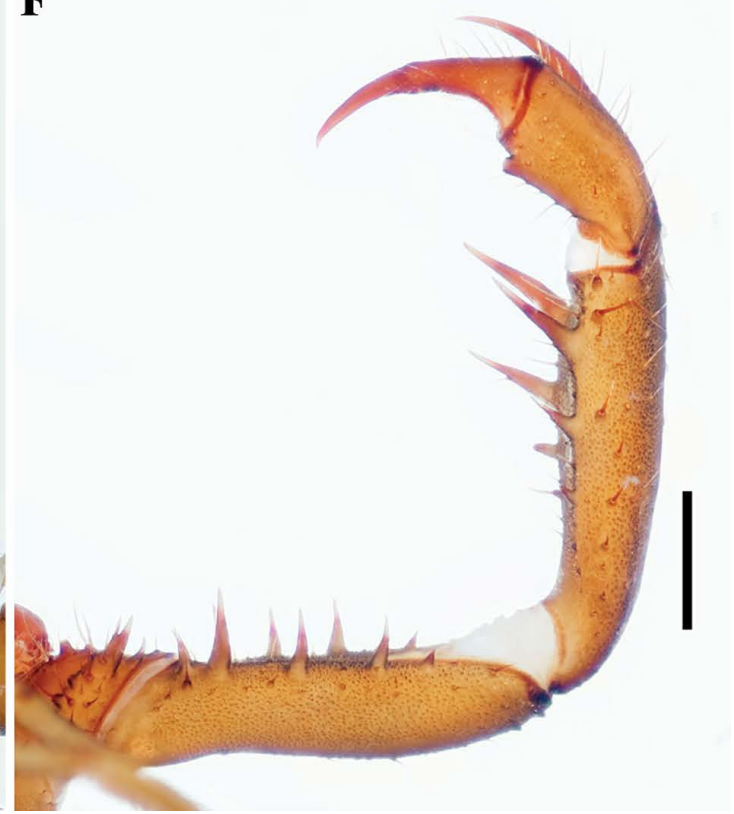

Fig. 105. Sarax bilua sp. nov. (AMCC [LP 5564]), general morphology, 9 . A. Habitus, dorsal view. B. Sternum, ventral view. C. Frontal process. D. Pedipalp tarsus, frontal view. E. Pedipalp, dorsal view. F. Pedipalp, ventral view. Scale bars: A, E-F $=1 \mathrm{~mm}$; B-D $=0.5 \mathrm{~mm}$. 


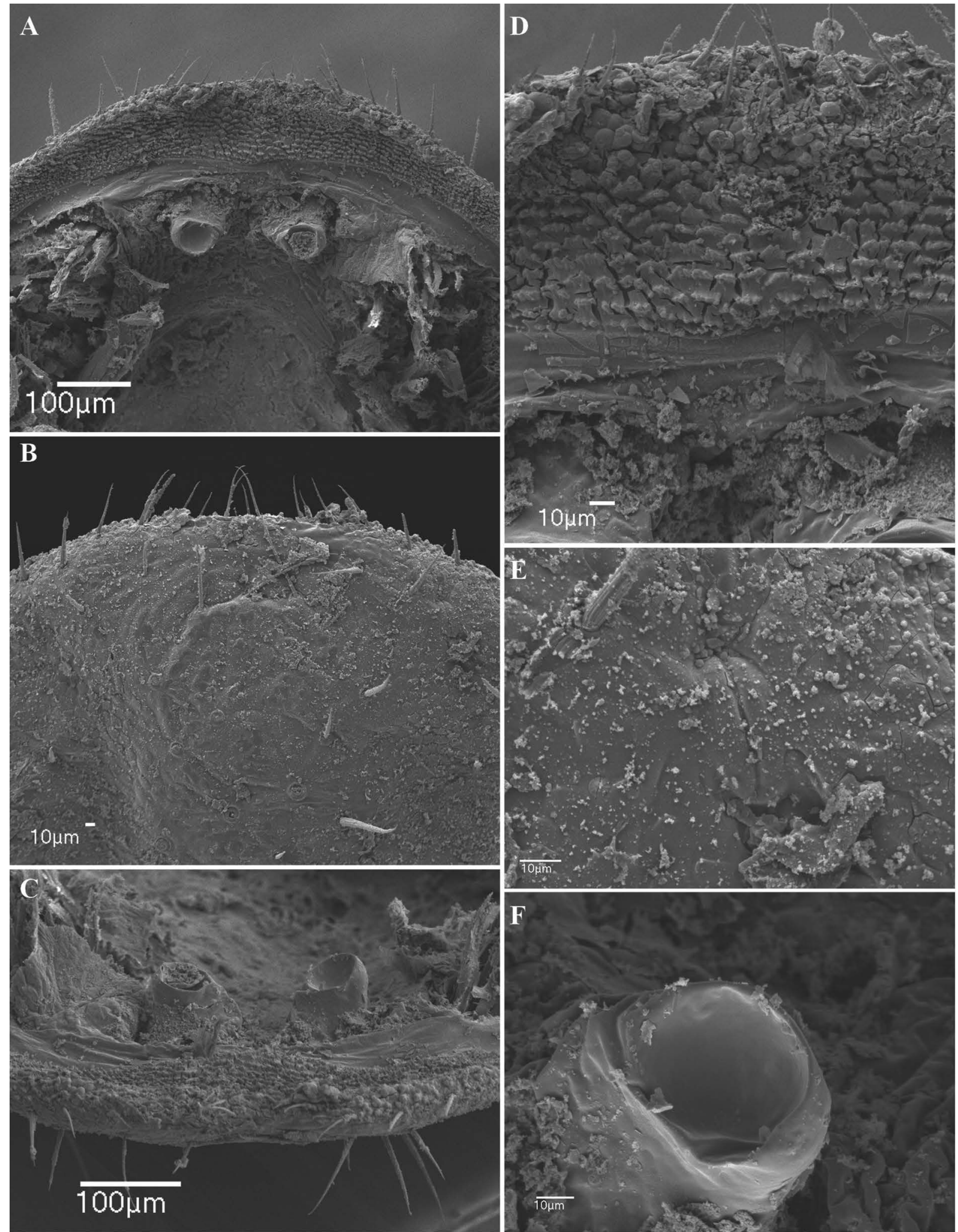

Fig. 106. Sarax bilua sp. nov. (AMCC [LP 5564]), female gonopod and genital operculum. A. Plungerlike gonopod, dorsal view. B. Posterior margin of genital operculum, ventral view. C. Gonopods, posterior view. D. Genital operculum between gonopods. E. Glandular openings on margin of genital operculum. F. Inside gonopod projection. 

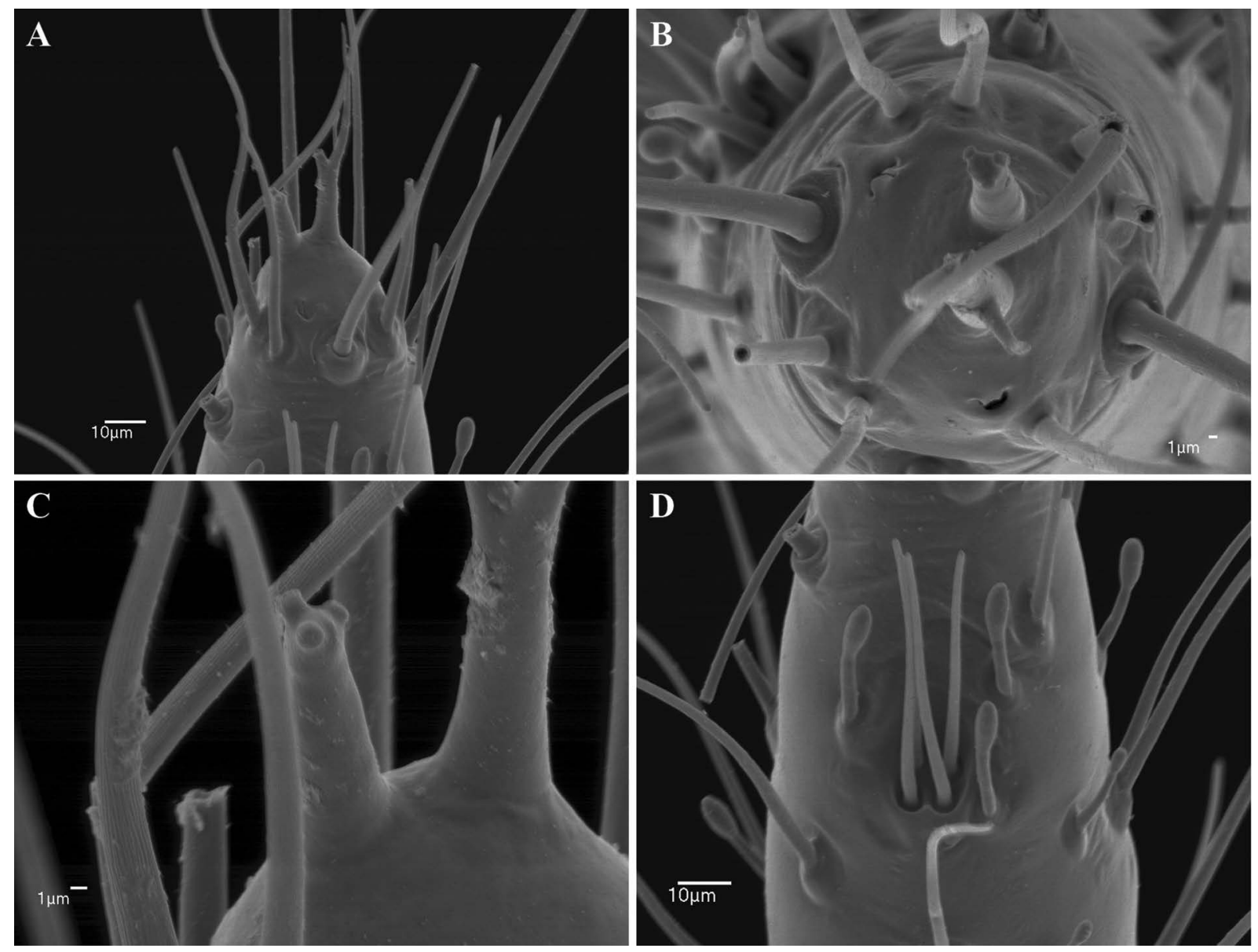

Fig. 107. Sarax bilua sp. nov. (AMCC [LP 5564]), antenniform leg I, . . A. Apex of distal article of tarsus showing claw and tarsal organ, lateral view. B. Claw and tarsal organ, frontal view. C. Tarsal organ. D. Rod sensilla and setae. 

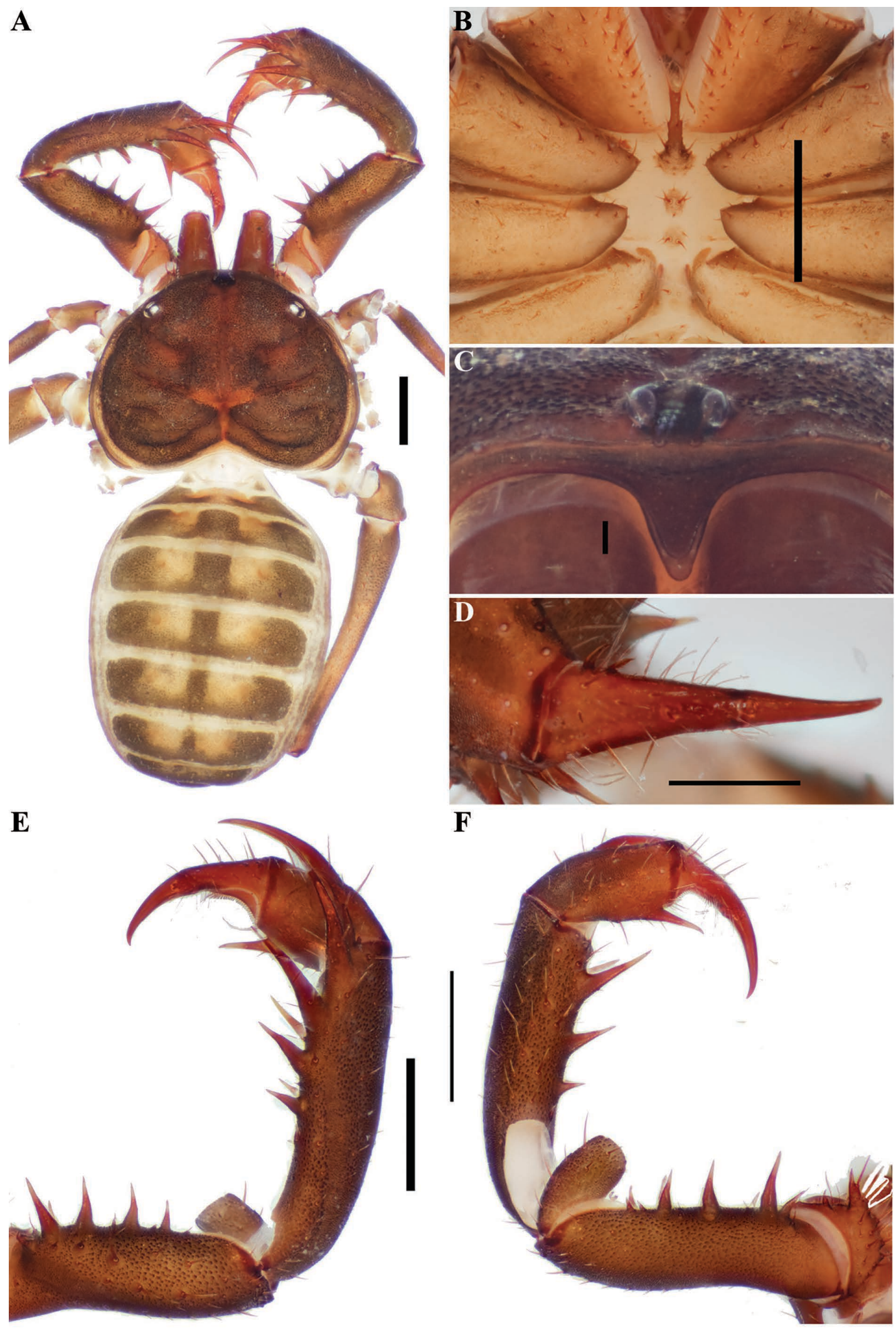

Fig. 108. Sarax brachydactylus Simon, 1892 (AMCC [LP 1926]), general morphology, ㅇ. A. Habitus, dorsal view. B. Sternum, ventral view. C. Frontal process. D. Pedipalp tarsus, frontal view. E. Pedipalp, dorsal view. F. Pedipalp, ventral view. Scale bars: A-B, D-F $=1 \mathrm{~mm} ; \mathrm{C}=0.1 \mathrm{~mm}$. 
$\mathbf{A}$

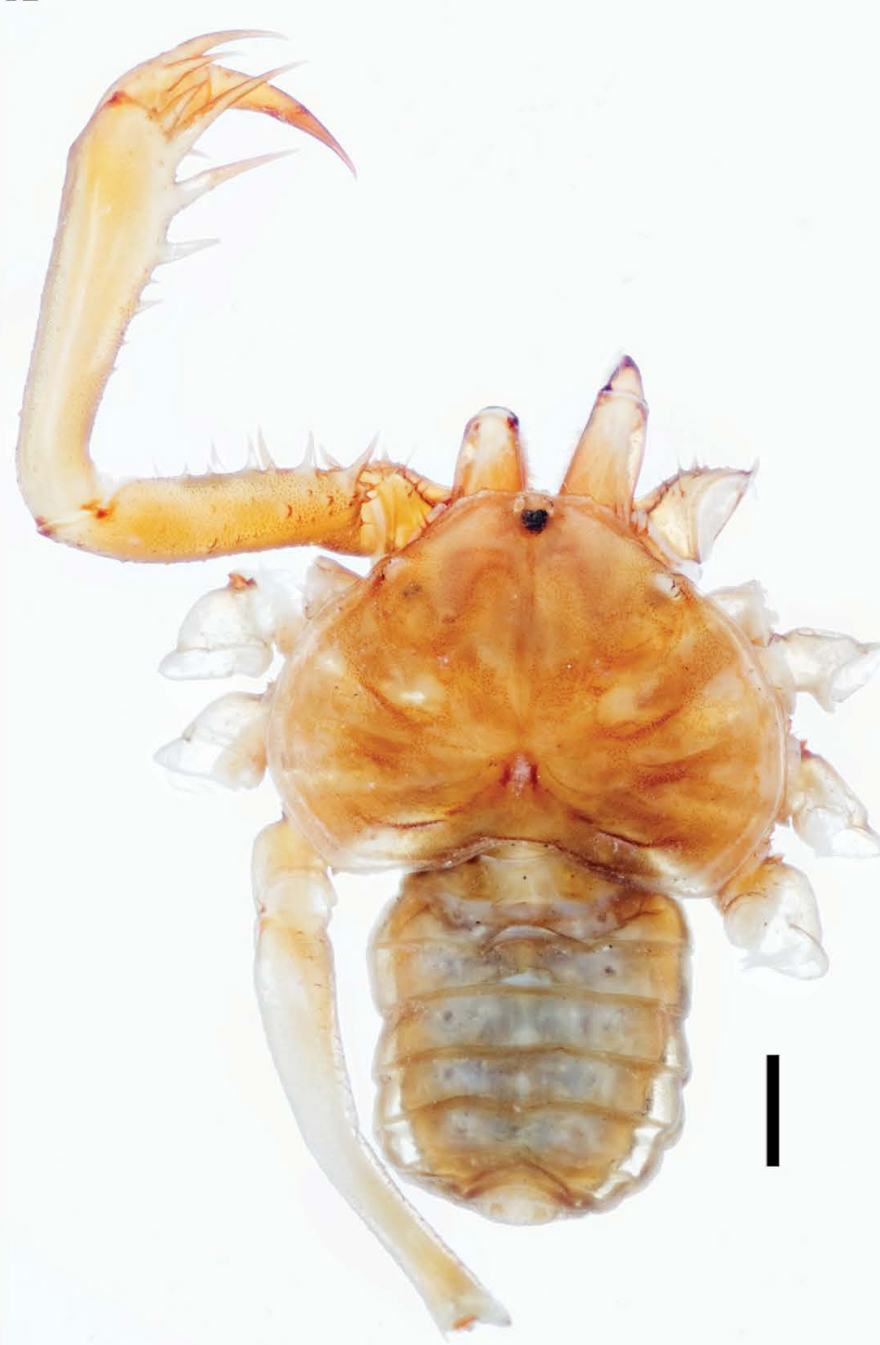

B
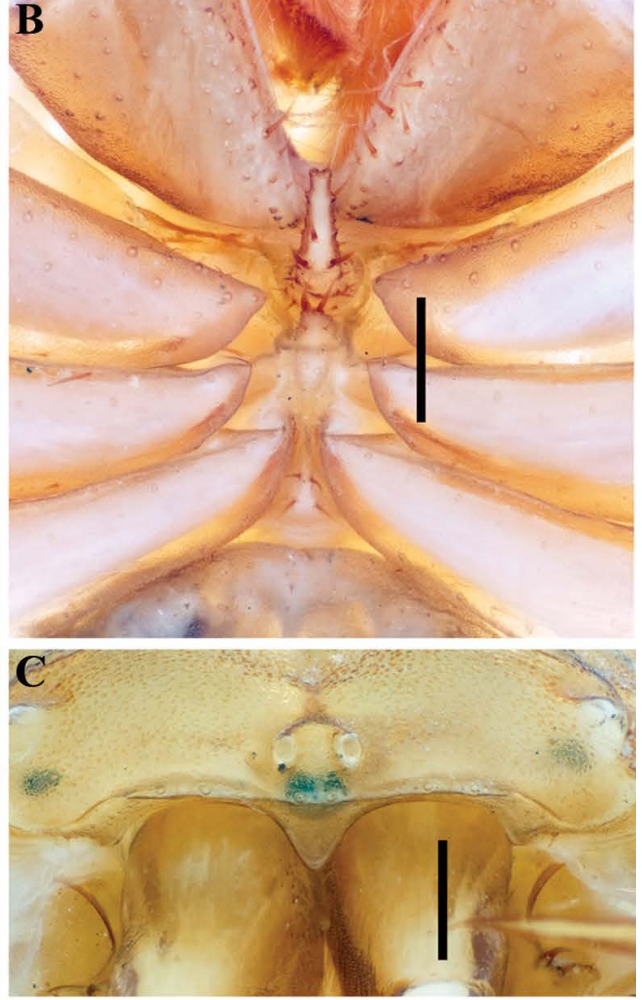

D

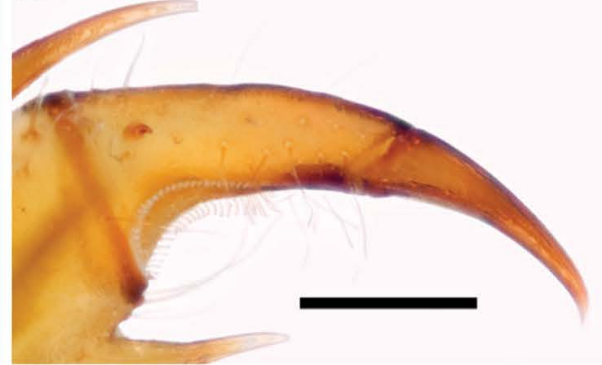

$\mathbf{E}$

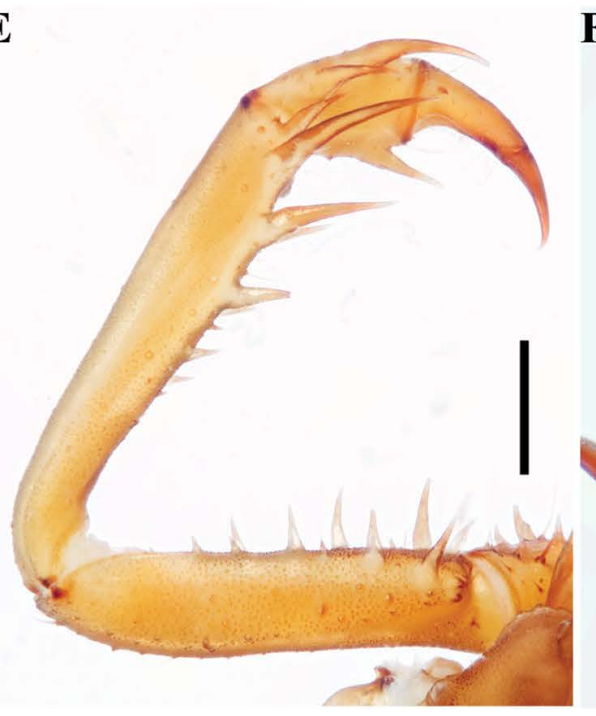

F

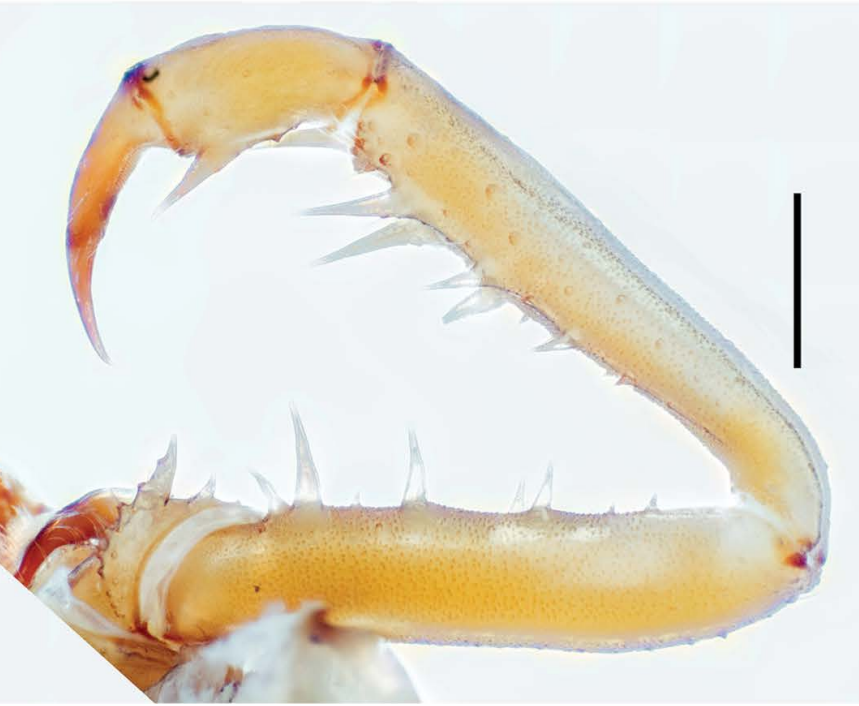

Fig. 109. Sarax dunni sp. nov. (NMNZ), general morphology, $q$. A. Habitus, dorsal view. B. Sternum, ventral view. C. Frontal process. D. Pedipalp tarsus, frontal view. E. Pedipalp, dorsal view. F. Pedipalp, ventral view. Scale bars: A, E-F $=1 \mathrm{~mm}$; $\mathrm{B}-\mathrm{D}=0.5 \mathrm{~mm}$. 

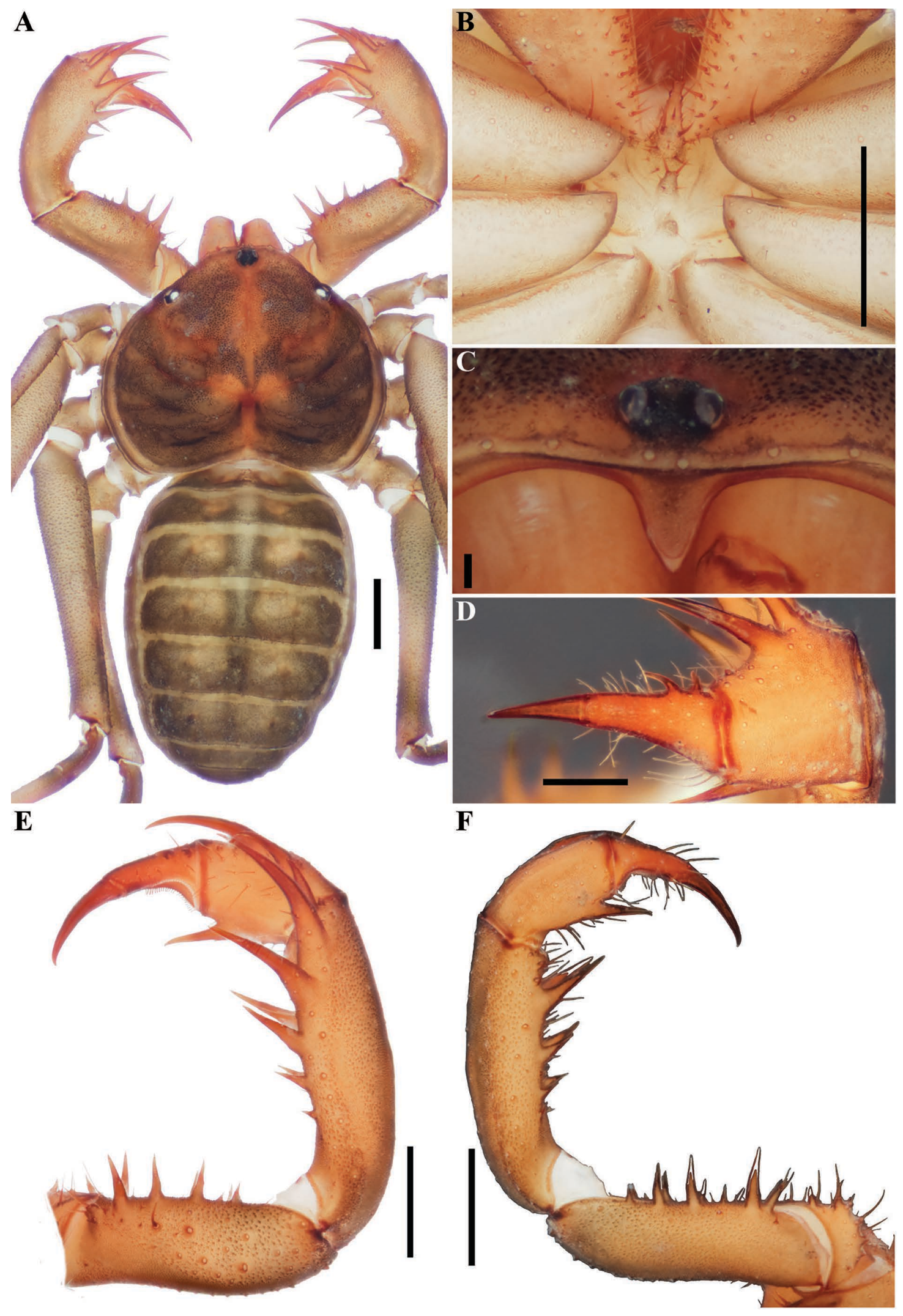

Fig. 110. Sarax gravelyi sp. nov. (AMCC [11995]), general morphology, + . A. Habitus, dorsal view. B. Sternum, ventral view. C. Frontal process. D. Pedipalp tarsus, frontal view. E. Pedipalp, dorsal view. F. Pedipalp, ventral view. Scale bars: $A-B, E-F=1 \mathrm{~mm} ; C=0.1 \mathrm{~mm} ; \mathrm{D}=0.5 \mathrm{~mm}$. 
MIRANDA G.S. et al., Systematic revision of Charinidae (Arachnida, Amblypygi)

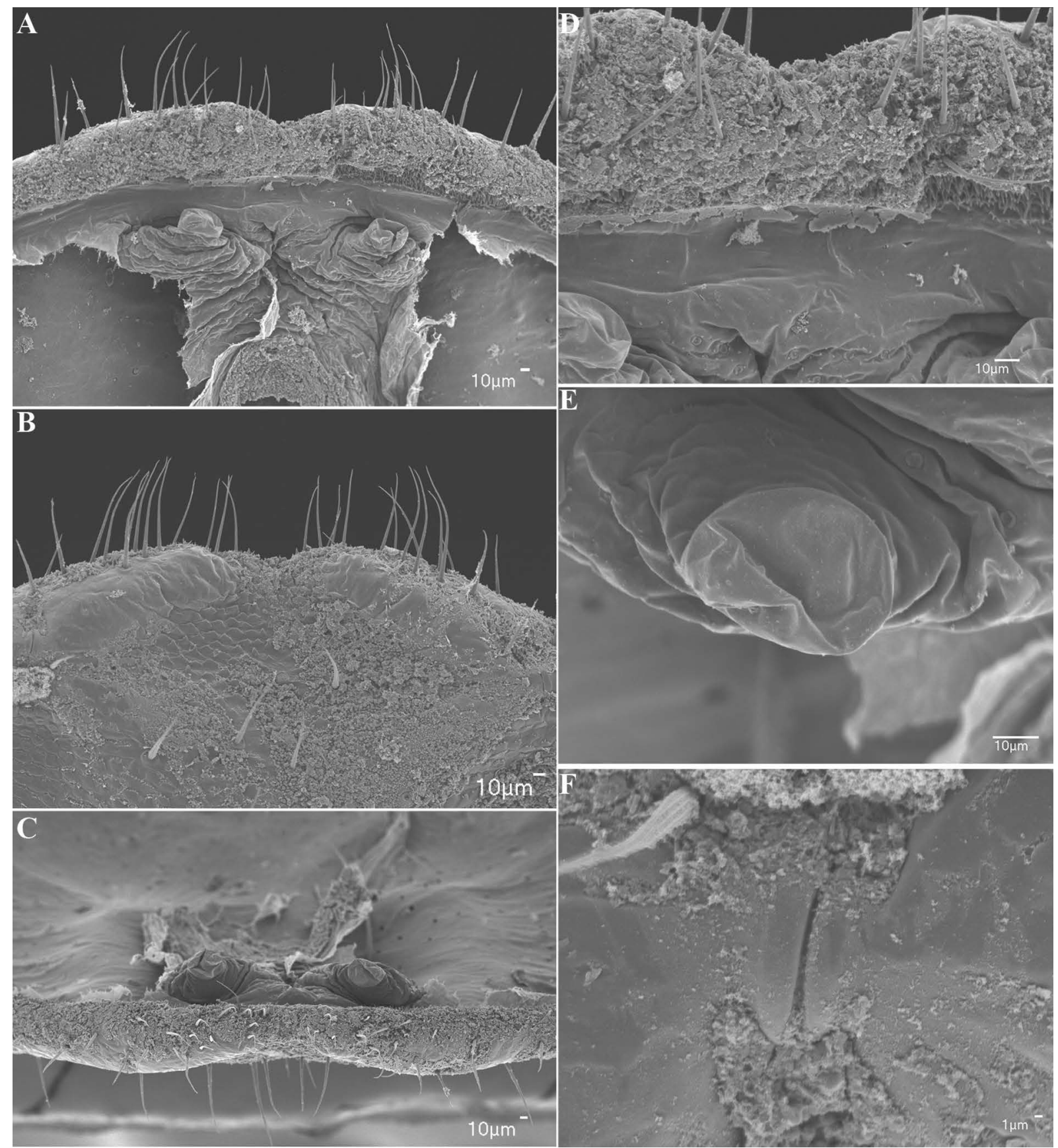

Fig. 111. Sarax gravelyi sp. nov. (AMCC [11995]), female gonopod and genital operculum. A. Fingerlike gonopod, dorsal view. B. Posterior margin of genital operculum, ventral view. C. Gonopods, posterior view. D. Genital operculum between gonopods. E. Dextral gonopod. F. Glandular opening on margin of genital operculum. 


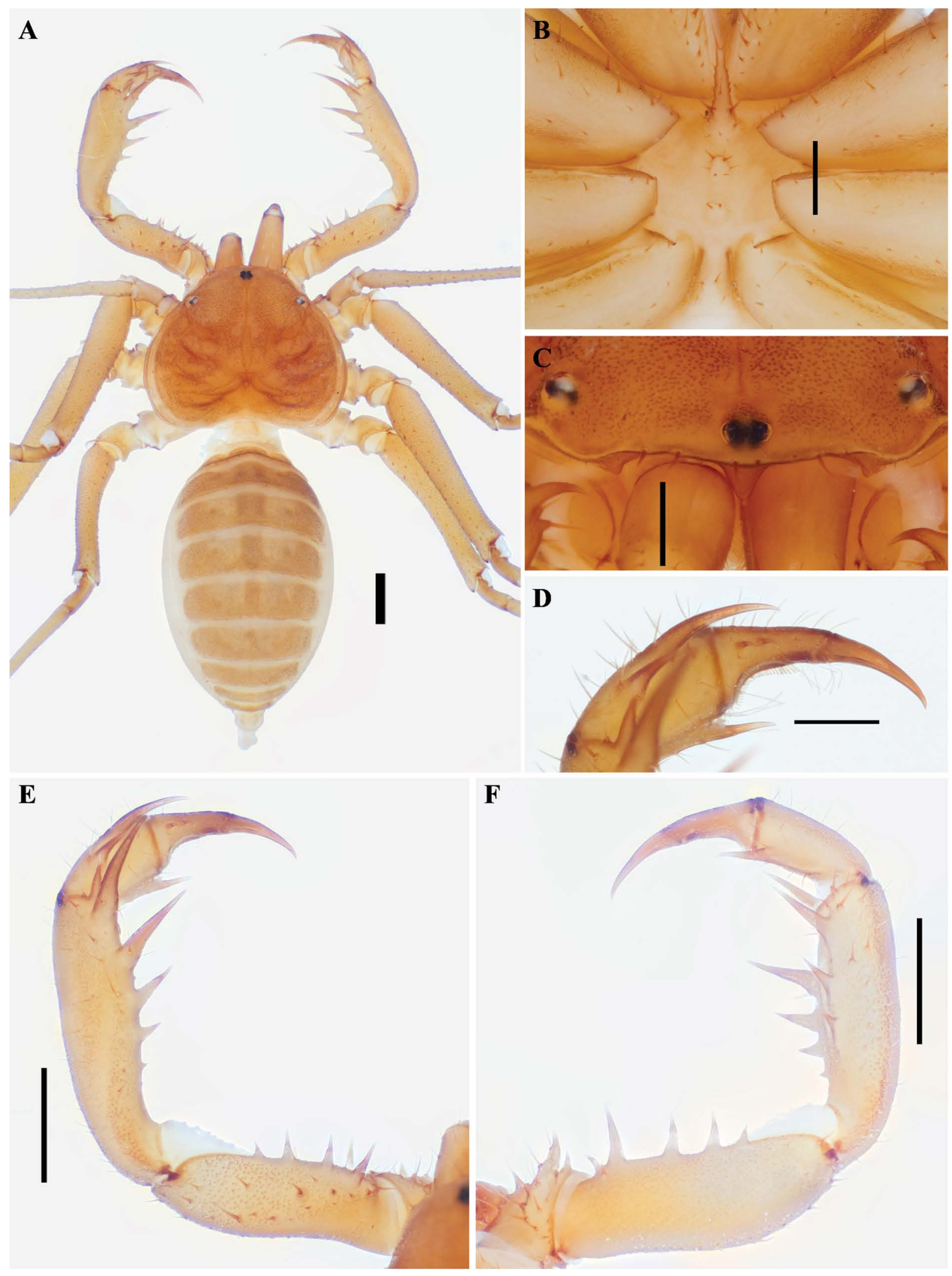

Fig. 112. Sarax indochinensis sp. nov. (ZMUC 21613), general morphology, . . A. Habitus, dorsal view. B. Sternum, ventral view. C. Frontal process. D. Pedipalp tarsus, frontal view. E. Pedipalp, dorsal view. F. Pedipalp, ventral view. Scale bars: A, E-F $=1 \mathrm{~mm}$; B-D $=0.5 \mathrm{~mm}$. 

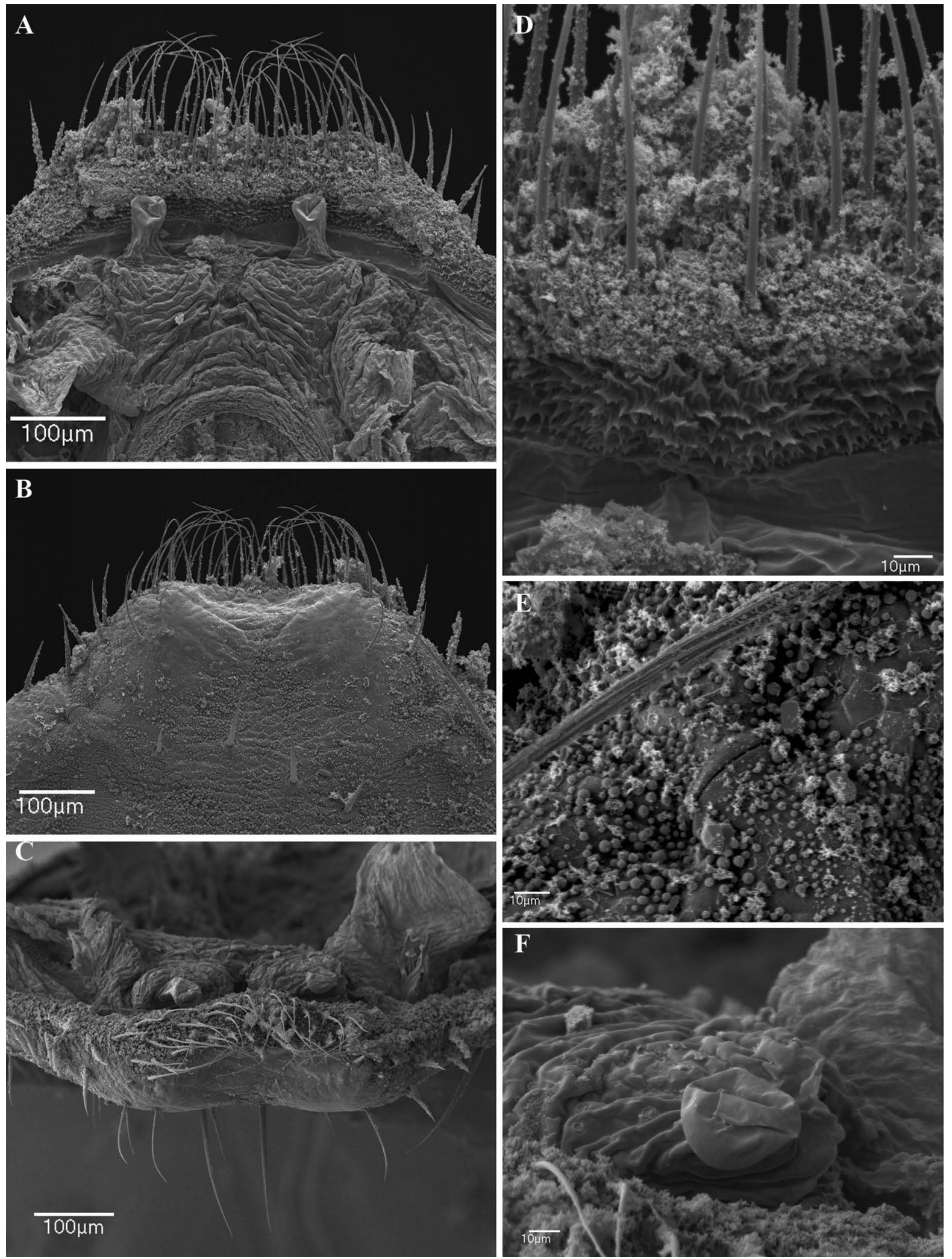

Fig. 113. Sarax indochinensis sp. nov. (ZMUC 21612), female gonopod and genital operculum. A. Fingerlike gonopod, dorsal view. B. Posterior margin of genital operculum, ventral view. C. Gonopods, posterior view. D. Genital operculum between gonopods. E. Glandular opening on margin of genital operculum. F. Dextral gonopod. 

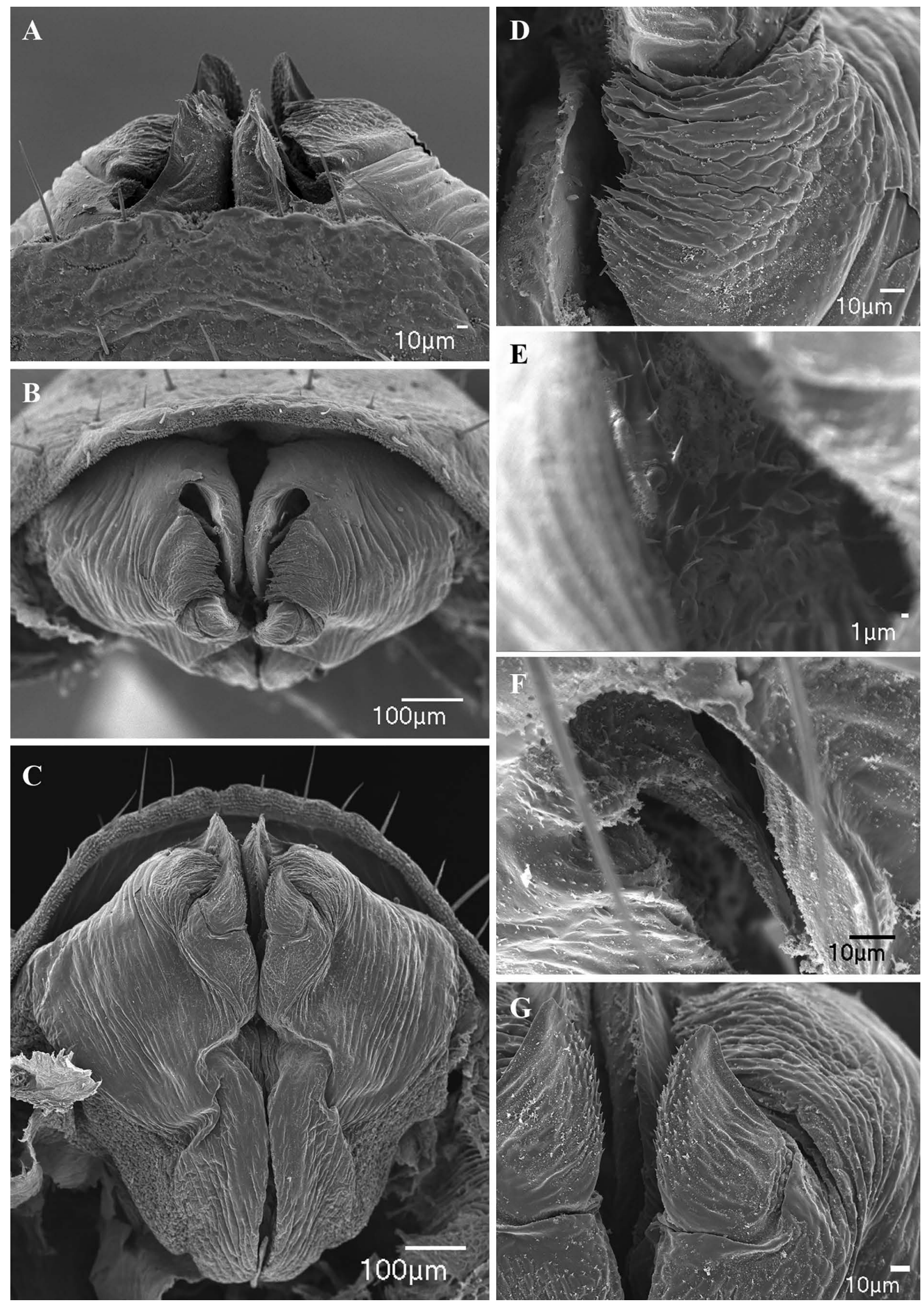

Fig. 114. Sarax indochinensis sp. nov. (ZMUC 21612), male gonopod. A. Ventral view. B. Posterior view. C. Dorsal view. D. Detail of lateral lobe 2. E. Detail of spiny inner region of fistula. F. Processus internus. G. Detail of apex of dorsal lobe. 
MIRANDA G.S. et al., Systematic revision of Charinidae (Arachnida, Amblypygi)
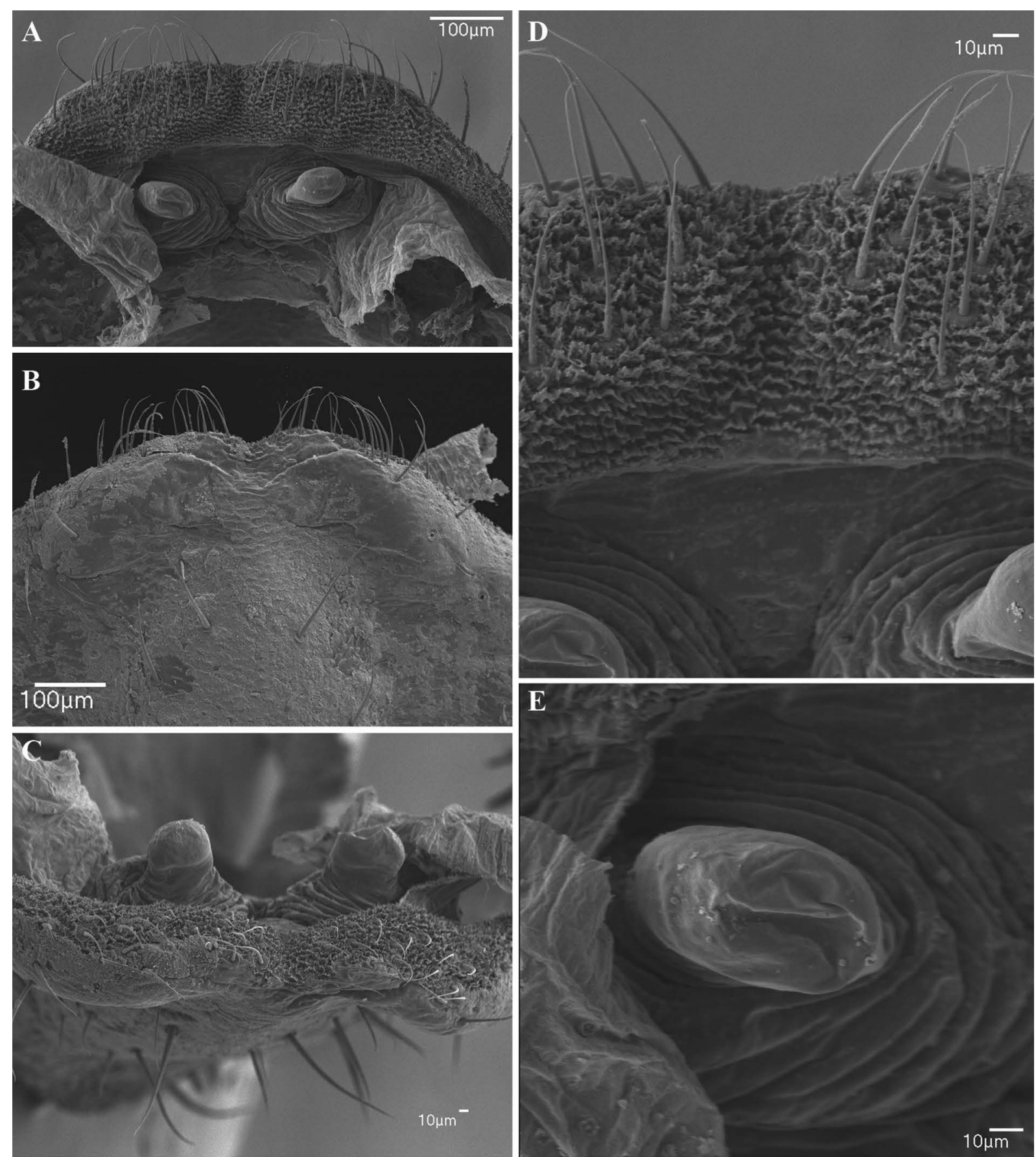

Fig. 115. Sarax javensis (Gravely, 1915) (WAM T80541), female gonopod and genital operculum. A. Finger-like gonopod, dorsal view. B. Posterior margin of genital operculum, ventral view. C. Gonopods, posterior view. D. Genital operculum between gonopods. F. Dextral gonopod. 

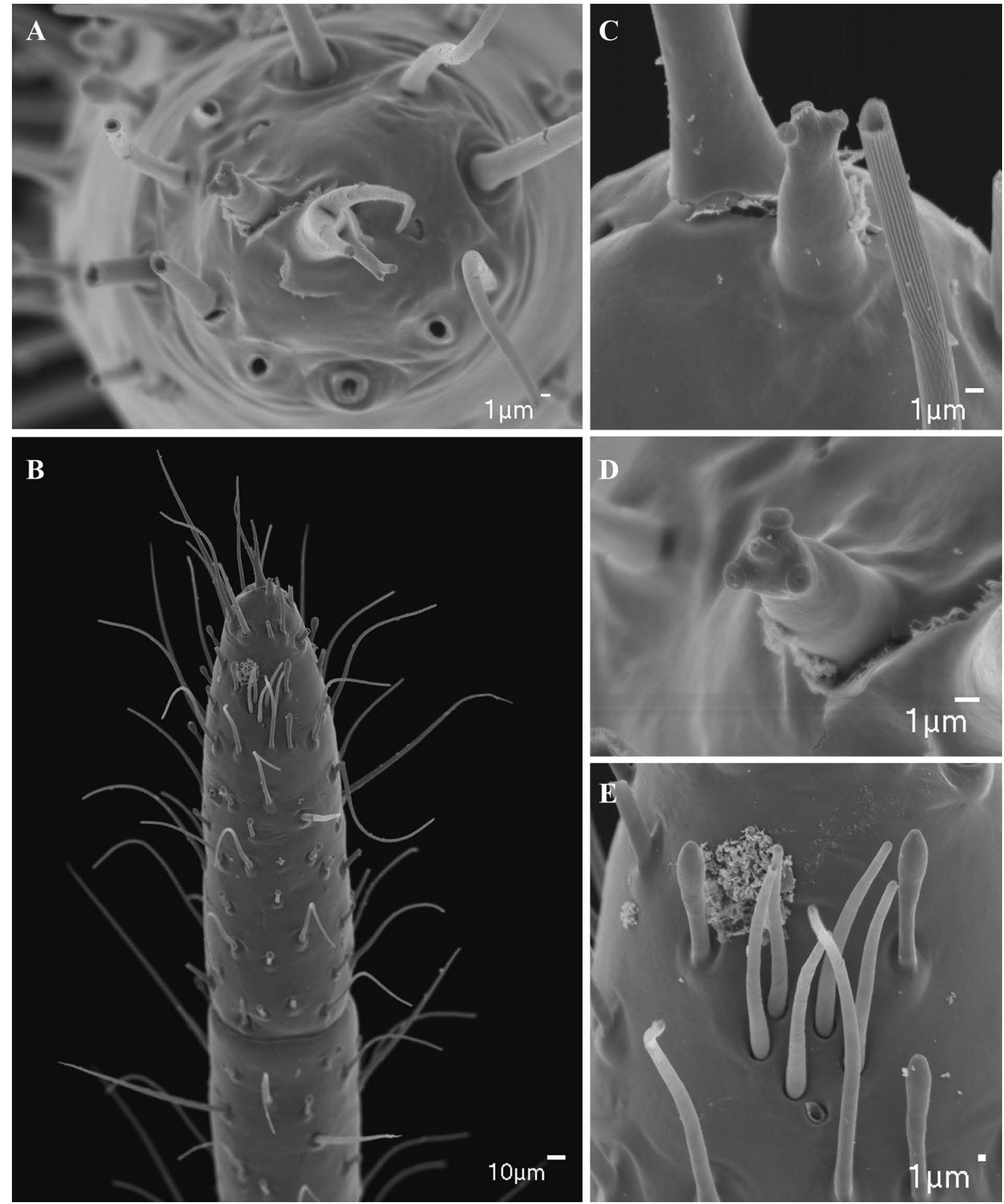

Fig. 116. Sarax javensis (Gravely, 1915) (WAM T80541), antenniform leg I, $\bigcirc$. A. Apex of distal article. B. Distal segment of tarsus, lateral view. C-D. Detail of tarsal organ. E. Rod sensilla and olfactory setae. 


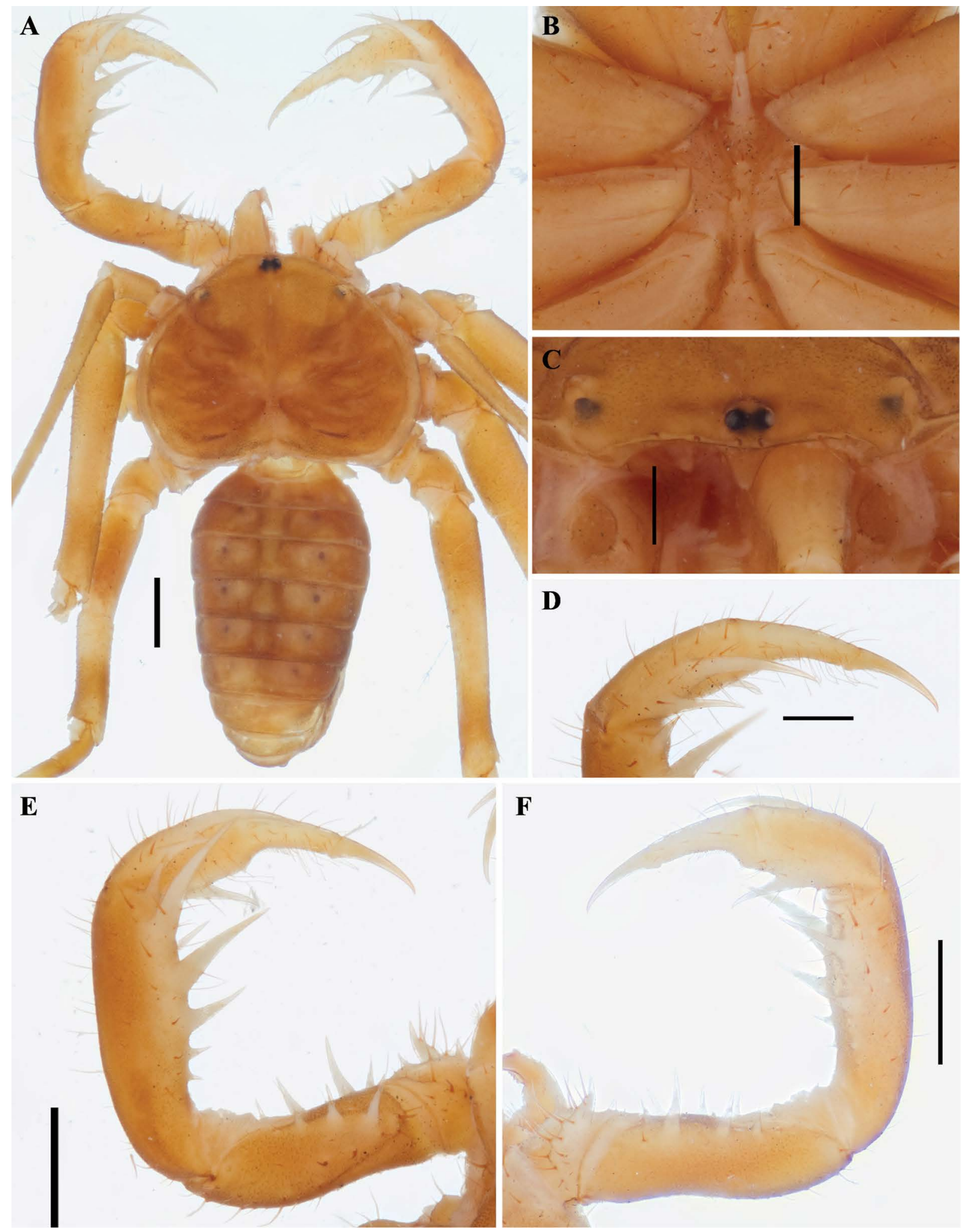

Fig. 117. Sarax lembeh sp. nov. (FMNH 3489485), general morphology, . . A. Habitus, dorsal view. B. Sternum, ventral view. C. Frontal process. D. Pedipalp tarsus, frontal view. E. Pedipalp, dorsal view. F. Pedipalp, ventral view. Scale bars: A, E-F $=1 \mathrm{~mm}$; B-D $=0.5 \mathrm{~mm}$. 


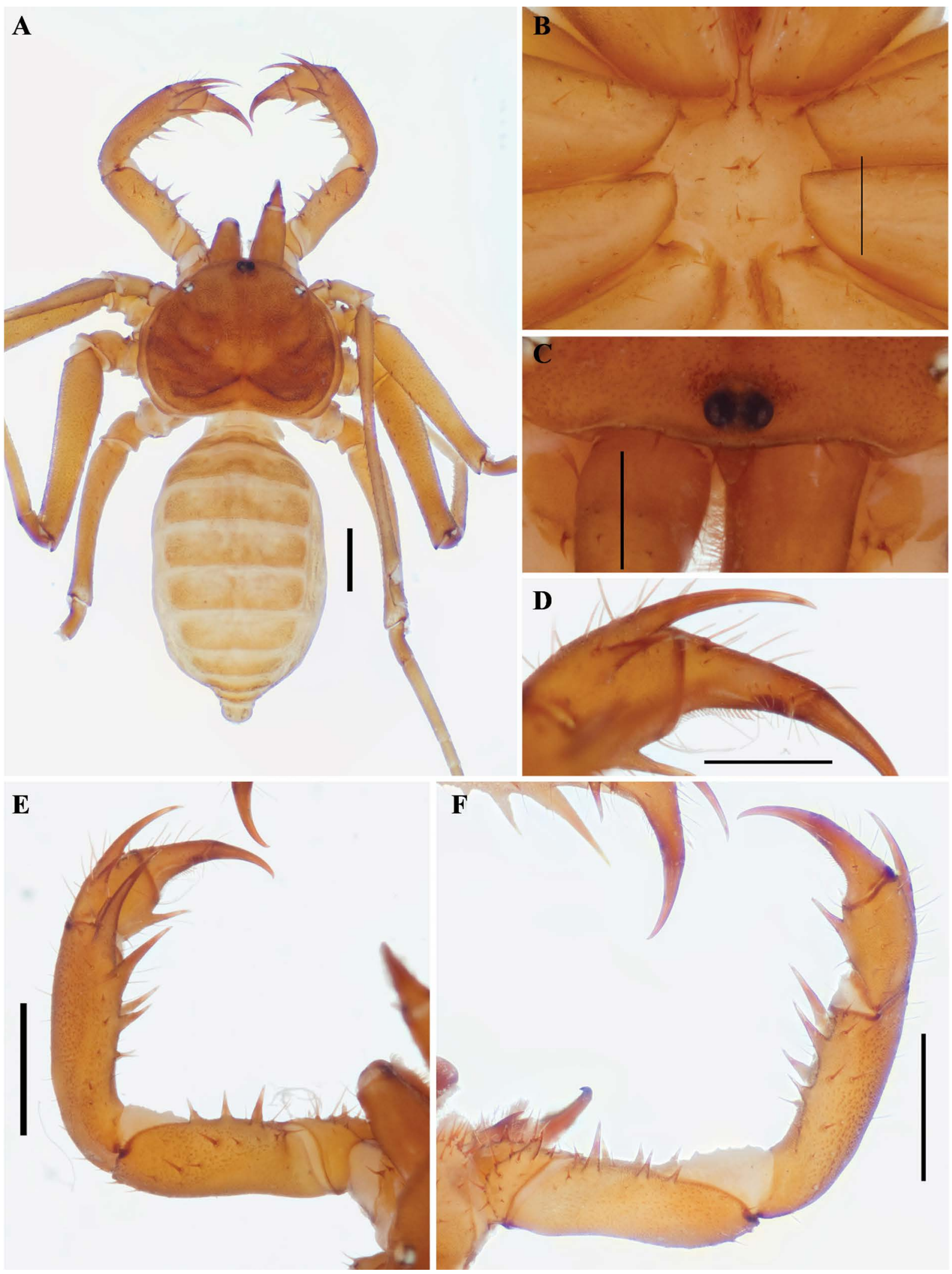

Fig. 118. Sarax palau sp. nov. (FMNH 3489487), general morphology, ${ }^{\circ}$. A. Habitus, dorsal view. B. Sternum, ventral view. C. Frontal process. D. Pedipalp tarsus, frontal view. E. Pedipalp, dorsal view. F. Pedipalp, ventral view. Scale bars: A, E-F $=1 \mathrm{~mm}$; B-D $=0.5 \mathrm{~mm}$. 

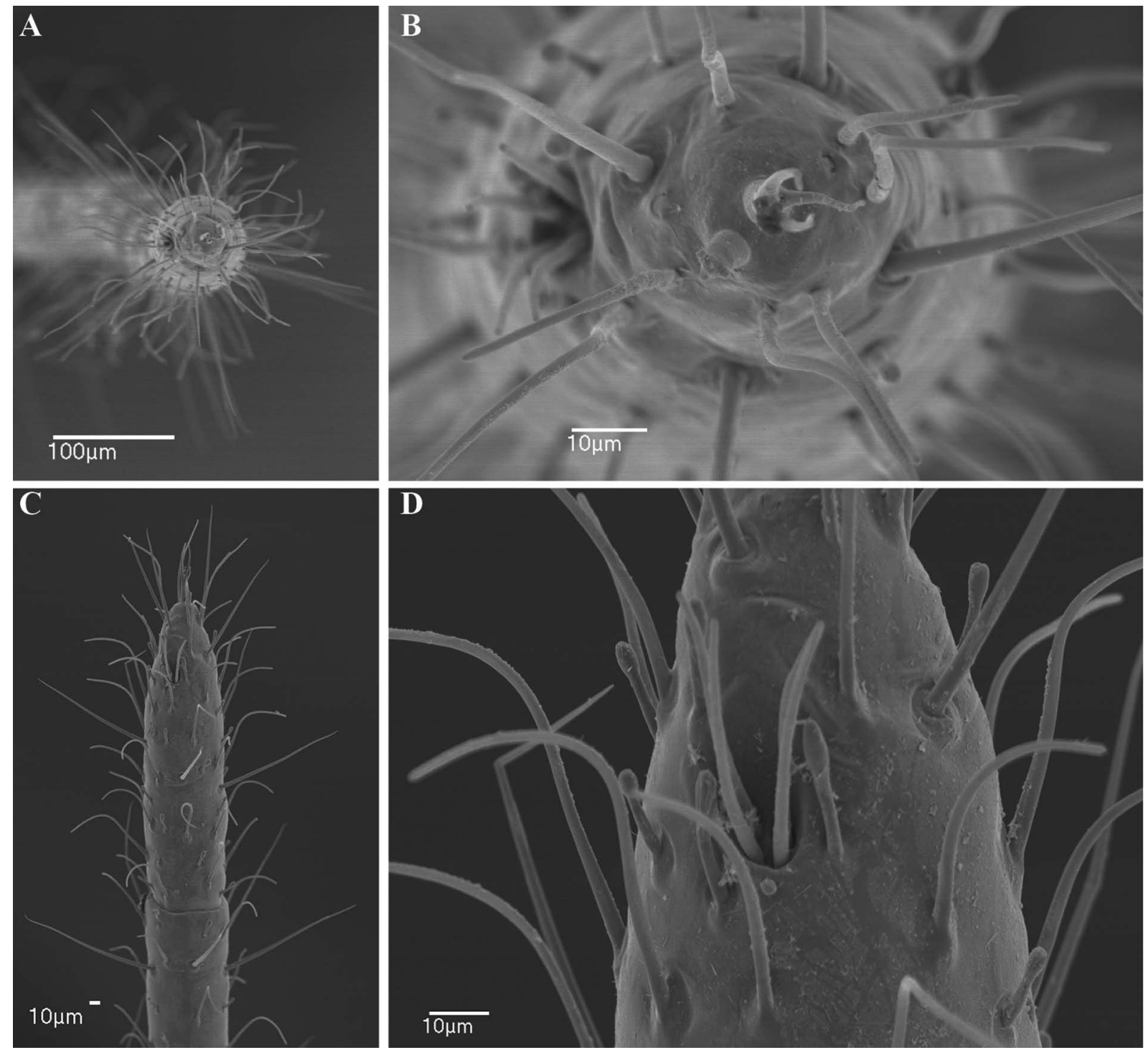

Fig. 119. Sarax palau sp. nov. (FMNH 348988), antenniform leg I, đ̃. A. Apex of distal article of tarsus. B. Distal segment of tarsus, frontal view. C. Leg I showing rod sensilla and olfactory setae, ventral view. D. Rod sensilla and olfactory setae. 

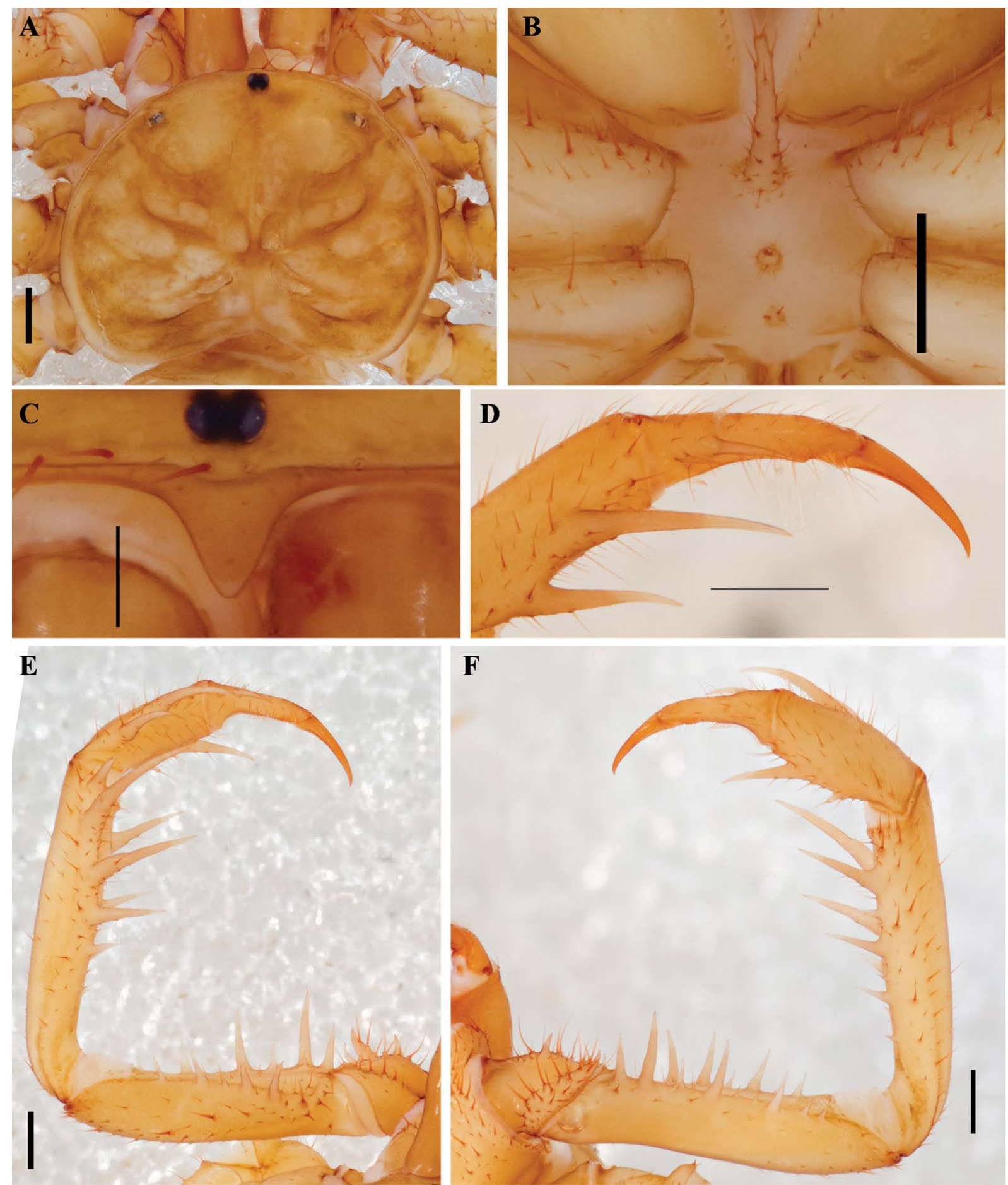

Fig. 120. Sarax rahmadii sp. nov. (WAM T63201), general morphology, ô. A. Carapace, dorsal view. B. Sternum, ventral view. C. Frontal process. D. Pedipalp tarsus, frontal view. E. Pedipalp, dorsal view. F. Pedipalp, ventral view. Scale bars: A-C $=0.5 \mathrm{~mm}$; $-\mathrm{F}=1 \mathrm{~mm}$. 
MIRANDA G.S. et al., Systematic revision of Charinidae (Arachnida, Amblypygi)
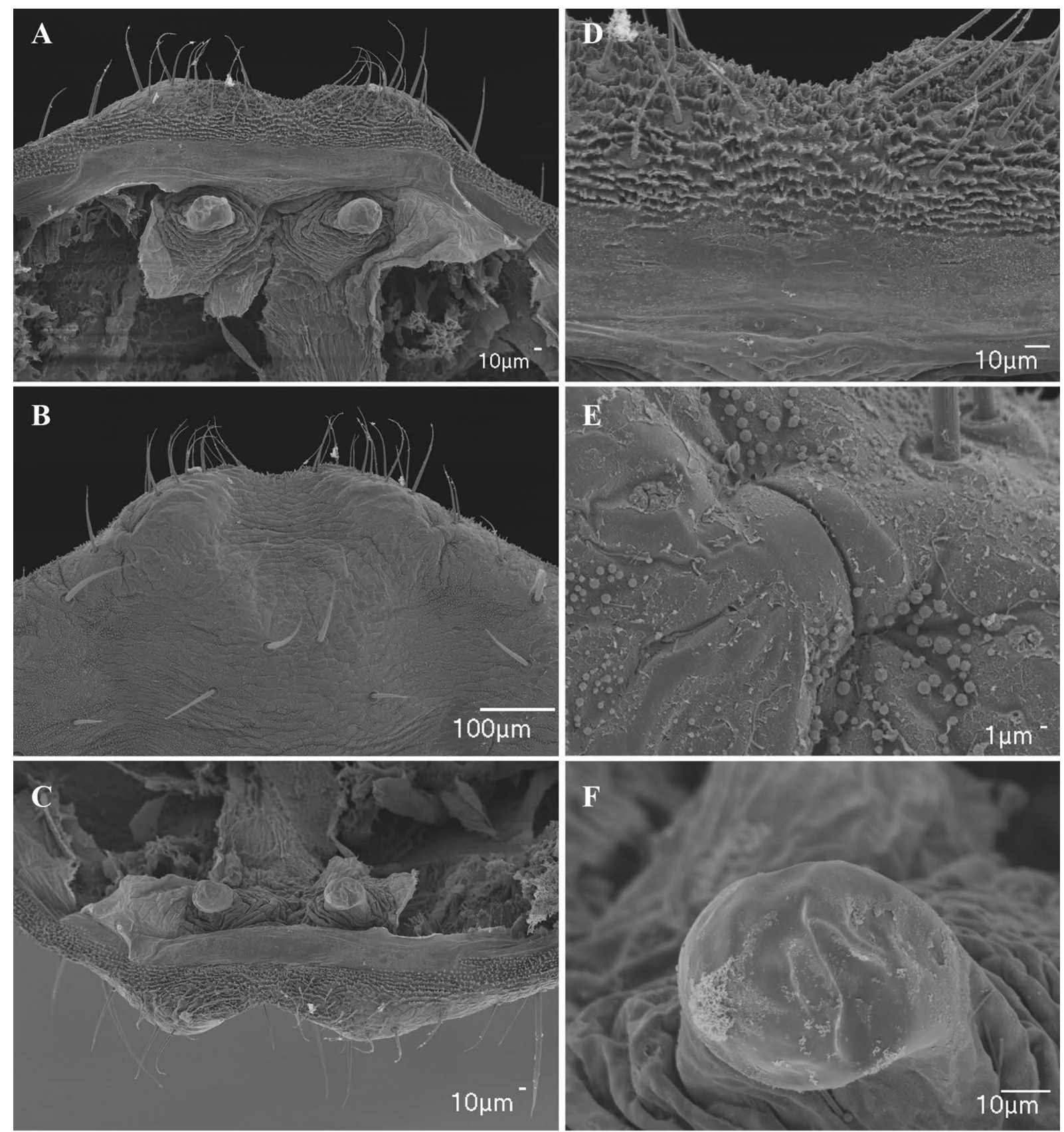

Fig. 121. Sarax rahmadii sp. nov. (WAM T63210), female gonopod and genital operculum. A. Gonopod, dorsal view. B. Genital operculum, ventral view. C. Gonopod and genital operculum, posterior view. D. Posterior margin of genital operculum. E. Gland on genital operculum, ventral view. F. Apex of sinistral gonopod. 

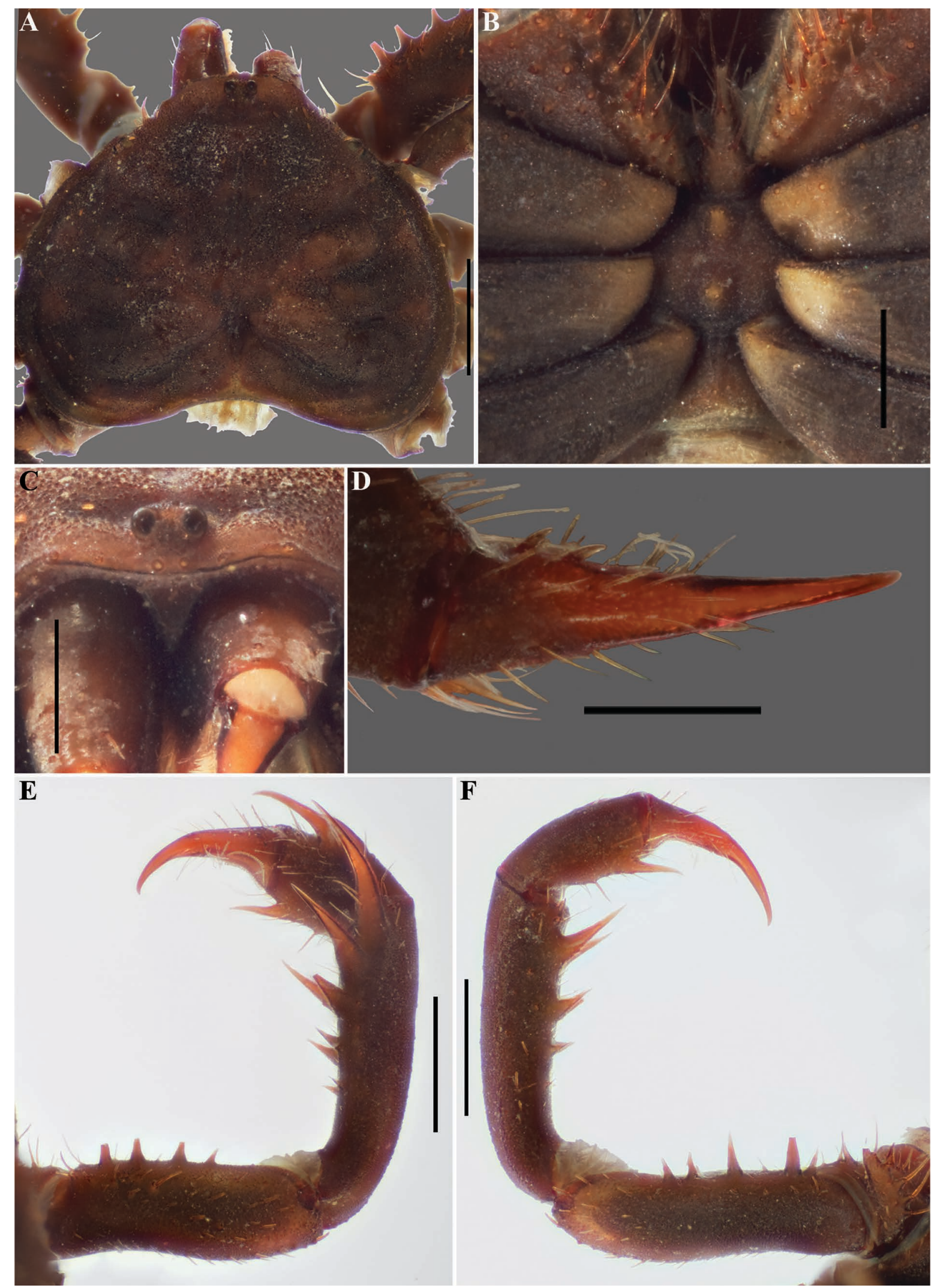

Fig. 122. Sarax rimosus (Simon, 1901) (CUMZ I.48100), general morphology, ․ . A. Carapace, dorsal view. B. Sternum, ventral view. C. Frontal process. D. Pedipalp tarsus, frontal view. E. Pedipalp, dorsal view. F. Pedipalp, ventral view. Scale bars: $\mathrm{A}, \mathrm{E}-\mathrm{F}=1 \mathrm{~mm}$; $\mathrm{B}-\mathrm{D}=0.5 \mathrm{~mm}$. 

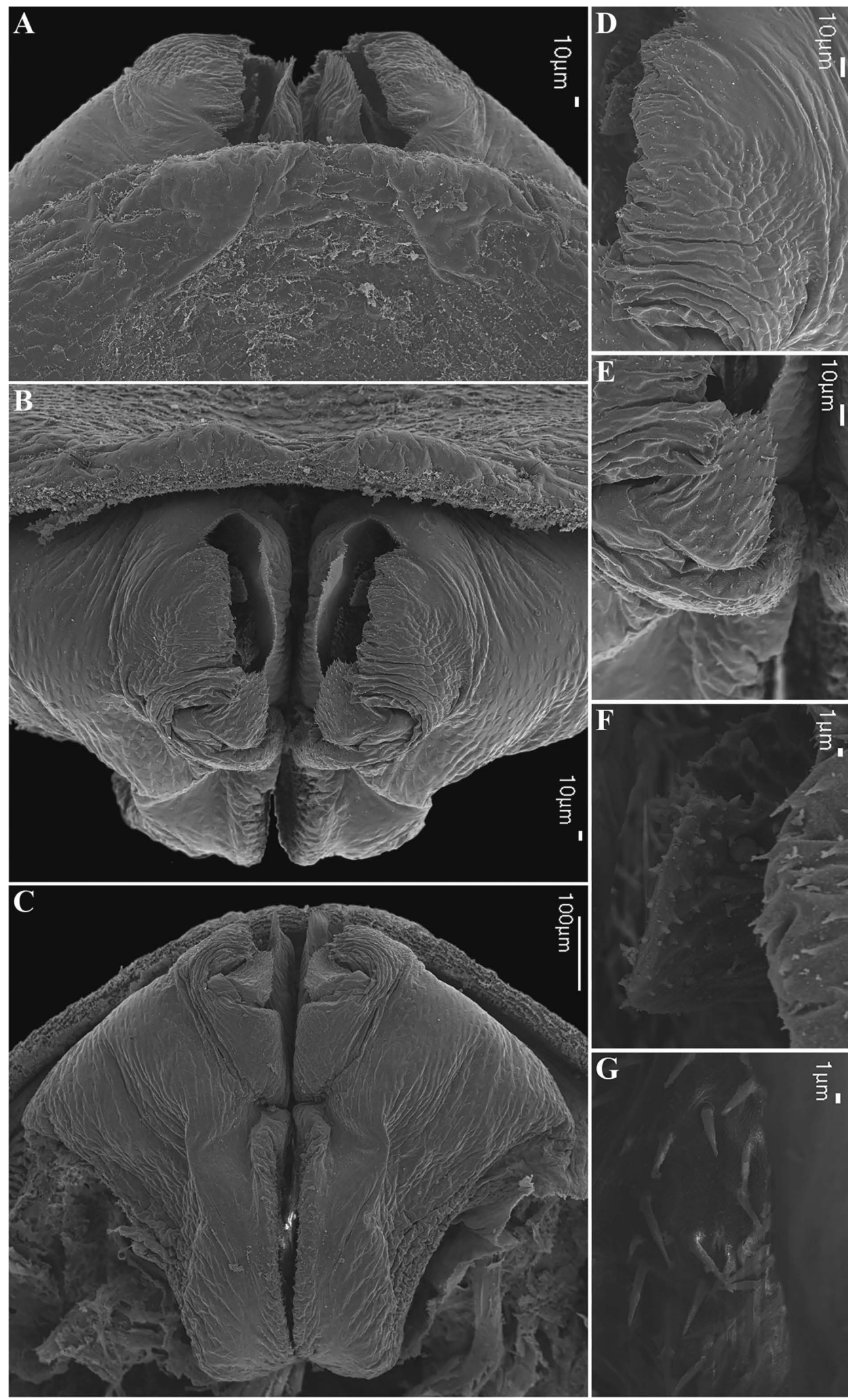

Fig. 123. Sarax rimosus (Simon, 1901) (AMCC [LP 11996]), male gonopod. A. Ventral view. B. Posterior view. C. Dorsal view. D. Dextral side of gonopod. E. Lateral lobe I. F. Processus internus. G. Internal detail of fistula with spiny projections. 


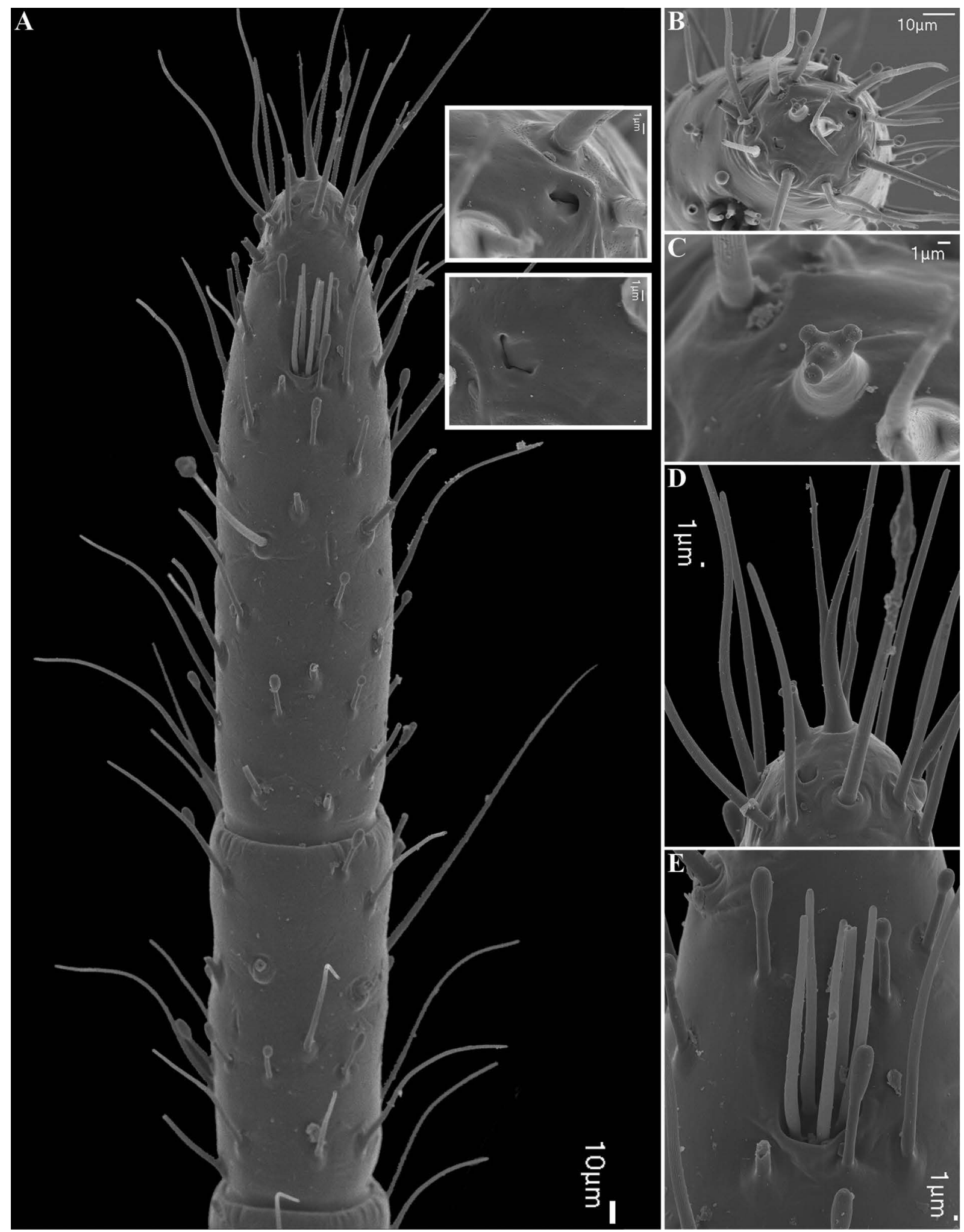

Fig. 124. Sarax rimosus (Simon, 1901) (AMCC [LP 11996]), antenniform leg I, o. A. Distal article of tarsus, lateral view. Insets: slit sensillae. B. Distal article of tarsus, frontal view. C. Tarsal organ near tarsal claw. D. Tarsal claw, lateral view. E. Rod sensilla and olfactory setae. 

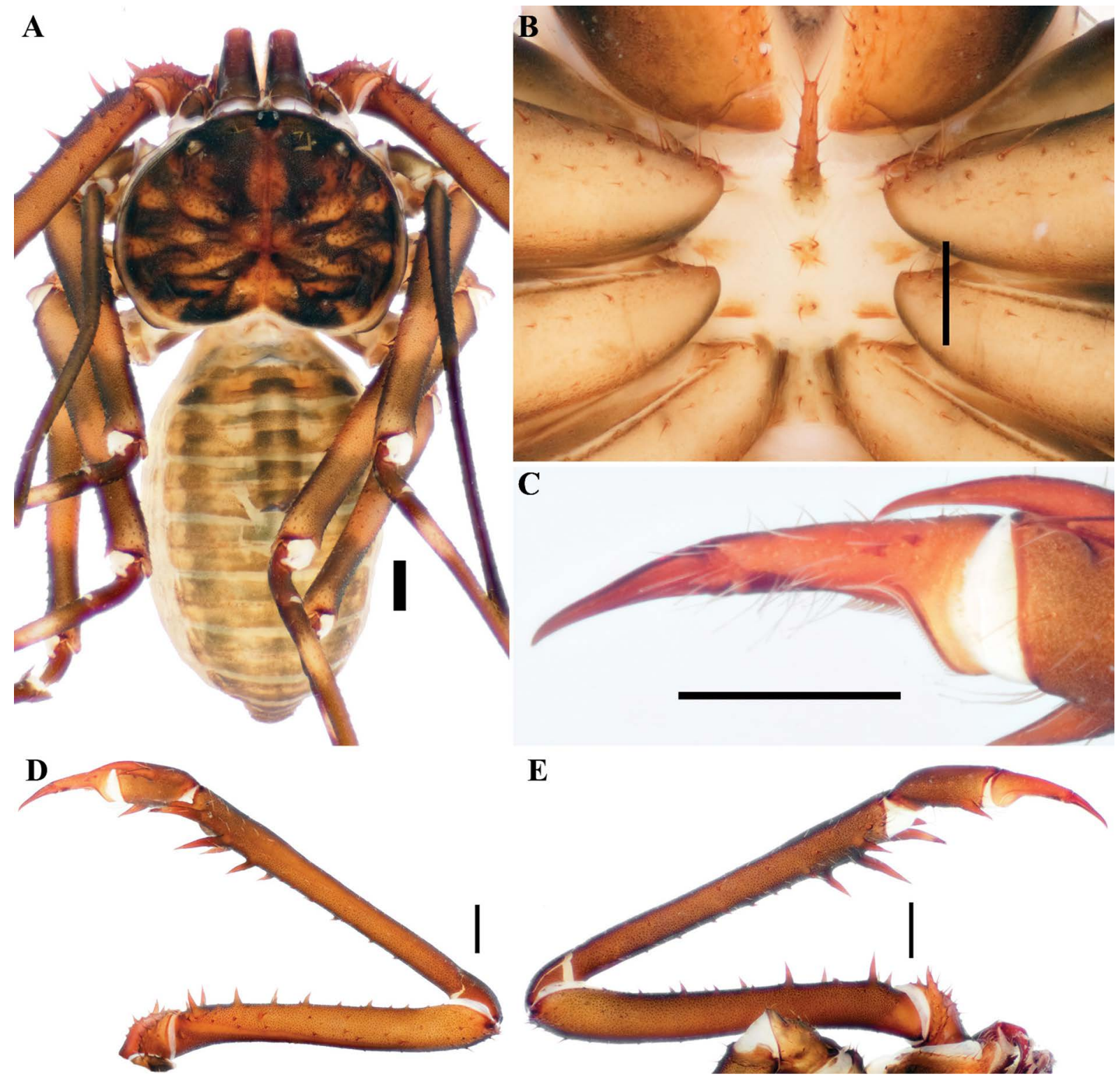

Fig. 125. Sarax sarawakensis (Thorell, 1888) (AMCC [LP 11594]), general morphology, ô. A. Habitus, dorsal view. B. Sternum, ventral view. C. Pedipalp tarsus, frontal view. D. Pedipalp, dorsal view. E. Pedipalp, ventral view. Scale bars: $1 \mathrm{~mm}$. 


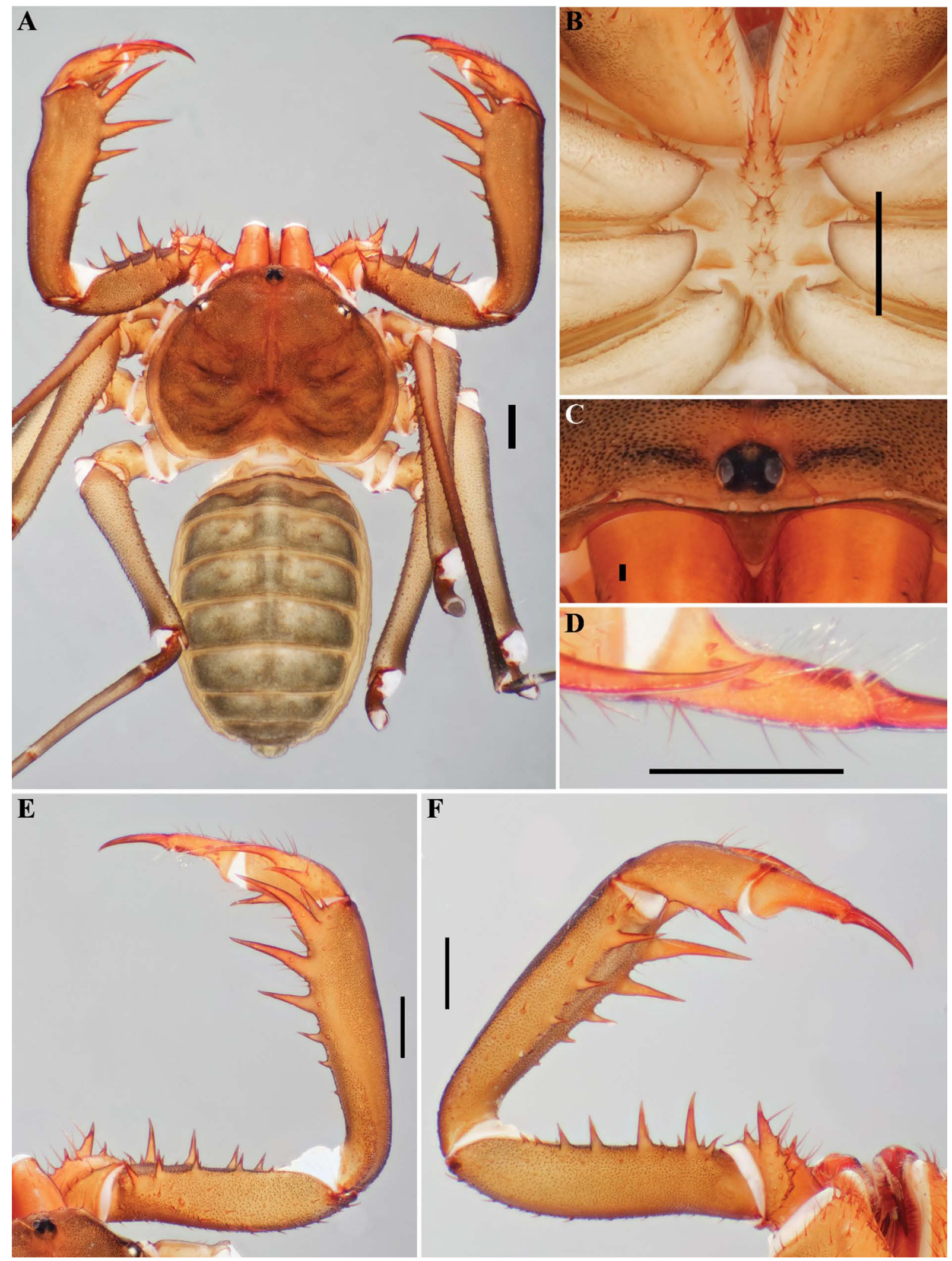

Fig. 126. Sarax tiomanensis sp. nov. (AMCC [LP 12001), general morphology, đ̃. A. Habitus, dorsal view. B. Sternum, ventral view. C. Frontal process. D. Pedipalp tarsus, frontal view. E. Pedipalp, dorsal view. F. Pedipalp, ventral view. Scale bars: A-B, D-F $=1 \mathrm{~mm} ; C=0.1 \mathrm{~mm}$. 


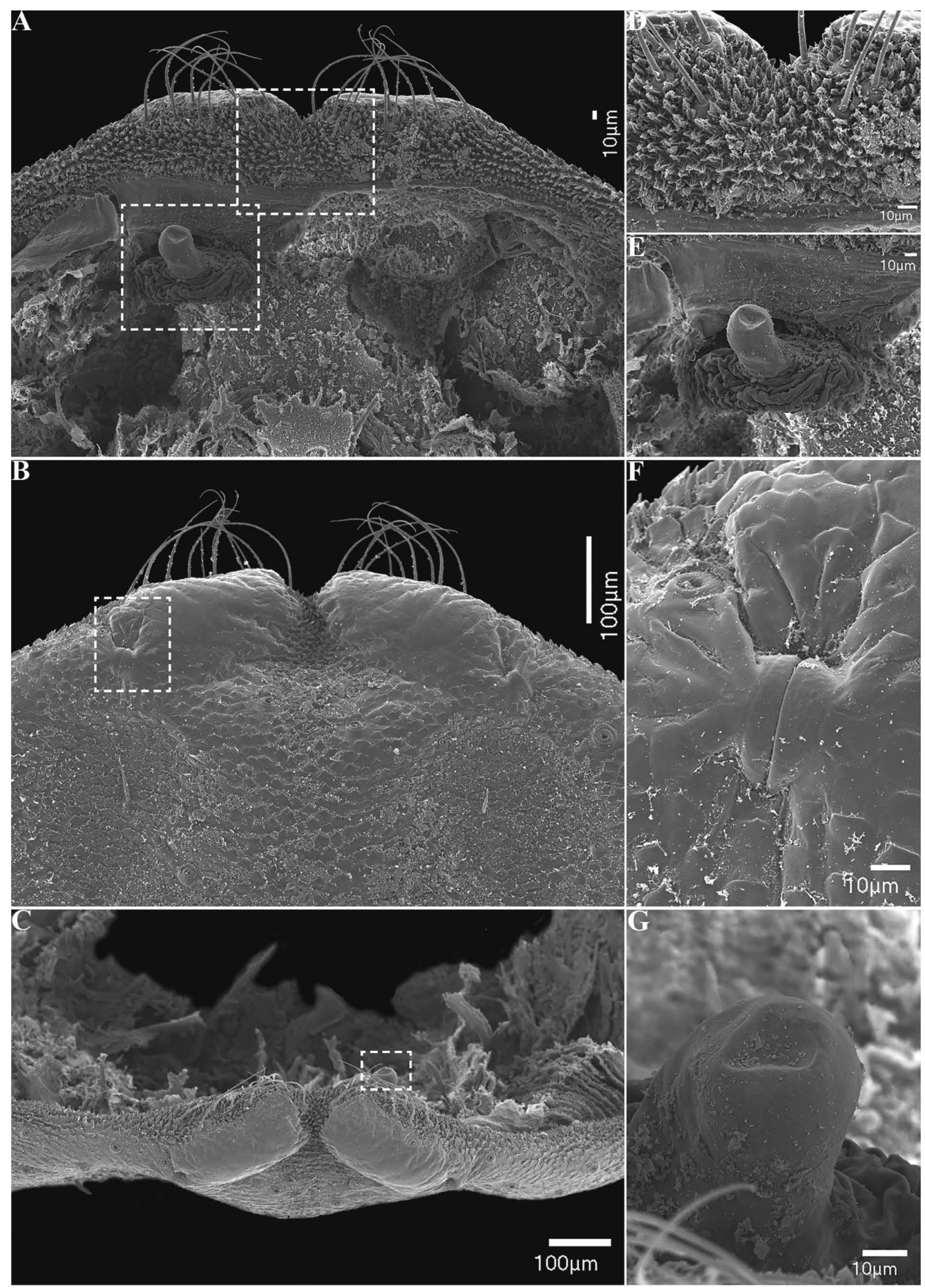

Fig. 127. Sarax tiomanensis sp. nov. (AMCC [LP 11998]), female gonopod and genital operculum. A. Finger-like gonopod, dorsal view. B. Posterior margin of genital operculum, ventral view. C. Gonopods, posterior view. D. Genital operculum between gonopods. E. Glandular openings inside gonopod projection. F. Dextral gonopod. 

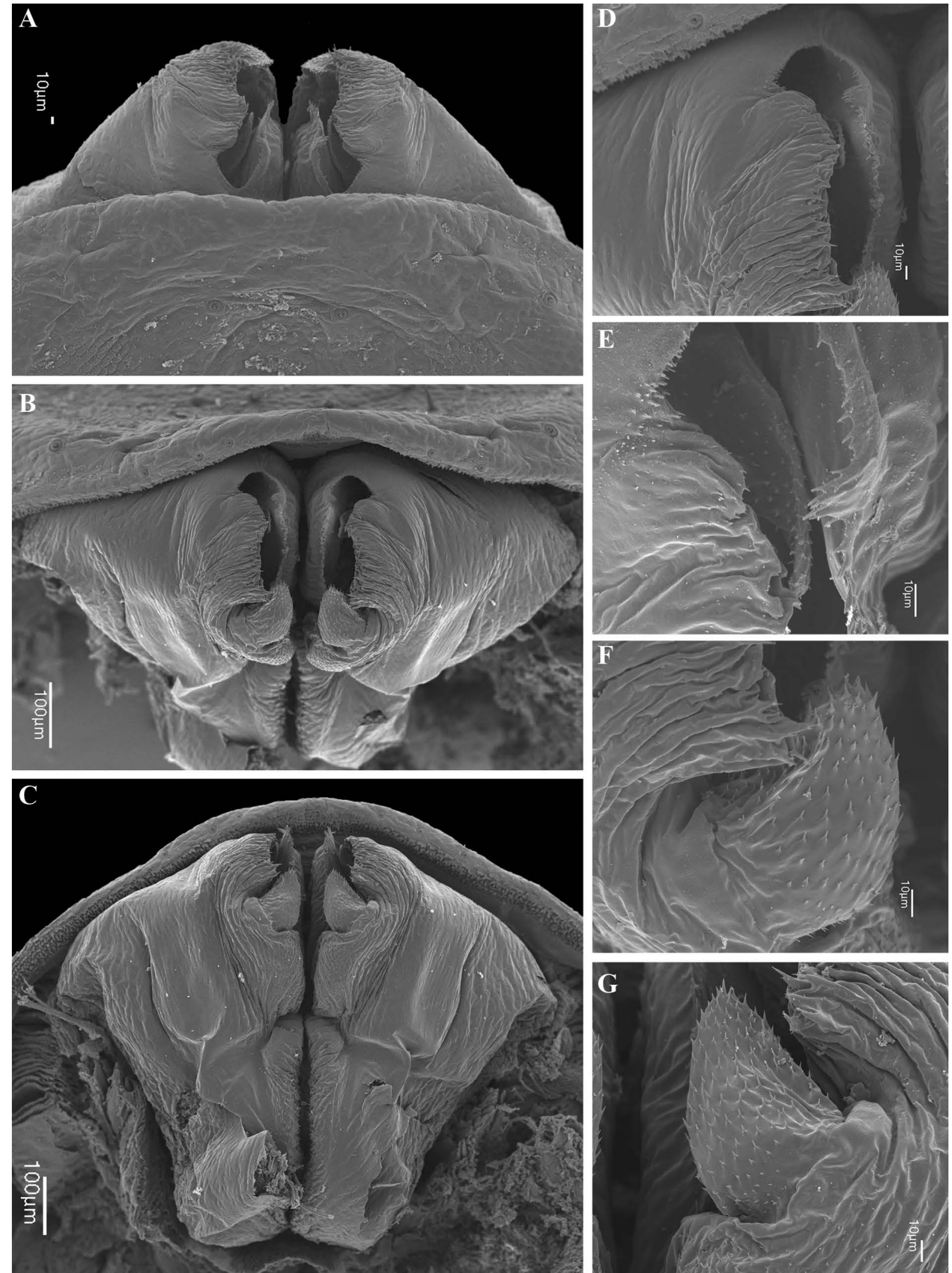

Fig. 128. Sarax tiomanensis sp. nov. (AMCC [LP 11998]), male gonopod. A. Ventral view. B. Posterior view. C. Dorsal view. D. Sinistral side of gonopod. E. Lateral lobe 2, processus internus and lamina medialis. F. Lateral lobe 2 and dorsal lobe. G. Dorsal lobe. 

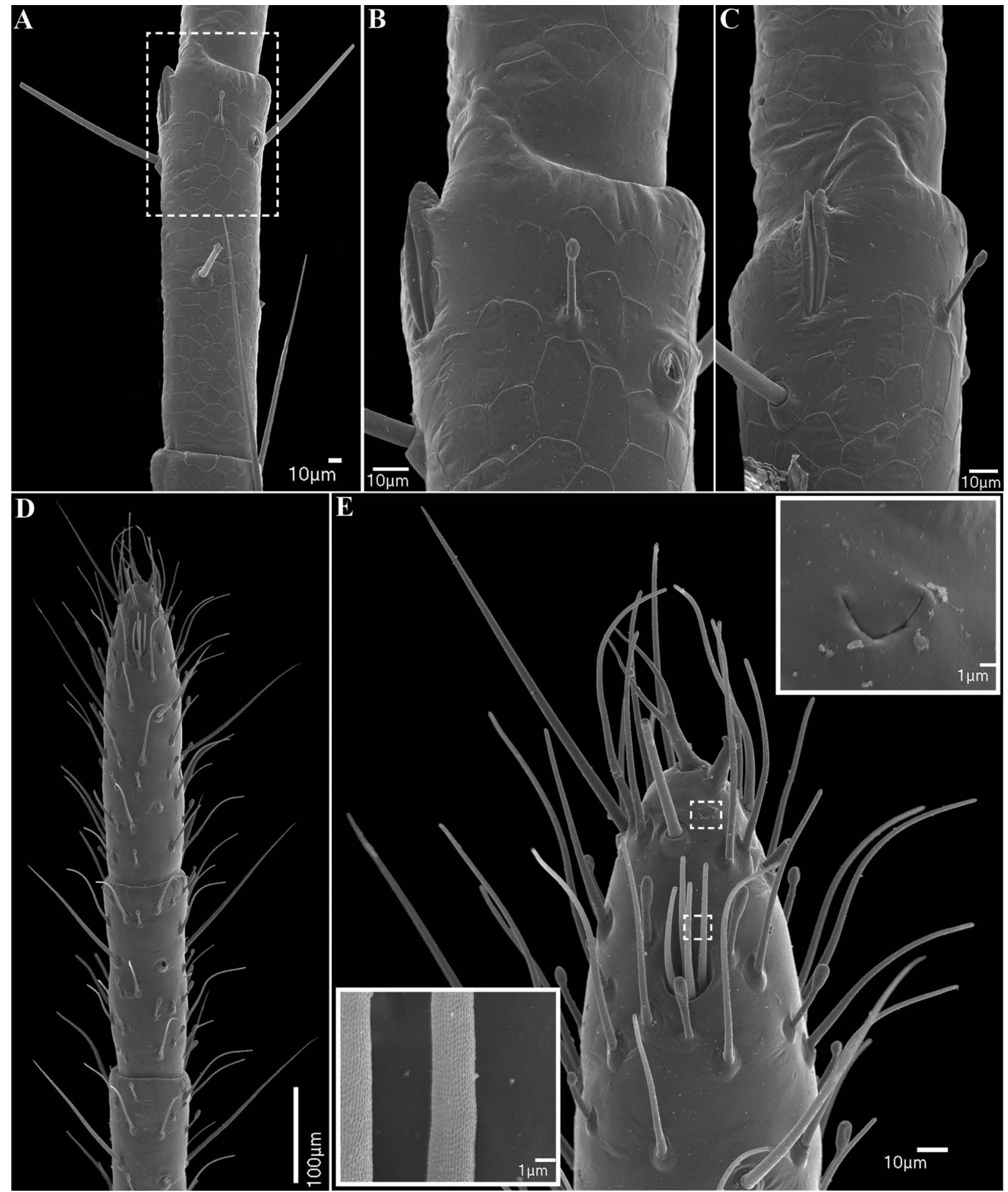

Fig. 129. Sarax tiomanensis sp. nov. (AMCC [LP 11998]), antenniform leg I, $q$. A. Tarsal article 19 with projected slit sensilla. B. Slit sensilla on tarsal article 19. C. Slit sensilla on tarsal article 19, frontal view. D. Apex of distal article of tarsus. E. Distal article of tarsus showing rod sensilla, modified claw and tarsal organ. Upper inset: slit sensilla near base of tarsal organ. Lower inset: olfactory setae. 

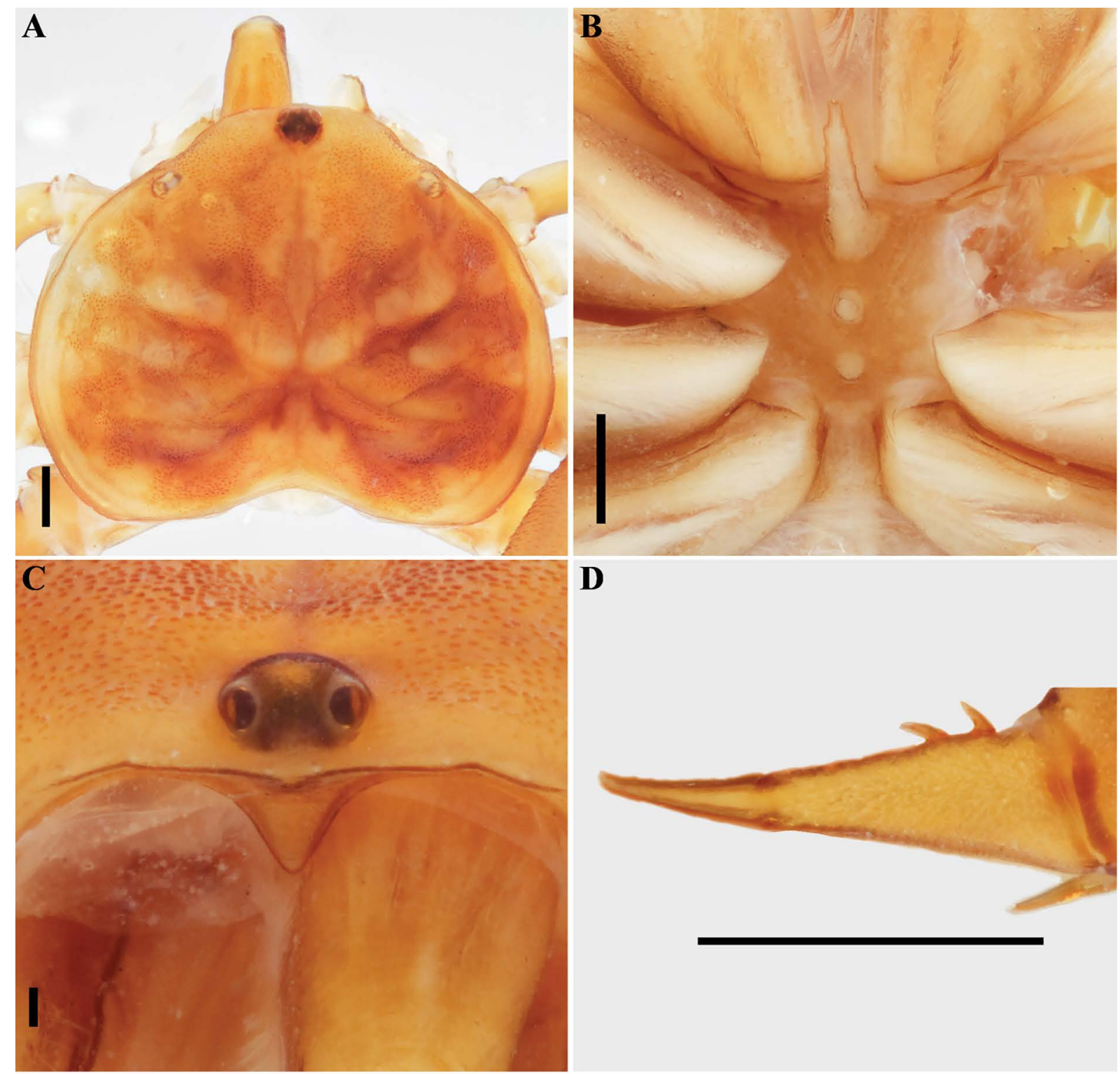

D
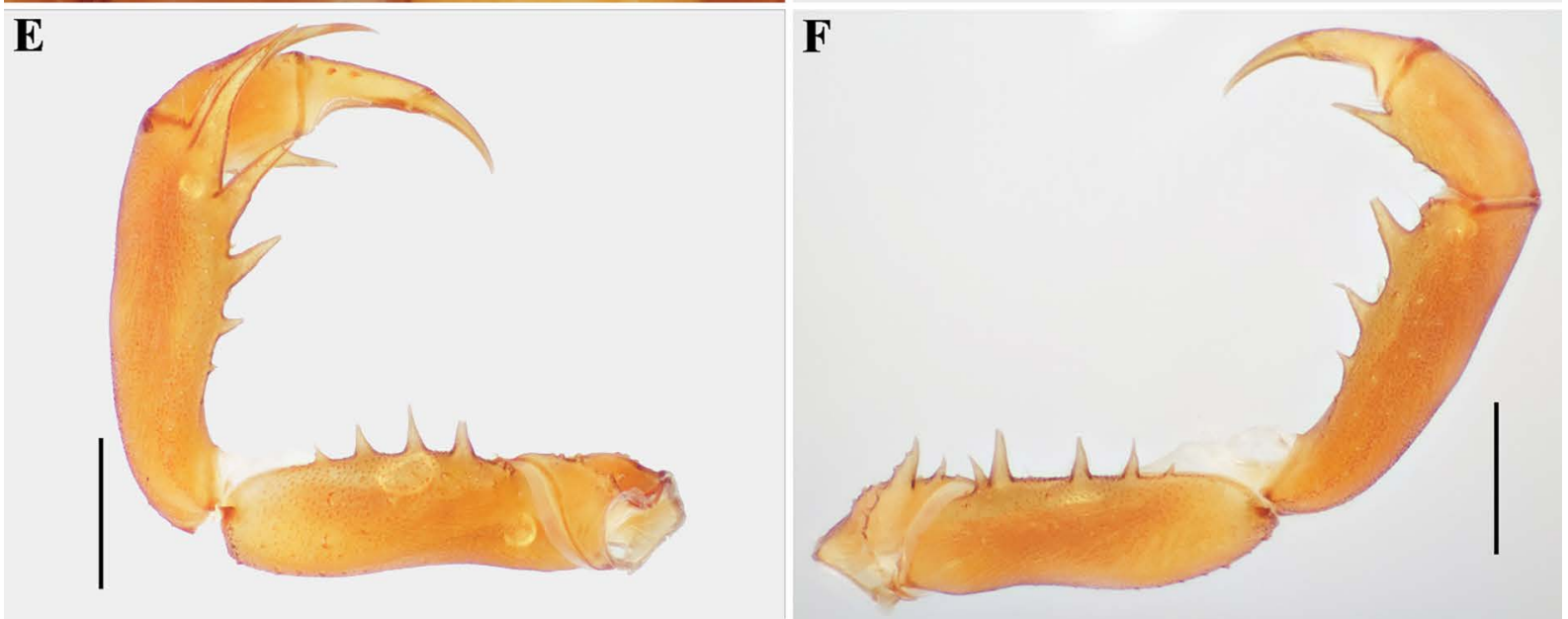

Fig. 130. Sarax willeyi Gravely, 1915 (SMF), general morphology, $q$. A. Carapace, dorsal view. B. Sternum, ventral view. C. Frontal process. D. Pedipalp tarsus, frontal view. E. Pedipalp, dorsal view. F. Pedipalp, ventral view. Scale bars: $A-B=0.5 \mathrm{~mm} ; C=0.1 \mathrm{~mm} ; \mathrm{D}-\mathrm{F}=1 \mathrm{~mm}$. 

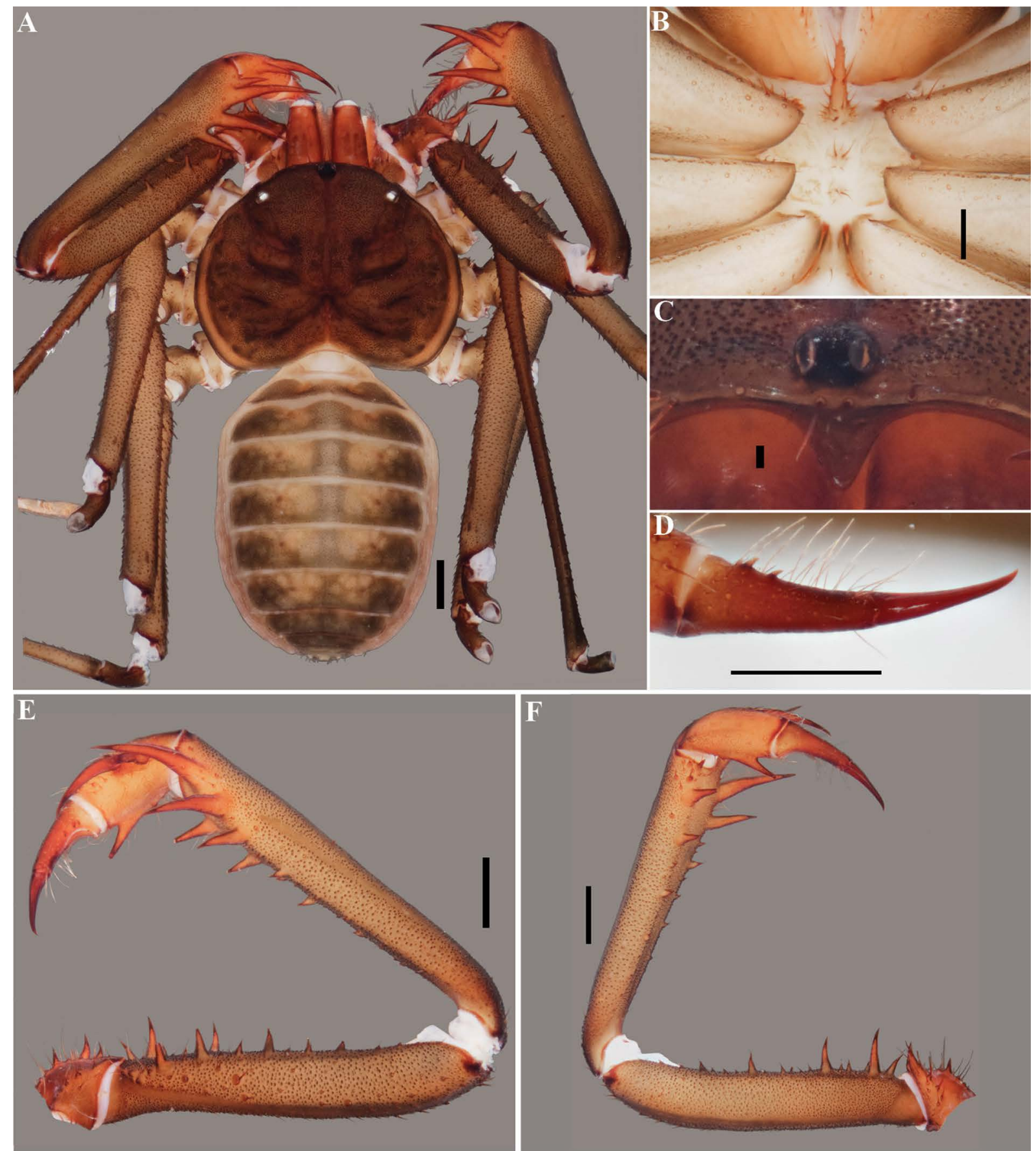

Fig. 131. Sarax yayukae Rahmadi, Harvey \& Kojima, 2010 (AMCC [LP 12109]), general morphology, ${ }^{\lambda}$. A. Habitus, dorsal view. B. Sternum, ventral view. C. Frontal process. D. Pedipalp tarsus, frontal view. E. Pedipalp, dorsal view. F. Pedipalp, ventral view. Scale bars: A-B, E-F $=1 \mathrm{~mm} ; \mathrm{C}=0.1 \mathrm{~mm}$; $\mathrm{D}=1 \mathrm{~mm}$. 

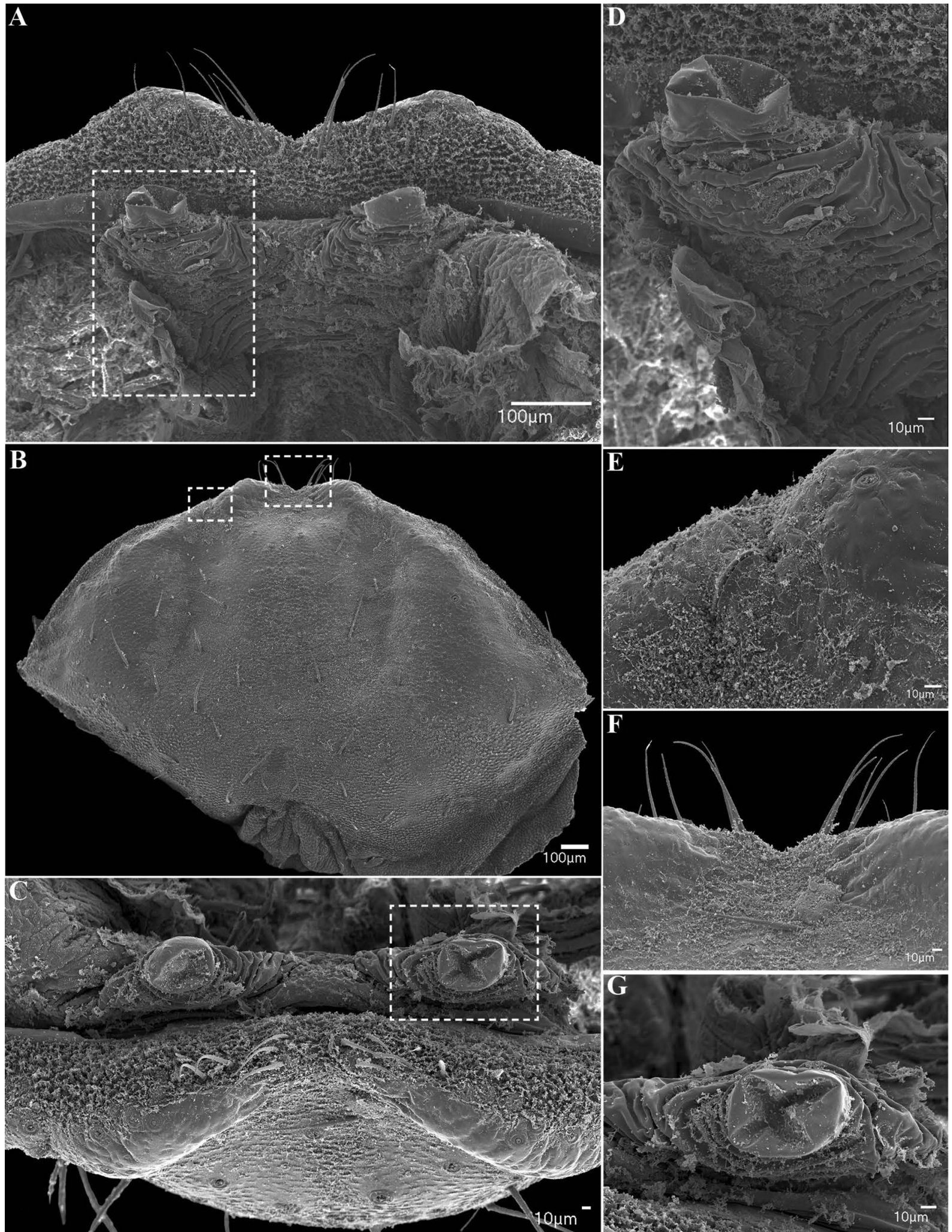

Fig. 132. Sarax yayukae Rahmadi, Harvey \& Kojima, 2010 (AMCC [LP 12109]), female gonopod and genital operculum. A. Plunger-like gonopod, dorsal view. B. Posterior margin of genital operculum, ventral view. C. Gonopods, posterior view. D. Sinistral gonopod. F. Glandular openings on margin of genital operculum. G. Genital operculum between gonopods. G. Sinistral gonopod, posterior view. 


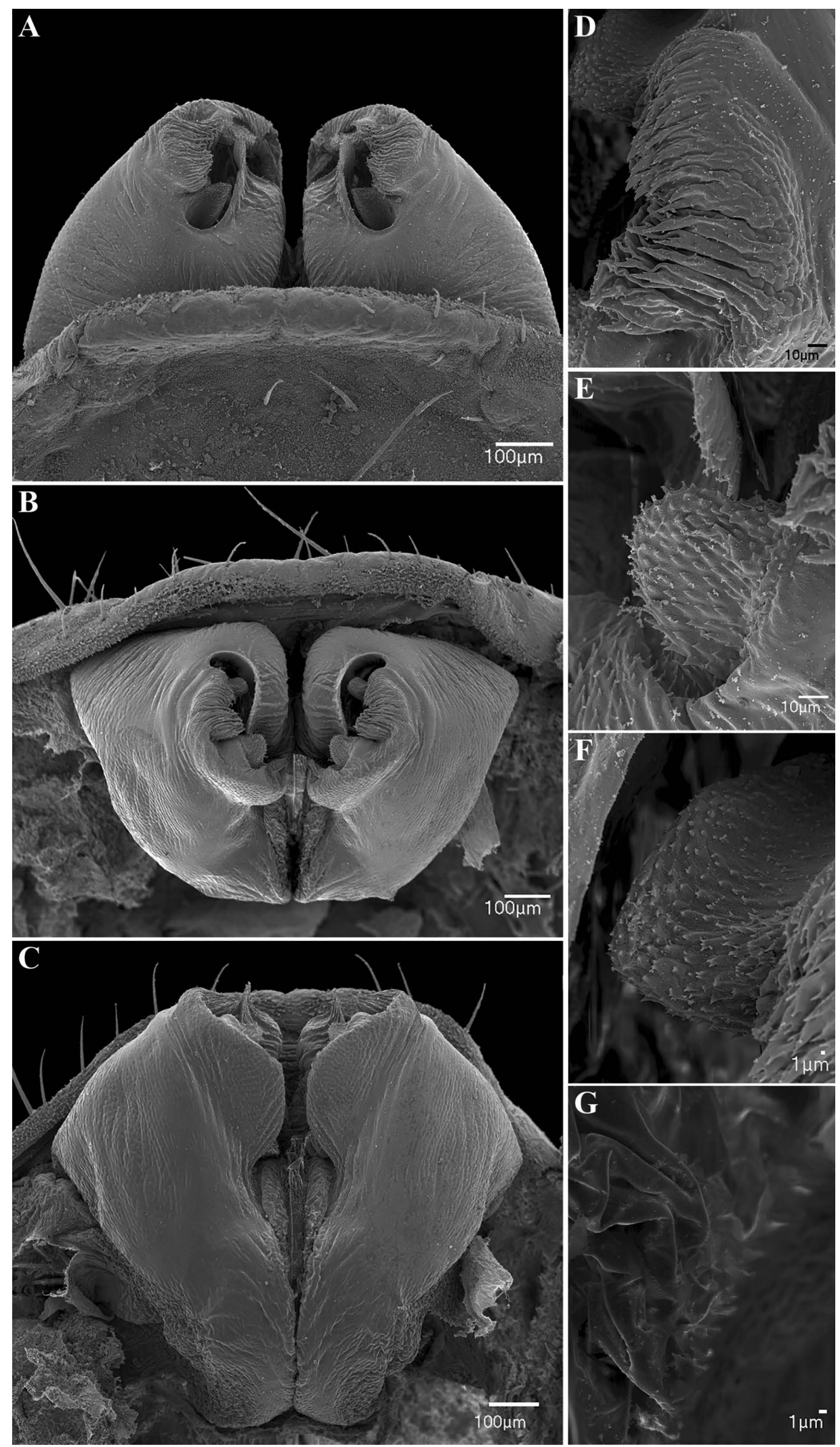

Fig. 133. Sarax yayukae Rahmadi, Harvey \& Kojima, 2010 (AMCC [LP 12109]), male gonopod. A. Ventral view. B. Posterior view. C. Dorsal view. D. Sinistral side of gonopod. E. Dorsal lobe. F. Processus internus. G. Internal region of fistula without spiny projections. 

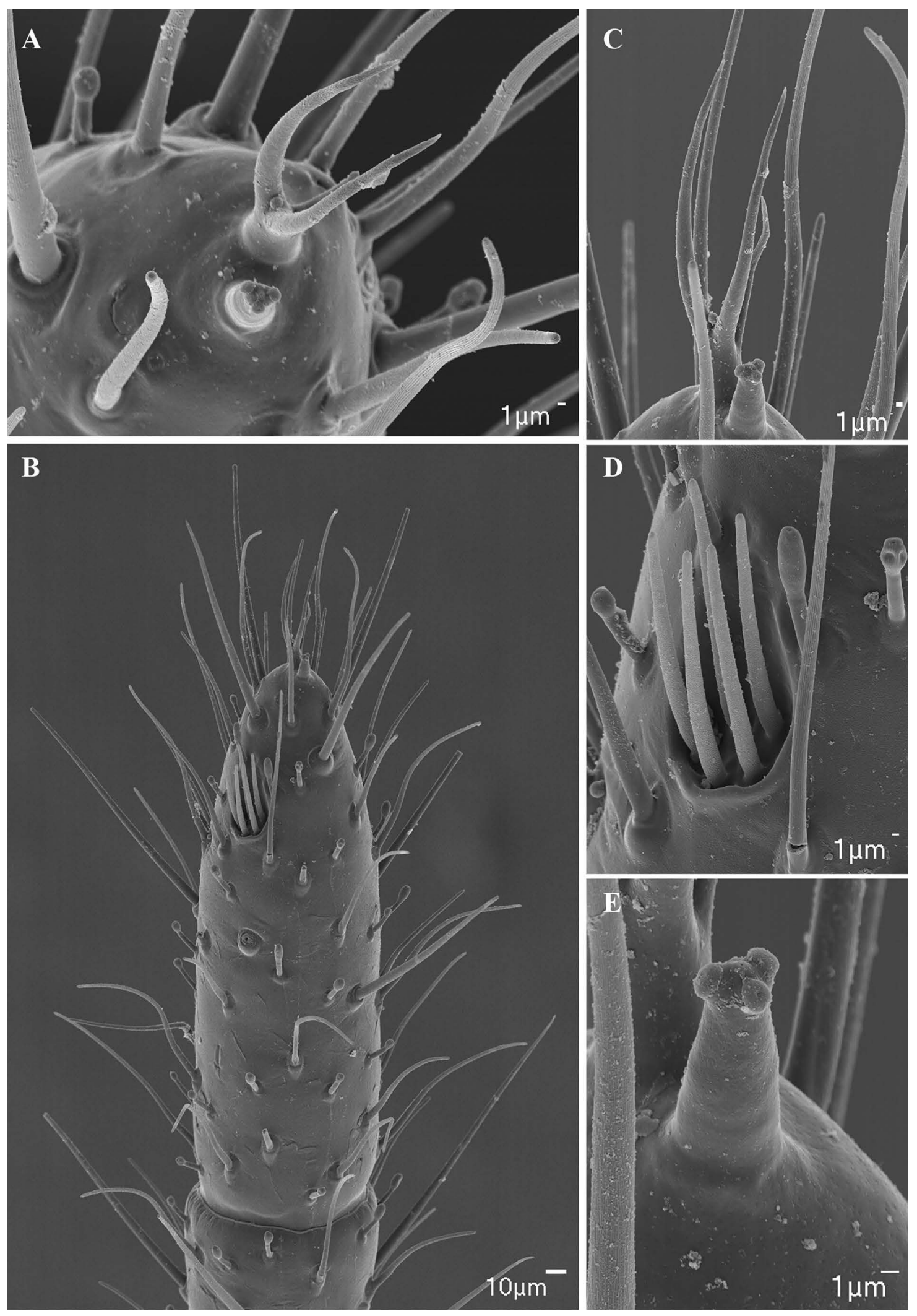

Fig. 134. Sarax yayukae Rahmadi, Harvey \& Kojima, 2010 (AMCC [LP 12109]), antenniform leg I, స. A. Apex of distal article. B. Distal segment of tarsus, lateral view. C. Apex of distal article of tarsus showing claw and tarsal organ. D. Rod sensilla and olfactory setae. E. Detail of tarsal organ. 
MIRANDA G.S. et al., Systematic revision of Charinidae (Arachnida, Amblypygi)

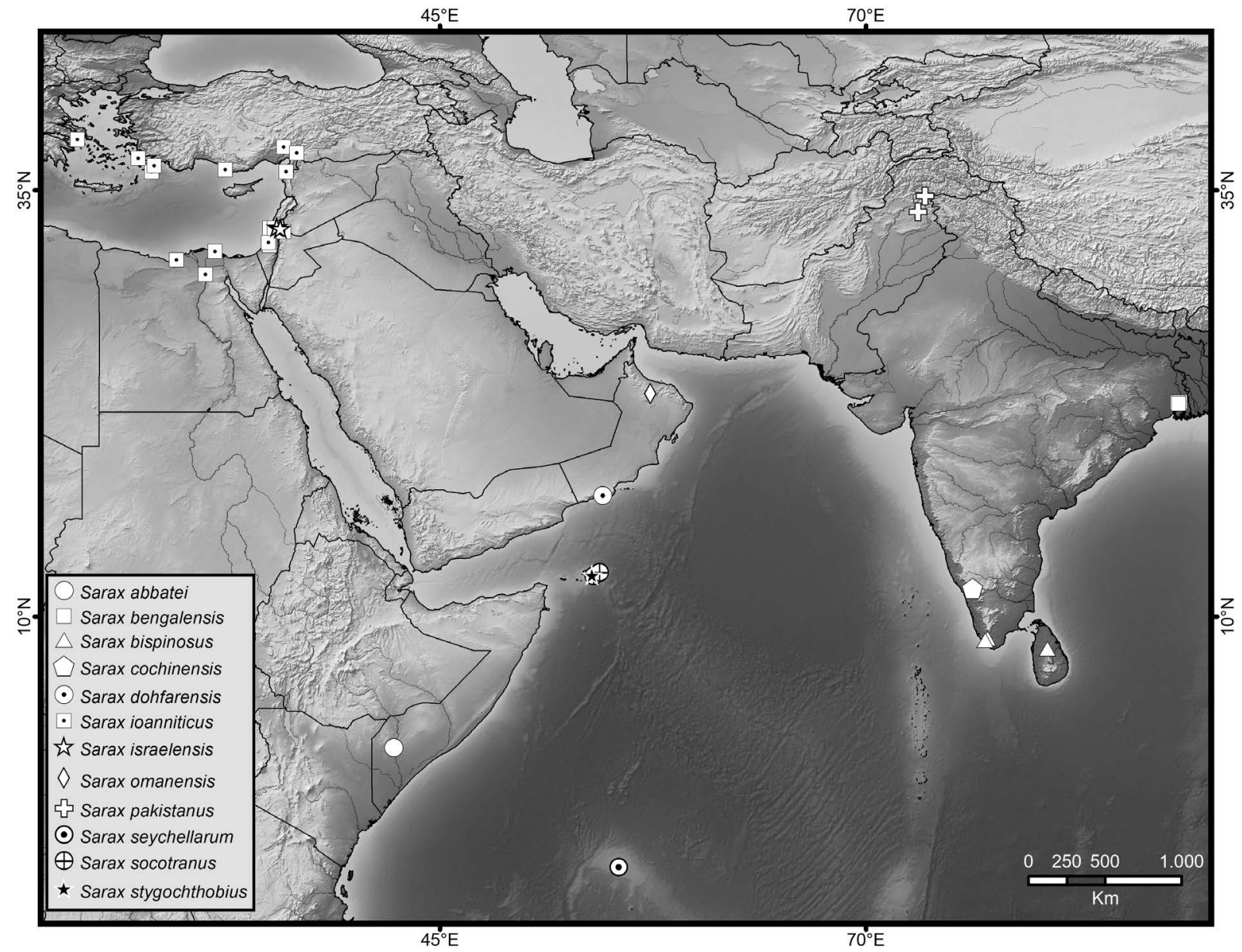

Fig. 135. Map plotting known distributions of species of Sarax Simon, 1892 in Africa, the Middle East and South Asia. 


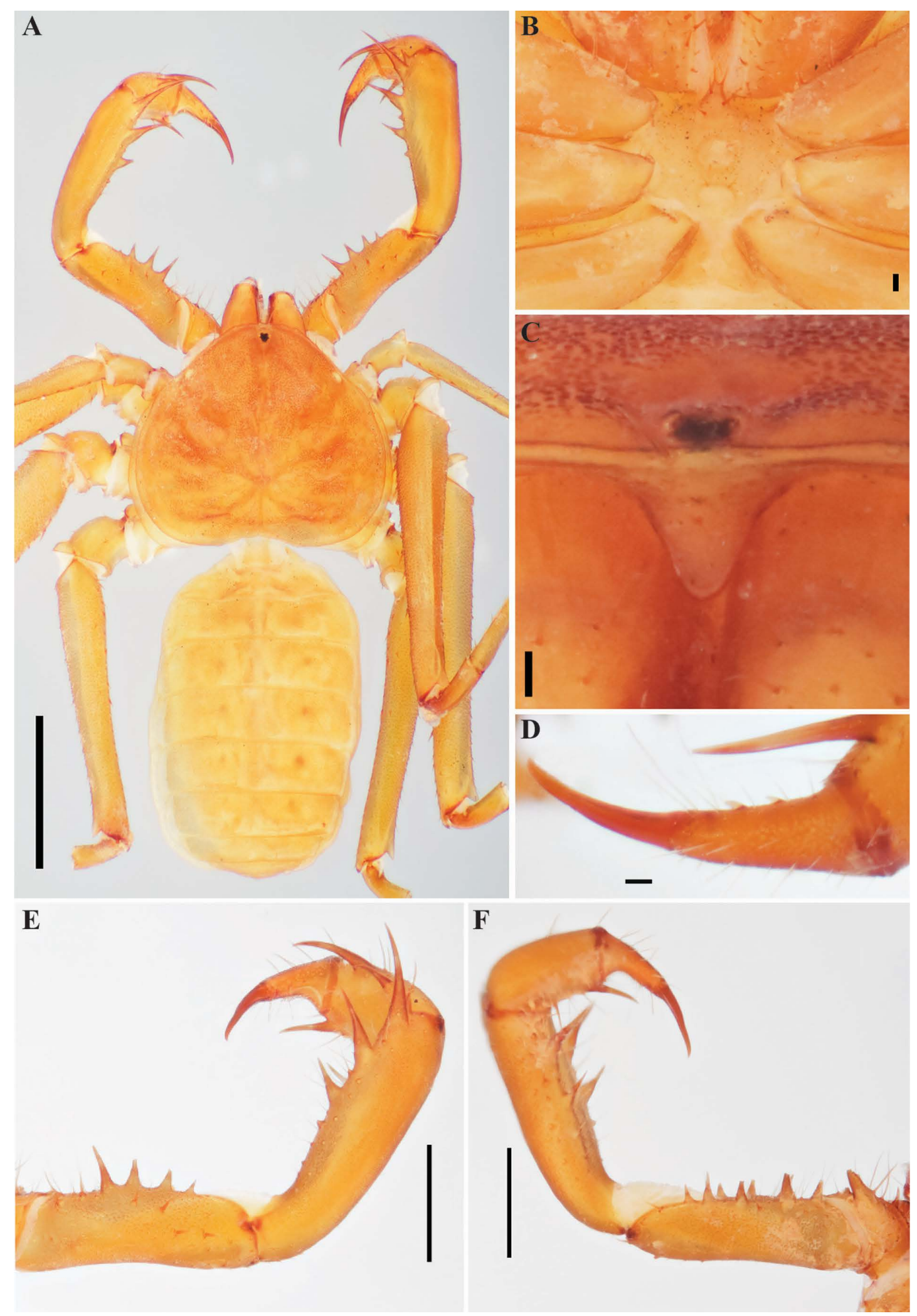

Fig. 136. Sarax abbatei (Delle Cave, 1986) comb. nov. (MZUF 1896-167), general morphology, . A. Habitus, dorsal view. B. Sternum, ventral view. C. Frontal process. D. Pedipalp tarsus, frontal view. E. Pedipalp, dorsal view. F. Pedipalp, ventral view. Scale bars: A, E-F $=1 \mathrm{~mm}$; B-D $=0.1 \mathrm{~mm}$. 
A

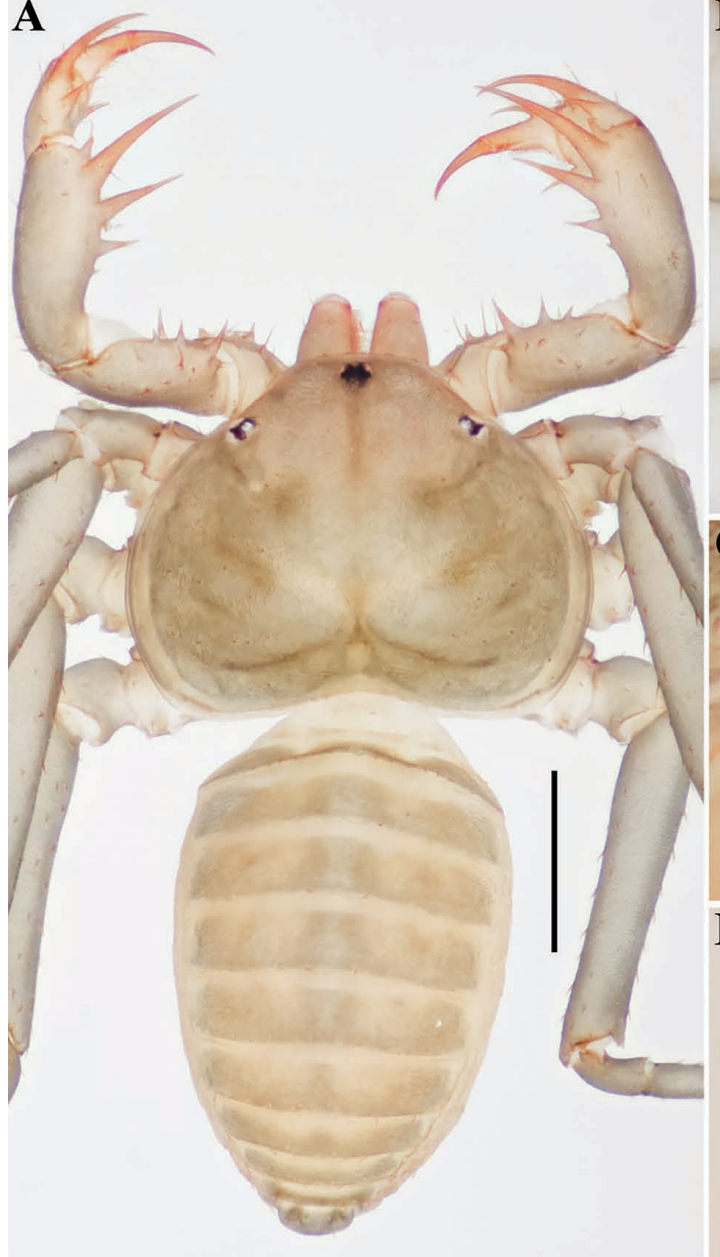

$\mathbf{E}$

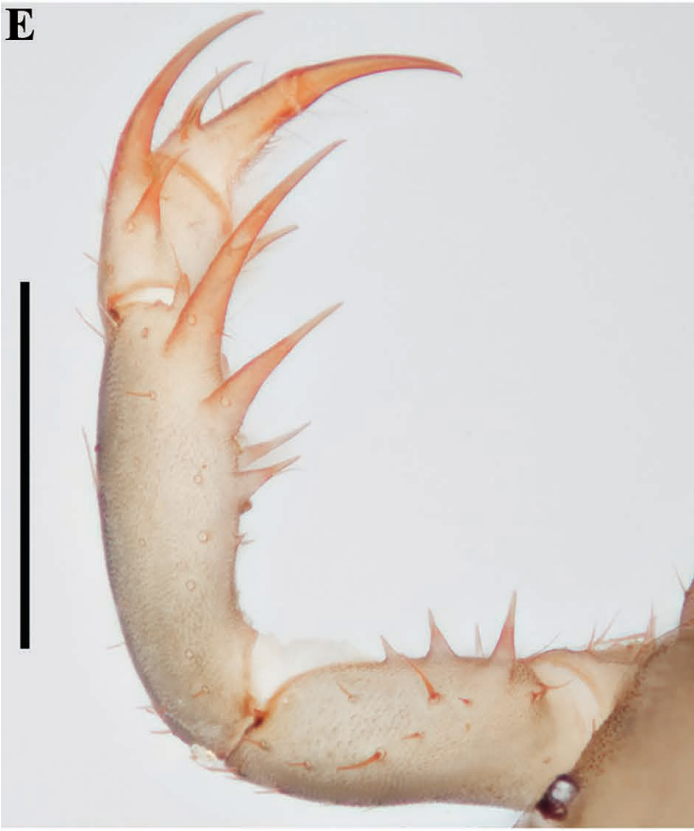

B

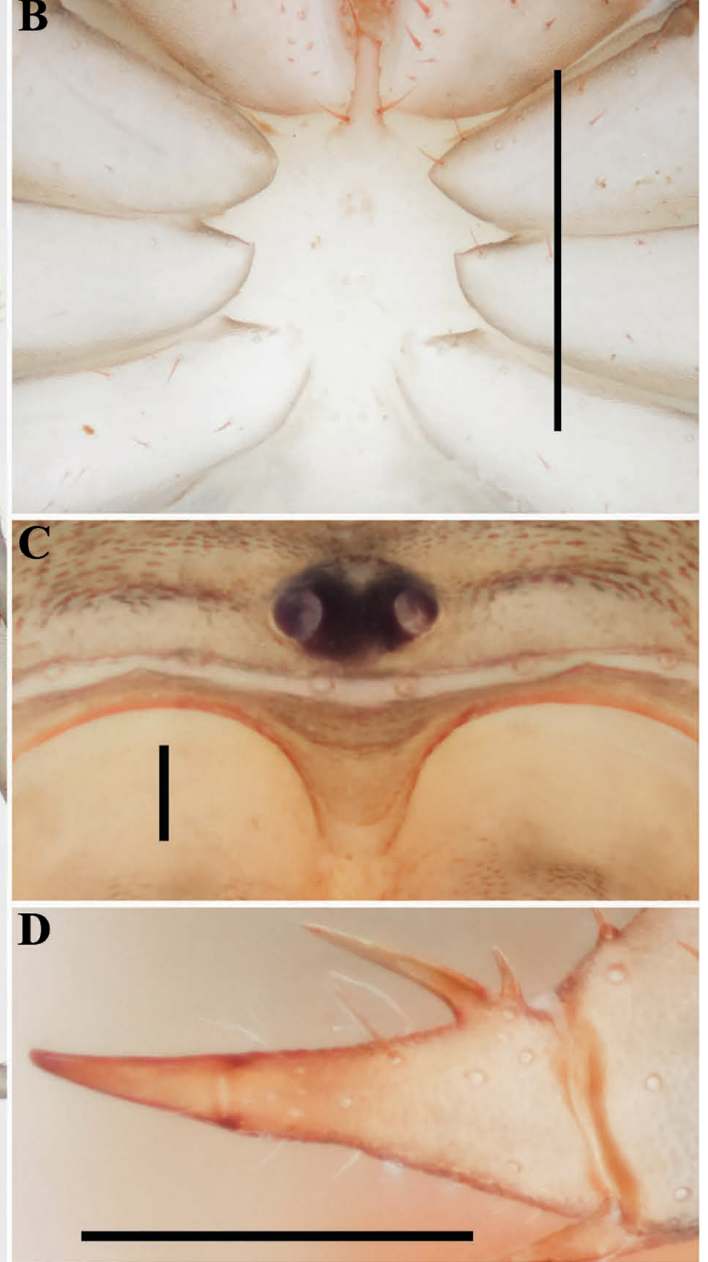

$\mathbf{F}$

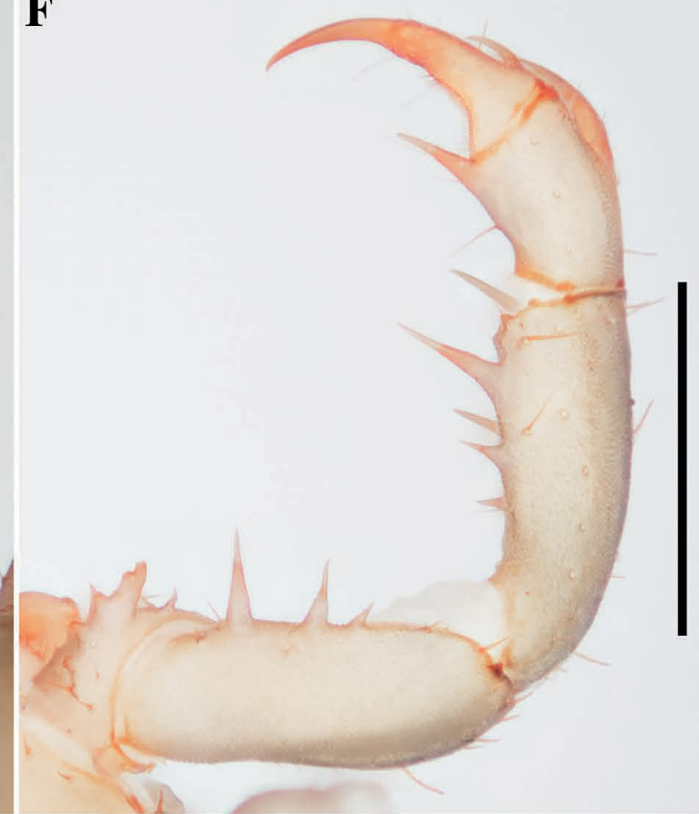

Fig. 137. Sarax bispinosus (Nair, 1934) (AMCC [LP 12298]), general morphology, §ิ. A. Habitus, dorsal view. B. Sternum, ventral view. C. Frontal process. D. Pedipalp tarsus, frontal view. E. Pedipalp, dorsal view. F. Pedipalp, ventral view. Scale bars: A-B, E-F $=1 \mathrm{~mm} ; \mathrm{C}=0.1 \mathrm{~mm} ; \mathrm{D}=0.5 \mathrm{~mm}$. 

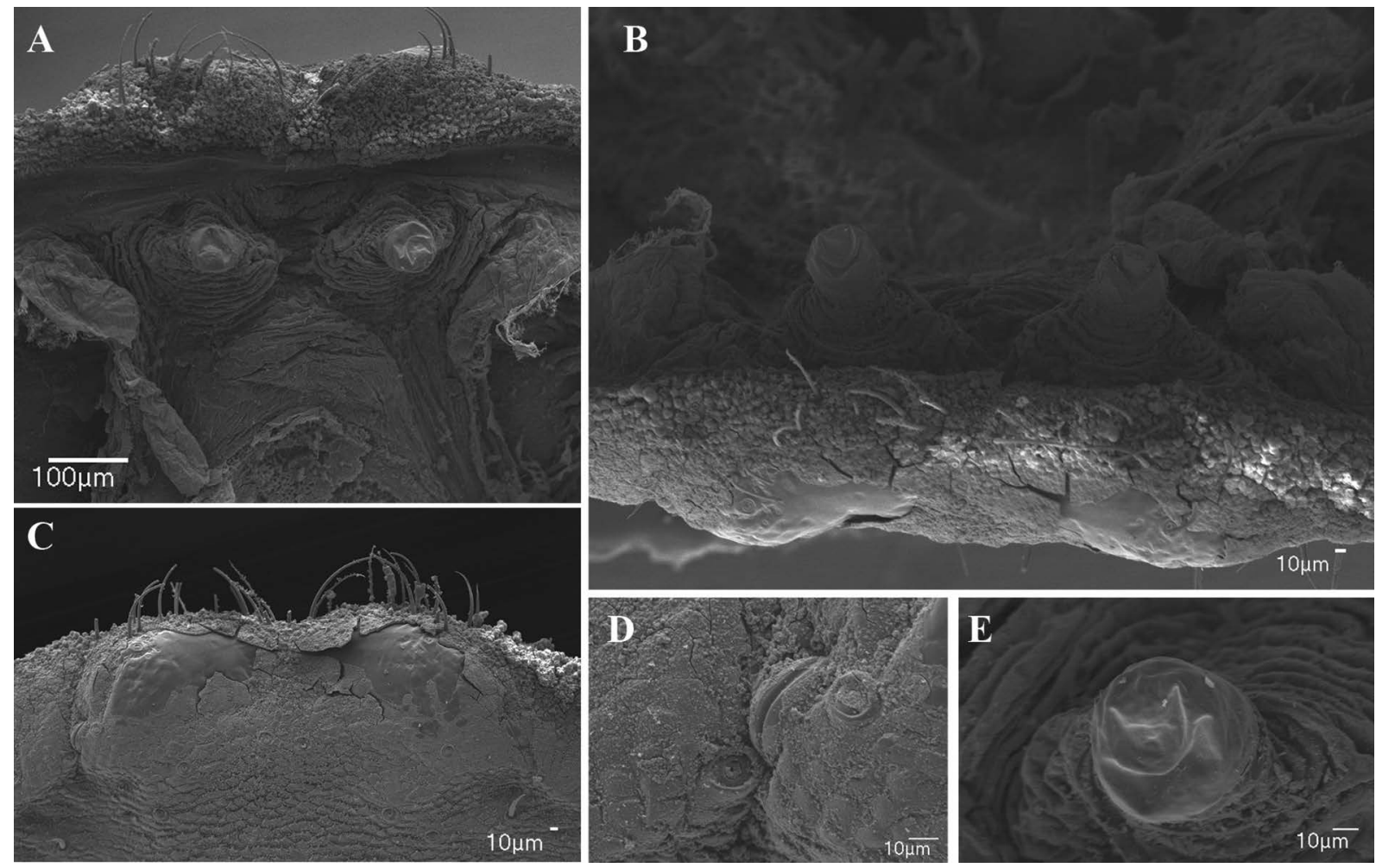

Fig. 138. Sarax bispinosus (Nair, 1934) (AMNH), female gonopod and genital operculum. A. Fingerlike gonopod, dorsal view. B. Gonopods, posterior view. C. Posterior margin of genital operculum, ventral view. D. Glandular opening on margin of genital operculum. E. Dextral gonopod. 

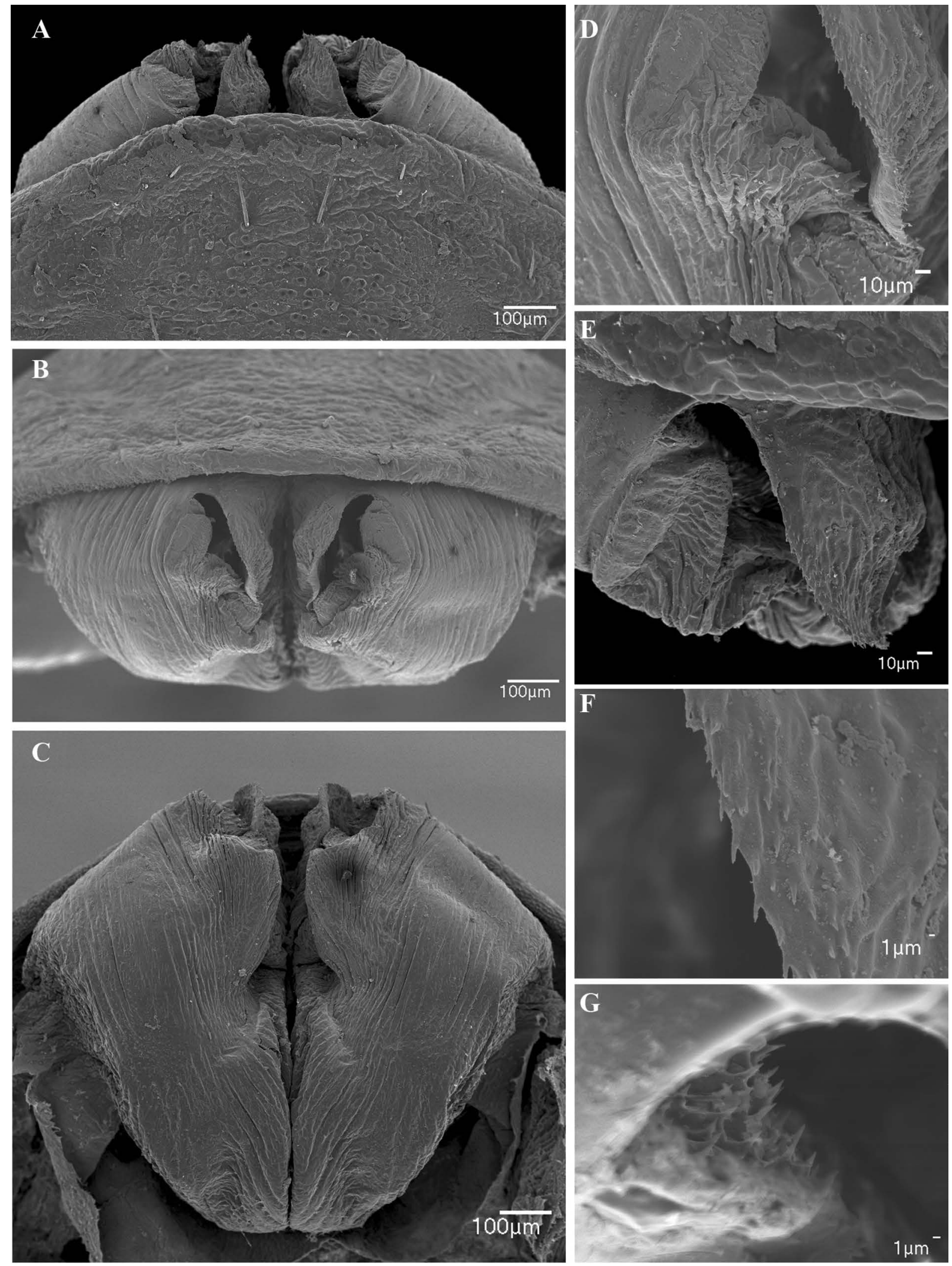

Fig. 139. Sarax bispinosus (Nair, 1934) (AMNH), male gonopod. A. Ventral view. B. Posterior view. C. Dorsal view. D. Sinistral side of gonopod. E. Lamina medialis. F. Margin of lamina medialis. G. Internal surface of fistula with spiny projections. 

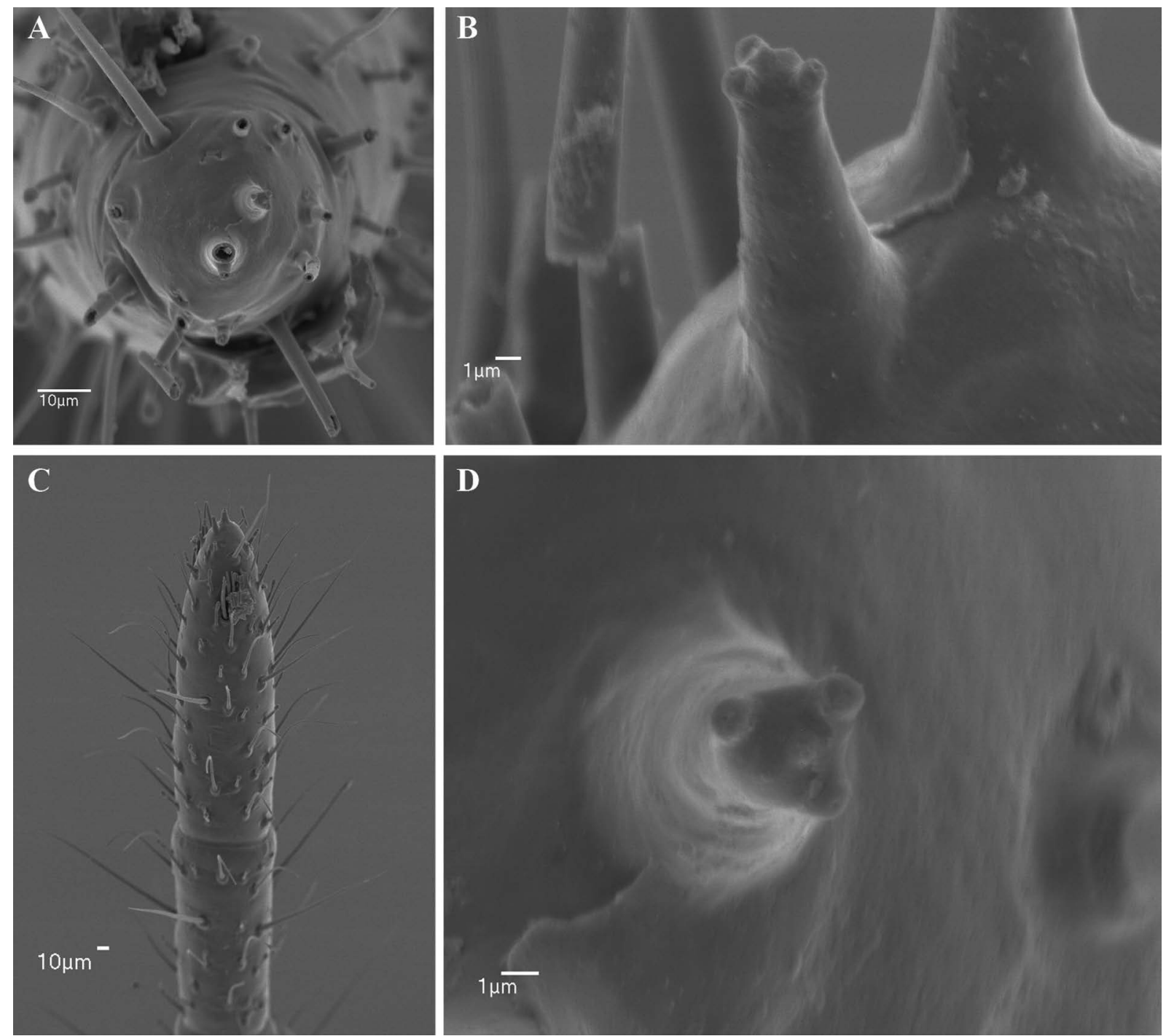

Fig. 140. Sarax bispinosus (Nair, 1934) (AMNH), antenniform leg I, Ô. A. Apex of distal article of tarsus. B. Tarsal organ near tarsal claw, lateral view. C. Distal article of tarsus showing rod sensilla. D. Tarsal organ near tarsal claw, frontal view. 

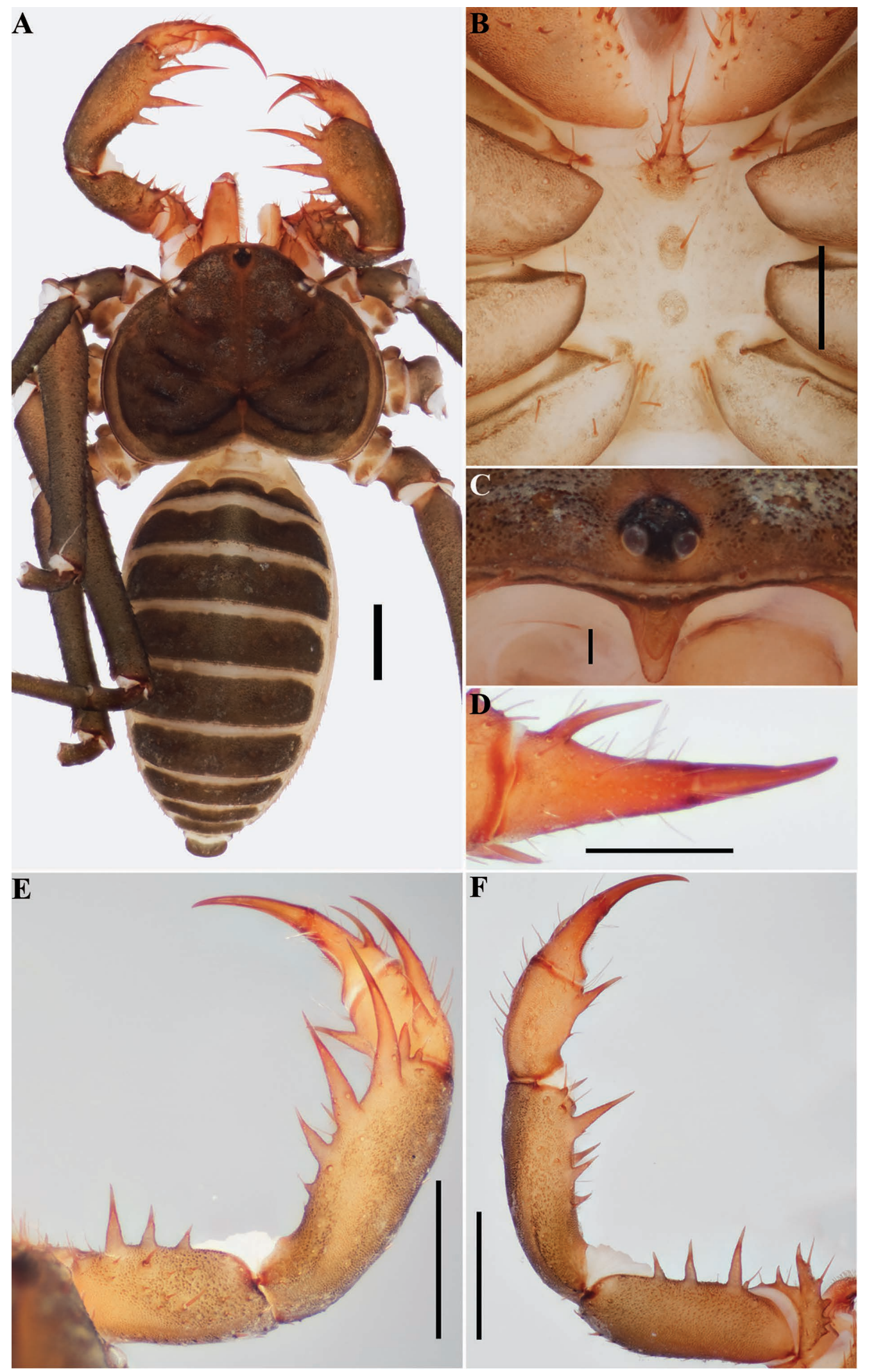

Fig. 141. Sarax cochinensis (Gravely, 1915) (AMCC [LP 13118]), general morphology, + . A. Habitus, dorsal view. B. Sternum, ventral view. C. Frontal process. D. Pedipalp tarsus, frontal view. E. Pedipalp, dorsal view. F. Pedipalp, ventral view. Scale bars: A-B, E-F $=1 \mathrm{~mm} ; \mathrm{C}=0.1 \mathrm{~mm}$; D $=0.5 \mathrm{~mm}$. 


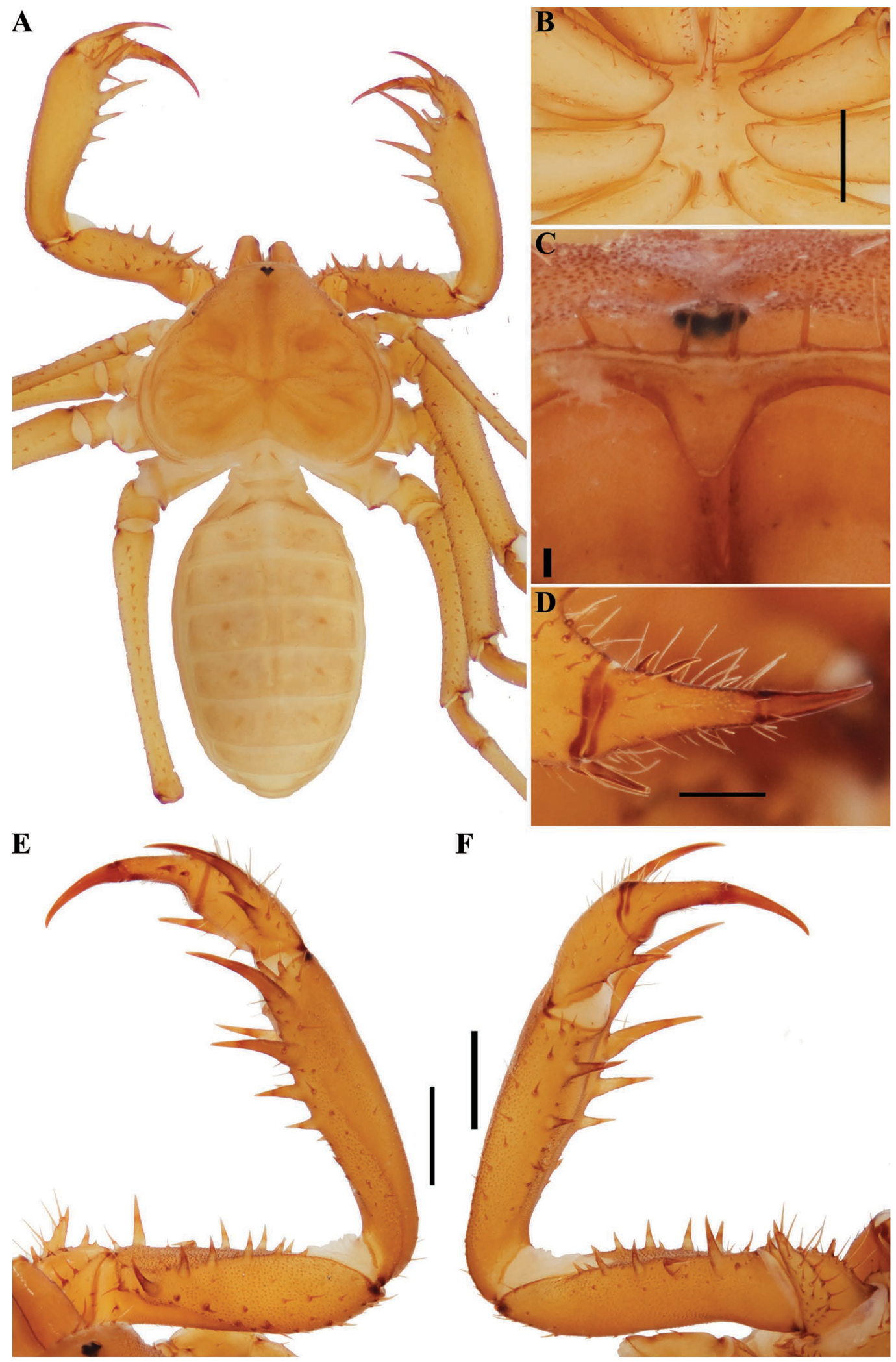

Fig. 142. Sarax ioanniticus (Weygoldt, 2005) comb. nov. (NHMW 19137), general morphology, . A. Habitus, dorsal view. B. Sternum, ventral view. C. Frontal process. D. Pedipalp tarsus, frontal view. E. Pedipalp, dorsal view. F. Pedipalp, ventral view. Scale bars: A-B, E-F = $1 \mathrm{~mm}$; C = $0.1 \mathrm{~mm}$; D = $0.5 \mathrm{~mm}$. 

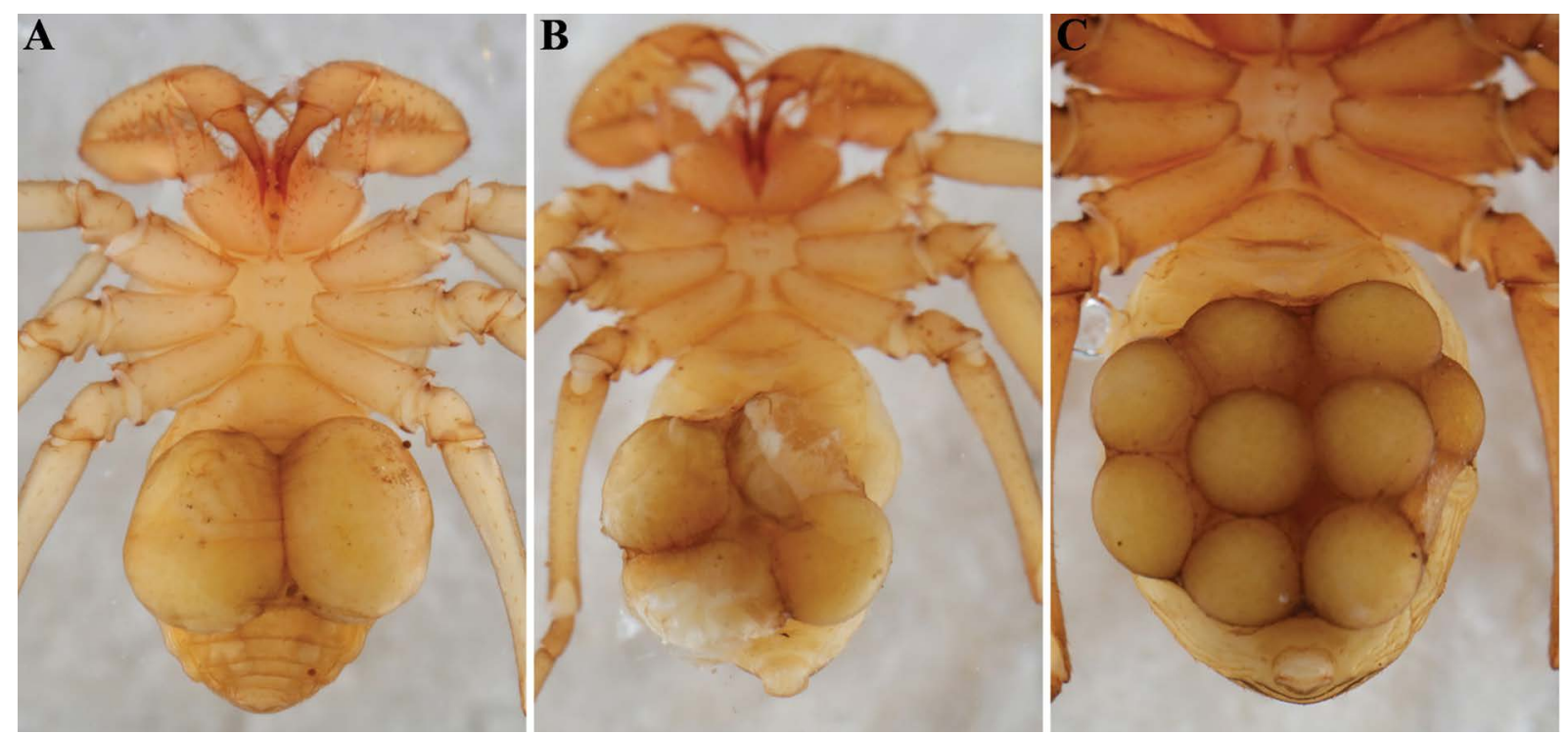

Fig. 143. Sarax ioanniticus (Weygoldt, 2005) comb. nov. (SMNS), $q$, at different developmental stages carrying egg sacs. 


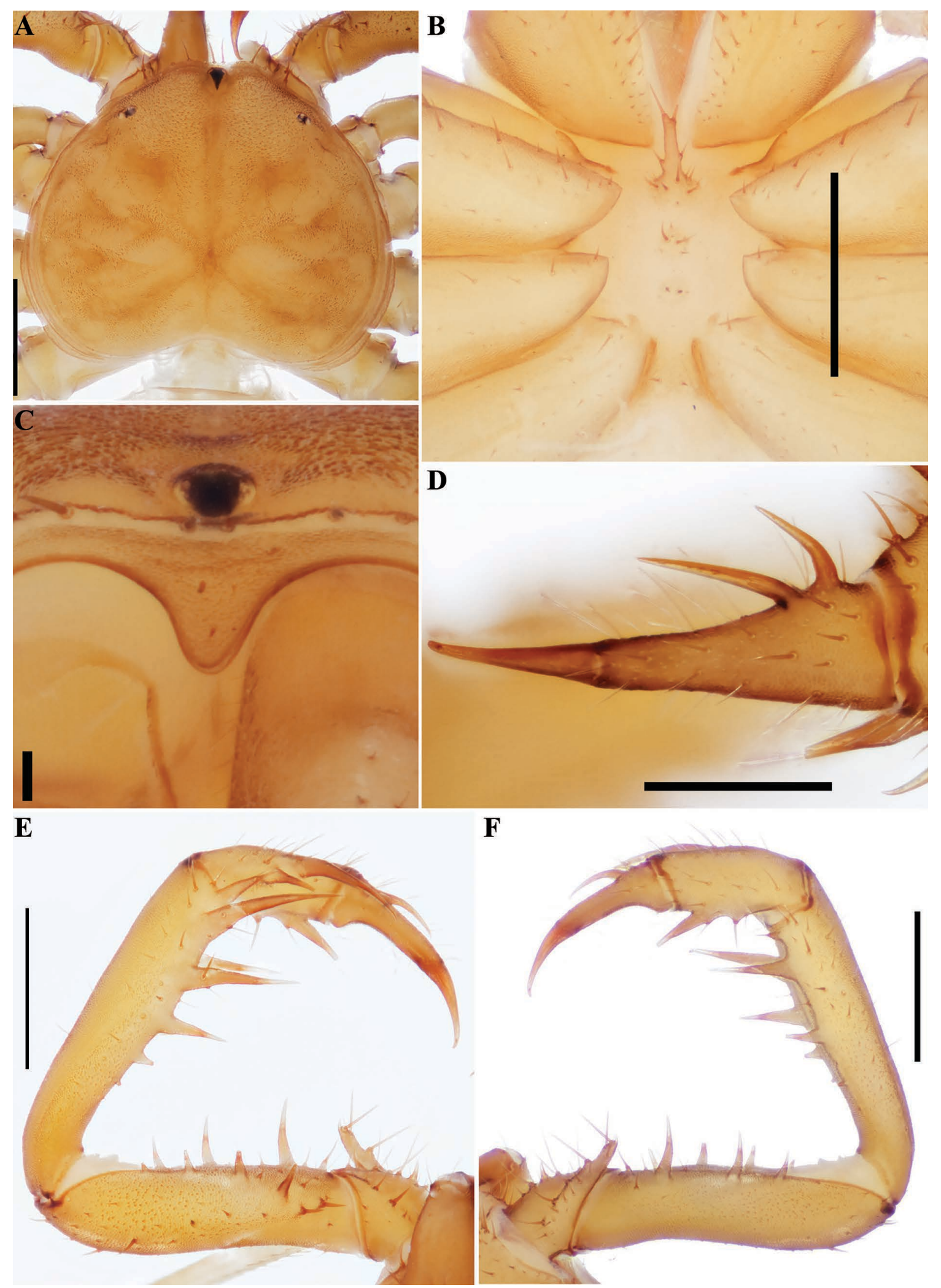

Fig. 144. Sarax pakistanus (Weygoldt, 2005) comb. nov. (MHNG), general morphology, ठ̊. A. Carapace, dorsal view. B. Sternum, ventral view. C. Frontal process. D. Pedipalp tarsus, frontal view. E. Pedipalp, dorsal view. F. Pedipalp, ventral view. Scale bars: A-B, E-F $=1 \mathrm{~mm} ; \mathrm{C}=0.1 \mathrm{~mm} ; \mathrm{D}=0.5 \mathrm{~mm}$. 
A

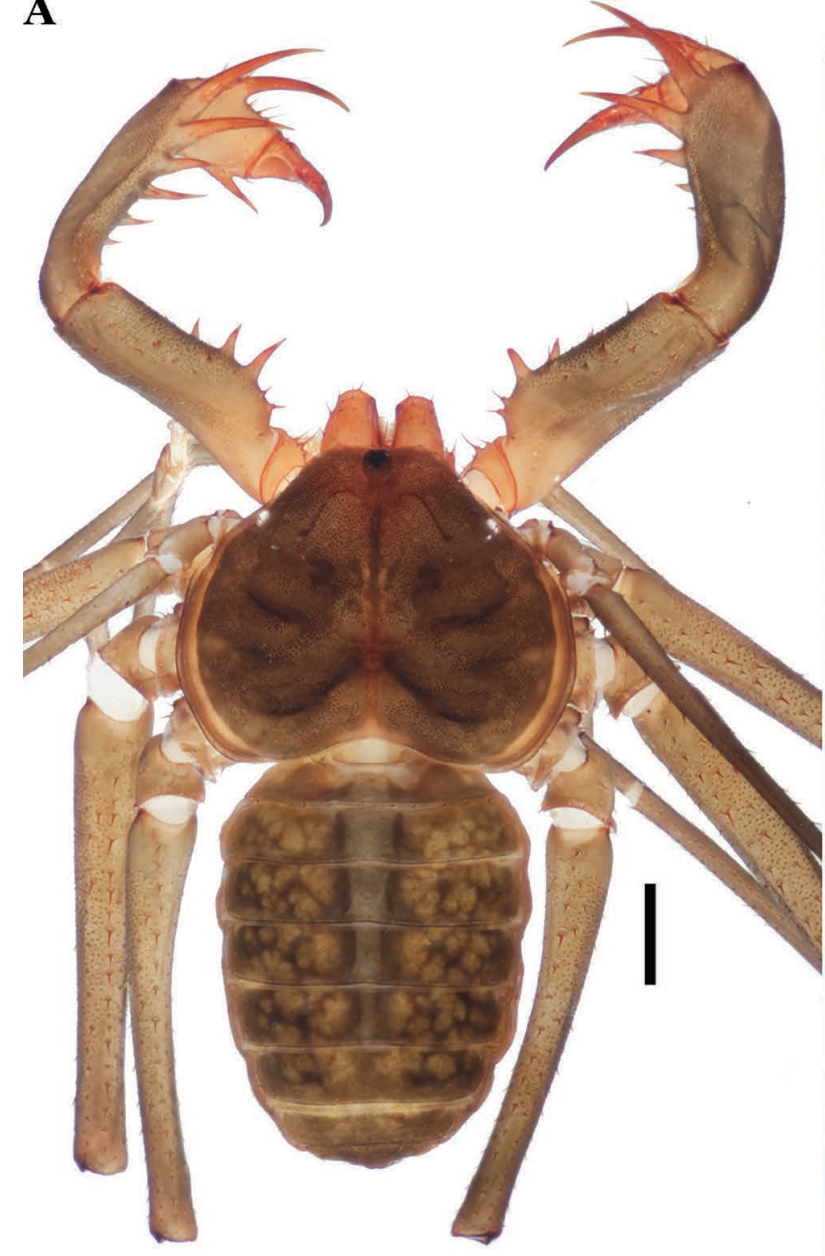

$\mathbf{E}$

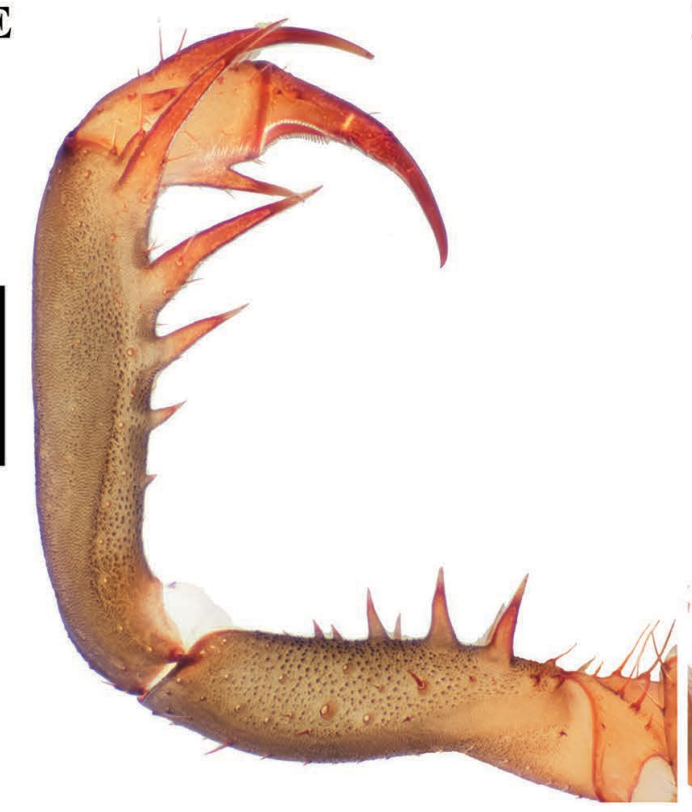

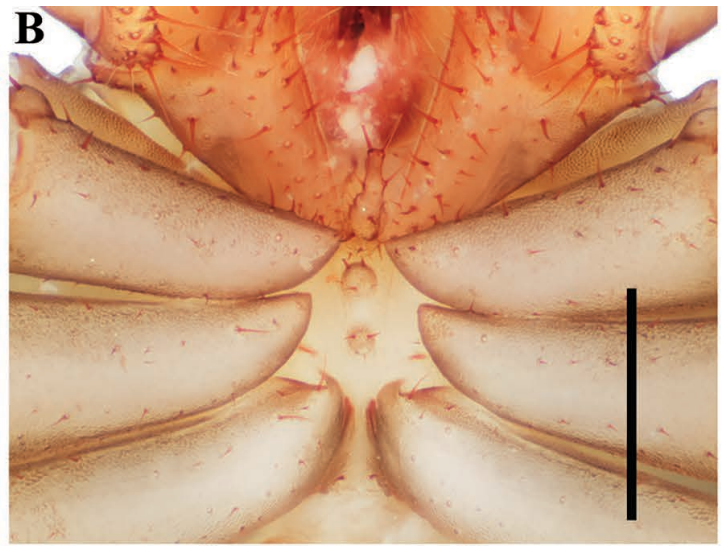

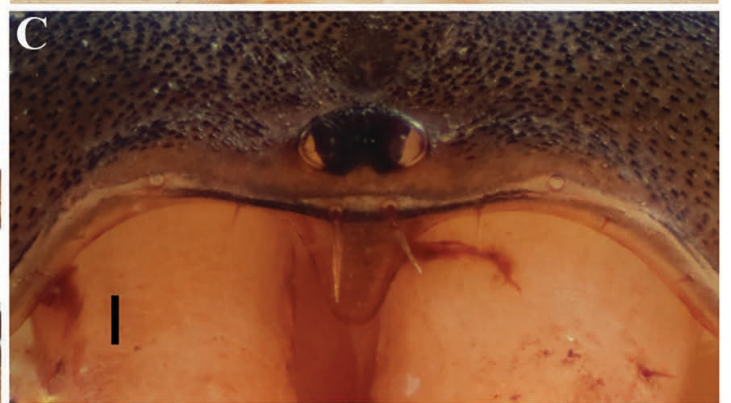

D

F

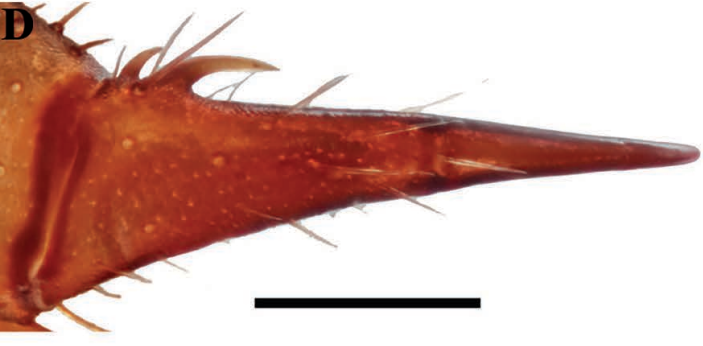




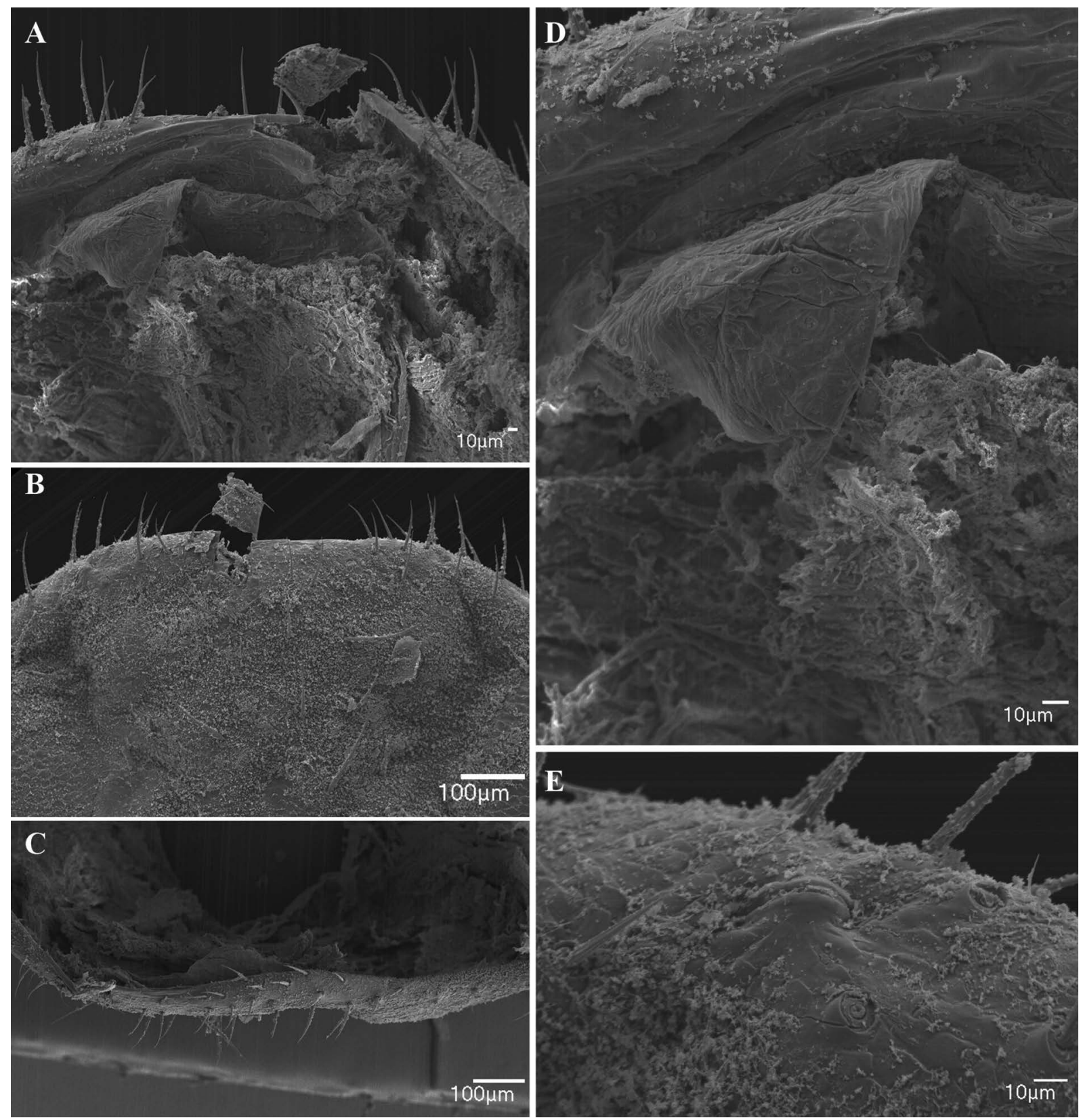

Fig. 146. Sarax seychellarum (Kraepelin, 1898) comb. nov. (AMCC [LP 9075]), female gonopod and genital operculum. A. Gonopod, dorsal view. B. Posterior margin of genital operculum, ventral view. C. Gonopods, posterior view. D. Sinistral side of gonopod. E. Glandular opening on margin of genital operculum. 

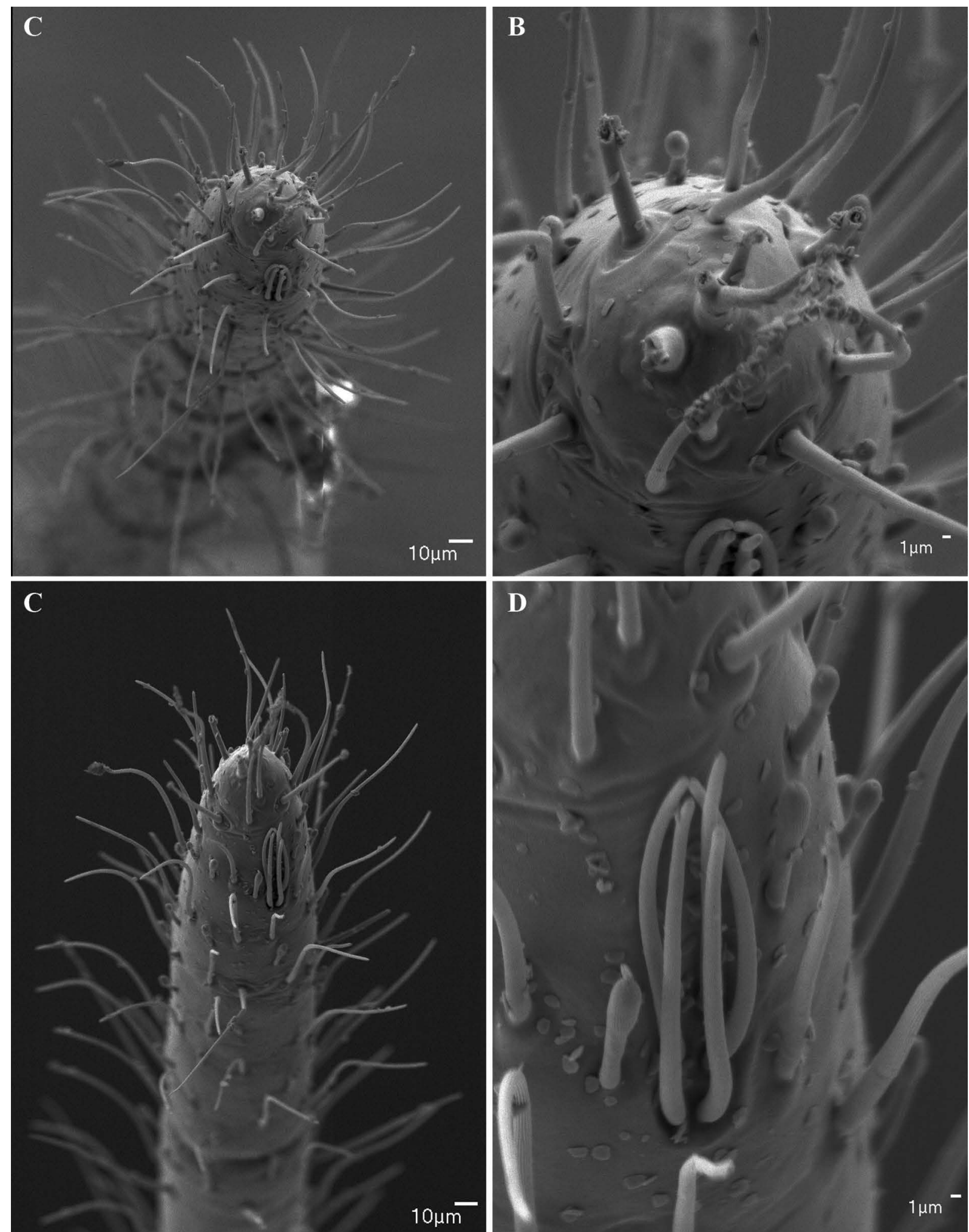

Fig. 147. Sarax seychellarum (Kraepelin, 1898) comb. nov. (AMCC [LP 9075]), antenniform leg I, ô. A. Apex of distal article of tarsus showing modified claw, rod sensilla and tarsal organ. B. Close-up of claw and tarsal organ. C. Apex of tarsus showing rod sensilla and olfactory setae, lateral view. D. Rod sensilla and olfactory setae. 


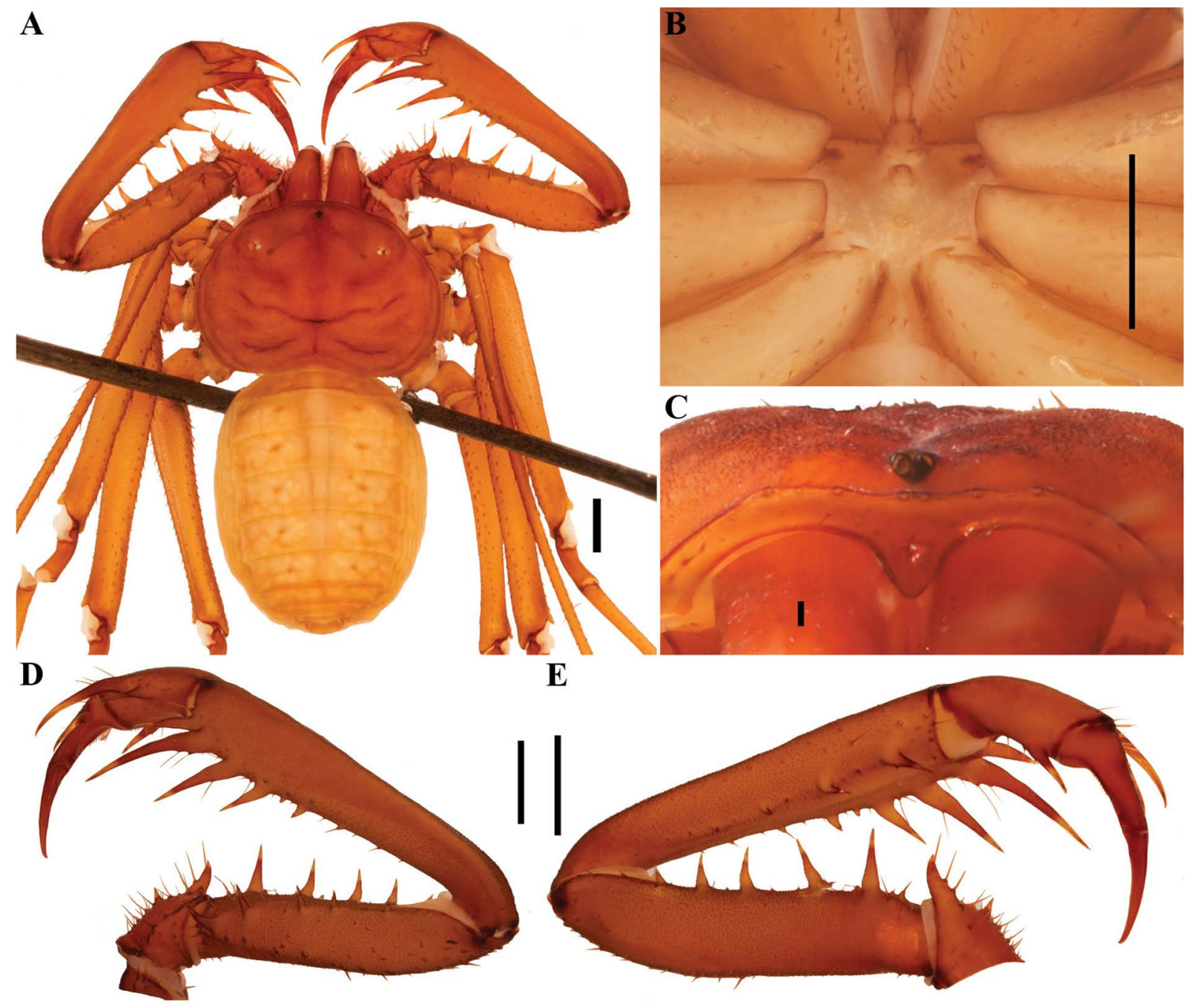

Fig. 148. Sarax socotranus (Weygoldt, Pohl \& Polak, 2002) comb. nov. (HLMD EA-45-HT), general morphology, ô. A. Habitus, dorsal view. B. Sternum, ventral view. C. Frontal process. D. Pedipalp, dorsal view. F. Pedipalp, ventral view. Scale bars: A-B, D-E $=1 \mathrm{~mm} ; \mathrm{C}=0.1 \mathrm{~mm}$. 


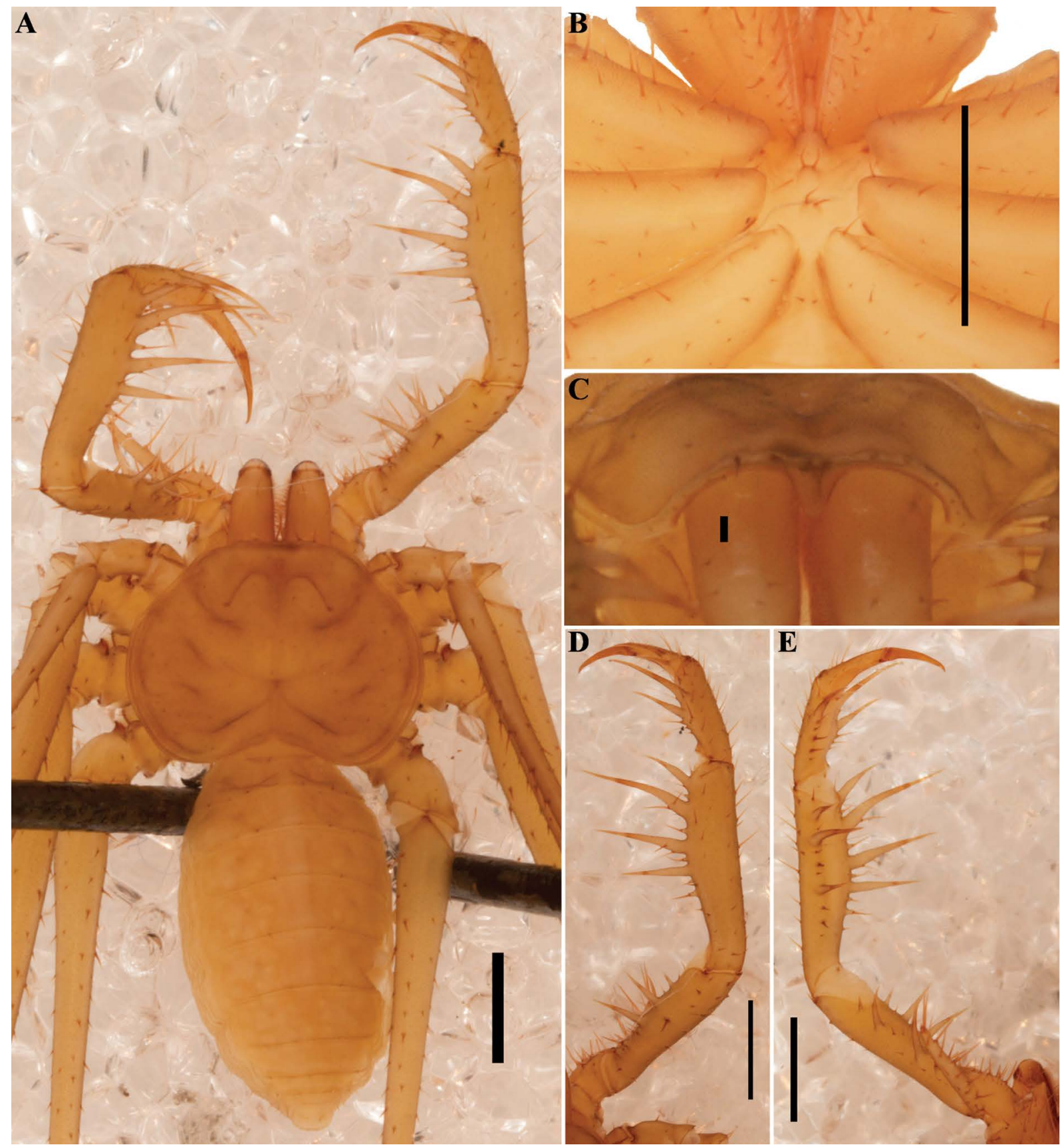

Fig. 149. Sarax stygochthobius (Weygoldt \& Van Damme, 2004) comb. nov. (HLMD EA-172-HT), general morphology, ô. A. Habitus, dorsal view. B. Sternum, ventral view. C. Frontal process. D. Pedipalp, dorsal view. F. Pedipalp, ventral view. Scale bars: A-B, D-E $=1 \mathrm{~mm} ; \mathrm{C}=0.1 \mathrm{~mm}$. 


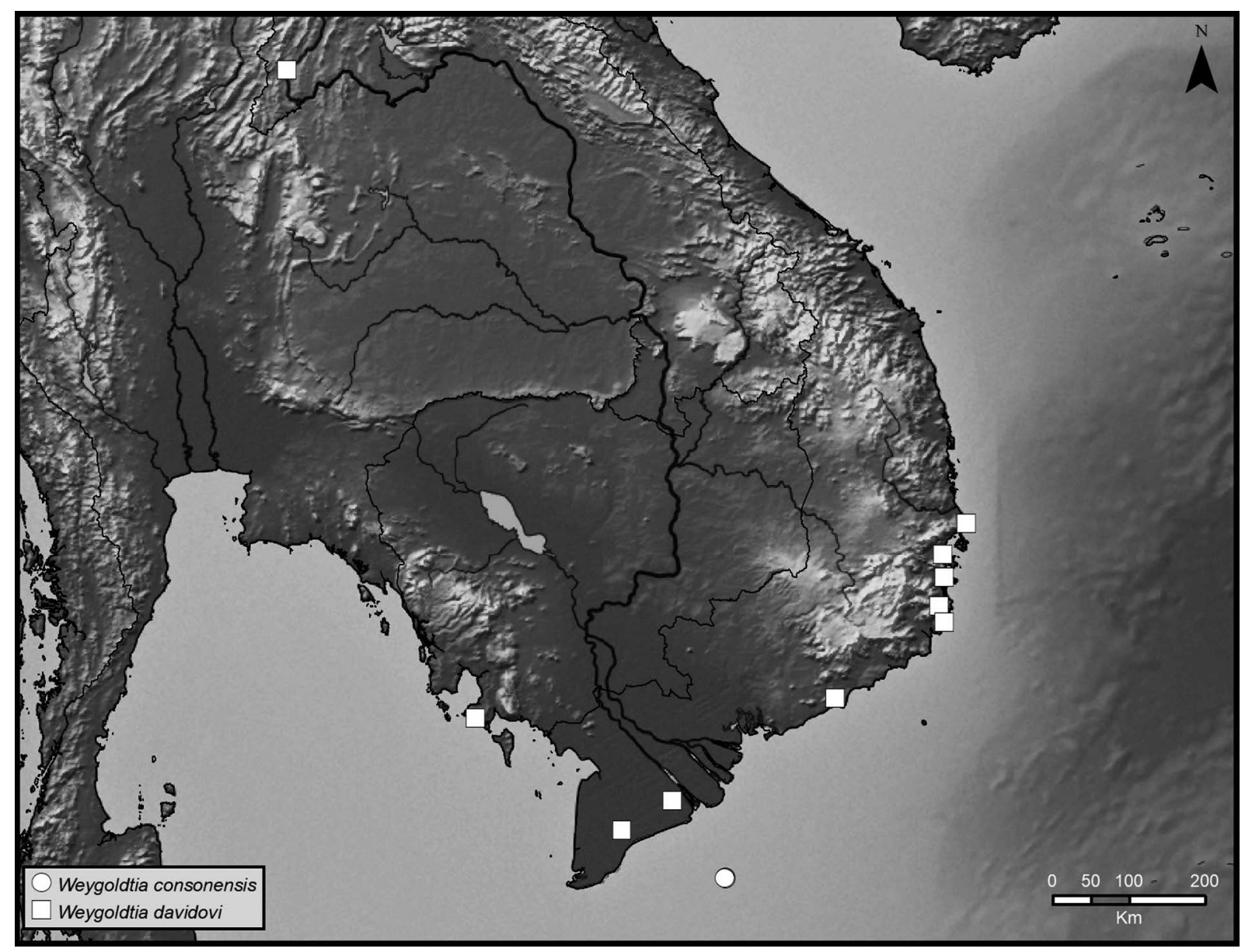

Fig. 150. Map plotting known distributions of species of Weygoldtia Miranda, Giupponi, Prendini \& Scharff, 2018 in Cambodia, Laos and Vietnam. 

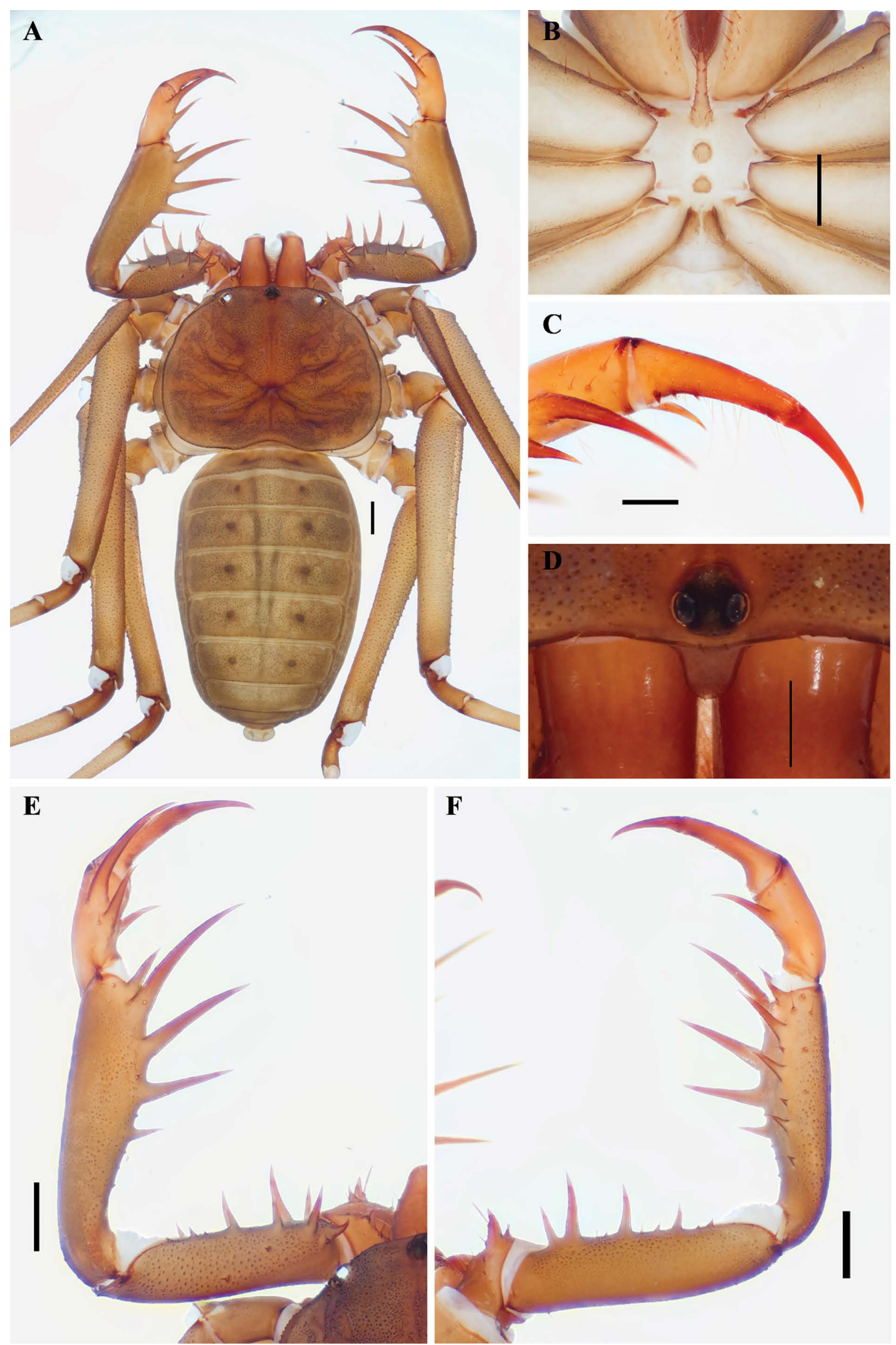

Fig. 151. Weygoldtia consonensis sp. nov. (AMNH), general morphology, ㅇ. A. Habitus, dorsal view. B. Sternum, ventral view. C. Frontal process. D. Pedipalp, dorsal view. F. Pedipalp, ventral view. Scale bars: A-B, E-F $=1 \mathrm{~mm}$; $\mathrm{C}-\mathrm{D}=0.5 \mathrm{~mm}$. 

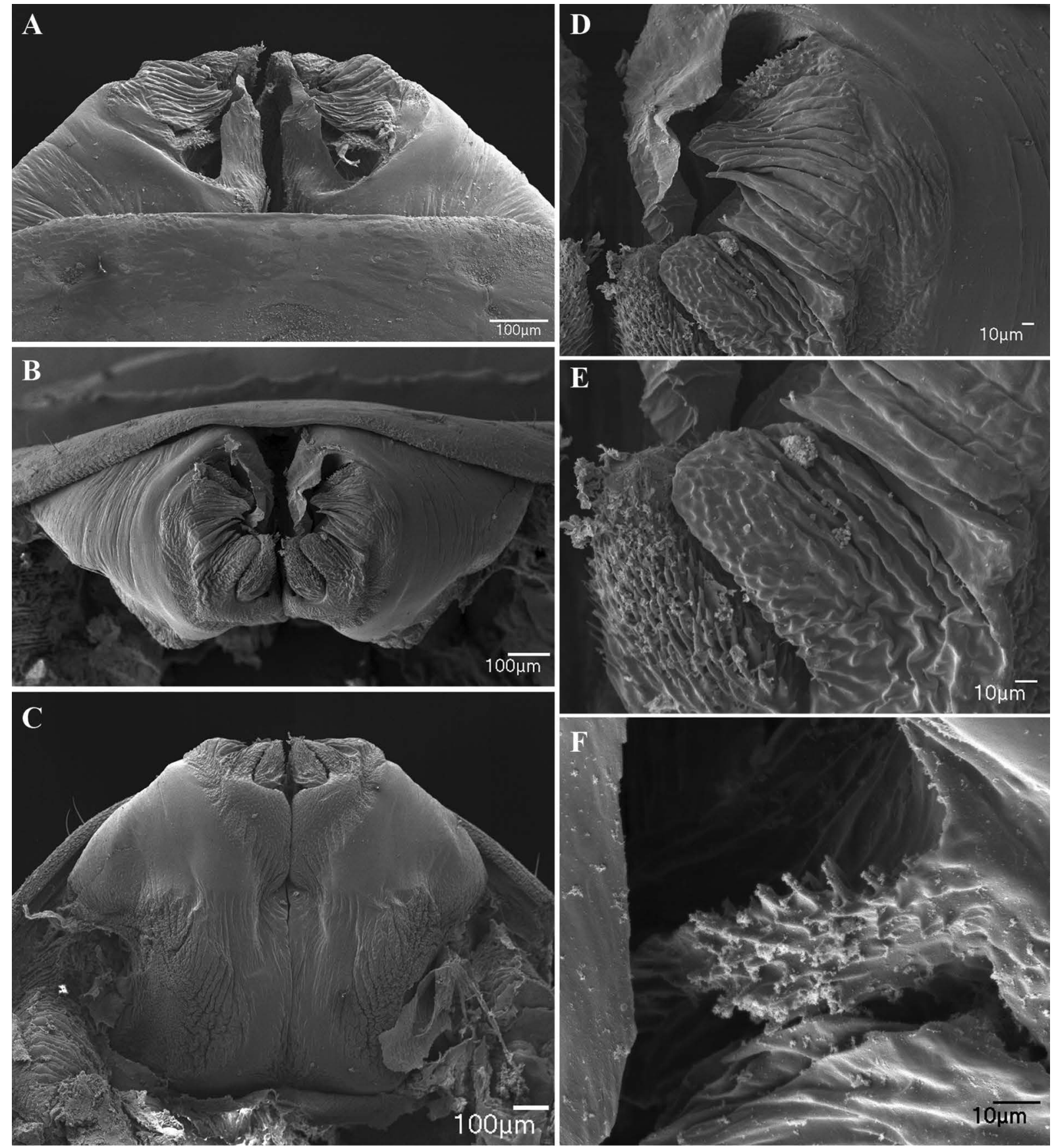

Fig. 152. Weygoldtia consonensis sp. nov. (AMNH), male gonopod. A. Ventral view. B. Posterior view. C. Dorsal view. D. Sinistral side of gonopod. E. Dorsal lobe. F. Processus internus. 
MIRANDA G.S. et al., Systematic revision of Charinidae (Arachnida, Amblypygi)
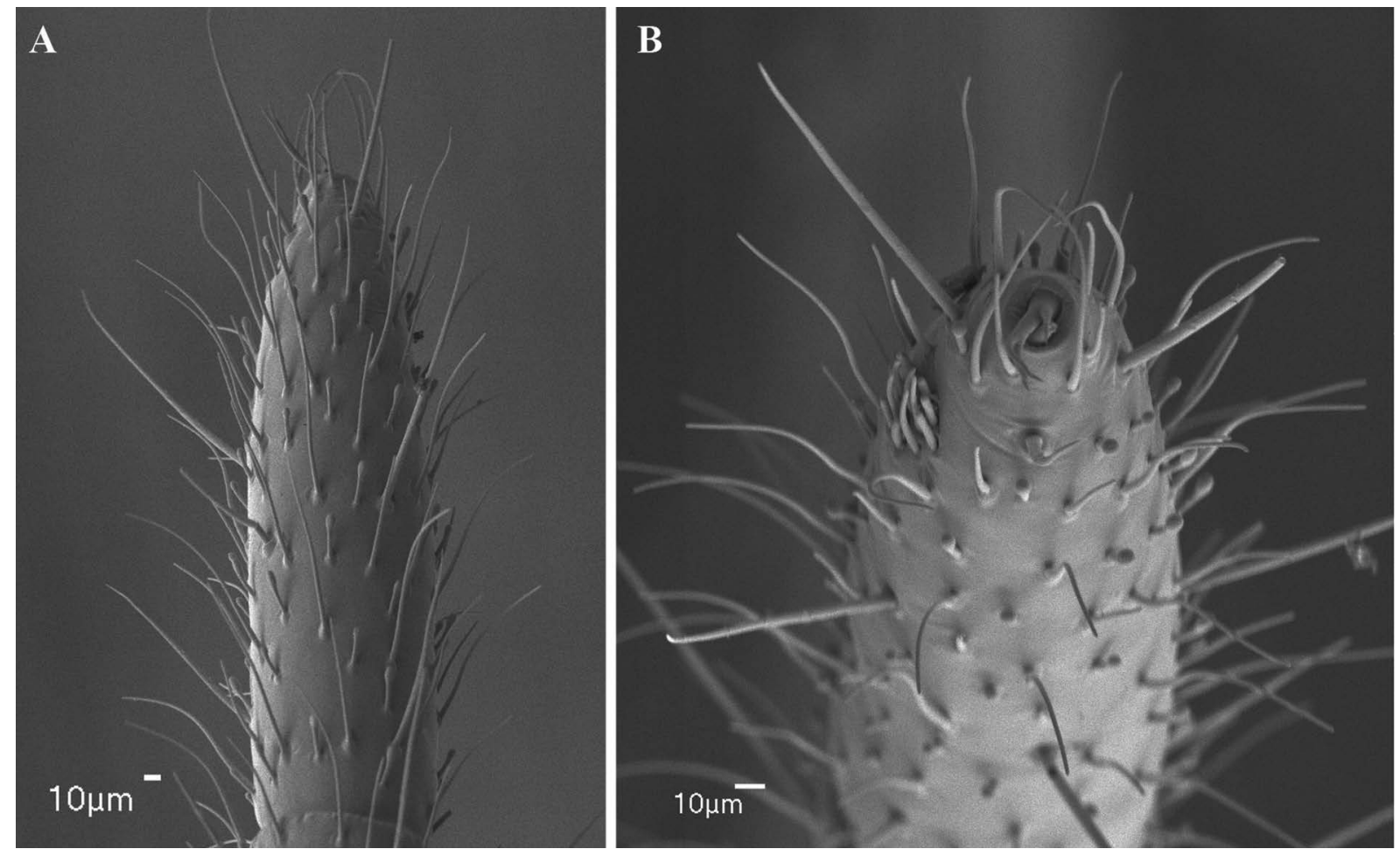

Fig. 153. Weygoldtia consonensis sp. nov. (AMNH), antenniform leg I, ठ̊. A. Apex of leg, lateral view. B. Modified claw, rod sensilla and tarsal organ. 